




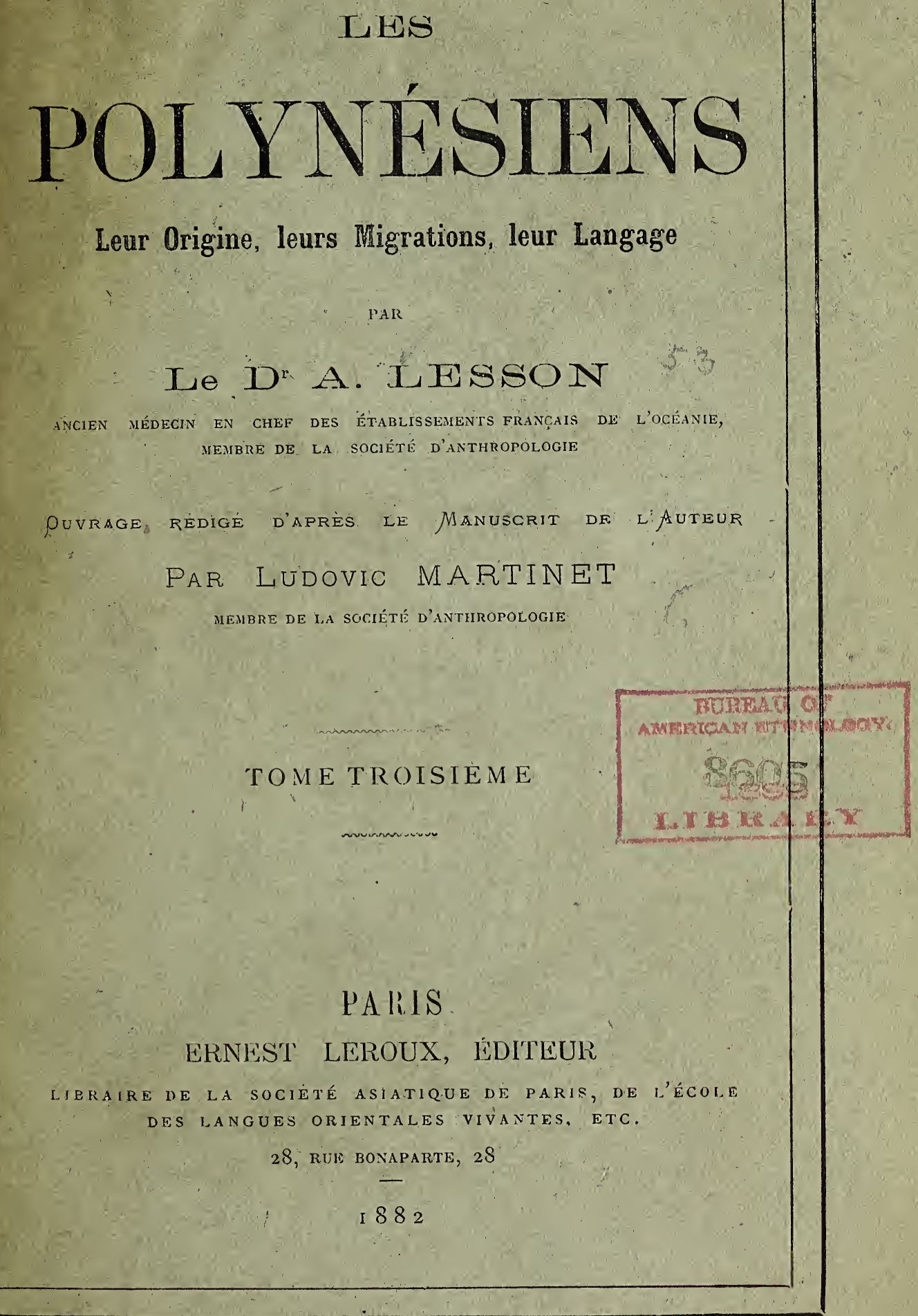



LES

\section{POLYNÉSIENS}


IXPRMERII A. DAIX, PLACB SANYT-ADDRE, 3. 


\section{LES}

SOA

\section{POLYNESIENS}

\section{Leur Origine, leurs Migrations, leur Langage}

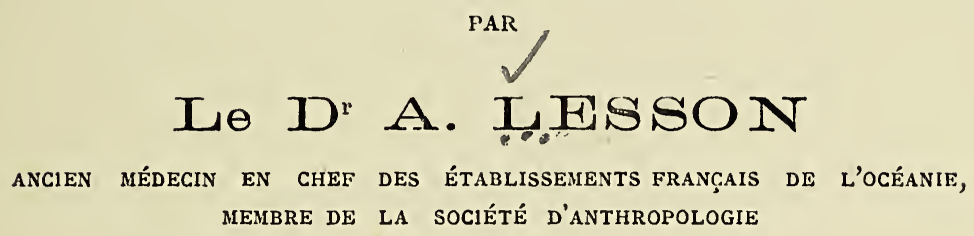

\section{BORFAU OF} AMERTCAN EIHNOLCAX;

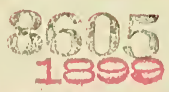

II E IE A BW Y

\section{PARIS}

ERNEST LEROUX, ÉDITEUR

Libraire De la SOCiÉté asiatiQue de Paris, De L'École DES LANGUES ORIE'NTALES VIVANTES, ETC.

28, RUE BONAPARTe, 28

I 882

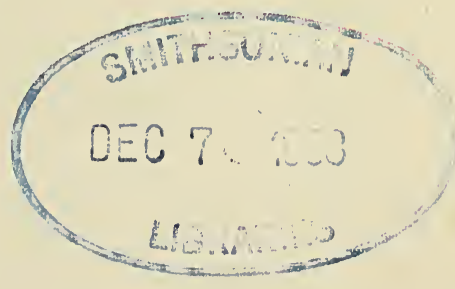




$$
\begin{aligned}
& \text { GNG } 70 \\
& 236 \\
& v^{3}
\end{aligned}
$$




\section{AVANT-PROPOS}

Depuis la pubiication de notre dernier volume, a paru en Angleterre une remarquable étude sur les Polynésiens (1). L'auteur, M. Abraham Fornander, qui résida 34 ans dans les îles Hawaii, y remplit pendant 19 ans des fonctions gouvernementales.

Les documents fournis par M. Fornander auraient dû être utilisés dans le texte spécial à chaque localité, particulièrement dans les chapitres relatifs aux archipels Hawaii et Marquises. Son ouvrage contient une masse de témoignages qui rendent notre théorie plus probable que toute autre et sur lesquels nous aurions pu facilement nous appuyer, si les deux premiers volumes de

(1) An account of the Polynesian Race, its origin and migrations, and the ancient history of the Hawaiian people, to the times of Kamehameha ler. 2 vol. London, Trübner, 1880. 
notre livre n'avaient pas été composés avant la publica tion du sien.

En effet, à part l'opinion de l'auteur Anglais sur le point de départ des Polynésiens, tous les témoignages qu'il rapporte sont, à son insu, il est vrai, favorables à la thèse que nous soutenons. Plus on lit son livre, plus on constate que nous avons trouvé la clef véritable de ses explications, de ses remarques consciencieuses, mais parfois fort embrouillées.

Fornander reconnaît lui-même que les légendes qu'il a recueillies ne viennent que du Sud, entre autres celle de Tahaï, qui indique la marche des émigrants et désigne plusieurs îles. Or le Tahaï des îles Hawaii n'est autre que le Tawhaki de la Nouvelle-Zélande. Plusieurs autres traditions des îles Marquises indiquent également toutes les îles où les émigrants du Sud ont fait étape avan't d'arriver dans cet archipel. Aussi, malgré sa croyance que les Polynésiens sont partis de la Malaisie et arrivés d'emblée aux îles Fiji, l'auteur Anglais montre, à chaque instant, que l'Hawahiki devait être situé plus à l'Ouest encore que les Fiji et non dans les îles Sandwich.

«En comparant les légendes de la Nouvelle-Zélande publiées par sir Grey, je trouve, dit-il (1), que les Néo. Zélandais prétendent descendre de l'île Savaii dans le groupe Samoa: ils prononcent ce mot Hawaïki et parmi les autres noms remarquables cités dans leurs récits;

(2) Ouvrage cité, t. Ier, p. 203, 
avant leur départ de l'Hawaïki, il en existe quatre paraissant appartenir à la ligne havaiienne Ulu, entre Aikanaka et Paumakua. Ils figurent, dans ces légendes de la Nouvelle-Zélande, comme chefs ou Ariki d'Hawaïki et ils y sont placés dans le même ordre de succession que dans les généalogies hawaiiennes. Voici leurs noms, avec la prononciation hawaiienne entre deux parenthèses: Hema (Hema), Tawhaki (Kahai), Wahieroa (Wahieloa), Raka (Laka).

« Chacun de ces chefs a, pour ainsi dire, été naturalisé et localisé sur le groupe Hawaii par les légendes hawaiiennes. Cependant, comme il n'est raisonnablement pas probable que les Néo-Zélandais soient partis du groupe Hawaiien au lieu du groupe Samoan, et comme il est positivement évident que ces chefs résidaient sur Hawaïki qu'jls connaissaient et d'où ils étaient partis pour la Nouvelle-Zélande, je suis forcé de conclure que leur introduction dans les généalogies hawaiiennes était le fait de cette période d'émigrations, à laquelle j'ai si souvent fait allusion ; ce fut une adaptation locale dans les âgres suivants de légendes antérieures, quand le souvenir de la mère-patrie fut devenu indistinct et quand on ne connaissait plus rien d'eux, sinon le fait principal qu'ils étaient sur la liste généalogique des chefs hawaiiens de la ligne Ulu. »

* Ainsi, d'après le témoignage des légendes Néo-Zélandaises, ces chefs, ajoute Fornander, n'étaient pas originaires des îles Hawaii du Pacifique Nord, dont les 
Néo-Zélandais n'avaient sans doute aucune idée, mais de la Savaii Samoane de l'Océan Pacifique du Sud, d'où ils prétendaient descendre, de laquelle ils avaient émigré, et d'où ils avaient emporté avec eux leur's légendes dans leurs nouvelles demeures, sur Ao-tea-roa ou Nouvelle-Zélande. »

La tradition Zélandaise est bien plus claire et notre système donne la clef véritable de tout ce que dit Fornander, qui se perd en vains efforts pour la découvrir. Il suffit, pour comprendre cette tradition, qu'elle ait été portée par des émigrants de l'Hawahiki tel que nous le croyons placé, c'est-à-dire sur l'Ile-dı-Milieu de la Nouvelle-Zélande. Alors tout s'explique de la façon la plus simple et la plus naturelle.

Il en est de même pour toutes les traditions rapportées par M. Fornander sur l'origine des îles Hawaii et sur celle de leurs habitants. Toutes viennent confirmer notre manière de voir ; toutes montrent que les Hawaiiens, quoiqu'ils n'aient conservé qu'une idée fort confuse de leur lieu d'origine, se regardent eux-mèmes comme des émigrants et non comme des autochthones des Havaii dont parle la légende. "Mais, ajoute Fornander, il y a trois des groupes Polynésiens, les groupes Harvaii, Samoa et Tonga, qui réclament pour chacun d'eux l'honneur d'avoir été le premier peuple, le premier nommé dans le Pacifique. Cependant tout concourt à montrer que le lieu d'origine de leurs ancêtres à tous était dans l'Ouest lointain, de même que la demeure de leurs dieux .» 
Les traditions Hawaiiennes, ajoute Formander, sont éloquentes sur la beauté et l'excellence de la terre particulière ou lieu de résidence des deux premiers êtres humains créés. Il portait un certain nombre de noms, de significations diverses; mais celui qui se présentait le plus souvent et qui passait po:ır être le plus ancien, était Kalana-i-Hau-Ola, « Kalana aves la vie ou rosée donnant la vie ». Ce lieu était situé dans une grande contrée du continent diversement appelé dans les légendes: KahikiHonua-Kele, Kahikiku, Kapakapaua-a-Kane, et Mololani.

Parmi les divers autres noms de cette première demeure, de ce paradis, conservés dans les chants et traditions, il faut citer: Pali-Uli, « la montagne bleue »; Aina-i-Ka-Kaupo-o-Kane, « la terre du cœur ou dans le cœur de Kane»; Aina-Wai-Akua-a-Kane, «la terre de l'eau divine de Kane ».

La tradition dit de «Pali-Uli » que c'était une terre sacrée, tapu; qu'un homme devait être juste pour l'atteindre; que celui qui voulait l'atteindre devait être excessivement saint; que s'il était coupable ou criminel, il ne pouvait pas y arriver; que s'il regardait derrière, s'il préférait sa famille, il ne pouvait pas entrer dans le Pali-Uli.

Le chant le décrit ainsi :

o Pali-Uli, aina huna a Kane, o ka aina $i$ Kalana-i-Hau-Loa, 
I Kahiki-ku, i Kapakapa-ua-a-Kane,

O ka aina $i$ kumu, $i$ iali,

O ka aina ai nui a ke Akua.

«O Pali-Uli, terre cachée de Kane,

«Terre dans Kalana-i-Hau-Ola,

«Dans Kahiki-ku, dans Kapakapa-ua-a-Kane,

«Terre avec des sources d'eau, grasse et humide,

« Terre grandement réjouie par le Dieu.»

L'Aina-Wai-Akua-a-Kane, ou, comme elle est plus généralement appelée dans les légendes, Aina-Wai-Olaa-Kane, «l'eau de vie de Kane, » est fréquemment citée dans les croyances populaires. Suivant les traditions, cette source de vie était une belle fontaine jaillissante, admirablement claire et transparente et entourée d'un lac. Ses bords étaient splendides. Elle avait trois issues: une pour $\mathrm{Ku}$, une pour Kane, une pour Lono. Par ces issues, les poissons pénétraient dans le lac. Si les poissons du lac étaient jetés sur le sol ou sur le feu, ils ne mouraient pas. Si un homme avait été tué et si, après sa mort, il était plongé dans cette eau, ii revenait aussitôt à la vie.

Dans la légende d'Aukele-Nui-a-Iku, le héros visita Kalana-i-Hau-Ola; à l'aide de son dieu protecteur, il obtint de l'eau de cette fontaine de vie et, avec elle, il ressuscita ses frères qui avaient élé tués longtemps auparavant.

Cette fontaine de vic est certainement la fameuse sour- 
ce si connuedes légendes Néo-Zélandaises; et tout indique que les mots Pali-Uli, Kapakapaua, Kahikiku, Kalana-i-Hau-Ola, Aina-i-Ka-Kaupo-o-Kane, qui est évidemmeni l'Upoko-Tane des Maori, désignaient des noms et des localités de la Nouvelle-Zèlande, et plutôt de l'Iledu-Milieu que de l'Ile-Nord. C'est ce que nous mettrons en évidence quand nous aborderons l'étude de la marche des migrations. 



\title{
LES POLYNESIENS
}

\section{TROISIËME PARTIE}

\section{LIVRE PREMIER}

\author{
2monnmon \\ NOUVELLE-ZÉLANDE \\ CONSIDÉRATIONS GÉNÉRALES SUR LA \\ NOUVELLE-ZÉLANDE
}

RÉFLEXIONS PRÉLIMINAIRES.

Comme nous ne cherchons pas à écrire l'histoire de la Nouvelle-Zélande, nous devons évidemment nous abstenir de toutes les considérations qui n'ont pas un rapport direct avec la question qui nous occupe. Il suffira donc de mettre sous les yeux du lecteur les principaux faits géographiques, météorologiques, anthropologiques et autres, qu'il lui est indispensable de connaître pour asseoir son opinion sur le système que nous allons développer.

Nous ne dirons ici rien des mœurs, des usages et des idées religieuses des Nouveaux-Zélandais ; nous ne parlerons pas non plus de leurs migrations, ni de leur langage, que nous aurons à examiner, dans les chapitres suivants ; mais nous les étudierons surtout au point de vue anthropologique; nous chercherons à démontrer que l'on a admis à tort plusieurs races ou variétés d'hommes à la Nou- 
velle-Zélande et que l'on a, égralement à tort, prétendu que la population primitive forme une race mêlée.

Toutefois, en raison de l'intérêt qu'elles hous semblent offrir, nous présenterons incidemment quelques recherches linguistiques : c'est ainsi que nous tâcherons d'expliquer les noms donnés par les indigènes aux îles de la NouvelleZélande et aux diverses tribus qui composent la population, et que nous indiquerons également les divisions établies parmi elles.

Nous bornerons, du reste, la description des îles à ce qui sera strictement nécessaire pour qu'on s'en figure biẹn l'étendue et pour qu'on comprenne qu'une population considérable a pu s'y former. De même, nous serons bref au sujet de la température, de la pluic et de l'humidité, toutes choses ayant peu ou point de rapport avec la recherche du lieu d'origine des indigènes et celle de leurs migrations. Mais nous ferons, au contraire, ressortir avec soin la force et la direction des vents ordinairement régnants, parce qu'elles aident à faire comprendre ces migrations.

Quant à l'histoire naturclle, comme nous ne pourrions en parler que superficiellement, même en le faisant longuement, nous nous contenterons de donner quelques listes, avec les noms indigènes revus par nous, ainsi que des extraits du savant missionnaire anglais Taylor sur les quadrupèdes, les principaux oiseaux, et quelques autres parties de la faune de la Nouvelle-Zélande. On lira avec intérêt ces études d'un homme si compétent, et auquel on a fait tant d'emprunts, en pays étrangers, sans jamais le citer. C'est à lui également que nous nous adresserons pour dire quelques mots surla géologie, les tremblements de terre et les îles disparues dans le détroit de Cook, d'après les traditions. Pour le surplus, nous renvoyons à la traduction de son ouvrage faite par nous, et encore inédite.

Les renseignements sur les devises des Tribus, sur les étymologies des noms qu'elles portent, sur les divisions établies parmi la population, et quelques autres encore, ne sauraient être cunsidérés comme des hors-d'œuvre : tout indirects que sont ces renseignements, ils n'aident pas moins, 
à notre avis, à caractériser la race qui les fournit, et c'est à ce titre que nous avons avons cru devoir en parler incidemment.

En somme, dans ces considérations générales, nous n'insisterons, en raison de leur importance pour la question à résoudre, que sur deux choses principales : les vents, et les caractères physiques de la population de la Nouvelle-Zélande. 


\section{CHAPITRE PREMIER}

\section{GÉOGRAPHIE ET HISTOIRE NATURELLE}

Aperçu géographique et topographique sur le groupe de la Nouvelle-Zélande. - Trois îles principales. - Description de l'Ile-Nord. - Description de l'Ile-du-Milieu. - Examen des noms donnés par les pre. miers navigateurs. - Recherches linguistiques : Pounamu; Kawaï; Kaikoura ; Pakeha. - Météorologie. - Vents régnants. - Noms des vents. - Tempêtes. - Température. - Tableaux météorologiques. Géologie. - Constitution volcanique. - Iles disparues. - Botanique. - Nature et espèces des différentes plantes. - Le groupe de la Nouvelle-Zélande constitue un centre botanique. - Faune. - Mammifères terrestres : Kuri ; Kiore ; Kaurehe. - Oiseaux : Kiwi ; Moa : Remarques sur l'extinction des Moa. - Ruru ; Kakapo. - Reptiles ; lézards. - Amphibies. - Poissons. - Coquilles. - La géologie, la faune et la flore prouvent que les îles de la Nouvelle-Zélande ont été un centre de création.

APERCU GÉOGRAPHIQUE ET TOPOGRAPHIQUE. - La Nouvelle. Zélande n'est point une seule terre, comme le croyait son découvreur (1), mais bien un groupe de plusieurs îles situées entre les parallèles de $34^{\circ} 12^{\prime}$ et $47^{\circ} 20^{\prime}$ de latitude méridionale, et s'étendant du $163^{\circ} 44^{\prime}$ au $176^{\circ} 21^{\prime}$ de longitude orientale du méridien de Paris. Tasman, soupconnant d'aioord qu'elle était jointe au Staten-Land, contrée signalée par Lemaire et Schouten à l'List de la Terre de Feu, lui don-

(1) La Nouvelle-Zélande fut découverte par Abel Tasman, le 13 ou le 14 décembre 1642. Pour quelques-uns cependant ce fut un navigateur espagnol, pour d'autres le Francais Paulmier de Gonneville, qui aperçut le premier les rivages de la Nouvelle-Zélande. 
na le même nom, en l'honneur des États geénéraux; mais peu après cette terre, presque inconnue alors, reçut, on ne sait de qui, le nom de Nouvelle-Zélande (1). C'est ce nom qui a été adopté par tous les géographes, non pas sans inconvénient pour l'ethnologie polynésienne, comme on le verra; et c'est lui qu'on trouve indiqué dans la carte de Bellin, qui a été publiée dans le voyage d'Anson, en 1751. La baie où Tasman mouilla le 18 décembre, et qu'il nomma Baie des Meurtriers, est située par $40^{\circ} 49^{\prime}$ Lat. et $169^{\circ} 4 l^{\prime}$ Long.

Parmi les îles qui composent ce groupe, il en est surtout deux qui sont fortgrandes. Leur direction générale est du SudOuest au Nord-Est du Monde, et elles sont entourées d'une vingtaine de petites îles, disséminées sur les côtes. Une troisième île, assez grande aussi, sans l'être autant que les premières, a été nommée île Stewart par les Anglais : c'est la plus méridionale du groupe ; elle forme, par sa pointe Sud, le Cap du Sud. Les indigènes l'appellent Ra-ki-ura. Enfin l'île appelée par Cook Entry-Island, porte le nom maori de Kapiti.

ILE-NoRd. - L'Ile-Nord, la première des deux plus grrandes, ou l'Ika-na-Maui de la plupart des navigateurs, a presque la forme d'un triangle rectangle, dont la base fait suite à ladirection générale de la seconde grande île : elle s'étend, comme celle-ci, du Sud-Ouest au Nord-Est et elle se termine par une pointe appelée Cap-Est. Dece cap, ou sommet de l'angle droit, jusqu'au Cap-Nord, la côte se dirig'e au N.-O , oì le triangle se ferme au cap Maria Van-Diemen. La chainc de montagnes de cette île semble être la continuation de celle de l'autre île : comme elle, elle court du Sud-Ouest au Nord-Est du Monde ; elle est formée de montagnes teès éln-

(1) Il est toutefois à remarquor qus c'est vers 1665, que par un décret des Etats généraux, la partic Ouest de la Terie Australe fut appelée Nouvelle.Hollande. 
vées, et dont les sommets sont presque toujours couverts de neige (1).

On donne à cette île une longueur de cinq cents milles, (près de 700 kilomètres) (2), et une largeur variable de cinq à trois cents milles; le développement de ses côtes n'a pas moins de quatre cents lieues, et même plus si l'on en suit exactement les contours: les Anglais le portent à quinzè cents milles. Enfin, on évalue sa surface à 3567 lieues carrées.

C'est entre le Cap-Nord et le cap Colleville, sur la côte Est, vis-à-vis la Grande-Barrière, et une foule d'autres îles moins grandes, que se trouvent les magnifiques baies ou hâvres appelés Maunganui (Baie des Iles), Wangaroa, Hauraki (Auckland), Baie Mercure, Tauranga, etc. Il n'y a g'uère, entre le Cap-Est, qui est éloigné du cap Palliser de 300 milles, que le port Napier, dans la baie Hawke ; mais, sur la côte de cette île qui forme le côté Nord dı reétroit de Cook, et l'avoisinant, se voient de nombreux ports dont quelques-uns sont occupés aujourd'hui par des établissements anglais, ainsi que des rivières encore plus nombreuses. C'est là que se trouvent le port Nicholson, presque à l'entrée orientale du détroit, puis, en allant vers le N.-O., les îles de l'Entrée, Mana et autres, Taranaki, etc., et, plus particulièrement, les rivières Wanganui, Patea, Kahupokonui, qui sont si souvent citées dans les anciennes traditions, en mème temps que les ports de la côte Ouest, qu'il serait trop long d'énumérer.

ILE-DU-Milieu. - L'autre grande île, celle que d'Urville appelle l'Ile-du-Sud et que les Anglais désignent parle nom d'lle-du-Milieu, Middle-Island, à cause de sa position entre l'Ile-Nord et l'île Stewart, n'a pas moins de cent cinquantecinq licues marines détendue daus la plus grande dimension, (5jJ milles, d'après Thompson.) Sa largeur moyenne

(1) Ruapahu, par exemple, a 10,236 pieds anglais de liauteur ; le 'Tungi-riro est un peu moins élevé.

() Il faut 3 milles anglais pour faire une lieue. 
est de trente-trois lieues (110 milles, Th.) On estime sa surface à 5115 lieues carrées, dont la plus grande partie est occupée par la haute chaîne de montag'nes qui se prolonge dans toute son étendue, du S.-O. au N.-E. du Monde. Plusieurs de ces montagnes, qui sont fort élevées, restent en tout temps couvertes de neige. (1) Comme elles sont plus rapprochées de la côte occidentale de l'île, elles laissent, entre elles et la côte Est, de vastes terrains, qui descendent en pentes douces vers la mer. Leur grande élévation met la partie orientale de l'île à l'abri des vents d'Ouest régnants : par suite, elle jouit d'un très beau climat, et elle offre de grandes plaines et des terrains bien arrosés, qui expliquent pourquoi ce côté de l'île était plus habité que l'autre.

Du cap Farewell de l'Ile-du-Milieu jusqu'au cap Campbell, on compte directement à peu près 50 milles. C'est sur le côté du détroit de Cook que se trouvent les nombreux et beaux ports visités et découverts par Cook et par d'Urville. L'île qui porte le nom de ce dernier navigateur n'est séparée que par un étroit canal de l'Ile-du-Milieu, et c'est tout près de lá, dans un lieu vu pour la première fois par l'Astrolabe, qu'a été fondée, en 1842, la ville de Nelson.

Du cap Campbell au cap Bluff, qui se trouve dans la partie Sud, on compte cinq cents milles. Les ports principaux que l'on rencontre sur la côte de l'Ile-du-Milieu, c'est-idire sur le côté Est et le côté Sud, sont les ports appelés Hakaroa, Victoria, Otago (Dunedin.)

De l'extrémité S.ง.৩. de l'ìle, jusqu'iu hâvre Milford, il y a cent vingt milles. C'est dans cet espaso qlas re trouvent les canaux, ports et bassins, qui donnent i cette portion de l'île, une ressemblance si grande avec lo côté Onest de l'extrémité Sud de l'Amérique.

(1) La vraie direction est du N.-N.-E. au S.-S.-O. Cette chaîne a de 4 à 5000 pieds. La ligne de congélation porpétuelle est à 810 । pieds. Le mont Aspiring, couvert de glates, à 10,1000 pleds ce haut:. Le mont Cook, le plus liaut, à 1 ?,000 pieds : il est à 3 j milles de lia côte Ouest. 
On ne compte que cinquante milles du hâvre Milford à la baie Jackson.

De la baie Jackson, enfin, jusqu'au cap Farewell, il y a trois cents milles.

C'est-à-dire que, en comptant la ligne de côte depuis le cap Farewell, jusqu'au cap Campbell, le développement des côtes de l'Ile-du-Milieu n'a pas moins de 1020 milles, ou à peu près trois cent quarante lieues. D'Urville l'estimait même davantage.

En résumé, l'Ile-Nord a près de 500 milles de long et une largeur très variable; L'Ile-du-Milieu a 550 milles de long sur une largeur moyenne de 110 milles; et l'île Stewart, qui a une forme triangulaire, mesure environ trente milles sur chaque côté. Cette dernière est séparée de l'Ile-du-Milieu par le détroit de Foveaux, qui a environ quinze milles de largeur.

D'après d'Urville (1), le détroit de Cook, qui sépare l'Ile-duMilieu de l'Ile-Nord, n'a pas moins de 30 lieues dans sa plus grande largeur, entre les caps Farewell et Borell. Le même marin ne lui donne que dix milles, là où il est le plus étroit, c'est-à-dire entre la pointe Te-Ra-Whiti, près de la baie Palliser et l'île Arapaoa; mais il a probablement exagéré. Ce qu'il y a de positif, c'est que Thompson porte cette largeur à dix-huit milles, et Dieffenbach dit même trente mil . les. Parkinson donne à ce détroit 30 milles de long et 14 de large (2).

Quoiqu'il en soit, ce qu'il importe de remarquer, pour bien comprendre quelques-unes des traditions maori, c'est que le flot arrive dans le détroit de Cook du S.-E, et se dirige au N.-O. avec une grande vitesse, et que le jusant s'en retourne du N.-O. au S.-E. avec plus de force encore.

Nous ajouterons ici que le cap Foulwind gît par $41^{\circ} 46^{\prime} \mathrm{L}$. S. et 16908' Long. E.

Le cap Furewell està 14 milles de la baie de Tasman :

(1) Vorage de l'Astrolabe, p. 352.

(2) Voyage sur l'Endeavour, trad. par Henry, 2 vol. Paris, an V. p. 212. 
cette baie a 40 milles de large, de l'Est à l'Ouest, et 45 du Nord au Sud.

La baie de l'Amirauté a 15 milles de large.

Du cap Komaru à Cloudy-Bay, on compte 22 milles, et de Cloudy-Bay au cap Campbell, 12 milles.

L'extrémité Ouest du détroit de Cook, entre les caps Farewell et Borell, mesure 20 lieues ; son ouverture à l'Est, entre les caps Campbell et Kawa.Kawa, est de 40 milles.

Nous dirons encore que, d'après Cook, la Nouvelle-Zélande est à 280 lieues environ de Van-Diemen ; et, d'après Thompson, à 1200 milles à peu près de l'Australie. Suivant ce dernier, la ligne de développement des contours de tout le groupe n'aurait pas moins de 3120 milles. On sait que Crozet plaçait la Nouvelle-Zélande à 300 lieues de la Nouvelle-Hoilande, et que Cook portait cette distance à 780 milles.

Cent lieues plus loin, à l'Est de l'Ile-du-Milieu, sont les îles Chatham ; un peu plus vers le Sud-Est, l'île Antipode. $\mathrm{Au}$ Sud de l'île Stewart, au delà du $50^{\circ}$ parallèle, se trouvent les îles Auckland ; 3 degrés plus près du Sud, les îles Campbell et Macquarie ; et vers le $58^{\circ}$ degré, l'île Emerald. Toutes ces îles semblent avoir été, à une époque, reliées plus ou moins directement à la Nouvelle-Zélande proprement dite.

Noms donnés Par Cook et d'Urville. - Dès 1770 , Cook donna, comme noms des deux principales îles : Tovaï ou Tovy-Poennamoo, et Eaheinomauwe; le premier nom fut appliqué par lui à l'íle la plus Sud, le second à l'île la plus Nord. 11 ajoutait qu'il n'était pas sûr que l'île Sud fut comprise tout entière sous le premier nom ; mais il croyait que l'Ile-du-Milieu et l'ìle Stewart ne faisaient qu'une seule île. (1) Parkinson appelle l'lle-du-Milieu: Tooai-Panomoo.

Ce sontces noms que d'Urville a rendus, le premier par Tavaï-Pounamou, et l'autre par Ika-na-Maui : c'est ainsi que les missionnaires avaient appris qu'ils devaient l'être. Mais on ne comprend pas qu'il ait dit, dans ses recherches

(1) Voir à ce sujet, Vie de Cook, trad. par Castera, p. 92. 
sur la Nouvelle-Zélande : (1) "Quant aux noms que doivent porter ces deux grandes îles dans l'idiome du pays, Cook avait déjà annoncé ceux de Tovy-Poenammoo et d'Eaheinamawe avec une sorte d'incertitude. „La citation faite prouve que Cook a nettement donné ce dernier nom à l'Ile-Nord, et l'autre à une portion au moins de l'Ile-Sud, quoique d'Urville dise : “L'Astrolabe, en 1827, constata, qu'au détroit de Cook au moins, les naturels désignaient par ces noms les terres situées respectivement au Sud-Ouest et au Nord-Ouest du détroit. Sans doute il y eut erreur de transcription sur le manuscrit de Cook pour le dernier de ces noms. »

Cela, en effet, ne paraît pas très clair ; il est certain que s'il y a eu une erreur pour l'une des îles, il y a eu erreur également pour l'autre; mais, on l'a vu, Cook a appliqué nettement à chacune des îles le nom adopté par lui.

Du reste, on lit encore dans le Voyage de l'Astrolabe(2): « J'apprends de Tehinoui et Kakiore, à n'en pas douter, que l'île méridionale, du moins la partie qu'ils connaissent. porte indifféremment le nom de Kä̈-Koura ou de TavaiPounamou, et que celle du Nord s'appelle réellement Ikana-Maui. »

Enfin, d'Urville dit ailleurs : (3) "Pour éviter les inconvénients de l'orthographe anglaise, j'ai adopté définitivement Tawai-Pounamou pour l'île australe, et Ika-na. Maui pour l'île septentrionale, " c'est-à-dire ce qui avait été fait par Cook. Et il terminai î en disant : a Il est possible néanmoins que ces désignations ne doivent réellement s'appliquer qu'aux districts roisins du détroit de Cook; mais nous les emploierons, du moins jusqu'ì ce que l'on connaisse positivement ceux qui sont usités parmi les naturels. Suivant M. Kendall, le vrai nom de l'Ile-Nord était Ika-na-Maui, et celui de l'autre Kaï-Kohura. »

Aujourd'hui, comme on va voir, malgréle long séjour des

(1) Voyage cutour dit Monde, t. It, $2^{\circ}$ partie, p. 332.

(2) P. ¿ 0 .

(3) Voyage de l'Astrolabe, t. 11, ふैe partie, p. 333. 
Anglais sur ces îles, on n'est guère plus fixé que d'Urville sur le véritable nom de chacune d'elles, et, à plus forte raison, sur la signification de ces mots, sur le compte desquels ne s'accordent même pas les écrivains les plus autorisés.

C'est ainsi que Shortland dit: (1) “ Le nom de Tovy-Poenammoo, qui devrait être écrit Tewaï-Pounamu, c'est-à-dire l'eau du Pounamu, et qui est encore regardé par beaucoup de personnes comme le nom de l'Ile-du.Milieu, est, ainsi que le soupconnait le capitaine Cook, seulement le nom d'un lieu particulier où les indigènes trouvent le talc ou jade vert, avec lequel ils font des ornements et des haches, et non le nom général de toutle distrič Sud. "Et il ajoute: « Eaheinomawe, qu'on pensait être le nom de l'IleNord de la Nouvelle-Zélande, était l'expression : He ahi no Maui, le feu de Maui.

"Il est probable, dit-il, que le vieux chef de Totaranui, qui donnait les renseignements à Cook, n'avait pas compris qu'on lui demandait seulement le nom de la terre, au Nord du détroit, mais plutôt ce qu'il y avait de remarquable dans cette direction. Sa réponse : « He ahi no Maui, » doit avoir été faite en pensant à la montagne brûlante, Tongariro, absolument comme il avait répondu, pour l'lle-duMilieu, à la question faite, en citant la célèbre eau de Pounamu placée au loin. (2) »

Plus récemment, M. Thompson, l'historien de la Nouvelle-Zélande, a cherché, lui aussi, à expliquer l'origine des mots entendus par Cook, et il l'a fait un peu différemment.

Suivant lui, ces noms auraient été donnés au grand navigateur anglais, pour répondre à la demande qu'il faisait ; mais on lui aurait dit, pour l'Ile-Nord, au lieu de : "Feu de Maui, » que c'était. "Une chose pèchée de la mer par Maui, "He mea lii no Marii; et, pour l'Ile-du-Milieu, «que c'était le lieu du jade vert, „Te-vahi Pounamu.

De sorte que, pour 'Thompson, ce n'est plus le Te Ika na

(1) The Southern districts of New-Zcaland, p. 155.

(2) Southern districts, p. 156. 
Maui des voyageurs anciens, mot qui a été écrit par Cook Eaheinomawe, mais seulement la chose, he mea. Ce qui ne l'a pas empêché, dans la carte qui accompagne son livre, de l'appeler, en changeant encore un peu : Te Ika a Maui, au lieu de He Mea ki no Maui ; et d'y remplacer le mot Wahi, d'abord indiqué par lui pour l'Ile-du-Milieu, par le mot Te Waï Pounamu, c'est-à-dire l'eau du jade vert, que Shortland regarde comme étant le véritable (l).

En somme, c'est avec raison, croyons-nous, que, dans sa préface, Taylor dit que Ika-na-Maui était l'ancien nom de l'Ile-Nord et que c'est ce nom qui fut indiqué à Cook; mais il aurait dû ajouter : pour l'Ile-Nord seulement et non pour tout le groupe. Cook, du reste, l'exprime lui-même en cherchant à rendre le son du nom de l'autre grande île entendu par lui. En ce qui concerne cette dernière, peut-être, au lieu de Tewaï ou Tawaï, faudrait-il plutôt lire Hawaï, avec le $h$ fortement aspiré. Ce serait une des meilleures preuves que l'Ile-du-Milieu est bien réellement l'Hawahiki.

Quoi qu'il en soit, en présence de ces divergences, nous croyons devoir ajouter ici quelques recherches linguistiques sur l'étymologie des noms donnés par les premiers navigateurs aux principales îles de la Nouvelle-Zélande. Elles

(1) Cette assertion de Thompson nous rappelle ce qui est arrivé si souvent à Cook, et particulièrement dans l'une des îles de la Société, à Eimeo .

Il existe dans lî̀le Eimeo une baie appelée Opunohu; c'est celle que Cook fit connaître sous le nom de Talou-Harbour, que lui donnent encore beaucoup de cartes.

Tout près de l'entrée de cette baie, il y a, à droite, un petit rocher appelé par les indigènes Tareu ou mieux Tarehu, mot qui signifie, faire illusion. Il est probable que Cook regardait ce rocher, quand il demanda le norn de la baie dans laquelle il entrait, et qu'on lui répondit en lui donnant le nom du rocher sur lequel il fixait les yeux. Il prit naturellement ce nom pour celui de la baie Opunohu, mais il l'estropia, suivant son habitude. L'erreur de son était facile, et l'erreur d'application la compléta. Cook, l'ailleurs, avait, dans ce moment, bien autre chose à faire qu'à s'occuper de linguistique. 
montreront combien ces noms ont été mal entendus et mal écrits, et combien leur véritable signification est restée obscure.

Recherches linguistiques. - Remarquons d'abord que Poennamoo ou Pounamou, tel que l'écrit d'Urville, n'est pas un mot maori, et que Cook n'a pas dit Tavaï, comme le fait d'Urville, mais bien Tovy ou Tovaï, en français.

Dès lors, ce ne peut être que l'un des mots suivants, réunis et n'en faisant qu'un pour les oreilles européennes:

Po, nuit, saison; lieu ou se réunissent les esprits ; être tard.

$E$, préposition : par ; interject. vocative ; particule empioyée pour conjuguerle présent et le futur des verbes.

Namu, moustiques ou mouches de sable (1).

Le mot Tovy, ainsi écrit par Cook, doit être prononcé Tovaï ou Towaï. Or, voyons quel est le mot maori qui a pu être entendu par le navigateur anglais :

Towai, est le nom d'une plante, Leptospermum racemosum; mais le mot Tovaï n'existe pas, et le mot Tavaï, adopté par d'Urville, n'existe pas davantage.

Tawai, est au contraire maori; il a plusieurs significa-tions : subs. : canot ou pirogue, sans bords attachés, synonyme de tiwaï, pirogue; adj. : tracassé ; verbe : tourmenter, railler.

Tawhar est le nom d'un arbre, et il signifie en outre: grandir, imiter, copier, suivre.

Tawahi signifie : de l'autre côté.

Ta, warteau, vent, escope ; couper, abattre, tatouer, respirer.

Whai, fixe, fixé, qui retourne toujours au même lieu. Wai, eau, rivière.

(1) Il est à remarquer que les moustiques et les mouches de sable sont très communs à la Nouvelle-Zélande. Forster se plaint beaucoup des mouches de sable noires qu'il nomme Tipula alis incumbentibus. Elles étaient fort nombreuses à la baie Dusky, et leurs piqûres causaient des démangeaisons insupportables. 
On a dit que ces mots Tovy-Poenamoo, de Cook, signifiaient " poisson ou île produisant la pierre appelée jade vert, " d'après les croyances maori. Mais il est certain que cette pierrea aussi d'autres noms : tel est celui de Kahurangi, joyau, chose précieuse, mot-à-mot « robe des cieux, vêtement céleste, » qu'on lui donne quand elle est pure, transparente. Chaque qualité de jade a son nom particulier.

Il est vrai que, dans son dictionnaire, Dieffenbach a donné au jade vert le nom de pcunamu; mais on sait qu'il a fort peu de valeur linguistique.

D'un autre côté, comme on vient de le voir, d'Urville a transcrit le Poenammoo de Cook par Pounamou. Il est a croire que, suivant son habitude, il n'a pas donné toute sa valeur à chaque lettre de la syllabe pou, qu'il n'a pas voulu dire po-ou, mais seulement pou, que, d'après l'orthographe adoptée par les missionnaires anglais pour les langues polynésiennes, nous écrivons $p u$. Or, en Maori :

$P u$, signifie : subst. tribu; adject. identique, précis.

$\boldsymbol{P o - u}$, poteau pour une maison, palissade.

Nous sommes à peu près certain que, d'Urville a voulu écrire $p u$, et ce mot signifiant tribu, on peut supposer qu'on aura répondu tout simplement à Cook, qui interrogeait sur l'île : «On est tracassé (sur cette terre), par des tribus ou nuées de moustiques; » ou encore, "La nuit, par des moustiques. »

T'awai, tourmenté, tracassé.

Po, nuit.

$E$, par.

Namu, mouches de sable ou moustiques.

Que cette supposition soit vraie ou fausse, il est certain que les mots Tovai ou Tavai Poenammoo ou Pounamou, ainsi écrits, ne sont pas des mots zélandais; en outre, Williams et les autres missionnaires anglais, si versés dans la langue maori, n'ont jamais donné ces noms comme étant ceux de l'île à laquelle Cook et d'Urville les ont appliqués. Mais aucun d'eux n'a encore fait: connaître le véritable nom de cette île, et tous les Anglais, navigateurs, missionnaires 
ou géographes, se sont contentés de l'appeler Middle-Island, Ile-du-Milieu.

Le missionnaire Williams parle bien, il est vrai, dans son dictionnaire, du mot pounamu, comme d'un nom maoli ; mais il ne lui donne absolument que la signification de bouteille en goëmon, ou seulement de bouteille, comme si ce nom n'avait été appliqué que par extension. Il ne désigne le jade vert par aucun mot.

Il n'en est̂ pas de même, il faut le dire, de tous les écrivains qui l'ont suivi ou précédé. On vient de voir que Dieffenbach avait déjà dit que pounamu était le nom du jade : c'est égralement ce nom que lui accordent Shortland et Thompson. Seulement Shortland, après avoir cité des vers maori, où se trouve cette désignation, fait la remarque importante que le kahurangi ou pierre verte, pounamu, de première eau, est d'un plus grand prix que l'ornement qui est fait avec la dent d'un énorme requin, le Maka-o-T'aniwha. Ce nom de kahurangi serait donc au moins celui du jade fin transformé en ornement (1).

Voici, du reste, les vers maori où se trouve le mot pouna$m u$; ces vers ont probablement été donnés par quelque élève des missions.

\section{E hara tena:}

Cela est sans valeur :

He iwi ika tena.

C'est un os de poisson.

Ka-pu-ano ko te iti pounamu.

Mais ce qui en a, c'est le petit pounamu,

Ko te kino ruamata,

Cette ancienne source (provenance) du diable,

$E$ tau te wheoro

Dont la renommée

Ki tua atu o te rangi. E :

S'étend jusqu'aux limites des cieux. Eh !

Shortland ne souligne que le mot traduit et ne dit rien de plus de sa signification.

(1) Nous croyons, avec Taylor, (p. 120), quau lieu de kahurang $i_{i}$ il faut lire tuku rangi : tuku descendre; rangi, eiel. 
Comme Thompson, le révérend Taylor (1) appelle le jade vert, pounamu; il dit qu'il est abondant dans l'Ile-du-Milieu qui a tiré son nom de cette roche.

En résumé, malgré cet accord des écrivains, nous sommes convaincu qu'il y a eu erreur dans l'application de ce mot. Ce qui semblerait faire croire qu'il a un tout autre sens, c'est le proverbe maori suivant, traduit par Taylor, et où il a, du moins, une signification toute différente : $\mathrm{He}$ pounamu ka kano rua (2) \& Un lézard de deux couleurs ou changeant de couleur comme le caméléon. »

Ce proverbe maori s'appliquerait donc aux gens à double face, à double apparence; mais nous croyons que la traduction de Taylor n'est pas exacte.

On sait, du reste, que c'est sur le territoire des Ngatimamoe, dans l'Ile-du-Milieu, que se trouvait le jade vert, c'està-dire dans l'O.-N.-O. de la péninsule de Banks ou le S.-O. du cap Karaka (Campbell). Il se trouvait de plus dans un ou plusieurs lacs, mais surtout dans celui de Wakatipua, comme nous le dirons quand nous en serons aux localités de l'Ile-du-Milieu.

Quoi qu'il en soit, le nom véritable de l'Ile-du-Milieu, Middle-Island, des Anglais, n'a encore jamais été donné par les navigateurs, les missionnaires et les géographes ; mais, pour nous, ce nom n'est autre que celui de Kawaï, qui, nous en sommes convaincu, est celui que Cook a rendu par Tovy et d'Urville par Tavaï, en se rapprochant beaucoup plus que le navigateur anglais de sa prononciation maori.

Kawaï, en Maori, signifie race, lignée, rejetons des plantes. Or, il est à remarquer qu'aux Fiji, Kawaï est le nom d'une espèce de petite igname ressemblant à la patate malaie, et que là on nomme Kumara, le Convolvulus batatas, patate douce de la Nouvelle-Zélande, qui y estaussi appelée Kawai-ni-Papalangi.

D'Urville rapporte qu'ayant interrogé, à ce sujet, l'un des

(1) Ouvr. cité, p. 120 et 244.

(2) Kakano, graine, semence ; rua, double, deux. 
chefs de l'Ile-Nord ou Ika-na-Maui, Tuai lui dit que le véritable nom des indigènes de la grande île Sud, était KaiKoura, et non Kai-Kohura comme il a écrit, c'est-à-dire mangeurs d'écrevisses. C'était également l'opinion du missionnaire Kendall, qui tenait ce renseignement du même chef de l'Ile-Nord. Ils n'avaient pas remarqué que ce n'était qu'une épithète de mépris donnée par des ennemis, absolument comme cela a lieu aux Marquises, à Tahiti, etc., et que, par conséquènt, ce n’était probablement pas le véritable nom. Par contre, Tuaï appelait les habitants de l'Ile-Nord Kainga-Maori, mot que d'Urville a mal écrit en disant Kainga-Maodi. Kainga signifiant lieu de séjour, demeure, village, et Maori, indigènes, naturels, habitants du pays, on peut traduire Kainga-Maori par autochthones. (1)

Pour le chef zélandais Tuai, l'Ile-Nord aurait donc été le point d'origine des Maori de l'Ile-du-Milieu ; mais, comme

(1) A l'occasion du mot Kainga-Maori, qu'on nous permette de préciser la signification du mot pakcha, qui a beaucoup intrigué d'Urville. Il disait qu'il était employé pour désigner tous les Européens, ou plutôt tous les blancs, tandis qu'il signifie étranger. « Je n'ai jamais pu savoir, ajoute-t-il, d'où cette désignation tirait son origine. Ce qui m'a surpris, c'est qu'elle m'a semblé adoptée sur les divers points de la Nouvelle-Zélande, et cela donne lieu de croire que cette dénomination existait même avant les voyages de Cook. Les Nouveaux-Lélandais avaient done, depuis longtemps, connaissance d'une race d'hommes distincte de celle à laquelle ils appartenaient. »

Ce mot pakcha, en effet, ne veut dire qu'étranger, qui n'est pas du pays ; comme le mot maori signifie indigène, qui est du pays. Nous ajouterons seulement que si l'expression Pakeha est aussi générale, cela prouve que la langue de toutes les tribus zćlandaises est absolument la même; mais elles ont pourtant d'autres mots signifiant la même chose, tels que Tauhou, Putere, Konene (a). Il est plus que probable que le mot Pakeha cxistait avant l'arrivée de Cook, et même ajouterons-nous, avant l'arrivée de Tasman Evidemment, puisque les Maori avaient le mot, ils possédaier $t$ depuislongtempsla connaissance d'étrangersvenus de points différents de leur île, quand ce ne seraient que ceux que Cook rapporte être venus d'Hea wise.

(a) Ce dernier nom est donné à l'éniigré a'us e tribu raincue. disparue mais aussi à tout émigrant étranger. 
on verra plus loin, ce chef était probablement aveugié par son patriotisme. Toujours est-il que ce ce sont ces renseignements qui ont fait dire par d'Urville, d'abord, et, depuis, par plusieurs autres écrivains, tels que Shortland, Thomp. son, etc., que l'lle-Nord avait probablement peuplé les autres îles de la Nouvelle-Zélande. Nous démontrerons que cette opinion est complètement détruite par la traduction des légendes maori, publiées par le gouverneur Grey.

En définitive, un seul nom, parmi ceux donnés aux deux grrandes îles par les premiers navigateurs, est bien certain, c'est celui d'Ika-na-Maui (1), pour l'Ile-Nord. Mais ce nom n'eș́ lui-même qu'un surnom donné en souvenir de Maui, comme celui d'Aotearoa a été donné par Turi, l'un des premiersémigrants d'Hawahiki. Avant ces noms, comme nous le montrerons, cette île était appelée, d'après les traditions: Nuku-roa ef Uku-rangi ; ou encore Tua-whenua ou Tauwhenua, c'est-à-dire la grande terre et la terre étrangère (2).

Nous croyons que l'Ile-du-Milieu, dont le nom n'a été Lonné par personne jusqu'à ce jour, doit être appelée Kawai.

Nous ajouterons que, si Dieffenbach a été bien informé, le mot Kaikoura, en outre de la signification que lui donnent d'Urville et Kendall, est aussi le nom d'une chaîne de montagnes del'Ile-du-Milieu ou Kawaï, et qu'enfin ce même mot Kaikoura, d'après quelques-uns, ou Kaikora (3), d'après les cartes, était lenom d'une localité qui touche le cap Looker'son de Cook, sur la côte Est de l'Ile-du-Milieu.

Quant a l'ille Stewart, nous avons vu plus haut que les

(1) Ika, poisson ; na, de ; Maui, Maui.

(2) Nuhu, étendue, distance; roa, grande, longue.

Uku, argile blanche; rangi, ciel, du ciel.

Tuawhenua, grande terre.

Tauvhenua, terre étrangère.

(3) Kaï, manger, mangeur ; Koura, écrevisse de mer et d'eau douce; kora, feu, bois à brûler; korora, oiseau, manchot, pingouin. 
indigènes lui donnent le nom de Raki-ura (1), mot qui semble désigner une terre noire, aride, desséchée.

MÉrÉorologie. - Nous devons signaler les vents de la Nouvelle-Zélande avec d'autant plus c'e soin, que ce sont eux qui aideront le plus à faire comprendre la thèse que. nous soutenons.

«Nulle part, dans le monde, a dit d'Urville (2), les vents ne règnent avec autant de fureur que sur les côtes de la Nouvelle-Zélande, et si elles avaient été connues des anciens, il est bien certain que c'est là qu'ils eussent établi l'empire d'Eole. Le temps en apparence le plus beau, le ciel le plus pur, ne peuvent offrir de garanties contre leur violence.

- Tasman, le premier, éprouva la violence des vents qui règnent dans ces paragres. Cook, dans sa belle reconnaissance, manqua plus d'une fois en être la victime. Ils mirent Surville à deux doigts de sa perte et n'éparg’nèrent point Marion. La Coquille, en juin 1823, vit un rude échantillon de ces tourmentes; enfin, sur l'Astrolabe, ces bourrasques terribles nous tourmentèrent cruellement, quoique nous fus. sions alor's au milieu de l'été. »

Tous les navigateurs ont pu d'ailleurs s'apercevoir de la force avec laquelle soufflent les vents dans ces parages; et si Cook, particulièrement dans ses deux premiers voyages, eut beaucoup à en souffrir, d'Utrville, sur l'Astrolabe, en janvier 1527, ne fut pas plus épargné, comrıe il le rapporte dans son Journal de Voyage (3). On y voit que l'Astrolabe, partie du port Jackson le 19 décembre, resta plus de 25 jours pour atteindre la Nouvelle-Zélande, après avoir recu un coup de vent de S.-E. d'abord, puis deux violents du N.-O., et que, pendant son exploration des deux îles, ces mêmes vents souffièrent, de manière à compromettre quel-

(1) Raki sec, sèche, desséché ; ura, être brun, foncé ; briller, en parlant du lever ou du coucher du soleil.

(2) Vorage de l'Astrolabe, p. 33\%.

(3) T. II, Ire partie, p. 2. 
quefois le navire, variant du N.-O. àl'O.-S.-O, S.-O, O. et O.N.-O. On peut lire, à la page 49 du journal, le coup de vent de N.-O. reçu au mouillage près de l'entrée du Bassin des Courants, et pages 121,133 , celui du N.-N.-E. et N'-N.-O qui manqua faire périr $\mathrm{l}^{\prime}$ Astrolabe dans la Baie d'Abondance.

Les vents les plus fréquents et les plus furieux de ces îles sont justement les vents de N.-O et de S.-O, variant à l'O.N.-O. et à l'Ouest. On a remarqué que les vents qui règnentà la Baie des Iles, pendant 1 hiver, c'est-à-dire de février jusqu'a la fin de septembre, sont les vents du Sud et du SudOuest, et qu'ils continuent mème souvent de souffler de cette partie jusqu'à la fin d'octobre.

Ces vents de Sud-Ouest et de Sud sont violents durant l'hiver; ils occasionnent naturellement de très grosses mers surtout sur la côte occidentale qu'ils rendent presque inabordable pendant toute cette saison.

Pendant tous les mois d'été, au contraire, les vents d'Est dominent.(On a remarqué qu'ils fraîchissent tous les quinze jours $u$ u trois semaines, au point de devenir de petits coups de vent qui durent rarement plus de deux ou trois jours.

Ainsi, les vents de la Nouvelle-Zélande permettent, à certaine époque, d'aller aussi bien dans le Nord-Est que dans l'Est et, comme on le verra, si le chant traditionnel rapporté par Kendall est peu exact, il semble faire allusion du moins à quelque départ de la Nouvelle-Zélande pour l'Océanie, en montrant en même temps qu'un prêtre était à la tête des émigrants.

S'il fallait en croire d'Urville (1), les principaux vents devraient, d'après les renseignements qui lui furent donnés par le chef Rangi, dans la baie Huraki, être ainsi désignés :

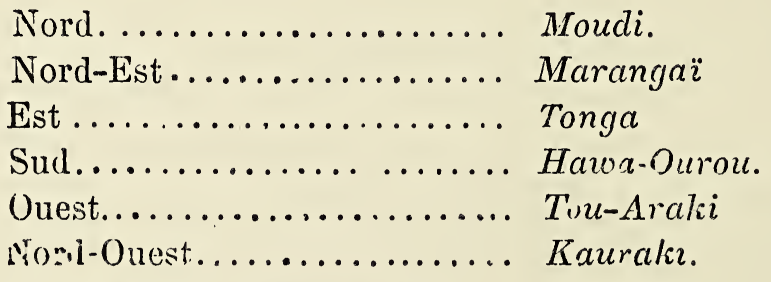

(1) Ouvr, eité, t. Il, Irn partic, p. 171. 
Or Moudi n'est pas Maori ; peut-être faut-il lire Muri, qui est le nom donné à une brise de vent quelconque. D'Urville dit, avec raison (1), que les noms Tolaga et Tegadou, sont inconnus des habitants de la Nouvelle-Zélande, et qu'il est avéré depuis longtemps que Cook, si plein de sagacité d'ailleurs, avait très peu d'..ptituda à saisir les noms des peuples qu'il visitait, et surtout à les représenter par l'écriture; maisil nous suffira de donner, $d$ après les missionnaires anglais, les noms véritables des principaux vents, pour monter qu'on peut en dire tout autant de lui.

Ces noms sunt les suivants :

Nord, - Kotiu

Nord-Est, - Pawha-karua (Williams); Tokarau (Taylor.)

Nord-Ouest, - Hauatiu; Tupatiu; Kotiu; Tuaraki.

Sud-Est, - Putonga-marangaï. (2)

Est, - Paeroa, (chez les Whakatane;.

Sud, - Tonga.

Sud-Ouest, - Tonga-ko-taratara.

Ouest. - Haucuru ; Hauarahi; Kapekape, (au cap Est).

D'après Dieffenbach, ces noms seraient :

Nord, - Hauraro.

Nord-Est, - Marangai-hauraro.

Nord-Ouest, - Hauraro-hauuuru.

Est, - Marangai.

Sud-Est, - Tonga-marangai.

Sud, - Toriga

Sud-Ouest, - Tonga-hauauru.

Nous croyons ces noms moins exacts que les précédents.

Nous devons faire remarquer ici qu'on n'est pas encore bien fixé, même aujourd'hui, sur la valeur exacte des mots Tonga et Tokarau. Ainsi, Taylor avance, à la page 113 de son ouvrage, que le mot Tonga, signifie vent de Nord-Est, et, à la page 187, que c'est le nom donné par les Maori au vent du Sud. A la page 188, il dit que Tokarau est le vent du Nord-Est ; mais il est évident qu'il se trompe, quand

(1) T. II, lre partie, p. 106.

(2)-Marangai ne signifie que grain, vent frais, mauvais temps. 
il prétend que ce mot, sous la forme de Tokalau, signifie Nord aux Fiji. Le savant linguiste Hazlewood, si autorisé pour ces îles, dit, en effet, dans son dictionnaire, que ce mot signifie seulement vent d'Est (1).

Il y a une remarque importante à faire à l'occasion de ce vent d'Est, suffocant, à certaines époques de l'année, pour les ̂̂les Fiji, et que, il est vrai, le même Hazlewood dit, ailleurs, souffler du Nord, de novembre à avril : c'est qu'en plusieurs endroits, sur la côte Est et dans l'intérieur de l'Ile-du-Milieu, où existent des chaînes de montagnes s'élevant à 3000 pieds environ au-dessus du niveau de la mer, on éprouve parfois, dans l'été, un vent chaud et sec. Ce vent chaud fond la neige des sommets des montagnes, et cette fonte enfle les rivières qui se répandent sur les plaines et les dévastent suivant la configuration des terres. Heureusement pour la végétation que ce vent chaud qui la brûle, et qui élève le thermomètre de 20 ou 30 degrés, précède or dinairement la pluie.

En somme, on l'a dit avec raison, il n'y a peut-être pas de contrée en Europe où l'atmosphère soit plus fréquemment agitée par les vents que la Nouvelle-Zélande. C'est surtout en se rapprochant du Sud que les vents se succèdent arec violence. Le détroit de Foveaux est encore plus renommé que celui de Cook par ses grains et ses coups de vent. Mais nous le répéterons, les plus fréquents, en même temps que les plus furienx, sont ceux de la partie de l'Ouest, c'est-àdire, depuis le Sud-Ouest jusqu'au Nord-Ouest.

Nous ajouterons, comme remarque de quelque intérêt pour les linguistes, qu'on appelle, à la Nouvelle-Zélande : Le jour, - Awatea.

Le matin, - Ka-mo-ronga-te-ra. (Le soleil se dirige en haut.)

Midi, - Ka-poutumaro te ra. (Le soleil se tient droit comme un poteau.)

(1) Aux Fiji, toka est le verbe être ; lau signifie : a au vent »; tandis que ra signifie : " sous le vent ». Il est curieux de voir les Fijiens exprimer l'Ouest par $r a$ : ce mot ne serait-il pas le diminutif de raro qui, à la Nouvelle-Zèlande, signifie : " dessous, en bas ?» 
Après-midi. - Ka-titaha-te ra. (Le soleil a passé (baissé par dessus).

Le soir, - Ahi-ahi. (Le temps des feux).

Le coucher du soleil, - $K a$-to-te-ra. (Le soleil se couchè). Minuit, - Ka waea te po, Ka waea te ao. (La nuit et le jou sont divisés).

Le lever du soleil, - Ka elee te ra. (Le soleil monte).

Le point du jour, - Ka whakaataata te ata. (Les apparences (ombres) du jour se montrent.)

Le vent,-Matangi; Hau; Muri; Ko hengihengi; Kotengi. tengi.

La brise, - Muri.

La brise de terre, - Paraki; Parera.

La brise de mer, - Muritä̈.

Le vent debout, - Hautumu.

Le vent frais, - Paroro.

Le calme, - Marino.

Le vent frais avec mauvais temps, - Marangä̈.

Le revolin, - Haupongi; Haupurohu; Hauripo; Haurutu.

Le Nord, point cardinal, - Nota. (1)

Le Sud, id. - Tonga.

L'Est, id. - Rawhiti; Whitinga o te ra (lever du soleil) ; Putanga o te ra

L'Ouest, id. - Ka to te ra (le soleil se couche.)

La température de la Nouvelle-Zélande est variable, mais tempérée. Elle varie le même jour de 40 à 70 degrés Fareinheit, ( $4^{\circ} 5$ à $21^{\circ}$ cent.) dans l'espace qui sépare le cap Nord de l'île Stewart.

(1) D'après Taylor, c'est le nom de l'étoile du Nord: ce serait plutôt raro.

Il est à remarquer, à propos de ce mot nota, désignant le point cardinal Nord, que les (îrecs, dans l'origine, donnaient le nom de vòtos à tous les vents qui venaient de l'Equateur, et celui de $\beta$ op'šs; à tous ceux qui soufflaient de la bande du pôle, entre l'Orient et le Couchant. C'est plus tard seulement qu'ils distinguèrent les vents qui soufflent des 4 points cardinaux en ; Bops̀ $\alpha$ s Nord ; Eüeros

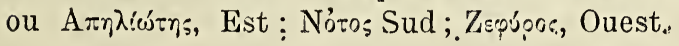


La température des nuits est plus froide que celle des jours d'environ 12 degrés cent.

Les mois les plus chauds sont janvier et février qui correspondent a juillet et août en France, et les mois les plus froids sont juin et juillet qui correspondent à décembre et janvier.

La différence entre la moyenne température des mois les plus froids et les plus chauds, dans l'année, est d'environ 20 degrés cent.

Les grandes variations de température sont plus fréquentes dans l'Ile-du-Milieu que dans l'Ile-Nord.

On a remarqué que la température de l'intérieur est plus chaude pendant l'été, et plus froide pendant l'hiver que celle des côtes.

En résumé, la température moyenne, dans l'lle-Nord, est de $57^{\circ} \mathrm{F}$. $\left(14^{\circ} \mathrm{C}\right.$.) et de $52^{\circ} \mathrm{F}$. ( $11^{\circ} \mathrm{C}$.) dans l'Iie-du-Milieu.

La neige tombe quelquefois dans l'Ile-Nord et dans l'Iledu-Milieu ; elle couvre, pendant toute l'année, les sommets des plus hautes montagnes des deux îles : Ruapahu, (10,000 pieds, Tongariro, dans l'lle-Nord, et les montagnes de l'Ile-du-Milieu appelées les Alpes du Sud, monts Cook, etc.

Quelquefois aussi on observe de la glace pendant l'hiver.

Il tombe beaucoup de pluie à Taranaki. (New-Plimouth) sur l'Ile-Nord; et à Otakou, (Dunedin), sur l'Ile-du-Milieu ; mais le nombre des jours de pluie est plus grand dans l'lleNord que dans l'Ile-du-Milieu.

On comprend, d'après cela, qu'il existe constamment une humidité considérable, attribuée aussi, pendant les temps secs, à l'évaporation continue venant de la mer du Sud.

Ajoutons enfin que les vents de l'Equateur, amenant avec eux la pluie, font baisser le thermomètre, et que les vents de Sud, ou vents polaires, qui sont fréquemment accompagrnés de beau temps, le font monter.

Les tableaux suivants donneront une idée exacte de la météorologie de la Nouvelle-Zélande. 
LES POI YNESIENS.

\begin{tabular}{|c|c|c|}
\hline (5) & ลฺฺ & $=\infty 0^{N}= \pm 2$ \\
\hline$\left|\begin{array}{l}z z z \\
z i\end{array}\right|$ & 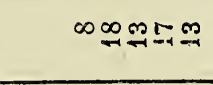 & 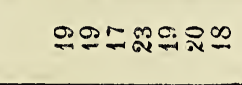 \\
\hline te & $* 0=\infty$ & 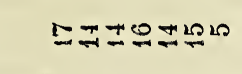 \\
\hline 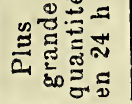 & 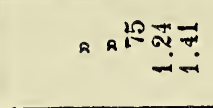 & 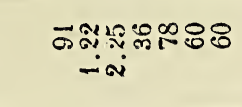 \\
\hline 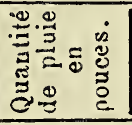 & a & 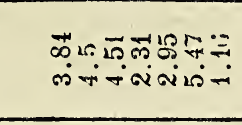 \\
\hline 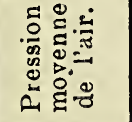 & 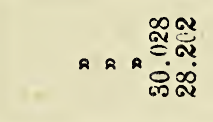 & 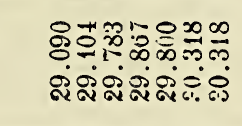 \\
\hline 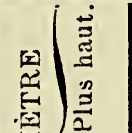 & ×ละ & 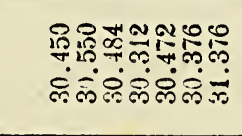 \\
\hline 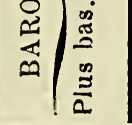 & 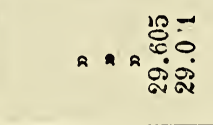 & 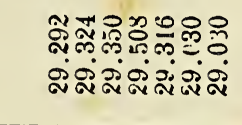 \\
\hline 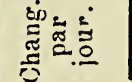 & 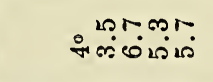 & 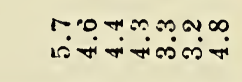 \\
\hline 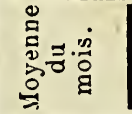 & 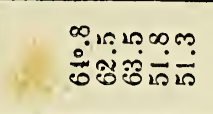 & 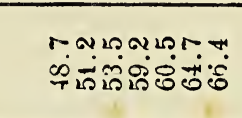 \\
\hline 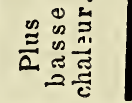 & 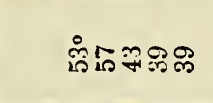 & 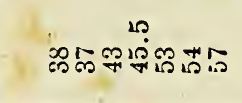 \\
\hline 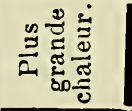 & 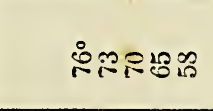 & ‥ \\
\hline 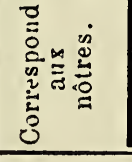 & 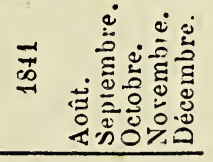 & N \\
\hline : & 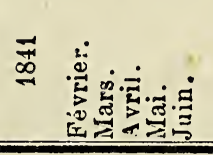 & 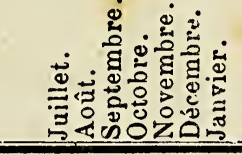 \\
\hline
\end{tabular}




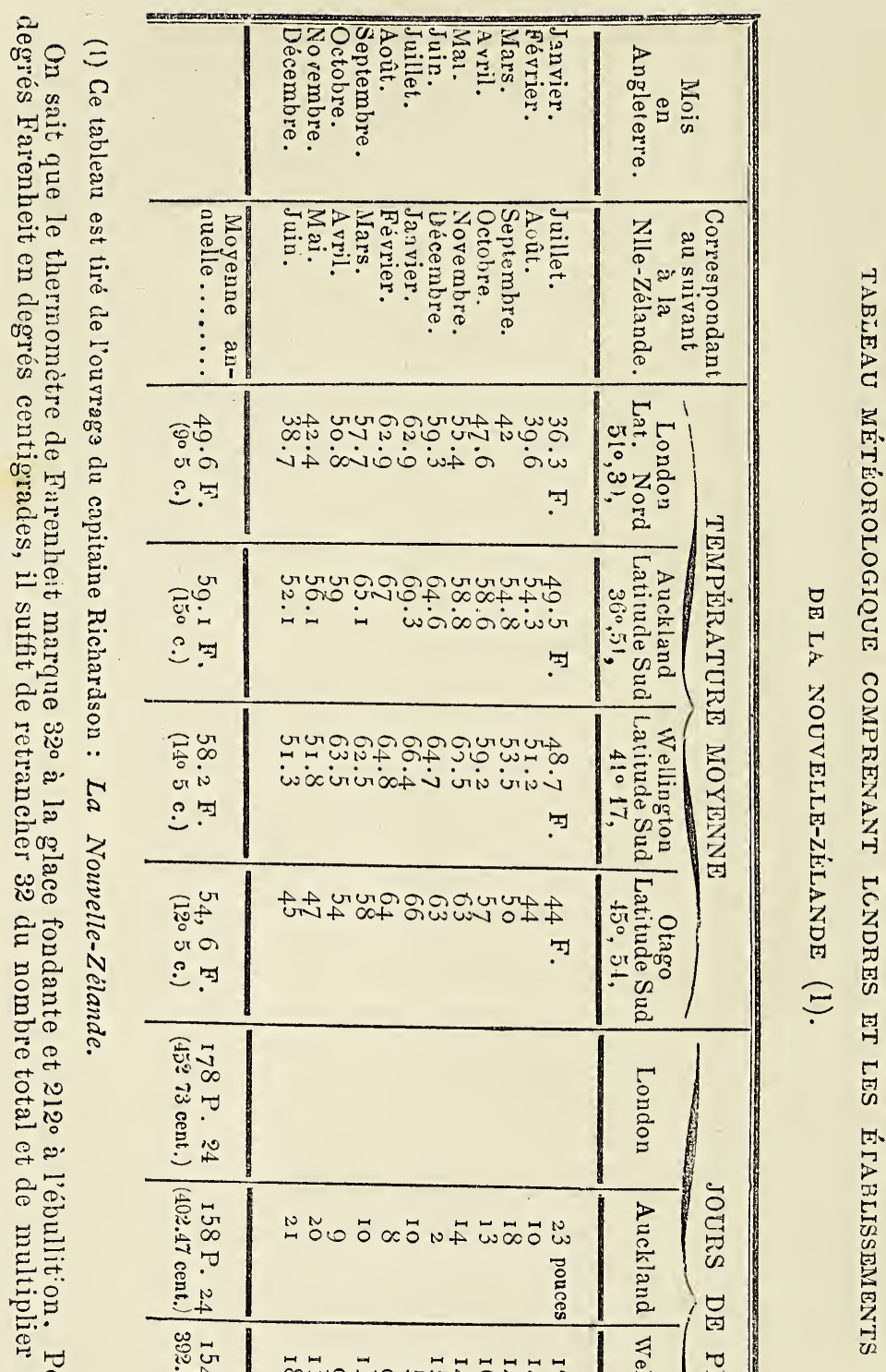


TABLEAU DE LA TEMPÉRATURE MOYENNE (1)

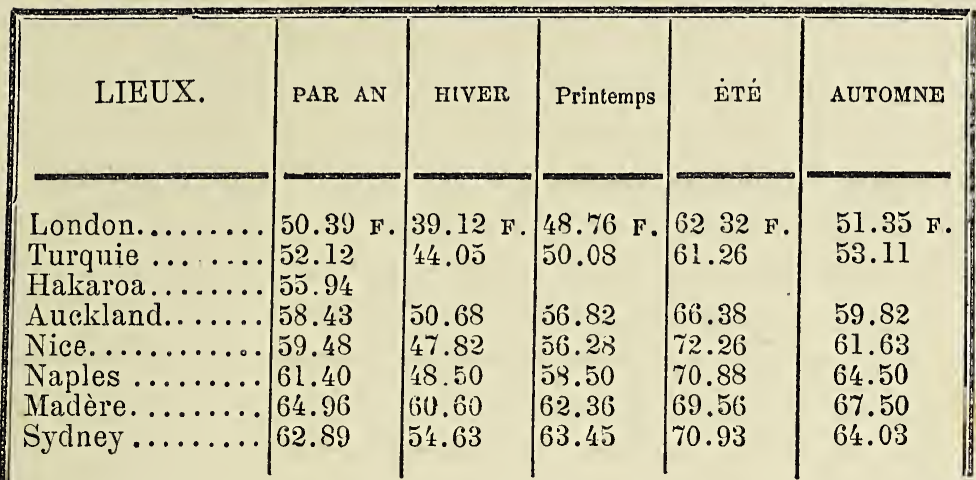

Nombre de jours de pluie à Wellington en dix mois, 133.

Nombre de jours pendant lesquels le vent a soufflé du Nord ou du Nord-Ouest, 202.

Nombre de jours pendant lesquels le vent a soufflé du Sud ou du Sud-Est, 141 .

(1) Ce tableau est extrait do l'ourrage du Docteur Shortland.

TABLEAU DONNANT QUELQUES-UNS DES ÉLÉMENTS DU CI.IMAT

DE LA NOUYELLE-ZELLANDE (1)

\begin{tabular}{|c|c|c|c|c|c|c|c|}
\hline \multirow[b]{2}{*}{ LIEUX } & \multirow[b]{2}{*}{ LATITUDE } & \multirow[b]{2}{*}{$\begin{array}{l}\text { MOYENNE } \\
\text { températur } \\
\text { annuelle }\end{array}$} & \multirow[b]{2}{*}{$\begin{array}{c}\text { Calcul } \\
\text { en } \\
\text { poilces de } \\
\text { la pluie } \\
\text { tombée. }\end{array}$} & \multirow[b]{2}{*}{$\begin{array}{l}\text { Nombre } \\
\text { dejours } \\
\text { pendant } \\
\text { lesquels } \\
\text { la pluie } \\
\text { a } \\
\text { tombé }\end{array}$} & \multirow[b]{2}{*}{$\begin{array}{c}\text { Hoyenn } \\
\text { annuelle } \\
\text { du } \\
\text { baromèt. }\end{array}$} & \multicolumn{2}{|c|}{ Température } \\
\hline & & & & & & $\begin{array}{l}\text { des } \\
\text { mois } \\
\text { les } \\
\text { plus } \\
\text { froids }\end{array}$ & $\begin{array}{c}\text { des } \\
\text { mois } \\
\text { les } \\
\text { plus } \\
\text { chaud }\end{array}$ \\
\hline$\Xi K$ & $35.20 \mathrm{~s}$. & & & 147 & & 47 & 60 \\
\hline uckla & $36.51) \mathrm{s}$. & $59 . / 12$ & $15.1 / 2$ & 160 & 2995 & 51 & 68 \\
\hline & s. & & 59 & 125 & 29.86 & 46 & $6 \dot{z}$ \\
\hline & $41.16 \mathrm{~s}$. & 56 & $49.1 / 4$ & 99 & 29.79 & 45 & 65 \\
\hline gٔ Nelson. & $41.15 \mathrm{~s}$. & $5 t^{\prime}$ & $34.1 / 2$ & 120 & 29.79 & 44 & 64 \\
\hline 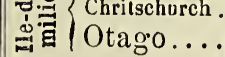 & $\mid \begin{array}{l}43.35 \\
45.46\end{array}$ & 53 & 31 & 61 & 29.74 & 40 & 64 \\
\hline & & & & 130 & 29.09 & 42 & 58 \\
\hline
\end{tabular}

(1) Ce tableau est extrait de l'ouvrage de Thompson, t. II, appendice 1. 
GÉologie. - Déjà les premiers navigateurs avaient remarqué que les îles de la Nouvelle-Zélande présentaient des traces de volcans. Rochon disait, quand il publia le journal de Crozet: (1) « En parcourant la Nouvelle-Zélande, on rencontre à chaque pas des traces de volcans, de ia lave mêlée de scories, du basalte, de la pierre ponce, des blocs de ces verres noirs qu'on sait n'ètre qu'une fusion de matières vitrifiables au feu des volcans, des terres cuites, etc. D

Ainsi, on avait signalé de ces traces sur les bords de la Mokoia, dans le canal del'Astrolabe, sur les îles Rangitoto, à Korea, dans la baie Inutile, sur les bords du canal de la Reine Charlotte, etc. On voit, dans le voyage de d'Urville, que ce qu'il appelle Pouhia-i.Wakidi, c'est-à-dire l'île Wakaari, dans la baie d'Abondance, est un petit volcan en activité.

Depuis, toutes les observations ont confirmécelles des premiers navigateurs, et l'on peut dire que la Nouvelle-Zélande est une contrée volcanique.

Cela est particulièrement appuyé par les lignes suivantes, empruntées au révérend Taylor (2), et qui suffiront à le prouver pour l'Ile-Nord.

* La Nouvelle-Zélande présente une longue ligne de cratères qui s'étend d'une extrémité à l'autre du pays ; par le fait, presque la moitié des montagnes sont des cratères éteints (3). Cependant l'action volcanique paraît avoir été plus grande en certaines localités. Dans le Nord, le centre était à O-Taua, près de la Baie des Iles. Un immense cratère s'élève au-dessus du niveau du pays environnant, avec de profonds précipices en rochers, qui s'abaissent vers l'inté rieur comme pour former un vaste bol de plusieurs milles de diamètre. Cela a été certainement un vaste cratère ; mais, quand il commença à s'épuiser, il s'en forma une série de plus petits, sur les côtés. Ceux-ci sont encore plus ou moins en action ; ils sont surtout pleins d'eau profonde, d'où s'échappent de toutes parts des ruisseaux !pleins de gaz. Un

(1) Ouvr. cité, p. 367 .

(2) Ouvr. cité, p. 122.

(3) D'après Thompson, il n'y aurait pas de cratères éteints dans l'Ile-du-Milieu. 
de ces lacs-cratères contient de la boue blanche, qui bouillonne en différents endroits. Dans un autre, le gaz échauffé est émis par une multitule de pores, et le plus haut degré de température est $196^{\circ}$ Fareinheit. Le sol semble s'abaisser constamment. Il est évident qu'après son extinction, le grand cratère s'est couvert de la végétation pressée du Kauri, dont les feuilles ont formé, en plusieurs endroits, un litde tourbe qui a presque douze pieds d'épaisseur. On voit de tous côtés les fortes racines conservées en grand nombre dans le sol, et quelques-unes mêmes des plus petites sont encore enveloppées de soufre pur. Les lacs sont également pleins de bois ; les feuilles et les cônes mêmes des arbres sont aussi frais que s'ils venaient de tomber tout récemment.

“ Le grand centre de l'action volcanique s'étend de l'île Blanche ou Whakaari à Roto-Rua, et se rend de là à Whanganui, en passant par Taupo et Tongariro, c'est-àdire en faisunt ainsi un trajet de près de 200 milles. Le nombre des gouffres bouillants, des solfatares et des étangs de boue en ébullition, est considérable sur cette ligne, et on en trouve de tous les côtés, aussi bien dans les forêts, dans les plaines, que dans l'eau des lacs. Les lacs d'eau chaude à citer sont surtout ceux appelés Roto-Mahana et Roto-Aürea. Ce dernier est près du Tongariro qui a 10,236 pieds d'élévation. »

Naturellement les tremblements de terre sont très fréquents, et parfois très-violents : le détroit de Cook en est le centre, et, après chaque tremblement, on trouve des blocs de bitume sur la côte Ouest de l'Ile-Nord. On a rencontré, au cap Pallisser, à 200 pieds de hauteur, des térébratules; de même que sur le mont Grey, dans l'Ile-du-Milieu, à 300 pieds, et à 1180 pieds, près de la baie Hawke, sur l'Ile-Nord.

En somme, de toutes ses observations, le studieux missionnaire a pu conclure que l'Ile-du-Milieu s'est déjà beaucoup élevée et qu'elle continue à le faire. Il pense que c'est à l'abaissement de température, résultant de cette élévation, plutôt qu'a l'action de l'homme, qu'est due l'extinction, à peu près complète dans cette île, des Moa (Dinornis), ainsi 
que la disparition du Kauri (1), (Dammara australis), beau conifère qui ne se trouve pas plus Sud que Kawhia, sur la côte Ouest, et que la baie d'Abondance, sur la côte Est, mais que l'on rencontre à l'île des Pins et à l'extrémité Sud de la Nouvelle-Calédonie.

Les indigènes ont, du reste, plusieurs traditions qui rapportent que des terres ou îles ont été englouties à la suite de tremblements de terre.

Ainsi l'une de ces traditions dit qu'une île, sur laquelle existait un très grand $\mathrm{Pa}$, près de Taranaki, a été subitement submergée et a disparu avec ses habitants dans l'es. pace d'une nuit.

Une autre rapporte qu'une autre île a disparu de la même manière à Patea.

Enfin, une troisième dit qu'une île, appelée Titapua, a également été engloutie dans le détroit de Cook.

Ce qui prouve bien que la Nouvelle-Zélande a été profondément bouleversée, à une époque reculée, c'est que plusieurs des iles qui l'avoisinent, dans l'Est, ne semblent être que des fragments de l'Ile-Nord. Cela résulte, entre autres, d'une observation curieuse rapportée par Dieffenbach : le Kiwi se trouve sur la petite île Barrière, île inhabitée, qui est placée à environ neuf milles de la grande Ile-Nord. Or, dit-il, comment un oiseau qui ne peut pas voler, aurait il pu s'y rendre en traversant la mer ? Il n'y a qu'une manière d'expliquer sa présence sur cette île, c'est qu'autrefois elle était unie à la grande terre, Tuawhenua; et il ajoute: " Nous avons une preuve certaine d'une déchirure semblable, dans l'existence, sur une petite île rocheuse de la baie d'Abondance, d'une iguane qui est presque éteinte sur la grande terre. »

Botanique. - Comme nous reviendrons nécessairement sur la botanique et la faune de la Nouvelle-Zélande, quand nous en serons aux conclusions de cet ouvrage, nous nous bornerons ici à emprunter aux écrivains les plus compétents quelques remarques sur la première.

(1) Ouvr. cité, p. 220。 
C'està Taylor surtout que nous demanderons ces remarques. « La botanique de la Nouvelle-Zélande, dit-il (1), est du plus grand intérêt, non pas tant par la beauté de sa flore, que par ce fait qu'elle a un caractère particulier et distinct, indiquant qu'elle est un centrebotanique. »

C'est ce qu'ont signalé les derniers explorateurs, et ce fait tend à appuyer la conjecture, hasardée par lui, que la NouvelleZélande est un débri d'autres terres. Il est bien vrai, ajoutet-il, qu'on a découvert, à la Nouvelle-Zélande, 89 espèces de l'Amérique du Sud; que $\mathbf{7 7}$ se trouvent en Australie et dans l'Amérique méridionale, sur lesquelles 50 sont communes à l'Europe, et que 60 plantes de toute la flore sont européennes ; cependant, le fait qu'il y a 26 genres et 507 espèces, c'est-à-dire plus des deux tiers de la totalité, particulières à la Nouvelle-Zélande, établit son droit à avoir un centre botanique propre.

Il porte (2) le nombre des espèces de plantes déjà connues à 632 , dont 314 sont dycolytédones ou endogènes, et 318 monocolytédones ou cellulaires. Et il conclut de cette disproportion, ainsi que nous l'avons montré un peu plus haut, que cette contrée a été séparée d'une autre terre, dans les temps les plus anciens, et qu'elle a conservé sa flore primi . tive : « Elle est encore, dit-il, à son âgee de fouçère. »

Le grand nombre des arbres, le petit nombre des plantes herbacées, l'absence presque complète des plantes annuelles, et surtout la grande quantité des fougères, sont les caractères les plus remarquables de la flore. Ce sont surtout ces dernières qui la caractérisent.

En effet, si en Angleterre (3) il n'y a pas plus de 35 arbres inđ̋igènes sur 1400 espèces, à la Nouvelle-Zélande les arbres à fleurs, comprenant des arbrisseaux au-dessus de 20 pieds, dépassent le nombre de 113, c'est-à-dire qu'ils forment presque le $3 / 6$ de la flore, en outre des 156 arbrisseaux et plantes à tiges ligneuses.

On compte :

(1) Ouvr. cité, p. 431.

(2) Ibid. p. 433.

(3) Ibid. p. 424. 
117 espèces de fougères, y compris les lycopodes ; 730 plantes ;

450 mousses et hépatiques.

Total 1200 d'après le docteur Hooker.

Les algues s'élèvent, d'après le Docteur Harvey, à 300 .

Les ordres les plus nombreux en espèces sont:

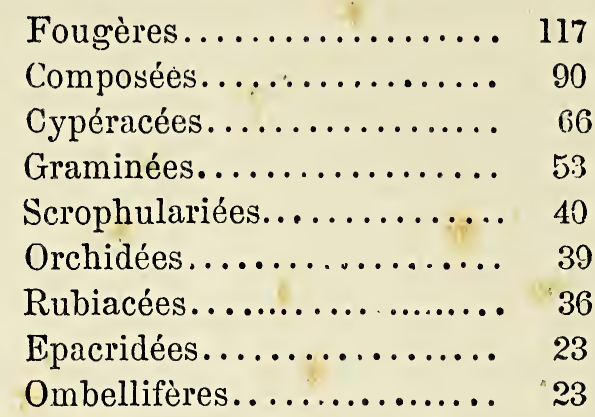

En somme, la flore se compose d'environ 2000 espèces conrues et décrites, et le $\mathrm{D}^{r}$ Hooker a annoncé qu'on en trouverait encore autant et mème plus.

Le même botaniste estime que les fungi seront trouvés en nombre de plus de 1000 espèces.

Il pense que les conifères, quand tous seront connus, formeront la famille la plus nombreuse. Jusqu'à présent,ils ont des espèces moins nombreuses que celles connues des autres ordres.

Sur 117 fougères,

43 seulement sont particulières à la Nouvelle-Zélande;

30 se trouvent dans l'Amérique du Sud ;

61 dans l'Australie et la Tasmanie;

25 sont communes à l'Australie, à la Nouvelle-Zélande et à l'Amérique du Sud ;

10 seulement se retrouvent en Europe.

La couleur caractéristique de la végétation à la Nouvelle. Zélande est un vert foncé ou sombre.

Taylor conclut de tout cela que la Nouvelle-Zélande, y compris les îles Aukland, Chatham, Macquarie et quelques autres, forment un centre botanique, de même que l'Australie et d'autres continents, car, dit-il, cette flore diffère 
autant de celle de la Nouvelle-Hollande, que celle ci differe de celle de toute autre partie du globe.

Thompson signale, lui aussi, la singularité de cette flore, qu'il dit, comme tous les botanistes, être caractérisée relativement par son grand nombre d'arbres et de fougères, par le petit nombre des plantes herbacées, et par le manque absolu des plantes annuelles. En Angleterre, ajoute-t-il, il y a 40 arbres indigènes, et 120 à la Nouvelle-Zélande. 50 r espèces de plantes à fleur's, ou plus des $2 / 3$ re cette division du règne végétal, trouvées à la Nouvelle-Zélande, lui sont particulières.

Sur le tiers restant, il y a :

123 plantes australiennes ;

87 de l'Amérique du Sud ;

77 communes au loin ;

60 Européennes ;

50 antarctiques.

Il indique, comme Taylor, les ordres botaniques offrant le plus d'espèces, mais en faisant remarquer que les individus de chaque espèce, à l'exception des fougères, sont souvent peu nombreux, et que pas un ne présente un caractère particulier dans le paysage.

Le paysage de la Nouvelle-Zélande r'est ni doux, ni gai, dit-il avec raison; mais il est grand et sombre. Presque tous les arbres de la Nouvelle-Zélande sont toujours verts : par conséquent les forèts ne sont jamais sans feuilles, et le changement des saisons modifie peu leur apparence ; elles sont plus vertes l'hiver que l'été ; l'abondance de la végétation, les arbres fougères, le nikau, le dracœna terminalis et la fleur vert foncé des fougères cryptogames leur donnent quelque chose d'apparence tropicale.

Les plantes à fleurs à la Nouvelle Zélande, répète-t-il ailleurs, sont peu nombreuses. La Grande-Bretagne en a plus de 1400, et la Nouvelle-Zélande en possède à peine i50. Il avait d'abord dit 507 espèces.

Nous ne dirons rien de la description enthousiaste et vraie qu'il fait des forêts de la Nouvelle-Zélande : on peut la lire, d'ailleurs, dans l'article publié par le naturaliste 
Hochstetter: elle s'y trouveà peu près textuellement. S' 101 avons tenu à citer ces deux autorités, et surtout la premièr si compétente, c'est que nous pensons, avec ces savant que la Nouvelle-Zélande est un centre de création.

Faune. - Comparée à celle d'autres contrées, la faune de la Nouvelle-Zélande est véritablement pauvre, surtout dans l'ordre des mammifères terrestres ; mais, comme le dit Thompson (1), elle est bien digne de fixer l'attention des naturalistes, parce qu'elle est la preuve la plus convaincante que chaque partie de la terre a ses animaux, comme ses végétaux particuliers.

C'était ce qu'avait déjà dit le liév. Taylor, à l'occasion de la géologie de la Nouvelle-Zélande : "Ces îles, dit-il, (2) se montrent aux yeux du géologue comme les fragments déchirés d'une ancienne ligne de continent. Chaque ligne possède de tels traits distinctifs dans sa fiore, sa zoologie et son ornithologie, que chacune d'elles indique qu'elle est un centre à part. L'Australie diffère dans ses diverses productions de toute autre partie du globe. La Nouvelle-Zé. lande aussi en diffère autant que la première fait du reste du monde.

«Si ces conjectures avaient quelque valeur, ajoute-t-il, les îles dela Nouvelle-Zélande, comme débris del'une des diverses lignes continentales citées, auraient une antiquité égale, qui détruirait la croyance ordinaire que leur origine est comparativement récente. "

C'était ce qu'il avait répété (3), en disant que a la botanique de la Nouvelle-Zélande est extrèmement intéressante, non pas tant par la beauté de sa flore, qu'en raison de ce fait qu'elle a un caractère particulier et distinct, montrant qu'elle est son propre centre botanique. »

Et c'est ce que nous soutiendrons nous-même,quand nous

(1) The Story of the Nesv-Zealand, vol, I, p. 20.

(2) Te Ika-a-Maui, p. 2?0.

(3) Ouvr. cité, p. 431. 
ci. serons á l'examen du lieu d'origgine des Nouveaux-Zélandais.

En résumé, on compte seulement:

4 espèces de mammifères terrestres: 2 chauve-souris, 1 chien et 1 rat;

13 espèces de mammifères marins ;

83 espèces d'oiseaux, tandis qu'il y ena273 en Angleterre. Plus 14 espèces d'oiseaux, disparues et reconstituées d'après leurs ossements par le savant Owen.

On trouve à la Nouvelle-Zélande au moins six lézards, tous inoffensifs : mais il n'y a point de serpents. Il paraît que les lézards étaient beaucoup plus nombreur autrefois, et qu'il y en avait même de très gros : ils deviennent chaque jour de plus en plus rares.

On compte environ 100 poissons; plus de 100 espèces d'insectes, et de nombreuses coquilles, parmi lesquelles se trou-• vent: l'Helyx Busbyi (Gray), le Bulimus Hongi (Lesson), le Trochus Cookii, le Trochus impérialis, etc.

Nous nous bornerons à réunir ici quelques renseignement sur les mammifères,les principaux oiseaux, les lézards, et les grenouilles, observés depuis la colonisation.

Mammiféres terrestres. - Forster, le premier, a vu et décrit l'une des chauves-souris, qu'il a appelée Vespertilio Tuberculatus : C'est le Pelrapeka des indigènes.

L'autre espèce est admise par les royageurs Dieffenbach, Thompson et le missionnaire Taylor ; mais sa description n'est donnée nulle part; ce dernier dit seulement : La plus commune est très petite, de couleur brun jaunâtre, avec de petites oreilles arrondies.

Kuri est le nom donné au chien indigène, qui a été vu pár Cook ; les habitants de l'Ile-Nord attribuent son introduction aux émigrants d'Hawahiki. C'était, dit le missionnaire Taylor, un petit chien à longues oreilles, d'un brun sale ou de couleur jaunâtre, avec une queue touffue : il est maintenant presque éteint.

Le Kuri ne paraît pas ressembler au Dingo australien, ajoute-t-il, mais il est probablement de la même espèce 
que celui que l'on trouve dans les îles Polynésiennes.

Thompson n'admet pas que les chiens ni les rats fussent indigènes à la Nouvelle-Zélande. Voici ce qu'il écrit à ce sujet: (1)

a On compte, parmi les mammifères indigènes de la Nouvelle-Zélande, les chiens et les rats, mais à tort. Il est vrai que le capitaine Cook a trouvé des chiens et des rats en 1769, mais ces deux animaux avaient été apportés dans le pays par les Nouveaux-Zélandais, et il est à remarquer que tous les deux sont presque éteints aujourd'hui.

« Le grand rat de Norway, importé dans la NouvelleZélande par les colons anglo-saxons, a détruit le rat indigène ; et les chiens indigènes, qu'on élevait et propageait anciennement pour servir de nourriture, ont tous été mangés et détruits, parce qu'après l'introduction des cochons, les Nouveaux-Zélandais n'ont pris aucune précaution pour en conserver la race. Des voyageurs attentifs peuvent encore voir, de temps en temps, sur les bords du lac Taupo, quelques mauvais chiens croisés de chiens maori et anglais, ayant la queue touffue, le poil couleur de renard, les oreilles droites et un hurlement au lieu d'un aboiement. Ce sont les derniers vestiges de la race des chiens apportés par les naturels de la Nouvelle-Zélande (lle-Nord.) Ce que les bergers de l'Ile-du-Milieu appellent chiens indigènes, sont des animax anglais libres, non sauvages.

"Il est prouvé que le véritable chien indigène a été introduit à la Nouvelle-Zélande, et par les traditions, et par le mot maori employé pour désigner le chien, mot qui est toutà-fait polynésien, et par les os calcinés d'hommes, de moa et de chiens, qui ont été trouvés par M. Mantell sur un banc de sable, près de Taranaki, l'un des points les plus anciennement occnpés par les Nouveaux-Zélandais (2).

«Il est également prouvé, par les traditious et par l'existence de rats semblables dans toute la Polynésie, que les rats indigènes de la Nouvelle.Zélande, qui étaient petits et frugivores, y ont été introduits. »

(1) Ouvrage cité, vol. I. p. 21.

(2) Cons. au sujet des Moa, W. B. Mantell, Address on the Moa, in Transact. and Proceed. of New-Zealand, 1869. 
Ce n'est point ici le lieu de prouver qu'il serait tout aussi logique de conclure, d'après son nom, que le chien a été introduit en Polynésie par la Nouvelle-Zélande, et que, quand les traditions parlent du lieu d'origine des Maori sous le nom d'Hawahiki, elles ne veulent pas du tout parler de la Polynésie. Nous aurons d'ailleurs à y revenir longuement plus tard; aussi, nous bornerons-nous à dire ici qu'il s'en faut que la provenance polynésienne du chien et du rat soit démontrée, comme l'avance $M$. Thompson.

Pour soutenir que l'Hawahiki était situé à Savaii, ce savant s'appuie sur John Williams, d'après lequel il existe des chiens sauvages aux îles Samoa, ressemblant aux chiens domestiques vus par Cook, à la Nouvelle-Zélande. Mais, en réalité, il ne s'appuie que sur un fait, au moins insuffisant, et ne permettant pas de dire que les chiens des Samoa et ceux de la Nouvelle-Zélande sont identiques, puisque John Williams se borne à en donner la description suivante :

"Une particularité de l'histoire naturelle du groupe Samoa, est qu'on trouve un chien sauvage dans les montagnes. J'ai vivement regretté de ne pouvoir m'en procurer un. D'après la description qui m'cn a été faite, il semble être un petit animal, de couleur noire, gris sale ou de plomb, avec peu ou pas de poil, et de grandes oreilles droites. $>$

Il n'y a, en résumé, qu'un fait certain, c'est que les traditions disent bien que les chiens et les rats, comme un assez bon nombre de plantes, d'oiseaux et même d'insectes, ont été apportés à l'Ile-Nord de la Nouvelle-Zélande par les émigrants venant d'Hawahiki, mais sans spécifier où était situé cet Hawahiki ou pays d'origine.

Kiore est le nom maori du rat, que nous regardons, contrairement à Thompson, comme indigène, au moins, dans une des deux grandes îles de la Nouvelle-Zélande. Il n'a guère que la moitié du volume du rat de Norway (mus ratus) ; il était partout très commun autrefois, et alors il était très recherché comme nourriture.

Il est à remarquer que les naturels appellent le rat de 
Norway : Pou Hawahiki, Kiore Pakeha, et Kainga Rua, ce qui signifie rat étranger. (1)

En outre de ces quatre mammifères terrestres, un autre, comme l'apprend Cook, aurait été vu par quelques-uns de ses matelots, dans les environs du Canal de la Reine-Charlotte. Cet animal lui fut décrit comme étant couleur de souris, gros à peu près comme un chat, et ayant quatre jambes courtes. Depuis, Mantell a appris, de naturels de l'Iledu-Milieu, qu'un quadrupède disparu y existait autrefois ; il était appelé, d'après Thompson, Kaurehe. Suivant eux, ce quadrupède ressemblait à un castor, à une loutre ou à un blaireau. Mais Thompson dit (2) qu'il s'est vainement livré à de sérieuses recherches à ce sujet, et qu'il n'a jamais pu rencontrer un Maori ayant vu un pareil animal, ou en ayant seulement entendu parler.

A cette occasion nous nous contenterons de faire remarquer que c'est le mot kararehe que Mantell a bien probablement cru entendre: d'après W. Williams, ce mot, en Maori, signifie seulement quadrupède et non chien, comme l'ont dit quelques voyageurs. Suivant ce savant, si versé dans la langue maori, le chien est appelé Kirehe, Kuri, Nane et Peropero. Il se pourrait donc que le premier mot eût été entendu et transformé en Kaurehe, qui ne paraît pas être maori. Dans ce cas, les matelots de Cook n'auraient vu bien probablement qu'un chien; car, si on décompose le mot kaurehe, on trouve que kau signifie nu, seulement, et que rche veut dire, ridé. Toujours est-il que, d'après Williams, Kararehe est le nom donné aux quadrupèdes en général.

D'un autre côté, un nommé Seymour, demeurant ì Otaki, a assuré à M. Taylor qu'il avait vu plusieurs fois, dans l'Ile. du-Milieu, près de la baie Dusky, sur la côte Sud-Ouest, un animal qu'il appelait rat musqué, à cause de l'odeur qu'il

(1) Pou signifiant poteau, il est probable que c'est le mot $p u$,tribu, véritable, identique, c'est-à-dire véritable rat d'Hawahiki. Quant à Kaingarua, ce serait rat (sous-entendu) de magasin, de village. Nous savons que le mot Pakeha signifie étranger.

(2) Ouv. cité, vol. 1, p. 21. 
émettait. Il disait que sa queue était grosse et qu'elle ressernblait au Pirori mûr, ou fruit de Kiekie, qui ne diffère pas de la queue d'un castor. Ce récit était appuyé par Tamihana-te-Rauparaha, qui disait que le volume de cet animal était donble de celui du rat de Norway, et qu'il avait une queue plate.

Un autre homme, habitant le pays depuis plus de vingt ans, lui a dit qu'il n'avait pas vu lui-même des castors, mais qu'il avait plusieurs fois rencontré leurs habitations. Il avaitété surpris en royant de petits ruisseaux barrés par des digues, et de petites maisons, comme des ruches d'abeilles, élevées sur un côté, et ayant deux ouvertures, l'une en haut et l'autre en bas de la digue.

Un autre habitant disait avoir vu ces grands rats, mais il n'avait pu les atteindre, parce qu'il avaient disparu en se jetant à l'eau.

Enfin un autre, encore, disait avoir rencontré ce qu'il appelait une espèce de loutre d'eau douce : ce n'était probablement, dit Taylor, que le castor dont il a été parlé.

Remarques sur quelques oiseaux. - Kiwi. - L'un des oiseaux les plus remarquables de la Nouvelle-Zélande est le Kiwi ou Apteryx australis, de la famille des autruches; il est encore assez abondant dans plusieurs parties des îles. Il est gros comme une poule adılte, et cependant il pond un œuf qui a huit pouces d'épaisseur et douze de hauteur. Voici ce qu'en dit Taylor :

Il y a deux variétés de Kiwi : l'une plus grande que l'autre et d'une couleur plus foncée; celle-ci ne pond qu'un œuf ; l'autre, d'ın rouge ordinaire, pond deux œufs qui sont plus petits. Cet oiseau a des ailes rudimentaires, terminées par une petite griffe ; le bec est long et légèrement courbé ; les narines sont à l'extrémité. Ses plumes, qui sont garnies à leur pointe par une espèce de griffe, sont très estimées pour faire des manteaux que les chefs portent seuls.

Le Kiwi creuse des terriers et y dépose ses œufs ; le plus généralement il les place à la racine des Rata. On dit qu'ils 
mettent trois ans á éclore, et souvent le trou se bouche tellement par l'accroissement des racines, que le jeunc oiseau ne peut sortir et finit par périr. Le Kiwi-parure est la plus grande espèce, et le Kivi-hoïhoï, la plus petite. La plus grande espèce, plus grosse que le dindon, paraît avoir été trouvée à la baic Dusky, dans l'lle-du-Milieu; elle vit surtout dans les montagnes neigeuses. Il en aurait même existé une autre espèce, d'après les naturels, laquelle n'avait pas moins de sept pieds de haut; mais il y a longtemps qu'elle aurait disparu, comme tant d'autres de la même famille et do celle des Moa.

Le Kiwi est un oiseau de nuit ; il trouve sa nourriture à l'aide de l'odorat. Il plonge son bec dans la terre avec promptitude pour y chercher les vers, et, dans le même moment, il émet un bruit de ronflement. Il donne un coup de pied avec une grande force, et exprime sa colère par un sifflement ou un grognement. On l'apprivoise facilement. Le cri qu'il pousse est tout-à-fait semblable au nom qu'on lui a donné. Le Kiwi est un oiseau laid à voir, avec ses jambes courtes et minces et ses ongles très forts : il n'a pas de queue. Dans les temps très pluvieux, il est souvent chassé des forèts et forcé d'aller chercher sa pâture dans la plaine. Quand il dort, il s'appuie sur son bec. Les naturels fixent toujours une plume ou deux de cet oiseau à leur Paua ou hameçon à poisson. C'est un bon manger, ayant plutôt la saveur du bœuf que celle d'un oiseau; les meilleurs morceaux sont les côtes et les cuisses.

Celui de la grande espèce trouvée dans l'lle-du-Milieu pèse, dit-on, jusqu'a 18 livres; il est si fort qu'on ne peut pas le prendre d'une seule main, et si le capteur ne fait pas la plus grande attention, il lui échappe en le frappant avec ses ailes. Toko-Eka est le nom de cette espèce de Kiwi. Quelques personnes l'ont décrit comme ayant un plumage rouge brun. On le prend en étendant un vêtement blanc sur le sol, qu'il croit alors ètre couvert de neige.

Celui auquel les indigènes donnent scpt pieds de haut, et qui paraît avoir disparu, est appelé Kiwi-papa-whenua. Il avait un très long bec, avec lequel il faisait de grands 
trous dans la terre pour y chercher des vers. Il existe encore des personnes vivantes qui prétendent l'avoir vu. Rauparaha m'a diit, ajoute Taylor, en avoir mangé alors qu'il étaitjeune. Quand ce chef mourut,son corps fut orné de quelques-unes des plumes de cet oiseau.

Moa. - De tous les oiseaux qui ont vécu autrefois à la Nouvelle-Zélande, le plus remarquable, sans contredit, est le Moa, Dinornis d'Owen. C'était peut-être le plus grand oiseau qu'on ait jamais vu. J'ai le premier, dit Taylor (1), découvert ses restes, en 1839, à Tauranga et à Waïapu (Baie d'Abondance et Cap Est.) Mais en 1844, j’ai rencontré un très grand amas d'os de cet oiseau, mèlés à ceux de phoques; ils étaient réunis dans de petits monticules à l'embouchure de la Waingongoro ; chaque tas était composé d'os de plusieurs espèces d'apteryx. Ils abondent dans presque tous les points de l'Ile-Nord, an Sud de Mokau, et partout dans l'Ile-du -Milieu ; mais ils n'ont pas été découverts plus au Nord, probablement parce qu'il n'y avait pas de plaines herbeuses capables de leur fournir une nourriture suffisante.

Là où l'on trouve les restes des Moa, il y a ordinairement un petit tas de cailloux arrondis, en quartz, à peu près gros comme des noix, qui avaient sans doute été avalés pour faciliter la digestion. Il est probable que ce gigantesque oiseau n'avait pas moins de seize pieds de haut; ses os ont la moitié de l'épaisseur de ceux de l'éléphant (2).

(1) Ouvr. cité, p. 398.

(1) Ed. Lartet a fait, dans la séance du ler août 1867, de la Société d'anthropologie de Paris, une comınunication établissant que des silex taillés seraient associés à des ossements fossiles, en Océanie. En 1847, dans la région occidentale de l'Ile-Nord de la Nouvelle-Zélande, on trouva à Terangatapu, et à Waingongoro, en creusant un lit de sable, renfermant de l'argile, du fer titanifère, etc, des ossements de dinornis, de phoque (Phoca leptony $x$ ) qui vit encore aujourd'hui dans les parages de la Nouvelle-Zélande, et de chien, assez semblable au Canis australis ou Dingo de la Nouvelle-Hollande. Avec ces dèbris furent recueillis quelques silex noirâtres, ou roches de même apparence taillés en forme de 
Thompson donne la figure du squelette du Dinornis éléphantopus, reconstruit par Owen; et il apprend que, de. puis la découverte de Taylor, des os de Moa ont été trouvés dans les lits de rivières, les marais, les forêts des deux îles et dans des cavernes qui en étaient quelguefois remplies; mais surtout dans l'Ile-du-Milieu.

D'après Taylor, on rencontre rarement les restes des Moa, sans qu'ils soient mêlés à ceux de plusieurs espèces différentes du même oiseau (1); d'où l'on doit inférer, dit-il, qu'autrefois le climat leur était plus favorable, puisqu'on les troure en abondance et que ce n'est que depuis une époque peu reculée qu'on rencontre leurs os à l'état fossile.

On ne peut, suivant lui, attribuer leur extinction, qu'au changement du climat, et il pense que l'homme n'y est pour rien. Qu'ils aient existé à une période éloignée, leurs os le prouvent, les traditions indigènes l'assurent également, et il y a encore des chants de chasse qui s'appliquent aux Moa. On peut mème se demander, ajoute-t-il, s'il n'en existe pas encore dans l'lle-du-Milieu. A ce sujet, le savant missionnaire rapporte un récit trop favorable à cette dernière supposition pour que nous ne le fassions pas connầ. tre (2) :

a M. Meurant, interprète du gouvernement, m'a dit avoir vu en 1823, dans le Hâvre Molyneux, de la chair de Moa ; depuis, il a vu des plumes de Moa dans la chevelure des indigènes. Ces plumes étaient de couleur noire ou brune, à bord pourpre, et ayant des tuyaux aussi gros que ceux de l'albatros pour le volume, mais plus forts et plus épais. Il a vu un os de Moa, qui arait quatre pouces près de la hanche et était aussi gros que son genou ; il était encore recouvert couteau. Il y avait aussi des débris d'obsidienne. Quelques-uns des os portaient des entailles et des traces d'un travail en apparence exécuté avec une pierre tranchante ; d'autres avaient visiblement subi l'action du feu.

(1) On en a reconnu 4 espèces ; Dinornis, la plus grande ; Palapteryx, 2e grandeur; Aptornis, 3 e grandeur ; et la plus petite,Notornis, qui a été vue vivante en $185^{\prime \prime}$, à la baie Dusky.

(2) Ouvr. cité, ‥ 238 , 
de chair et de tendons. La chair ressemblait à du bœuf : Les esclaves qui étaient de l'intérieur, disaient qu'il y avait encore des Moa dans cette partie de l'île. Les indigènes lui racontèrent que le Moa, dont il avait vu la chair, était mort quand il avait été trouvé par hasard par eux, et qu'ils avaient souvent essayé d'en prendre au piége, mais sans succès. Un homme, nommé George Pauley, vivant aujourd'hui dans le détroit de Foveaux, lui dit qu'il avait vu le Moa ; il le décrivait comme un monstre énorme, ayant près de 20 pieds de haut. Il l'avait vu près d'un lac de l'intérieur ; il s'éloigna de lui en courant, et l'oiseau fit de même. Il avait rencontré ses pas avant d'arriver à la rivière Taïri, et dans les montagnes. Thomas Chasseland, l'homme qui servait d'interprète à M. Meurand, et qui était très versé dans la langue maori, avait vu, lui aussi, de la chair de Moa, etil avait d'abord cru que c'était de la chair humaine."

Il se pourrait donc, d'après ces récits, qu'il existât encore quelques Moa dans l'Ile-du-Milieu, mais bien probablement en petit nombre, puisqu'ils sont si rarement aperçus, et qu'on ne rencontre, pour ainsi dire, jamais que leurs traces, comme cela est arrivé, il n'y a que quelques années, aux fameux explorateurs de cette île, les docteurs Haast et Hector.

Dans une note, Taylor, pour prouver que l'homme n'est pour rien dans la destruction des Moa, fait remarquer que les plus vieux naturels affirment que, depuis leurs plus anciens jours, il y a eu une forte extinction des oiseaux qui étaient considérés comme des moyens de subsistance, tels que le Kiwi, le Weka et le Kakapo. Cela ne doit pas être attribué à la venue des Européens, répéte-t-il, mais plutôt à quelque autre cause, peut-être au changement de climat. Le chat, le chien et le rat européens, récemment introduits, sont de grands destructeurs ; mais les provisions des indigènes avaient commencé à décroître avant leur introduction, tellement même, qu'ils pâtissaient de l'absence de nourriture avant l'arrivée des Européens. Aussi, conclut le pieux missionnaire, est-ce à la Providence qu'il faut attribuer, parmi d'autres bienfaits, celui d'avoir fourni de nou- 
veaux moyens de subsistance aux aborigènes de ces îles, alors que les leurs avaient tant diminué !

C'était, en somme, au climat qu'il attribuait surtout la disparition des Moa, c'est-à-dire à l'élévation, chaque jour de plus en plus grande, des montagnes de l'Ile-du-Milieu, et par conséquent à l'abaissement de la température. Mais nous ferons remarquer que son assertion, relativement aux Moa, semble être démentie par ce seul fait que les docteurs Hector, Haast et autres voyageurs, n'ont trouvé des traces de ces oiseaux, dans ces dernières années, que sur les sommets des plus hautes montagnes neigeuses, tels que ceux des monts Richards, dans l'Ile-du-Milieu.

En voyant, comme l'a fait remarquer lui-même M. Taylor, que les Moa semblent ne pas s'être avancés plus Nord que Mokau, dans l'Ile-Nord, ne serait-il pas plus logique de penser qu'ils ne se sont arrêtés là que parce que la température n'était plus assez froide pour eux, au lieu d'admettre qu'ils ne l'ont fait que parce qu'il n'y avait pas de nourriture à leur convenance plus au Nord que Mokau ?

Il est vrai qu'on explique très bien leur séquestration dans les lieux déserts et impraticables, par l'instinct de conservation qu'on leur suppose; mais il nous semble qu'on aurait dû en voir, du moins de temps en temps : or, à part le fait précédemment cité, il n'y en a guère d'autres exemples, pour les Européens, que les traces signalées.

D'après Thompson, la presque extinction des Moa n'aurait eu lieu que par des causes naturelles. Les arrivants dans le pays se seraient mis à les massacrer pour leur chair, leurs os et leurs plumes : la chair et les œufs étaient mangés (1); les os employés à faire des hameçons; les crânes à conserver la poudre à tatouer, et les plumes à orner leur tête.Les causes naturelles qui auraientrendu l'extinction des Moa plus rapide, auraient été aussi, d'après lui, les changements géologiques survenus avec le temps dans la contrée

(1) Un œuf trouvé n'avait pas moins de 9 pouces de diamètre et 37 de circonférence. 
La Nouvelle-Zélande, ajoute-t-il, était peut ètre un grand continent, quand les Moa furent d'abord créés, car il est difficile de comprendre que de pareils oiseaux gigantesques aient pu naître, pour vivre et mourir dans la petite portion du globe qui est maintenant connue sous ce nom.

Nous ne pouvons émettre ici les idées que font naître une pareille réflexion; mais la remarque de M. Thompson que toutes les îles, qui ont possédé autrefois de grands oiseaux à ailes rudimentaires, sont situées dans l'hémisphère Sud, est bien digne de la plus sérieuse attention. Tout le monde sait que l'lle Maurice, où a été vu un oiseau encore vivant de la même famille, en 1658, par Bontius, n'avait pas plus de quadrupèdes que la Nouvelle-Zélande, pas plus de crapauds et de serpents qu'elle, et que le Dodo y a complètement disparu, peu de temps après l'établissement des Européens : bien longtemps, par conséquent, avant que les Moa en aient fait autant à la Nouvelle-Zélande, puisqu'il paraîtraity en exister encore quelques rares spécimens.

Que ces oiseaux se soient propagés, dans ces deux contrées, par suite de l'absence des quadrupèdes, on peut le sup. poser en voyant le nombre considérable des espèces trou. vées, à la Nouvelle-Zélande du moins ; car on sait que, dès 1859, M. Owen était parvenu à en reconstituer quatorze espèces, dont une seule, la plus petite, le Notornis, a été retrouvée vivante. Mais, à l'île Maurice, il n'y avait, d'après tous les récits, qu'une seule espèce, probablement la même qu'on a vue à l'île Rodrigue, distante de Maurice de cent soixante lieues environ.

C'est à Leguat, gentilhomme bressan, forcé de fuir la France pour ses opinions religieuses, et relégué avec un certain nombre de compatriotes sur cette île déserte, qu'on en doit la connaissance. Il donne à cet oiseau le nom de Solitaire et raconte longuement la fidélité du couple apparié. Nous ne pourons que renvoyer à son livre pour les renseignements curieux qu'il en donne. Mais, pour qu'on ne doute pas que cet oiseau était bien de la famille du Dronte, trouvé également à Madagascar, nous citerons la 
description qu'il en a faite (1), et qui est accompagnée d'un dessin de l'animal :

Pieds et bec de coq d'Inde, ce dernier un peu plus crochu ;

Cou long, droit, plus long que celui du dindon;

Presque pas de queue, mais derrière arrondi comme une croupe de cheval ;

Tête sans crête, ni huppe ;

Plumage du mâle ordinairement grisâtre et brun, celui de la femelle plus beau, de couleur blonde ou brune, avec deux saillies sur le jabot;

On trouve toujours une pierre dans leur gésier ;

Ces oiseaux, dont les ailes sont rudimentaires, ne volent pas : ils s'en servent pour se battre;

Il y en avait beaucoup sur l'île, vivant toujours séparés des autres couples.

Ruru. - Si nous ajoutons quelques lignes encore sur l'oiseau appelé Ruru par les indigènes, c'est qu'il a été figu ré pour la première fois et nommé Noctua Zelandica par les naturalistes de l'Astrolabe, Quoy et Gaimard. (2)

R. P. Lesson l'a décrit dans son traité d'ornithologie (3). Cette chouette, dit-il, a le dessus de la tête, du dos, des ailes, d'un brun marron clair, couvert de taches rousses arrondies. Le bec est petit, très recourbé, pointu, marbré de noir et de blanchâtre. Les soies qui l'entourent ont leur extrémité noire, ainsi que le reste de leur tige, dont les barbules sont blanches à la base. Les joues et la partie antérieure du front près de l'œil sont blanchâtres; la poitrine et le ventre sont fauves et ornés de flammes d'un joli brun; les grandes pennes et la queue ont des bandes trans versales brunes. On en compte environ neuf sur cette dernière, qui est fort longue et légèrement arrondie. Les ailes,

(1) Voyage et aventures de François Leguat et de ses compagnons en deux îles désertes des Indes.Orientales. etc., planch., cartes et figures. Londres 2 vol. in-18, 1720. 1er vol. p. 98.

Leguat, parti du Texel en juillet 1690, débarqua à l'Ile Rodrigue en avril 1691.

(2) Voyage de l'Astrolabe, pl. 2, fig. 1re, t. I, p. 168.

(3) Traité d'ornithologie, etc., 1 vol. in-8o, avec atlas。 Paris, 1831. Levrault. 
assez longues et pointues, arrivent au milieu de la queue. Les couvertures alaires inférieures sont d'un rouge vif, et les grandes pennes ont de larges taches blanches sûr un fond grisâtre. Les plumes des tarses et celles qui soutiennent la queue sont d'un roux vif. Les pieds sont forts, les ongles grands et noirs. Cette espèce est un peu plus petite que la chevêche Mauge avec laquelle elle a de grands rap. ports, mais elle en diffère par les taches du dos qui sont plus nombreuses et plus régulières. Sa longueur totale est de onze pouces. Elle habite la baie Tasman, dans le détroit de Cook, à la Nouvelle-Zélande.

Kakapo. - Plusieurs royageurs parlent d'un oiseau appelé Kakapo que ne cite pas W. Williams. Suivant Dieffenbach, c'était un grand et beau coucou (Centropus), qui n'a pas été vu depuis longtemps et qui, d'après les indigènes, aurait été détruit par les chats apportés par les Européens. N'est-ce pas plutôt le Kokoka?

'i'aylor le décrit comme un perroquet; il dit que c'est l'oiseau le plus remarquable de cette famille, et qu'il est aussi appelé Tarepo. Il en donne une figure sous le nom de Strigops habroptilus perroquet de nuit. Voici la description qu'il fait de cet oiseau :

"Il est aussi gros qu'une poule, de couleur jaune verdâtre, claire, avec des bandes brunes, de grandes moustaches noires; il fréquente les montagnes et les précipices. Bien qu'il possède des ailes, il ne s'en sert que rarement. Il va par troupes: l'un d'eux est généralement en observation et veille si bien qu'on n'en peut jamais approcher du côté du vent. Par son aspect, il ressemble ì la chouette. Les indigènes disent qu'il en existe deux espèces, dont l'une est aussi grosse que le Kiwi. Il est excessivement rare et ii sera bientôt éteint dans l'Ile-Nord. J'en ai vu seulement deux individus pris dans cette île. C'est un manger délicat. Cet oiseau remarquable est plus abondant dans l'Ile-du-Milieu. »

Reptiles. - Il n'y a pas de serpents ; et, parmi les lézards, 
nous ne citerons que le Ruatara ou ignane,(Tiliqua $Z$ colan.. dica), et le Kakariki (Nauitinus élégans).

Le premier a environ 16 pouces de long, dit Taylor; sa tête est grosse et son œii doux. Il a une rangée d'épines blanches sur le dos, avec quelques-unes pareilles, mais noires sur la queue. Ses dents sont arrondies, et sa langue triangulaire. Ses orteils sont déliés et, quand il se chauffe au soleil, il se met sur le dos. On ne le trouve que sur les petites îles du détroit de Cook ou sur la côte Est de l'IleNord. Il est de couleur brun foncé, mélangé de jaune. Les naturels en ont horreur, quoiqu'il soit tout-à-fait inoffensif.

Le second est un beau lézard vert, luisant, d'environ huit pouces de long.

On dit que des lézards noirs, ayant du poil ou du duvet, et longs de quatre pieds, abondent dans le lac du Jade vert sur l'Ile-du-Milieu. Un nommé Hawkins, qui a habité cette partie de l'île pendant plusieurs années, passe pour avoir pris un de ces lézards, qu'il aurait tenu attaché à l'aide d'une chaîne à chien. Ils sont amphibies.

Les naturels de Waïkato, de même que les habitants de quelques autres points de la Nouvelle-Zélande, rapportent qu'à l'arrivée de leurs ancêtres (à l'Ile-Nord), il y existait des reptiles amphibies, ressemblant, par la forme et l'aspect, au Ngarara ou iguane, mais d'un volume si considérable qu'ils étaient capables de dévorer un homme avec la plus grande facilité.

Une de leurs traditions dit qu'un de ces animaux vivait dans les environs de Pirongia, et qu'il finit par être tué, après avoir dévoré plusieurs personnes de la tribu.

Les naturels de Roto-Rua ont également une tradition d'après laquelle leurs ancêtres prirent un pareil monstre à l'aide d'un piège.

La même tradition est retrouvée dans le détroit de Cook.

Faut-il en conclure, dit Shortland (1), qu'un énorme sau-

(1) Ouvr. cité, p. శ2. 
rien, ressemblant au crocodile, a autrefois été indigène à la Nouvelle-Zélande? Il pense que cela ne scra admissible que quand on aura rencontré quelques restes fossiles. En attcudant, il aime mieux reléguer la tradition parmi les anciennes fubles, et supposer que les Nouveaux-Zélandais ont rapporté à la Nouvelle-Zélande des évènements fabuleux, ou qui ponvaient être arrivés dans la contrée d'où ils venaient.

Amphibies. - Jusqu'à ces derniers temps on n'arait pas cru qu'il existât des grenouilles à la Nouvelle-Zélande; M. Pollack avait bien dit qu'il n'avait pas pu dormir à cause de leurs coassements; mais aucun autre voyageur n'en avait rencontré, quoique le pays eùt été traversé en tout sens. La découverte des grenouilles était réservée aux chercheurs d'or du hâvre Coromandel : ce fut dans ce lieu qu'ils en trouvèrent trois petites en 1852. " Plus tard, dit Taylor, j'ai appris qu'on en avait rencontré par hasard une dans le voisinage d'Auckland. Excepté ces cas, je n'en ai vu aucune, et je n’ai pas appris que d'autres en aient vu : elles doivent être excessivement rares, et si je n'avais pas entendu dire par les indigènes qu'il y a une grosse grenouille sur l'île Mana, j'aurais été porté à croire que celles de Coromandel y avaient été apportées accidentellement de Sydney. Les indigènes en décrivent une grosse qu'ils appellent Mokomokai et A-maru-te-ware-aïtu. Ils disent qu'elle a été autrefois très abondante sur cette île, qu'elle était aussi grosse qu'un poulet et que, dans son état de tétard, elle avait plus d'un pied de long. Ils affirment aussi qu'il y en avait une plus petite clans la mème localité, mais l'existence du tétard de grenouille ne repose que sur leurs récits. »

Nous ne ferons qu'une seule remarque à ce sujet, c'est que les indigènes n'ont pas de noms pour désigner les grenouilles.

Poissuns. - Coquilles. - Nous avons dit queles poissons de la Nouvelle-Zélande sont très nombreux. Nous renvoyons, iII. 
pour ce qui les concerne, à la longue et savante liste qu'en donne Taylor. Ika est le nom générique de tous les poissons. A part l'anguille, qui atteint quelquefois le poids de 50 livres, il n'y a pas de poissons d'eau douce.

En ce qui concerne les coquilles, le nom des univalves est Pupu ; celui des bivalves est Pipi et Anga.

Pupu-rangi, coquille du ciel, est le nom de l'Helyx Busbyi. Cette belle coquille se tient au sommet des grands arbres des forêts, d'où elle tombe pendant les grands vents : de là son nom. On ne la trouve pas plus au Sud qu'Auckland, dans l'Ile-Nord. Sir Grey en a trouvé un échantillon dans la baie du Massacre de l'Ile-du-Milieu. Pupu-harakeke, est le Bulimus Hongi de R. P. Lesson qui, le premier, l'a fait connaître. Ce bulime abonde près du cap Nord, sur les Phormium.

Enfin nous nous bornerons à mentionner, en terminant, un curieux animal-plante, particulier à la Nouvelle-Zélande, dont Taylor a donné la description et la figure aux pages 422 et 425 de son livre : c'est la Chenille-jonc, Sphoeria Robertsia des naturalistes, Awéto-hotete des indigènes.

En résumé, ainsi que nous l'avons déjà dit en discutant l'hypothèse d'un continent submergé (1), l'ossature de la Nouvelle-Zélande, surtout celle de l'Ile-du-Milieu, est formée par une puissante formation de roches serpentineuses. Puis viennent des terrains cristallins, au-dessus desquels se sont déposés des couches métamorphiques et des sédiments plus récents, associés à des mélaphyres et à d'autres roches éruptives.

Cette constitution geéologique montre que la NouvelleZélande a dû, à une époque, faire partie d'un massif continental plus étendu. Les plaines se seront alors affaissées en suivant une direction du Sud-Est au Nord-Ouest. La double ligne de faîte de la Nouvelle-Zélande, parallèle aux systèmes de soulèvements des Alpes principales et du Ténare, se prolonge, au Nord, jusqu'à la Nouvelle-Calédo-

(1) ler vol., p. 426, note. 
nie, en passant par les îles King et Norfolk, et traverse, au Sud, les îles Auckland, Campbell, Macquarie, Balleny, pour aboutir à la terre Victoria, dominée par les monts Melbourne, Terror, Erebus, d'une hauteur de 3900 à 4000 mètres.

La preuve que la Nouvelle.Zélande a été reliée à dés terres australes disparues, c'est qu'elle a une faune et une flore spéciales, qui doivent la faire regarder comme un centre de création. Tout tend à prouver qu'à une époque géologique peu reculée, les îlots épars autour des deux grandes îles formaient avec elles un continent dont ils ne sont plus que des débris. On trouve, en effet, sur quelques-uns de ces îlots, de même que sur les grandes îles, des espèces animales et végétales des plus caractéristiques et spéciales à cette contrée. La faune et la flore viennent donc cor roborer la géologie.

C'est la région du monde où croissent les Phormiums, qui existent également aux îles Norfolk, Chatham et de l'Antipode. C'était le pays des oiseaux gigantesques, aujourd'hui disparus, tels que les Moa ou Dinornis. C'est là seulement, et nulle part ailleurs, que vivent les Apteryx, oiseaux de la taille d'un dindom, ne volant pas, faciles à prendre dans leurs terriers, et qui seront bientôt presque tous détruits. Les Nestors, type de perroquets particulier au pays, se retrouvent aux îles Chatham.

La perruche de la Nouvelle-Zélande, (Platycercus Nova$Z$ élandice), habite les grandes îles et, plus au Sud, les îles Auckland ; à l'Est, les îles Chatham, l'île de l'Antipode, et jusqu'à l'île Macquarie, peu éloignée de la grande banquise. Or les perroquets ne franchissent jamais de grands espaces et ne vivent guère que dans les pays chauds. C'est encore là un indice que toutes ces îles ont été jadis réunies, et qu'elles ne sont séparées que depuis une époque géologique fort récente. Bien mieux, il existe à la Nourelle-Zélande un perroquet d'un vert gris, gros comme une poule, qui ne perche pas et qui se loge dans les trous : c'est le Strigops, véritable oíseau de nuit, contrairement à ce qui a lieu pour tous les autres perroquets. Or, ce perroquet noc- 
turne, incapable d'exécuter un long voyage, se retrouve aux îles Chatham, distantes de 160 lieues environ.

Il faut donc admettre que, du $34^{\mathrm{e}}$ au $54^{9}$ degré de latitude australe cnviron, existait, dans les temps géologiques mo. dernes, un continent qui n'a laissé, comme témoins de son existence, que deux grandes îles, une île moyenne et un certain nombre d'îlots.

Nous venons de voir que Taylor, se basant sur la disproportion des plantes mono et dicotylédones, était disposé à regarder les îles de la Nouvelle-Zélande comme ayant été séparées d'autres terres à une époque reculée. «Ce fait, ditil (1), joint à l'absence totale de quadrupèdes et à l'ancienne existence d'un grand nombre d'oiseaux à åiles rudimentaires, peut être regardé comme la preuve qu'elle a été séparée d'autres parties, dans les plus anciens temps et qu'elle a ainsi conservé sa flore primitive : elle est encore dans son âgre de fougère. »

Nous avons vu également que Thompson se demande, à propos des Moa, si la Nouvelle-Zélande n'était pas un grand continent, lors de la création de ces oiseaux gigantesques, dont autrement, dit-il, il serait difficile de comprendre l'existence sur une terre aussi restreinte.

(1) Ouv. cité, p. 433. 


\section{CHAPITRE DEUXIEME}

mommonomanc.

MAORI.

Population de la Nouvelle-Zélande. - Evaluations contradictoires taites par les voyageurs. - Recensements. - Extinction graduelle des indigènes, - Etymologie du mot Maori. - Division des Maori en nations, tribus et sous-tribus. - Opinions de Shortland et de Thompson. - Iwi ; Hapu. - Devises caractéristiques des tribus. - Signification du mot Ngati. - Unité de race à la Nouvelle-Zélande. - Examen critique des opinions contraires. - Caractères physiques des Néo-Zélandais, d'après les différents observateurs : Crozet; d'Urville; Moërenhoüt; Dieffenbach: Shortland; Taylor; Thompson. - Les Maori ne forment qu'une seule race et ne parlent qu'une même langue. - Les variétés signalées parmi eux ne sont que de simples nuances. - Caractères physiques des Néo-Zélandais, d'après nous-même. - Leurs caractères crâniens. - Portraits de Néo-Zélandais. - Les Maori étaient le plus beau type de la race polynésienne. - Comparaison de leurs caractéres physiques et moraux au commencement du siècle et ì notre époque : Quoy ; Marsden; Thompson.

Population. - En 1830, d'Urville pensait qu'en prenant 50,010 habitants pour l'ile Tavai-Pounamu, et en en donnant 200,000 à Ika-na-Maui, on ne pouvait pas commettre une grande erreur. Voici ce qu'il dit à cet sujet (1) :

"Forster ne porta qu'à cenı mille le nombre total des habitants ; mais il est hors de doute que cet observateur,

(1) T. II, 2॰ partie p. 571 . 
disposé à l'exagération pour d'autres archipels et notamment pour les îles de la Société, était resté au-dessous de la vérité pour la Nouvelle-Zélande.

"M. Kendall m'a souvent dit que Ika-na-Maui pouvait compter un million d'habitants. M. Williams estimait le nombre à 500,000, enfin $M$. Nicholas le réduisait à 150,000 . Pour moi, je pense qu'en prenant pour Ika-na-Maui le chiffre de 200,000 , on ne pourra pas commettre une grande erreur. Quant à Tavaï-Pounamou, on ne peut guère lui donner plus de 50,000 habitants. L'introduction des armes à feu a été funeste à certaines parties de cette contrée. Les habitants de Huraki et des rives de la baie d'Abondance jusqu'au cap Est, en ont souffert d'une manière cruelle, et des contrées, naguère occupées par une population nombreuse, sont aujourd'hui presque entièrement déserıes. "

Faisons remarquer que c'est à peu près dans une même période que toutes les estimations ontété faites parles voyarreurs et les missionnaires; il en est bien probablement de ces estimations comme de celles de Tahiti, c'est-à.dire qu'elles ont été exagérées dans un sens ou dans l'autre. Mais il n'est pourtant pas moins vrai que, jusque dans les derniers temps, la population de la Nouvelle-Zélande a été portée à un chiffre considérable par tous ceux qui en ont parlé. D'Urville, en ne lui donnant que 250,000 âmes ne l'exagérait certainement pas.

Nous croyons qu'il était particulièrement au-dessous de lia vérité, quand il n'attribuait que 50,000 âmes à la grande île du Milieu, qu'il appelle Ile-Sud (1), et qu'il connaissait à peine, puisqu'il n'avait vu qu'un seul point de cette île, dans le détroit de Cook. Il fondait son opinion sur ce que les intempéries, plus grandes sur la côte Ouest de cette île, empêchaient qu'elle ne fût habitée. Aussi n'at-on cessé, depuis lui, de répéter que la côte occidentale était déserte, à cause de la violence des vents qui s'y font sentir. On sait aujourd'hui avec certitude que cette île était non seulement plus peuplée qu'on ne croyait, mais qu'elle

(1) D'après Cook qui croyait que l'île Stewart faisait partie de la grande île dite aujourd'hui Ile-du-Milieu. 
était habitée mêmesur sa côte Ouest, qu'on disait si déserte. Elle l'est même encore dans une foule de points, sur cette côte, malgré les émigrations qui ont eu lieu autrefois et dont nous aurons à parler plus tard.

Déjà, du reste, M. César Moreau avait cherché à rectifier l'exagération de cette opinion, dans un tableau qui a étépublié à Londres en 1827. Comme on l'a vu, la Nouvelle-Zélande méridionale ou Tavai-Pounamu est plus grandequela Nouvelle-Zélande septentrionale, ou Ika-na-Maui, puisqu'ellemesure 36,000milles carrés contre 26,000. Au lieu d'une population aussi inférieure que celle estimée par d'Urville, M. Moreau lui donnait 90,000 habitants, et il réduisait, au contraire, à 70,000 celle que d'Urville disait être de 200 mille, sur l'IleNord. Nous n'aurions pu dire à cette époque si les données de cet écrivain étaient plus exactes ; mais, avec les faits modernes, avec la connaissance des traditions maori, mises en lumière dans ces dernier's temps, nous serions porté à le croire. On verra bientôt que, si l'Hawahiki était véritablement placé là où nous croyons qu'il l'était, il faut admettre, au contraire, que cette terre était autrefois très peuplée pour avoir pu fournir à l'Ile-Nord autant d'émigrants qu'elle en a fourni, d'après les traditions elles-mêmes. Peut-être même pourrait-on trouver, dans ces émigrations répétées, l'explication du nombre restreint d'habitants rencontrés par les premiers explorateurs sur une île aussi étendue que l'Ile-duMilieu.

Voici, du reste, les estimations successives faites pour tout l'A rchipel :

En 1769, Cook portait la population à 400,000 habitants;

En 1778, Forster................ 100,000 -

En 1815, Nicholas.............. 150,000 -

En 1815, Williams............. 500,000 -

En 1815, Kendall............... 1,000,000 -

En 1830, d'Urville................ 250,000 -

En 1843, Dieffenbach............ 114,000 -

En 1849, la populat. n'était plus que de $109,000 \quad-$

En 1854, Shortland la portait à..... 100,000 -

En 1855, Taylor............... $65,000 \quad-$ 
En 1859, Thompson............ 54,600 habitants. En 1878, dernier recensement....... 42,8i9 -

Quel qu'ait pu être le chiffre véritable, il faut bien recon naître, malgré les assertions contraires de Thompson et autres, que le contact européen a été plus nuisible qu'utile aux populations de la Nouvelle-Zélande. On ne peut que gémir sur une diminution aussi rapide, et qui n'a certes pas été entravée, au contraire, par les conflits survenus entre les Maori et leurs protecteurs. Il est même surprenant que les guerres d'extermination des Anglais et surtout l'action des liqueurs fortes et empoisonnées vendues par leurs commerçants, n'aient pas encore complètement détruit les Néo-Zélandais, comme l'ont été les Tasmaniens par les mêmes procédés des mêmes civilisés.

D'autres causes encore viennent contribuer à cette effrayante dépopulation. En outre des guerres, il faut mettre en première ligne l'intempérance provoquée par les dominateurs étrangers, et le défaut de précautions hygiéniques qui préparent le terrain à la tuberculose, à la rougeole, à la coqueluche, à la fièrre typhoïde, à la variole et à d'autres épidémies. Mais une des causes les plus saisissantes consiste dans la diminution des femmes : dans certains districts, il ne naît plus de filles. (1) A mesure que la mortalité augmente, la natalité diminue ; en 1859, d'après Colenso, un seul chef, sur onze mariés dans la même tribu, avait des enfants. Le capitaine Delapelin, sur 80 Sandwichiennes mariées, n'en trouvait que 39 qui fussent mères. Dans la baie Taio-Hae, des Marquises, le capitaine Jouan n'a constaté, en trois ans, que 3 ou 4 naissances, tandis que le chiffre des habitants descendait de 400 à 250 .

Car la dépopulation atteint tous les archipels polynésiens: En 1778, les Sandwich avaient 300,000 habitants; en 1861 elles n'en avaient plus que 6,7,08'; Tahiti, de 240,000, en $1774(\cdot 2)$, est tombé en 1857, à $7,212.11$ en est de même pour

(1) Voy. Revue d'Anthrop, 1879, p. $36 \%$.

(1) Ce chiffro, donne par Cook, est évidemment exagéré. La population ne sumble pas avoil dû jamais dépasser, 30 à 40,000 habi- 
les Samoa et les Tunga qui cominencent à être fortement atteintes.

Dans la lutte entre les envahisseurs et les indigèness, la victoire, pour le règne animal, comme pour le règne végétal, s'est surtout déclarée en faveur des envahisseurs ; mais nulle part le fait n'est aussi frappant qu'à la Nouvelle-Zélande, où les espèces européennes, loin d'avoir à lutter, sem. blent acquérir d'emblée une vitalité nouvelle. Partout, les flores et les faunes indigènes disparaissent en mème temps que l'homme lui-même. Les races européennes prospèrent merveilleusement, là même où s'éteint la race indigène ; et, d'après M. de Quatrefages (1), il en serait de même pour les métis, quoiqu'il ne fasse qu'effleurer légèrement ce sujet : Il est vrai que la plupart des observateurs s'accordent pour reconnaître le contraire.

Cette dépopulation graduelle des îles polynésiennes, dépopulation que l'on a attribuée surtoutaux maladies importées, à la phthisie, à la syphilis, à la petite vérole, ainsi qu'à l'asservissement, aux changements de coutumes, etc., a, suivant nous, pour cause dominante, capitale, l'abus des liqueurs alcooliques, abus auquel on pousse surtout les femmes, et par suite, les débauches, les excès auxquels elles se livrent avec les Européens, sans parler des avortements et des maladies de toute sorte qui résultent de leur dévergondage à outrance. Ne savons-nous pas que chez nous aussi les femmes publiques deviennent stériles ? La race polynésienne, quoique toujour's jeune, ne semble plus être aujourd'hui qu'une race usée, vieillie, au contact malsain des envahisseurs étrang’ers. Si sa faculté g’énésique s'épuise depuis que nous vivons avec elle, ce n'est pas tant par suite de la lutte pour l'existence, c'est tout simplement, ce qui est bien plus grave, par suite d'un empoisonnement conduisant à sa destruction progressive. Il y a là une des plus vastes questions sociales qui s'imposent aux méditations du moraliste.

Les voyagres de découvertes ont été plus nuisibles qu'utitants. Il faut, du reste, se défier beaucoup des évaluations approximatives faites par les premiers explorateurs.

(1) Revue scientifique, 9 juin $187 \%$. 
les au bonheur de l'espèce humaine en général, et surtout au bonheur des peuples découverts. Sans contredit, les découvertes ont profité aux peuples qui les ont faites : elles leur ont donné la richesse ; elles leur ont permis de placer et d'utiliser le trop plein de leur population; mais à quel prix ? En exaltant le fanatisme, en corrompant les mœurs des nations. N'est-ce pas la soif de l'or et ủu sang, inspirée par la conquête du Nouveau-Monde, qui, dans une large mesure, a contribué à éveiller des appétits inconnus, à assouvir des passions latentes, à perpétrer des crimes et des forfaits inouis, à légitimer cette conception inique : la force prime le droit?

Quant aux nations conquises, elles n'ont eu qu'à souffrir tandis que les conquérants s'enrichissaient à leurs dépens. En Océanie, les naturels n'ont obtenu de notre conquête d'autres résultats que la spoliation, la démoralisation, la dépopulation graduelle. De Tahiti aux Marquises, de l'Ile de Pâques à la Nouvelle-Zélande, un concert de malédictions pourrait s'élever unanime contre l'influence néfaste des envahisseurs étrangers.

* Après toutes les observations que j'ai pu faire dans mes voyages, disait Madame Pfeiffer, (1) non seulement dans l'Inde Hollandaise, mais aussi dans toutes les contrées en dehors de l'Europe, je serais presque tentée d'affirmer que les peuples les plus heureux sont ceux qui ne sont pas tombés sous la domination des blancs. Ils ont sans doute aussi leurs souffrances et bien des vexations à subir; mais cer. tainement elles sont moins affreuses que celles que leur font essuyer les cupides Européens."

De son côté, Hamilton, médecin de la Pandora, s'écrie (2): « Heureux aurait été le peuple de Tahiti s'il n'avait jamais été visité par les Européens. Car, à notre honte, on peut dire que la maladie et la poudre à canon sont les seules choses ou le seul bénéfice qu'ils aient reçu de nous en retour de leur hospitalité et de leur douceur. »

(1) Mon premier yoyage, p. 305.

(2) A Voyage round the World, p. 54. 
MAORI est le nom que se donnent les habitants de la Nouvelle-Zélande, quelle que soit l'île: ce nom signifie « naturel, indigène, du pays. »

D'après 'Taylor, le mot Maori a la signification du mot maure ou nègre ; il lui ressemble, en effet, mais il ressem. ble surtout au mot Mauri, qui était employé anciennement.

La racine de ce mot, dit-il, est uri, signifiant noir : d'où mauri, le cœur, le sang noir. Uri est, en outre, la racine de plusieurs autres mots, tels que pouri, nuit; kokouri, sombre, nuageux; wheuri, eau noire, profonde ; tua uriuri, amoncellement de nuages noirs; lkauri, Dammara australis, pin dont la résine brûlée est noire et sert au tatouage.

Mais Uri, et c'est sans doute sa véritable signification, veut dire aussi : postérité, descendance ; ou mieux, origine, vestige : Uri Tangata, le commencement de l'homme.

Le mot maori, en somme, est le contraire du mot pakeha étranger. Pourtant, il doit signifier plus encore, puisqu'on l'applique à l'eau douce, et que l'on dit : he waï maori « une eau douce, de source, naturelle.» Dans ce cas, ilsemble qu'on le traduise par : eau bonne, potable, vraie, de source.

Quelle que soit la véritable signification de ce mot, il est certain que c'est le nom que s'appliquent à elles-mêmes toutes les populations de la Nouvelle-Zélande, comme le font d'ailleurs tous les Polynésiens, en modifiant seulement ce motsuivant les nécessités de l'euphonie adoptée. C'est ce qu'établit le tableau suivant. 
Signification du mot Maori.

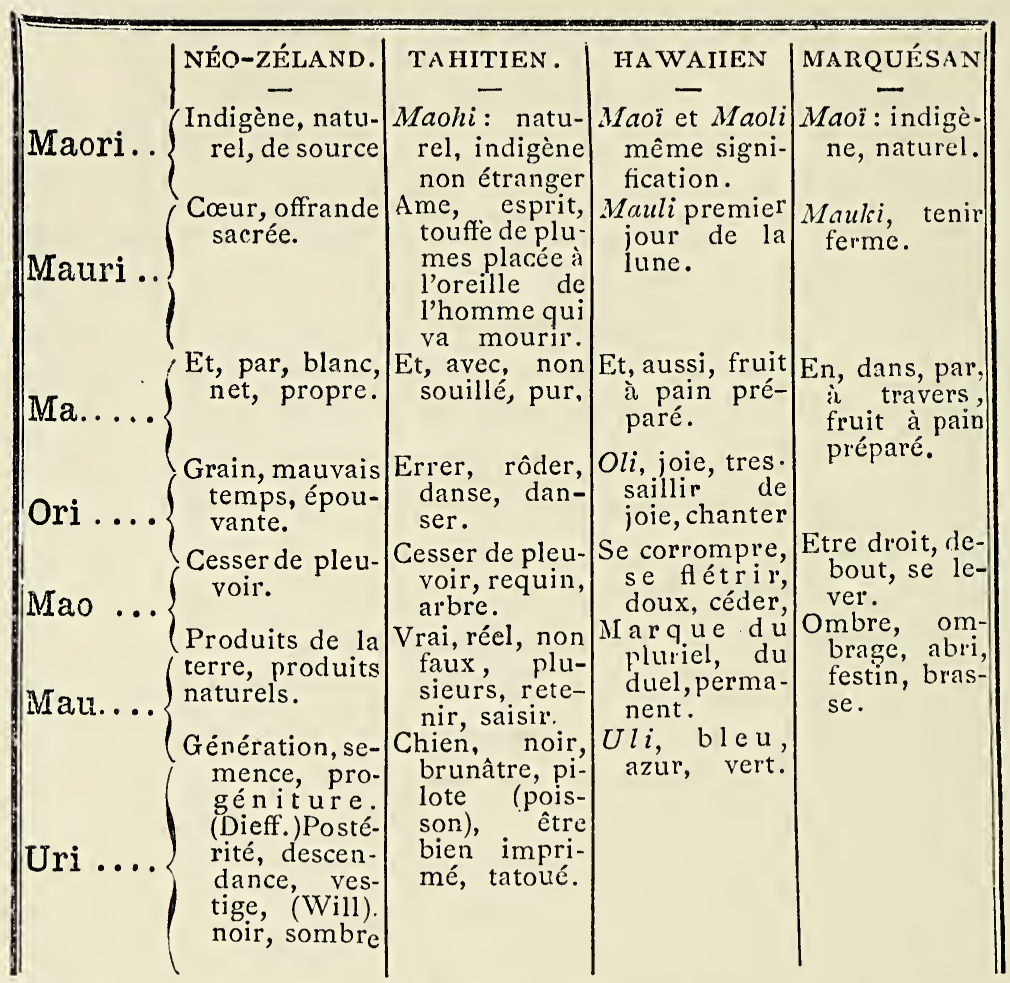

Nous adoptons le mot Maori, parce que non -seulement ce mot se trouve d. la Nouvelle-Zélande mais, avec la même signification, dans tous les archipels polynésiens. Il nous semble aussi plus euphonique que Mauri (pron. Maouri), qui est pourtant, croyons-nous, le véritable nom que les Néo.Zélandais se donnaient dans l'origine. Ce dernier se compose des racines ma et uri, ou plutôt mieux encore des racines mau et uri, dont l'un des $u$ aurait été élidé par euphonie. Sa signification serait donc: $\ll$ les produits naturels du sol, les purs descendants, les vrais indigènes du pays.» $\mathrm{A}$ Tahiti, où le mot mauri est toujours usité, il signifie esprit, âme, mânes.

$A$ priori, on peut conclure d'une pareille dénomination que les Nouveaux-Zélandais se considéraient non-seulement comme formant une race à part, mais aussi comme 
appartenant tous à cette seulo race, dans leurs îles. C'est ce que nous aurons bientôt à démontrer, quand nous examinerons les opinions contraires émises à ce sujet par presque tous les écrivains. (1)

Les populations de la Nouvelle-Zélande se divisent en nations qui se subdivisent elles-mêmes en tribus et en soustribus.

Shortland pensait que le mot Waka, canot, était le terme employé pour indiquer les grandes divisions, parce cue ce mot se rapportait à l'origine des tribus, arrivées à ia Nouvelle-Zélande dans leurs canots. Comme i les croyait venues dans trois cancts principaux, il était porté à ne reconnaître que rrois principales divisions. Mais ce n'est pas du tout le mot waka qui est placé devant les noms de tribus et une foule diautres noms, c'est tout simplement le mot whaka, faire.

Ne pouvant entrer ici dans les développements linguistiques nécessaires pour le prouver, nous nous bornerons à cette seule observation : Iwi et Hapu sont, d'après Shortland

(1) Comme c'est seulement dans la langue d'un peuple qu'il faut chercher l'interprétation de son nom national, il sembie que ce nom de Maori ou Mauri n'a pu être adopté, comme expression générique de la race, qu'après la connaissance par celle-ci de quelqu'autre peuple. Peut-être existait-il auparavant un autre nom, que le nom actuel n'a fait que remplacer, suivant une habitude encore générale. Mais il est bien évideut que c'est dans le pays d'origine lui-même que ce mot a dû être appliqué pour la première fois, puisque, dans les autres îles, les naturels de la mêue race n'emploient que ce mot pour se désigner eux-mêmes. Il est bien difficile de dire quel est le peuple étranger dont ils auraient pu avoir connaissance. Peut-être pourrait-on supposer que quelques Mélanésiens ont été entraînés jusque chez eux ; mais il est impossible d'affirmer à ce sujet quelque chose de positif.

On sait, du reste, que certains noms primitifs fixent, sur une seule nation, l'idée du genre humain tout entier; que d'autres rappellent la valeur guerrière, la force, l'habileté, la puissance supérieure, etc. Ce nom de Maori, siornifierait donc, en résumé, soit vraie race, postérité, mau uri, en élidant mau en ma, dernière syllabe qui signific aussi production du sol; soit, comme on le traduit geénéralement, indigène, naturel. Ces deux signnifications, on le voit, sont à peu près identiques. 
et tous les autres observateurs, les mots employés pour désigner ?es autres divisions. Or, pour que le lecteur puisse être fixé, nous transcrivons littéralement les remarques de Shortland lui-même (1) :

" Les divisions primitives qui sont en quelque sorte les trois principales divisions formées chacune par les tribus descendues des équipages du Tä̈nui, de l'Arawa et du Te Mata-atua, sont parfois désignées par l'expression Waka, canot, d'après leur provenance des équipages des différents canots. Le terme Iwi, ordinairement traduit par tribu, s'applique aussi à ces trois divisions primitives, mais, plus généralement, à leurs plus grandes subdivisions; les plus petites étant appelées Hapu. Ainsi chaque Waka contient plus ou moins d'Iwi, et chaque Iwi, plus ou moins d'Hapu. Cela fait voir de quelle manière ces subdivisions ont été formées. Les noms distinctifs des Iwi et des Hapu, sont généralement tirés des ancêtres. Les premiers colons ne semblent pas être restés ensemble en un seul corps, mais ils paraissent s'être dispersés aussitôt après leur arrivée, chaque famille cherchant pour elle-même une localité à sa convenance, où elle se fixa.

“ Nous trouvons, à la troisième génération, une partie de l'équipage de l'Arawa établie à Taupo tout-à-fait au centre de lî̀le. La postérité de chacune de ces communautés augmentant en nombre, elle se distingua avec le temps par le nom de quelque ancêtre commun en renom. C'est ainsi que deux des Iwi, auxquelles appartiennent des descendants de l'équipage de l'Arawa, sont désignées par les noms de Tapuika et Waitaha; la première ayant pris le nom du petit-fils de Tia, etla dernière celui du petit-fils de He, qui sont regardés tous les deux comme ayant fait le voyage d'Hawahiki à la Nouvelle-Zélande. Une autre Iwi importante, appelée Ngati-Wakaue, tire son nom de Wakaue le septième descendant d'Hou, chef qui faisait partie de l'équipage de l'Arawa.

" Quand une Iwi devenait nombreuse et puissante, elle se subdivisait $\in \mathrm{n}$ portions appelées Hapu, qui se distin-

(1) Traditions and Superstitions of the New-Zealanders, p. 223. 
guaient aussi les unes des autres par le nom de quelque ancêtre sous lequel elle avait opéré sa séparation. »

On verra tout-à-l'heure jusqu'à quel point étaient portées ces subdivisions.

Dans une lettre écrite par lui d'Hakaroa, le 15 août 1843, Shortland dit encore : « Il est digne de remarque que chacune des grandes divisions qui existent parmi les habitants de l'Ile-Nord, a son dialecte particulier, et il est probable que le terme Waka, canot, qui est employé pour indiquer les divisions principales se rapporte à cette origine des tribus. Aujourd'hui ces Waka sont divisées en plusieurs Iwi distinctes, chacune desquelles est subdivisée encore en Hapu, ou communautés plus petites.

* Le territoire de chaque Waka est subdivisé en districts possédés par chaque Iwi, et chaque district est partagé par les différentes Hapu et les familles des chefs. »

Ainsi Waka, Iwi et Hapu, telles sont les dénominations données aux diverses divisions de la population à l'lleNord.

A cette occasion, nous ferons une remarque des plus importantes pour l'opinion que nous soutenons: quand les écrivains parlent des Nouveaux-Zélandais, il ne s'agit jamais que des populations de l'Ile-Nord. ll semble qu'on ne sache absolument rien sur celles de l'Ile-du-Milieu, et qu'on se contente toujours, $\dot{a}$ priori, de considérer cette île comme peuplée après coup par l'Ile-Nord; on la laisse toujours à l'écart, dans la plupart des renseignements qui sont donnés surce que l'on appelle la Nouvelle-Zélande. Or, c'est là, comme on le verra, que se trouve l'obstacle principal à la découverte du véritable lieu de provenance des habitants de l'Ile-Nord. Nous aurons occasion de revenir sur cette observation importante quand nous en serons arrivé à démontrer quel était le lieu d'origine des NouveauxZélandais.

Shortland avance que les habitants de l'Ile-Nord ont trois dialectes particuliers correspondant à chacune des grandes divisions établies parmi eux : cette assertion ne doit pas être complètement exacte. On sai que W. Wil- 
liams, l'auteur du dictionnaire Maori, a cité six à sept dialectes différents, qu'il a appelés, d'après les tribus principales : Rarawa, Waïkato, Tauranga, Cap-Est, Ng ititoa et Ngapuhi; nous sommes presque certain qu'il y en a un grand nombre d'autres. Peut-ètre même pourrait-on dire qu'il y en a presque autant que de tribus, etque l'épithète de jargons ou patois leur conviendrait tout aussi bien, sinon mieux, que celle de dialectes. Néanmoins, comme c'est ce dernier mot qui a été admis, nous l'accepterons ici, faute de pouvoir entrer dans les témoignages de linguistique nécessaires pour résoudre cette question, renvoyant d'ailleurs à nos recherchos spéciales à ce sujet.

Déjà, avant Shortland, le Dr Dieffenbach qui, lui aussi, ne parlait jamais que des habitants de l'lle-Nord, avait attribué l'arrivée de toutes les tribus, aux canots venus de l'Hawahiki : seulement il avait reconnu cinq sources principales.

D'après lui, ce serait à l'Arawa, le plus grand canot venu d'Hawahiki, que seraient dus : les Ngapuhi, qui auraient débarqué à la baie des Iles; les Rarewa, à Oruru ou baie Lauriston; les Ngate-Wakaua et les Ngate-Roi-Rangi, à Maketu, dans la baie d'Abondance; les premiers seraient allés se fixer à Rotorua, et les seconds au lac Taupo.

En s'arrêtant à Kauwhia, sur la côte Ouest de l'Ile-Nord, le Tä̈nui aurait donné naissance aux nombreuses tribus Waïkato.

Le canot le Matatua aurait débarqué à Whakatane sur la côte Est, dans la baie d'Abondance de Cook, et, avec le temps, une branche serait allée se fixer à Taranaki, sur la côte opposée. C'est dans ce canot que seraient arrivées, entre autres tribus, celle de Ngati-Kahungunu.

Enfin, dans le Tokomaru, seraient venus les Ngati-Awa, et, dans l'Aotea, les Whanganui et les Ngati-Mamui.

Toutes ces indications, il est sans doute inutile de le dire, sont incertaines; elles varient, pour ainsi dire: autant qu'il $\mathrm{y}$ a de personnes à les donner. On verra plus tard que les canots qui ont amené les émigrants d'Hawahiki, étaient bien plus nombreux que ne l'ont dit Dieffenbach et Short- 
land, et qu'il y en avait an moins douzo ì quatorze, l'apris le studieux missionnaire Taylor.

Il est probable que c'est aux renseignements donnés par ce missionnaile, en 1855, que Thompson doit l'idée des 18 nations qu'il dit exister sur l'lle-Nord, et dont il donne les noms dans un tableau que nous extrayons de son ouvrage publié en 1859. Comme Shortland, il cite d'ailleurs, lui aussi, les restes, dans l'Ile-du-Milieu, d'une nation qui était appelée $\mathrm{Ng}$ atimamoe et qu'il croyait ètre une colonie de Whanganui. Nous espérons démontrer que c'était, au contraire, la nation la plus ancienne de l'lle-du-Milieu, et que c'est elle qui avait fourni à l'lle-Nord la colonie appelée Whanganui. Du reste, comme ses prédécesseurs, Thompson dit que ces 18 nations étaient subdivisées en nombreuses tribus. Pour donner une idée de la multiplicité de ces subdivisions, il rapporte le tableau, dressé en 1859 par le révérend Colenso, qui montre toutes les tribus d'une seule nation appelée Ngati Kahungunu. Il en résulte que les 3704 personnes qui composaient cette nation, étaient subdivisées en 45 tribus, c'est-à-dire que la moyenne de chacune de ces tribus se bornait à 82 personnes.

Voici ce tableau, tel que l'a donné Thompson :

\section{Noms des Subdivisons ou Hapu :}

I. Ngatirangirangi.

2. Ngatimoe.

3. Ngatiraiuri.

4. Ngatikurumokihi.

5. Ngatitu.

6 . Ngatimawete.

7. Ngatihekawera.

8. Nyatimatepu.

9. Ngatihinepare.

ı. Ngatihineura.

I 1. Ngateparau.

12. Ngatihori.

13. Ngatirangikoranak

14. Ngatimatehaere.

15. Ngatipoporo.
I6. Te Paneiri.

17. Ngaitekura.

I8. Nyaitewatiuapiti.

19. Nuaitemawakawa 33. Ngatimaru.

3. Te Matemahue

2 I. Ngatikurukuru. 36. Ngatiruatapu.

22. Nyatipahoro. 37. Ngaitahu.

23. N Yaikahukuranui. 38. Te Parupuwa.

24. Ngatihamiti. 39. Ngatikaingaahi.

25. Ngatip shoi. 40. Ye Matehau.

26. Nitititu. 4r. Ngatiwakarere.

27. Nitirongomaiaua. 42. Ngatikainoke.

28. N.ritiuranga. 43. Ngatiaomataura.

29. Ngatımahu. 44. Ngatitutaiaroa.

30. Ngateas. 45. Ngatimutuahi.

I) semble bien évident, conme le fait remarquer Thompson, que si l'on prend un pareil tableau comme spécimen de toutes les nations maori, une tribu devait être composée de plusieurs familles, et une nation de plusieurs tribus. 
Quoiqu'il on soit, les inđig żnes, pour établir leurs caractères distinctifs entre tribus, ont adopté différentes sentences ou devises : Shortland, Taylor et Thompson donnent à ces devises le nom de Motto. Il est probable que ce mot n'est pas le véritable, car moto, en Maori, signifie seulement boxer, frapper avec le poing. Nous croyons que l'expression indigène est Motu, qui signifie divisé, ètre séparé, division, séparation, marque distinctive.

Chaque tribu a son Motu: ces devises, pour quelques tribus, peuvent être regardées comme un cri de guerre; pour d'autres, elles ont été appliquées comme terme de reproche, de dérision. La plupart d'entre elles ne sont dues qu'à quelques circonstances particulières. Nous croyons inutile de relater ici les recherches étymologiques que nous avons faites sur les noms de ces tribus ; nous nous bornerons à essayer de préciser la signification du mot Ngati, que l'on trouve placé devant la plupart des noms donnés aux tribus maori.

Ngati s'écrit soit en un seul mot, soit en séparant les syllabes : Nga-ti ; dans ce cas, s'il signifie «descendants, » comme on l'admet généralement, cette séparation marquerait l'élision: Nga-ati. W. Williams l'écrit des deux manières; Sir Grey en deux mots. Dieffenbach orthographie Nga-te ; voici la raison qu'il en donne : a Quand les tribus zélandaises, issues des cinq principales, se répandirent plus tard dans d'autres lieux, le fondateur d'une nouvelle tribu lui donnait son nom, et elle était appelée nga, (génitif pluriel de l'article,) en ajoutant les hommes, te tangata, de ce chef. $\gg$

Nous croyons cette explication insuffisante : d'après les missionnaires anglais les plus compétents en pareille matière, nga n'est point un nom, mais seulement une particule employée pour former le pluriel des substantifs. W. Williams, entre autres, après avoir dit que c'était une particule, se borne à ajouter que ce mot a encore la signification de respirer.

Quelques-uns ont vu dans ce signe un autre genre de particule, une sorte de titre de noblesse, analogue ànos par- 
ticules de, du, des. Mais il semble évident $c_{i}$ ıe, dans ce cas, surtout lorsque l'on écrit Nga-te, la particule nga placée devant les noms ne signifie absolument que l'article pluriel les. Alors ce signe n'aurait que la valeur des mots bé ou $b a$, que les Bechuanas, au rapport de Livingstone, mettent devant les noms de leurs nombreuses tribus. Chaque tribu, dit-il, porte un nom collectif tiré le plus souvent du nom d'un animal. On forme le nom de la tribu en faisant précéder le nom de l'animal de la syllabe be ou ba, qui signifie « ceux ». Ainsi, les Ba-Kuena sont « ceux de l'alligator ; les Ba-Hapi sont « ceux du poisson »; les Ba-Taous, « ceux du lion $»$; etc. Et il ajoute : Le nom collectif de Be-Chuana signifie “ les égaux » : be, ceux ; chuana, égal, pareil. Polii désigner un seul individu, on remplace la préfixe be ou ba par le ou mo: ainsi on dit un Le-Chuana, deux Be-Chuana; un Mo-Kuena, un Mo-Tlapi, deux Ba-Kuena, etc.

En somme, quand on se sert du mot nga seulement, il semble ne signifier que a les » ou « ceux » c'est-à-dire qu'il n’est que signe du pluriel. Peut-être encore n'est-il que la première syllabe du mot ngati, adopté par presque tous les écrivains dans le sens de « famille $»$, et il correspondrait par conséquent à l'O' des Irlandais et au Mac des Ecossais.

En effet, c'est ce mot Ngati qui précède généralement les noms des nations et des tribus. Thompson a même fait remarquer le premier, à cette occasion, que sur les 18 nations historiques admises pal lui, 16 commencent leurs noms par cette appellation caractéristique, et qu'il en est de même pour $39 \mathrm{Hapu}$, sur les 45 appartenant à la nation NgatiKahungunu. On verra q'il n'en était pas autrement dans les îles Hervey, et qu'à Rarotonga, particulièrement, la population était partagée, d'après son origine, en deux grandes divisions : les Ngati-Karika, et les Ngati-Tangiia. Quant au mot Ngaï, qui est placé devant les noms de deux ou trois tribus de la Nouvelle-Zélande, il n'est bien probablement que le mot Ngati élidé, de mème qu'ailleurs, au Cap-Hst, par exemple, où le $n g$ est remplacé par le $n$, il est employé sous la forme Naiti.

Ngati, en résumé, n'est, pour nous, que la réunion des 
deux mots nga et ati, élidés par euphonie et signifiant : le premier “ les », le second a descendant, postérité. »C'est pendant notre séjour à Tahiti, et en voyant que ce mot était la préfixe patronymique employée devant les noms des pa. rents ou des ancètres, que cette étymologie nous parut la véritable. Là, en effet, on dit par exemple, Ati-Juda, pour dire: a les Juifs, les descendants de Juda. » En outre, ce mot y signifie : "s'attacher à une personne, l'allier, unir. "

Il est vrai qu'on ne trouve pas ce mot dans le dictionnaire Maori de W. Williaas ; suivant lui, en Maori, postérité se dit uri; mais on n'y trouve pas davantage les mot $n g a-a t i, n g a-a-i t i$. Or quand on sait que ce dictionnaire est loin, d'après l'auteur lui-même, et surtout d'après Sir Grey et autres (1), de faire connaître tous les mots de la langue maori, sans parler de ceux qu'il a évité d'y inscrire, tels que penis, stercus, pudendum et vingt autres, il est bien permis de croire que son silence ne suffit pas pour démontrer l'aỏsence certaine de ces mots. S'il ne les a pas citės, c'est qu'il les a oubliés comme tant d'autres, ou qu'ils n'étaient pas venues à sa connaissance. Sa mission étant de faire disparaître les vicilles croyances, il est à supposer qu'il ne devait pas y attacher grande importance et qu'il n'aimait pas à les colliger. C'est d'autant plus à regretter, de la part d'un homme aussi versé que lui dans la langue maori, qu'il aurait trouvé, dans ces vieilles traditions, une foule de mots dont il ne parle pas.

Le mot ati est réellement un mot maori ; il appartenait, dans l'Ile-du-Milieu, à l'une des plus anciennes tribus, à celle qui avait pour grand-prêtre le fameux Kae, que fit mourir Jinirau, pour se venger de la mort de sa baleine apprivoisée : c'était la tribu des Ati-Hapai; elle fut exterminée par Whakatau, qui incendia ensuite leur grande maison commune nommée Tihi ou Tini-o-Manono. Ati était donc, comme on le voit, un mot maori ; et, en le trourant conservé aujourd'hui en Polynésie, alors qu'il semble inusité

(1) Thompson, tout en le reconnaissant comme le meilleur vocabulaire, disait qu'il ne contenait pas la moitié des mots de la langue. 
là où il figure dans les traditions les plus anciennes, il nous sera facile de montrer plus tard qu'il est lui-même un témoignage favorable à la thèse que nous soutenons.

Cette étymologie du mot ngati, est également celle que reconnaîtle docteur Shortland. Pour lui aussi, ce n'est que ie mot composé nga-ati, mot qui signifie " postérité, descendants. "Il ajoute que les autres expressions employées dans le mème sens, sont: te ati, singulier de nga-ati; ngaiti pour nga-aïti; naïti pour nga-aiti; te aïtanga, comme dans te Aïtanga-Kuri (1), nom d'une tribu de l'lle--du-Milieu; $n g a$, pluriel de l'article défini, comme dans Nga-Puhi (2)

Une pareille antorité venant appuyer l'interprétation que nous avons donnée àce mot, nous pensons qu'il ne peut plus rester de doute sur sa signification véritable. Nous ajouterons néanmoins que ngatı pourrait, à la NouvelleZélande, dériver tout simplement du mot ngaki, transformé avec le temps : il signifierait a!ors \& bécher, cultiver, cultivateur, vengrer, vengeur, " et, pir extension, « soldat, défenseur, serviteur. »

Unité de race a la Nouvelle-ZÉladnde. - Une question beaucoup plus importante pour lè sujet qui nous occupe, c'est de rechercher si la population de la Nouvelle-Zélande, qu’on s'accorde généralement à faire venir de la Polynésie, appartient à une seule ou a plusieurs races.

Pour nous, après avoir vu les Nuuveaux-Zélandais sur les points les plus divers de leurs îles, et à une époque où leurs caractères typiques ne s'étaient pas le moindrement modifiés ; après avoir assisté, sur les lieux mèmes, aux divergences d'opinions du chef de l'expédition et de ses compagnons ; après avoir pu remarquer combien il est difficile d'apprécier sainement les caractères physiques d'un peuple, quand on n'a pas fait d'études spéciales; enfin,

(1) Ai qui, probablement pour kai, homme ; tanga, division, assemblée ; kuri, chien : c'est-à-dire la division, la tribu du chien ou des chiens.

(2) Puhi, anguille. 
après avoir pu comparer les habitants de la Nouvelle-Zélande à tous ceux dits de race polynésienne, aussi bien qu'à ceux des îles Mélanésiennes : Fiji, Hébrides, Vanikoro, etc., et ceux de la Malaisie, nous sommes resté convaincu que la population de la Nouvelle-Zélande, contrairement à ce qu'on a dit, n'est formée que par une seule espèce d'hommes, et qu'elle n'appartient qu'à une seule et même race, race tout-à-fait distincte de toutes les autres, par ses caractères physiques et moraux.

Nous savons bien que la plupart des écrivains ont avancé, en se répétant, qu'il y a plusieurs races d'hommes à la Nouvelle-Zélande; mais cette assertion, renouvelée, depuis Queiros et de Brosses, par d'Urville et une foule d'autemrs contemporains, pour la Polynésie en général, et en particulier pour la Nouvelle-Zélande ; cette assertion, basée sur les observations superficielles du second de Marion, le capitaine Crozet, dont Rochon a publié le journal en 1783, est parfaitement inexacte, et nous allons essayer de le prouver.

Voici les observations consignées dans les journaux de Crozet, qui était à la Nouvelle-Zélande en 1772 : « Je remarquai avec étonnement, parmi les sauvages qui vinrent à bord du vaisseau, dès les premiers jours, trois espèces d'hornmes, dont les uns, qui paraissaient les vrais indigènes, sont d'un blanc tirant sur le jaune: ceux-ci sont les plus grands et leur taille ordinaire est cinq pieds neuf à dix pouces. Leurs cheveux noirs sont lisses et plats. Des hommes plus basanés et un peu moins grands, ont les cheveux un peu crépus. Enfin de véritables nègres, à têtes cotonnées, et moins grands que les autres, mais en général plus larges de poitrine. Les premiers ont très peu de barbe, et les nègres en ont beaucoup.

a Les observations que j'ai faites tous les jours suivants à terre, dans leur's peuplades, m'ont confirmé l'exactitude de ma première remarque. En général, ces trois espèces d'hommes sont fort beaux et bien faits, la tête d'une belle 
forme, de grands yeux; tous ont des nez aquilins (1) de belle proportion, ainsi que la bouche; les dents belles et très blanches, le corps bien musclé, les bras nerveux, les mains fortes, la poitrine large, la voix extrêmement haute, peu de ventre, presque imberbes, les jambes bien proportionnées, un peu grosses, les pieds larges, les doigts bien écartés. Les femmes ne sont pas si bien àbeaucoup près ; elles sont en général plus mal, de figure courte, la taille fort épaisse, les mamelles volumineuses, les cuisses et les jambes grosses, d'un tempérament qui paraît fort amoureux, au lieu que les hommes sont très indifférents. »

Ailleurs, Crozet ajoute : (2) \& Il est sans doute surprenant que nous ayons trouvé, dans cette extrémite de la terre, dans des îles inconnues̃ jusqu'à ce jour et sans aucune communication avec le globe, trois espèces d'hommes, des blancs, des noirs et des basanés ou jaunes. Il y a toute apparence que les blancs sont les indigènes. La couleur de ceux-ci est, en général, comme celle des peuples méridionaux de l'Europe. J'en ai vu trois ou quatre qui avaient les cheveux rouges. Il y en avait parmi eux qui étaient aussi blancs que nos matelots; et nous avons vu souvent, sur nos vaisseaux, un grand jeune homme bien fait, de 5 pieds onze pouces, qui eûtpu passer pour un Européen par la couleur et par ses traits. J'ai vu une fille de 15 ou 16 ans aussi blanche que nos françaises.

"Divers évènements de navigation auront pu transporter à la Nouvelle-Zélande des noirs de la Nouvelle-Hollande, qui en est éloignée aujourd'hui de près de 300 lieues,

(1) Ainsi voilà des nègres qui ont des traits de blancs, et certes on devait peu s'y attendre ! Cela serait suffisant, quand il n'y aurait pas d'autres motifs, pour inontrer que l'observation de Crozet est inexacte. Le reste convient parfaitement à tous les Zélandais. Si d'Urville a répété, comme on verra, la même assertion à peu près dans les mêmes termes, c'est qu'il avait besoin de l'opinion de ses devanciers pour en avoir lui-même une en anthropologie.

(2) Nouveau Voyage, p. 137 et Voyage aux Indes-Orientales, p 364 . 
mais qui n'a peut-être pas toujours été si éloig'née. Cette dernière île, la plus grande de toutes celles que nous connaissons, a été certainement peuplée par les noirs de la Nouvelle-Guinée, qui n'en est séparée aue par un détroit de la lar'̌eur d'une rivièrc : ces nègres, transplantés à la Nouvelle-Zélande, s'y seront alliés.avec les femmes du pays, et, de ces alliances, seront sortis les basanés qu'on y voit aujourd'hui.

«Au reste, il est à remarquer que, dans presque toutes les îles qui s'étendent depuis Formose et les Philippines jusqu'à la Nouvelle-Zélande, dans les vastes archipels qui occupent un espace de plus de 1500 lieues en longueur, entre les mers de la Chine, des Indes, de l'Afrique, d'un côté, et de celles de l'Amérique, de l'autre, on trouvè partout un mélange prodigieux d'hommes de différentes couleurs et figures, des blancs, surtout des nègres et des basanés. Les côtes de Formose sont habitées par des Chinois ; les côtes de l'île Luçon et de la plupart des autres Philippines par des colonies malaises, et leurs intérieurs, les forêts et les montagnes, par de vrais sauvages indigènes. Il en est de même de Bornéo, où l'on trouve des nègres à laine, ¡insi qu'aux Moluques, à la Nouvelle-Guinée, à Timor, à la Nouvelle-Hollande, et enfin à la Nouvelle-Zélande. On trouvera peut-être les mêmes mélanges aux Terres australes dont les Frrançais et les Anglais tentent aujourd'hui la découverte à l'envie les uns des autres. Ce qu'il y a de plus singulier, c'est que nos navigateurs ont trouvé tout récemment les mêmes mélanges jusqu'au milieu de la mer du Sud, dans l'île de Taïty. »

Nous n'arons pas hésité de rapporter en entier cet extrait, malgré son étendue, parce qu'il est ce qu'on a dit de plus explicite, dès les premiers voyages, en faveur de la pluralité des espèces, à la Nouvelle-Zélande comme en polynésie, et qu'il est cause que presque tous les écrivains, surtout en France, ont soutenu que la Nouvelle-Zélande présente plusieurs races d'hommes.

Avant de faire nos objections, nous ferons remarquer d'a- 
bord que les lignes de Crozet ne sont que la paraphrase de Queiros et de de Brosses.

C'est ain §i que Queiros, dans l'extrait ủe Torquemada cité par de Brosses, (1) dit, en parlant de la terre Del Espiritu Santo : «Nos gens virent sur la plage un $g$ : and nombre de cochons, semblables à ceux d'Espagne, et grand numbre d'habitants de trois couleurs. Les uns tout noirs;les autres fort blancs et à cheveux et à barbe rougre ; !es autres mulâtres ; ce qui les étonna fort et leur parut un indice de la grande étendue que cette contrée derait avoir. »

On lit encore, dans l'extrait du mémoire présenté au roi d'Espagne, et rapporté par de Brosses : « Les habitants de cette partie du monde sont très nombreux et de direrses couleurs : blancs, noirs, olivàtres ou de couleurs mélangées. Il y en a de roug'eâtres, peut-être pour avoir été brûlés par l'ardeur du soleil. Les uns ont les cheveux noirs, longs et épais; d'autres aussi les ont jaunes et luisants : ce qui peut être un indice qu'il y a eu parmi eux du mélange dans les espèces. $»$

Dans un extrait d'un autre mémoire, il dit, en parlant de Taumako, Chicayna, etc., que le prisonnier fait par lui à Taumako était de cette île, "dont les habitants sont les uns noirs, à cheveux longs et frisés ; les autres blancs, à cheveux roux et crépus. $\triangleright$

Enfin, en parlant des îles Marquises, Queiros avait déjà dit : "Parmi ces insulaires, on voit des blancs, des noirs et quelques mulâtres; cette diversité de couleur, prouve qu'ils ont des communications avec d'autres pays. Il faut donc nécessairement croire qu'au Sud-Est et au SudOuest, et plus à l'Ouest, il y a d'autres îles qui forment une chaîne ou un continent, qui s'étend jusqu'à la Nouvelle-Guinée, s'approche des Philippines et des Terres australes du détroit de Magellan, puisqu'il n'y a pas d'autres lieux connus d'où les peuples qui habitent ces îles puissent être venus; à moins qu'on ne veuille soutenir qu'il ont été particulièrement créés. De quelque côté qu'on les suppose

(1) Histoire des navigations aux Terres australes, t. Ier, p. 325. 
partis, il faudra nécessairement admettre une chaîne d'iles ou un continent. $»$

C'est après cela que de Brosses lui-même ajoutait : « Un sujet d'étomnement est de trouver en Polynésie tant de races d'hommes de diverses espèces et de couleurs différentes, placés dans les mêmes climats, à de si petites distancez les uns des autres. Il y en a de blancs, de basanés, de noirs, de mulâtres, d'autres même à peau truitée. On y trouve des noirs à nez écrasé, des noirs à cheveux longs, et des noirs à cheveux jaunes, noirs ou rouges, si toutefois ceux-ci ne les teignent pas en couleur, comme il est assez croyable. La peau truitée de quelques-uns, semblable à celle des métis nés de blancs et de mulâtres, qu'on nomme quarterons, parce qu'il y a dans leur sang un quart de race nègre et trois-quarts de race d'Europe, paraît prouver avec assez d'évidence qu'il y a eu du mélange dans les espèces, et que les insulaires sont dans l'usage de communiquer ensemble, dans les longues chaînes d'îles, des unes aux autres. D'où il suit que, n'ayant pas des pirog'ues capables de soutenir une fort longue traversée de mer, il faut que les îles rangées à la file ne soient éloignées entre elles que d'une médiocre distance; ce que l'expérience a vérifié dans toutes celles qui ont été découvertes. "

Comme on le voit, bien avant Crozet, on avait cru reconnaître plusieurs espèces d'hommes différentes parmi les populations découvertes en Polynésie.

On pourrait presque trouver Cirozet modeste de ne citer que trois espèces d'hommes distinctes à la Nouvelle-Zélande; car, là aussi, s'il eût voulu, il aurait pu rencontrer toutes les nuances observées par les premiers explorateurs de la Polynésie. Mais ce n'étaient que des nuances, qui n'autorisaient pas, à notre aqis, à y voir autant d'espèces ou races différentes. Il nous semble même que c'est à cette conclusion négative que conduisent certaines remarques des écrivains modernes, qui soutiennent que la NouvelleZélande est peuplée d'au moins deux races différentes: d'Urville, Dieffenbach, Shortland et Thompson, pour ne 
citer que ceux qui ont pu parler d'un pareil sujet avec autorité, sont de cet avis.

Dans les extraits que nous allons donner de ces écrivains on verra, en effet, que si tous s'accordent à reconnaître plusieurs races distinctes, comme (Jrozet, tous s'accordent aussi à réfuter ce dernier, dans ses autres assertions. Mais tous à peu près différent dans leurs interprétations, ou explications des faits.

Ainsi Dieffenbach remarque que si le capitaine Crozet, Français qui a visité autrefois la Nouvelle-Zélande, dit avoir trouvé, au cap Nord, une tribu plus noire que les autres, lui n'a rien observé de pareil, quoiqu'il ait visité tous ies indig’ènes.

Ainsi Shortland combat l'explication donnée par Crozet du mélange observé par lui ; jamais il n'a pu se convaincre de la vérité de cette assertion, avancée par d'Urville, que les plus noirs sont les esclaves; car il a rencontré la chevelure crépue, aussi bien parmi les gentilshommes que parmi les esclaves.

Ainsi Thompson, tout en admettant trois variétés, bien que naturellement il diffère sur la désignation des couleurs, dit que l'explication de Crozet, sur le mélange des Nouveaux-Zélandais, n'est appuyée par aucun témoignage.

Enfin, d'Urville lui-même dit que ce n'est pas, comme le croyait Crozet, la race blanche qui était aborigène, mais bien la race la plus foncée en couleur.

En un mot, tous apportent quelques témoignag*es qui, s'ils ne suffisent pas pour détruire leurs observations, aident, tout au moins, à faire douter de leur exactitude.

On comprend parfaitement que cette croyance en plusieurs espèces d'hommes, à la Nouvelle-Zélande, ait été généralement admise ; il était tout naturel qu'on l'adoptât après Cook, rapportant qu'on lui avait affirmé, à T'ahiti, que des hommes plus noirs que le reste de la population existaient peu de temps encore avant son arrivée; après d'Urville, répétant cette assertion. Aussi est-ce l'opinion qui est actuellement soutenue par la plupart des savants 
français, et particulièrement par MM. Broca, de Quatrefages, Topinard, Hamy, etc. (1)

MM. de Quatrefages et Hamy, dans le septième fascicule des Crânia ethnica, spécialement consacré aux races Papua et Australiennes, ont affirmé que les Papua ont contribué, dans une limite assez restreinte, il est vrai, au peuplement de l'archipel de la Nouvelle-Zélande, et qu'ils ont fourni un certain nombre d'éléments ethniques à Madagascar. Ils prétendent avoir suivi leurs traces à travers les migrations qui se sont effectuées en Polynésie, même à l'Orient des Polynésiens, puisque, disent-ils, on rencontre des crânes à caractères papua jusqu'à l'île de Pâques.

M. Hamy affirme en outre que I'élément papou est bien marqué à la Nouvelle-Zélande ; il base cette affirmation sur les traditions recueillies par Grey et Colenso. Ce dernier, ajoute-t-il, a découvert, dans l'intérieur, des ruines qu'il regarde comme antérieures à l'arrivée des Maori; or les ossements trouvés au milieu de ces ruines seraient des ossements de Papous. Parmi les têtes desséchées, préparées par les Néo-Zélandais et rapportées en Europe, il y en aurait autant à cheveux laineux qu'à cheveux lisses. Le crâne mélanésien, étudié par Huxley, et que Sedgewick regardait comme Néo-Zélandais, en est une preuve. A quoi M. Topinard répondit que ce crâne, type de l'extrême dolichocéphalie, est originaire dess Nouvelles-Hébrides et non de la Nouvelle-Zélande.

Pour nous, et nous croyons pouvoir l'affirmer, l'existence de plusieurs races, ou tout au moins de deux races, aussi bien à Tahiti qu'à la Nouvelle-Zélande, est une assertion parfaitement inexacte. Cette assertion est démentie non-seulement par les renseignements obtenus depuis les premières observations, mais elle l'est aussi et surtout par

(1) Voy. à ce sujet : Bull. soc. d'Anthrop. 1862, p. $309 ; 1872$, p. 416; 1878, p. 504. Revue d'Anthrop., 1872, p. 23; 1864, p. 95. Etudes sur la Polynésie in Revue des Deux-Mondes, 1863. Crania Ethnica, \%e fascic. Assoc. Franç. pour l'avanc. des sciences, session de Paris, 1878, etc. 
la linguistique. C'est ce qu'ont prouvé les beaux travaux faits sur ce sujet par les missionnaires anglais.

Nous pourrions ajouter qu'après avoir longtemps habité Tahiti, après avoir fait partie de l'un des voyages de d'Ur. ville, après avoir visité, avec l'Astrolabe et le Pylade, toutes les îles de la Polynésie ainsi que li Nouvelle-Zélande, nous n'avons jamais pu, malgré nos demandes à ce sujet, dans les îles Tahiti ou Marquises, apprendre qu'une population noire y eût p̣récédé celle qui s'appelle elle-même Maohi, Maoi et Maori. En outre, nous l'avons déja dit, rien dans.la langue indique que cette population y ait jamais existé.

En ce qui concerne la Nouvelle-Zélande, le peu d'entente des"écrivains entre eux et les remarques particulières qu'ils font sur les caractères de ces races, suffiraient déjà, à notre avis, pour faire douter de l'exactitude de leurs observations, quand mème la linguistique ne les détruirait pas complètement.

Sans doute, comme ils le disent, il y a des différences considérables entre les hommes d'une même nation ou tribu: les uns sont grands, les autres petits; les uns sont bruns, les autres plus blancs ; mais les caractères par lesquels ils cherchent à les distinguer sont évidemment insuffisants, car ils varient constamment, suivant les localités, les habitudes, l'intelligence, etc., et ils ne sont appuyés que sur quelques irrégularités de développement. Il existe certainement, là comme partout, des nuances variées; il y a mème, entre les extrèmes, de très grandes différences, comme nous en avons observé souvent à Tahiti entre les membres d'une même famille; mais ce ne sont que des nuances, et Crozet, pour ce qui le conccrne, s'est chargé de détruire lui-même une partie de son assertion, quand il dit que les trois espèces d'hommes observées p:rr lui à la Nouvelle-Zélande sont beaux, bien faits, et 'in'ils ont tous le nez aquilin. Beaucoup de Zélandais, en effe't, ont le nez de cette forme. On cite même la tribu Ngatiwhakawa comme ayant le nez juif, ce qui a porté Taylor à regarder les Zélandais comme les descendants de l'une de ces fameuses 
tribus juives dont on n'a plus entendu parler après leur émigration. Mais il faut remarquer que généralement le nez ne paraît surtout présenter cette forme que par suite du tatouage qui le recouvre: c'est une simple apparence. En réalité le nez zélandais est.identique au nez polynésien ; comme lui, il est aplati et élargi à la base.

Nous avons assez observé les Nouveaux-Zélandais, alors qu'ils n'avaient vu que peu d'Européens et qu'ils avaient conservé tous les caractères de leur race, pour pouvoir assurer que leurs cheveux sont généralement d'un beau noir, frisés, lisses ou bouclés; ils n'ont rien de ceux du nègre ou même de ceux des Australiens (1). Comme partout, les cheveux sont plus ou moins bien entretenus, et c'est probablement l'inculture de quelques têtes qui y aura fait croire qu'ils avaient des caractères nègres. Quant aux cheveux rouges, plus particulièrement signalés par Crozet, et que, depuis Queiros, on a observés dans'une foule d'îles de la Polynésie, de même qu'aux Fiji, ils sont fort communs, aujourd'hui encore. Mais tous les voyageurs en Océanie savent par quels moyens, et dans quel but ils sont ainsi colorés. Ce n'est qu'une affaire de goût et de coquetterie. Aussi a-t-on, avec raison, cité plus particulièrement les fils des chefs, comme sacrifiant davantage à cette mode.

Relativement àl'explication que Crozet donne de la variété des chevelures, à la Nouvelle-Zélande, variété qu'il attribue à la venue d'Australiens transportés jusque-là par les vents, il suffira de dire qu'elle est d'autant plus difficile à admettre que les Australiens ne sont point navigateurs et qu'ils manquent même de moyens de transport. Il est vrai

(1) Dans ses deux mémoires d' «obsèrvations microscopiques sur la chevelure, „Pruner-bey a montré que les caractères différentiels de la chevelure des races humaines résident surtout dans la forme présentée par les sections transversales du cheveu. Chez les Australiens, les sections passent de la forme ovale pointue vers l'arrondie, et sont comparables à la chevelure kole dans l'Inde. Chez les Malais, les contours presque ronds forment la règle. Ces contours ronds sont, au contraire, l'exception chez les Polynésiens, dont les coupes sont étroites, pas autant toutefois que celles des Sémites et des Ariens. 
qu'il en suppose la possibilité à une époque où, suivant lui, la Nouvelle-Zélande n'était peut-être pas aussi éloignée qu'elle l'est présentement de l'Australie; mais cette supposition est inadmissible. On sait que le comte Carli admettait, au contraire, que la Nourelle.Hollande était séparée de la Nouvelle-Zélande bien avant la submersion du continent qui liait celle-ci aux îles de la Société. De son côté, le président de Brosses prouvait que ces îles n'avaient pu être réunies en aucun temps, parce que les animaux malfaisants ou venimeux de l'une manquaient dans l'autre. La faune et la flore des deux terres sont entièrement dissemblables ; il en est de même de leur géologie. Contrairement à la Nouvelle-Zélande, l'Australie semble être relativement récente; le continent australien est en grande partie de formation secondaire. Il émerge avec une grande rapidité, ainsi que l'ont constaté : Becker, près d'Hobson's Bay; Darwin, près d'Hobart-Town, et Grégoire, dans le détroit de Bass.

Si Crozet avait donné cette explication, c'est qu'il était partisan de l'origine biblique : il fallait bien qu'il pût faire arriver les tribus à travers la Nouvelle-Guinée, la NouvelleHollande, la Nourelle-Zélande et les îles Polynésiennes jusqu'en Amérique, qu'il regardait commeayant été peuplée par cette voie. C'était le meilleur moyen pour aplanir toute difficulté. Mais cela même n'expliquait pas d'où étaient venus les blancs qu'il avait trouvés à la Nouvelle-Zélande et qu'il regardait comme en étant les véritables indigènes.

D'Urville, tout en partageant l'opinion de Crozet, la modifiait en ce sens qu'il n'admettait que deux variétés « assez distinctes n d'hommes, au lieu de trois. C'est lui qui, le premier, fournit des arguments sérieux contre les observations de Crozet.

" Les voyageurs qui visitèrent ces grandes îles australes, dit-il, remarquèrent sans peine dans leur population deux variétés assez distinctes. Les individus qui appartiennent à l'une de ces variétés sont des hommes bien faits, d'une taille élevée, qui dépasse souvent cinq pieds quatre 
pouces. Leur teint n'est guère plus foncé en conleur que celui d'un Sicilien ou d'un Espagnol très brun; leur che. veux sont longs, plats, lisses et quelquefois châtains ; leurs yeux sont grands et bien fendus; enfin ils ont peu de poil sur le corps.

"Les hommes de l'autre variété sont petits, plus trapus et généralement plus larges de carrure; leur couleur est aussi foncée que celle des mulâtres, et souvent bien davantage; ils ont des cheveux crèpus, unc barbe frisée; enfin leurs yeux sont plus petits, plus perçants, et toutes les parties de leur corps sont beaucoup plus velues.

« Loin de partager l'opinion de Crozet touchant l'origine de ces deux races, je crois au contraire que la race des individus plus foncés en couleur est celle des réritables abo. rigènes du pays, de ceux au moins qui y ont paru les premiers. Les blancs sont de lia race des conquérants et sont arrivés beaucoup plus tard dans ces contrées. Cette opinion, du reste, se rattache à un système particulier, sur la population des îles de l'Océanie, que je compte développer plus amplement à li suite dı voyage proprement dit.

“ Du mélange continuel de ces deux races, on sent bien qu'il a dû résulter une foule de nuances diverses dans lia constitution, le teint et les caractères physiques des habitants de la Nouvelle-Zélande. Ce sera une de ces nuances, sans doute celle qui participe à peu près également des deux races primitives, que Crozet crut devoir signaler comme une troisième espèce d'hommes vraiment distincte, d'autant plus qu'il nous a semblé exagérer les caractères des races blanche et noire.

« Du reste, nous convenons avec ce navigateur que tous ces insulaires sont généralement beaux, bien pris dans leur taille, doués par la nature de membres vigoureux et bien proportionnés. Tous ont les dents superbes, les mains fortes, la voix haute, et le ventre peu proéminent. »

De sorte que d'Urville n'admettait que deux races au lieu des trois de Crozet : la blanche et la noire. Celle-ci, d'après son système, avait précédé la blinche en venant de Tahiti. Quant à la troisième espèce d'hommes de Crozet, elle n'é- 
tait pour lui que le résultat du mélange des deux premières races, c'est-à-dire une race métisse. Dès ce moment, on voit poindre la croyance en une race mélangée ou mixte, qui, pour plusieurs observateurs anglais, est anjourd'hui la seule existante à la Nouvelle-Zélande.

Du reste, d'Urrille convenait, en finissant, que tous ces insulaires blancs, noirs et métis, étaient généralement beaux et bien proportionnés, comme s'ils n'eussent différé foncièrement que par la couleur. Mais, sans s'en douter peut-être, il citait, dans le cours de son texte, des faits qui montraient qu'en tous cas ces différences n'étaient pas très grandes, et qui, surtout, semblaient les expliquer parfaitement.

C'est ainsi qu'on lit, dans la relation de son voyage (1): a Une des pirogues (nous nous trouvions alors dans la baie Tasman), portait dix naturels et l'autre neuf; la moitié de ces gens paraissait ètre d'un rang supérieur, à en juger d'après leur tatouage, leurs belles formes et l'expression distinguée de leurs visages ; les autres, privés de tatouaģe. aux traits communs et insignifiants, esclaves sans doute, ou appartenant à la basse classe, eussent été volontiers pris pour des hommes d'une autre race, tant ils semblaient différer des chefs au premier abord. $>$

D'Urville dit encore (2) :

a Il n'est pas douteux que la coutume qu'ont prise ces insulaires de s'enduire le corps et le visage d'huile de poisson et d'ocre, jointe à leur exposition habituelle aux intempéries de l'air, ne fasse, à la longue, contracter à leur peau une couleur plus foncée qu'elle ne le serait s'ils suivaient les mœurs européennes. "

Telle est, en effet, la cause la plus ordinaire des quelques différences qui ont fait admettre par presque tous les observateurs plusieurs races, aussi bien à la Nouvelle-Zélande qu'en Polynésie.

On comprend très bien que, sur leurs assertions, les sa-

(1) Ouvr. cité, t. II, lre partie, p. 25.

(2) Ouvr. cité, t. II, 2e partie, p. 3.30 . 
vants, non voyag'eurs, aient cru à l'existence de deux races, au moins à la Nouvelle-Zélande; mais on conviendra que les données fournies jusqu'à présent par Crozet et d'Urville, et avant eux par Banks (1), ne semblent guère suffisantes pour qu'on puisse accepter sans hésitation une semblable affirmation. Nous croyons même que ces données suffiraient plutôt à entraîner le doute et à montrer le peu d'exactitude des premières observations.

Bien longtemps avant nous, Moërenhoüt était déjà arrivé à une conclusion semblable. Voici, en effet, ce qu'il dit dans son Voyage aux Iles du Grand Océan (2) : « Il n'y a presque pas un navigateur, un voyageur ou un auteur qui, partant de la Polynésie, ne fasse mention du mélange des races ou des castes ; et moi, après six années de séjour dans plusieurs de ces îles, après six ans de voyages dans un grand nombre d'autres, et d'observations des plus consciencieuses, je n'ai rien trouvé qui vînt à l'appui de cette opinion. Je n'y ai jamais vu un seul individu à cheveux crépus. Si le teint des uns est un peu plus foncé que celui des autres, cette différence n'estjamais plus sensible que celle que nous remarquons chez nous dans nos familles; et si des peuples entiers diffèrent entre eux, cela tient absolument à des localités ou à leur manière de vivre, puisque cette différence disparaît dès qu'ils résident quelque temps dans le même lieu. Ainsi les habitants des Iles Basses de l'archipel Dang'ereux, en apparence si différents de ceux d'O-Tahiti, changent entièrement après un séjour de quelque temps dans cette dernière île; très noirs en arrivant de leur's terres nues et peu boisées, il n'est pas rare de les voir devenir aussi blancs et même plus blancs que les habitants des îles élevées. »

(1) Banks lui-même n'avait pas échappé à ce que nous regardons comme une erreur d'observation, mais du moins il n'avait exprimé son opinion que sous forme dubitative. En effet, à la page 53 de son journal, il dit, en parlant de Tahiti: "La différence que l'on * remarque dans la taille et la couleur des habitants d'Otaheite - ferait croire que ce peuple est composé de deux différentes ra« ces.

(2) T. II, p. 247, note: 
Nous-mème, nous avons cherché vainement pendant tous nos voyages et notre long séjour en Océanie à retrouver ces races si distinctes pour les anciens voyageurs. Comme partout, nous avons vu des nuances, voila tout, mais partout un seul et même type. Il est donc inutile de dire que nous partageons en tous points, à cet égard, l'opinion de Moërenhoüt.

Après tout ce que nous venons de dire, nous n'avons plus besoin de chercher à relever certaines assertions du président de Brosses. Ces assertions avaient pour excuse celle du navigateur espagnol Queiros, dont elles n'étaient à peu près que la reproduction. Néanmoins elles démontrent que, dès cette époque, la race polynésienne des Samoa ou des Tunga avait envoyé, volontairement ou non, des colonies i la Terre du St-Esprit. Ces colonies, qui y ontété découvertes par Forster et Cook, expliquent parfaitement l'observation du voyageur espagnol. Mais c'étaient des colonies de la même race que celle qui peuple la Nouvelle-Zélanıle, parties des archipels dont les habitants, au dire de tous les an ciens voyageurs, étaient autrefois des navigateurs excessivement entreprenants. (1).

Le voyageur moderne qui, après Crozet et d'Urville, a le plus contribué à faire admettre l'existence de plusieur's races distinctes à la Nouvelle-Zélande, est le docteur anglais Dieffenbach. Nous ne pouvons, à cause de cela, nous dispenser de rapporter ses paroles, qui aideront peut-être elles mêmes à faire douter de cette existence. En tout cas, elles feront connaitre les premières observations un peu exactes, faites après celles des naturalistes de l'Astrolabe, sur les caractères physiques des Nouveaux-Zélandais.

" Il paraît, dit-il (2), que la population indigène de la Nouvelle-Zélande était originairement composée de deux différentes races de la famille humaine, qui ont conservé

(1) Nous ferons remarquer que Larwin, qui a visité la NouvelleZélande avec Fitz-Roy, ne dit rien d'intéressant sur les Maori ni sur leurs caractères anthropologiques. 11 est vrai qu'il n'a relâchè qu'à la baie des Iles et qu'il n'a pu en étudier que les environs.

(2) Travels in New-Zealand, vol. II, p. 7, et suiv: 
quelques-uns de leurs caractères primitifs, quoiqu'elles se soient mélangées avec le temps, et qu'il en soit résulté des variétés intermédiaires.

«Les hommes appartenant à la première des races, et qui sont de beaucoup plus nombreux, sont généralement grands, bien faits, à muscles prononcés, et acquièrent rarement de l'embonpoint. Leur taille varie comme chez les Européens : leurs crânes approchent souvent des têtes les meilleures et les plus intelligentes parmi les Européens : cependant il faut dire qu'ils sont plus développés du front à l'occiput. Le front lui-même est élevé, mais n'est pas développé dens les régions temporales; le bord supérieur du coronal est large ; cet os n'a pas de suture ; l'occiput est bien développé et indique une grande propension aux instincts animaux, sans cependant l'emporter sur l'intelligence. Dans un crâne que je possède, provenant d'un homme des tribus intérieures de Roto-Rua, les sinus frontaux sont très grands ; le crâne est allongé, le front un peu incliné ; la partie osseuse du nez est très déprimée et les os nasaux sont beaucoup plus courbés que chez les Européens (1). Le maxillaire supérieur fait une grande saillie, particulièrement dans la partie qui s'étend d'une incisive à l'autre. Les os sont épais et lourds en comparaison de ceux des Européens, et il semble que c'est un caractère général. Les os wormiens manquent, etc. Ce crâne est certainement l'un de ceux qui possèdent tous les caractères propres à la race, mais les crànes de beaucoup de Zélandais ne diffèrent en rien de ceux des Européens.

a La couleur de la peau est brun-clair, variant beaucoup dans ses nuances ; quelquefois elle est plus claire que celle des habitants du Sud de la France. Le nez est droit et bien fait, souvent aquilin ; la bouche généralement grande; les lèvres sont le plus ordinairement plus développées que celles des Européens; les yeux sont noirs vifs, et pleins d'expression ; la chevelure est généralement noire et droite

(1) On sait que, d'après M. Broca, l'indice nasal des Néo-Zélan. dais est 52,80, et leur indice céphalique 75, d'après $M$. Barnard Davis. 
ou légèrement frisée; les dents sont blanches et régulières, et persistent jusqu'à un âge avancé ; les pieds et les mains sont bien proportionnés.

* Quelques naturels ont les chereux rouges ou bruns, et la peau très claire. Les naturels qui vivent près des sources sulfureuses des bords du lac Roto-Rua, ont l'émail de leurs dents jaune, ce qui résulte probablement de l'action corrosive des eaux thermales.

* La seconde race a, sans aucun doute, une origine différente. Cela est démontré par moins de régularité dans la forme du crâne, qui est plutôt aplati sur les côtés ; par la largeur du visage, qui est plein; par la proéminence des pommettes; par des lèvres grosses, des oreilles petites, une chevelure frisée et grossière, quoique non laineuse; par une couleur plus noire de la peau et une petite figure plus mal proportionnée.

«Cette race, qui est mêlée, dans des proportions diverses avec la première, est beaucoup moins nombreuse : elle ne prédomine dans aucun point de l'île, n'occupe aucun lieu distinct dans la tribu, et il n'y a aucune différence faite par elle entre les deux races ; seulement, je ferai remarquer que je n'ai jamais vu quelque homme d'importance appartenant à cette race, et que, bien que libres, les hommes de cette race tiennent le rang inférieur : d'où l'on peut peut-être inférer qu'ils se sont alliés aux anciens émigrants dans le pays, quoique les légrendes et les traditions ne disent rien à ce sujet.

« De l'existence de deux races à la Nouvelle-Zélande, il faudrait conclure que la plus noire était la race possédant le sol, avant l'arrivée d'une souche d'origine polynésienne ; qu'elle a été conquise par la dernière et presque exterminée. Et cette opinion est celle que l'on a adoptée pour toutes les îles polynésiennes. Mais je ferai observer qu'il est très douteux que les différences, observées parmi les indigènes de la Nouvelle-Zélande, soient réellement dues à pareille cause. On trouve de semblables variétés dans toutes les îles polynésiennes, et il est probable qu'elles sont la conséquence de la différence des castes, si geénéralement établies 
parmi les habitants des îles du Grand-Océan. Si une partie de la population de la Nouvelle-Zélande était une race distincte, fait qui ne peut pas être nié quant aux autres îles, comment se fait-il qu'il n'y ait aucune trace d'un pareil mélange dans le langage, où elles auraient dû être le plus durables, ou dans les traditions, qui auraient certainement conservé le souvenir de la conquête d'une race par l'autre, si cela était réellement arrivé ?

«Le capitaine Crozet, Français qui visita autrefois la Nouvelle-Zélande, dit qu'il trouva une tribu au Cap Nord, plus noire que les autres. Je n'ai rien observé de pareil, quoique j'aie visité tous les indigènes; je n'ai pas vu que ces individus plus noirs fussent plus communs dans l'intérieur et je dirai qu'ils l'étaient souvent moins. Il y a certainement une plus grande variété de couleur et de forme extérieure parmi les indigènes de la Nouvelle-Zélande, qu'on ne devrait s'y attendre ; circonstance qui prouve, soit un ancien mélange de différentes races, soit une différence de conditions sociales qui expliquent difficilement le fait. Tous les Néo-Zélandais parlent des Mangomango, noirs, de la Nouvelle-Galles du Sud, comme n'ayant pas de rapports avec eux, et comme leur étant inférieurs ; mais ils ne font jamais une pareille distinction pour leurs propres tribus. "

Après cettc iongue citation, que nous "avons faite pour montrer comment s'est successivement furmée l'opinion que deux races distinctes ont existé dans le principe à la Nou. velle-Zélande, nous croyons qu'il est inutile de mettre en relief la faiblesse de certains arguments ainsi que les objections que l'auteur adresse lui-même à quelques-uns d'entre eux. Nous dirons seulement qu'il est impossible, à notre avis, de pouvoir conclure de cette citation que la population maori se trouve formée, ou a jamais été formée de deux races distinctes.

Dieffenbach écrivait les lignes précédentes en 1843. Nous allons voir maintenant un autre voyageur anglais, le $\mathrm{D}^{\mathrm{r}}$ Shortland, qui 10 à 12 ans plus|tard, (1854-56), déclarait ne reconnaître dans la population Maori qu'une race mélan- 
geée, et présentait quelques objections sérieuses aux assertions de d'Urville et de Crozet. Il est vrai qu'il était forcé de recourir aux suppositions les plus multipliées pour appuyer son hypothèse.

« Les habitants actuels de la Nouvelle-Zélande, dit-il, (1) sont évidemment une race mêlée en certaine proportion, formée de deux éléments, l'un qui peut être appelé pur Indien, et l'autre Papou.

"Les caractères physiques des premiers sont: une peau brune ou couleur de cuivre, une chevelure noire, quelquefois rousse, droite, ondée ou frisée, et un nez passablement bien fait, quelquefois même aquilin.

«Chez ceux où prédomine l'élément papou, la peau est beaucoup plus noire, la chevelure noire est frisée, mais ne croissant pas en touffes séparées comme ceille des vrais $\mathrm{Pa}$ pous; le nez plat et large aux narines, et les lèvres plus pleines et plus saillantes. Toutes les variétés intermédiaires aux deux extrêmes peuvent être rencontrées, mais le type du visage est principalement indien.

* Pour expliquer ce mélange, quelques personnes ont supposé qu'une race papoue a été trouvée en possession du sol par les Nouveaux-Zélandais, à leur arrivée, et qu'il est résulté, par suite des alliances qui se sont opérées, une race mélangée. On a même dit que l'élément papou appartient plus particulièrement aux esclaves, qu'on suppose sortis principalement de la race vaincue et dégradée. Cependant je n'ai jamais pu acquérir la conviction que cette dernière assertion était le moindrement fondée, ayant remarqué que la chevelure crépue se rencontre aussi bien parmi les Rangatira, ou gentilshommes, que parmi les esclaves. Les traditions disent d'ailleurs, en parlant de la contrée, qu'elle 'était inhabitée à l'arrivée des canots venant d'Hawahiki. Sur les autres îles de la Polynésie on a également trouvé, dans une partie de la population, tous les caractères papous."

M. Shortland trouve à ce fait une explication facile : « Si l'on suppose, dit-il, comme cela paraît certain, que l'archi-

(1) Traditions and Superstitions, 20 Edit., p. 43 et suiv. 
pel indien et la péninsule malaie étaient primitivement ha. bités par des Papous, et que la race brune ou couleur de cuivre a envahi leur pays et pris possession d'une partie, ces traces de race mélangée ou métisse s'expliquent facilement, car il doit s'être écoulé un temps fort long entre leur première invasion de la péninsule malaie et leur conquête des îles Philippines, d'où nous supposons que les ancêtres cies Polynésiens ont émigré. Or, pendant le temps passé en contact par les deux races, pendant que l'une était supplantée ou absorbée par l'autre, il n'est pas douteux que des alliances ont dû s'établir entre les individus de sexes opposés, et donner naissance à la race, paraissant mêlée, qui a été observée à la Nouvelle-Zélande. "

Il est encore inutile de chercher à faire remarquer ici combien est hypothétique cette dernière explication de $\mathrm{M}$. Shortland : elle ne repose sur aucun fondement et elle est même plutôt démentie par les faits, puisque, comme nous l'avons dit au commencement de ce livre, les caractères piysiques des Indiens, Malais ou autres sont tout autres que ceux des Nouveaux-Zélandais. Ce qu'il importe seulement de prendre en considération, c'est le fait observé par lui : que les cheveux crépus se rencontrent aussi bien parmi les chefs que parmi les esclaves, et qu'ils poussent autrement que ceux des vrais Papous. Il s'abstient complètement de parler de cheveux laineux, tandis que son successeur immédiat n'hésite pas, au contraire, à dire qu'on rencontre parfois une chevelure laineuse.

Celui-ci, auteur d'un excellent livre sur la Nouvelle-Zélande, est le studieux missionnaire anglais Taylor: moins apte sans doute que le docteur Shortland, à saisir les caractères différentiels d'une chevelure, il devait surtout ne pas y attacher la même importance qu'un anthropologiste. Aussi est-il à croire que le révérend Taylor s'est mépris, car quelques années après, le docteur Thompson, après avoir observé les Nouveaux-Zélandais pendant un bon nombre d'années, ne dit rien lui non plus touchant leur cheve. lure laineuse bien qu'il précise la nature des cheveux pré- 
sentée par les trois mélanges qui, suivant lui, forment la population.

Voici ce que dit Taylor à ce sujet: (1) "Les Nouveaux-Zélandais sont décidément une race mixte; quelques-uns ont une chevelure laineuse, d'autres en ont une brune ou blonde; quelques-uns ont des nuances plus foncées que les autres. »

Et il ajoute en note: «Quelques-uns sont si noirs qu'ils sont plaisantés par les autres et appelés Pokerekahu, mot qui est le nom d'une pomme de terre (Kumara) très noire. De fait, ils ont plusieurs expressions de reproche pour les personnes noires, telles que Kiwakiwa, Pungapunga.

« Beaucoup, dit-il encore, ont les traits de la race tartar'e : l'œil oblique, la face jaune et la dépression remarquable de l'espace qui existe entre les yeux, de telle sorte que le nez n'a pas d'origine, semblent indiquer clairement qu'il y a au moins quelque chose de la race chinoise ou japonaise. Cette supposition se trouve fortement appuyée par l'habitude commune aux chefs des deux contrées d'attacher leur chevelure au sommet de la tète, fait qui avait frappé Tasman.

« Il y a de bonnes raisons, dit-il en terminant, de supposer qu'une jonque japonaise au moins, s'il n'y en a pas eu plusieurs, a atteint la Nouvelle-Zélande et a contribué aux caractères de la race aussi bien qu'à ses coutumes. \Nous avons déjà dit que le révérend Taylor était assez disposé à voir dans les Maori les descendants directs de ces tribus d'Israël, dont on n'a plus entendu parler après leur départ.

Est-il nécessaire de faire remarquer combien de pareilles assertions sont insuffisantes pour établir l'existence d'un mélange ? Nous ne le pensons pas. Il est évident que les termes employés par les indigènes à l'égard de ceux qui sont plus noirs sont plutôt des plaisanteries, des moqueries que de véritables reproches : ce sont des épithètes telles que celles de moricaud, noiraud, nègre, etc., que nous appliquons à ceux qui, chez nous, sont d'une couleur très foncée. Quant à la chevelure laineuse indiquée par 'Taylor, nous croyons

(1) Le Ika a Maui, p. 184. 
qu'il a pu en voir pendant qu'il était à la Nouvelle-Zélande, mais sur des métis provenant de nègres véritables, que les baleiniers ont transportés dans ces îles depuis un certain nombre d'années. Nous croyons aussi que c'est probable. ment le désir de mieux faire comprendre la venue de jonques japonaises à la Nouvelle-Zélande, qui lui a fait signaler l'œil oblique de beaucoup de Maori, et la dépression nasale, si remarquable chez les Chinois. Pourtant, ici encore, il a peut-être vu des métis de ces derniers, qui y ont paru entre 1840 et 1850 . En tout cas, il est certainement le premier qui ait indiqué cette obliquité de l'œil, si particulière à la race jaune ou mongolique.

Quoiqu'il en soit, il cherche à appuyer la provenance de quelques jonques japonaises par un fait que nous croyons devoir rapporter ici :

«Vers 1839, dit-il, un des membres de la mission, pendant qu'il visitait Wangari, trouva quelques indigènes occupés à faire cuire des pataîes dans une vieille cloche. Frappé de cette circonstance autant que de la forme de la cloche, il leur demanda où ils se l'étaient procurée. On lui répondit que, quelques années auparavant, un ouragan ayant abattu un grand arbre, on trouva la cloche enfermée dans ses racines, et que, depuis, ils ne cessèrent de s'en servir pour faire cuire leurs pommes de terre en ayant soin de boucher d'abord, par une pomme de terre, le trou qui existait là où le battant était fixé. La cloche fut immédiatement achetée, etj'eus le plaisir de la voir. Le bord était dentelé, comme s'il eût été brisé : il y avait autour une légende qui semblait être japonaise, les caractères étant trop carrés et trop réguliers pour être chinois. »

Là se bornent les renseignements donnés ; c'est regrettable, car il est certain qu'il n'y a pas que la manière d'attacher les cheveux qui rapproche les Japonais des Maori ; c'est ce que nous établirons plus amplement lorsque nous chercherons à suivre la marche des migrations polynésiennes ailleurs que vers les îles de l'Océanie.

Nous allons examiner maintenant si le $\mathrm{D}^{\mathrm{c}}$ Thompson, 
dont aujourd'hui on invoque tant l'autorité, établit mieux et plus netîement que ses devanciers les caractères distinc tifs des variétés constițant la race mêlée qu'il a observée à la Nouvelle-Zélande.

Voici comment il décrit les caractères physiques de la population :(1) «es Nouveaux-Zélandais ont unetaille presque égale à celle des Anglais, et ils sont plus grands que les habitants des contrées tempérées, sur le continent européen : la hauteur moyenne des hommes est de cinq pieds six pouces et un quart. Les chefs de naissance ne sont pas plus grands que les hommes nés libres, mais ils sont plus grands et mieux constitués que les esclaves. Le plus grand Zélandais que j'aie observé avait six pieds cinq pouces et demi. Les Nouveaux-Zélandais sont égaux aux Anglais par le poids de leur corps et l'ampleur de leur poitrine : Dix poids de douze livres est leur pesanteur moyenne sans vètement.

" La forme de leur corps est particulière et cette particularité consiste en ce qu'ils ont de plus long's corps et de plus longrs bras, avec des jambes plus courtes, que les Anglais de même taille. L'allongement des bras se trouve dans les avant-bras et le raccourcissement des jambes dans les os au-dessous des genoux ; les os des jambes des Nouveaux-Zélandais ont véritablement un pouce et demi de moins que les mèmes os chez les Anglais. La longueur de leur corps est produite par l'épaisseur des os de l'épine dorsale et des cartilag’es qui existent entre les os.

“ De telles particularités physiques, quoique légæères, déterminent une différence singulière dans l'aspect des deux races établies dans la colonie, et personne ne peut voir des Nouveaux-Zélandais vêtus en Européens sans reconnaître aussitôt que ce ne sont pas des Anglais.

«Les extrémités inférieures des Nouveaux-Zélandais sont vigoureuses; mais en raison de leur brièveté au-dessous des grenoux, les gras de leurs jambes sont rarement élevés, et, en marchant, ils tournent sur leurs orteils, font des pas plus courts et avancent moins que les Anglais.

(1) The Story of the New-Zealand, ch. IV, p. 69 et suiv. 
“Les pieds des Nouveaux-Zélandais sont courts et larges, et la courbure du pied est souvent mal conformée ; lèurs mains sont petites et vont en diminuant en forme de cône.

« La chevelure est abondante et généralement noire, (black); mais quelques-uns l'ont avec une légère teinte rouge de rouille, (With a rusty -red tinge.) Cette coloration rouge, qu'on trouve pareillement dans la chevelure des autres races polynésiennes, a été attribuée à l'usage de lavages alcalins; mais tel n'est pas le cas parmi les Nouveaux-Zélandais. Quelques-uns ont les cheveux tout droits, (lank head hair.) Quelques autres les ont frisés (frizzly ;) mais le plus grand nombre a la chevelure noire, légèrement ondoyante (dark hair with a slight wawe in it.) La chevelure paraît grossière (coarse) ; mais quand elle a été lavée, huilée et brossée, elle a la couleur noire du corbeau, et une douceur de duvet. Leur barbe et leurs moustaches, depuis qu'ils ont perdu l'habitude de s'arracher les poils, sont parfois considérables; mais le tronc a peu de poils, et les indigènes voient avec étonuement le système pileux des Anglais. Peu de Nouveaux-Zélandais deviennent chauves, quoiqu'il en ait beaucoup de gris.

"Comme tous les peuples vivant dans l'état de nature, les Nouveaux-Zélandais ont de belles dents. Le nez est court et large avec une paroi imparfaite, mais quelquesuns ont le nez bien fait, et beaucoup de naturels de Rotorua l'ont de forme juive.

« La peau est de couleur olive foncé, (olive-brown,) ne différant pas d'une aveline préparée, mais il y a différentes nuances : quelques Nouveaux-Zélandais l'ont si belle qu'on peut voir leur face rougir, tandis que d'autres sont si noirs qu'on distingue difficilement les marques du tatouage.

4 Les parties blanches des yeux des Nouveaux-Zélandais sont moins claires que les mêmes parties chez les Anglais; la pupille est noire (dark), et grande, l'iris brun (brown) jamais bleu ; les demi-sang même l'ont rarement bleu, quoique les descendants des demi-sang et des Européens aient souvent les yeux bleus. La bouche est grossière, la face 
large et la lèvre supérieure longue. Le front est haut, étroit, fuyant et pyramidal ; la peau est froide, et la circulation du sang est moins forte que chez les Anglais.

" La grandeur des yeux et leur couleur obscure (dark ness), donnent aux Zélandais un air de gravité. Quand ils sont jeunes, leur expression est généralement ouverte et heureuse. Dans le milieu de la vie, elle est endormie, chagrine etpensive; et, quand ils sont vieux, cette dernière expression n'est presque plus que de la tristesse, (sadness). Par suite du manque de culture intellectuelle, il n'y a pas beaucoup de figures différentes, et les émotions de l'âme sont les seules qui se réfléchissent légèrement sur leurs faces.

a Des voyageurs ont remarqué une odeur particulière et distinctive parmi les différentes races d'hommes. Les maisons chinoises sont parfumées de musc, les villes hindoues d'ail, et les huttes de la Nouvelle-Zélande se distinguent par l'odeur du poisson séché.

"Les hommes revêtus de leur costume indigène semblent être des lions dans leurs forêts ; vètus en Européens, ils sont trapus et vulgaires.

" Les femmes sont moins belles que les hommes, quoique les jeunes soient toujours agréables. Leurs cils sont très grands, et l'habitude qu'ont les filles de lancer, à travers, des œillades de leurs yeux éveillés, donne à leurs visages une douceur indescriptible, en même temps que leurs voix molles donnent a leur langage un charme particulier : quand elles parlent, il y a vraiment quelque chose d'émouvant dans leur voix, qui devient plaintive dès qu'elles font allusion aux personnes qui leur sont chères. Elles ont, en outre, un laisser-aller et une aisance de manières, inconnus parmi beaucoup d'autres racès, qui les rendent charmantes à entendre et agréables à voir. (1) :

(1) Liddiard Nicholas, le compagnon du Rev. Samuel Marsden, a tracé un portrait enthousiaste de la sœur de la femme de Tuatara, roi de Tepuna, alors âgée de 17 ans environ: traits réguliers, expression du visage calme, digne, suave, éclat et velouté des yeux; joues rosées, etc, rienn n'y manque, pas méme la simplicité 
Cette description de Thompson n'a, à notre avis, qu'un défaut, c'est de s'appliquer plus aux hommes du peuple qu'aux autres classes : autrement, depuis notre passage, la nation aurait bien dégénéré. On pourra s'en convaincre en lisant plus loin les caractères physiques que nous avons observés sur place une trentaine d’années auparavant.

« Les Nouveaux-Zélandais, continue Thompson, forment une race métisse et peuvent être divisés en bruns, rougeâ. tres et noirs. Sur 100 individus, 87 ont la peau brune, avec une chevelure noire, droite et ondée, 10 ont la peau couleur brun rougeâtre, (reddish-brown,) avec une chevelure courte, frisée, ou longue et droite, ayant une légrère teinte rouge de rouille; et 3 ont la peau noire, avec une chevelure noire frisée (black skin, with dark frizzly hair,) ne se répandant pourtant pas sur la tête comme chez les nègres̃, mais poussant en touffes qui, si on les laisse se joindre, s'entortiller, les unes autour des autres, forment des boucles en spirale.

«Dans quelques tribus, les hommes noirs et rougeâtres sont plus nombreux que dans d'autres. Les chefs sont grénéralement bruns, (brown-coloured), parfois rougeâtres, rarement noirs (black). Chaque tribu, cependant, possède les trois variétés, qui parlent toutes le même langage et sont arrivées à la Nouvelle-Zélande à la même époque.

" Crozet a expliqué ce mélange d'hommes en supposant que la Nouvelle-Zélande a été habitée anciennement par une race noire semblable aux Australiens ; mais il n'y a pas de témoignagre qui appuie cette opinion d'une manière évidente. Mème chez les Malais de Sumatra, il y a des variétés un peu analogues à celles que nous venons de décrire parmi les Nouveaux-Zélandais, quoique ces variétés aient été

des manières, dénotant l'absence de l'art chez une aussi belle fille, si bien douée de toutes les grâces que peut accorder la nature. (Voy. Narrative of a voyage to Ncw.Zealand, performed in the years 1814 and 1815 , in company with the Rev. Samuel Marsden, by John Liddiard Nicholas, 2 vol. London, 181\%.) Le Dr Brassac, au contraire, (Archives de médecine navale, 18\%6, p. 322), dit que les femmes sont généralement petites, 'laides, à chevelure noire, épaisse, non lạineuse, à peau jaune, à nez èpaté, avec des yeux grands et noirs, la bouche large, les lèvres épaisses. 
accrues chez ceux-ci par suite de leur mélange avec les Polynésiens-Micronésiens et les Mélanésiens, avant leur arrivée à la Nouvelie-Zélande. »

Ainsi, comme ses devanciers, M. Thompson admet trois espèces d'hommes, formant la race mélangée qui, suivant lui aussi, occupe la Nouvelle-Zélande. Il suppose seulement que le mélange avec les Mélanésiens a dû s'opérer pendant le trajet des émigrants, parce qu'il n'admet pas que l'lle-Nord de la Nouvelle-Zélande fût habitée avantleur venue : pourtant les traditions l'établissent d'une manière irréfutable.

Il fait venir de Sumatra deux races d'émigrants : la brune, celle des Polynésiens, se subdivisant en vrais Polynésiens et en Micronésiens, et la noire, celle des Mélanésiens. Il semble donc en résulter que, pour lui, l'une des trois variétés ne devait être que le résultat du mélange des deuxautres. C'est, sans doute, celle qu'il appelle rougeâtre. Il est bien remarquable queThompson, qui a écrit en 1859, après dix années de séjour à la Nouvelle-Zélande, ne cite pas une seule fois les cheveux laineux que quelques observateur's ont cru voir ; il ne parle que de cheveux' crépus ou frisés, et encore a-t-il le soin de faire observer qu'ils ne poussent pas comme ceux des nègres. c'est-à-dire par touffes, ainsi que Shortland l'avait avancé. Pour lui, le nez est généralement court et large, et il cite les nez juifs de Rotorua, comme Taylor a cité ceux des Ngatiwhakawa ou Ngatiwhakane, qui semblent être de la mème famille. Il fait remarquer, pour la première fois, l'abondance de la barbe, quand elle est conservée par les indigènes. Enfin il cite un fait, à notre avis plus important que tous les autres, si l'observation est exacte, ce dont nous ne doutons pas, c'estque les os de l'avant-bras sont plus longs etque ceux des jambes sont plus courts, comparés aux os des mêmes parties chez les Européens. La longueur du tronc est également relativement plus grande.

Quelle que soit l'importance des observations et des remarques de M. Thompson, cela suffit-il pour qu'on admette avec lui les trois variétés qu'il reconnaît dans la population de la Nouvelle-Zélande? Nous ne le pensons pas. Il nous 
semble même que les chiffres proportionnels qu'il donne seraient plutôt faits pour faire douter de leur existence : Il est difficile de comprendre que dans une tribu, aussi mélangée que l'on voudra, il n'y ait seulement que 10 ou 3 personnes sur 100, des deux variétés inférieures.

Pour nous, nous l'avons déjà dit, toutes ces variétés. commetoutes celles admises par les prédécesseurs de Thompson, sont identiques à celles que l'on rencontre dans la race blanche elle-même. Elle sont dues aux causes que nous avons indiquées, causes qui font qu'en Europe, par exemple, telles familles, tels membres d'une famille sont ou plus blancs ou plus noirs, ou bien bâtis ou mal conformés ; que telles populations l'emportent en beauté sur d'autres, etc. Mais elles ne proviennent pas de mélanges, qui étaient impossibles à la Nouvelle-Zélande, avant l'arrivée des Européens, par suite de son isolement complet, dû à sa position et aux vents ordinairement régnants.

Ces variétés, en un mot, ne sont que des nuances, et l'on s'est évidemment mépris quand on a cru voir autrefois, comme on le dit, une prédominance de sang nègre chez les Maori. S'il y a quelques métis nègres aujourd'hui, cela n'a lieu que depuis une époque assez peu reculée : avant, il ne pouvait pas en naître, toutes les tribus des deux grandes îles appartenant à une mème race, parlant absolument la même langue ou ses dialectes, langue qui est pure ellemême de tout mélange. Cette pureté de langage n'existerait certainement pas si plusieurs races se fussent trouvées en contact pendant un temps plus ou moins long.

C'est donc avec raison, à notre avis, que Dieffenbach a dit : il serait bien étrange qu'aucune trace des populations qui auraient précédé les Maori, ou seraient venues se juindre à eux, n'eût été conservée ni par le langage, ni par les traditions. Et il avait peut-être d'autant plus raison de le dire, que les vaincus n'adoptent pas aussi aisément qu'on semble le croire la langue de leurs vainqueurs, surtout quand les devx langues diffèrent autant que le Mélanésien du Polynésien. Si le fait avait eu lieu à la Nouvelle-Zélande, il aurait dû en rester quelques traces : or, jamais au- 
cun observateur, ni les studieux Williams et Taylor, ni les autres missionnaires anglais, n'ont signalé rien de pareil dans le langage; ils ont vu des difrérences locales, mais toutes découlant d'une même langue, la langue Maori, parlée dans tout le groupe, avec des formes qui, comme celles de la race elle-même, dépendaient parfois des localités : ils ont constaté des locutions particulières, mais toujours propres au Maori, et sans la moindre apparence d'une autre langue. Il y aurait à faire sur ce sujet de bien curieuses études ; mais il n'appartient guère qu'à ceux qui ont résidé longtemps à la Nouvelle-Zélande de s'y livrer avec fruit.

En résumé, de même qu'il n'existe qu'une seule langue à la Nouvelle-Zélande, de même il n'y a, pour nous, qu'une seule race dans tout le groupe des îles qui portent ce norn.

Voici les principaux caractères physiques, que nous avons nous-même observés sur les lieux, dans le détroit de Cook, au Cap Est, dans la baie d'Abondance, la baie des Iles, etc., avant que le contact des Maori avec les blancs et les noirs ne les eût altérés, sans parler des nouvelles habitudes contractées par un grand nombre de tribus, des vices de toutes sortes qu'elles ont pris aux Européens et de la démoralisation qui s'est emparée de la plupart d'entre elles.

Ces caractères sont :

Front plus ou moins haut, un peu fuyant, variant de largeur ;

Cheveux épais, noirs, lisses, bouclés ou frisés, parfuis, mais rarement, de couleur rouille sale; d'autres fois, crépus, jamais laineux;

Nez aplati, large à sa base, parfois convexe, ne paraissant autant aquilin à l'œil que par suite de la forme du tatonage qui le recouvre, et de la saillie plus grande des os nasaux ;

Yeux grands, noirs, à cils longs et noirs, surtout chez les femmes, surmontés de forts sourcils, vifs, expressifs; bouche grande, avec de belles dents ; lèvres fortes et épais- 
ses; barbe fournie noire, devenant blanche, de même que la chevelure, chez les vieillards ;

Oreilles plutôt grandes que moyennes;

Mains petites chez les femmes, mais fortes chez les hommes, de même que les pieds ;

Membres vigoureux ;

Taille variable.

L'indice céphalique des Néo-Zéland ais est de 75, c'està-dire sensiblement égal à celui des autres Polynésiens; mais leur indice nasal, 52.80, est un peu plus élevé que celui des Tahitiens, 51.50, et surtout des Marquésans, 49.25. M. Broca (1) explique cette augmentation de l'indice nasal en disant que les Mélanésiens ont été les premiers habitants de la Nouvelle-Zélande, et qu'il reste encore des noirs dans les montagnes centrales des deux îles principales. Nous ne partageons pas cette manière de voir, surtout la dernière ; mais nous devons néanmoins faire remarquer que si les Néo-Zélandais eussent primitivement possédé l'indice nasal des Tahitiens, par exemple, cette augmentation s'expliquerait parfaitement par leur croisement avec la race noire papua, si elle avait existé sur l'lle-Nord avant ou après leur arrivée. On voit donc quelle importance il y aurait à savoir si, dans l'Ile-du-Milieu, la moyenne de l'indice nasal diffère de celle de l'Ile-Nord.

$\mathrm{Si}$, à ces carractères, on ajoute ceux que Dieffenbach donne à la tète, dans les deux races admises par lui, ainsi que ceux que Thompson donne à la Longueur ou à la briéveté relative de certains os, on a, à notre avis, les véritables caractères physiques des Néo-Zélandais.

11 importe toutefois de dire quelques mots sur la couleur de leur peau. Bien que les Néo-Zélandais habitent en dehors des tropiques, cette couleur, en général, est un peu plus foncée que celle de la plupart des chefs des îles intertropicales; elle se rapproche de celle des habitants des Paumotu. Mais cela semble être dû surtout à certains usages, à une plus grande activité, à moins de précautions et

(1) Revue d'Anthropologie, 1872, Recherches sur l'Indice nasal. 
aux intempéries plus considérables du pays (1). Ainsi que Crozet l'a remarqué le premier, beaucoup d'hommes et de femmes sont non senlement de la couleur des habitants des îles Tunga et Tahiti, mais même de celle des Européens d $v^{x}$ Midi. Il n'est pas douteux que si le climat de la NouvelleZélande permettait, aussi bien que celui des îles Océaniennes, de se baigner fréquemment, si le genre de vie était le même, si au lieu d'ocre on employait le hena avec l'huile, etc., les corps de Maori paraîtraient à l'œil beaucoup moins bruns qu'ils ne le sont.

Qui ne sait que les sauvages des îles Parmotu, complètement polynésiens sous tous les rapports, de même que les habitants de l'Ile de Pâques, sont plus bruns parce que l'eau douce abondante manque sur leurs îles, et parce que, faute d'arbres, ils se garantissent plus difficilement des rayons solaires? Il leur suffit de vivre pendint quelque temps sur les îles hautes, pour prendre une couleur moins foncée.

Qui ignore que les sauvages de Van Diemen, que, du temps de Péron, on regardait comme une espèce de nègres, à cause de leur couleur surtout, ne devaient cette couleur qu'à la couche épaisse de cosmétique ou de malpropreté qu! les recouvrait? Dès que cette couche était enlevée, elle laissait voir une teinte infiniment moins fortc.

Comme en Polynésie d'ailleurs, mais en proportion moindre, les chefs, à la Nouvelle-Zélande, sont généralement moins foncés que le peuple, mais, là aussi pourtant, rien n'est plus commun que d'en voir de fort bruns.

Nous ferons enfin observer que les chefs Zélandais n'acquièrent jamais cet embonpoint auquel arrivent si geénéralement les chefs polynésiens : cela tient à une vie plus active, à moins de soins et de ménag'ements, à l'influence du climat et à une alimentation moins facile et moins abondante.

Nous pouvons dire, à cette occasion, après avoil vu pres

(1) Nous rappellerons, à cette occasion, qu'à Tahiti, le guerriè Hitoti, mort pendant le Protectorat, était noir comparativement $\hat{a}$ son frère, l'orateur Upufara, qui sortait moins et prenait plus de précautions que lui. 
que tous les pørtraits de Nouveaux-Zélandais qui ont été publiés, que si l'on veut en avoir une idée à peu près exacte, il faut s'adresser à ceux qui figurent dans l'Atlas de l'Astrolabe. Le peintre de cette expédition, M. de Sainson (1), a rendu si exactement la plupart, que nous croyons, en les regardant, voir les personnages qu'ils représentent. Nous nous bornerons à citer le chef de Uaua et sa femme. C'est ce chef dont parle d'Urville sous le nom de Rau Tangi (2). Mais il faut se garder de chercher le type Zélandais dans l'Atlas de Labillardière, car il y est excessivement mal rendu : l'homme y est représenté comme le dieu d'un fleuve grec, et la jeune femme semble avoir été dessinée d'après quelque grisette d'atelier.

Il résulte évidemment de toutes les observations faites par les voyageurs, que les Maori ont complètement les caractères de la famille polynésienne : en réalité, à part l'indice nasal, il n'y a véritablement d'autres différences que celles résultant d'un climat plus rude; car nous l'avons dit, le langage lui-même est identique. Si beaucoup d'écrivains ont cru qu'il différait du Polynésien, c'est, nous le montrerons, parce qu'il est plus complet, plus mâle, qu'en un mot il possède, sans qu'on s'en soit aperçu, tous les caractères d'une langue mère.

Nous le répéterons donc : si les Nouveaux-Zélandais sont plus robustes et plus endurcis que les Polynésiens, c'est parce qu'ils sont exposés à de plus grandes privations, à de plus nombreuses vicissitudes atmosphériques, et particulièrement à un abaissement de température parfois assez considérable, sans parler des guerres incessantee auxquelles ils se livrent, etc. Par suite, leur physionomie a dû prendre nécessairement un caractère plus sévère, et l'espèce de tatouage adoptée n'a pas peu contribué à augmenter cette sévérité. Mais, sous tous les autres rapports, ce sont absolument les mèmes caractères physiques extérieurs que ceux possédés par les Polynésiens.

(1) M. de Sainson est mort à Paris en novembre 1874.

(2) Voyage de l'Astrolabe, t. II, Ire partie, p. 104 
Aussi est-ce ce qui a fait dire, avec raison, parBory de Saint. Vincent, que les hommes et les femmes de la NouvelleZélande l'emportentsur les autres Polynésiens (1). C'est même ce que disait $M$. de Quatrefages, peu avantageusement peut-être pour la question qu'il soutenait, quand il écrivait : (2) « La conservation du type dans des îles trèséloignées, et sous des latitudes très diverses, se comprend très bien, si l'on songe que le climat des îles varie infiniment moins que celui des continents, lorsque la latitude change. Les conditions du milieu sont donc à peu près les mêmes dans la plupart des archipels de la Polynésie, et, dans ces archipels, les hommes se ressemblent beaucoup. Mais, dans le groupe de la Nouvelle-Zélande, où le climat est tout-à-fait différent, les hommes se présentent à nous avec des caractères qui les distinguent des autres Polynésiens, et les Néo-Zélandais sont supérieurs aux autres insulaires. ”

Il est vrai qu'une quinzaine d'années plus tard, M. de Quatrefages, dans un discours prononcé à une séance générale de la Société d'acclimatation, se contredit de tout en tout et arrive à des conclusions diamétralement opposéess (3). Après avoir dit: "Les Malaisiens de Bouro se sont donc merveilleusement acclimatés en Polynésie, v il ajoute que le changement de climat ne fut pas favorable $\dot{a}$ toutes les populations et principalement à celles de la NouvelleZélande. «On comprend, dit-il, que les populations façonnée:; aux chaleur's des tropiques ont dû souftirir sous ce nouveau climat. Peut.être faut-il attribuer à cette cause la diminution de la taille dans les familles des chefs, diminution signalée dans les récits historiques et constatée par les observations comparatives faites à Tahiti et à Samoa. Quoiqu'il en soit, lors de la découverte de la Nouvelle-Zélande les Maori étaient parfaitement acclimatds. »

Cette prétendue diminution de la taille ne vient ici que pour les besoins de la cause. C'est une erreur évidente, car

(1) L'homme, Liv. I, p. 299.

(2) Bulletins soc. d'Anthrop. 1860, p. 201 et Revue des Deux-Mondes, 18004 .

(3) Revue scientifique, 9 juin $187 \%$. 
les chefs et les guerriers maori vus par nous en 1827, étaient des plus grands et des plus beaux parmi les Polynésiens; ils n'auraient certainement pas formé une population aussi vigoureuse, s'ils étaient venus de l'Equateur dans les régions australes. Le chef Rangi, de la baie Huraki, ne mesurait pas moins de 5 pieds 9 pouces, et la plupart de ses guerriers avaient une taille pareille.

Quoiqu'il en soit, la Nouvelle-Zélande possède, suivant nous, non-seulement une population identique à celle de la Polynésie, mais une population qui n'est formée que par une seule et même race, dont nous ferons bientôt connaître le lieu d'origine. Cette opinion n'est pas seulement la nôtre, c'était celle que formulait, dès 1827 , le naturaliste Quoy, compagnon de d'Urville (1). Nous croyons devoir citer en entier son appréciation qui résume parfaitement ce qu était, à cette époque, la Nouvelle-Zélande, ou du moins ses habitants, sous le rapport des caractères physiques :

« Après avoir parcouru la moitié des côtes de la Nouvelle-Zélande, et vu un assez grand nombre de ses habitants, nous réunissons ici ce que nous avons à en dire.

« Cette terre, par sa graudeur, comme par sa nombreuse population, est certainement une des plus importantes de l'Océan Austral, malgré sa position reculée vers le Sud. Sa température, ni trop chaude, ni trop froide, est aussi saine qu'elle est propre i la culture de toutes les productions d'Europe. Sur plusieurs points, sa végétation, dans laquelle on distingue des fougères en arbre et des dracœnas qui figurent des palmiers, ressemble à celle des tropiques par son abondance et sa vigueur; et, maly"ré la privation des plantes qui fournissent à l'homme une nourritnre abondante, les heureuses influences dont nous venons de parler ont contribué au développement d'une des plus belles races de la Polynésie.

“ En effet, les navigateurs ont remarqué qu'en goénéral les Zélandais étaient grands, robustes, d'un physique agréable, quoiqu'ils se défigurassent, surtout les chefs, par un

(1) Voyage de l'Astrolabe, T. II, lere partie, p. 282, note. 
tatouage en incision, dont la distribution ne contribue pas peu à leur faire paraître à tous le nez aquilin, forme cependant assez commune parmi eux, et qui est jointe à l'écartement des narines.

«Leurs cheveux sont long, noirs et lisses, ainsi que la barbe, et leurs dents sont admirables. Le caractère de la physionomie est aussi varié qu'en Europe; et, pour tout dire en un mot, nous trouvions dans ces insulaires des ressemblances avec celles qu'on nous a transmises de Brutus, de Socrate, etc.

" La basse classe a les formes plus petites et moins belles ; peu des individus en sont tatoués, privilége qui semble appartenir aux guerriers, et, par conséquent, aux chefs qui sont tous guerriers. Il faut voir cet ornement pour juger combien il doit être douloureux à acquérir.

"Les femmes sont loin d'approcher des hommes en beauté. Presque toutes petites (1), elles n'ont rien de ce naturel gracieux qu'on trouve quelquefois parmi les peuplades non civilisées, que nous avons souvent rencontrées aux îles Sandwich. Les femmes des chefs seules sont tatouées aux lèvres et sur les épaules d'une manière particulière. »

Comme on voit, il n'existait, pour ce naturaliste, qu'une seule race à la Nouvelle-Zélande ; et, nous devons le répéter, il observait les habitants en mème temps que d'Urville et nous-mème, sur l'Astrolabe, en 1827. Nous nous rappelons encore les curieuses discussions qui avaient lieu, entre eux, à ce sujet, le chef de l'expédition étant toujours convaincu qu'il avait raison.

Bien que cela soit inutile pour la question que nous désirons résoudre, nous croyons pourtant devoir parler des caractères moralnx des Nouveaux-Zélandais ; car c'est surtout au moral que, suivant nous, les Maori méritent d'ètre cités, et nous croyons qu'il n'est pas d'hommes de cette race qui soient plus remarquables sous ce rapport.

On a parlé bien diversement des qualités morales des Nouveaux-Zélandais : d'après les uns, ils sont braves, in .

(1) Cette observation n'est pas tout-à-fait juste. 
telligents, mais cruels; d'après d'autres, ils sont lâches mais bons.

Banks, Anderson et Forster ont les premiers rendu justice à leurs bonnes qualirés, tout en mentionnant leurs défauts. Ainsi, suivant le premier, les Néo-Zélandais sont d'un caractère doux et affable, pleins de bons procédés à l'égard les uns des autres, quand ils sont amis ou alliés. Forster dit que cette nation est hospitalière et généreuse, qu'elle connaît les sentiments de bienfaisance et d'humanité ; que les guerriers sont intrépides et hardis, et qu’en général les individus ont un jugement sain, du goût et de l'industrie. Enfin Anderson fait remarquer la vive affection qu'ils portent à leurs pareñts et à leurs amis, et les marques de sensibilité qu'ils donnent lorsqu'ils viennent à les perdre.

Mais tous ces voyageurs n'avaient vu les Nouveaux-Zélandais qu'en passant, et c'est au directeur et fondateur des missions anglaises, au Révérend Samuel Marsden, (1) qu'il faut demander son opinion pour en avoir une plus exacte.

Or, voici ce qu'on lit dans ses notes de voyage, publiées par la Société, et réunies par d'Urville dans les pièces justificatives qui accompagnent le récit du voyage de l'Astrolabe : « Depuis que j'ai fait connaissance arec ces peuples, je les ai toujours considérés comme la plus belle et la plus noble race de païens connus dans le monde civilisé. J'ai toujours été persuadé que si l'on pouvait introduire chez eux les arts de la civilisation et la connaissance de la religion chrétienne, on en ferait une grande nation. Je suis encore plus confirmé dans cette opinion depuis que je les ai visités, car je les ai trouvés encore plus civilisés que je ne supposais. 》

Ailleurs, il dit : « Je ne crois pas que nulle part au monde il y ait présentement, ni qu'il ait jamais existé un peuple, à l'état de nature, qui l'emporte sur les habitants de la

(1) Nous avons eu l'avantage de le connaître au port Jackson en 1827. C'est lui qui, de 1815 à 183\%, introduisit le premier des missionnaires en Nouvelle-Zélande, et, par le fait, conquit cette vaste possession à l'Angleterre. 
Nouvelle-Zélande, sous le rapport de la force corporelle et des qualités intellectuelles. $\bowtie$

«Les Nouveaux-Zélandais, dit-il encore, sont avides d'instruction; ils ont un jugement prompt et une bonne mémoire."

C'est encore lui qui écrivait dans le Missionary Register: "Les Néo-Zélandais sont naturellement g’énéreux, doux, affectionnés; par les qualités morales, ils feraient souvent rougir bien des gens réputés chrétiens. »

Certes, rien de plus flatteur ne peut être dit en faveur d'une race, et pourtant le Rév. Marsden n'était pas un enthousiaste. C'était seulement un observateur exact et profond, auquel les évènements, survenus depuis quelques années à la Nouvelle-Zélande, semblent donner raison.

Ellis, après les avoir vus un instant, ditlui-mème :(l) « Les habitants forment une race robuste, forte, active, non-seulement capable de grands exercices physiques, mais aussi d'une haute culture morale; ils ont une grande intelligence. $\gg$

Enfin tous les missionnaires anglais ont vanté leur aptitude à toutes sortes de métiers, 1els que ceux de charpentier, scieur-de-long, maçon, forgeron, armurier, etc., et ils ont observé que les enfants, pour apprendre à lire et à écrire, déploient une facilité au moins égale à celle des enfants anglais.

Les renseignements s'accordent d'ailleurs à dire que les Nouveaux-Zélandais sont fiers, orgueilleux, jaloux les uns des autres, très irritables et implacables dans leurs vengeances ; mais sensibles, généreux, sincères, probes, hospitaliers, amis fidèles, dévoués et constants, et surtout parents tendres et affectueux. Le voyageur Nicholas a même été jusqu'à dire que, dans les relations privées, il n'est pas d'homme plus aimant que le Nouveau-Zélindais, et il vantait surtout leur bonne foi entre gens de la mème tribu.

Telles étaient les qualités et les défauts que possédlaient les Nouveaux-Zélandais au début de leurs relations suivies

(1) Polynesians Researches, vol. II, p 35. 
avec les Européens. Mais il pariît que, depuis, leurs vices et leur défauts n'ont fait qu'augrmenter en raison directe de la durée de ces relations, et qu'ils sont devenus, au dire des Anglais, dissimulés, avares, défiants, exigeants et arrogants. On le comprend aisément quand, comme nous, on a vu les exemples que donnent les gens qui s'appellent civilisés, et la conduite qu'ils tiennent à l'égard des populations demi-sauvages, quand ils vivent parmi elles.

Aussi Thompson, entre autres, est-il sévère sur les facultés mentales des Nouveaux-Zélandais. Il leur accorde une grande mémoire mais peu d'imagination. Ils ont, suivant lui, peu de raison et de jugement; et il résumeleur's facultés en disant qu'ils ont les goûts des enfants et les passions des hommes. Il les trouve sans génie pour découvrir et incapables de généraliser; cependant il les reconnaît aptes à apprendre.

a Le plaisir et la peine, dit-il (1), naissent chez eux des causes les plus variées. Leur goût pour la nouveauté est une passion ; mais il est presque impossible de les étonner. Ils excellent à imiter, et leurs bouffonneries les amusent. La vanité, l'arrogance et l'indépendance sont générales, mais ils sont plus vains qu'orgueilleux. Dans toutes leur actions, ils ne pensent qu'à leur propre intérèt et ils ne sont point arrêtés par l'équité. Ils ne peuvent supporter une injure; ils manquent du courage moral qui fait qae les hommes obéissent à la raison et à la conscience et, dans les combats d'armes à feu, ils s'exposent rarement ouvertement, mais ils espèrent éviter le danger par leur agilité et leurs ruses. Ils apprécient la vie, mais meurent avec indifférence, quand le mort est inévitable : ce qui n'est pas une preuve de courage. Ils ont peu de bienveillance les uns pour les autres: des amis absents depuis longtemps sont salués par une profusion de larmes; mais, pareils à des enfants, leur chagrin est sans durée. lls sont généralement hospitaliers pour les étrangers et partagent avec le voyageur leur nourriture, en le renvoyant avec des cadeaux. La gratitude leur est

(1) The Story of the New-Zealand, vol. I, p. 85. 
inconnue, et on ne trouve dans leur langage aucun mot qui l'exprime. L'amour du pays est mal compris ; mais ils aiment mourir et être enterrés parmi leurs parents. Le vol est rare parmi eux. La vengeance est leur plus forte passion, et ce sentiment dure pendant plusieurs générations. Ils sont jaloux les uns des autres et aiment inspirer la terreur. Leurs conversations sont sensuelles et indécentes. Ils gardent difficilement un secret. Ils sont fanfarons. Ils abordent leurs égaux sans légèreté, et leurs supérieurs sans crainte. Ils regardent comme honteux de se laisser aller à la colère. Ils sont plus enjoués que rỉeurs. Ils sont généreux en présents ; mais les présents sont une manière de trafiquer, car ils attendent toujours quelque chose en retour. Ils possèdent un grand flux de paroles et sont passionnés pour l'éloquence et les discours. Ils sont sales et indolents. Ils sont forts contre le faible, mais faibles contre le fort. Quand ils sont domptés, soit physiquement, soit mentalement, ils deviennent aussi maniables que des enfants ; mais il faut que ce moyen soit employé avec justice, car ils se soumettent plus aisément à une direction douce et habile qu'à une force inal appliquée. s

Enfin Thompson termine en disant : “ En voyant que les têtes des Nouveaux-Zélandais sont plus petites que celles des Anglais, jl en résulte que la force et l'étendue de leurs facultés sont moindres ; et comme l'esprit hnmain, pareil aux liqueurs fermentées, mûrit suivant sa force, les enfants indigènes sont plus intelligrents à dix ans que les cnfants anglais; mais, comme règle, peu de Nouveaux-Zélandais pourraient apprendre de manière à égaler les Anglais dans leurs plus hautes facultés, et pas un dans leurs plus mauvaises passions.

"Ce caractère des Nouveaux-Zélandais est moins avar.tageux que celui qu'on a ordinairement donné. Il est cependant une esquisse tracée d'apris l'histoire de ce peuple, et d'après une observation personnelle faite parmi eux pendant leurs jours de bonheur et de chagrin, e'; pendant leurs heures de maladie et de mort. 
Nous n'ajouterons que quelques mots pour dire que M. Thompson, qui n'a vu les Nouveaux-Zélandais qu'entre 1848 et 1858, c'est-à-dire à une époque où ils étaient démoralisés, traqués par leurs envahisseurs et déji saturés des vices Européens, a probablement rendu exactement l'état moral actuel de la population ; mais peut-ètre aussi l'a-t-il jugée trop sévèrement et n'a-t-il pas mis assez en relief les qualités qu'elle a conservées, malgré le contact avec les blancs, qualités qu'il reconnaîtlui aussi.

Il l'a dit lui-même d'ailleurs : (1) \& Les Nouveaux-Zélan. dais de la génération actuelle ont deux caractères: l'un pour les Européens et qui varie suivant que les Européens sont missionnaires ou marchands; l'autre pour leur propre race. Le premier est acquis, le dernier est naturel ; et il est difficile de décrire ces deux caractères sans renvoyer aux plus hautes facultés de l'esprit humain."

Il ajoute : « S'il est certain, en pesant la quantité de graines de mil contenues dans des crânes et en mesurant avec des instruments et le compas, que les têtes des Nouveaux-Zélandais sont plus petites que les têtes des Anglais, les Zélandais sont inférieurs aux Anglais en capacité intellectuelle. Ce volume moindre du cerveau est produit par le défaut d'exercice des plus hautes facultés intellectuelles; car, de mème que les muscles s'atrophient par défaut de travail, de même il est tout naturel que des générations d'indolence mentale diminuent le volume des cerveaux. Al'appui de ceite induction, des voyagreurs éclairés ont déjà appris que les têtes de la race nègre, aux EtatsUnis, ont commencé à prendre plus de développement de. puis que cette race est entrée dans la carrière intellectuelle. (Lyell). »

Nous sommes de l'avis de Thompson : Les NouveauxŻ́landais ne sont pas, par eux-mêmes, ce qu'ils se montrent et ce qu'ils sont aux yeux des Européens. Si nous les croyons aujourd'hui ce qu'il les a vus, c'est qu'il n'a pu observer qu'une pupulation, la plupart du temps dégénérée,

(1) Ouvrage cité, p. 81. 
LES POLYNÉSIENS.

avilie, troublée, démoralisée, toujours sur le qui-vive et. en lutte avec ses protecteurs officiels. Nous ne savons si, par les moyens qu'emploient les Anglais, le cerveau des Néo-Zélandais acquerra plus de dévelcppement un jour. Mais, quoiqu'il devienne, notre conviction, après avoir vu tous les descendants de cette race en Polynésie, et quoique nous ayons, avec Marsden surtout, une opinion très-favorable de son aptitude intellectuelle, est qu'elle ne dépassera jamais certain niveau, pas plus du reste que la race noire. 


\title{
LIVRE DEUXIÈME
}

\author{
NOU、VELLE - ZÉLANDE
}

\section{LIEU D'ORIGINE DES POLYNÉSIENS.}

REMARQUES PRÉLIMINAIRES.

\begin{abstract}
Analogies du Tahitien et du Maori. - Usage de l'arc et des flèches. Premiers partisans de l'origine Néo-Zélandaise des Polynésiens : Banks ; Crozet; Bory-de-Saint-Vincent .
\end{abstract}

C'est de la Nouvelle-Zélande, avons-nous dit, que sont parties les colonies qui ont peuplé les îles Tunga. Nous allons maintenant exposer les témoignages appuyant le plus cette opinion, si contraire à celle qui est geénéralement admise. Ces témoignages, il est vrai, sont plutôt des déductions et des raisonnements que des preuves péremptoires et démonstratives; mais, nous en sommes certain, ils soutiennent notre hypothèse beaucoup mieux que ceux que l'on a invoqués jusqu'ici en faveur de l'hypothèse opposée. Pour cette dernière, en effet, on se borne le plus souvent à des assertions que l'on ne songe même pas à justifier. Ceux qui veulent que la Nouvelle-Zélande ait été peuplée par la Polynésie, gardent le plus profond silence sur les obstacles de toute sorte, tels que vents contraires, îles jetées sur la route, etc., qui se seraient opposés à ce peuplement. Ils s'évertuent, au contraire, à trouver, dans 
des faits et des circonstances qui ne résistent pas au moindre examen, des obstacles insurmontables à un départ de la Nouvelle-Zélande vers la Polynésie. Lorsque nous en serons à la réfutation des objections que l'on a opposées à une provenance Maori des Polynésiens, nous démontrerons que ces prétendus obstacles prouvent plutôt le contraire de ce qu'on en a déduit.

Le $1^{\text {er }}$ voyage de Cook en 1769 et celui de Marion en 1772 ayant permis de reconnaître l'affinité du langage des habitants de la Nouvelle-Zélande avec celui des Tahitiens, les navigateurs en conclurent avec raison que l'un des deux pays avait été peuplé par l'autre, bien qu'ils soient séparés par une distance de plus de 800 lieues (1). C'est à Banks et à Crozet, compagnons de Cook et de Mírion, que l'on doit la première remarque de cette analogie, confirmée successivement par tous les visiteurs de ces deux archipels.

Mais si, grâce au Tahitien Tupaia, Cook, Banks, Solander, Parkinson et Monkhouse, lors du voyag'e de l'Endeavour, avaient pu remarquer cette analogie, en voyant Tupaia converser avec les Nouveaux-Zélandais, ils n'avaient fait pour ainsi dire que la soupçonner. Il était rěservé à Crozet, le second de Marion sur le Mascarin, de la prouver d'une manière positive, en causant lui-même avec les habitants du Port-Marion ou de la Trahison, dans la Baie des !les, à l'aide du vocabulaire que Bougainville avait rapporté de Tahiti, et dont une copie arait été remise à Marion, par l'intendant Poivre. Voici, en effet, ce que dit Crozet (2):

* A peine fûmes-nous mouillés dans le port des Iles (de Cook), qu'il nous vint à bord une quantité de pirogues qui nous apportèrent du poisson en abondance. Nous ne savions quel lanģage parler à ces sauvages. J'imaginai par hasard de prendre un vocabulaire de l'île de Taïty, que nous avait remis l'intendant de l'Ile de France. Je lus quelques mots de ce vocabulaire, et je vis, avec la plus

(I) Crozet disait 600 lieues ; Carli 2580 milles, ou près de 1000 lieues; d'autres 43 degrés ou 860 lieues.

(2) Rochon, Nouveau voyage à la mer du Sud, etc., p. 48. 
grande surprise, que les sauvages m'entendaient parfaitement. Je reconnus bientôt que la langue du pays ou nous étions, était absolument la même que celle de Taity, éloignée de plus de 600 Iieues de la Nouvelle-Zélande. »

Ce fait prouve combien ce vocabulaire devait être mieux fait que ceux des officiers de Cook, qui ne pouvaient pas se faire entendre avec le leur aux îles Marquises, ainsi que l'a fait remarquer Cook lui-mème.

Malgré cette analogie, bien reconnue de tous, on douta longtemps que les uns ou les autres eussent pu faire avec leurs pirogues le trajet qui les sépare, et l'on verra que ce doute existe encore aujourd'hui pour quelques-uns. Cependant, comme il fallait pour ainsi dire opter, puisque, malgré la difficulté de se rendre compte de cette navigation, elle seule pouvait expliquer comment des nations si éloignées avaient pu appeler les mêmes choses par les mêmes noms, adopter les mèmes usages, leš mèmes ustensiles, avoir les mêmes croyances religieuses, etc., on aima mieux voir le point de départ des émigrants en Polynésie qu'à la Nouvelle-Zélande. Alors les uns le placèrent dans une île, les autres dans une autrc, ceux-ci à Tahiti, ceux-là aux Sandwich ou aux Samoa.

Dès le début pourtant, ce qui nous semble digne de remarque, Banks avait été d'un avis différent: il disait que non seulement cette analogie de langage prouvait nécessairement une émigration, mais que très probablement cette émigration avait eu lieu de la Nouvelle-Zélande vers Tahiti. Et il ajoutait : L'usage de l'arc et des flèches étant inconnu à la Nouvelle-Zélande, tandis qu'il existe à Tahiti, il faut admettre que les Tahitiens ont découvert cet usage, ou ne l'ont reçu qu'après la séparation; il n'est pas admissible que les habitants de la Nouvelle-Zélande aient pu le perdre après l'avoir eu.

Nous allons revenir tout à l'heure sur cet usage; mais ici, pour ne pas laisser de doute sur cette opinion de Banks, nous croyons devoir citer la paraphrase qu'en a donnée Parkinson qui, comme on sait, s'appropria et donna l'occasion à son frère de publier les découvertes botaniques de 
Banks et de Solander, ainsi que les calculs des compagnons de Cook sur le passage de Vénus, qu'un secrétaire infidèle lui avait permis de copier. Voici les paroles de Parkinson qui, naturellement, avait la même manière de voir que sir Banks, aux gages duquel il était comme dessinateur (1).

" J'ai déjà dit quelque chose du langage des habitants de la Nouvelle-Zélande, et de son affinité avec celui d'O-Taïti. Le vocabulaire suivant démontrera évidemment cet accord. Cette circonstance extraordinaire porte à conclure que l'un des deux pays a été peuplé par l'autre, quoique à une distance de plus de neuf cents milles, et qu'ils ne soient séparés, du moins, à notre connaissance, que par l'Océan. Nous ne pouvons croire qu'une telle navigation soit praticable avec les petits canots de ces peuples, qui paraissent n'avoir jamais eu d'autres vaisseaux. Il serait cependant difficile de rendre autrement raison du motif qui aurait porté des nations, si éloignées, et sans aucune communication entre elles, à fixer les mèmes sons pour les mèmes choses. Cette opinion acquiert encore plus de force, lorsque l'on compare les usages et les manières de ces deux différents peuples, de même que leurs instruments de guerre et leurs ustensiles de ménage qui se ressemblent en beaucoup de points. L'émigration que nous croyons la cause de cette ressem. blance, fut, sans doute, de la Nouvelle-Zélandeà O-Taïti; car les habitants de la première ne connaissaient point l'usage des arcs et des flèches, au lieu que le peuple d'O-Taiti s'en sert avec une grande dextérité, en ayant, sans doute, découvert accidentellement l'usage, après leur séparation ; et l'on ne peut supposer que les habitants de la NouvelleZélande eussent perdu une découverte si précieuse, s'ils l'avaient jamais connue. »

Ainsi, comme on voit, dès la découverte, Banks admettait, comme nous le soutenons aujourdhui, que c'est par la Nouvelle-Zélande que la Polynésie avait été peuplée. Seulement, il s'appuyait sur un fait qui ne pouvait aroir la valeur qu'il lui donnait.

(1) Sydney Parkinson, Voyage autour du monde, ler vol. p. 225. 
D'après Banks et Parkinson, l'usage de l'arc et des flèches existait d'une manière certaine à Tahiti, en 1769, quoiqu'en aient dit quelques écrivains. Ils ne sont pas, d'ailleurs, les seuls à en parler, car c'est ce qu'a dit aussi Cook, de même que Fèche, chevalier de Suzannet, qui accompagnait Bougainville dans son voyage de découvertes (1). Entre autres faits, Cook rapporte, dans son voyage, qu'il fut forcé, le 12 juin 1769, d'exercer la rigueur de la discipline, parce que quelques Indiens étaient venus se plaindre que deux matelots leur avaient pris de force leurs arcs et leurs flèches. Il est donc bien certain que les arcs et les flèches étaient connus à Tahiti, et que, par conséquent, c'està tort que les voyageurs ont répété le contraire. Seulement il y a une distinction importante à faire à ce sujet.

Si l'usage de l'arc existait à Tahiti, il était, pour ainsi dire, réservé aux chefs, et n'était, pour eux et leur affidés, qu'un moyen d'amusement, mais jamais une arme de guerre. L'arc, à ce titrẹ, était non-seulement très employé dans les Iles de la Société, mais il l'était peut-être plus encore aux Marquises, ainsi que dans les îles Tunga et Samoa, d'après Roggeween. On connaît ce que Mariner raconte des parties de chasse de Finau, à l'aide de cette arme, dans les îles Hapaï, et l'on peut voir, dans le petit livre de G. Hamilton, médecin de la Pandora, envoyée à la recherches des mutins de la Bounty, et dont la fin fut si malheureuse, que cet usage fut remarqué également par lui, en 1791, à Tahiti, a Ils connaissaient, dit-il, l'arc et les flèches, mais ne s'en servaient que dans leurs amusements. »

Fait bien curieux, depuis cette époque les navigateurs n'ont jamais parlé de l'arc, soit comme arme de guerre, soit comme moyen d'amusement; mais on pense avec raison que l'arc et les flèches n'ont jamais été employés comme armes de guerre par les populations polynésiennes. C'est, en effet, ce qui nous a toujours été répondu par les indigènes des Marquises et des Iles de la Société ou autres, que nous avons fait questionner ou que nous avons questionnés

(1) Voir manuscrit de la bibliothèque du Muséum d'Histoire naturelle de Paris. 
nous-même à ce sujet. En eût-il été autrement dans les îles Tunga et Samoa, à une certaine époque, que cela ne servirait pas à prouver que cet usage, comme arme le guerre, a pu être employé également par tous les autres archipels; là, en effet, le voisinagre des populations mélanésiennes, qui se servent constamment de l'arc et des flèches comme armes de guerre, expliquerait facilement leur usage accidentel, dans le même but, par les Polynésiens qui les touchaient. C'est aux Fijiens, en effet, qu'est dû bien probablement cet usage parmi les Tongans et les Samıans, au moins comme moyen d'amusement. On s'explique donc parfaitement que la connaissance en ait été portée nonseulement à Tahiti, mais jusque dans les îles plus au SudEst et au Nord-Est, puisque ces îles ont été peuplées, directement ou indirectement, par les Tunga et les Samoa.

Mais comment s'expliquer la présence des mèmes armes autrefois à la Nouvelle-Zélande ? Car c'est un fait certain: l'arc et les flèches y étaient connus, et ils n'y servaient également que comme amusement. L'arc y était appelé KoPere, et les flèches, Pere. Déjà, à l'arrivée des successeurs de Cook, cet usage paraissait ne plus exister, car pas un navigateur n'en parle. Dira-t-on que les Maori l'avaient reçu des Polynésiens?

Maisles noms polynésiens ne sont plus les mêmes : aux Tunga, on appelle l'arc Fana et les flèches Ngahau, Kapo (1); à Tahiti, l'arc se nomme Fana, et les flèches Tea, Au, ou mieux Ohe. Pourquoi, s'ils étaient venus de la Polynésie, les Maori auraient-ils changé ces noms ? N'auraient-ils donc. pas pu inventer l'arc eux-mêmes ? Ils ont bien inventé les cerfs-volants, les toupies, etc., comme l'attestent les plus vieilles traditions et les missionnaires anglais.

En résumé, que la connaissance de l'arc et des flèches ait été portée par les Mélanésiens, ou qu'ils aient été inventés par la race polynésienne même, en Polynésie comme à la Nouvelle-Zélande, et uniquement utilisés comme moyen d'amusement, il est bien évident que cet usage ne

(1) Ngahau est le mot fijien Ngassau. Voy. Ellis, Recherches, p. 321 et Hazelewood. Diction. Fijien. 
prouve pas plus l'origine polynésienne des Nouveaux-Zélandais que l'origine zélandaise des Polynésiens.

Lorsqu'il concluait, d'après l'absence de l'arc et des flèches à la Nouvelle-Zélande, que la Polynésie avait été peuplée probablement par cette île, Banks oubliait que Tahiti ou les Samoa auraient pu expédier des colonies avant la découverte de l'arc. En outre, il s'appuyait sur un fait d'observation qui semble inexact. Quoiqu'il en soit, il croyait pouvoir attribuer le peuplement de Taliti à la Nouvelle-Zélande.

Après Banks, Crozet, cet observateur remarquable, qui publia sur la Nouvelle-Zélande des documents si importants qu'on en appelle encore tous les jours à eux, Crozet, lui aussi, semble pouvoir ètre considéré comme un partisan de l'origine néo-zélandaise des Polynésiens. Voici ce qu'il dit à ce sujet (1):

a Il a peut-être été un temps où la Nouvelle-Zélande communiquait avec cette île Taïty, qui en est séparée aujourd'hui par une mer sans fond, de plus de six cents lieves d'étendue. Nous avons trouvé à la Nouvelle-Zélande la langue de Taïty, avec quelques différences seulement dans un petit nombre de mots, et il y a beaucoup de conformité entre ces deux peuples aujourd'hui très séparés.

* Je ne serais même pas éloigné de croire que c'est par la Nouvelle-Zélande, par les Terres Australes et parles îles de la mer du Sud, que l'Amérique a été peuplée. »

Sans nous arrèter à montrer ici que les analogies citées par lui sont encore plus grandes qu'il ne croyait entre les habitants de Tahiti et de la Nouvelle-Zélande, tandis qu'il n'y en a aucume entre eux et ceux d'Amérique, nous ferons seulement remarquer qu'il admettait que les migrations s'étaient opérées du Sud-Ouest vers le Nord-Est, et que la Nouvelle-Zélande, au lieu de recevoir des colonies de la Polynésie, lui avait plutôt envoyé ses émigrants. Il ne se fondait, il est vrai, que sur l'analogie du langage, ce qui puuvait aussi bien prouver le contraire; mais sa croyance

(i) Noitveau voyage à la mer du Sud, etc., p. 140. 
au peuplement de l'Amérique par la Nouvelle-Zélande ne peut laisser aucun doute sur sa pensée.

Enfin, longtemps après Banks et C'rozet, Bory de SaintVincent exprima nettement l'opinion que la Polynésie avaitété peuplée par la Nouvelle-Zélande.Voici ce qu'il dit(1), en parlant de la race qu'il appelle océanique, c'est-à-dire la race polynésienne actuelle.

* La Nouvelle-Zélande, où l'on voit des monts fort élevés, et qui dut saillir au-dessus de la mer quand la Nouvelle-Hollande était encore inondée, nous semblerait être le lieu dont elle sortit pour s'étendre vers le Nord et dans tous les archipels de l'Océan Pacifique que n'occupent pas des Mélanésiens, des Papous ou même des Siniques et des Hindous, qui ont aussi pénétré dans quelques parties de l'Océanique. Le méridien de la Nouvelle-Zélande, qui passe à peu près entre les îles Fidji et celles dont Tongatabou est la plus grande, formerait la limite occidentale, etc. (2)"

Et quelques pages plus loin, il ajoute : «En attendant qu'on nous prouve la possibilité d'une origine américaine, nous continuerons à reconnaître le point d'où s'irradia la race océanique dans la Nouvelle-Zélande. »

Enfin, il dit encore à la page 177 du $2^{\circ}$ volume : "Ce n'est que sur la race océanique de l'espèce neptunienne qu'on peut hasarder des conjectures probables. Nous avons cru apercevoir son point de départ dans la Nouvelle-Zélande. »

Nous nous bornerons à corstater ici ces assertions qui, nécessairement, à l'époque de leur publicati on, ne pouvaient pas être appuyées par des témoignages bien importants ou bien nombreux.

Bientôt nous espérons pouvoir démontrer que cette opinion est celle qui approche le plus de la vérité : cependaut,

(1) L'Homme, lor volume, 2e édition, p. 299 et 314.

(2) Il dit en note a'opinion qui admet que la Nouvelle-Hollande est sortie plus récemment du sein des eaux est généralement reçue ; et quoique l'intérieur du pays soit pour nous couvert d'un voile mysterieux, ce qu'on connaîtdu littoral donne le plus grand poids à notre façon de voir. (Lesson, Voyage de la Coquille autour du monde, section Zoologique). » 
tout en la partageant, nous sommes forcé de reconnaître qu'à l'exception de Bory de Saint-Vincent, et peut-être de Banks et de Crozet, tous les ethnologues ont une opinion diamétralement opposée : tous soutiennent que la Nouvelle-Zélande, au lieu d'envoyer ses enfants peupler la Polynésie, a été peuplée elle-même par des émigrants venant de cette dernière contrée.

Nous allons donc commencer par réfuter les arguments sur lesquels ils s'appuient, avant d'exposer ceux qui nous portent à avoir une opinion contraire à la leur. 


\section{CHAPITRE PREMIER}

EXPOSE ET RÉFUTATION DES OBJECTIONS.

Objections faites contre le peuplement de la Polynésie par la NouvelleZélande :- Pirogues Néo-Zélandaises; - Existence, à la Nouvelle Zélande, de canots doubles et de pirogues à balancier. - Absence des Mauri à la Nouvelle.Hollande. - Uwhi. - Kawa. - Cochons et poules. - Direction des vents.

L'écrivain qui a fait le plus d'objections à la possibilité du peuplement de la Polynésie par la Nouvelle-Zélande, celui qui certainement a présenté les arguments les plus forts, nous l'avons déjà dit précédemment, c'est Dumont d'Urville.

Il nous suffira donc de les examiner pour répondre en même temps aux objections de tous les autres écrivains. Pourtant, avant d'entamer cet examen, qu'il nous soit permis de faire remarquer que d'Urville semble avoir hésité à se prononcer. Voici, en effet, ce quu'il dit (1):

« Maintenant, examinons quelle sera l'hypothèse la plus vraisemblable touchant les terres que l'espèce humaine a dû occuper les premières dans la Polynésie et touchant la direction qu'elle a dù suivre dans ses migrations.

"La vaste étendue des terres de la Nouvelle-Zélande, leur situation sous un climat tempéré, la force et la vigueur de la race qui les habite, pourraient d'abord donner lieu de penser que ce fut là le berceau ou du moins la première

(l) Voyage de l'Astrolabe, Philolngie, p. 277. 
station de la race polynésienne; mais des considérations puissantes obligent de repousser cette hypothèse. »

Certainement d'Urville était alors plus près de la vérité qu'il ne s'en doutait; mais les puissantes considérations qui l'entrainaient n'avaient pas l'importance qu'il leur accordait. On va en juger :

$1^{\text {re }}$ Objection. - Il objecte d'abord que, sous le rapport de la navigation, les Nouveaux-Zélandais sont loin d'avoir atteint au même degré de perfection que les peuples de la zone équatoriale : "Il n'est guère probable, dit-il, que leurs longues pirogues non pontées, étroites et incapables de manœuvrer à la voile, aient pu les transporter à de grandes distances de leur's côtes. »

Examinons donc cette première objection qui a été faite également par tous ceux qui se sont occupés de cette question.

Ce fut l'observation de ces pirogues, « longues, étroites et non pontées »qui porta, en effet, Cook et les premiers navigateurs dans ces mers, à douter de la possibilité de voyager d'un archipel à l'autre, et même quelques navigateurs plus récents à nier formellement la possibilité du départ de colonies zélandaises pour l'Océanie. Pour d'Urville c'était l'objection capitale. Nous ferons l'aveu que nous avions d'abord douté nous-même qu'un voyage un peu long pût être accompli au moyen de ces pirogues. Mais, en observant davantage, nous avons fini par être convaincu que les raisons données n'ont pas l'importance qu'on leur a attribuée et qu'elles sont même inexactes et spécieuses. En effet, s'il peut paraître impossible qu'avec de petites pirogues longues et étroites, les Zélandais aient osé s'aventurer à de grandes distances et aient pu arriver sains et saufs, il est évident que ce n'est que dans l'intérêt de la thèse soutenue qu'on a prétendu qu'elles ne pouvaient manœuvrer à la voile, et qu'elles manquaient absolument de cordages. Il est bien certain, au contraire, que les pirogues zélandaises, loin d'ètre toujours étroites, sont, parfois et souvent mème, aussi profondes et larges en même temp.; qu'elles sont lon- 
gues (1): Quelques-unes ne portent pas moins de 60, 80 ou 100 rameurs, bien assis sur des bancs ; elles vont à de très grandes distances de leur point de départ, à plusieurs centaines de lieues, de la Baie des Iles, par exemple, jusqu'à Otokou, dans le Sud de l'Ile-du-Milieu, et en grand nombre à la fois, pour y porter la guerre. Il n'est pas moins certain qu'elles ont des voiles dont elles se servent, et que la Nouvelle-Zélande produit les meilleurs cordages et notamment le Phormium tenax qui sert à les faire. Ces pirogues enfin sont si peu étroites, que d'Urville lui-même, après avoir dit, il est vrai, le contraire (2), nous apprend (3) « qu'elles ont quelquefois quatre pieds de profondeur, cinq à six de largeur, et quatre-vingts pieds de long'eur. " Il dit même qu'elles manœuvrent très bien, en portant 80 à 100 hommes, et qu'elles peuvent filer sept nœuds avec une belle mer (4).

Sans nous arrèter à faire remarquer ce qu'il y a de contradictoire dans les assertions de d'Urville, on comprend que de pareilles pirogues auraient certainement pu atteindre les premières îles Polynésiennes, qui ne sont pas éloignées de plus de trois cents lieues ; du moins, quel-ques-unes auraient pu être entraînées jusque-là par des coups de vent du S.-O au N.-O. Mais, que de pareils voyages aient pu être faits ou non par ces pirogues, il est certain, comme on va voir, qu'ils auraient pu être opérés aussi fa. cilement par des pirogues doubles que ceux qu'on croit avoir été faits de la Polynésie vers la Nouvelle-Zélande.

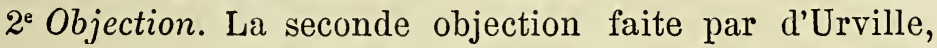
comme par presque tous les ethnologues, est que les pirogues de la Nouvelle-Zélande manquent de balancier, et qu'elles diffèrent de forme de celles de la Polynésie.

En effet, la forme des pirogues actuelles de la Nouvelle-

(1) Cook vit, dans la baie de Talaga, un bateau de 20 mètres de longueur sur plus d'un mètre et demi de largeur, avec la carène formée de trois troncs d'arbres évidés. La proue était ornée de sculptures et les parois extérieures garnies de bas-reliefs.

(2) Philologie de l'Astrolabe, p. $27 \%$.

(3) Ouvr. cité, t. II, 2e partie, p. 492.

(4) Ibid., p. 493. 
Zélande diffère complètement aujourd'hui; de plus, toutes les pirogues de cette forme sont sans balancier. Mais, malgré qu'il paraisse à priori plus difficile de réfuter cette objection que la précédente, ce n'est évidemment encore qu'une objection spécieuse. Il nous semble d'ailleurs que d'Urville, en s'appuyant sur ce fait pour nier la possibilité du peuplement de la Polynésie par la Nouvelle-Zélande, n'a pas fait attention que la même objection pouvait lui être faite, quand il donne aux Zélandais une origine polynésienne. Car si les Zélandais sont, comme il le pense, des colonies tahitiennes, il restait à dire comment il se fait qu'une fois à la Nouvelle-Zélande ces colonies aient perdu leur primitive architecture navale, c'est-à-dire la forme et la construction des pirogues qui les y avaient transportés. La difficulté, comme on voit, est la même dans les deux cas.

Pour.soutenir son opinion, d'Urville, il est vrai, dit (1) qu'il regarde comme naturel de supposer que les premiers individus qui allèrent à la Nouvelle-Zélande se trouvèrent privés, sur cette terre, des ressources de tout genre que le règne végétal leur offrait sur leurs terres fécondes des tropiques, et qu'ils oublièrent leur industrie primitive. "Pour eux, dit.il, plus de cocotiers, de bananiers, d'hibiscus, dont les fibres et les feuilles leur étaient si utiles; par conséquent, plus de moyens faciles de fabriquer des voiles et des cordages en abondance. » Mais nous l'avons déja dit, il s'est trompé ; car il faudrait évidemment, pour que cette assertion fût exacte, qu'on ne trouvât pas, à la NouvelleZélande, les arbres les plus convenables pour faire des pirogues et les plantes textiles les plus capables de servir à la fabrication des étoffes et des cordag'es : or, on les y rencontre au contraire en grand nombre.

Quand il ajoute (2) que la violence des vents et l'inclémence de la mer durent amortir le penchant naturel des Zélandais, ce n'est encore qu'une supposition, utile à l'opi-

(1) Philologie du Voyage de l'Astrolabe, p. 27\%

(2) Ouvr, cité, p. 278, 
nion qu'il veut faire adopter. Il eût été certainement plus naturel d'admettre que c'était plutôt, pour eux, un motif de chercher des mers et des vents moins tempétueux; car on sait que les émigrations ont généralement lieu des tẹrres ingrates et à intempéries vers les contrées tempérées et fertiles, et l'on verra plus loin qu'eiles ne se sont pas faites autrement pour le peuplement de l'Ile-Nord de la NouvelleZélande, quoiqu'elles aient été pour ainsi dire forcées.

Sans doute, jusqu'à présent, aucune bonne raison n'a été donnée du changement réel survenu dans l'architecture des pirogues de la Nouvelle-Zélande; il reste toujours à en découvrir la cause. Mais si l'on admet que la Polynésie a été peuplée par la Nouvelle-Zélande, il nous semble que cela permet d'expliquer plus aisément cette transformation, contrairement à ce qu'a avancé d'Urville. En effet, c'est là où manquait le bois assez fort pour ètre creusé profondément et pour garder son équilibre sur l'eau, sans contrepoids, qu'il aurait nécessairement fallu recourir au balancier. Mais, on va le voir, il n'est même pas nécessaire d'avoir besoin d'une pareille explication. Si l'on dit généralement que les Nouveaux-Zélandais ne se servent que des pirogues sans balancier, il est pourtant un fait certain, c'est que les premiers navigateurs, ceux-là mêmes qui s'appuient sur l'absence de ce balancier pour nier l'origine zélandaise des Polynésiens, établissent par leur's écrits qu'il y avait, de leur temps, à la Nouvelle-Zélande, des pirogues à balancier et même des doubles pirogrues: fait, dirons-nous en passant, qui prouve avec quelle partialité certains navigateurs écrivent leurs voyages.

Comme on en pourrait douter, nous allons faire ici quelques citations, tirées non-seulement des plus anciens voyageurs, mais même du voyage de celui qui s'est le plus appuyé, de nos jours, sur l'absence du balancier pour nier la possibilité des migrations zélandaises vers l'Océanie.

Ainsi, on en lit divers exemples dans les voyagres de Cook; nous n'en citerons qu'un seul, renvoyant pour les autres à son texte. 
a Le 14 février, dit l'auteur de la vie de Cook (1), dans l'après-midi, M. Banks étant allé, avec le petit canot, s'amuser à chasser, tout-à-coup nos voyageurs, avec leurs lunettes d'approche, virent quatre doubles pirogues contenant cinquante-sept hommes armés, qui étaient partis du rivage et qui s'avançaient vers M. Banks. M. Cook, inquiet pour la sûreté de son ami, etc. »

Nous emprunterons les exemples suivants au dessinateur de Banks, Parkinson, qui mourut à Batavia ou, plus exactement, quelques jours après le départ de l'Endeavour de ce point.

On lit, dans le $1^{\text {ar }}$ volume de ses observations, publiées par son frère (2) : "Près de Motu Hora, dans la baie d'Abondance, un canot s'approcha de l'Endeavour ; il était double et différent, à beaucoup d'égards, de ceux qu'on avait vus précédemment. "Ceux.ci, dit-il ailleurs, n'étaient que des canots long's et simples, ou à simples balanciers (3).

La forme, du reste, semblait varier beaucoup, car il ajoute : (4) « A la pointe Stérile, près de la baie d'Abondance, on vit des canots faits d'un seul tronc d'arbre et de la forme d'un baquet de boucher, sans ornement. »

Et plus loin : (5) «Quelques canots plus larges et d'une meilleure espèce vinrent nous trouver. »

Plus loin encore : (6) « L'après midi, quatre canots doubles, dans lesquels on compta cinquante-sept Indiens, vinrent à nous etc. DC'était par le travers de Toaipoona moo, ainsi qu'il appelle l'Ile-du-Milieu, ou terre de Poonamoo, en venant de Castle-point, et après avoir doublé les courants de Cook, car alors le détroit n'avait pas d'autre nom.

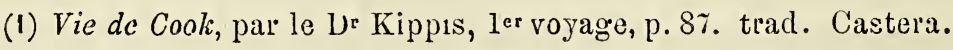

(2) Voyage autour du monde sur l'Endeavour, trad. Hənry, p. 176.

(3) Ouvr. cité, ler vol. p. 184.

(4) Ibid., p. 179.

(5) Ibid., p. 182.

(6) Ibid., p. 214. 
Le mème écrivain, dans son $2^{\mathbf{e}}$ volume, dit, en parlınt de la baie Dusky, sur l'lle-du-Milieu : «On vit, sur la grève d'une crique, près des huttes, une petite pirogue double, assez grande cependant pour transporter toute la famille de place en place. »

Dans le même volume, il fait dire à Cook: "Le 3, un. de nos bateaux fut chassé par une grande double pirogue remplie d'Indiens. „ On était alors dans le canal de la Reine Charlotte.

Enfin, quelques lignes plus loin : « Vers cinq heures, nous aperçumes une grande double pirogue montée par vingt ou trente hommes.

Mais la citation la plus importante, puisqu'elle prouve que les doubles canots étaient employés à la Nouvelle-Zélande dès 1642, est celle que nous emprunterons au découvreur'de la Nouvelle-Zélande lui-même, à Abel Tasman, qui appela d'abord cette terre Staten-Land. (1)

On lui fait dire, en parlant des indigènes de la baie appelée par lui Baie du Massacre : « Ces geens, autant que nous pûmes en juger, étaient à peu près de la stature ordinaire chez nous, fortement charpentés et doués d'une voix sing'ulièrement rauque. Leur couleur tient le milieu entre le brun et le jaune. Leur chevelure noire est nouée au sommet de leur tête, à la mode des Japonais, et une grande plume blanche est fixée dans cette espèce de chignon. Leurs barques se composent de deux canots longs attachés ensemble, et sur lesquels sont fixées des planches qui servent de siége. Leurs rames ont plus d'une brasse de longueur et sont aiguisées à leur extrémité. ”

Les doubles canots existaient donc à la Nouvelle Zélande, et sur l'Ile-du-Milieu, à l'époque de la découverte de Tasman; et l'on va voir qu'il y en avait encore. lors du voyage d'exploration de la corvette l'Astrolabe, en 1827.

Ainsi d'Urville dit lui-même :(2) « Ces piroğues sont en outre crnées de touffes de plumes, de poils et de feuillages

(1) Histoire générale des vorages, par W. Desborough Cooley, trad. par Joanne et Old Nick, t. II, liv. IV, p. 286.

(2) Voyage de l'Astrolabe, t. II. 2e partie, p. 494. 
de diverses sortes. Quelquefois elles sont réunies deux à deux, et une douzaine de ces doubles pirogues peut fournir une puissante escadre. »

Il répète, dans les pièces justificatives : (1) a Leurs embarcations étaient de longues et étroites pirogues, réunies deux à deux et recouvertes de planches pour s'asseoir."

S'il y avait des doubles pirogues, il y avait donc des pirogues à balancier, car l'on sait que l'une des deux pirogues, en g'enéral plus petite, n'a d'autre but que d'en servir. Il en faut conclure que c'est à tort que le révérend Taylor a dit qu'il n'existait plus de ces doubles pirogues depuis près d'un demi-siècle, de même que e'est probablement à tort qu'il a conclu, d'un pareil fait, que les Nouveaux-Zélandais ont rétrogradé (2) : ce fait, il nous semble, indique plutôt qu'ils ont progressé.

Ainsi donc, non-seulement on a vu des doubles pirogues à la Nouvelle-Zélande dès 1642 et 1770, mais, d'après d'Urville lui-même, il y en avait encore en 1827. D'où il faut conclure, du moins, qu'on s'est à tort appuyé sur leur absence complète pour nier la possibilité de migrations zélandaises vers la Polynésie. Les migrations auraient pu être faites à l'aide de ces doubles pirogues, qui existaient certainement, à une époque fort éloignée, à la Nouvelle-Zélande, puisque, dans les légendes maori publiées par sir Grey, légendes qui ne sont, pour la plupart, que les récits des émigrations d'Hawahiki vers l'Ile-Nord de la Nouvelle.Zélande ou Aotearoa, on voit que les canots étaient souvent doubles et à plate-formes comme ceux de l'Océanie:tel était, entre autres, le canot l'Arawa, dont nous ferons plus tard connaître l'itinéraire.

Il est bien vrai, dirons-nous en passant, que ces mèmes légendes ont, dans ces dernières années, porté M. de Quatrefages à soutenir l'opinion d'Horatio Hale, sur l'origine polynésienne des Maori : tant est inculquée la croyance

(3) T. III, 1re partie, p. $1^{\text {re }}$ et suivantes des pièces justificatives.

(2) Te Ika a Maui, p. \%. 
que les doubles pirogues n'appartiennent qu'à la Polynésie, tant on est loin de se douter de la véritable situation qu'occupait l'Hawahiki. Mais ces légendes, il nous sera trèsfacile de le montrer, ont été inexactement interprétées, et si l'on s'en est servi pour étayer l'origine polynésienne des Maori, c'est qu'on y a vu à peu près le contraire de ce qu'elles disent.

Puisque les émigrants étaient venus dans des doubles pirogues, l'usage de ces dernières était évidemment aussi connu dans le lieu de leur arrivée que dans celui de leur départ, quelle qu'eût pu être la situation de ce dernier. Si on y avait réfléchi, on n'aurait pas invoqué cette forme de pirog'ues en faveur d'une provenance plutôt que d'une autre. Si les Zélandais de l'Ile-Nord, n'emploient plus aujourd'hui que des pirogues simples ou sans balancier, ce n'est pas, comme le disait d'Urville, parce que le bois leur manquait, puisque le contraire est plutôt vrai. lès lors, s'ils ont abandonné l'usage des doubles pirog'ues, c'est sans doute parce qu'ils l'ont fait volontairemènt.

Il est difficile de dire quel a pu être le motif véritable de cet abandon de l'ancienne architecture navale. Mais nous serions assez porté à croire qu'il n'a eu lieu que dans un but politique, dans le but d'empêcher les émigrations vers l'Océanie, en rendant, par la suppression du balancier ou du double canot, les longs voyages en pleine mer sinon impossibles, du moins très difficiles. Il se pourrait cependant que la découverte de l'art du lestage ait été tout simplement la raison de cette innovation; et cette raison, qui est la plus simple, est peut-être aussi la meilleure. Toujours est-il que l'usage des doubles canots était général à l'époque jusqu'à laquelle l'histoire permet de remonter d'une manière à peu près certaine, c'est-à-dire il y a au moins 500 ou 600 ans.

En résumé, il n'y a donc plus à se demander comment des pirogues sans balancier, des pirogues simples et faites comme elles le sont aujourd'hui, auraient pu parcourir l'espace considérable qui sépare la Nouvelle-Zélande des Iles de la Société et autres îles Polynésiennes, puisque les 
Nouveaux-Zélandais possédaient des pirogues doubles, véritables grands navires, qu'ils auraient employés nécessairement de préférence. Mais, nous l'avons dit, ces pirogues auraient-elles été seulement ce qu'elles sont de nos jours, que rien ne se serait opposé formellement à leur traversée en pleine mer, vu leur grandeur et la facilité de les faire évoluer. C'est ce qu'a reconnu d'Urville lui-même, quoiqu'il dise également le contraire dans un autre passage de son texte.

On comprend que 300 à 400 lieues, avec des vents poussant toujours dans la même direction, puissent être franchies, même facilement, avec de pareils moyens.

Bientôt, quand nous démontrerons que l'Hawahiki, ou point de départ des émigrants, était placé encore plus à l'Ouest que l'île abordée et peuplée par eux à la NouvelleZélande, et quand nous tracerons l'itinéraire des canots, il ne restera plus rien, croyons-nous, des doutes d'abord soulevés par Banks, et qui ont si bien servi à d'Urville pour combattre l'idée que la Nouvelle-Zélande a été l'officine des Polynésiens. Mais, nous le répéterons, pour nous il ne peut y avoir de doutes, car les traditions, aussi haut qu'elles re. montent, indiquent que l'usage des doubles canots ou des canots à balancier était comnu à la Nouvelle-Zélande. Or, comme c'est à l'époque où les habitants se servaient de ces canots qu'a eu lieu l'émigration de l'lle-Nord de la Nouvelle-Zélande vers les îles polynésiennes, rien de plus simple que l'existence, dans toute la Polynésie, de canots doubles ou à balancier. Mais ce qui semble bien prouver que la transformation des pirogues doubles, difficiles à manœuvrer à lamer, difficiles à hâler sur le rivage, en pirogues longues, larges et profondes, très faciles à conduire, surtout à la pagaie, était un grand progrès, c'est qu'en Polynésie même, parmi des populations inférieures à leurs voisines par leur position, et qu'on sait issues des Iles de la Société, chez les habitants des îles Paumotu, on trouve une architecture bien supérieure à celle de toute la Polynésie d’il y a cent ans. 


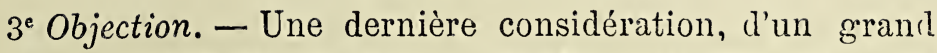
poids pour d'Urville, était que si la Nouvelle-Zélande avait pu peupler les îles de l'Océanie, rien ne l'aurait empêchée de peupler également la Nouvelle-Hollande. « Or, disait-il (1), rien de semblable n'a eu lieu, et la race noire, réduite au dernier degré de misère et de faiblesse, est restée seule et paisible maîtresse de ce continent. Les Zélandais n'avaicnt pas même atteint les îles Norfolk et Philip, à peine distantes de 140 lieues de la pointe septentrionale de leur patrie. \$

Et il terminait en disant : « Tous ces motifs réunis nous portent donc à considérer la Nouvelle-Zélande comme la dernière des terres de l'Océanie occupée par la race polynésienne.

Cette objection que si la Noüvelle-Zélande eût peuplé l'Océanie, elle eût également peuplé la Nouvelle-Hollandc, a certainement moins de valeur que les ojections précédentes. Il est évident, en effet, que ce n'est point arec les vents du Sud-Est ou de l'Est, qui eussent été nécessairos pour conduire les migrations polynésicnnes à la NouvelleZélande, que cette dernière contrée aurait pu envoyer des colonies en Océanie; elle ne l'aurait pu faire qu'arec des vents de la partie de l'Ouest, du Sud-Ouest au Nord-Ouest: or ces vents expliquent parfaitement in eux seuls pourquoi la Nouvelle.Hollande n'a pas reçu de colonies zélandaises.

D'un autre côté, on n'a jamais vu non plus de colonies polynésiennes poussées jusqu'à cette grande terre par les vents d'Est ou de Sud-Est, les seuls dont il eût fallu profíto: pour arriver à la Nouvelle-Zélande : ce fait serait inexplic:able si les Zélandais étaient venus, comme on le croit, des île: Samoa.Il est plus que probable, en effet,que si l'on fat pa:ti de ces îles ou de Tahiti pour se rendre à la Nonvelle-Zélan . de, quelques pirogues au moins se seraient trouvées entraînées par les vents à la Nouvelle-Hollande, et, comme les peuplades australiennes sont rares et disséminées, les Polynésiens y seraient certainement restés.

C'est, à n'en pas douter, parce que d'Urville, imitant en cela Moërenhoüt, regardait, dans ce moment, les vents d'Esti

(1) Loc cit. p. 278 
et de Sud-Est comme les seuls ayant poussé les migrations vers la Nouvelle-Zélande, qu'il s'est montré si disposé à nier la possibilité des migrations zélandaises vers la Polynésie. Mais, nous le répéterons, l'absence de colonies polynésiennes à la Nouvelle-Hollande, de même que celle de colonies zélandaises sur cette grande terre si voisine, suffisent, à elles seules, à prouver que le départ des émigrants n'avait pas eu líeu avec ces vents, mais avec des vents tout à fait contraires, les poussant justement vers l'Est et le NordEst et les éloignant de la Nouvelle-Hollande.

Quant à ce que dit d'Urville, que les Zélandais n'avaient même pás atteint les îles Norfolk et Philip, qui sont à peine à 140 lieues de la pointe septentrionale de leur patrie, il faut du moins reconnaître qu'il n'en a pas été de même pour l'histoire naturelle.

En effet, Philip, le fondateur de la colonie du Port-Jackson, a trouvé à Norfolkles mêmesarbres et les mêmes plan * tes qu'à la Nouvelle-Zélande. Lors des premières visites, cet. te île produisait surtout une espèce de pin, l'araucaria excel$s a$, très gros et très élevé; les choux palmistes, l'oseille sauvage, le laiteron et le fenouil marin, croissaient en grande quantité sur le rivage. Parmi les autres plantes, nous citerons un poivrier, le bananier sauvage, J'arbre fougère et sur'tout le lin, phormium tenax, qui s'élevait jusçu'à huit pieds.

Les mêmes espèces de pigeons, de perruches, de perroquets, qu'a la Nouvelle-Zélande,y furent encore rencontrées, de mème que des râles et quelques petits oiseaux, et l'on n'y vit qu'un seul quadrupède, le rat.

Enfin la constitution géologique est la même, et il y existe également des sources d'eau chaude.

Mais, à notre avis, l'absence des Nouveaux-Zélandais sur cette île, prouvait elle-même encore que les migrations n'avaient dû s'opérer qu'avec des vents qui les en éloignaient, comme ils les éloignaient de la Nouvelle-Hollande, c'està-dire avec des vents de la partie de l'Ouest. Norfolk se trouve, en effet, dans le $\mathrm{N}-\mathrm{O}$. ou le $\mathrm{N}_{\mathrm{o}-\mathrm{N}}$.-O. du Cap Nord 
de la Nouvelle-Zélande, et, par conséquent, la route ne pouvait être tout au plus que le Nord-Est.

Seulement la présence du phormium et de quelques autres plantes zélandaises, à Norfolk, prouve l'existence du courant qui a été signalé, entre autres, par M. de Kerhallet, et qui explique si bien, de même que les vents le font pour les colonies zélandaises, pourquoi cette plante n'a pas été trourée à la Nouvelle-Hollande. Mais cette faune et cette flore identiques prouvent peut-être aussi, comme nous l'avons déjà dit (1), que Norfolk et Philip faisaient autrefois partie d'un groupe de terres australes, en partie disparues et dont il ne subsiste que les grandes îles de la Nouvelle-Zélande et quelques îlots épars. Norfolk, en effet, se trouve à égrale distance de la Nouvelle-Zélande et de la Nouvelle-Calédonie et sur le prolongement de leurs lignes de faîte.

Autres objections. - Les autres objections faites par d'Urville n'ont, à côté des précédentes, pour ainsi dire aucune importance.

Ainsi il commet une erreur, quand il prétend que le mot ouwi, igname, analogue de $l^{\prime}$ Océanien ouhi, oufi, est une preuve que les Nouveaux-Zélandais sont originaires des îles polynésiennes, puisque, dit-il, «ils ont le mot sans la chose. » Les Zélandais ont une igname semblable à celle des îles de la Société et des Tunga. Ce qu'ils appellent uwhi, mot écrit ouwi par d'Urville, est une racine de la même famille, une patate qu'ils nomment patate d'hiver et qui, par conséquent, est la plus usitée comme nourriture (2). Il est donc tout naturel que les émigrants de la NouvelleZélande aient donné à l'igname des îles Océaniennes le nom qu'ils appliquaient, dans leur île, à une plante analogue qui leur était si utile. Il suffic seulement de supposer

(1) Voyez ci-dessus, vol. I, p. 501.

(2) Taylor, p. 183, dit que uwhi ou ufi, nom de l'igname des îles de la mer du Sud, désigne, à la Nouvelie-Zélande, une petite igname indigène et la racine d'une fougère comestible qui ressemble parfaitement à l'iguame. Uwhikaho, d'après W. Williams, est le nom donné par les Maori à l'igname. 
qu'ils sunt arrivés dans ces îles sans leur patate d'hiver.

La patate douce est appelée Irumara ì la Nouvelle-Zé. lande. Or, aux îles Fiji, on donne le même nom au convolvulus batatas, pomme de terre douce de la Nouvelle-Zélande. Mais là, ils appellent kawai une petite igname qui, d'après Wilkes, ressemblerait à la patate malaie ? Et, comme si ce nom, d'origine toute maori, ne suffisait pas à faire soupçonner une origine étrangère, les Fijiens appellent encore la pomme de terre douce : kawaï ni papalagi, c'est-ìdire la pomme de terre des etrangers ou d'une contrée étrangère.

Si l'on remarque que le $p$ est rarement employé aux Fiji, qu'il ne se trouve que dans quelques mots provenant d'un autre dialecte, et qu'il est généralement changé en $b$ ou en $v$, n'est-il pas permis, en voyant ces mots complètement maori, kumara, kawaï, papa, conservés exceptionnellement dans les îles Fiji, de supposer qu'ils proviennent de la Nouvelle-Zélande?

D'Urville n'est probablement pas plus exact quand il sappuie sur le mot lkawa pour prourer l'origine polynésienne des Maori (1). Non-seulement les Zélandais avaient ce mot, mais il existe à la Nouvelle-Zélande une plante de la même famille que le piper methysticum, le piper cxcelsum, qui est appelé liawaliawa.

Il est vrai que les habitants de la Nourelle-Zélande ne savaient pas en faire une boisson enivrante; mais, à notre avis, c'est une raison de plus pour qu'on n'admette pas leur provenance de la Polynésie.

Il estévident que s'ils étaient partis, comme on le dit, de Tahiti ou des Samoa, ils auraient su faire cetie liqueur, puisqu'elle y est usitée et tirée d'un poivrier analogue.

Il est certainement plus facile de comprendre que, paris en ignorant cet usage, ils l'aient appris, comme celui de l'arc et des flèches, peut-être des habitants des îles intertro-

(1) « De mûne, dit-il, le mot kava y exprime toute espèce de liqueur forte, et vient de la boisson awa ou ava, usitée sur toutes les terres intertropicales de la Polynésie, et même sur une grande partie de la Micronésie et de la Mélanésie. " 
picales, et probablement des Fiji qui le possédaient, tandis qu'il est inconnu dans la plupart des autres îles à populations mélanésiennes et même micronésiennes.

Le noin seul, tel qu'il esí employé à la Nouvelle-Zélande, expliquerait le exit; Kawa, en Maori, signifie a aigre, désagréable, qui déplaît », et « cérémonie religieuse faite lors de l'achèvement d'une maison. „Or, tous ceux qui ont goouté le Kawa savent que cette boisson semble désagréable et qu'elle faitéprouver une saveur d'abord douce, puis piquante et âcre.

A Tahiti, le mot ava, qui est presque identique, est à la fois le nom de la plante et de la boisson qu'on fait avec elle. Il y signifie aussi liqueurs enivrantes en geénéral.

Nous ne savons si ce mot y a les autres significations du mot kawa de la Nouvelle-Zélande; mais il est certain qu'il y précédait, comme aux Tung d, presque toutes les cérémonies. Ce mot a étë écrit par Mariner cava, ce qui démontre que c'est absolument le mot kazva.

Ajoutons enfin que si les faits semblent indiquer que les Polynésiens ont appris l'usage de la boisson faite avec le piper methysticum, de leurs vuisins les Fijiens, ces mèmes mots prouvent que c'est aux Polynésiens eux-mèmes qu'ils sont dus, puisque plante et breuvage portent un nom tout différent aux îles Fiji, celui de Yakona. En empruntant l'usage de cette boisson aux Fijiens, ils lui auraient donné, suivant leur habitude, le nom qui rendait la première impression éprouvée, faisant en cela le contraire de ce que nous les avons vu faire pour le nom de leur premier chef.

Thompson, frappé comme tous les observateurs, de l'absence de la liqueur Ava ou Kava dans les îles de la Nouvelle. Zélande, s'est contenté de signaler la singularité de ce fait, sans en tirer aucune conséquence. Il est singulier, dit-il, en voyant croître à la Nouvelle-Zélande, le piper, qu'il appelle à tort methysticum, " il est singulier que les Nouveaux-Zélandais aient oublié l'art d'extraire un breuvage enivrant de la racine de cette plante. »

En effet, il serait sinģulier que, venant de la Polynésie, ils l'eussent oublié, de mème qu'ils paraissent l'avoir fait, 
comme on va voir, pour les cochons, les poules, etc. N'en faut-il pas plutôt conclure qu'ils venaient d'une contrée où rien de tout cela n'existait?

Le révérend Taylor ne dit absolument rien du Kawa comme boisson à la Nouvelle-Zélande, mais il dit, ce qui est digne de remarque, que les naturels mâchent la racine du piper excelsum, le représentant du piper methysticum, pour se guérir des maux de dents, et queles colons, avec la feuille, font du thé et une excellente bière. Il cite un autre piper, qui est celui de d'Urville.

Quant au cochon, « resté étranger à la Nouvelle-Zélande, » comme le dit d'Urville, on a toujours répété, en effet, depuis Cook, qui se vante de l'y avoir porté, qu'il n'existait pas dans ce grroupe d'îles, et qu'il n'a pu par conséquent ètre porté dans les îles polynésiennes par des émigrants de la Nouvelle-Zélande. On aurait également pu ajouter que, s'il y eûtexisté, on en eût conservé le souvenir dans les traditions, tandis qu'il n'y en a aucun.

Crozet, le premier, a signalé nettement l'absence du cochon à la Nouvelle-Zélande. Voici ce qu'il écrit à ce sujet :

« Nous avions sur notre vaisseau quelques cochons, des moutons du Cap de Bonne-Espérance et des cabris, dont la vue causait le plus grand étonnement aux sauvages, toutes Jes fois qu'ils venaient ¿ bord. Ils les regardaient avec la plus grande surprise, ce qui prouve qu'ils n'ont point de tels animaux dans leur pays. Ils n'avaient également jamais vu de poules ni de canards sauvages ; ils paraissaient fort étonnés d'en voir dans nos cagres. Ils n'ont absolument, comme animal domestique, que leurs chiens. Je n'ai vu dans le pays d'autres quadrupèdes que des chiens et des rats. »

Le chef Rangi (1), rericontré par nous dans la baie Hauraki en 182\%, est venu confirmer cetce observation de Crozet, en assurant positivement à d'Urville que c'était à Marion que ses compatriotes devaient les cochons, les raves, les choux

(1) Voir son portrait dans l'Atlas de l'Astrolabe, et ce qu'en dit d'Urville dans le texte du voyage, t. II, p. 164 . 
et les navets, qu'ils possèdent aujourd'hui. C'est ce qui a fait dire, au commandant de l'Astrolabe: (1) “ Malgré les injustes réclamations des Anglais, la chose paraîtra plus que probable, quand on voudra bien réfléchir que Marion séjourna plus de deux mois sur ce point, (Baie des Iles, 1772); qu'il y fit défricher un jardin et planter toutes sortes de graines. Cook, au contraire, qui n'y parut que dans son premier voyagre, n'y passa que cinq à six jours, et il ne dit nulle part qu'il ait laissé aux naturels aucune de ces productions, ce qu'il n'eût pas manqué de mentionner dans le cas contraire. (2) 》

Comme d'Urville, nous pensons que c'est plutôt aux na. vires de Marion qu'à celui de Cook qu'est due l'introduction des cochons à la Nouvelle-Zélande, et probablement aussi le nom de poaka qu'ils y portent aujourd'hui. Si Cook, en rapportant une tradition obtenue par lui dans son premier voyag'e, les appelle booah, c'est que cette tradition lui était traduite par Tupaia qui, naturellement, se servait du nom de son pays pour désigner les animaux dont la tradition voulait parler (3).

L'absence du cochon à la Nouvelle-Zélande doit d'autant moins être mise en doute, qu'aucune des lég’endes connues et qui sont si nombreuses, n'y fait allusion, tandis, au contraire, que dans la Polynésie, tout est rapporté, pour ainsi

(1) T. II, 1re partie, p. $23 \%$

(2) D'après le Rev. Taylor, il semblerait que Cook a laissé des cochons à la Nouvelle-Zélande, mais qu'ils y ont été aussitôt détruits. Voici ses paroles, (p. 195): «Ceux donnés par Cook étaient d'une grande espèce, qui succomba vite, parce que les indigènes voulurent s'en servir comme de cheval. » D'où donc venaient les autres, sinon de Marion ? En véritable Anglais, Taylor répond (p. 208 et 285), que c'est le gouverneur King qui les leur a donnés en 1800 .

(3) Les insulaires de la Baie Tranquille dirent à Cook que leurs ancêtres avaient visité, dans une très grande pirogue, une vaste contrée nommée Ulimaroa, située dans le N.-N.-O, à un mui* environ de navigation, et où les habitants mangeaient des animaux nommés booah. 
dire, à cet animal, qui est le seul terme de comparaison pour désigner les quadrupèdes Européens (1).

Comment admettre que les émigrants, en les supposant venus, ccinme on le dit généralement, de la Polynésie, puis retournés et revenus encore à la Nouvelle-Zélande, n'en auraient pas au moins amené quelques-uns avec eux? Cela semble impossible. S'ils n'en ont pas amené, c'est tout simplement parce qu'ils ne venaient pas d'une contrée où existait le cochon.

En supposant, au contraire, que l'émigration s'est faite de la Nouvelle-Zélande vers la Polynésie, on comprend très bien qu'ils aient trouvé là, dans les îles habitées ou non, le cochon, qui semble particulier à l'Océanie. Car il est à remarquer qu'on le trouve, même de nos jours, sur des îles désertes. Celles-ci, il est vrai, peuvent avoir été momentanément habitées, telle que l'île Motane, dite Robinson par les baleiniers (2), et qui fait partie du groupe Sud-Est des Marquises. Mais n'eût-il pas existé sur ces îles, qu'il était certainement très répandu sur toutes celles occupées par la race mélanésienne, à l'exception peut-être des Viti, si les traditions disent vrai, quand elles semblent attribuer aux Samoa ou aux Tunga les premiers cochons introduits dans ces îles.

Ce qui semble prouver que le cochon a été rencontré en Polynésie par des émigrants auxquels il était tout-à-fait inconnu, c'est que cet animal est devenu pour eux le type d'un monstre fabuleux, contre lequel les légendes font lutter les premiers chefs de ces émigrants : nous avons dit ail leurs ce que l'on rapporte, à ce sujet, dans les îles de la Société, du fameux chef Hiro. Il est évident que les émigrants eussent montré moins de surprise à ia vue de cet animal, s'il eût été connu d'eux.

D'où rous croyons pouvoir conclure que l'absence des cochons à la Nouvelle-Zélande, lors des visites des premiers Européens, et l'ignorance dans laquelle étaient les habi-

(1) Voy. ci-dessus, vol. II, p. $43 \%$

(2) Nous tenons ce fait de déserteurs américains ayant séjourné sur cette île, et qui noas ont doané leur journal. 
tants à leur sujet, prouve plus en faveur de l'origine zélandaise des Polynésiens que de l'origine polynésienne des Nouveaux-Zélandais.

Il n'y a pas, du reste, que l'absence du cochon, en faveur de la thèse que nous soutenons: celle de la poule, signalée pour la première fois également par Crozet, n'est pas moins significative.

On ne comprendrait pas, en effet, que, venant de la Polynésie, les émigrants n'en eussent pas apporté au moins quelquez-unes. On ne comprendrait pas surtout que, prenant leur nom seulement, ils l'eussent appliqué à un oiseau tout particulier et colossal, qui n'a jamais été vu qu'à la NouvelleZélande.

Nous avons déjà dit que le Moa est l'un de ces oiseaux gigantesques, nommés Dinornis, qui ont vécu autrefois à la Nouvelle-Zélande, et dont on ne trouve plus aujourd'hui que les ossements, quoique quelques colons assurent qu'il se rencontre encore dans los parties les plus reculées de l'Ile-du-Milieu. On sait, d'un autre côté, que, dans toute la Polynésie, le nom de Moa est le seul qui soit donné à la poule, ainsi que Lemaire l'avait déjà remarqué.

N'est-il pas dès lors à supposer que, forcés de s'éloigner sans pouvoir emporter leur Dinornis, et trouvant, dans les îles abordées par eux, la poule qui leur était inconnue, mais qui, par sa forme, leur rappelait le plus le Moa, ce sont les Néo-Zélandais qui l'auront ainsi appelée pour faire revivre le souvenir de l'oiseau de leur pays? On sait quel est le nom qu'ils donnèrent aux premières poules introduites à la Nouvelle Zélande: par imitation du chant du coq, ils les appelèrent Tikaokao. (1)

Il est bien vrai pourtant que si les Polynésiens sétaient rendus à la Nouvelle-Zélande sans la poule, ils auraient tout aussi bien pu, absolument pour les mêmes raisons, donner au Dinornis le nom de Moa. Mais cela n'expliquerait pas comment ce nom est le scul employé dans toute la

(i) Quand les poules furent introduites à la Nouvelle-Zélande, les naturels les appelèrent aussitôt. d'après leur cri, tikaokao, de même qu'ils appelèrent les canards francs rake rake, coui coui. 
Polynésie pour désigner la poule; en outre, ils ne se seraient certainement pas montrés aussi surpris, devant Crozet, à la vue des poules et des cochons. Ils en auraient, dans ce cas, nécessairement conservé quelque souvenir. Or, nous l'avons dit, aucune tradition ne fait allusion à l'un ou à l'autre de ces animaux.

Sans doute tout cela est très hypothétique; mais nous devons dire encore qu'à Tahiti, de même qu'aux Marquises, en outre de sa signification poule, le mot moa, en s'écrivant il est vrai $m o^{\prime} a$, signifie sacré, consacré aux dieux.

Ne pourrait=on pas supposer, dès lors, que ce serait en souvenir du Dinornis manquant, que les émigrants auraient donné cette extension au mot moa, comme pour le consacrer.

Il est du reste certain qu'à la Nouvelle-Zélande, le mot moa, en outre de sa première signification, ne signifie plus que « certaine pierre, couche de terre dans un jardin, » mais rien de pareil à « sacré ».

Ici, nous pourrions citer encore une dernière objection, reposant sur l'impossibilité de communiquer de Tahiti à la Nouvelle-Zélande et réciproquement, par suite des vents. Cette objection a été faite par M. de Bovis, dans son mémoire sur l'Etat de la Société tahitienne à l'arrivée des Européens, dont nous avons déjà parlé à propos de la provenance des Polynésiens d'un continent englouti.

Mais cette objection étant aussi contraire à la croyance du peuplement de la Polynésie par la Nouvelle-Zélande qu'à celui de la Nouvelle-Zélande par la Polynésie, il nous suffira de citer les paroles de cet officier de marine, dont l'assertion est détruite par les faits, puisque les populations sont certainement de même race.

« La Nouvelle-Zélande, Tahiti et les îles Sandwich, ditil, sont séparées par de vastes mers où règnent, d'un côté, les ouragans et les vents variables, et de l'autre, des brises régulières qui obligent ordinairement un navire à faire le plus près pour aller de l'une à l'autre. Y a-t-il un arin qui puisse jamais croire qu'il a été possible à des pi- 
rogues et même à des navires sans boussole de communiquer de l'une à l'autre de ces contrées ? Enfin est-il croyable que Tahiti ait peuplé ces deux pays, ou enfin, plus généralement, qu'un de ces trois pays ait envoyé des colo nies dans les deux autres ? J'en appelle à la carte. »

C'est d'ailleurs à la carte et aux vents, que nous allons nous-même en appeler, pour montrer que s'il est impossible, comme nous le croyons nous aussi, de communiquer régulièrement d'un archipel à l'autre, c'est justement une raison de comprendre que toutes les pirogues aient été entraînées d'un même côté. 


\section{CHAPITRE DEUXIĖME}

\section{TÉMOIGNAGES FAVORABLES}

Légende de Kendali. - Chant cité par Taylor. - Mots communs aux deux contrées : Macri ; - Maui ; - O-tu ; - Tina ; - Rama et Tiare ; Motu et Fatu ; - Ariki ; - Tui-Tunga; - Vea-iti. - Jade vert. Coutume d'avaler l'œil de la victime. - Absence de colonies polyné. siennes ou zélandaises à la Nouvelle-Hollande.

Telles sont, en résumé, les diverses objections faites à la possibilité d'une origine zélandaise des Polynésiens par presque tous les écrivains et surtout par Dumont d'Urville. On conviendra que, si la réfutation que nous venons d'en essayer ne leur enlève pas à peu près toute leur importance, plusieurs de ces objections sont du moins plus favorables que contraires à l'opinion que nous soutenons.

Nous allons maintenant présenter quelques-uns des témoignages qui nous semblent appuyer le plus l'opinion que la Polynésie a été peuplée par la Nouvelle-Zélande. Malheureusement ces témoignag'es ne sont qu'indirects, et ils nous obligeront à entrer dans d'assez longs détails. Mais tels qu'ils sont, nous avons la conviction qu'ils aideront à faire comprendre l'origine maori des Polynésiens.

Nous demanderons ces témoignages aux sources les plus diverses : Légendes, usages, comparaison des. mot.̇, his toire naturelle, géographie, déductions linguistiques, seront successivement mis à contribution. De même que le savant américain Horatio Hale s'est particulièrement adressé à la philologie pour tracer l'itinéraire des migrations po- 
lynésiennes, de même c'est à la philologie que nous demanderons surtout des preuves à l'appui de notre opinion ; mais nous nous aiderons en même temps de la critique, car il est certain que plusieurs traditions ont été mal interprétées.

L'ordre que nous suivrons sera le suivant:

$1^{\circ}$ Légende de Kendall, et chant cíé par Taylor ;

$2^{\circ}$ Examen des mots: Maori, Maui, O-Tu, Tina, Rama, Tiare, Motu, Ariki, Tui-Tunga, Veachi ;

$3^{\circ}$ Jade vert ;

$4^{\circ}$ Coutume d'avaler l'œil de la victime dans les sacrifices humains ;

$5^{\circ}$ Absence de toute colonie polynésienne ou zélandaise à la Nouvelle-Hollande, et de Nouveaux-Hollandais à la Nouvelle Zélande ;

$6^{\circ}$ Examen de la langue maori, langue mère du polynésien ; appréciation en passant des idées de M. Gaussin à ce sujet ; opinion de I. Williams; légende de Karika, etc.

$1^{\circ}$ - La seule légrende ou tradition zélandaise qui semble indiquer nettement un départ de la Nouvelle-Zélande pour la Polynésie, est le chant qui a été rapporté pour la première fois par le studieux missionnaire Kendall (1). Tout inexact qu'est peut-être ce chant, il prouve au moins qu'un entrainement, causé par les vents du Nord ou du Nord-Ouest, s'est opéré de l'Ile-Nord de la Nouvelle-Zélande vers le Sud-Est.

Bientôt, on verra Dieffenbach, d'Urville, Hale, Gaussin et quelques autres, soutenir que l'Ile-Nord de lin NourelleZélande a plutôt reçu des colonies renant du Nord et de l'Est, et qu'elle n'en a pas envoyé elle-même dàns cette direction. Le chant rapporté par Kendall contrarie leur opinion, qui s'appuie sur une lég'ende différente de la même contrée ; mais nous ne voyons pas pourquci cette tradition, soutenue par toutes nos autres recherches, ne serait pas plus proche de la vérité que celle qu'ils invoquent. Nous mon.

(I) Grammairc zélandaise, publiée par le professeur Lée, en 1820, sur les documents de M. Kendall. 
trerons, en effet, que les émigrants, en partant d'Hawahiki, avaient dû même se diriger vers l'Est pour atteindre l'IleNord de la Nouvelle-Zélande, ce qui semble être déjà en sa faveur.

Ce chant, malheureusement, est un peu obscur; mais, comme il nous semble corroboré par un autre chant de deuil, rapporté par le révérend líaylor, dans son livre si plein de faits, nous n'hésitons pas à lui accorder une certaine importance.

Voici le texte du chant maori, et la traduction qui en a été donnée par d'Urville, en copiant celle de Tiendall.

$E$ taka to e au ki te tiu marangaï.

I wiwa maï aï koinga tu anga,

Taï rawa nei ki te puke ki ere atu.

E tata te wiounga te kaï ki a taiwa.

Ki a koe, e Taua, ka wiwa, ki te Tonga,

Hau $i$ o maï e kahu, e Turiki,

$E$ takowe e o mo tokou neï rangi.

Ka taï ki reira, aku rangi auraki.

" Le fort et irrisistible vent qui souffle du Nord orageux a fait une impression si profonde sur mon esprit, en pensant à toi, ô Taua, que j'ai gravi la montagrne jusqu'au sommet le plus élevé pour être témoin de ton départ.... Les ragues roulantes vont presque aussi loin que Stivers.(1). Tu es en-

(1) Dumont d'Urville (t. II, 2e part. p. 504) dit que le mot Stivers, cité par la traduction, est le nom d'un navigateur qui, au rapport des Néo-Zélandais, aurait visité la Baie des Iles avant le capitaine Cook. Tout le portait à considérer ce mot comme la désignation de de Surville. Mais il faut remarquer que ce mot n'existe nullement dans le texte maori transcrit par Kendall, et qu'il ne pouvait pas s'y trouver, ainsi écrit du moins.

Nous ferons également remarquer que les beaux sentiments ex. primés dans cette traduction ne se trouvent pas non plus dans le texte Maori. Mais on les rencontre, et avec les mêmes expressions, dans une chanson Bouguise que de Rienzi a fait connaître (Ucéanie, p. 585.) La ressemblance est complète. Il est même probable que c'est de Rienzi qui a imité Kendall sans le citer, suivant son habitude; à moins que les deux versions ne soient particulières à chaque pays. Voici cette chanson, qui est intitulée "l'amour constant." 
traîné vers l'Est, loin au large. Tu m'as donné une natte pour la porter par amour pour toi, et ce souvenir de ta part me rendra heureux quand je la nouerai sur mes épaules. Quand tu seras arrivé au port où tu veux aller, mes affections y seront avec toi.»

Il résulte de ce chant, s'il est exact, que c'est vers l'Est que Taua se trouvait entraîné. Mais la traduction de Kendall est-elle bien exacte elle-même ? Nous craignnons qu'elle ne le soit pas, et nous le regrettons dans l'intérêt de la thèse que nous soutenons ; mais la vérité avant tout.

Disons d'abord ce que signifient les mots du chant maori et quelles corrections doivent être faites à plusieurs d'entre eux.

Taka, échoir, arriver.

Toe, rester, demeurer, au lieu de to $e$.

Kotiu, Nord et Nord-Ouest, au lieu de ki te tiu.

Marangai, vent frais, mauvais temps.

Wiwa, n'est pas maori. Serait-ce ui-wa ou uiua? ui, demander, chercher; wa, temps, saison, pays ; $u a$, pluie, pleuvoir.

Koinga, pointe ou bord.

Anga, dériver, chasser.

Rawa, gros, grosse.

Nei, ne pas, pendant que, arec, à.

Tata, proche, près de.

Whiunga, action de fouetter, ou whionga, siffler, au lieu de wiounga.

" Brani, ô mon bien aimé, j’ai gravi le mont escarpé pour suivre des yeux ton départ. Les vents fougueux d'Outara (le Nord), père des tempêtes, font une profonde impression sur mon âme. Elle est tourmentée parce que j'ignore ta destinée. La vag'ue mugissante arrivant de la grande terre, mère de Kalamatan (Bornéo), vient chaque jour rouler sur le rivage; et toi, exilé de ta patrie, tu vogues au gré des vents, tu cours trafiquer à Tanna-Papoua (la Nouvelle-Guinée), près des monts d'où s'élance le soleil. Sur mes épaules flotte le Sabok (écharpe) que tu portais : Tu me l'as donné pour gage de ton amour. Doux souvenir ! Sur quelque rivage que tu portes tes pas, sois-moi fidèle : partout mon amour te suivia constamment. 
Kawiwa doit être remplacé par $K a-w h i u-u a$, été, aller, fouetter.

Tonga, signifie Est d'après Kendall, mais Williams dit qu'il signifie Sud.

Nau, toi, doit remplacer hau, qui veut dire être grand, illustre.

Kahu, vêtement.

Turiki, couvrir, doit être remplacé par turuki.

Takowe, doit être remplacé par tako ue; tako, écrasé,

Mo, pour. fatigué ; ue, gouverner.

Tokou, mon, ma, mes, doit être remplacé par toku.

Ki reira, là, J.

$A k u$, mon, ma, mes.

$A$ uralii, se hâter, se presser.

Comme on voit, d'après la traduction, le mot kotiu, quoiqu'il soit mal écrit, comme tant d'autres, dit bien coup de vent du Nord ou du Nord-Ouest et rend par conséquent exactement le texte. Mais en est-il de même pour le mot tonga ? D'Urville, dans le vocabulaire maori qu'il a publié, n'hésite pas : il dit qu'il signifie vent d'Est, d'après Kendall. Mais un missionnaire ordinairement plus exact, W. Williams, avance au contraire qu'il signifie vent du Sud. Lequel croire ? Nous avouerons que nous croyons à plus d'exactitude chez ce dernier; mais, comme il se pourrait que Kendall eût été plus près de la vérité cette fois, il est au moins nécessaire d'avoir d'autres témoignages pour prononcer. Cependant Dieffenbach dit également que Tonga signifie vent du Sud.

Quoiqu'il en soit, d'après Kendall, c'est bien "vers les régions où le soleil se lève, » c'est-à-dire vers l'Est, qu'était entraìné le canot monté par Taua (1). Toutefois nous conviendrons qu'une pareille tradition n'est guère explicite; et, si elle ne renferme pas d'erreur d'interprétation, il se pourrait également fort bien que cet entraînement vers l'Est n'eût été qu'accidentel.

(1) Taua signifie pleureur, porteur de deuil ; armée, nous deux; nager ; etc. 
Mais Taylor (1) cite un autre exemple d'entraînement vers l'Est, tiré d'un chant de deuil ou de regrets : le chef Rangi-Whakau-rua parlant de ses ancètres à sa fille, lui dit: ils vivaient et demeuraient arec moi à Tahoraparoa (2) sur un point nommé Haumapu; mais un jour \&ils sont entraînés vers Paerau. "C'est ainsi du moins que le missionnaire traduit ces mots : Ka ruia ratou $7 i$ raro ki Pae. rau; et il explique que Paerau était une région des ténèbres une des demeures des âmes.

Nais Paerau (3) ne semble pas être Maori, en un seul mot du moins; Williams particulièrement ne le cite pas dans son dictionnaire. Ce mot doit être écrit paeroa, qui signifie horizon grand, lointain. C'est donc bien probablement ce mot qui, rapporté par la légende, a été mal entendu, et par suite mal écrit; et alors cette phrase : $k a$ ruia ratou $7 i$ raro ki Paeroa, doit être ainsi traduite: "Ils sont entraînés sous l'horizon lointain. $\gg$

Nous ajouterons que Paeroa est le nom que les Whakatane, habitants de la Baie d'Abondance, donnent à l'Est du Monde. Dès lors, comme on le roit, les ancêtres de RangiWhakau rua auraient, eux aussi, été entraînés vers le côté où le soleil se lève, c'est-à-dire vers la Polynésie.

Sous la réserve de ces observations, voici, tel qu'il a été donné par Taylor, le texte maori des a Lamentations de Rangi-Whakaurua, » que nous faisons suivre du mot-à-mot et d'un essai de traduction française.

\section{TE TANGI A TE RANGI WHAKAURUA.}

Nei lia noho $i$ te po roa o matiti.

Mokowhiti noa te tau o taku ate.

Nuliumai, e hine, kia piri mai koe ;

(1) Te Ika a Maui, p. 143.

(2) Tahoraparoa est le nom générique de la terre : tahora, plaine ; pa, village fortifié; roa, grand.

(3) Pae, horizon ; rau, feuille, cent. Ce mot ainsi écrit n'a pas de sens. A Tahiti, pae signifie pousser, chasser, aller sous le vent, mais sans désighnation de rumb; paeau, côté, division ; rau, feuille, cent, b aucoup, indéfiniment. 
Waka rukeruke noa $i$ runga $i$ aku ringa.

Kia marama au, ine titiro ki uta.

Ki te waka tuku mai, ki te ao rere mai ;

Paneke ake ana te tara ki Haumapu.

Ko o tipuna $i$ ora, i hoki mai ki au;

Ka ruia ratou ki raro ki Paerau.

E Toko ma, e! nau mai ki ko nei.

Ka puhangarua au, nga toro a tawhiti,

He maka whiu hau, kia turakina atu.

Nga uru rakauki Tahora paroa

Kia mauri ake ai te aroha.

I au, ki taku vhenua.

MOT-A-MOT.

Nei, ici.

$K a$, particule pour former le présent, le futur et parfois le passé.

Noho, demeurer, s'asseoir, passer,

$I$ te po roa, dans les nuits longues.

Oma, courir.

Titi, briller, brillantes.

Mokowhiti, sauter.

Noa, inutilement, en vain.

Te tau, l'assaut, le chant.

Otaku ate, de mon foie.

Nuku, venir,

Mai, vers.

$\widetilde{E}$ hine, ma fille,

Kia, particule pour former l'impératif.

Piri mai koe, approcher vers toi.

Waka, pirogue.

Ruke, renverser, jeter.

Noa, commun, sans importance.

$I$, particule pour former l'accusatif.

Runga, en haut,

$I$, par, à, de.

$A k u$, mon, ma, mes

Ringaringa, main.

Kia, particule pour former l'impératif. 
Marama, clair, clarté.

$A u$, je, moi,

$M e$, particule : il faut, ${ }^{\circ}$ préfixe.

Titiro, voir, regarder.

$K i$ uta, à, vers, rivag'e, terre, intérieur.

$K i$ te waka, à, vers la pirogue.

Tuhu mai, descendre.

$K i$ te ao, vers le jour, lumière.

Rere mai, courir, voler, venir vers.

Paneke, glisser, avancer,

Ake, en avant.

Ana tara, son courage, ardeur.

Ki Haumapu, vers Haumapu, nom de lieu : hau, coin, illustre ; mapu, soupir, palpitations.

Ko, préfixe, ici, là.

O-tipuna, le grand-père, ancêtres (au Cap-Est.)

I ora, à vie, vivre, santé, être en santé,

I hoki, à revenir, aussi, à cause de.

Mai ki au, vers moi.

$K a$, particule.

Ruia, participe passé de rui, dispersé, écart,

Ratou, eux, ils, elles.

Ki raro, à vers dessous, sous.

$K i$, vers, à.

Paerau, n'est pas Maori : il faut lire paeroa : pae, horizon ; roa grand, lointain. Ce mot, chez les Whatkatane, signifie Est, vent d'Est.

E Tokoma e. Mon cher Toko.

Nau, de toi.

Mai, vers.

$K i$, ̀̀.

$K o$, ici, là, vers

$\mathrm{Nei}$, ici, en vue.

$K a$, particule pour former le présent, le futur et quelquefois le passé des verbes.

Puhanga, blesser, percer, vider, tirer, lancer, jeter.

Rua, fosse, magasin, deux.

$A u$, je, moi. 
Nga, particule pour former le pluriel des substantifs, respirer.

Toro, s'étendre, se répandre, déployer, regarder.

$A$, ̀̀, de, et, comme.

Tawhiti, fuir, s'enfuir, distance, éloignement

$H e$, erreur, méprise, être dans l'erreur ; un, une.

$M a k a$, réservé, craintif, ètre craintif, lancer, jeter, mettre.

Whiu pour Wiu, fouet, fouetter, aller, placer, jeter.

Hau, vent.

Kia, particule pour former l'impératif.

Turaki $n a$, coup en poussant, action de pousser, renverser. Atu, d'ici, de là.

Nga, les.

Uru, partie supérieure d'une couche de plantation.

Rakau, arbres, bois.

$K i$ Tahoraparoa, de Tahoraparoa: tahora, plaine: pa forteresse ; roa, grand, grande.

Kia, particule pour former l'impératif.

Mauri, cœur.

Ake, en haut, en avant.

$A i$, qui, lequel, marque du futur.

T'e aroha, l'affection, l'amour.

I au, pour moi.

Ki taku whenua, et ma terre.

LAMENTATIONS DE RANGI WHAKAURUA. (I)

Je m'assieds ici pendant les longues nuits étoilées ;

En vain j'y exhale ma tristesse.

Viens, ma fille, approche-toi de moi :

Si la pirogue chavirait, tu serais à portée de ma main.

Ne masque pas ma vue : il faut que je voie le rivage,

Car la pirogue approche et le jour vient vite ;

Elle glisse rapidement vers Kaumapu.

Là vivaient tes ancètres, ils revenaient vers moi ;

(1) Rangi, ciel, cieux; Whakau, accomplir une cerémonie religieuse; rua, deux, fosse, magiasin. Peut-être faut-il lire roa, grand. Ce mot signifierait alors Grand.Prêtre des Cieux. 
Mais ils ont été dispersés sous l'horizon lointain.

O mon cher Toko ! tu es venu jusque-là à ma vue;

Mon cœur fut transpercé en ies voyant s'éloigner,

Entraînés par un coup de ventqui renversa, çà et là,

La cime élevée des arbres de Tahoraparoa.

Que dans ton cœur grandisse l'amour,

Pour moi et pour ma terre!

En résumé, si ces traditions ne précisentpas plus la route suivie qu'elles ne déterminent le but et le motif du départ, elles indiquent du moins que cette route était presque contraire à celle qu'auraient faite les émigrants, pour atteindre la Nouvelle-Zèlande en venant de Savaii ; elles montrent la possibilité de ce voyage ; elles ouvrent une série de probabilités que vont nous fournir certains mots communs aux deux contrées, et elles préparent pour ainsi dire aux preuves formelles, que nous donneront la linguistique ainsi que la critique de quelques autres traditions.

$2^{\circ}$ Maori. - Nous nous sommes suffisamment étendu sur ce mot dans le chapitre précédent; nous avons montré qu'il se retrouve partout, avec la mème signification, daus toute la Polynésie et qu'il a seulement subi quelques changements nécessités par l'euphonie adoptée dans les différents arshipels. Nous avons également dit que l'ancieu mot employé, avant qu'on n'adoptât maori, était mauri, dont la racine uri signifie postérité, lig'née : telle est du moins l'opinion de Taylor. Nous nous bornerons à ajouter ici que tous les mots tels que maohi, maoi, maoli, usités dans les différents archipels polynésiens, dérivent nécessairement du maori Néo-Zélandais, qui est le mot le plus complet et qui, par conséquent, les a fournis.

Maui. - Nous savons déjà que, d'après l'une des traditions tahitiennes, les îles de la Société ont dû être produites lorsque Maui, le Josué des Tahitiens, était occupé à traîner, de l'Ouest à l'Est, à travers l'Océan, une grande terre que les indigènes supposent située dans l'Est de leurs îles; nous 
savons également que les îles Tunga ont une tradition toutà-fait semblable, rapportée par Pritchard.

Il en est de même pour les îles Hawaï où, d'après Fornander (1), la légende montre Maui-Tikitiki pêchant les diverses îles de l'archipel avec son hamecon, tachant de les hâler à terre à Hilo et de les joindre à Hawaii. Près de $\mathrm{Pu}$ nepa, district Nord de Kohala, sur Hawaii, on montre encore l'empreinte de son hameçon appelé Manaia Kalana.

Il est inutile de faire remarquer ici combien cette croyance a dû porter quelques écrivains à admettre l'existence d'un continent submergé dans l'Est de la Polynésie : il est évident, en effet, que cette légende et la direction des vents alisés d'Est et de-Sud-Est, ont dû le plus contribuer à cette opinion. Mais nous signalerons du moins la direction suivie, d'après les traditions, et le nom de l'être divin qui passe pour avoir opéré le prodige.

Maui est encore plus connu à la Nouvelle-Zélande qu'en Polynésie ; mais là, il n'est point un dieu créateur, comme quelques voyageurs l'ont dit. C'était un héros divinisé à la suite de ses exploits merveilleux. Il vivait en Hawahiki du temps des Tinirau, des Kae, etc. Un jour, il pêcha à la ligne, en s'éloignant un peu d'Hawahiki, l'Ile-Nord de la Nouvello-Zélande, qui fut surnommée depuis a le poisson de Maui : » il alla s'y fixer et mourir, etil y devint pourainsi dire prophète et demi-dieu.

Déjà, dès [1814, Marsden (2) avait rapporté, comme le tenant d'un prêtre de l'Ile-Nord, que Maui était le premier homme venu d'Hawahiki sur cette île, qu'il avait quitté sa patrie avec ses compagnons, à la suite de troubles publics, et qu'enfin, conduit par le tonnerre, il était venu débarquer à Hauraki, la rivière Thames de Cook. Marsden ajoutait que son nom était en grande vénération et qu'il était honoré comme divinité. Depuis on a pu se procurer les traditions les plus complètes sur ce héros. Il résulte particulièrement de celles publiées par Sir Grey, Shortland et Taylor, que,

(I) An account of the Polynesian Race, etc. t. I, p. 108.

(2) Voyage de l'Astrolabe, pièces justificatives, p. 352. 
dans son pays, ce n'était guère qu'un vaurien courageux et entreprenant, tuant son beau-frère parce qu'il avait été plus heureux que lui à la pêche, allant arracher le feu à Mauika, et finissant par succomber en voulant tuer sa grand'mère, la déesse de la nuit, ou, comme le ảit une autre tradition, en voulant, pour se rendre immortel, se tremper, comme le soleil et la lune, dans la fameuse fontaine de vie d'Hawahiki. Ainsi s'explique comment il n'est pas devenu prophète en son pays.

Son mythe n'est absolument connu qu'à l'Ile-Nord de la Nouvelle-Zélande, et c'est à peine si son nom l'est dans l'Ile-du-Milieu. De nos recherches, il résulte qu'avant de s'enfuir à l'lle-Nord, il habitait près de la presqu'île de Banks, où l'on retrouve encore des souvenirs de sa famille et particulièrement de son beau frère; c'est avec le temps qu'on lui a attribué, dans sa nourelle patrie, les hauts faits de Tawhaki, le plus grand héros de l'Ile-du-Milieu, et même ceux de son frère aîné, surnommé Rupe ou le Pigeon.

Quoique ce nom de Maui soit plus connu dans l'Ile-Nord de la Nouvelle-Zélande qu'il ne semble l'être dans les îles polynésiennes, néanmoins, là aussi, on retrouve son souvenir soit comme héros fabuleux, soit comme demi-dieu, soit comme prophète. Dans toutes, il y a plusieurs Maui, de même qu'à la Nouvelle Zélande, où le célèbre Maui Potiki avait quatre ou cinq frères; dans toutes existe une tradition, identique par le fond, mais de moins en moins complète et nette à mesure qu'on avance vers l'Est et le Nord de la Polynésie. C'est ainsi que nous avons trouvé nous-même trois Maui aux îles Marquises, sans parler de celui qu'on y y appelle Maui-Ke ou dieu du feu ; (l) c'estainsi qu'aux îles Sandwich, des légendes de Maui, de ses quatre frères, de leur mère A-Kalana, Karana ou Taranga, de leur grand' mère Hina-Mahuia, ont été trouvées sur tous les groupes avec de légères variantes. Une île de l'archipel porte même le nom de Maui. On a vu qu'à Tahiti, Maui était le nom

(1) Le même que Mahui ou mieux Maui-ka de la Nouvelle-Zélande, Mafuie des Samoa. Mahuie de Tahiti, et Mahuia des îles Hawaii. 
d'un prophète ou d'un sage, dont les traditions font un prêtre, et auquel elles font jouer le rôle de Josué ; on a vu aussi qu'une autre tradition attribuait à un Maui le transport d'un continent vers l'Est, en venant de l'Ouest.

Partout donc existait la même tradition, plus ou moins modifiée par les détails, quoique complètementidentique par le fond, mais devenant de plus en plus fabuleuse, de plus en plus incomplète à mesure qu'on s'éloignait de l'Ile-Nord de la Nouvelle-Zélande, où elle est au contraire explicite et aussi complète qu'un mythe peut l'ètre. N'en faut-il pas conclure que c'est la contrée ayant conservé la tradition la plus pure qui a dû la fournir à celles qui n'en ont plus qu'un souvenir confus?

Pour nous, nous n'hésitons pas à l'admettre : c'est l'Ile-Nord de la Nouvelle-Zélande qui a fourni cette tradition à la Polynésie; sans cela, il serait impossible d'expliquer l'absence du mythe de Maui dans l'Ile-du-Milieu qui la touche, et qu'on croit si généralement avoir été peuplée par elle. Il est bien évident que si les habitants de l'lle-duMilieu avaient été fournis par l'Ile-Nord, ils auraient eu la même tradition à cet égard, et ils auraient appelé du même nom leur dieu de la guerre; on sait, au contraire, depuis les recherches du savant missionnaire anglais Taylor, qu'ils ont un mythe tout autre que celui de Maui, et qu'ils donnent à leur dieu de la guerre un nom tout différent de celui qui est donné au mème dieu dans l'Ile-Nord.

L'un autre côté, quand on remarque que la Polynésie entière possède justement le mythe de l'Ile-Nord de la Nouvelle-Zélande, et qu'elle donne à son dieu de la guerre le nom que l'Ile-Nord lui attribue, n'est-ce pas un témoignage en faveur du peuplement de la Polynésie par l'lle-Nord de la Nouvelle-Zélande?

Tout ceci, il faut l'avouer, est fort hypothétique ; mais en rapprochant les faits, en remarquant la direction que la tradition fait suivre à Maui quand .1 traîna une terre de l'Ouest a l'Est, en tenant compte surtuut de l'absence certaine du mythe de Maui dans l'Ile-du-Milieu de la NouvelleZélande, où il est remplacé par celui de Tawhaki qui vivat 
avant lui, il nous semble que ces conjectures ne sont pas tout-à-fait sans fondement.

S'il peut sembler difficile d'expliquer pourquoi les croyances mythologiques, rapprochées par le fond dans les deux grandes îles de la Nouvelle-Zélande, diffèrent dans chacune d'elles par les détails et surtout par le nom des héros, c'est, à notre avis, qu'on oublie que Maui, en s'expatriant à la lète d'une bande d'hommes aussi mal famés que lui dans son pays, dut bien vite devenir la terreur de toutes les populations d'Aotearoa ou Ile-Nord de la Nouvelle-Zélande. Naturellement, après sa mort, sinon de son vivant, on lui attrioua presque tous les faits mythologiques de la patrie première, conservés dans la mémoire, et son nom remplaça celui de Tawhaki. Le mythe de Maui, brodé, augmenté arec le temps, fut bientôt seul connu à l'IleNord, d'où il fut porté par les émigrants de cette île, dans toute la Polynésie et jusquu'aux Sandwich, où les premiers Européens trouvèrent des hommes qui šinstituaient prêtres de Maui. Maui, en un mot, accapara si bien tous les hauts faits de ses devanciers, ou de ses contemporains quon voit des traditions lui attribuer ceux de son frère aîné Rupe, qui, comme Tawhaki, aurait fait une ascension au ciel (1).

O-tu. - Le mot o-tu vient également appuyer notre conjecture. Tous les voyageur's l'ont écrit Otou. D'après Mar* chand c'était, de son temps (1797), le nom du chef de Vaitahu

(1) « Les exploits de Maui pour découvrir le feu appartiennent à tous les groupes avec des variantes. L'ancêtre déifiée et grand' mère de Maui, à la Nouvelle-Zélande, appelée Mahuika par les légendes, est évidemment la même que sa grand'mère Hina-Mahuia dans les îles Hawaii (Généalogie d'Uluj; et la Mafuie des Samoa trahit un souvenir confus des mêmes lég’endes. Ces légendes étaient incontestablement plus vieilles que l'exode des Polynésiens dans la Pacifique. Il est juste de conclure, à cause de cela, que la famille de Maui et ces légrendes n'étaient pas, non seulement indigènes aux îles Hawaii ou contemporaines de quelques-uns des chefs de la ligne Nanaulu, mais qu'il faut même se demander si leur origine ne date pas de la période pré-pacifique de la race polynésienne. Fornander, An account of the Polynesian race, t. I, p. 108. 
sur l'île Christine, où la France fit un instant un établissement si funeste au commandant Hallet et à plusieurs autres. Cook écrivit ce nom Honou. Mariner, qui l'entendit aux îles Tunga, l'estropia comme presque tous les autres et le rendit par How. A Tahiti, c'était, à l'arrivée de Cook, le nom de celui qui devint peu après Pomare $1^{\text {er }}$. Partout enfin ce nom était appliqué au premier chef de l'endroit.

Or, dans l'Ile-Nord de la Nouvelle-Zélande, il était avant tout le nom du dieu de la guerre, ainsi que le prouve le fameux pihe ou chant de mort zélandais rapporté par Kendall. Ce nom y était aussi la désignation d'un cap près du cap Nord (1). Ilans l'Ile du-Milieu, au contraire, le dieu de la guerre était Maru (2) et non O-tu.

A Tahiti, d'après le dictionnaire publié par les missionnaires anglais, le mot tu ou o-tu (3) signifie un dieu. C'était l'ancien nom du dieu de la guerre parmiles ancêtres des Tahitiens; ce n'est que plus tard qu'il a été changé en celui d'Oro, à la suite de quelque conquête faite par leurs grands ancêtres, les habitants de Raiatea qui, eux-mèmes, possédaient d'abord le mot O-Tu avant d'adopter le mot Oro. Aux Manaia ce mot est Koro.

Avec M. de Quatrefages, nous croyons que Oro (4) n'était qu'un chef déifié, comme Hiro, Tangaloa ou Taaroa. De même qu'on a donné, par flatterie, le nom de Maui à l'ancien

(1) Non loin du cap O-tu est le cap Reinga des indigènes, où, de tous les points de l'Ile-Nord, les âmes (Wairua et non waidoua comme on a dit) accourent pour retourner au pays d'origine.

(2) Il est à remarquer que Maru ètait également le nom du dieu de la guerre aux îles Sandwich (Voy. Taylor, p. 35.)

(3) Il est inutile de dire que $O$ doit être séparé de $T u: O$ est la préfixe placée devant les noms au nominatif. $T u$ est à Tahiti, comme à la Nouvelle-Zélande, aux Marquises etc., le nom d'un dieu (a). Ce mot d'ailleurs a plusieurs autres significations.

(4) Oro, en Tahitien, signifie ratisser, racler le taro ; en Maori, moudre, aiguiser.

(a) Au Japon, koo ou $k u$ (pron. $k o u$ ) est le titre qui répond à celui do Seigneur: on ne le donne qu'aux personves de la plus haute distinction, (Yoy. Thunberg, t. III), 
mythe de l'Ile-du-Milieu, modifié et embelli par les habitants de l'Ile-Nord de la Nouvelle-Zélande, de même, pensons-nous, on a donné, pour un motif semblable, le nom d'Oro àl'ancien dieu appelé jusque -lì $\mathrm{O}$-tu. Tous les peuples procèdent de la même manière. Il est certain que ce mot Oro ne reparaît pas dans les traditions des autres archipels; il ne se trouve même pas parmi les noms des dieux des îles Samoa donnés par Pritchard. Celui qui portait ce nom était presque certainement aussi un chef important, le premier, si l'on veut, arrivé à Raiatea avec ses compagnons ; mais c'était un étranger qui, avec un nom ainsi orthographié, ne pouvait être un Samoan, comme on le croit : Il faudrait admettre alors qu'il avait quitté les Samoa avant que ces îles, qui parlaient évidemment la langue du pays d'origine à l'arrivée de leurs premiers habitants, n'eussent transformé leur langue en un dialecte où le $r$ se trouvait remplacé par le $l$ comme aux Tunga.

Ainsi écrit, du reste, ce mot était lui-même maori ; peutêtre n'était-il que le mot O-rongo élidé, comme nous l'avons déjà dit.

Tina. - Ce mot que, seul, Bligh a dit être le nom de 0-Tu, plus tard Pomare $1^{\text {or }}$ à Tahiti, vaut également la peine qu'on s'y arrète uninstant. Si ce mot a été exactement entendu par Bligh, son équivalent en Maori est tina qui signifie rester calme à travers la peur, être sans peur. Mais ne seraitce pas plutôt le mot tana, qui est le nom de la deuxième caste à la Nquvelle-Zélande (1) et qui équivaut à prince,

(I) D'après les écrivains modernes, et particulièrement d'après Thompson (p. 94), il existerait six castes à la Nouvelle-Zélande :

\begin{tabular}{|c|c|c|}
\hline 10 Ariki & & \\
\hline 2. Tana & - & Premier chef, roi. \\
\hline 30 Rang & - & suprême. \\
\hline - Tutua & & Classe moyenne. \\
\hline ware & & Basse classe. \\
\hline Taurakaral & & \\
\hline
\end{tabular}

Ces six rangs, ajoute Thompson, ne sont pas très bien définis et ne peuvent être distingués que par ceux qui ont fait une étude 
membre de la famille du chef suprème ? Ce mot tana a plusieurs significations à Tahiti : c'est le nom d'un poisson rougge; c'est aussi, de même qu'à la Nouvelle-Zélande, le pronom possessif son, sa, ses. Peut-être aussi B!igh a-t-il entendu tinai qui, en Tahitien, signifie éteindre une lumière, un feu, faire cesser quelque chose, diviser de l'eau; et auquel correspondrait le maori tine $i$ éteindre, détruire, abattre. Quoiqu'il en soit, tina n'est pas tahitien, et nous croyons qu'il s'agit plutôt du mot tana.

Rama et Tiare. - A la Nouvelle-Zélande, Rama signifie torche, et tiare, odeur.

Aux Marquises, le mot ama, qui est le mème que rama, est donné à l'Aleurites triloba, et le mot tiae, qui est le mème que tiare, a été appliqué à une plante, le Gardenia florida.

A Tahiti, tiare est donné aussi au Gardenia, comme aux Marquises. Mais il n'en est plus de même pour l'arbre à noix de Bancoul, qui s'appelle Tiaïri au lieu de Rama. Li', rama est le nom donné, comme à la Nouvelle-Zélande, à la torche employée par les pêcheurs.

Aux Sandwich, lama, pour rama, signifie également lumière, torche et une espèce de bois; mais le Bancoulier y est appelé Kuikui, de même qu'aux Samoa où il se nomme Tuitui.

En supposant les migrations opérées de la Nouvelle-Zélande, ne peut-on pas croire que les premiers émigrants, en voyant brûler si bien les noix de l'Aleurites ou Bancoulier, leur auront appliqué le nom rama, torche; de même qu'en sentantl'odeur suave du Gardenia, plante qui leur était également inconnue, ils lui ont appliqué le mot tiare, odeur?

Il est vrai qu'on peut objecter que les nouveaux arrivés, fussent-ils allés de Tahiti ou des Samoa à la Nouvelle: Zélande, auraient pu procéder de la même manière, et attentive de ce sujet. Nous croyons que la division n'est pas exacte : il est certain que tutua signifie pauvre homme, personne basse. 
donner le nom de Tiare à la plante inconnue qui leur rappelait la leur parson odeur. Mais ce mot n'étant, à Tahiti, d'où l'on fait surtout provenir les habitants de l'Ile-Nord de la Nouvelle-Zélande, que le nom d'une plante, il semble moins naturel qu'il soit devenu un nom abstrait a la Nouvelle-Zélande. C'est pourquoi nous croyons pouvoir le considérer comme ayant plutôt été donné par des émigrants maori à la plante d'odeur si agréable, rencontrée par eux en Polynésie. La mème observation peut se faire également au sujet du mot rama. Il nous semble donc plus facile de comprendre le changement qui se serait fait dans l'application et la signification de ces mots en admettant leur origine zélandaise, qu'en faisant le contraire.

Motu et Fatu. - Les deux mots motu et fatu nous semblent aussi pouvoir ètre interprétés de la même manière.

M. Gaussin cherche à mettre en relief la différence existant entre ces mots, dans le but de prouver que les habitants de la Nouvelle-Zélande et des îles Marquises tirent leur origine d'un lieu où doit se trouver des motu de corail : il soutient donc tout simplement l'opinion de Hale sur le lieu du départ des émigrants de la Polynésie pour la NouvelleZélande.

D'après lui, à Tahiti, le mot fatu est employé pour désigner un îlnt élevé, un rocher, et le mot motu, un îlot plat, formé par le corail, ou plutòt le récif élevé à fleur d'eau. Aux Marquises, motu et fatu sont employés indifféremment pour désigner un îlot, un rocher, car, dans cet archipel, il n'existe pas de motu de corail. M. Gaussin conclut, de la synonymie des deux mots à la Nouvelle-Zélande et aux Marquises, que les habitants de ces deux archipels tirent leur origine d'un lieu où il doit se trouver des motu de corail.

Mais il est probable qu'il y a là erreur : il est certain qu'à la Nouvelle-Zélande motu ne signifie que : île plate, basse, de mème que ce mot signifie, à Tahiti (1), île, île basse, jar

(1) Dictionnaire T.zhitien, p. 147. 
opposition, à renua, terre élevée, île où il y a une terre élevée. Quant au mot fatu il veut dire (1) : maître, posses. seur, tisser, tresser, partie cartilagineuse de l'huître, mais non pas île, rocher. Aux îles Marquises, il signifie, d'après le P. Mathias : père ou mère nourricier, mamelle, lier, attacher, sustenter, espèce d'écr'evisse.

L'explication de M. Gaussin tombe donc d'elle:même, et rien ne s'oppose à ce que la Nouvelle-Zélande ait fourni a la fois les émigrants et le mot avec sa signification.

Ariki. - Un mot qui, plus que tous les autres, doit appeler l'attention, est celui d'Ariki ; car si notre hypothèse est la plus voisine de la vérité, commenous espérons le prouver, ce mot, à lui seul, fait comprendre que la Polynésie ait pu être peuplée par la Nouvelle-Zélande.

Voici ce que dit M. Gaussin à ce sujet : (2) a Il y a eu, à la Nouvelle-Zélande, dans la signification du mot ariki, un changement qui peut nous éclairer sur l'histoire des peuples de cette île. Ariki, qui ailleurs représente le pouvoir royal appuyé sur la théocratie, ne signifie que pontife et les chefs suprêmes sont appelés Rangatiras, titre qui, dans la Polynésie, désigne les petits chefs, les nobles, les propriétaires. N'est-ce point là un trait évident du développement naturel des Sociétés? N'y devons-nous pas voir une preuve de la révolution faite au profit des chefs militaires contre les rois théocrates ? N'est-ce pas la même révolution qui a eu lieu à Rome à la chute de la royauté ? Nous pouvons mème faire ressortir davantage l'analogie. En effet, les mots rex et ariki ont été conservés pour désigner les pontifes, l'un à Rome, l'autre à la Nouvelle-Zélande. On comprend qu'un pareil changement dans les institutions sociales ait pu s'effectuer là où la population s'est élevée jusqu'à un million d'âmes, plutôt que sur les petites îles de la Polynésie, où il est rare de trouver vingt mille habitants sous la même autorité.»

(1) Id., p. 83.

(2) Ourr. cité, p. 124. 
Puis il ajoute : "Aux Marquises, le mot hakaiki (ariki), est au contraire d'un usage général. Nous devons attribuer ce résultat à la nature du pays qui a produit le fractionnement de la population. Les seuls endroits habitables sont quelques vallées encaissées, séparées les unes des autres par des crêtes de montagnes presque infranchissables ; chacune de ces vallées a dû nécessairement devenir une unité politique. Les Rangatiras, par suite de la faiblesse du pouvoir, ont pu se constituer Ariki, non par une révolution sociale, comme à la Nouvelle-Zélande. mais par une simple usurpation individuelle de l'autorité et sans altérer l'institution même. Cependant, le titre Rangatira se trouve quelquefois employé avec le sens de possesseur de terre ou conquérant. En un mot, on peut dire qu'aux Marquises la classe des Rangatira s'est fondue dans celle des Ariki, mais sans la remplacer, comme à la Nouvelle-Zélande. »

Nous sommes de l'avis de M. Gaussin quand il dit qu'une révolution s'est faite, à la Nouvelle-Zélande, au profit des chefs militaires contre les chefs religieux : ceux-ci, avec le, temps, avaient su acquérir tous les pouvoirs, ou, du moins, ils agissaient comme s'ils les avaient possédés légalement. Mais ce qu'il importe de remarquer, c'est que la séparation des pouvoirs, à la Nouvelle-Zélande, semblait remonter à une époque fort reculée, qu'il est impossible de déterminer, car il existait a la fois des chefs militaires et des Ariki dans les traditions les plus anciennes, telles que celles de Tinirau, de Whakatau, de Poporokewa (1), du temps de Maui, de Kae et de Uenuku.

Ces traditions montrent q̨ue les Ariki ou pontifes n'avaient là, comme ailleurs, autant de pouvoirs, que grâce aux moyens dont ils disposaient et à leur habileté. Mais, dès lors, ils étaient ou ils devaient être hiérarchiquement inférieurs aux chefs militaires des tribus.

Il est impossible de dire à quelle époque ce résultat avait eté obtenu : ce n'était bien probablement que longtemps après sacréation qu'on avait dû donner au motariki, unepa -

(1) Poporokewa était le chef des Ati-Hapai, dont Kae, qui eut pour successeur Uenuku, était le pontife. 
reille extension. Sil'on s'en rapporte à Shortland(1), écrivain si rersé dans les choses de la Nouvelle-Zélande, ariki ne signifie littéralementque « héritier mâle ou femelle n et c'est à tort, d'après lui, qu'on le traduit par les termes a seigneur, maître, roi. a Pour Taylor, ariki signifierait pontife et non prêtre qui se rend par Tohunga : tino ariki signifierait chef des prêtres ou très ariki. Toujours est-il, comme le dit $M$. Gaussin, que ce titre est celui que les premiers voyageurs, ainsi que leurs successeurs, ont trouvé réservé aux pontifes dans la Nouvelle-Zélande, tandis que les chefs des tribus y portaient le nom de Rangatira (2).

De nos jours encore, un même chef peut porter les deux titres à la fois. Il suffit pour cela qu'il soit chef de tribu et chargé de fonction sacerdotale. Ainsi le révérend Marsden, dans son $3^{\circ}$ voyage à la Nouvelle-Zélande, en 1820 , fait remarquer que le titre Ariki était donné à Te Puhi le premier chef d'une tribu, qui était en même temps chef de la religion ; et d'Urville apprend que le Zélandais Te Hinui que nous avons pris en 1827 à Te-Ra-Whiti, darıs le détroit de Cook, et conduit jusqu'a la baie Tolaga ou Uana, était en même temps Rangatira-nui et Ariki, c'est-à-dire premier chef et grand-prêtre de son canton. Il faut en conclure, croyonsnous, que si les titres sont séparés aujourd'hui, comme ils paraissent l'avoir été de tout temps, d'après les plus vieilles traditions, les chefs civils et militaires n'avaient certainement pas besoin, en arrêtant le clergé dans ses empiètements, de songrer à lui prendre en même temps le titrequ'il s'était donné, et qui semblait bien lui appartenir par son origine d'apparence toute cléricale. En effet, riki signifie

(1) Traditions and Superstitions, p. 104.

(2) Maori : ranga, compagnie de personnes, avancer, pousser en avant; tira; compagnie de travailleurs, nageoire de poisson; tiratu, mât d'un canot.

Tahiti : raatira, chef inférieur ; raa consacré, sacré, nom de l'un des principaux dieux; tira, mât d'un navire à voile; pièce ou bâton élevé, droit dans un maraë.

Marquises: tia mât. Les Marquésans n'ayant ni le $r$ ni le $n g$, la mot ranya ou raa ne pourrait être que aa qui n'est pas Marquésan. 
littéralement a petit » et $a$, « entraîner, dirig’er, conduire. »

D'après cela il n'y aurait donc pas eu, comme on le dit, changement dans la signification du mot ariki, mais seulement reprise de la puissance usurpée par les Ariki. Cette puissance, au moment de la lutte, devait être considérable, à en juger par les traditions qui fout connaître les guerres survenues dans la patrie première, ainsi que les migrations vers l'lle-Nord de la Nouvelle-Zélande, qui en furent le résultat. Ces traditions donnent, en effet, les noms de tous les chefs prêtres ou chefs qui, une fois vaincus, durent chercher leur salut dans la fuite (1). On voit figurer parmi eux les pontifes les plus renommés ou leur enfants, tels que Ngatoro-i-Rangi, Rata, Raumati, etc.

En somme, les Ariki auraient tout simplement conservé leur ancien titre, momentanément bien déchu, etles Rangatira ou chefs militaires et civils auraienteux-mêmes gardéle leur. C'est, du moins, ce qui résulte de tous les documents qui sont venus à la connaissance des Européens depuis quelques années. Si la révolution paraît avoir été, cette fois, aussi profonde, c'est, comme on verra plus tard, que la guerre civile s'était étendue à presque toutes les tribus de la patrie première ou Hawahiki, et qu'elle devait recommencer pres que aussitôt dans la nouvelle patrie, Aotearoa ou Ile-Nord de la Nouvelle-Zélande. Si la cause principale des émigrations n'eût pas été la lutte des chefs militaires contre les théocrates, on ne comprendrait pas l'arrivée ì la fois dans l'lle-Nord des partis qui étaient opposés en Hawahiki : Tels que les enfants du grand prêtre Uenuku qui avait été si longtemps vainqueur d'Hou, - et ceux d'Hou eux-mêmes qui cependant, avant de partir, avaient tué Uenuku. Pour s'expliquer un pareil fait, il faut absolument admettre qu'il y avait eu un troisième parti et que c'est ce troisième parti

(1) Voir à ce sujet les légendes de Tinirau, Rata, Whakatau, Kae, etc., dans Sir Grey, Shortland et Taylor, et l'appendice inséré à la fin de ce volume. 
qui était resté le maître et avait expulsé les vainqueurs et les vaincus demeurés fidèles à leur cause.

Il est fort probable que les Rangatira, parvenus à mâ̂triser les Ariki et leurs adhérents, se sont mis en leur lieu et place pour toutes les choses temporelles; c'est peut-être alors que les premiers chefs de chaque nation ou tribu, pour se distinguer davantage, se firent appeler Rangatiranui, comme nous avons entendu Tehinui se désigner sur l'Astrolabe. Mais il n'est pas moins vrai que ce titre, avant l'émigration de la plupart des partisans du pouvoir théocratique c'est-à-dire de la grande émigration racontée par les légendes de Sir Grey, était déjà celui des premiers chefs des tribus en Hawahiki. Depuis quand ? Il serait oiseux de le rechercher. Ce serait donc à tort, en définitive, qu'on le supposerait, à la Nouvelle-Zélande, inférieur à celui d'Ariki, qui semble n'avoir été, de tout temps, que le titre réservé aux chefs du clergé.

D’un autre côté, il est̂ certain, ainsi que le fait remarquer M. Gaussin, qu'il n'en était pas de même en Polynésie, quand les premiers explorateurs s'y présentèrent. Là, en effet, le titre Raatira (Rangatira) (1), à Tahiti du moins, désigne les petits chefs, les nobles, les propriétaires; et il paraissait aussi parfois y signifier « conquérants». Ceci s'explique parfaitement, quand on sait que la forme du gouvernement, à l'arrivée des Européens dans cette île, était une sorte de monarchie aristocratique. Mais lí ce titre était inférieur à celui d'Ariki, contrairement à ce que nous venons de voir pour la Nouvelle-Zélande, et celui d'Ariki, dans toutes les autres îles polynésiennes, était également le titre du pouvoir le plus élevé. Ici donc plus de doute : tous les voyageurs ont fait la mème observation, et il suffit de se rappeler que c'est le titre que prenait la reine Pomare, pour être convaincu de son exactitude. Seulement l'orthographe de ce mot varie suivant les dialectes: aux Tunga,

(1) Ce titre ne se trouve ni aux Tunga, ni aux Marquises, ni aux Samon, sous un nom approchant. 
c'est eiki; à Tahiti, arii ; aux Mangareva, aux Manaia, etc., ariki; aux Marquises, hakahiki, et aux Sandwich, alii.

Al'occasion du mot hakaiki(1) des Marquises, M. Gaussin pense que son usage n'est dû qu'à la nature du pays qui a produit le fractionnement de la population. Nous ne sommes pas de son avis : il est certain, d'abord, que ce mot est le même dans toutes les îles polynésiennes, et que, si les Marquises ont des vallées étroites et isolées qui l'expliquent, les îles Sandwich, par exemple, qui l'emploient comme Tahiti, présentent en outre de fort grands espaces qui auraient certainement permis à de grandes agglomérations de devenir une unité politique. Sans doute certains petits chefs, par suite de la.faiblesse du pouvoir, ont pu, à certaines époques, se constituer Ariki, par une simple usurpation individuelle; nous en avons nous-même observé un exemple à Nuku-Hiva (2) et nous savons que d'autres ont été vus aux îles Tunga et à Tahiti. Bien probablement aussi, comme l'avarce M. Gaussin, la classe des Rangatira, aux Marquises, s'est fondue dans celle des Ariki (Hakaiki), car il n'y a même pas, en apparence, de mot équivalent à rangatira, à moins que ce ne soit celui de tuhuka, maître, habile. IIais cela n'explique pas pourquoi ce titre Ariki est devenu dans toutes les îles polynésiennes celui du pouvoir suprême, contrairement à ce qui avait lieu à la Nouvelle-Zélande ; cela n'explique pas non plus pourquoi les Rangatira (Raatira) ne sont à Tahiti que des nobles, des chefs inférieurs.

L'adoption du mot Ariki dans toute la Polynésie, comme titre despremiers chefs, nous paraissant due à une toute autre cause que celle indiquée, nous allons essayer de faire connaître cette cause, qui vient elle-mème appuyer l'opinion que la Nouvelle-Zélande a peuplé la Polynésie.

(1) Haka, faire; hiki, élever, nourrir; iki petit.

(2) O-Tetui, devenu Ariki sous le nom de Umatoto, et père de notre ami Tuhuka, était d'origine populaire. (V. Notes manuscrites sur les Marquises, p. 867.) 
Nous avons dit précédemment que toutes les traditions maori établissent que les luttes, en Hawahiki, avaient souvent lieu entre les tribus d'une même nation; comme les luttes devinrent générales, il est presque certain, même en admettant que d'autres causes aient contribué au départ d'un certain nombre de canots, que la cause principale a dû être le soulèvement d'une partie de la population contre l'autre, en un mot, ainsi que le dit M. Gaussin, celui des Rangatira et de leurs partisans, contre le pouvoir théocratique. Il suffit de parcourir les traditions rapportées par Sir Grey pour en être convaincu.

Par cela même, il est bien évident aussi que les émigrants, allant se fixer sur l'Ile-Nord de la Nouvelle-Zélande, ne pouvaient guère être que les partisans de ce pouvoir, ce que semble attester d'ailleurs la présence à la fois, sur cette terre, des noms des chefs et des Ariki les plus renommés et les plus nobles en Hawahiki. Imbus des idées qui venaient de leur être si funestes, ils ne pouvaient pas manquer d'es. sayer de les faire revivre. C'est ce qu'ils firent, comme le prouve, entre autres, l'exemple du grand-prètre Ngatoro-iRangi, dans la baie d'Abondance. Mais, presque aussitôt, de nouvelles luttes survenant (1), et les guerres se succédant, force fut au parti vaincu de chercher de nouveau son salut dans une nouvelle émigration. Cette fois, n'ayant, comme on verra, pour ainsi dire pas de choix, il dut se diriger vers la Polynésie.

En arrivant dans les îles polynésiennes, après tant d'épreuves déjà supportées pour ce que les émigrants devaient, eux aussi, appeler la bonne cause, ils ne pouvaient qu'y implanter le régime théocratique, malgré qu'il les eût forcés à émigrer, et cela dut même leur être d'autant plus facile, qu'il n'y avait probablement, quoiqu'on ait cru le contraire, personne sur les premières îles abordées qui

(1) Fait curieux à noter, c'est Raumati, l'un des fils de Uenuku, le grand-prêtre d'Hawahiki, tue par Tama-te-Kapua, fils d'Hou,qui commence en incendiant le canot de ce dernier. 
pût les en empècher. Jamais circonstances plus favorables ne s'étaient présentées pour eux : la longueur de la traversée et ses dangers avaient dû augmenter le sentiment religieux et la confiance dans les chefs, et telles étaient ces circonstances, qu'il suffisait devouloir, pour établir en entier le régime qu'on avait si vainement rêvé pour la Nouvelle-Zélande.

On n'y manqua pas, à en juger par les plus anciens documents obtenus sur ces îles : ces documents démontrent que le gouvernement y fut tout d'abord théoratique pur, avant d'arriver aux changements qui en avaient fait, à Tahiti, par exemple, une espèce de self-government (1). Le titre Ariki, qui était celui des chefs émigrants, $\mathrm{y}$ fut naturellement adopté comme celui du pouvoir le plus élevé, et comme ce sont les premières îles occupées, c'est-à-dire les Tunga, les Samoa, les îles de la Société et Manaia, qui envoyèrent leurs colonies peupler les îles plus orientales, cela seul explique, à notre avis, que ce titre soit devenu partout celui des premiers chefs.

Mais, parce qu'il était devenu partout le titre du pouvoir suprême à l'arrivée des Européens, il ne faut pas croire qu'il n'y avait pas eu, là aussi, des efforts faits pour renverser ou diminuer le pouvoir que le parti théocratique s'était arrogé. L'histoire de la Polynésie apprend, au contraire, que ce titre n'était qu'une usurpation des hommes, princes ou Raatira, qui l'avaient pris en même temps que le pouvoir, soit aux Tunga, comme Finau I ${ }^{\text {er }}$, soit àTahiti, comme Poma$1 \because I^{\text {er }}$, ou même aux Marquises, comme O-te-Tui. Pour en arriver là, il avait dû évidemment se passer plus d'une révolution qui, en définitive, avait eu pour résultat, comme à la Nouvelle-Zélande, de ramener à de justes limites le pouvoir thévcratique, resté tout puissant pendant une période qu'il est impossible de fixer. Cela semble prouver que la distinction devait exister dès le principe entre les pouvoirs.

On sait qu'à l'arrivée de Mariner aux îles Tunga, toute l'influence du fameux Tuitonga, comme autorité civile et

(!) Voir nos recherches sur cette île, p. 547 et suiv. 
militaire, avait disparu, enlevée par l'usurpateur Finau Ier, et que celui-ci, à la morí du Tuitonga, abolit même jusqu'à la fonction. Cependant ce qui semble prouver encore que le pouvoir avait dû ètre tout théocratique d'abord, ou sous la dépendance du Tuitonga, c'est que ce nom ne signifie que roi ou mieux premier chef de Tonga, signification qu'il avait aux îles Samoa, et qu'il avait aussi aux îles Fiji, auxquelles il avait été emprunté pour remplacer le titre Ariki, probablement à l'époque où quelque usurpateur avait pris ce dernier titre en même temps que le pouvoir.

A l'arrivée des premiers Européens aux îles de la Société, le titre Ariki, sous la forme Arii, était non-seulement celui du premier chef des principales tribus, mais aussi celui des chefs de districts. A cette époque, le clergé n'était plus, pour les Arii, qu'un moyer pour gouverner, tant on avait réduit son influence. Toutefois l'histoire apprend encore qu'à cette même époque, il n'était pas plus facile à manier que le clergé de beaucoup d'autres contrées, où les rois emploient une partie de leur règne à se défendre contre l'empiètement de l'église et l'autre à venger les intérêts de cette même église, à laquelle leur prestige est attaché.

On connaît le fait du grand-prètre Tupaia, partant avec Cook pour échapper à la vengeance de Pomare ${ }^{\text {er }}$, contre lequel il n'avait cessé de conspirer en faveur de la reine légitime O-Puria, l'Oberea de Wallis ; on connaîtéçalement celui du grand prètre Haamenemene, du temps de Pomare II, qui fut assassiné par ordre de la femme de Pomare ${ }^{\text {er }}$, parce qu'il ne cessait de conspirer contre ce chef usurpateur. Le même fait s'est passé aux îles Sandwich, ainsi que le prouve l'usurpation de Tamehameha Ir. Nous avons vu nous-même un fait analogue aux îles Marquises, où probablement, comme dans toutes les autres, il avait dû se présenter plus d'une fois avant l'arrivée des Européens.

Quoi qu'il en soit, à l'époque de la venue de ceux-ci en Polynésie, le titre des premiers chefs n'était bien, comme 
on l'a dit, et comme il l'est encore, que celui d'Ariki, qu'ils fussent légitimes ou usurpateurs. Partout, dans ces îles comme à la Nouvelle-Zélande, la séparatión des pouvoirs était opérée; seulement elle était plus ou moins complète suivant les îles. Dans quelques-unes, le clergé avait encore une puissance assez grande. Mais à peine quelques années se furent-elles écoulées, qu'il ne restait pour ainsi dire plus rien de cette puissance, là mème où les missionnaires européens n'avaient pas eu l'occasion d'agir. C'est ainsi que nous avons pu observer, lors de la prise de possession des îles Marquises, qu'il n'y avait guère de croyants aux anciens dieux, et de respectueux pour les prêtres, que les plus superstiticux de la nation : tous les chefs, grands ou petits, et même les cheffesses, se montraient incrédules (1). Aussi là, déjà, tous les temples étaient-ils presque abandonnés et en ruine. Mais, par contre, il y arait, comme nous avons dit, presque autant d'Hakaïki que de personnes nobles dans la population. En voyant que, pour se distinguer, le premier chef des Teii; protégé par la France, se faisait appeler Hakaiki-nui, a le grand chef, » il est au moins probable que ce mot, dans ces îles, avait ce scns, comme celui d'Haatepeiu pour les femmes titrées ; mais, peut-être, dans l'origine, il n’avait signifié, cornme à la Nouvelle-Zélande, que l'aîné, le chef d'une famille. Après cela, que le mot hakaïki n'ait dû sa conservation dans ces îles, comme le pense M. Gaussin, qu'aux séparations naturelles existant entrc les tribus, ou qu'il soit dû, ccmme nous le pensons, à quelque colonie partie d'une île où régnnait le pouroir théocratique ; que sa conservation ne soit que le résultat d'une pareille origine, aussi bien pour les familles légitimes que pour celles qui se sont mises à leur place, il est bien certain qu'il semble y remplacer le titre Rangatira de la Nóuvelle-Zélande et Raatira des Iles de la Société, íitre qui ne pouvait s'y trouver

(1) Voyez Journal de notre séjour aux Marquises, où nous relatons le récit de nos rapports avec le grand-prêtre des Teii et avec diverses cheffesses ou micux grandes prêtresses de l'ìle. 
puisque les Marquésans n'ont l'usage du $r$ ni du $n g$ (1). Cette absence du dernier mot peut même expliquer l'abondance du mot ariki (hakaiki), quoiqu'elle puisse être due, soit à ce qu'on lui a conservé, aux Marquises, la signification primitive qu'il paraît avoir eue, c'est-à-dire « héritier, chef de famille », en un mot a ainé, mâle ou femelle »; soit encore, comme nous l'avons dit, à ce qu'il signifie «noble », nom qui, du temps de Mariner (2), était, aux îles Tunga, donné à tous les chefs et à ceux qui descendaient plus ou moins directement de la famille du Tui. tonga et de celle du Vea-iti.

En somme, quelle que soit la raison qui ait fait adopter en Polynésie le mot Ariki, qui paraît n'avoir été, en tout temps, à la Nouvelle-Zélande, que le titre des chefs du clerg’é, il est bien certain que c'est le titre que prenaient les chefs polynésiens à l'arrivée des Européens, et que c'est encore celui qu'ils prennent. Ce choix seul fait comprendre comment il se fait qu'aux îles de la Société, les Raatira aient été trouvés une classe inférieure. Pour arriver là il a fallu une longue durée d'un gouvernement théocratique pendant lequel, presque certainement, ont dû s'éloigner les colonies qui sont allées peupler d'autres îles. Un pareil état de choses n'existait évidemment pas aux Iles de la Société depuis un temps aussi long que dans les îles Tunga et Samoa, puisque les Raatira y possédaient encore une assez grande influence comme corps, tandis qu'ils n'étaient pour ainsi dire plus que des espèces de majordomes dans les autres archipels, sous les noms, aux Samoa de Matabole, et aux Tunga de Tulafale.

Fait bien curieux, du reste, mais que nous ne pouvons qu'indiquer ici, les récits des voyageurs ne signalent la classe des Rangatira en Polynésie, et sous ce nom mème, que dans les île.s les plus Sud de l'Océan Pacifique, c'est-à-

(1) Voir ce que nous venons de dire à ce sujet, p. 162, note.

(z) Hariner écrit Egi pour Eiki. 
dire dans celles qui s'étendent depuis la Nouvelle-Zélande de l'Uuest jusqu'à Pâques dans l'Est, et particulièrement dans l'ìle Rarotonga du groupe Hervey (1). Mais il est à peu près certain qu'il y avait partout ailleurs, aux Sandwich comme aux Marquises, une classe analogue, et que cette classe était celle des guerriers, des nobles, menant leurs vassaux à la guerre à l'appel de l'Arii, comme cela s'est pratiqué ailleurs. A Tahiti, elle avait conservé son nom, comme on vient de le voir, mais elle n'était pour ainsi plus que la classe de propriétaires fonciers, et après avoir été enrichie, elle semblait avoir déjà perdu une partie du souvenir de son origine, lors de la venue des Européens. Il suffira de lire ce que disent Ellis et Moërenhoüt du ròle des Raatira dans la société tahitienne, pour en être convaincu.

De tout ce qui précède, il semble résulter, en définitive, que les révolutions qui ont amené plus d'une fois, dans les îles polynésiennes, des usurpateurs à la place des chefs légitimes, sembleraient n'avoir eu pour cause que la nécessité, comme à la Nouvelle-Zélande, de restreindre la puissance des chefs du clergé et de les contraindre à se borner au pouvoir spirituel. Mais là, la révolution a été plus grande qu'à la Nouvelle-Zélande, puisque les chefs militaires ne se sont pas bornés à réduire la puissance des Ariki, en leur enlevant les pouvoirs usurpés par eux et en rendant le clergé un simple moyen de gouvernement, mais qu'ils ont pris jusqu'à leur titre.

Il nous semble enfin que les considérations que nous venons de présenter expliquent mieux la suprématic spirituelle du Tuitonga et du Veachi, que l'hypothèse de MM. Hale et de Quatrefages, pour lesquels cette suprématie provient d'une colonie arrivée directement de Bouro-la-Sainte.

Nous renons d'écrire le mot Veachi : ce mot n'est ni poly nésien, ni maori; comme tant d'autres, il n'est que de

(1) Voir J. Williams, A Narrative, etc. p. 214. 
l'invention de Mariner. On peut voir aux mots chi, chichi. chino-chi, etc., des dictionnairss de cet historien des îles Tunga, que la syllabe chi n'est évidemment que le mot iti; par conséquent, il faut lire Vea-iti, au lieu de Vea-chi, comme le répète Dumont d'Urville lui-même.

Or, vea signifie " porteur de paroles, messager de chef ou de roi »; c'était, pour ainsi dire, le lieutenant du TuiTonga; c'est le Vea-iti qu'on voyait partout, sans doute pour laisser au Tui-Tonga un caractère plus sacré, absolument comme cela se passe dans d'autres contrées. Quant au mot $i t i$, il signifie petit, et est mis ici probablement par antithèse.

Le Vea-iti était toujours le descendant de l'aîné de la famille sacerdotale la plus sacrée ; à Tongatapu, c'était celle des Fatafaï qui donnait le Tuitonga, et ce dernier, quoique grand pontife, était assujetti au baisement des pieds du Vea (1).

Le Vea était, en un mot, une sorte de Tuitonga futur, et c'est pour cela sans doute que, d'après la coutume d'honorer le prétendant à un titre, plus que son père, le Tuitonga lui-même était tenu de lui rendre hommage. En attendant sa nomination, c'était une espèce de lieutenant du Tuitonga, un porteur de paroles.

Puisqu'il faut écrire Vea-iti au lieu de Veachi, il n'est pas étonnant que Mariner, ainsi que le dit Martin, n'ait jamais pu parvenir à découvrir la signification de ce mot, qui n'existait pas. Nous sommes seulement surpris qu'il ne l'ait pas forgée, comme il en a tant forgé d'autres.

Le mot vea n'existe pas plus à la Nouvelle-Zélande que le mot wea; on n'y trouve, s'en rapprochant un peu, que wera, chaud, ètre chaud, brûlé, etc. Existait-il, dans cette

(1) Le Tuitonga et le Veaiti étaient les personnes les plus sacrées. Nous avons vu les chefs éviterle desc sndant des Fatafaï,pour ne pas avoir à se prosterner devant lui. On a comparé avec raison le Tuitonga au Daïri du Japon, au Lama d'ı Thibet et au Pape de Rome, puisque ses fonctions étaient toutes spirituelles. 
contrée, quelque fonction pareille ? Il est certain qu'il y avait dés messagers ; mais on connaît trop peu les usages sacrés des Míaori pour en parler avec quelque exactitude. Messager, à la Nouvelle-Zélande, serend par kaikaiwaiu et korere. Tout ce que nous pouvons dire c'est que, quand on avance que les Arii étaient plus sacrés en Polynésie qu'à la Nouvelle-Zélande, on oublie probablement qu'ils l'étaient eux-mêmes considérablement. Ainsi, d'après Taylor, nonseulement ils étaient sacrés, mais on supposait qu'ils avaientle pouvoir de converser à volonté avec leurs ancêtres les dieux, et de fait, ajoute-t-il, ils étaient eux-mêmes des dieux sur la terre.

De tout ce qui précède, on peut supposer que c'est plutôt la Nouvelle-Zélande qui a peuplé la Polynésie que la Polynésie la Nouvelle-Zélande. Il est bien évident, en effet, que si cette dernière cût été peuplée par la Polynésie, comme on le croit, ce serait le mot Ariki, que les émigrants, une fois à la Nourelle-Zélande, auraient continué d'employer pour désigner leurs chefs, au lieu de le donner aux prêtres ou aux chefs seulement du clergé. On comprend au contraire parfaitement que les Ariki, chassés de l'Hawahiki, se soient contentés de ce titre, en reprenant leur influence dans la Polynésie.

$3^{\circ}$ Jade veri. - La présence du jade vert, jade oriental, néphrite, ou jade néphritique, dans la plupart des îles Polynésiennes, sous la forme de haches surtout, peut être encore considérée comme un témoignnage favorable au peuplement de la Polynésie par la Nouvelle-Zélande. Il paraît certain aujourd'hui que le jade vert ne se trouve sur aucune des îles Polynésiennes proprement dites. Cependant tous les anciens navigateurs ont signalé son existence, sous des formes différentes, dans les diverses îles qu'ils ont visitées; tous ont fait remarquer le prix qu'y attachaient les indigènes, preuve convaincante de sa rareté. On y te- 
nait tant, lors des premiers voyages, qu'il était presque impossible d'en obtenir par échange. Ce ne fut qu'après l'introduction des haches européennes, que les habitants des îles polynésiennes commencèrent à se dessaisir des leurs. Mais, bientôt, à mesure qu'ils apprécièrent davantage le fer, leur engouement pour lui devint tel, qu'ils livrèrent pour ainsi tout ce qu'ils possédaient en jade : aussi aujourd'hui est-il presque impossible d'en rencontrer dans les îles Polynésiennes qui ont été fréquemment visitées.

D'un autre côté, on sait qu'une seule des îles de la Nouvelle-Zélande produit $d u$ jade, et nous avons nous-même entendu dire à d'Urville, par le chef Tehinui, pris par nous dans le détroit de Cook et déposé plus tard à la baie HuaHua, que l'lie-Nord produisait des cochons, mais pas de jade, et que l'Ile-du-Milieu produisait au contraire du jade mais pas de cochons (1). Or, c'est dans l'Ile-du-Milieu que Forster a rencontré des veines de cette pierre, sur les bords du détroit de Cook, et c'est dans cette même île que, d'après Shortland (2), on trouve des échantillons de jade en blocs détachés dans plusieurs des torrents qui descendent des montagnes sur la côte Ouest. Mais les endroits près desquels on en trouve le plus, dit-il, sont Arehura et Ohonu, sur la côte Nord-Ouest; Wakatipua, lac renommé de l'intérieur et l'une des sources de la rivière Matau; enfin Piopiotahi, torrent sur la côte Sud-Ouest de la mème île.

On sait aussi qu'on attribuait au jade une origine sacrée, et que le plus estimé était justement celui du lac Wakatipua, à plusieurs journées de marche dans le Sud-Ouest du détroit de Cook (3). Nous ne rapporterons pas ici toutes les fables débitées à son sujet; mais si nous avions à choisir parmi les légendes maori, nous préférerions celle qui attribue son

(1) D'Urville cite ce fait, t. II, p. 81, des Voyages.

(2) Traditions and superstitions, p. 34.

(3) Voir à ce sujet les traditions publiées par Sir Gruy, Shortland, Taylor, ete. 
origine à Hine-te-Hiwa-Hiwa, la dernière femme de Tinirau, sœur de Rupe : sur le point d'être tuée par les deux autres épouses plus anciennes, elle se défendit en leur jetant des pierres qui, en pénétrant dans leur corps en colère, se changèrent en pierres vertes.

Le jade était si bien borné, pour le groupe de la NouvelleZélande du moins, à l'Ile-du Milieu, qu'on voit, dans les légendes maori, et particulièrement dans Shortland (1), que le désir de posséder le Pounamu, "qui se trouve seulement sur l'Ile-du-Milieu », a poussé les habitants de l'fleNord, les plus voisins, à envahir plusieurs points de l'Iledu-Milieu: ils espéraient s'emparer des lieux produisant cette pierre précieuse. C'est ce que répète Thompson (2), qu. dit aussi que le lac « où il se trouvait, avait ses bords rocheux tout en jade. » Enfin Dieffenbach et Taylor disent eux-mêmes que le jade était produit seulement par l'lledu-Milieu.

Il n'y a donc pas à en douter, pour la Nouvelle-Zélande : c'était bien dans l'Ile-du-Milieu seulement qu'il existait (3). Mais, s'il n'était pas fourni par quelqu'une des îles Polynésiennes, que faudrait-il conclure de sa présence, si commune, sous forme de haches ou d'ornements, dans toutes ces îles ? Evidemment qu'il y aurait été porté par ceux qui le possédaient, c'est-à-dire par les Nouveaux-Zélandais de

(1) Southern districts, p. 99.

(2) The Story of the New-Zealand, t. I, p. 7 et 14.

(3) On verra plus tard que, d'après les traditions, le jade se trouvait possédé par quelques chefs, en Hawahiki. L'un d'eux, Ngahue, fut forcé de s'expatrier avec son bloc de jade, afin de pouvoir le conserver; ilalla le cacherà Arehura, dont le nom rappelle justement un des lieux qui en produisent le plus abondamment sur la côte Ouest de l'Ile-du-Milieu. On verra également que Ngahue, qui possédait du jade en Hawahiki, était d'un endroit voisin de ceux qui le produisaient, et que l'Hawahiki lui-même se trouvait sur l'Ile-du-Milieu, de mème que les rivières et les lacs produisant le jade vert : en effet, ce n'est absolument que sur cette île qu'ont été rencontrés les noms signalés par les légendes. 
l'Ile-du-Milieu, s'arrêtant d'abord sur l'lle-Nord, comme nous le démontrerons, et émigrant ensuite, immédiatement ou plus tard, directement vers les îles polynésiennes. Cela expliquerait parfaitement l'importance que les indigènes attachaient à sa possession lors des premières visites européennes, importance qui devait être d'autant plus grande, qu'il n'y avait pas eu de nouvelles émigrations depuis bien des siècles.

D'un autre côté, si le jade n'avait pu être fourni par quelqu'une des îles Polynésiennes, il est évident qu'il faudrait aussi conclure que l'Hawahiki ne pouvait pas être, comme l'a dit Hale, l'île Savaii, dans les Samoa. On ne comprendrait pas que son possesseur eût déjà fait un voyage si lointain pour se le procurer et que la légende qui donne tant de détails sur le voyage de Ngahue, allant cacher son jade à Arehura, garde sur celui-ci le plus profond silence. Plus tard, nous aurons à revenir longuement sur un pareil sujet; nous nous bornerons à répéter ici que pas un voyageur n'a signalé l'existence du jade dans les îles polynésiennes proprement dites : ni Forster, ni les missionnaires longtemps résidents dans ces îles, ni les voyageurs modernes, n'en ont parlé. Nous-même, pendant une résidence de dix années aux Marquises et dans les îles de la Société, ou pendant nos voyages aux Sandwich, aux Tunga et autres îles polynésiennes, nous n'avons jamais entendu dire que le jade y eût été rencontré à l'état naturel.

On pourrait donc, d'après cela, inférer que le jade a pu être porté en Polynésie par les émigrants qui sont allés s'y établir, quelque fùt leur point de départ. Mais, si aucune île polynésienne proprement dite ne paraît en posséder, on sait aujourd'hui que plusieurs des îles mélanésiennes en contiennent : ce sont la Louisiade, les Hébrides et la Nouvelle-Calédonie. Dans celle-cii, la présence du jade a été constatée par tous les navigateurs, et particulièrement, dans ces dernières années, par M. J. Garnier, ingénieur des mines. Les Nouveaux-Calédoniens, comme les Néo-Zélan- 
dais, dit.il (1), ont su utiliser les rares gisements de jade que possèdent leur île à la confection de haches. Mais auourd'hui ils ont perdu de vue cette industrie, et ils se contentent d'habitude d'attacher à ces instruments des idées superstitieuses. Ils iguorent d'où elles proviennent et désignent toujours, lorsqu'on les interroge à cet égard, un point éloigné de leurs tribus. J'ai cependant été assez heureux pour découvrir le banc d'où l'on extrayait ce jade à la Nouvelle-Calédonie, et reconnaître les points où il avait été fouillé. $n$

C'est sur l'île Ouen, à peu de distance de la NouvelleCalédonie, auprès du sommet du Nogougneto, que M. Garnier rencontra un gisement de jade (?). Le banc de cette roche y affleure le sol sur une longueur considérable. Le chef Zachario lui apprit que cette pierre, avant l'arrivée des Européens, servait à faire les haches et qu'on venait la chercher autrefois des îles Loyalty. Mais des combats acharnés avaient alors lieu entre les étrangers et les habitants de l'île. La pierre, éclatée par le choc en écailles minces et de grande dimension, était polie à l'aide de sables rudes et fins, et l'on percait, avec des cailloux très durs et effilés, les trous destinés à fixer le manche. La vie d'un homme, dit M. Garnier (3), ne suffisait pas toujours à accomplir ce travail. Cependant chaque chef possśdait sa hache et c'était sa plus grande richesse. Pour l'une d'elles, on achetait la paix, on se procurait de grandes pirogues, etc. Avec les petits fragments, on faisait des collier's.

Toutefois la description que M. J. Garnier fait de ce jade ne convient pas complètement à celui de la Nouvelle-Zélande. Ces roches, dit-il, (4) « étaient légèrement translucides, d'un blanc très-pur, au milieu duquel couraient des veines d'un beau vert tendre. "Or le jade de la Nouvelle-

(1) Mémoire sur les migrations humaines en Océanie, p. 58 .

(2) Océanie, les îles des Pins, Loyaity et Tahiti, p. 82.

(3) Ibid. p. 84.

(4) Ibid. p. 82 . 
Zélande, et les haches rencontrées dans les îles Polynésiennes, sont grénéralenient de couleur vert sombre et opaque. Il en est de même des haches de la Nouvelle-Calédonie que nous avons vues. Peut-être existe-t-il dans cette île d'autres gisements restés inconnus à l'habile observateur (1).

Déjà, avant M. Garnier, M. de Rochas, chirurgien de la marine, avait constaté que la serpentine verte est très commune en Nouvelle-Calédonie (2); on pent être convaincu de la vérité do cette assertion, quand on a vu les divers instruments faits avec cette pierre et rapportés en si grand nombre de cette île, depuis son occupation par la France. Mais cette serpentine est-elle bien le jade qui a fourni les instruments et les ornements rencontrés en Polynésie par les premiers navigateurs? Nous avons pu nousmême comparer sur les lieux ces diverses substances, et il nous a semblé que la serpentine de la Nouvelle-Calédonie diffère du jade de la Nouvelle-Zélande, qui esi généralement plus fin et plus beau, et duquel se rapprochent da. vantage les instruments trouvés dans les îles Polynésiennes (3).

(1) M. de Mortillet, en présentant à la Société d'anthropologie, dans la sćance du 3 juillet 1879, la hache de Sinerani, chef de Mare, l'une des I.oyalty, dit : « la hache est en jade vert marbré de vert blanchâtre, roche qui a servi à faire toutes les haches Néo-Calédoniennes. 》

(2) Bull. Soc. d'Anth. vol. I.

(3) On sait que lé jade vert, décrit par le minéralogiste Philip sous le nom de néphrite, existe dans le Hartz, la Corse, la Chine, l'Egypte, et on vient de le voir, dans l'Ile-du-Milieu de la Nouvelle-Zélande, la Louisiade, les Hébrides et la Nouvelle-Calédonie, s'il est le même que la serpentine. M. Schlagintweit en trouvé des carrières dans les chaines de la Haute-Asie. « Ce minéral, dans l'état de pureté où il se présente, est si rare et si estimé, dit il, que, malgré les longueur's et les périls du voyage, on vient l'exploiter chaque année, dès que la saison permet de. séjourner dans ces déserts élevés. » Les carrières les plus riches visitées par lui dans le Künlün, sont celles de Goulbagashen, par 
Shortland a vu travailler le jade pendant son long séjour dans la Nouvelle-Zélande. Voici ce qu'il écrit à ce su-

$36^{\circ} 9^{\prime}$ Lat. N. et $7 \% \circ{ }^{\prime} \supset^{\prime}$ Long. E. Green., et à une élévation de 12252 pieds anglais. Les Tourkezas donnent à cette pierre le nom de Yashem. (Comptes-rendus du Congrès international d'anthropologie et d'archéologie préhistoriques, tenu à Paris en 1867.)

M. Blondel, dans son Etude historique, archéologique et littéraire (Paris, Leroux, 18\%5), apprend que le jade est appelé Yu par les Chinois et que ses principaux gisements en Chine sont Taï-Thong et les environs de Klotan dans la Tartarie Chinoise. Khotan est même nommé Yu-Thien, c'est-ì-dire, « pays du jade. » Il raprelle que le jade est commun en Russie, dans le Groënland, la Turquie, la Pologne et la Suisse.

D'après l'auteur, la différence serait grande entre les jades de la Chine, du Japon et de l'Inde, et ceux de l'Océanie. «Quant aux prétendus jades d'Europe, d'Amérique et d'Océanie, qui portaient autrefois le nom de jade de Saussure, et prennent en. core aujourd'hui celui de jadéite ou néphrite, ce sont des variétes très inférieures de feldspath compacte. 》(Ouvr. cite, p. 1\%.)

De tout temps le jade a été pour les Chinois la matière des amulettes les plus précieuses. On y attachait des idées superstitieuses qui ont conservé leur caractère jusqu'i notre époque. Lo précieux Lui-Ko:ıng.Chi, Pierre du Dieu du Tonnerre, que le prêtre bouddhiste Ni-tchingr-jou donna à l'Empereur Son-Troung au s: siècle de notre ère, était formé par deux morcenux de néphrite verte ayant la forme d'une hache polie.

M.M. Damour et Fischer ont publié, dans la Revue archéologique de juillet I878, une « notice sur la distribution geographique des haclies et autres oojets en jade néphrite et en jadéite. »

Les gisements de ces deux substances minérales sont très rares. On n'en connaît de bien constatés que sur un petit nombre de points du Continent asiatique et de quelques îles de l'Océanie. D'après La Condamine, il en existe probablement aussi en Amérique, dans les alluvions du fleuve des Amazones. On n'en cite aucun en Europe ni en Afrique. C'est ce qui a porté plusieurs archéologues à émettre l'opinion que les haches et autres objets préhistoriques en jade néphrite et en jadéite, recueillis journellement dans nos contrées, ont été importés par des peuplades qui ont émigré du continent asiatique vers les diverses régions de l'Europe. D'autres archéologues, au contraire, pensent que si l'on ne retrouve plus actuellement ces gisements dans nos régions, c'est parce qu'ils ont été épuisés par les hommes des premiers âges du monde, ou qu'ils ont disparu ensevelis sous des éboulis ou des alluvions modernes. Peut-être alors, pourrait-on, par des 
jet (1): "Pour rechercher cette pierre, les indigènes des autres lieux avaient à faire de longs voyages et à traverser les montagnes de l'Est à l'Ouest. Quand ils s'en étaient procuré, ils la façonnaient et la polissaient en la frottant sur des blocs plats de pierre de sable. Cela n'est pas un mince travail, et il faut souvent deux générations pour finir une pareille arme : d'où sa grande valeur, qui est aussi due à I'extrême dureté de cette pierre, ce qui permet de lui donner un bord très tranchant.

* Quelques-uns ont répandu l'étrange croyance, que les naturels trouvaient cette pierre dans un état de mollesse ; on ne savait pas qu'ils avaient pu trouver l'art de la faconner d'une autre manière. M. Banks et le capitaine Cook avaient exprimé aussi leur surprise, en se demandant comment ils y parvenaient avec une pierre, si dure, qu'elle était capable de résister au fer. Mais la pierre de sable la coupe aussi facilement que ferait le fer; on y pratique des trous à l'aide d'un peu de sable fin dur et d'eau et d'un bâtonnet pointu, par un procédé simple, etc. » (2).

"Un fait surprenant, dit M. Schlagintweit, (3) c'est que le jade est si tendre, en sortant de la carrière, qu'on le raye avec la pointe d'un couteau et qu'on peut le faconner etle polir avec un autre morceau de jade déjà exposé à l'air depuis quelque temps. Mais il durcit rapidement: quelques semaines suffisent à le changer presque complètement.» M. Blondel, de son côté (4), après avoir cité le jade vert sombre qui vient de Sumatra, de l'Amérique du Sud et de

recherches persévérantes, retrouver ces gisements sur les terrains qui les récèlent encore. (Voy. Comptes-rendus de l'Académie des sciences, t. LXI, 21 et 28 août I865; Matériaux pour l'histoire de l'homme, 1866 et 18\%8.)

(1) The Southern districis of New-Zealand, p. 36.

(2) Shortland décrit et figure ce procédé à la page 118 de son ouvrage.

(3) Congrès international d'Anthropologie et d'Archéologie préhistoriques, Comptes-rendus, Paris, 1867.

(4) Etude historique, archéologique et littéraire, Paris, 1875. 
la Nouvelle-Zélande, parle aussi de la croyance des indigènes de cette dernière contrée, qui prétendent que le jade est retiré d'un lac, à l'état de vase malléable comme de l'argile, et qu'il ne prend sa dureté qu'à l'air extérieur. Mais, pas plus que Shortland, il ne croit à cette assertion, et il rapporte le procédé employé en Chine pour le travailler. Ce procédé est le même que celui des Néo-Zélandais, mais il est moins grossier.

Nous sommes également de cet avis, car nous avons vu travailler aux Marquises des pierres presque aussi dures que le jade, telles que des trachytes, des basaltes, etc. On sait du reste, que les haches ou Mere, à la Nouvelle-Zélande, ne sont pas faites uniquement avec le jade, et que d'autres roches, évidemment déjà dures quand on les faconne, sont employẻes à cet usage. Il nous resíe encore un Mere de l'une de ces roches.

Quoiqu'il en soit, si la serpentine de la Nouvelle-Calédonie et des Hébrides était la même pierre qui porte le nom de jade à la Nouvelle-Zélande, il faudrait bien reconnaître que les îles polynésiennes auraient pu se la procurer sans avoir recours à l'Ile-du-Milieu de la Nuuvelle-Zélande. Mais alors cela indiquerait que des rapports avaient nécessairement lieu, à une époque assez éloignée, entre les îles polynésiennes, puisque celles-ci possédaient tant d'objets en jade à l'arrivée des premiers navigateurs Européens.

- On sait que l'une des îles Hébrides porte le nom polynésien de Futuna, ce qui, de même que sa population et son langage, atteste que lî̀le a dû probablement ètre occupée de bonne heure et longtemps par des Polynésiens. Jans quel 'but? Nous n'oserions dire que c'était pour être à même de se procurer plus facilement du jade et l'échanger avec les Polynésiens des îles plus à l'Est et plus au Sud; mais ii est certain que les Polynésiens de ces îles connaissaient parfaitement Futuna et que les légrendes conservées citent fréquemment le nom polynésien de cetto île, qui est l'île Erronan des cartes. C'est dans cette île que Ko-moala a été porté par un coup de vent depuis les Fiji ; or comme son 
canot y a été saisi avec son chargement de bois de santal, on doit inférer que l'île, a cette époque assez rapprochée de nous, n'avait, comme Lakemba, dans les Fiji, qu'une colonie de Polynésiens, et que la majorité de sa population était de race mélanésienne.

On voit figurer, au n 58 de la carte de Tupaia, une île désignée par le nom de O-Reeva-Va ou O-Reeva-Vai. Forster, d'après Tupaia, fait remarquer que c'était de là que Raiatea tirait ses belles haches. (1) a On ne sait pas, ajoute-t-il, s'il parlait de haches en fer, ou de haches en pierres. Si c'étaient des haches en fer, elles devaient avoir été portées par Tasman, qui était dans ces parages en 1642, ou par Schouten et Lemaire, en 1616. "Il n'y a pas à en douter, il ne s'agissait que de haches en pierre. Comme l'île Manaia est encore renommée par la confection de ses laches, ou du moins par la solidité et l'ornementation des manches qu'on leur applique, nous avions été porté d'abord à ne voir dans l'île 0-Reeva-Vaï de la carte de Tupaia, que l'île Manaia des îles Hervey. Mais, en réfléchissant que Futuna était si bien connue des Polynésiens, et qu'elle est si voisine de la Nouvelle-Calédonie, où se trouvent des mines de serpentine ou jade, nous nous demandons aujourd'hui, si cette île O-Reeva-Vaï, ne serait pas la Nouvelle-Calédonie elle-même. On la voit figurer sur la carte de Tupaia, sous le $\mathrm{n}^{0}$ 59, au Nord d'une île Taïnuna; mais comme la carte est renversée, elle devrait ètre plus Sud, et si Taïnuna était, comme nous le croyons, l'île Futuna, ce serait une probabilité de plus, car l'une et l'autre occupent bien la limite Ouest sur la carte, et jamais les navigateurs n'ont rencontré ni signalé d'île appelée Taïnuna.

D'un autre côté, c'est en vain que les voyageurs ont cherché à se procurer le nom indigène de la Nouvelle-Calédo-

(1) Cette île git par 19031' et $167^{\circ} 46^{\prime}$. Forster le premier a signalé ses habitants comme étant de race polynésienne. Il a reconnu au contraire le langage mélanésien dans l'île voisine appelée Annaton; mais il est presque certain que la majorité des hakitants de Futuna étaient mélanésiens et parlaient le mélanésien. On a déjà vu que deux autres îles du même nom existent en Polỵnésie. 
nie : jamais on ne leur a donné que des noms de localités Nous-même, malgré nos instances, nous n'avons pu parvenir à obtenir le nom geénérique de cette île. Vainement, depuis que nous sommes de retour en France, nous avons prié plusieurs de nos amis et connaissances de nous renseigner à ce sujet: pas un, jusqu'a ce jour, n'a pu obtenir de réponse satisfaisante. Pourtant ce nom a dî exister, autrement ce serait la seule exception de ce grenre. Op l'étymologie des mots O-Reeva-Va ou O-Reeva-Vaï s'applique parfaitement à la Nouvelle.Calédonie, terre élevée, hachée, coupée sur les bords, à mer profonde, et où les pins paraissent se dresser comme des mats de navire (1).

Que cette supposition soit exacte ou non, il est certain que si la serpentine de la Nouvelle-Calédonie et des îles Hébrides est la même que le jade de la Nouvelle-Zélande, les Polynésiens auraient pu se procurer cette pierre sans avoir besoin de la recevoir de la Nouvelle-Zélande. Mais il reste à savoir si la pierre désignée sous ces noms par les voyageurs est bien la même. Ce qui pourrait peut-être le faire croire, c'est qu'il existe à la Nouvelle-Zélande des jades de qualités différentes, se distinguant par leurs nuances et leur transparence, ayant des noms particuliers et une valeur relative (2). La grande quantité d'instruments et d'ornements en jade qui a été vue en Polynésie par les premiers navigateurs, serait elle-même favorable à cette opinion. Mais, quoiqu'il en soit, si nous parvenons à démontrer que la Polynésie a été peuplée par la Nouvelle.Zélande, il faudra bien admettre au moins que les émigrants y

(1) En Tahitien, o, c'est, il y a ; reva, abîme, profondeur inconnue; vaï, eau; $v a$, grain, chute de pluie subite.Rivarira, beaucoup, abondant; rivarivaitau, abondant.

En Mari, rewa, mat de navire, être élevé ; riwha, crevasses fentes, être haché, coupé, rompu ; wa, pays, contrée; wai, eal.

(2) Le plus estimé y est appelé kahu rangi, vêtement du ciel. M. Shortland, ( $\rho .34$. South. districts) décrit celui du chef Te Heuheu, à Taupo : il était de couleur vert pâle, mélangé d'opale, présentant une apparence ondée, comme celle d'un maquereau azuré, et transparent sur les bords. 
arrivaient avec leurs propres instruments et ornements de jade ; car les Néo-Zélandais marchent encore moins que les autres Polynésiens sans leurs armes.

En résumé, que le jarde trouvé en Polynésie ait été apporté de la Nouvelle-Zélande, ou qu'il soit venu de quelque île Mélanésienne plus voisine des îles Polynésiennes, il est certain qu'à l'arrivée des Européens, il était très répandu dans ces dernières îles, quoiqu'elles n'en produisent pas. On peut donc en inférer que des relations avaient nécessairement dû exister, et existaient peut-être encore à ce sujet, entre les îles Polynésiennes et les îles Mélanésiennes.

4. Coutume d'avaler l'œil de la victime. - La coutume d'avaler l'œil de la victime, lors des sacrifices humains, ou d'en faire le simulacre, nous semble pouvoir être également invoquée en faveur de l'opinion que nous soutenons.

Tous les voyageurs anciens ont signalé cet usage aux Sandwich, à Tahiti, et dans plusieurs autres îles de la Polynésie.

Or, à la Nouvelle-Zélande, c'est dans l'œil, et particulièrement dans l'œil gauche, qu'on place le siége de l'âme : en avalant l'œil, on croit mieux anéantir le Waïrua, souffle, esprit, âme de son ennemi.

C'est donc une même coutume dans toutes les îles, et elle provient évidemment de la même source.

S'il est vrai qu'un chef de la Nouvelle-Zélande, au moment même où il vient d'abattre son ennemi, lui arrache l'œil gauche et l'avale dans le but que nous venons d'indiquer, ne doit-on pas supposer que cette coutume provient de la Nouvelle-Zélande plutôt que d'un archipel de la Polynésie? Il est, en effet, plus naturel d'admettre qu'elle a pris naissance parmi des hommes plus guerriers, quoique de la même race, et restés anthropophages jusqu'à une époque très voisine de la nôtre, que de l'attribuer à des populations à mœurs plus douces, telles que celles de Tahiti, des Samoa et des Tunga. Lors de la découverte des îles de la Société, il y avait longtemps déjà que les Tahitiens 
avaient cessé d'être anthropophages ; mais ils avaient conservé l'usage des sacrifices humains dont ils étaient même prodigues, comme aux Marquises et aux Sandwich; ils avaient conservé particulièrement celui de faire le simulacre d'avaler l'œil, afin d'attester le droit du vainqueur.

\section{$5^{\circ}$ Absence des Polynésiens à la Nouvelle-Hollande et des} Australiens à la Nouvelle-Zélande. - L'absence apparente de toute colonie polynésienne ou néo-zélandaise en Australie prouve, en faveur du peuplement de la Polynésie par la Nouvelle-Zélande, beaucoup mieux que tous les autres faits.

Cette absence de colonies polynésiennes sur les rivages, le plus souvent déserts. de l'Australie, serait inexplicable si le peuplement de la Nouvelle-Zélande s'était opéré, comme le dit M. Hale, par des émigrants venant de Savaii, ou, comme le dit M. de Quatrefages, par des émigrants partis, en dernier lieu, des îles du groupe Hervey de Cook. On sait que les vents d'Est, de Nord-Est, et mème de Sud-Est d'après d'Urville, qui sont nécessaires pour atteindre la Nouvelle-Zélande, en partant des Samoa, sont si violentr. parfois, qu'ils entraînent malgré elles les pirogues, et qu'ils les poussent tantôt aux Tunga, tantôt aux Fiji, tantôt aux Hébrides, comme le prouve la grande majorité des faits d'entraînement. Il est donc probable que, si telle avait été la provenance des émigrants, ils auraient presque nécessairement, en aussi petit nombre que l'on voudra, été en-traînés, jetés sur les côtes de la Nouvelle-Hollande, pas suite de sa position et de son étendue. Or, aucun navigateur n'en a jamais cité un seul exemple; les renseignements obtenus depuis les premiers voyages, n'en disent absolument rien non plus, et il est à remarquer que les traditions de tous les archipels polynésiens, aussi bien que celles de la Nouvelle-Zélande, se taisent également à ce sujet. Enfin il n'y a que deux mots à peu près analogues à deux mots polynésiens (1). C'est, sur cette terre, le seul vestige de la

(1) Voy. Parkinson, ler Voyage de Cook, p. 233. On sait que ces deux mots sont Hale mai et Aita. Voyez ci-dessus, vol. I, p. 103. 
langue polynésienne : d'oủ l'on peut inférer, ̀̀ priori, que les migrations n'ont pas pu se faire avec des vents de la partie de l'Est.

Mais ce ne sont pas les Polynésiens seuls qui font défaut, sur les côtes Estet Sud -Est de l'Australie. On n'y a pas plus trouvé de colonies zélandaises que de colonies polynésiennes; d'Urville s'appuyait même sur ce fait pour nier le peuplement de la Polynésie par les Maori.

Evidemment, pour que pareils faits aient pu se présenter, il a fallu qu'il existât une impossibilité matérielle : cette impossibilité n'a été que la direction et la force des rents qui ont servi aux migrations.

Qu'on jette les yeux sur la carte, et l'on verra qu'en partant de Ja Nouvelle-Zélande avec des vents soufflant entre le Nord-Ouest et le Sud-Ouest, vents qui sont les plus forts et les plus fréquents, il était impossible aux émigrants de toucher à la Nouvelle-Hollande, tout en faisant route à l'Est, ou même au Nord-Est et au Nord : à peine partis, les canots se trouvaient avoir doublé le point de la Nouvelle-Hollande qui se trouve plus à l'Ouest que la NouvelleZélande. Cela explique suffisamment comment il se fait que pas un Maori n'ait été trouvé sur les côtes de la NouvelleHollande. Mais, de plus, cela explique, ce qui ne nous semble pas avoir encore été remarqué, que la dispersion des Polynésiens ne s'est opérée, pour ainsi dire, que d'un seul côté de l'Océan Pacifique, et ce fait montre lui-même qu'il n'a pu être produit que par des vents de la partie de l'Ouest.

En somme, l'absence des Polynésiens et des NouveauxZélandais sur les bords du grand continent australien, vient donc, à notre avis, prouver plus en faveur des migrations maori vers la Polynésie qu'en faveur des migrations polynésieunes vers la Nouvelle-Zélande. Elle s'explique parfaitement, en admettant la Nouvelle.Zélande comme point de départ des migrations, tandis, au contraire, qu'elle est inexplicable si l'on admet, avec Hale, que les migrations qui ont peupié la Nouvelle-Zélande sont venues des Samoa, arec Disffenbach des Sandwich, avec d'Urville de Tahiti, 
et mème des îles Hervey avec M. de Quatrefages. Dans le premier cas, les vents qui ont emporté les émigrants suffisent, seuls à expliquer les faits; dans le second, il serait impossible de comprendre que quelques pirogues au moins n'eussent pas été jetées sur quelque point de la côte orientale de l'Australie. (1)

Quant à l'absence d'indigènes de la Nouvelle-Hollande à la Nouvelle-Zélande, absence qui pournous est un fait presque certain, quoiqu'en aient dit quelques écrivains, elle estencore plus facile à expliquer. En effet, quand il n'y aurait pas eu manque complet de moyens de transport, les vents d'Ouest et de Nord-Ouest, qui auraient pu les conduire à la Nouvelle-Zélande, soufflent avec trop de violence, et ceux du Nord sont trop dangereux, pour que les indigènes aient jamais pu oser s'aventurer sur la mer pendant leur durée. Nous avons déjà dit, d'ailleurs, que les Australiens ne sont pas navigateurs.

Peut-être peut-on voir, dans les lignes suivantes de Shortland, un témoignage en faveur de la possibilité des migrations maori vers la Polynésie. Après avoir parlé de l'émigration qui s'est probablement faite d'Hawahiki cinq ou six cents ans auparavant, il ajoute (2): "On dit que plusieurs canots partirent à la même époque pour aller à la recherche de nouvelles terres. Une partie seulement de ces canots toucha à la Nouvelle-Zélande (Ile-Nord), et chaque endroit où les canots étaient halés à terre devenait la propriété des équipages qui, de ce centre, irradiaient sur les districts les plus fertiles, jusqu'au moment où ils devenaient des tribus nombreuses. »

Shortland ne dit pas ce que devinrent les autres canots qui n'atteignirent pas l'Ile-Nord de la Nouvelle-Zélande;

(1) Comme on l'a vu dans le premier volume, nous admettons pourtant que les Polynésiens ont contribué à la frrmation des Australiens, en arrivant dans l'Australie, soit par la NouvelleGuinée, et les îles de la Mrlaisie, d'abord pauplées par eux, soit par des colonies directes, bientôt absorbées par la race noire préexistante.

(2) Ouvr. cité, p. 304. 
on peut en conclure qu'ils allèrent ailleurs chercher une nouvelle patrie. Dès lors, n'est-il pas supposable que quelques-uns de ces canots, entraînés par les vents, auraient pu être portés dès cette époque jusqu'en Polynésie? Si l'Hawahiki était bien placé là où nous le croyons, ce serait évidemment une probabilité de plus.

Aucune tradition ne faisant allusion à ce fait, il est bien à regretter que Shorlland n'ait pas précisé la source de ses renseignements à ce sujet; mais il nous semble que la conjecture que nous faisons n'est pas sans vraisemblance, si on rapproche son assertion de cet autre fait, rapporté par les traditions, que quelques canots, venant d'Hawahiki, lors de la grande émigration, n'ont pu aborder à l'Ile-Nord parce que les populations primitives s'y sont opposées : tel, par exemple, le Pangatoru, commandé par le chef RakiWananga-Ora, sans qu'il soit dit où il alla ensuite, pas plus que le canot de Ruaeo, le Pukea-te-awanui, etc.

Dans ce cas, les émigrations pour la Polynésie seraient contemporaines de celles d'Hawahiki à l'Ile-Nord de la Nouvelle-Zélande. Mais, comme on verra, il est possible qu'il y en ait eu de bien antérieures, en outre de celles qui ont été postérieures. 


\title{
CHAPITRE TROISIÈME.
}

\author{
EXAMEN LINGUISTIQUE.
}

Comparaison du Maori et des dialectes polynésiens. - La langue maori est la langue polynésienne la moins altérée. - Opinion de M. Gaussin. - Opinion de M. John Williams. - Tradition relative au peuplement de Rarotonga. - Chant d'Oromea. - Le Maori était la langue primitive des Polyrésiens. - Alphabets des principaux archipels polynésiens: Nouvelle-Zélande ; Tunga; Samoa ; Rarotonga ; Tahiti ; Mangareva ; Paumotu; Marquises; Sandwich. - Ces alphabets dérivent tous de celui de la Nouvelle-Zélande. - Le Maori est la langue-mère des dialectes polynésiens. - Les noms de lieux en Polynésie ont une origine Néo-Zélandaise. - Conclusions. - Fables Néo-Zélandaises.

Ainsi donc, de toutes les inductions tirées jusqu'ici du rapprochement de certains faits et de certains mots, il résulte déjà, suivant nous, quelques probabilités en faveur de notre hypothèse. Mais ce ne sont pas les seuls témoignages. Nous allons maintenant en demander de plus précis encore à la linguistique qui, si elle n'est pas, comme on l'a cru longtemps, le plus sûr moyen d'arriver à la solution de l'origine des peuples, est du moins, chez les populations sans annales, celui qui aide le plus ì suivre leurs migrations.

Or tous les mots polynésiens, malgré leur changement d'orthographe avec le temps, ont non-seulement la plus grande analogie avec ceux de la Nouvelle Zélande, ce qui prouve leur origine commune, mais ils ont jusqu'à la mème signification : ces derniers ont donc dû être les seuls parlés à l'époque des migrations, ce qui prouve qu'ils étaient la langue primitive. 
Nous ne pouvons entrer ici dans les développements que nécessiterait un pareil sujet, pour qu'il fùt accepté sans conteste; nous nous bornerons à dire quelques mots sur la langue de la Nouvelle-Zélande, que nous comparerons rapidement avec les dialectes des archipels polynésiens. Cela suffira, nous l'espérons, pour démontrer que le Maori était bien la langue mère. Nous renverrons d'ailleurs, pour tout ce qui appartient à la grammaire, au savant travail de M. Gaussin sur les dialectes polynésiens et à nos introductions aux vocabulaires Tahitien et Zélandais, que nous̃avons traduits.

M. Gaussin (1) regarde le dialecte de la Nouvelle-Zélande comme étant un des dialectes polynésiens qui a subi le moins d'altération. Il attribue ce résultat à la. nature du climat, à l'activité des habitants et à l'étendue de la population. "Cette conservation des sons, ajoute-t-il, concorde d'ailleurs avec celle des formes grammaticales. Par une étude plus approfondie, on établirait peut-être que ce dialecte se trouve en progrès sur les autres.»

Déjà il avait dit, en parlant de la préposition kei : (2) « Ce n'est pas le seul cas où ce dialecte présente plus de ressources, pour répondre aux besoins de la pensée ; la population, plus nombreuse à la Nouvelle-Zélande qu'ailleurs, a dû, en effet, conserver, plus facilement que celle des autres îles, les richesses du langage primitif. »

Ainsi il reconnaît non-seulement la grande analogie de la langue maori avec ce qu'il appelle la langue primitive parlée par les Polynésiens, avant leur dispersion sur les îles qu'ils occupent maintenant, mais aussi sa supériorité mème sur les autres dialectes polynésiens, quoique cette langue ne suit pour lui que l'un des dialectes, l'un des débris de celle qu'il appelait a langue polynésienne. »

« On peut dès maintenant, dit-il à ce sujet (3), se rendre compte, en considérant chaque dialecte comme étant composé des débris dune langue plus raste, qui serait encore

(1) Du dialecte deTahiti, etc., p. $26 \%$.

(2) Id. p. 196.

(3) Ouvrage cité, p. $\%$ 
parlée aujourd'hui intégralement, avec quelques altérations dans sa pureté, non plus en un seul lieu et par un seul peuple, mais dans les différentes îles et par l'ensemble des peuples de la Polynésie. C'est cette langue que nous appelons la langue polynésienne. Les diverses variations des différents dialectes, ajoute-t-il (1), concourent à nous démontrer la vérité de l'hypothèse que nous venons de faire, savoir, celle d'une langue primitive parlée par les Polynésiens arant leur dispersion. Nous n'entendons rien préjuger sur le point de départ qui a pu être soit l'une de ces îles mêmes, soit une autre île située plus à l'Ouest. ’

Enfin, M. Gaussin montre clairement plus loin (2) qu'il est possible de reconstruire, "avec certitude ", la langue mère des Polynésiens, le langage primitivement parlé par leurs ancètres.

Mais, qu'est-ce qui permet cette reconstruction? Tout simplement lit lang'ue, ou ce qu'il appelle le dialecte maori.

Il n'est pas supposable que M. Gaussin ne l'ait pas vu. S'il s'en est apercu, comme semblent l'attester les citations que nous avons faites, pourquoi, dans tout son livre, s'est-il abstenu de l'indiquer? Pourquoi n'a-t-il pas disting'ué le dialecte maori, comme il a distingué, dans tous ses exemples, les dialectes tahitien, marquésan et autres ? Car c'est un fait bien à remarquer : excepté dans des cas assez rares, ce dialecte n'a pas été mis en regard des autres comme terme de comparaison.

Mais pourquoi surtout n’a-t-il donné, pour mots de la langue reconstituée et appelée par lui primitive ou polynésienne, que des mots maori? Oar ce qui n'est pas moins remarquable, tous les mots intitulés par lui « polynésiens , ne sont que des mots maori: tels sont liumara, punga, rakau, ariki, etc.

Serait ce qu'en reconnaissant le rapport plus grand de ces mots avec ce qu'il appelle la langue primitive, M. Giaussin n'aurait pas trouvé que ce rapprochement fût assez

(1) Ibid. p. 9 .

(2) Ibid. p. 23, 2' . 
grand pour faire du Maori une langue? (1) Muis alors pourquoi ne pas traiter ce qu'il croit être le dialecte polynésien le moins altéré, c'est-à-dire le dialecte maori, comme les dialectes tahitien et autres? Pourquoi ne pas les mettre en regard comme exemples comparatifs ? Pourquoi surtout, en s'abstenant, ne prendre justement, pour type de la langue polynésienne, ancienne ou primitive, admise par lui, que les mots de ce dialecî maori?

En définitive, du choix fait par M. Gaussin, et même de son silence, il n'y a guère, croyons-nous, qu'une conclusion possible : c'est qu'il a bien reconnu que la langue, ou comme il l'appelle, le dialecte maori, était le plus proche de sa langue primitive, mais qu'il lui a été impossible, après avoir admis l'hypothèse de Hale sur le peuplement de la Nouvelle-Zélande par la Polynésie, de faire de cette langue autre chose qu'un simple dialecte polynésien.

Et cependant il se sert de cette langue pour reconstituer celle qu'il croit avoir été la langue mère ; et il ne paraît pas éloigné de regarder cettc dernière comme ayant existé et pris naissance en Malaisie, de même que ceux qui l'auraient portée dans la Polynésie. Mais, on en conviendra. du moment que cette langue primitive pouvait être reconstituée avec le dialecte maori, il semble qu'il eût été plus simple de regarder le Maori comme la langue mère.

Pour nous, c'est aujourd'hui un fait certain. Le dialecte maori n'est que la fameuse langue primitive tant cherchée par les ethnologues et surtout par Crawfurd. Avec elle, tous les dialectes polynésiens sont expiiqués. Ainsi, si comme le dit M. Gaussin, les mots tahitien toï et marquésans taki, tahi, « pleurer, » ne rappellent plus que le son ngi, de tangi, quelle est la langue, ou pour nous servir de l'expression consacrée à son sujet, quel est le dialecte qui pos-

(1) Faisons remarquer ea passant que le R. Taylor dit (p. 7) que « l'abondance, la richesse du langage maori, sa grande affinité, non-seulement par les mots, mais aussi par la grammaire avec le Sanskrit, font remonter à une époque où la littérature ne devait pas être inconnue. 
sède le mot tangi? Toujours le langage de la NouvelleZélande.

M. de Bovis, dans son mémoire sur l'état de la société de Tahiti, avait déjà dit, à propos du peuplement des îles : “Cependant les habitants parlent bien la même langue et appartiennent bien à la même race. Vous trouverez dans l'un des idiomes quelques aspirations, quelques contractions de plus ou de moins, mais si vous restituez la lettre omise ou l'aspiration tombée en désuétude, ce sera tout-à-fait la même langue. Il y a si peu à s'y méprendre, qu'une grammaire polynésienne, dans laquelle on prendrait, par exemple, le Tahitien pour base, parce que c'est la langue où il y a le moins de lettres, et où on placerait au-dessus des mots certaines lettres en caractères rouges, noirs ou verts, selon qu'elles appartiendraient anx Sandwich, à la Nouvelle-Zélande ou à T'ahiti, pourrait servir de grammaire générale pour les trois pays, en y comprenant les Paumotu. ๖

Personne ne doute plus aujourd'hui de l'analogie des dialectes polynésiens entr'eux; mais ce qui n'avait pas été remarqué jusqu ici, croyons-nous, c'est que, sans recourir aux divers archipels pour former une grammaire comme l'indique M. de Bovis, il suffit, comme l'a prouvé M. Gaussin par les mots quil a cités, de s'adresser à la langue maori qui, suivant les localités où elle est parlée sur les deux grandes îles de la Nouvelle-Zélande, emploie ou supprime l'une ou plusieurs des lettres que suppriment ou emploient plus particulièrement certains dialectes de la Polynésie : telles sont, les lettres $l, n, n g$, $v$, etc. C'est ainsi que, suivant les localités, le mot « homme », à la Nouvelle-Zélande, se rend par tangata, tanata, kakata. Aussi M. W. Williams, l'auteur du dictionnaire maori, reconnaît-il un grand nombre de dialectes à la Nouvelle-Zélande : le Waikato, le Rarewa, le Tauranga, le Cap-Est, le Ngatitoa, le Ngapuhi, etc.

L'erreur de M. Gaussin nous ayant parủ manifeste, nous avons voulu la signaler ici, afin d'appeler l'attention des linguistes sur ce sujet si important. Mais, en attendant qu'elle soit démontrée, nous croyons pouvoir conclure, de 
tointes les recherches et observations que nous avons faites, que le Maori, ainsi que les indigènes de la Nouvelle-Zélande appellent leur langue, est non pas, comme on l'a dit, l'un des dialectes polynésiens, mais bien la lang'ue mère de tous les dialectes de la Polynésie; autrement, en paraphrasant la conclusion de M. Gaussin, nous croyons que chaque dialecte polynésien se trouve composé des débris d'une langue principale, encore parlée aujourd'hui, intégralement et sans altération, par un peuple qui n'est autre que celui de la Nouvelle-Zélande.

On verra, du reste, au fur et à mesure que nous avancerous, quelles sont les bases principales de cette conclusion. Nous allons maintenant faire connaître ici l'opinion de John Williams sur l'analogie du langage des îles Hervey avec celui de la Nouvelle-Zélande, et sur son analogie plus grande avec le langage maori, qu'avec tous les autres dia. lectes polynésiens.

M. J. Williams avait longtemps résidé dans le groupe des îles Hervey; il avait visité à peu près tous les archipels de la Polynésie, ainsi que la Nouvelle-Zélande; il avait mème pu comparer les Mélanésiens aux Polynésiens en allant se fixer dans l'une des îles Hébrides, où, comme on sait, il fut tué par les indig̀ènes : pour toutes ces raisons, son opinion est de la plus haute importance.

Or voici ce qu'il dit: « Le dialecte des îles Hervey est non-seulement parlé dans ce groupe, mais aussi dans celui de Maniki (1), dans les îles Paumotu, et même dans l'archipel des Gambier. » Et il ajoute : «Ce dialecte diffère très peu de celui de la Nouvelle-Zélande. » Il trouve même qu'il est plus original, et qu'il a une affinité plus grande avec les dialectes de la Polynésie qu'avec celui de Tahiti. Il fait en outre la remarque que le dialecte des îles Hervey et de Rarutonga se distingue du Tahitien par deux particularités : par le rejet des lettres $f$ et $h$, et par l'usage du $k$ et du $n g$. Enfin, il termine en disant: $(2)$ \& Le dialecte des Nou-

(i) Le groupe Maniki n'est autre que le groupe d’ìles appelées Humphrey sur les cartes.

(2) Ibid. p. 534 . 
veaux-Zélandais est, dans sa principale particularité, semblable à celui de Rarotonga ; la seule différence étant que les Nouveaux-Zélandais se servent $d u h$, qui n'est pas employé par les habitants de Rarotonga. "

Il cite, comme exemples, quelques mots, à côté desquels nous placerons les mots pareils usités à la Nouvelle-Zélande, afin 'de montrer quel est le degré d'analogie entre ces dialectes :

$\begin{array}{llll} & \text { Tahiti } & \text { Iles Hervey } & \text { Nouvelle-Zélande. } \\ \text { Pirogue } & \text { Vaa } & \text { Vaka } & \text { Waka } \\ \text { Maison } & \text { Fare } & \text { Are } & \text { Whare } \\ \text { Nourriture } & \text { Maa } & \text { Manga } & \text { Oranga } \\ \text { Affection } & \text { Aroha } & \text { Aroa } & \text { Aroha }\end{array}$

Après cela, M. Williams n'hésite pas à voir le pays d'origine des habitants des îles Hervey, dans Tahiti et les îles Samoa. Une tradition, obtenue par lui à Rarotonga même, ne laisse, dit-il, aucun doute à cet égard.

Naturellement, depuis, tous les ethnologues et plus récemment encore M. de Quatrefages, ont adopté cette opinion: on peut, pour ainsi dire, la regarder comme la seule admise aujourd'hui, et l'on s'est même appuyé sur elle pour aider à démontrer le peuplement de la Nouvelle-Zélande par la Polynésie.

Mais ici encore, malgré l'autorité imposante de J. Williams, malgré l'adoption [faite par tous les savants de cette opinion, nous croyons qu'il n'est pas permis de la partager complètement. Nous croyons que la tradition qui lui sert de base prouve plutôt en faveur du peuplement de la Polynésie par la Nouvelle-Zélande, qu'en faveur du peuplement de la Nouvelle-Zélande par la Polynésie, ou qu'elle montre, tout au moins, que le langage de ces trois peuples, à l'époque du peuplement de Rarotonga, était absolument le même, c'est-à-dire qu'il n'était autre que le Maori. Cee fait seul est déjà un témoignage favorable à la thèse que nous soutenons. C'est ce que nous allons essayer de démontrer. 
Nous commencerons par l'exposé de la tradition : elle est fort étendue, mais nous croyons devoir la présenter in extenso, parce que toutes les versions données par Hale, d'Urville et autres sont incomplètes et tronquées, pour ainsi dire, suivant le besoin de l'opinion soutenue.

Nous le répéterons : par les phrases et les mots cités du langage d'alors, cette tradition semble prouver, d'une ma. nière incontestable, que ce n'étaient que des phrases et des mots maori ; car le Maori est la seule langue à laquelle ils appartiennent, et aucun des archipels des Iles de la Société, des Amis et des Marquises n'en emploie de pareils. J. Williams, en rapportant cette tradition, ne paraît pas en avoir fait la remarque.

Il semble enfin résulter, de certains passages de cette légende, que les habitants de Rarotonga seraient plutôt originaires dés îles Tunga que des îles Samoa et Tahiti, et que, par conséquent, ils dépendraient indirectement des Maori, si leurs ancêtres n'étaient pas venus directement de la Nouvelle-Zélande.

Voici le texte de cette tradition, telle qu'elle est rapportée par J. Williams (1).

* La légende rapporte que Karika, l'un des ancêtres de Makea, le roi de Rarotonga lors des premières visites des missionnaires anglais, venait d'une île située à l'Ouest et nommée Manuka.

a Karika était un grand guerrier et un grand navigateur; c'est dans un de ses voyages sur mer qu'il avait découvert l'île de Rarotonga, alors inhabitée.

« Après y être demeuré quelque temps, il venait de reprendre la mer, quand il rencontra en route Tangiia.

« Ce dernier était un chef du district de Faaa, à Tahiti : ayant abattu un arbre à pain favori, et offensé ainsi son rère Tutabu-aru-roa, « le poursuivant infatigable, " il s'était, pour éviter sa colère, enfui avec toute sa famille, parmi laquelle se trouvaient deux jolies filles.

- Il s'était d'abord dirigé vers Huahine, à environ cent

(1) A narrative of missionary interprises in the South sea $I s^{2}$ lands, p. 192. 
milles à l'Ouest de Tahiti, et il y était arrivé sain et sauf ; mais à peine s'y trouvait-il depuis quelques jours, que Tutabu s'y présenta avec ses mille (tini) (1), bien décidé à tuer son frère.

« Afin de lui échapper, Tangiia partit immédiatement pour Raiatea, où il fut suivi de près par Tutabu. S'étant enfui de nouveau pour Porapora, Tutabu y arriva presque aussitôt que lui.

« Il prit alors le parti de se diriger vers Maupiti, la dernière des Iles de la Société, mais Tutabu ne tarda pas à y arriver : si bien que, voyant qu'il lui était impossible d'échapper à son implacable ennemi, Tangiia n'eut d'autre ressource que de se lancer sur l'Océan à la recherche de quelque refuge.

a Il était déjà en mer depuis longtemps quand il rencontra Karika, qui venait de l'île Rarotonga et qui était d'abord parti de Manuka.

a Celui-ci, après avoir amarré son canot à celui de Tangiia, allait l'attaquer, quand il vit Tangiia faire acte de soumission et lui offrir l'emblème de la suprématie à la fois civile et religieuse, en lui disant : tena mai te vaevae roa, « tu as les jambes longues » ou " l'homme t'appartient. » A quoi Karika répondit : « tu as les jambes courtes n, ou " la tortue t'appartient. "Celle-ci étant sacrée, était considérée comme l'emblême de la suprématie dans les affaires religieuses. «En toi est le Butunga-apinga-katoatoa, la source de tout trésor, " ajouta-t-il, et il se réserva seulement pour lui son Takaï-kete, ou la nourriture que le peupie de son district doit lui fournir.

« En entendant ces paroles, Karika fut satisfait; il accueillit amicalement Tangiia, et accepta de lui l'une de ses jolies filles pour femme.

"Ce fut après cela que le brave guerrier apprit à son ami qu'il avait découvert une île charmante, et qu'il lui dit dans quelle direction elle se trouvait, promettant de re.

(1) M. Williams traduit ainsi le mot tini, qui signifie multitude, grand nombre. 
venir pour s'y établir, quand il aurait rempli le but de son voyage du moment.

* Tangiia, prenant alors congé de son formidable allié, se dirigea vers Rarotonga. Dès qu'il y fut arrivé, il se fixa sur la côte Est.

a Peu de temps après, Karika revint à cette île, et il alla s'établir avec sa « tini » sur la côte Nord.

* Ils n'y étaient que depuis peu de temps, se félicitant de leur tranquillité, quand, à la grande surprise et consternation de Tangiia, parut, à l'entrée de la baie, la flotte de son ennemi déterminé Tutabu.

- L'infatigable poursuivant s'était décidé à parcourir l'Océan pour y trouver son adversaire; maintenant qu'il l'avait découvert, il pensait bien pouvoir le détruire.

* Tangiia expédia aussitôtun méssager à son ami Karika, pour le prévenir de l'arrivée de Tutabu et lui demander son appui dans le combat qui ne pouvait manquer d'avoir lieu. Il espérait qu'en réunissant leurs forces la victoire serait pour eux.

* Karika s'empressa de réunir sa tini et l'envoya aussitôt au secours de son ami. Un engagement désespéré avec Tutabu s'en suivit, et ce dernier fut battu et tué.

" La première pensée des vainqueurs fut de le faire cuire au four ; mais ils trouvèrent bientôt que c'était plus difficile que de le tuer. En effet, quoiqu'ils eussent chauffé à fond un grand four et placé dans son intérieur un grand nom . bre de pierres chaudes, ils constatèrent, en le découvrant, que le four était froid,et que Tutabu n'était pas cuit.

* Cela les décida à porter le corps dans le district le plus voisin, après y avoir préparé un autre four. Mais ce fut aussi vainement qu'ils le chauffèrent avec un autre bois : le corps de Tutabu ne se trouva pas plus cuit.

a Ils eurent beau répéter cette tentative dans chaque district de l'île, jusqu'à leur arrivée au premier point de départ, le résultat fut toujours le même. C'est pour cela qu'ils donnèrent au district le nom de Taa-na, qui signifie $\alpha$ cuit au four plusieurs fois. »

«Dans cette tradition, dit Williams, il y a beaucoup plus 
de fable que j'en ai mentionné. Ainsi le canot qui aurait conduit Tangiia jusqu'à Rarotonga, aurait été construit dans le monde invisible; il aurait été apporté par des oiseaux sur le sommet d'une montagne, pendant une nuit, et il y aurait été transformé en un grand canot-maison pour recevoir Tangiia. Ce navire célèbre avait neuf à dix noms remarquables, tirés des circonstances de sa cons. truction, de son origine et autres accidents; mais son principal nom était Tarä̈-po, ou « construit dans le monde invisible. »

J. Williams ajoute : « Cet aperçu, dépouillé de ce qu'il a de fabuleux, est certainement acceptable d'après diverses circonstances, car les Tahitiens et les insulaires des autres îles de la Société possèdent, concernant Tangiia et Tutabu, d'autres traditions qui établissent que c'étaient deux grands voyageurs, qu'ils avaient eu une grande dispute d'intérêt, et qu'ils habitaient le district de Faaa à Tahiti. Cette opinion est appuyée également par le fait que les îles d'où proviennent leur ancêtres, au dire des habitants de Rarotonga, sont à peu près à égale distance de Raratonga, Tahiti étant à l'Est, et Manuka à l'Ouest d'elle. De plus, le langage des habitants actuels est pur tahitien, avec prononciation dure des consonnes, et avec le son nasal qui caractérise les dialectes de l'Ouest. Enfin nous pouvons encore y ajouter une preuve évidente, tirée des divisions politiques toujours existantes dans l'île : La population y est divisée en deux tribus, désignées par les noms de NgatiKarika ou les descendants de Karika et de NgatiTangiia, ou les descendants de Tangiia ; les premiers occupent le côté Nord et les derniers le côté Est. »

Comme on le voit, pour mieux soutenir son upınion, M. Williams dit d'abord que Tahiti est à l'Est de Rarotonga, ce qui n'est pas tout-à-fait exact, puisqu'elle se trouve dans le Nord-Est.

D'un autre côté si Manuka, ou l'île qu'il appelle ainsi, st. trouvait véritablement à l'Ouest, comme il le dit, ce ne pouvait et ce ne peut être que Namuka des Iles des Amis, visitée par La Pérouse ; car si c'était l'île Manua des Samoa, 
il faudrait la placer dans le Nord-Ouest, qui est sa position relative. Cette île serait à la même distance à peu près de Tahiti, comme il le dit ; mais il est évident que ce n'est pas elle, puisque celle dont parle la légende était à l'Ouest. Or, à l'Ouest, il n'y a que Namuka, qui est beaucoup plus voisine de Rarotonga.

Puis, si le langage est pur tahitien, comme il l'avance, il faut bien reconnaître qu'on ne le voit guère dans les mots qu'il cite, tels que Karika, Tutabu, Tangiia, Ngati, etc. (1) Williams avoue d'ailleurs que la prononciation dans cette île est dure, gutturale, et que le son nasal y est conservé ; ce n'était donc pas sûrement le Tahitien actuel.

Williams a certainement raison d'orthographier ngati, en un seul mot, quoiqu'il soit probablement composé de deux, nga et ati élidés ; mais il a tort de le considérer comme un mot tahitien, car il n'est absolument que maori. Ainsi que nous l'avons vu plus haut, nga, particule inconnue aux Tahitiens, est le signe du pluriel dans la langue maori; le ng manque de même dans les îles Samoa et Sandwich, tandis qu'il se trouve dans les îles Tunga, Mangareva. Pâques et aussi, comme on le voit par cette citation de Williams, dans l'île Rarotonga. Pour ce seul motif, cette dernière île n'aurait donc pu le recevoir de Tahiti ou des Samoa, mais seulement de la Nouvelle-Zélande ou des 'I'unga.

On sait qu'à Tahiti, du reste, la dernière syllabe de ce mot ngati est la seule employée, c'est-à-dire que le $n g$ est

(1) Le mot karika ainsi écrit n'est, il est vrai, ni Tahitien, ni Tonga, ni Maori; mais en en faisant deux mots, il ne se retrouve que dans cette dernière langue : kari, bois ; ka, brûlé.

Il en est de même du mot tangiia, qu'il faut aussi écrire en deux mots : tangi n'est pas Tahitien, mais Maori; il signifie crier, beugler ; ia, il, c'est.

En Maori, $t u$, être, rester, etc.; tapu sacré, rite sacré, sainteté.

Le mot rarotonga est également tout maori : raro, sous, dessous ; tonga, vent du Sud. C'est en miême temps le nom d'une île du détroit de Foveaux, appelée par les Anglais, Ile-du-Centre. C'est donc la Nourelle-Zélande qui a imposé ce nom à l'une des îles Hervey. 
supprimé ; là, ati signifie : s'attacher à une personne, être adhérent, s'associer, s'unir, et probablement lui appartenir. Mais il n'est arrivé là sans doute que par extension, car il est avant tout la préfixe patronymique qu'on met devant les noms des ancêtres, pour désigner les descendants. C'est donc bien le même mot que ngati pour lasignification, mais rẻduit à sa dernière syllabe seulement.

Par conséquent, lorsque M. Williams dit que Ngati Karika et Ngati Tangiia signifient les descendants de Karika et de Tangiia, il rend exactement le sens de ces mots, mais il a tort de les considérer comme des mots tahitiens ou samoans, car ces mots, ainsi prononcés, ne peuvent provenir de ces archipels.

Nous venons de dire que les mots karika et tangiia ne sont pas plus tahitiens que ngati, et que le mot karika ne peut même être maori qu'à condition d'être écrit ainsi : kari-ka; il ne se trouve de la sorte qu'à la Nouvelle-Zélande. Tangi, au contraire, existe en un seul mot à la Nouvelle-Zélande, où il signifie, crier, beugler, etc. Mais là encore, il faudrait écrire tangi-ia, en deux mots, ce dernier n'étant que le pronom. Or, puisque les mots entiers ou séparés ne se trouvent qu'à la Nouvelle-Zélande, il faut bien reconnaître qu'ils sont plus maori que tahitiens.

Le mot tutabu lui-même n'est probablement qu'un mot maori, mal' écrit et mal entendu par les premiers missionnaires, qui ont fini, on le sait, par supprimer le $b$ qu'ils avaient d'abord adopté pour rendre le son $p$ : celui-ci est le seul, à notre avis, qui soit prononcé par les Polynésiens. Les auteurs du dictionnaire tahitien ont mème fini par écrire : tu-tapu, mot que nous avons entendu nous-même à Tahiti, et qui signifie * la divinité sacrée. ๖

D'un autre côté, en rendant aru roa par « le poursuivant infatigable », M. Williams a parfaitement rendu, croyonsnous, la véritable signification de ces mots ; mais c'est justement pour cela que nous y voyons une nouvelle preuve en faveur de l'opinion que nous soutenons. En effet, ces mots n'ont cette signification qu'en Maori : là, aru signifie « poursuite, poursuivre, suivre » et roa signifie « grand. » 
A Tahiti, au contraire, aru roa veut dire seulement: " grand filet, grande vague, grande joie ", et il ne désigne rien de plus.

On le voit, toutes ces expressions sont maori ; et si l'on admettait, comme le dit M. Williams, que Karika et Tangiia étaient de Tahiti ou des Samoa, il faudrait du moins reconnaître qu'à cette époque la langue n'avait pas encore subi de changements, et qu'elle était absolument la même à Tahiti, aux Samoa et à la Nouvelle-Zélande.

Puisque la langue Maori est la plus complète, comme l'ont remarqué tous les linguistes, puisqu'elle est la moins émasculée, comme l'a dit M. Pruner-bey, puisqu'elle était la langue parlée alors par les découvreurs, il faut en conclure que c'est la Nouvelle-Zélande, plutôt que Tahiti ou les Samoa, qui a envoyé, directement ou indirectement, ses colonies à Rarotonga et dans le reste du groupe. Dans ces ìles, ces colonies n'ont fait subir, avec les années, que très peu de changements à leur langue, tandis que certains archipels l'ont transformée en dialectes plus distincts, quoiqu'elle fût nécessairement la même au début.

Cette tradition est regardée, depuis Hale, comme ce qu'il y a de plus favorable à l'opinion de cet écrivain : c'est au contraire, à notre avis, l'un des exemples qui appuient le plus l'origine zélandaise des Polynésiens.

Des légendes maori établissent que le nom de Karika était très commun à la Nouvelle-Zélande : un Karika était frère des émigrants d'Hawahiki, nommés Hatupatu, Hanui, et Haroa, qui étaient allés se fixer près des lacs Taupo et Rotorua. C'était un guerrier célèbre, très entreprenant, et l'on pourrait supposer, sans trop conjecturer, que c'est le inême qui joue un si grand rôle dans la tradition rapportée far J. Williams. Dans ce cas, plus de doute : c'était un Maori, qui serait arrivé indirectement à Rarotonga, en commençant par s'arrêter aux Tunga ou à Namuka, c'est-àdire, bien probablement à l'île appelée Manuka par la légende.

Alors le Tutabu de Williams n'aurait évidemment été que le Hatu-Patu de la légende maori rapportée par Sir 
Grey. Ce nom, d'après cela, serait mieux écrit Ha-tu-patu, s'il ne doi pas plutôt être écrit Ha-tu-tapu. Nous serions assez disposé, en effet, à croire que Sir Grey n'a pas bien entendu et que Williams était plus près de la vérité que ui quand il écrivait Tutabu, qui n'est que le mot Ha-tutapu, moins la première syllabe.

Quoiqu'il en soit, c'est toujours, à n'en pas douter, une même légende, et une légende de la Nouvelle-Zélande. Si Karika et Tangi-ia sont les ancêtres des habitants de Rarotonga, comme le dit M. Williams, on pourrait conclure de ce rapprochement même que cette île a été découverte et peuplée plutôt par des Zélandais que par des Tahitiens et des Tongans. Car, si la Nouvelle-Zélande n'est pas directement à l'Ouest, elle gît du moins au Sud-Ouest de Rarotonga, et, par conséquent, toujours plus à l'Ouest qu'elle, tandis que Tahiti se trouve dans le Nord-Est. Il est vrai que les îles Tunga sont directementà l'Ouest et que, dès lors, elles auraient bien pu être les premières à découvrir et à peupler Rarotonga (1). Seulement, dans ce cas, il faudrait reconnaître que lîle Manuka de M. Williams était l'île Namuka, l'une des riapaï, qui est bien directement à l'Ouest de Rarotonga, et à la distance de cinq à six cents milles. Cette ìle Na-Muka est la mème que les premiers navigateurs, et entre autres La Pérouse, qui y a relâché, ont appelée Anamoeka, Anamooka, etc.

Il est certain qu'il n'existe pas d'ille Manuka, ni dans le groupe des îles des Amis, ni dans celui des Samoa. Celle que Williams a prise pour elle, dans ces dernières îles, s'appelle Manua. Dans l'origine, c'était peut-être le nom que lui avaient donné les colonies parlant alors le Maori, car Manuka est encore un mot maori qui est donné à un arbre, le même que le Kahikatoa. Mais enfin, tel n'est pas son nom depuis les visites des premiers Européens et d'après J. Williams Jui-même, qui, dans son livre, se contente de lui

(1) On sait que dans une autre île du groupe Hervey, Aitutaki, les insulaires disent que leurs ancêtres sont venus d'une région sous le vent appelée par eux Avaïki. 
donner le nom de Manua. Nous croyons donc, d'après sa position surtout, qu'il n'a dû s'agir que de l'île Namuka. Ce nom seul vient lui-même à l'appui de la thèse que nous soutenons : en Maori, na signifie, voici, voilà, il y a, etc. et muka, lin ou phormium tenax. Des Maori seuls pouvaient penser au phormium, et se figurer en voir dans la contrée polynésienne abordée par eux.

Il n'est pas jusqu'aux mots tini et makea, qui ne prouvent en faveur de cette thèse.

Tini est un mot tout spécialement maori; il signifie multitude, grand nombre, comme si l'on disait troupe armée, phalange, etc. On a vu que Williams l'a traduit par 1000, ce qui revient à peu près au même, mais ne serait exact que si une armée était nécessairement composée d'un millier de combattants.

Quant au mot makea, il ne saurait être tahitien, puisque le $k$ n'est pas employé à Tahiti. En Maori, on le trouve en deux mots : ma, pur, blanc, net, propre; kea, mucus nasal, ou keha, puce.

Mais ce qui prouve bien mieux encore que ce mot est essentiellement maori, c'est qu'il était justement, comme l'apprend Sir Grey (l), l'un des noms du père de Maui le Zélandais.

Une autre tradition, citée également par J. Williams, nous paraît être tout aussi probante que la précédente. Elle a été donnée comme un exemple du langage de Rarotonga; à ce titre, elle offre le plus grand intérêt aux linguistes.

C'est un chant fait par le guerrier Oromea, que Karavai croyait avoir tué, et qui, n'étant qu'étourdi, était parvenu à s'échapper. Voici les paroles et la traduction de M. J. Williams (2).

Tari rau kuru ua ite Atua Karavai. E!

Kua ki a Vairota. E!

(1) Polynesian mythology, p. 32. L'autre nom du père de Maui était Tara-Hunga.

(2) Ouvr. cité, p. 212. 
Kare i Tutuki tika ia Oromea. E!

Te koto ua ra $i$ te tuporo $i$ te Manga. $E$ !

“Quelle charge de feuilles, de fruits à pain, Karavaï porte à ses dieux. Oh !

a Il a rempli Vairota (nom d'un marae). Oh!

« Mais il n'a pas tué complètement Oromea. Oh!

« Car il est occupé à battre du tambour et à danser gaaiement à Te Manga (nom d'un district). Oh ! »

Or on ne peut nier que tous ces mots n'appartiennent plutôt au Maori, qu'au Tahitien et au Samoan,

Nous pourrions citer encore les adieux faits par la population d'Aïtutaki (1) à M. Williams quittant l'île avec son navire (2) :

Kia ora e tama ma, 1 te aerenga $i$ te moana. $-E$ !

"Soyez heureux, chers amis,

"Soyez heureux dans votre voyage sur la mer. »

Ces mots sont pur maori : par conséquent, c'est toujours un témoignage plus favorable que contraire à notre thèse.

Le $k$, avons-nous dit, n'est pas usité à Tahiti, pas plus qu'il ne l'est aux Samoa. Donc ce sont bien des mots zélandais puisque, de plus, quelques-uns ont le $n g$ qui manque complètement à Tahiti et à peu près complètement aux îles Samoa.

$\mathrm{Au}$ surplus, nous rejetons à la fin de ce chapitre quelques fables Néo-Zélandaises, dont le texte, emprunté à l'ouvrage de Taylor, donnera une idée exacte du Maori.

Il résulte évidemment, des considérations linguistiques précédentes, que le Maori était la langue primitive. Les

(1) Il est curieux de voir que, à Aitutaki, le dieu appelé Oro à Raiatea et à Tahiti, était appelé Koro, mot tout maori, mais qui, il est vrai, est également fijien. (Voy. Th. Williams, Fiji and $F_{i-}$ jians, p. 51.)

(2) A narrative, etc.. p. 164. 
Polynésiens, dans l'origine, c'est-à-dire à leur arrivée dans les îles qu'ils occupent, avaient non-seulement la même langue, mais aussi la mème prononciation générale ou primitive, aussi bien à Tahiti que dans les autres archipels. Aux Marquises, par exemple, s'il y a des districts où elle ne s'est pas conservée, il y en a d'autres où elle existe encore. A Tahiti même, nous avons souvent remarqué que, contrairement à la majorité, des indigènes prononçaient comme l'auraient fait des Maori, et comme tous devaient le faire, à leur arrivée dans les îles de la Société et avant les modifications subies depuis par le langage. (On sait, du reste, et Moërenhoüt a montré, qu'il existait anciennement à Tahiti une langue uniquement comprise par les chefs et les prêtres, de même qu'aux Tunga et ailleurs. Quand on étudie le Tahitien on ne saurait douter que cette langue était le Maori. C'est ce que prouve aussi la facilité avec laquelle Tupaia, le grand-prètre tahitien compagnon de Cooź, put immédiatement converser avec les Néo-Zélandais.

On a objecté, il est vrai, que le Maori n'aurait pu être la source des divers dialectes de la Polynésie qui, comme aux Sandwich, aux Samoa, aux Tunga, emploient des lettres, telles que le $l$, le $v$, etc. : ces lettres, disait-on, sont inconnues aux Néo-Zélandais. Mais c'est une erreur, car la langue maori possède également ces lettres. Il est vrai qu'elles ne sont utilisées que par des populations de certaines localités de la Nouvelle-Zélande ; mais toutes y existent réellement, de même que, parfois, le ng fondamental, national pour ainsi dire, s'y trouve lui-même délaissé par certaines populations qui le remplacent par le $k$ ou le $n:$ Ex : Moeraki pour Moerangi.

Il existe, en réalité, une seule langue à la Nouvelle-Zélande, et les modifications de lettres usitées dans certains districts ne sont pas des dialectes, comme le disent les missionnaires, mais de simples jargons. Un pareil état de choses explique donc suffisamment les différences observées dans les îles polynésiennes. Ces différences ont dû naturellement, après la séparation, se prononcer de plus en plus avec le temps ; mais elles ne sauraient être considé- 
réés comme un obstacle au peuplement de la Polynésie par la Nouvelle-Zélande.

Depuis Pigafetta, tous les voyageurs qui ont donné à l'étude de l'homme l'importance qu'elle mérite, ont recueilli, dans les différents pays qu'ils ont visités, des vocabuaires plus ou moins complets. Quoiqu'il n'ait touché que dans les îles Mariannes, Philippines, Moluques et quelques autres voisines de ces dernières, Pigafetta, le premier, signale dans ces îles la présence d'un grand nombre de mots polynésiens. C'est sans doute cette conformité qui a donné l'idée de la ressemblance des idiomes polynésiens avec les Malayou.

Après Pigafetta, Forster dressa un tableau de 47 mots pris dans onze des dialectes de l'Océanie, et il mit en regard les mèmes mots en Malayou, en Mexicain, en Péruvien et en Chilien. Ce tableau montrait que les dialectes océaniens offraient des analogies avec le Malayou, mais nullement avec les langues américaines.

Dans le même temps, Anderson, le chirurgien de Cook, mettait en évidence, dans un tableau comparatif de 42 dialectes différents, l'analogie des idiomes océaniens avec le Malayou et le Madekass, à l'égard des noms de nombre.

Plus tard, le docteur Martin, à la fin de son ouvrage sur les îles Tunga, d'après les documents de Mariner, cita 55 mots malais qui se trouvaient, plus ou moins altérés, dans l'idiome tongan. Il est vrai que si l'analogie de la plupart de ces mots est indubitable, elle a été forcée pour quelques uns. On sait, du reste, qu'aucune confiance ne peut être accordée au vocabulaire fourni par Mariner et qu'il fourmille d'erreurs.

Le tableau de 15 mots publié par J. Williams vint prouver, ce qui n'a plus besoin d'ètre démontré aujourd'hui, l'analogie de tous les dialectes polynésiens entre eux et leur différence d'avec la langue des Fiji.

L'ouvrage le plus considérable sur ce sujet est celui que Dumont d'Urville inséra à la suite du Voyage de l'Astrolabe : ce travail se compose de tous les vocabulaires rédigés par Gaimard dans le cours de l'expédition, de ceux de 
Mariner et de celui de Madagascar recueilli et donné à d'Urville par le $\mathrm{D}^{\mathbf{r}}$ Chapelier. Malheureusement ce recueil immense est plein d'erreurs. Comme ses prédécesseurs, d'Urville a essayé un tableau comparatif en six langues: Madekasse, Malaie, Mawi, (1) Tongane, Tahitienne et Hawaiienne; mais ce tableau, quoique fort étendu, n'a rien appris de plus qu'on ne savait, et peut-être moins que ceux de $\mathbf{J}$. Williams et d'Anderson sur les rapports comparatifs des dialectes polynésiens. Seulement d'Urville concluait, de la comparaison de ces six langues, que les dialectes polynésiens offraient des traits de ressemblance avec la langue des Malais et celle des liabitants de Madagascar.

Le Rév. Whitmee dit, en parlant de la parenté des langages hawaiien, maori, tahitien, rarotongan, tongan et marquésan avec le Malai : "Ces langages ont verbalement beaucoup de ressemblance, de même que dans leurs formes grammaticales. Ils ressemblent aux langages parlés par les habitants les plus clairs de l'archipel indien. Mon étude actuelle sur eux me confirme dans l'opinion qu'ils sont tous, en mème temps que le langage de Madagascar, plus ou moins apparentés. Mais je doute que les langues malayopolynésiennes, ainsi que les appelle le baron Guill. de Humboldt, puissent être regardées, dans certain sens, comme des branches du Malai. Je regarderai plutôt tous ces langages, ainsi que ceux de l'archipel Indien et Madekasse, comme étant plus ou moins des branches variées sorties d'un tronc originel, qui maintenant ne se trouve plus dans aucun langage parlé. Le Malai lui-même, loin d'être la souche, est probablement la branche, la plus développée et la plus changée, sortie du tronc originel. Car il a sans doute été plus changé que les autres par les influences étrangères qui sont venues de l'Inde, et par son contact avec les Arabes. On ne peut douter que les Malayo-Polynésiens n'aient été séparés de leurs congénères, dans l'archi-

(1) Mawi est le nom donné par d'Urville à la langue des NéoZélandais ; il l'a tiré du mot Ika-na-Maui, nom que porte l'île la plus septentrionale du groupe de la Nouvelle-Zélande. C'était inutile, puisque les indigènes appellent leur langue le Maori. 
pel indien, avant que ces influences aient affecté le langage malai. Je ne veux pas théoriser sur une date insuffisante; mais, d'après le fait de la ressemblance qui existe, entre toutes les variétés des langues malayo-polynésiennes et d'après leur isolement, jugeant leur simplicité comparative, je pense qu'il est probable qu'une étude comparée de ces langages nous rendra capables de reconstruire le langage originel, duquel tous, y compris le Malai et le Madékasse, ont divergé » ( 1 ).

Pour nous, ce langage originel n'est autre que le Maori ; et nous allons jeter ici un rapide coup d'œil sur les divers alphabets des principaux archipels polynésiens, afin de bien établir qu'ils dérivent de celui de la Nouvelle-Zélande.

LETTRES COMPOSANT LES DIVERS ALPHABETS DES PRINCIPAUX ARCHIPELS POLYNÉSIENS.

\begin{tabular}{|c|c|c|c|c|c|c|c|c|c|c|c|c|}
\hline & 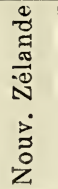 & 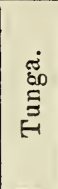 & 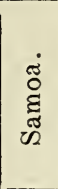 & 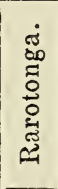 & : & 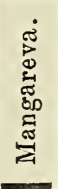 & 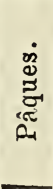 & 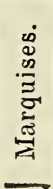 & 兽 & 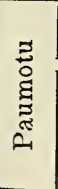 & 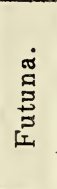 & 漓 \\
\hline $\begin{array}{l}A \\
B \\
C \\
D \\
E \\
F \\
G \\
H \\
I \\
K \\
L \\
M \\
N \\
O \\
P \\
Q \\
R \\
S \\
T \\
U \\
W \\
V \\
Y \\
N G\end{array}$ & 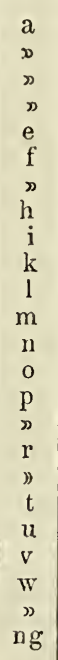 & 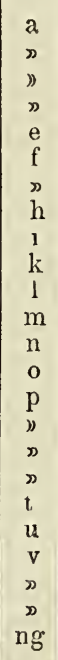 & 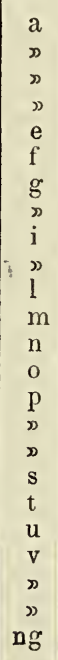 & 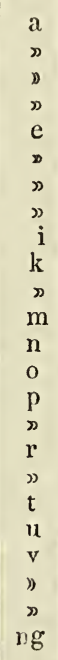 & 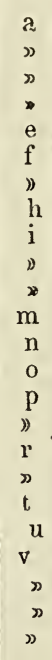 & 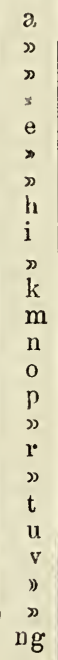 & 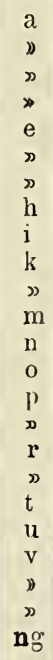 & 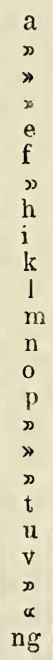 & 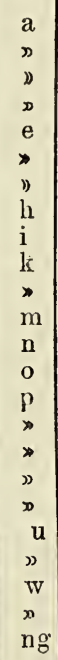 & 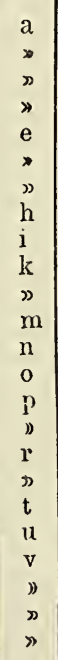 & 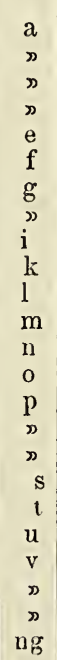 & $\begin{array}{l}a \\
b \\
c \\
d \\
e \\
ग \\
g \\
h \\
i \\
\text { k } \\
\text { l } \\
\text { m } \\
\text { n } \\
0 \\
\text { d } \\
q \\
r \\
\text { s } \\
t \\
u \\
v \\
w \\
y \\
ग\end{array}$ \\
\hline
\end{tabular}

(1) Pratt Dictionnaire Samoan-Anglais, édité par le Rev. Whitmee, Londres 1878. - Transactions of the Philological Societr, 1877-1879, p. 426 . 
A la Nouvelle-Zélande, le $h$ est prononcé avec une forte expiration ; ex : heö, assez; hiahia, désir; hine, fille. Le $r$ n'est pas guttural ; il tient à la fois du $l$ et du $d$; aussi cette lettre a souvent été prise pour un $d$ par les voyageurs, particulièrement par d'Urville. Le $n g$ existe dans toute sa pureté, mais pas partout; ex; tangata, homme, rangatira, chef, que l'on doit prononcer ta-nga-ta, ra-nga-tira. Cette nasale tientle milieu entre le $g n$ et le $n g$ français. Dans la Baie d'Abondance, plusieurs tribus remplacent le $n g$ par le $n$. Un fait qui n'avait pas été remarqué jusqu'ici, c'est que certaines tribus de la Nouvelle-Zélande emploient des lettres qu'on ne retrouve qu'aux Tunga, aux Samoa ou aux Sandwich. Ainsi, dans le détroit de Cook, ' le $l$ remplace le $r$ des autres localités. Frès de la Baie des Iles, les Ngapuhi prononcent le $h$ comme un sh, c'est-à-dire avec une forte expiration; les habitants de Taranaki le prononcent avec explosion. Le $v$ semble remplacer le $w$ dans d'autres lieux. Enfin le $f$ même est employé par quelques Maori : le mot terre, par exemple, est rendu, suivant les localités, par henua, whenua, venua it fenua.

Aux îles Tunga, le $f$, d'après Mariner, tiendrait souvent lieu du $v$ : Ex. facca, faire (préfixe), pour vhaka à la Nouvelle.Zélande, haa à Tahiti. Le $g$ est douteux, quoique Mariner écrive Lefuga, nom d'île (1) pour Rehunga (NouvelleZélandel. Is $h$ est très accentué ; cependant, d'après Mariner, le $h$, dias beaucoup de mots, serait remplacé par le $f$ : ainsi les mots zélandais huahua, bouton, pustule, hiainu, qui a beaucoup bu, ivre, tohunga, prètre, se prononceraient fuafua, fia-inu, tofunga. Le $l$ remplace le $r$ de quelques autres archipels (2) et parfois le $h$ : ainsi lae pour rae, front; laa pour raa, soleil ; luulu pour huruhuru, chevelure.

(1) Haché, laid, mauvais.

(2) Pruner-Bey a fait remarquer que la différence minime existant entre les lettres $r$ et $l$ est toute physiologique. C'est, dit-il, la pointe de la langue mise en vibration par le courant phonétique qui donne la consonne $r$; lorsqu'elle arrête plus complètement le courant, elle donne la consonne $l$. Telle est toute la différence. (Bull. Soc. d'Anthr., juin 1862, p. 368.) 
Mariner prétend que le $p$ est remplacé par le $b$; mais c'est une erreur. Le $b$, il est vrai, est quelquefois employé à la place du $p$, mais seulement daus les mots empruntés al Fijien qui ne se sert que du $b$. Mariner donne aussi aux Tongans l'usage du $j$ que n'emploie aucun autre dialecte polynésien. Mais les mots qu'il cite pour le démontrer ont tous été forgés, mal entendus ou mal rendus: ainsi $j i a$, faire des filets, n'est certainement que le mot polynésien hia tomber, (hinga à la Nouvelle-Zélande) ; jiawta, miroir, est pour whakaata, glace, miroir ; jienna, personne. est pour iana, pronom lui ; jio, regard, est pour hio, voir, regarder, en Tahitien. C'est également à tort que d'Urville croyait que les Tongans admettaient les sons $d$, tch et $s$.

Dans les îles Samoa, le $f$ remplace le $h$ : Ex. fuia, oiseau, pour huia ; mafuie, divinité, pour mahuic. Le $h$ est égaiement remplacé par le s; ex. Orosenga, Savaii, pour Orohenga, Havaii. Le $k$ n'est pas usité : on prononce manuao, oiseau, pour manukao; matuu, héron, pour matuku. Cependant Pritchard a cité le mot kupana, roter et le Rév. Whitmee les mots $p u k e$, prendre, attraper (1) et puketa, exclamation de triomphe.

Le $n g$ n'est généralement pas employé ; les Samoans disent manutagi, oiseau pour manutangi ; tagaloa, divinité, pour tangaloa; talaga, parent, pour taranga; papalagi, étranger, pour papalangi. Pritchard cite pourtant quelques mots qui prouvent que le $n g$ est au moins quelquefois usité ; et l'on peut inférer de l'accent adopté par les missionnaires pour représenter la prononciation de ces mots, que le $n g$ a dù être autrefois plus geénéralement employé. L'u sage fréquent des lettres $t, l$ et $s$ rend particulièrement doux le dialecte des îles Samoa.

Dans le dialecte de Rarotonga, le $f$ et le $h$ sont inconnus

(1) Whitmee a traduit le mot samoan puke far l'expression anglaise catch you, attrapez - vous.

Ce missionnaire fait en outre remarquer que, depuis un certain nombre d'années, la plupart des naturels prennent l'habitude, dans la conversation, de remplacer le $t$ par le $k$.

III. 
et ne sont pas suppléés par d'autres lettres; le ng existe dans toute sa pureté, ainsi que le $k$. Ce dialecte se rapproche beaucoup du Maori. Il en est de même dans les îles Australes, comprenant Rurutu, Raïvavaï, Tupuai, Rimatara, etc.

A Tahiti, le $f$ est usité comme aux Tunga, aux Samoa, aux Marquises. Le $h$ est toujours prononcé avec une forte expiration ; le $k$ n'est plus employé, la gutturale étant supplée et remplacée par $h$. Le $r$ existe comme à la. NouvelleZélande, excepté dans quelques mots tels que vau, huit pour varu ; vea brûlé, échaudé pour vera, être brûlé, échaudé; ainsi l'on dit: rehu, cendres ; taratane, femme mariée. Les Tahitiens n'ont donc pas plus le $k$ que les Samoans, mais ils ont le $r$ que les Samoans n'ont plus, après l'avoir possédé. On avait cru qu'à Tahiti, comme à la NouvelleZélande, le $r$ était quelquefois prononcé $d$; mais c'était une erreur d'audition, de même qu'on y croyait, par erreur aussi, le $p$ remplacé par le $b$. C'est donc à tort que les missionnaires anglais ont fait figurer dans leur diction. naire des mots où entrent le $b$ et le $d$. Orsmond était également tombé dans cette erreur; mais nous avons pu nous convaincre nous-même sur les.lieux que la lettre $b$ n'existe pas dans le dialecte tahitien. Le $g$ seul, que paraissent avoir les Samoans, n'est pas plus usité à Tahiti que le $k$ et le $n g$. Ce dialecte change souvent une consonne pour une autre : $f$ pour $h$ et $h$ pour $f$. Le Tahitien diffère donc du dialecte de Tungatapu en ce que ce dernier rejette le $r$ et se sert $d u l$ et du $k$. Il diffère du dialecte samoan, qui change le $r$ en $l$ et le $h$ en $s$, qui adopte le son nasal et qui rejette généralement le $k$, quoiqu'il le conserve encore dans quelques mots. Il diffère enfin du dialecte des îles Hervey, en ce que celui-ci rejette le $f$ et se sert du $k$ et du $n g$.

Le dialecte des îles Mangareva et Paumotu se rapproche beaucoup de celui des îles Hervey ou Manaia, et diffère très peu de celui de la Nouvelle-Zélande. Le $h$ s'y prononce avec une expiration oblitérée. Le $g$ est douteux, puisque le ng y existe dans toute sa pureté. Il en est de même aux 
Paumotu. Moërenhoüt a remarqué, le premier, que le dialecte des Mangareva se rapproche plus des dialectes de Rapa, de Raïvavaï, de Tupuaï que de tous les autres dialectes plus occidentaux. "Sans cesser d'être très analogue a celui de Tahiti, dit-il, il diffère cependant assez pour qu'il fùt difficile au chef de l'île de s'entendre d'abord facilement avec moi. "Nons pensons que cette difficulté ne venait que de l'observateur ; car pour nous, qui arons pu comparer sur les lieux mêmes, nous avons constaté pour ainsi dire le mème langagee, à l'exception de l'usage du $t_{i}$, et avec le $f$ en moins.

Aux îles Marquises, la lettre $f$ est employeje dans le groupe Sud-Est, mais, dans le groupe Nord-Ouest, elle est généralement supprimée et remplacée par $h$. Là on dit $h a$ pour fa, quatre ; hae pour fae, maison. Le $r$ existe, mais il varie suivant les groupes et il est ordinairement a peine prononcé. Tantôt cette leitre est remplacée par $n$ ou par $h$; tantôt elle est supprinée et on lui substitue une forte accentuation : Ex : aanui, route, pootu, beau, belle femme, pour aranui, purotu. Cependant elle se prononce nettement dans tororo, jurement Le ng n'existe aux Marquises que dans la tribu des Taipii. Dans le groupe Nord-Ouest, il est changeé en $k$, et dans le groupe Sud-Est en $n$. Le dialecte marquésan diffère donc de celui de Tahiti en ce qu'il emploie le $k$ et qu'il rejette le $r$ sans rien mettre à sa place.

Le dialecte des îles Sandwich diffère du Tahitien par le fréquent emploi du $k$ et du $l$ et par le rejet du $f$ qui est rem. placé par le $h$. Dans ce dialecte, $h$ se prononce en aspirant ou mieux en expirant fortement; le li remplace généralement le $t$; le $l$ remplace le $r$, conme aux Tunga et aux Samoa il remplace également le $h:$ ex. lei, couronne, pour hei, ornement du cou à la Nouvelle-Zélande, à Tahiti, etc. Le ng et le $f \mathrm{y}$ sont inusités ; la première lettre est changée en $n$. Le $t$, que l'on trouve dans presque tous les mots des voyageurs, probablement par erreur, est remplacé par le $k$. Il est certain, en effet, que les vocabulaires ne parlent point du $t$. On prononce et on doit écrire plutôt lkanai que tanai. Le mot atua, dieu, des autres îles polynésienness, y 
est rendu pal akua. Cependant le $t$ a dù certainement exister aux Sandwich.

En somme, cinq archipels polynésiens emploient le $f$ comme à la Nouvelle-Zélande; ce sont: les Tunga, les Samoa, les îles de la Société, les Marquises et Futuna.

Deux, les Samoa et Futuna, semblent employer le $g$ seul.

Le $h$ est usité partout, excepté dans les Samoa et l'archipel des Manaia.

Les îles Samoa et de la Société n'emploient pas le $k$ dont se servent tous les autres archipels. Pourtant quelques mots des Samoa l'ont conservé, et d'après le révérend Withmee, il parait ètre chaque jour plus usité.

Quatre archipels, les Tunga, les Samoa, les Hawaii et Futuma remplacent le $r$ par le $l$. Tahiti, qui supprime le $k$, conserve le $r$. On trouve pourtant quelquefois le $r$ aux Samoa, et aussi, mais plus rarement encore, dans quelques mots des Marquises.

Le $s$ n'est usité que dans les Samoa et à Futuna où il a toujours le son dur et où il a évidemment été emprunté aux Fijiens.

Le $t$, aux Sandwich, est généralement changé en $k$, mais pas toujours.

Le $v$ simple est employé dans beaucoup d'archipels où il semble remplacer le $w$ adopté par les Anglais.

Le $n g$ enfin inanque dans les îles de la Société, aux Sandwich et généraiement aux Samoa, quoiqu'on le trouve dans quelques mots : aux Marquises, il n'existe que dans la tribu des Taipii. Mais on rencontre cette nasale dans tous les autres archipels: Tunga, Manaia, Mangareva, Paumotu, Futuna et Pâques, où elle est prononcée de même qu'à la Nouvelle-Zélande.

Nous ajouterons enfin que ce nest pas seulement dans les archipels Tunga. Samoa de la Société et des Marquises, que la lettre $f$ remplace la lettre $h$, mais que certaines tribus de la Nouvelle-Zélande emploient elles-mèmes clairement le $f$ pour le $h$ : ce qui tend toujours à démontrer l existence, d'une langue primitive commune à tous les Polynésiens. 
Les Polynésiens, partis d'un même point, devaient avoir au début le même nombre de consonnes; leur langage c.evait être absolument le même lors des premières migrations. Or, il résulte des remarques linguistiques précédentes, que ce langage n'était autre que le Maori. C'est, en effet, l'iliome le plus complet, et il est impossible de n€ pas voir que tous les autres ne sont que les dialectes d'une même langue. Si, par exemple, on intercale entre les lettres conservées par l'idiome de Tahiti, qui est le plus émasculé, celles qui font partie des mots de même signification à la Nouvelle-Zélande, on obtient identiquement le dialecte maori. Si l'on remplace les quelques lettres usitées dans les dialectes tongan, samoan et hawaiien, par celles qu'emploie le Maori, on obtient également le même résultat. la même identité des mots dans leur orthographe et dans leur signification. Il en est de même pour tous les autres dialectes qui ne diffèrent du Maori qu'en expirations, aspirations ou contractions plus ou moins fortes et générales.

Ces conclusions sont surtout confirmées par l'existence, dans quelques districts de la Nouvelle Zélande, de plusieurs lettres que l'on croyait faire défaut au langage maori. Ce fait important et trop peu remarqué explique à lui seul la variation des alphabets suivant les lieux. On retrouve, en effet, à la Nouvelle-Zélande, toutes les lettres employées par les habitants de la Polynésie proprement dite, bien que ces lettres ne soient pas employées généralement par toutes les tribus, mais seulement par un certain nombre qui semblent s'en être réservé l'usage. On rencontre la lettre $l$ dans le détroit de Cook; ailleurs, des tribus emploient la lettre $f$; certaines autres prononcent le $h$ cumme si cette lettre était précédée d'un $s$; d'autres enfin remplacent le $n g$ par le $n$, ainsi que le font les Marquésans (1). N'en pourrait-on pas conclure que si la Nouvelle-Zélande

(1) Nous avons cru reconnaître la même variation dans l'emploi des lettres en Mélanésie. A Vanikoro, par exemple, nous avons entendu prononcer presque aussi souvent le $l$ que le $r$, Vanikolo que Vanikoro. 
est bien, comme nous l'admettons, le pays d'origine des Polynésiens, chacun des archipels de la Polynésie aurait recu des émigrants venant justement des points de la Nouvelle-Zélande où les lettres indiquées sont employées plus particulièrement? C'est ainsi, par exemple, que le langage des îles Tunga est surtout formé de mots employés par les tribus du Cap-Est, de la Baie d'Abondance, du détroit de Cook et des Waikato, c'est-à-dire par des tribus se servant des lettres $n, l$, ainsi que des lettres $k$ et $n g$. De mème les îles Hapai ont été probablement peuplées par les tribus maori qui portaient autrefois ce nom dans l'Hawahiki, et qui habitaient près de la célèbre Whare-Kura ou maison rouge, dont nous aurons à parler plus loin.

En résumé, quelle que soit la véritable explication de la suppression de certaines lettres dans quelques archipels, ailleurs de leur remplacement par d'autres, en un mot, de la différence de prononciatiou suivant les îles, il est démontré pour nous que le Maori est la langue-mère, et que les dialectes polynésiens n'en sont que des dérivés.

Les noms de lieux, en Polynésie, viennent, de leur côté, corroborer cette opinion. Les noms de lieux, on le sait, sont autant de monuments qui maintiennent le souvenir de la population primitive d'un pays. Or les noms des îles de la Polynésie éclairent et complètent les indications que nous venons de développer. On n'a pas assez remarqué, jusqu'à ce jour, que presque tous les noms servantà désigner les îles et les localités de la Polynésie, paraissent avoir une origine Néo-Zélandaise, et n'être que des noms maori, un peu modifiés arec le temps, mais composés toujour's des mêmes racines. Ce fait ne peut guère s'expliquer qu'en admettant que ces noms ont été apportés et donnés par des émigrants venant de la Nouvelle-Zélande.

On ne trouve, à la Nouvelle-Zélande, comme noms de localités; qu'un très petit nombre de mots des îles polynésiennes ; mais les noms qui ont servi à dénommer ces îles sunt surtout des mots abstraits, quand ils ne rappellent pas le souvenir de la patrie commune, de l'Hawahiki. Or on ne frencontre en Polynésịe que très peu des noms donnués aux 
localités de l'Hawahiki, tandis que tous, au contraire, existent dans l'une des îles de la Nouvelle-Zélande. C'est une preuve, comme nous le ferons voir, que l'Ile-du-Milieu de la Nouvelle-Zélande n'était autre que l'Hawahiki luimême. En outre, ce fait permet d'inférer à priori que le départ des émigrants de l'Ile-Nord n'a dû s'opérer qu'après un séjour assez long, puisqu'ils avaient déja perdu en partie le souvenir de ces localités du pays d'origine.

Quoiqu'il en soit, il est impossible en examinant, le dictionnaire à la main, les dénominations des îles polynésiennes, de ne pas reconnaître que ces noms ont conservé un cachet maori tout particulier, alors mème qu'ils ont déjà subi d'assez grandes modifications. Nous ne pouvons entrer ici dans les détails beaucoup trop étendus que comporterait un pareil sujet : il faudrait examiner, les uns après les autres, les noms de toutes les îles composant les différents archipels polynésiens. Mais le lecteur qui voudra se livrer à ce travail, comme nous l'avons fait nous-mème, verra facilement que tous ces noms se retrouvent sans exception dans le langage maori et que, par conséquent, ils ont dû être donnés par des émigrants venus directement de la NouvelleZélande.

Voici, en quelques mots, les conclusions qui découlent de cette longue étude :

C'est l'lle-Nord de la Nouvelle-Zélande qui a envoyé ses colonies peupler la Polynésie, au lieu d'en recevoir de cette contrée, comme on le croit généralement.

Ces colonies, parties de la Nouvelle-Zélande, n'ont dù se rendre en Polynésie que poussées par des vents d'Ouest ou de Sud-Ouest, puisque, comme nous l'avons montré, on n'a pas plus rencontré de Polynésiens que de Marri sur les côtes voisines de la Nouvelle-Hollande.

Enfin quand on remarque que, malgré les modifications apportées par le temps et l'isolement, la Polynésie présente tous les usages, toutes les croyances, etc., qu'elle a les mè- 
mes mœurs, qu'elle parle la même langue que la Nouvelle. Zélande, que ses habitants sont de la même race que les Maori, dont ils ont tous les caractères physiques extérieurs, on ne peut guère hésiter à regarder l'Ile-Nord de la Nou. velle-Zélande comme le point de départ des ancêtres des Polynésiens actuels.

On va voir maintenant que, si l'on a eu tant de peine à comprendre le peuplement de l'Ile-Nord de la NouvelleZélande, c'est parce que, jusqu'à ce jour, on a placé l'Hawahiki en Polynésie. 
FABLES NÉO-ZÉLANDAISES. (1)

\author{
Tuna Wapuku \\ L'Anguille et le Merlus.
}

WAPUKU. - Tehea tau wahi momona?

Quelle est la meilleure partie de ton corps?

Tuna. - Momona ake i taku

Je suis bonne depuis

Hiku, a taku tongahau;

Ma queue, jusqu'au milieu du corps ;

A ka eke ki runga ki

Et si tu vas jusqu'au sommet

A Tumatua, ka noho

De Tumatua, vous pourrez vous asseoir

Tau tokorua. Tehea tau?

Derx ensemble. Et toi, quelle est

ta meilleure partie?

W APUKU. - Momona a iku,

Je suis bon dans ma queue,

Momona a tara; ka kake

Et bon dans mes nageoires; si tu vas

I te kakenga i a Tumatua,

Au sommet du Tumatua,

Ka noho tau tokorua.

Vous pourrez vous asseoir deux ensemble.

Le wapuku demande encore à l'anguille quelle est sa partie la plus grasse. L'anguille regarde sa queue d'une façon significative. Elle adresse la même question au wapuku qui, ouvrant, à son tour. ses grands yeux, exprime ainsi que sa tête est la partie la plus grasse de son corps (2)

(1) Taylor, te Ika a Maui, p. 135.

(2) Partout où le texte maori est supprimé, c'est qu'il n'existe pas dans l'ouvrage de Taylor. 
Tuatara. - E te Kumukumu, Kumukumu,

Ka haere taua ki uta.

Alions tous deux dans l'intérieur.

Kumukumu. - Kahore; haere koe ki uta.

Non pas ; vas-y toi-même.

Tuatara, - E, haere mai,

Allons, viens,

Ka pau koe $i$ te Tangata.

Pour que tu sois détruit par l'homme.

Kumukumu. - Kahore; ekore au e pau:

Non pas ; je ne serai pas détruit :

Ko koe anake e pau.

C'est toi seul que l'homme détruira.

Tuatara. - Elkore au e pau:

Je ne serai point détruit :

Tutu aku tara, rarau alsu peke ;

Je n'aurai qu'à dresser mes piquants, et à sortir mes griffes ;

Mataku te Tangata, oma ki tawhiti.

L'homme sera effrayé, et il s'enfuira.

\section{L'A ute et le Whau. (1)}

Whau. - Hei kona koe,

Ah! voilà que tu sers,

Tu ai hei parepare.

A orner la tète des femmes.

AUTE. - Haere koe ki te

Et toi tu vas à la mer

(1) L'aute est une variété du Broussonetia papyrifera. - Le liber sert à faire des rubans.

Le whau est l'Enhelia arborescens (Hoheria ipopulnea); le bois de cet arbre est léger ; on l'emploie, en guise de liége, pour faire flotter les filets. 
Moana hei whau kupenga,

Pour faire flotter les filets,

Ka mutu hei pouto kupenga.

Et quand la pêche est finie, tu y restes attaché.

Morale, - Un emploi est aussi bon qu'un autre.

KaURI ToHora

Le Dammara australis et la Baleine.

Tohora. - E te Kauri, haere

Oh! Kauri, viens

Mai taua ki tai nei,

Avec moi à la mer.

KauRI. - Teka ra ko konei ra;

Non. Je préfère

Au lio taku wahi,

Mon propre élément.

Tohora. - Taua ra ka hoko kiri:

Alors changeons tous deux de peau :

Meake koe tuakina e te Tangata,

Car tu es en dangrer d'être abattu par l'homme,

A ka haua koe hei waka.

Et transformé en canot.

Ils tombèrent d'accord pour échanger leur peau : c'est ce qui fait que l'écorce du kauri, si mince, est pleine de résine, comme la peau de la baleine l'est d'huile.

Kione

Pouwhattere

Le Rat et le Perroquet rert.

Pouwhaltere. - O Kiore, lka piki taua ki runga.

O rat, montons tous deux la-haut (dans les arbres.)

Kione. - Ti te aha taua $i$ runga?

Et que ferons-nous tous les deux là-haut?

Pouphrattere. - Ki te kai pua rakau,

Nous mangerons le fruit des arbres. 
KIORE. - E aha te pua rakau?

Quelle espèce de fruit des arbres?

Pouwhaitere. - He Miro, he Kahikatea:

Ceux du Miro, ceux du Kahikatea. (1)

KIORE. - E tama ra e, ko te waka rua rua i a taua;

Mon ami, nos deux tribus vont en diminuant;

E tama ra e, e haere mai nei te Tangata;

Mon ami, voici que l'homme arrive ici;

E rona rona nei $i$ te kaki torete te wai, (2)

Bientôt il te tordra le cou,

Au, ti mau rawa.

Moi, je serai pris dans ses pièges.

Morale. - On n'échappe pas à la puissance de l'homme.

\section{NGERI NATIONAL DES TRIBUS NGATI-RAUKAWA ET NGATI-TOA.}

Awhea tou ure ka riri, Quand vous voulez que votre valeur s'emporte, Awhea tou ure ka tora, Quand vous voulez que votre valeur soit forte, $E$ ! kei te tai ka wiwi, Quand le flot murmure, $E$ ! kei te tai ka wawa, Quand le flot gronde, Tukua te ihu

Dites adieu (approchez votre nez)

$K i$ te tamaiti.

A vos enfants. Me pehea?

Que pouvez-vous faire de plus ?

Ka kite koe,

Vous voyez comment le brave,

(1) Le miro est le nom du Podocarpus-ferruginea, le kahikatea celui du Podocarpus excelsus.

(2) Torete te wai, imitation du cri de douleur de l'oiseau. 
I nga puke waka manamana,

De même que les hauts pics des montagnes,

A te toa haere ana.

Marche en avant.

Ka riro, e rongomaihiti !

Ils cèdent, ô renommée !

Cette traduction est de M. Shortland ( $p .171)$, mais elle est parfois inexacte et elle ne donne qu'une idée incomplète de l'énergie du texte. Awhea est ici pour ahea. Les mots wiwi et wawa sont une onomatopée qui représente le bruit du flot sur la plage. Le mot ure, qui est rendu par valeur, courage, signifie littéralement pénis et est employé ici au figuré. Peu de mots, du reste, jouent un aussi grand rôle que le mot ure dans les chants et les traditions des Naori, de mème que dans ceux des autres Polynésiens.

\section{CHANT FORT ANCIEN APPORTÉ D'HAWAHIKI.}

Ui mai te waero, ha!

Cherche (demande) la queue, quoi!

Ui mui te waero, ha!

Cherche (demande) la queue, quoi !

Ko roto ko tahu puta.

Elle est dedans, elle brûle dans le trou.

E puta aha te puta!

Quel drôle de trou est ce trou!

Erua nei kn te pula, ha!

lls sont deux là et ne font qu'un, quoi !

Au lieu de ui, peut-être faut-il lire hui, tressaillir, sauter, trembler. Shortland a traduit te waero par manteau, parce que le manteau Ihupuni était fait avec la queue d'un chien. Il a pu ainsi masquer l'indécence des paroles ; mais les der-. nières phrases ne permettent guère le doute. 


\section{CHANSON MAORI.}

Ekcre e pai ta te wahine.

Ka puta ki te mini.

Ka kuikui,

Ka koakoa,

$\mathrm{Ka}$ korerorero.

Mataku ana to whenua,

Oma ana te kiore.

Teneki.

MOT-A-MOT.

E kore, ne pas;

E pai, être bon ;

$T a$, aspersion, arrosement

Te wahine, de la femme ;

$K a$, partic. ; puta, ouverture, trou ;

Ki te mimi, au pisser.

Ka kui-kui, si vieille femme;

Ka koalkoa, elle est contente ;

Ka korerorero, elle bavarde ;

Mataku, épouvantée, terrifiée ;

Ana, ce, cet, il, elle ;

Te whenua, la terre;

Oma, fuir en courant;

Te 7iore, le rat;

Teneki, tout de même, ju:tement.

\section{HL PERUPERU. (1)}

Haere atu li mangareporepo,

I aha ka haere te tiare,

(1) Shortland, qui rapporte le texte de cette chanson maori, ainsi que celui de la précédente, n'en donne pas la traduction ;il se contente de dire en note: (Traditions, p. 1\%6). « Ce chant est très répandu, mais il n'est pas assez décent four qu'on le träduise. » 
LES POLYNÉSIENS.

223

I aha ka haere te tiare.

Hei whiu aha,

He aha kei rotu atu?

Ahe nihinihi.

He aha kei waho mai!

Ahe kiri tapa.

He aha kei o tapa?

Ahe liea. A! 


\section{LIVRE TROISIÈME}

\section{ORIGINE DES NÉO-ZÉLANDAIS.}

Distinction à établir entre les îles composant le groupe de la NouvelleZélande. - Traditions relatives à l'origine des Néo-Zélandais rapportées par Ćook : Ulimaroa ; - Arrivée d'étrangers à l'lle-Nord; Heawise. - Opinion de Bory de St-Vincent; de R. P. Lesson. Principales hypothèses émises sur l'origine des Néo-Zélandais.

1 - Origine tahitienne; Dumont d'Urville; son opinion sur les langues polynésiennes ; son explication du peuplement de la Nouvelle-Zélande ; réfutation de cette hypothèse.

2o Origine hawaiienne : Dieffenbach ; les Hawaiiens sont venus à la Nouvelle-Zélande en passant par l'île de Pàques : arrivée de trois canots ; introduction des Kumara à l'lle-Nord; réfutation de cette hypothèse.

$3^{\circ}$ Origine samoane $: \mathrm{H}$. Hale ; Savaii, première étape des émigrants malais et point de départ des colonies polynésiennes ; recherches linguistiques ; Savaii dérive d'Hawahiki ; réfutation de cette hypothèse. $4^{\circ}$ Origine samoane indirecte : Gaussin ; exposé et réfutation de cette hypothèse.

5० Origine hawaiienne et samoane : Shortland; exposé et réfutation de cette hypothèse. Erreurs d'interprétation : Wangaparaoa.

$6^{\circ}$ Origine samoane indirecte par Rarotonga: Thompson; raisons sur lesquelles repose cette hypothèse ; réfutation des preuves invoquées en sa faveur : Différences existant entre les Malais er Ies Néo-Zélandais ; croyance en un Hawahiki dans les îles Samoa; un seul Hawahiki; localités voisines de l'Hawahiki; direction de l'Hawahiki; route de l'Hawah:ki; chiens sauvages aux Samoa; époque des migrations. Erreurs et inexactitudes de l'ouvrage de Thomp;on.

$7^{\circ}$ Origine samoane indirecte: de Quatrefages; sa première opinion; sa deuxième opinion ; raisons sur lesquelles elle est appuyée; Rarotonga n'a pu peupler la Nouvelle-Zélavde; considérations linguistiques ; réfutation de cette hypothèse.

Nécessité d'une hypothèse rationnelle.

On a proposé plusieurs théories pour expliquer la provenance des Néo-Zélandais : aucune de ces théories n'est 
justifiable. C'est ce que l'on comprendra lorsque nous aurons exposé exactement chacune d'elles.

Avant tout, il faut établir une distinction indispensable, mais qui n'a encore jamais été faite : elle résulte des traditions elles-mêmes, et elle explique, à elle seule, l'erreur dans laquelle on est resté, jusqu'à ce jour, touchant le véritable lieu de départ des premiers habitants de l'Ile-Nord de la Nouvelle-Zélande. Tous les écrivains, quand ils parlent de ìa Nouvelle-Zélande, confondent, en effet, sous ce nom, les diverses îles qui composent le groupe. Cette manière de voir est assez exacte au point de vue des géộraphes européens; elle ne l'est pas pour les NouveauxZélandais eux-mêmes. Ceux-ci distinguent, au contrai. re, parfaitement les îles les unes des autres, et particulièrement les trois plus grandes : c'est ce que démontrent les travaux de Sir Grey, Taylor, Shortland et, pour ainsi dirê, de tous ceux qui ont parlé de la Nouvelle-Zélande depuis Cook. Les traditions rapportées par les deux premiers surtout, établissent nettement qu'il ne s'agit que de l'Ile-Nord de la Nouvelle-Zélande, quand elles parlent de l'île ou abordèrent les émigrants, en venant d'Hawahiki. Par le silence complet qu'elles gardent sur les deux autres grandes îles, tandis qu'elles' désignent plusieurs des petites îles avoisinant l'Ile-Nord, telles que l'Ile Blanche, l'Ile Mayor, les Iles de la Barrière, etc., toutes démontrent qu'il. ne faut pas confondre la partic Nord du groupe avec sa partie Sud. C'est parce que cette confusion a toujours été faite, que l'on n'a pu comprendre jusqu'à présent le texte des traditions et, par suite, la véritable situation de l'Hawahiki ou lieu de provenance des premiers émigrants : les développements dans lesquels nous allons entrer le démontreront surabondamment.

Après avoir rappelé les traditions incomplètes obtenues par Cook, dans ses différents voyages, et cherché à en montrer le peu de valeur, afin de répondro aux écrivains qui y ont encore recours; après avoir indiqué en quelques mots l'opinion de Crozet, de Bory de St-Vincent, de R.. P. Lesson, et rappelé les versions d'auteurs modernes qui ont 
parlé du fait rapporté à Cook, nous aborderons les nombreuses hypothèses, les plus ġenéralement acceptées, qu'on a émises pour expliquer le peuplement de l'Ile-Nord de la Nouvelle Zélande.

Ici encore nous suivrons l'ordre chronologique : on comprendra mieux ainsi les progrès faits peu à peu ver's la solution de la question qui nous occupe, et l'on apprendra en même temps à connaître à qui revient le mérite de certaines opinions.

Nous commencerons par l'hypothèse de d'Urville (1832); puis, successivement, nous examinerons celles de Dieffenbach (1813) ; Horatio Hale (1846); Gaussin (1853) ; Shortland (1854); Thompson (1859); de Quatrefages (1864 et 1866.)

Ce ne sera qu'après avoir réfuté chacune d'elles que nous exposerons notre opinion, en l'appuyant sur les nombreuses traditions publiées par MM. Taylor et Grey surtout, ainsi que sur celles du $\mathrm{D}^{r}$ Dieffenbach, quoique ce dernier en ait tiré une conclusion toute différente.

Voici quelles sont les traditions relatives ì l'origine des Néo-Zélandais, venues à la connaissance do Cook :

Pendant que le navigateur anglais se trouvait dans la Baie Douteuse, (1) en décembre 1769, il apprit̂́, ì l'aide de Tupaia, qu'à trois journées de navigation de pirogues, il y avait une pointe appelée Moore-IVhenua (2), où la terre se prolongeait au Sud et cessait de s'étendre à l'Ouest; il en conclut que c'était l'endroit découvert par Tasman. Voyant les Indiens si bien instruits, il leur fit demander s'il n'y avait pas plus loin quelque autre pays différent du leur. Ils lui répondirent « qu'ils n'en avaient jamais visité d'autres, mais que leurs ancêtres leur avaient dit qu'il y avait au N.-O.1/4 N. ou au N.-N.-O une contrée étendue, appelée

(1) Vie de Cook, par Kippis, p. 75. La Baie Douteuse (Utu-utu) se trouve entre le Cap-Nord de la Nouvelle-Zélande et la Baie des Iles.

(2) Le mot maori est Muri-Whenua. 
Ulimaroa, ou quelques-uns de leurs compatriotes étaient allés sur une grande pirogue. Il n'en revini qu'une partie, et ils rapportèrent qu'après un passage d'un mois, ils avaient vu un pays où les habitants mangeaient des cochons. Tupaia s'informa alors si ces navigateurs avaient ramené quelques cochons avec eux; ils répondirent que non. Il faut remarquer que, quand ils faisaient mention des cochons, ils n'en décrivaient pas la figure, mais qu'ils les désignaient seulement par le mot booah (1), nom qu'on leur donne dans la mer du Sud. »

Le 5 février 1770 , Cook se trouvant dans le canal de la Reine Charlotte, Tupaia obtenait presque la mème version, avec cette seule différence qu'il n'était plus parlé d'un dêpart de l'île. «Un vieillard, auquel Tupaia venait de demander s'il avait jamais entendu raconter qu'un raisseau, pareil à celui des Anglais, fût venu dans son pays, répondit que non, mais qu'on lui avait dit qu'autrefois un petit bâtiment, portant quatre hommes seulement, et qui était parti d'une terre éloignée nommée Ulimaroa, était venu sur leur côte; et qu'a leur arrivée les quatre hommes avaient été tués. On lui demanda alors où était située la terre d'Ulimaroa, et il montra le Nord. (2) »

Cook ajoute, à cette occasion, qu'il avait appris déjà quelque chose concernant Ulimaroa; que les habitants de la Baie des Iles lui avaient rapporté que leurs ancètres y ètaient allés, et que Tupaia en avait aussi quelques notions confuses ; mais qu'on ne pouvait rien conclure de certain d'après les traditions de Tupaia, ni d'après celles du vieillard zélandais.

En effet, ces rersions se contredisent. La dernière ne dit pas que ce bâtiment fût d'abord parii d'un point de l'île ; ce n'était évidemment qu'une petite pirogrue puisqu'il n'y avait que quatre hommes; et de leur massacre, on peut seulement conclure qu'ils étaient étrangers au point abor-

(1) Ce mot booah prouve que Castera, dans sa traduction de la vie de Cook, a parlé a tort de chiens au lieu de cochons.

(2) Ouvr. cité, p. 84 . 
dé. Or l'on n'a pas remarqué que ce point se trouvait de l'autre côté du détroit de Cook, sur l'Ile du-Milieu, c'est-à dire sur une autre île que l'Ile Nord. La terre d'où venait cette pirogue étant indiquée au Nord, c'est sans doute d'après ce fait, tant répété depuis, qu'on a dit que les NéoZélandais étaient venus du Nord. Mais, comme nous le montrons, ce fait prouverait piutôt que ce n'était qu'une pirogue de l'Ile-Nord elle-mème, allant aborder, volontairement ou non, sur l'ìle voisine, ou Ile-du-Milieu ; car c'est justement au Nord du canal dit de la Reine-Charlotte, que gît l'Ile-Nord de la Nouvelle-Zélande.

Quant au premier texte, il ne prouve absolument rien, ou plutôt il prouve que la pirogue dont il est parlé était d'abord partie de l'Ile-Nord et que, par conséquent, l'île était déjà peuplée.

Pourtant, ce sont ces deux récits, probablement d'un mème fait, récits sans aucune valeur, qui ont donné naissance i l'opinion, et qui ont fait soutenir par beaucoup d'écrivains, que la Nouvelle-Zélande a été peuplée par des émigrants venant du Nord.

Personne n'a pu dire quelle pouvait ètre la contréc appelée Ulimaroa : en la voyant ainsi désignée par Cook, qui n'a jamais pu rendre exactement un seul nom océanien, il était tout naturel de trouver quelque rapport entre ce mot et le mot Ulietea, de Cook, la Raiatea des indigènes des Iles de la Société ; mais ce n'était qu'un rapport apparent.

En effet, cette île Ulimaroa, d'après Cook, se trouvait placée dans le N.-O. 1/4 N. ou le N.-N.-O de la NouvelleZélande : or, ce n'est point dans cette direction que gìt l'ile Raiatea par rapport au groupe de la Nouvelle-Zélande. Dims la direction indiquée il n'y a, jusqu'a une fort grande distance, que des île telles que la Nouvelle-Calédonie, les Nouvelles-Hébrides, Vanikoro, les îles Salomon, etc. Il est vrai, ce qui n'avait pas été remarqué, croyons nous. qu'en poursuivant cette direction, on rencontre, dans les Carolines, une île nommée Olimarao, nom qui se rapproche beaucoup de l'Ulimaroa de 
Cook. Freycinet parle de cette île dans la relation de son voyage autour du monde et, quelques années après lui, en 1828, le navigateur russe Lutke, qui s'en croyait le découvreur, en fit la géographie. Elle forme, d'après lui, un petit groupe de huit à neuf milles de circuit, composé seulement de deux îlots bas et boisés, situés par $7^{\circ} 45^{\prime}$ de Lat, et $142^{\circ}$ 37' de Long. Est.

Il est donc certain que cette île gît à peu près comme il a été dit à Cook pour son île Ulimaroa, c'est-à-dire dans le N.-N. -O de la Nouvelle-Zélande, et il eût été certainement possible que la pirogue, arrivée à la Nouvelle-Zélande avec ses quatre hommes, fût partie de ce point, entrainée peutêtre par quelque fort coup de vent, comme Kadu, par exemple. Mais la distance parcourue aurait été tellement grande; tant d'autres îles se seraient rencontrées sur le chemin, qu'il nows semble bien difficile de pouvoir admettre une pareille provenance, surtout en présence du premier texte qui faisait partir la piroğue de l'Ile-Nord mème, avant qu'elle ne revînt d'Ulimar $\%$.

Quant au mot booah, que Cook a employé dans son récit, nous devons faire remarquer qu'il prouverait plutôt en faveurdes lles de la Société, puisqu'il est le nom du cochon dans ces îles. Mais comme ce nom a été donné à Cook par Tupaia, il est évident que le navigateur anglais n'a fait que reproduire le mot tahitien porté par l'animal décrit par les Nouveaux-Zélandais et prononcé par Tupaia. Ce qui d'ail leurs ne permet pas de douter de l'erreur de ceux qui croient qu'Ulimaroa aurait pu être l'île Raiatea (Ulietea de Cook), c'est que Cook ajoute : a Du reste Tupaia avait quelques idées vagues sur l'existence de la contrée appelée Ulima roa. $\gg$ Comment, en effet, si l'on eût voulu parler de Raiatea, Tupaia, qui était de cette île, n'aurait-il eu que des idées vagues sur elle?

Il est vrai que, depuis Cook, les observateurs modernes les plus compétents, Hale, Taylor et Thompson, ont, a l'aide de quelques détails, donné plus d'importance à ces mèmes traditions qui, à notre aris, en ont si peu telles qu'elles ont 
été fournies à Cook : d'après eux, ce ne serait plus une simple pirogue, mais un véritable navire.

Voici ce que dit Taylor à ce sujet: (1)

"Les indigènes du détroit de Cook ont couservé le souvenir traditionnel d'un bâtiment qui serait arrivé à Arapawa, (Queen's Charlotte Sound), avant le premier voyage de Cook. Ils nomment le capitaine Rongotute. L'équipage ayant commis des excès, les habitants furieux saisirent le navire, tuèrent tous les gens de l'équipage, les mangèrent, et, après avoir pillé le navire, ils en abandonnèrent la coque sur le rivage.

a Dans le butin se trouvaient de nombreuses assiettes qu ils appelèrent, en raison de leur forme, a la tête de Rewarewa. - Ce nom est celui de la maladie qui, il y a plusieurs années, a sévi sur eux et en a fait périr un grand nombre. Il doit aroir été donné parce qu'elle ressemblait a quelque chose de ponctué, la maladie laissant en effet des marques sur tout le corps, comme le fait la petite vérole.

a Ils brisèrent ces assiettes et, après avoir fait des trous dans les morceaux, ils les portèrent aux oreilles comme ornement. Il y avait, dit-on, un objet très ressemblant à un Mere et qui, à cause de cela, était fort estimé 11 est encore dans la possession de quelque personne de la tribu $\mathrm{Ngati-}$ Hiru. Les indigènes disent que ce fut alors pour la première fois qu'ils virent du fer, et qu'ils firent des haches arec les clous. $n$

Taylor ne dit point vers quelle époque ce fait serait arrivé; mais, d'après Thompson, ce serait vers 1740. Voici comment il le rapporte (2) :

"Une tradition établit qu'un vaisseau européen, commandé par un homme appelé Rongotute, arriva à la partie Sud de l'Ile-Nord de la Nouvelle-Zélande, vers 1740, et que, pour un motif quelconque, les naturels tuèrent l'équipage et pillèrent le navire. $\gg$

C'est évidemment le même fait emprunté à Taylor, avec

(1) Te Ika a Maui, p. 20\%

(2) The Stiory of the New-Zealand, t. I, p. 229 
moins de détails et la date en plus. Des dernières lignes du Révérend Taylor, il faut absolument reconnaître que c'était un navire venant d'un pays civilisé, et non plus une pirogue. A ce titre, quoique le fait se soit passé lui aussi justement dans le canal de la Reine-Charlotte, à Arapawa, on pourrait douter que c'est le même dont il a été parlé par le vieillard de Cook; mais, quand on sait combien facilement une tradition se modifie avec le temps et s'enrichit ou s'appauvrit suivant le narrateur, il est permis de croire que ce ne sont que des traditions différentes fondues en une seule. Il est certain que si la date donnée est exacte, ce n'aurait pu être Juan Fernandez, que quelques géographes croient être allé jusqu'a la Nouvelle-Zélande, parce qu'il disait s'être éloigné des côtes du Pérou jusqu'à environ 40 degrés en longitude avant de trouver la terre que nous croyons avoir démontré être le groupe Mangareva. Jüan Fernandez en serait revenu d'ailleurs, puisqu'il n'est mort qu'au moment de réaliser le projet qu'il avait formé d'aller coloniser cette terre. L'on sait cn outre qu'il n'a fait sa découverte qu'en 1770 .

Un seul navigateur, Lozier Bouvet, s'est approché de la Nouvelle-Zélande en 1739, mais il ne paraît pas avoir vu d'autre île que celle qu'il décourrit et qu'il appelia cap de la Circoncision.

Enfin Anson fit également son voyag’e si connu, vers cette époque, 1741; mais on sait qu'il n'alla pas de ce côté.

Il est un fait toutefois, rapporté par d'Urville, qui pourrait faire croire à la venue de quelque grand navire. Un vieillard fort âgé, des bords de Shouraki-Ang’a, dit-il (1), raconta en 1820 aux marins du Dromadery, qu'il tenait de son père, qu'à une époque fort ancienne, un canot monté par des hommes blancs et armés de mousquets sans ressorts, était entré dans la rivière. "Longtemps après cet évènement, ajoute d'Urville, un navire s'était perdu sur la côte ; l'équipagre d'un canot étant venu à terre pour prendre des provisions, fut massacré par les naturels. Personne ne

(1) Vol. II, 2e partie, p. 29t, Essai sur la Nouvelle-Zélante. 
vit les débris de ce naufrage. » (Extrait de Cruize, p. 87.) Et il se demande si ces traditions auraient quelque fondement ou bien si elles ne seraient qu'un souvenir, confus et altéré par le temps, du passage de Tasman sur les côtes de ces îles.

Shouraki-Anga gît sur la côte Est de l'Ile-Nord; il est par conséquent douteux qu'on ait voulu parler des navires de Tasman qui n'a pas passé sur cette côte. Pourquoi ne serait-ce pas quelque navire espagnol, ou plutôt le souvenir confus de la fin tragique de Marion, et surtout de sa chaloupe?

De ces derniers récits, pas plus que de ceux faits à Cook lui-même, on ne peut donc conclure avec quelque probabilité d'où venaient les habitants de la Nouvelle-Zélande. Ces récits ne se rapportent qu'à des faits sans importance pour la question qui nous occupe : ce ne sont que des accidents arrivés à quelques pirogues et peut-être à un navire de pays civilisé. Mais si le dernier doit paraître douteux, à cause du lieu mème où on l'a observé, les premiers sont absolument sans valeur.

Un fait de même nature, cité par M. Hale, serait peut. être plus digne d'attention, s'il était exact: il indiquerait, dans ce cas, que des émigrations d'Hawahiki à la NouvelleZélande se sont opérées justement dans l'année qui, d'après Thompson, a vu arriver sur la côte Sud de l'Ile-Nord le navire commandé par Rongotute, M. Hale dit, en effet : « ce fut dans l'année 1740, qu'arriva à la Baie des Iles une colonie de Polynésiens venant d'Hawahiki. »

D'après cela, cette colonie serait venue faire terre du côté opposé au point où le navire de Rongotute avait abordé. En outre, M. Hale se contente de son assertion, sans chercher à l'appuyer de quelque preuve. C'est d'autant plus à regretter qu'il a cité 'ce fait uniquement pour étayer son hypothèse d'une provenance pulynésienne. Mais, de son côté, M. Thompson s'est empressé de combattre cette asser. tion du savant américain, en disant (l) que des recherches

(1) The Story, etc. t. 1, page 66. 
attentives, faites par lui en 1850, sur les lieux mêmes où M. Hale avait puisé ses renseignements, l'ont mis à même d'assurer qu'il avait été mal informé, et qu'il ne s'est point fait d'émigrations modernes de la Polynésie à la NouvelleZélande.

Telles sont, en résumé, les traditions qui ont été premièrement obtenues par Cook; elles devaient être relatées ici, afin que le lecteur pût les apprécier : mais, comme on voit, elle n'aident en rien à retrouver le lieu d'origine des Nouveaux-Zélandais.

Touteiois le grand navigateur avait entendu parler d'une autre tradition, qui plaçait le lieu d'origine des NouveauxZélandais dans un pays appelé Heawise (1); et cette tradition était, sans qu'il s'en doutât, la seule véritable : c'est ce que démontrera tout ce que nous allons dire maintenant. Mais nous ne pouvons passer sous silence la bien curieuse étymologie que d'Urville a donnée à ce mot rendu, comme toujours, si incorrectement par Cook :

* Cook, dit-il, (2) au lieu de Heawise ou Heaveeje, n'aurait-il pas entendu plutôt Iwi, mot qui, en Maori, signifie à la fois os et tribu ? Et. nous signalerons la ressemblance avec le nom Eve, mère du genre humain, selon la Genèse. »

Cette ressemblance, il faut en convenir, est plus grande que celle d'Equus et d'Alfana, entre le mot qu'il suppose avoir été entendu et celui d'Eve ; mais elle n'existe pas, puisque le mot dit à Cook n'était autre que Hawahiki, ainsi qu'Horatio Hale, le premier, l'a remarqué.

Avant d'aborder l'examen critique des hypothèses qui sont le plus généralement admises, nous citerons encore, mais seulement pour mémoire, en raison de l'importance qu'on accorde d'ordinaire à l'opinion de ceux qui ont vu ou se sont occupés spécialement d'un sujet, lamanière de voir,

(1) Cook, ler voyago, t. IlI, p. 293.

(2) T. II, 2e partie, p. 290. 
sur cette question, de Bory de Saint-Vincent, de R.P. Lesson et de Crozet.

Le silence que ce dernier a gardé sur la provenance des Blancs, qui, avec les Basanés et les Noirs, forment, d'après lui, le fond de la population de la Baie des Iles, point de l'Ile-Nord où son navire était allé relâcher, est, en effet, remarquable : on pourrait peut-être conjecturer qu'il regardait les Blancs comme autochthones. Il semble du moins que c'est ce qui résulte de ce silence, alors qu'il explique l'existence des Basanés et des Noirs par le voisinage de la Nouvelle-Hollande, sans parler en aucune façon de l'origine des Blancs; cependant rien dans son texte ne le dit, et il faut convenir que cela d'ailleurs importe assez peu.

Comme on a vu précédemment, Crozet, Banks et Bory de Saint-Vincent étaient les seuls qui, avant nous, eussent admis que le peuplement de la Polynésie s'était, ou avait pu s'opérer par des colonies venant de la Nouvelle-Zélande. Mais Bory de Saint-Vincent lui-même n'avait rien dit d'explicite à cet égard ; c'est seulement par induction qu'on peut inférer qu'il était partisan de l'autochthonic des Nouveaux-Zélandais.

Voici ce qu'il dit à ce sujet (l) :

“ La race océanique paraît s'ètre séparée de la race malaise avant sa connaissance des métaux, si toutefois elle n'eut pas un berceau différent. La Nouvelle-Zélande, où l'on voit des monts fort élevés, et qui dut saillir au-dessus de la mer quand la Nouvelle-Hollande était encore inondée, nous semblerait être le lieu dont elle sortit pour s'étendre vers le Nord et dans tous les archipels de l'Océan Pacifique que n'occupent pas des Mélanésiens, des Papous ou même des Siniques et des Hindous, qui ont aussi pénétré dans quelques parties de l'Océanique. ”

«En attendant qu'on nous prouve la possibilité d'un peuplement par l'Amérique, nous continuerons, dit-il plus loin (2),

(1) L'homme, vol. I, p. 298.

(2) Ibid. p. 314. 
à reconnaître le point d'où s'irradia la race océanique dans la Nouvelle-Zélande. »

Enfin il répète ailleurs : (1). « Nous avons cru apercevoir le point de départ de la race océanique, la seule sur laquelle on peut hasarder des conjectures probables, dans la Nouvelle-Zélande."

On conviendra que si ces paroles ne disent pas nettement que Bory de Saint-Vincent regardait les Maori comme autochthones, elles le font du moins implicitement.

Nous verrons plus tard qu'il ne se trompait qu'à demi en cela et que, par conséquent, il était, dès lors, avec les données importantes qui lui manquaient, plus près de la vérité que ne le sont tous les ethnologues actuels.

On sait que l'ouvrage de Bory de Saint-Vincent, publié en partie en 1825, dans le Dictionnaire classique d'Histoire Naturelle, a paru complet et corrigé en 1827 , avec une dédicace à Georges Cuvier. L'auteur, dans sa classification des races humaines, s'est particulièrement appuyé, pour celles de l'Océanie, sur les renseignements fournis par le naturaliste R. P. Lesson, compagnon de Duperrey, pendant son voyage autour du monde. Il renvoie à la relation de ce royage, dans une note (2) qui montre parfaitement, du reste, que si il y aurait exagération ridicule à supposer que tous les Océaniens sont autochthones sur les moindres îles où on les rencontre, il ne serait guère plus philosophique de les faire venir «toujours $\gg$ des Hindous qui ne leur ressemblent pas plus, dit-il avec raison, que les Caraïbes ne ressemblent aux Allemands.

Cette note était une réponse à l'opinion du naturaliste de la Coquille, qui venait de donner l'Inde comme le point de départ des divers rameaux de la race océanienne. On a vu, qu'en parlant des Carolines, nous avons émis nousmême une manière de voir semblable à celle de Bory de Saint-Vincent, de mème que nous avons pensé, après lui,

(1) Ouvr. cité, vol. II, p. 1'r6.

(2) Quvr. cité, vol, I, p. 312 
que c'est par la Nouvelle-Zélande que la Polynésie a ét’́ peuplée.

Néanmoins ce que Bory de Saint-Vincent dit de la séparation de la race océanique de la race malaie, n'est pas exact, puisque les caractères des deux races ne sont pas du tout les mêmes, sous aucun rapport, ainsi que nous avons dejà eu tant d'occasions de le faire remarquer. Il est bien certain, en effet, que les caractères physiques, par exemple, diffèrent complètement dans les deux races, et que ceux qu'il donne à la race océanique sont très incomplets, parfois même inexacts, comme lorsqu'il dit que cette race a une oreille petite et des cheveux fins. Tous ceux quil'ont vue savent, au contraire, que l'oreille est toujours grande et que les cheveux sont toujours gros.

Seulement, et c'est ce que nous voulions surtout faire remarquer, cette filiation de la race océanique de la race malaie n'était pas pour lui fort probable, puisque, par une sorte d'intuition, il semblait admettre que la race océanique pouvait provenir d'une autre source, et qu'il disait : « si toutefois elle n'eut pas un berceau différent. D

Comme c'était de la Nouvelle-Zélande qu'il faisait partir les colonies allant peupler la Polynésie, sans rien dire, lui non plus, du lieu d'origine des premiers habitants, il est au mcins permis de croire, que s'il ne le disait pas formellement, il pensait que le peuple zélandais pouvait être l'un de ceux qu'il admettait comme autochthone.

Quoiqu'il en soit, vers la même époque, le naturaliste de la Coquille, après avoir également observé les NouveauxZélandais à la Baie des Iles, croyait qu'il pouvait placer dans l'Inde leur berceau, de même que celui des autres Polynésiens. Il était alors embarqué sur le navire où se trouvait Dumont d'Urville comme second, et il observait par conséquent en mème temps que ce marin, devenu si célèbre depuis. En outre de la relation officielle, il publia, à ce sujet, plusieurs articles dans divers recueils et particulièrement dans le Journal des Voyages de Ferussac. Nous em- 
pruntons le résumé de son opinion au grand travail qu'il publia plus tard (1).

"Les Zélandais ont une vieille tradition par laquelle ils ont appris que leurs pères partirent d'une très grande île, pour venir habiter la Nouvelle-Zélande; mais le voile qui couvre leur origine ne pourrait être déchiré que par les recherches ardues d'un homme instruit, établi dans les îles, et peut-être que le missionnaire Kendall aurait pu rendre ảe grands services, sous ce rapport, s'il n'arait pais été absorbé par une pensée dominante, et s'il ne rapportait pas exclusivement la croyance des Nouveaux-Zélandais au système de Pythagore, en les regardant comme une colonie d'Egyptiens. "

C'cst après cela qu'il ajoutait : « Nous avons déjà émis l'opinion que les divers rameaux de la race océanienne sont nés sur les rivages de l'lnde, dans les premiers temps de leur civilisation. Ce qui corrobore notre manière de voir, c'est la figure de jade que les Nouveaux-Zélandais portent suspendue au cou ; les cercles conservés dans leurs sculptures, et qui rappellent le serpent Calingam ; le Lingam qui paraît jouer un grand rôle dans leur mythologie; enfin une grande partie de leurs idées appartiennent au Gabéisme et découlent des anciennes traditions mystiques des Brahmanes. »

Nous renons de le dire, nous ne croyons pas à la possibilité d'une pareille provenance, les Hindous ne ressemblant nullement aux Nouveaux-Zélandais ; mais il n'est pas moins vrai que les témoignages qu'il trouve dans les faits qu'il cite, semblent dignes de la plus sérieuse attention, malgré la difficulté de les expliquer.

Nous allons maintenant examiner les hypothèses auxquelles on accorde le plus de créance.

(1) Voyage autour du Monde, entrepris par ordre du gouvernement sur la coivette la Coquille, par R. P. Lesson, membre correspondunt de l'Inetitut. Pourrat frères, Paris, 1839, t. II, p. 368. 
$1^{\text {re }}$ нуротнѐs: : Origine tahitienne des Nouveaux-Zélandais. - Dumont D'Urville est l'auteur de cette hypothèse.

Après avoir d'abord dit (1) que les Polynésiens sont arrivés d'Occident ou mème de l'Asie ; après avoir avancé plus tard (2) qu'ils sont venus d'un continent disparu situé dans le Sud-Est de l'Océan Pacifique, il finit par admettre que la Nouvelle-Zélande a été peuplée, aussi bien que les Samoa et les Sandwich, par la Polynésie; mais il ne le fait pas sans hésitation, cornme le prouvent les lignes suivantes: (3) « La vaste étendue des terres de la NouvelleZélande, leur situation sous un climat tempéré, la force et lia vigueur de la race qui les habite, pourraient d'abord donner lieu de penser que ce fut là le berceau ou du moins la première station de la race polynésienne; mais des considérations puissantes obligent de repousser cette hypothèse. ”

On a vu quelles sont ces considérations que nous avons longuement refutées, quand nous avons essayé de démontrer que le peuplement de la Polynésie a été fait par la Nouvelle-Zélande : nous n'y reviendrons donc pas ici.

D'Urville terminait en disant: «'Tous ces motif's réunis nous portent donc à considérer la Nouvelle-Zélande comme la dernière des terres de l'Océanie occupées par la race polynésienne. "C'était, en somme, le contre-pied de la croyance de Bory de Saint-Vincent que la Nouvelle-Zélande avait été la première terre exondée et que cette terre avait fourni leurs habitants aux îles Polynésiennes.

Pour Dumont d'Urville, c'était l'île T'ahiti qui avait été la première occupée par la race polynésienne et qui avait fourni des colonies non-seulement aux Sandwich et à toutes les îles de la Polynésie, mais aussi à la Nouvelle-Zélande : « Dans notre opinion, dit-il, (4) les îles Tahiti ont donc reçu, avant Hawaii et la Nouvelle-Zélande, la race qui habite aujourd'hui les trois groupes. »

(1) Mémoire sur les Iles du Grand-Océan, décembre 1831, p. 16.

(2) Philologie, $2^{\mathrm{c}}$ partie, p. 304.

(3) Philologie, p. $2 \%$.

(4) Philologie, p. 280. 
Pour appuyer cette opinion, d'Urville avait recours à quelques assertions qui, à notre avis, ne lui étaient guère favorables: S'il admettait, avec le plus grand nombre des ethnologues, que les îles Hawaii ont reçu leurs habitants de Tahiti, il disait encore, ce qui est plus difficile à comprendre, que la langue de Tahiti, toute altérée qu'elle était, se rapprochait plus souvent du type primitif que celle d'Hawaii, dans laquelle s'étaient introduites, avec les siècles, des corruptions plus profondes. Mais, ce qu'il ne disait pas, et ce qui eût été cependant plus exact, c'est que la langue de la Nouvelle-Zélande se rapproche davantage de ce type, car elle possède, comme celle de quelques autres iles polynésiennes, la naso-gutturale $n g$. Il est évident qu'il ne songeait, dans le moment, qu'à établir que Tahiti avait été la première contréc peuplée, puisqu'après cela il ajoutait (1) :

a En admettant que les îles Hawaii ont été peuplées par Tahiti, il faut admettre en mème temps que Tahiti peupla aussi la Nouvelle-Zélande à une époque où la langue était encore peu altérée, puisque les idiomes des Hawaii et de la Nouvelle-Zélande, situées dans des climats plus tempérés, conservent plus d'énergie que celui de Tahiti."

Du moment que d'Urville regardait Tahiti comme le berceau des deux autres archipels, cette explication devenait évidemment nécessaire; mais il reconnaissait lui-mème que la langue de Tahiti était comparativement celle d'un peuple d'enfant $\left(\boldsymbol{*}_{*}\right.$. Unc pareille conclusion doit d'autant plus surprendre, que les recherches de d'Urville sur les dialectes océaniens auraient dû le conduire à une conclusion toute opposée ; car il arait remarqué lui-même que le Mawi, comme il l'appelle, est resté plus près de la langue primitive que le Tahitien. Que Tahiti ait été peuplée, comme il le dit, avant les Sandwich, ce n'est plus, croyons-nous, une question : aucune contrée dans le Nord n'ayant pu fournir les habitants des îles Sandwich, il fallait récessairement

(1) Philolngie, p. 279.

(2) Philologie, p. 240 . 
qu'ils vinssent du Sud ou du Sud-Ouest. C'est, en effet, comme on a vu, ce que disent les traditions hawaiiennes, qui semblent les faire provenir plus particulièrement des Iles de la Société.

Mais que Tahiti ait peuplé aussi la Nouvelle-Zélande, comme le soutient d'Urville, c'est ce qui est contredit, comme nous l'avons déjà montré, par toutes les données précédemment examinées. Pour que cela eût pu aroir lieu, il faudrait admettre que la Nouveile-Zélande a été peuplée par des émigrants, suivant une route inverse à celle que l'on reconnait avoir été faite pour le peuplement des îles plus orientales que Tahiti, et s'éloignant avec des vents contraires; il faudrait supposer enfin que la langue la plus enfantine aurait donné naissance à celle que ceux-là même, qui lui refusent la qualité de langue-mère, considèrent aujourd'hui comme la plus voisine du type qu'ils appellent primitif, et qui n'est sans doute, dans leur pensée, que le Grand-Polynésien de Crawfurd. Il nous semble qu'il serait plus logique, d'après toutes ces observations, de penser le contraire. Ajoutons du reste que d'Urville, à ce sujet, se contentait de l'opinion de Crawfurd (1), sans trop la comprendre, comme il le prouve en appelant, avec Balbi, GrandOcéanien, ce que le savant anglais appelait Grand-Polynésien.

Après avoir dit que les langues polynésiennes ne doivent pas au Malayou leur analogie avec le Madekass, et que des mots communs au Madekass et au Polynésien ne se retrouvent pas dans le Malayou, il ajoute : « Ces considérations ne semblent-elles pas confirmer l'hypothèse que tous ces langages dériveraient d'une langue très ancienne, aujourd'hui perdue, et dont les traces sont restées plus ou moins pures et nombreuses dans les divers idiomes de l'Océanie? Nous rappellerons que c'était là l'opinion de Forster, cet observateur dont les aperçus généraux sur l'Océanie furent empreints d'un esprit de sagacité et de lucidité si étonnant. "

(1) Philologie, p. 275. 
On verra plus tard que cette manière de voir est adoptée presque textuellement par quelques écrivains modernes. En attendant, voici comment d'Urville expliquait le peuplement de la Nouvelle-Zélande par les Tahitiens (1) :

« Favorisés par les vents de Sud-Est, ils purent facilement atteindre les îles Nouka-Hiva et, de là, nul doute que, malgré la distancé, des pirogues égarées sur la surface des flots n'aient pu aborder aux îles Hawaii, qui se peuplèrent successivement de la même race. D'autre part, à l'aide des mêmes vents de Sud-Est, les Polynésiens poussèrent sans peine leurs aventureuses navigations vers le Sud Ouest, et c'est ainsi que les îles Chatham et de ìa Nouvelle-Zélande durent recevoir leurs colonies. $\gg$

Nous l'avouerons, cette assertion, quoique venant d'un marin célèbre, ne semble pas pouvoir être prise à la lettre. Il est difficile de comprendre qu'en partant de Tahiti, les pirogues aient pu atteindre, aussi facilement qu'il le suppose. et les Marquises dans le Nord-Est et les Chatham, dans le Sud-Ouest. Il est certain que les vents de Sud-Est sont a peu près traversiers ; mais, d'un autre côté, la distance est véritablement si grande, et telle est parfois la force de ces vents, qu il semble impossible d'admettre que les émigrants de Tahiti auraient pu atteindre d'emblée les îles Chatham surtout, qui gisent dans le Sud-Est de la Nouvelle-Zélande. On comprendrait mieux qu'ils fussent allés, avec ces vents là, jusqu'en Malaisie, comme quelques écrivains l'ont dit ; mais alors il faudrait se demander comment les îles plus sud et plus Sud-Est que Tahiti auraient été peuplées.

Il est vrai que d'Urville va au-devant de cette question, en disant : (2) \& Les: Tahitiens s'élancèrent dans toutes les directions, allant à la recherche de nouvelles terrus. "Ce qui, il faut le remarquer, fait du moins supposer que, pour ces voyages-là, ils avaient recour's nécessairement à d'autres vents que ceux du Sud-Est, c'est-à-dire, comme on le sou-

(1) Philologie, p. 280.

(2) P. 280, ourr. cit. 
tient grénéralement aujourd'hui, aux vents de la fartie de l'Ouest.

Qu'on nous permette, à cette occasion, de citer les lignes suivantes de d'Urville ; elles prouveront que cette question n'était guère plus claire pour lui que celle de la position de l'Ile Taumaco de Queiros: (1) « Les Polynésiens, dit-il, (2) n'eurent aucune peine ì se répandre sur les îles situées sous le vent, dans toute l'étendue de la zône équatoriale, si déjà elles n'étaient pas occupées par cette race. » Mais alors, d'où d'Urville supposait-il donc sortis les premiers habitants de cette race trouvés dans ces îles, lui qui regardait Tahiti comme le foyer principal, sinon comme l'unique centre de départ?

Puis il ajoute : "Parrenus aux îles Viti, la race mélanésienne, plus nombreuse et plus vigoureuse, leur opposa probablemenć une résistance qu'ils n'avaient point rencontrée ailleurs, et là fut le terme de leurs progrès vers l'Ouest, à cela près de quelques îles isolées, comme Rotuma, Tukopia, Anouta, et les îles basses voisines de Nitendi, où ils réussirent encore à s'établir. ”

Nous avons tenu i citer tout ce passagre, parce qu'il est curieux de voir d'Urville indiquer les Viti comme l'obstacle probable aux migrations polynésiennes vers l'Ouest, à l'instant mème où il cherche à faire adopter l'opinion que la Nouvelle-Zélande a probablement reçu ses habitants des îles de la Société. Il est vrai que l'obstacle n'est plus le même pour la Nouvelle-Zélande qui est, elle aussi, plus Ouest, ou mieux Sud-Ouest, et qu'on aurait pu y arriver directement sans rencontrer aucune agglomération de peuples. Mais la distance qui sépare les deux contrées est tellement grande, qu'elle doit être bien suffisante à elle seule pour empêcher de croire à un pareil voyage. On a même de la peine à l'admettre quand, avec les partisans

(1) Voir à ce sujet le texte du voyage de l'Astrolabe, et notre examen critique de la route faite par nous, Recherches sur l'Océanie.

(2) Philologie, p. 281。 
de l'origine polynésienne des Maori, on se borne à faire partir les émigrants des îles Samoa, Tunga on Hervey.

On l'a vu précédemment, nous pensons que les Fiji ont non-seulement pu être un obstacle au passage des Puiynésiens, dans le sens de l'Est à l'Ouest, comme le dit d'Urville, mais elles en auraient également été un si ces émigrants s'étaient dirigés de l'Ouest vers l'Est, comme on le croit généralement. On ne comprend pas, en effet, comment ce qui auraitété un empêchement dans un sens n'aurait pas pu l'être dans le sens opposé. Mais, nous l'avons dit aussi, cet empêchement n'a dû exister que pour les migrations secondaires, s'opérant arec d'autres vents, les mi-. grations principales ayant pu et dù atteindre les îles qu'elles habitent, sans même soupconner l'existence des îles voisines qui étaient peuplées par une autre race, poussées qu'elles étaient par des vents qui les en éloignaient.

Cette dernière assertion de d'Urville ne prouve, a notre avis, qu'une chose, c'est que, dans le moment, il ne songeait qu'à appuyer son hypothèse d'un continent subnergé, et de migrations opérées de l'Est vers l'Ouest. Mais pour lui, en résumé, c'était bien à Tahiti qu'était d'abord arrivée la race polynésienne, quelle que fùt son lieu d'origine, et c'étaient Tahiti et les autres îles de la Société qui avaient peuplé les Sandwich et la Nouvelle-Zélande, * en commen « çant par subjuguer et en finissant par détruire la race " mélanésienne qui les occupaitprimitivement, d'après tou* " tes les apparences (1)."

Nous avous précédemment fait connaître notre opinion à ce sujet nous n'y reviendrons donc pas et nous aborderons de suite l'examen de la seconde liypothèse par ordre de date, quoiqu'elle ait été émise assez longrtemps après la sienne.

2 HYPOTHÈSE : Origine hawaiienne des Nouveaux-Zélandais. - C'est à Dieffenbach qu'est due cette hypothèse

(1) Philologic, p. 280. 
¿doptée par quelques écrivains français et fondue dans celle de d'Urville.

Dieffenbach était à la Nouvelle-Zélande dans l'intervalle de 1839.1841. Il y avait été envoyé par les directeurs de la Compagnie de la Nouvelle-Zélande, en qualité de médecinnaturaliste ; ce fut sans doute à ses fonctions assujettissantes qu'il dut de ne pouvoir visiter que le détroit de Cook, l'lle-Nord, et exceptionnellement les îles Chatham. De retour à Lonỏres, après des recherches qui avaient duré dix-huit mois, il publia, en 1843, les deux volumes qui font connaitre ses observations et résument la plus grande partie des connaissances acquises sur la Nouvelle-Zélande jusqu'à cette époque. (1)

Pour qu'une pareille masse de matériaux ait pu êtro rassemblée en si peu de temps, il faut supposer que Dieffenbach a dî ètre aidé par quelques résidents; car c'est seulement par l'intermédiaire de ceux-ci que tout ce qui concerne particulièrement l'histoire et les traditions a pu lui parvenir. Il est évident que ce n'est point aux missionnaires anglais qu'il doit généralement ses renseignements ; pcit-être mẻme peut-on conclure, de l'inexactitude de quelques-uns, qu'ils proviennent de toute autre source. Mais il n'est pas moins vrai que Dieffenbach a été le premier à faire connaître des traditions ignorées jusque là, à en déduire une nouvelle explication des migrations polynésiennes, et à aider, par la quantité des matériaux recueillis, à résoudre la question si difficile de l'origine des Maori.

Sappuyant surtout sur l'une de ces traditions, il a cru voir que le peuplement de l'île Ika-na-Maui avait été opéré par trois canots venant de l'Est, au lieu de venir de l'Ouest, comme on le croit généralement. Puis, trouvant, avant que $M$. Hale n'émît la même opinion, que les mots Tawai et Hawahiki, de la Nouvelle-Zélande, étaientles mots Tauaï et Havaii des Sandwich, et que les mots Hawahiki et Havaii n'étaient eux-mêmes que le nom de l'île d'où étaient partis les canots, il n'hésita pas de conclure que certaine-

(1) Travels in New-Zcaland, by Ernest Dieffenbach, two vol. London, 1843. 
ment la Nouvelle-Zélande a reçu des habitants des îles Sandwich, non pas, il est vrai, directement, mais indirectement par l'lle de Pâques.

"Nous ne pouvons manquer, dit-il, (I) de reconnaître dans les noms Hawaïki et Tawai, les îles Sandwich et Tauai (2); mais ily a encore une preuve plus convaincante que les Sandwich sontla dernière source d'où les Zélandais sont sortis, c'est qu'ils ont des traditions qui les font remonter à des temps plus anciens encore, lorsque Maui et ses frères pèchèrent la Nouvelle-Zélande. (3).

Dieffenbach rapporte ainsi ce que les traditions lui ont appris (4) :

* Il n'y arait pas d'habitants sur la terre (5) arant l'arrivée de ceux qui l'occupent aujourd'hui, et cette terre était couverte de forêts. Trois canots arrivèrent alors d'une terre éloignée située à l'Est : ils s'appelaient Arawa, Kotahinui et Matatua. Ils portaient les te tupuna ou te kau matua (6). Dans l'Arawa étaient les ancètres les Nga-Pui (i) et des Rarewa, qui se tenaient devant; les Nga-te-Wakalla

(1) Ouvr. cité, t. II, ch. VI, p. 88.

(2) Il ajoute ici: «L Lune des différences ent:e le dialecte de la Nouvelle-Zelande et celni des îles Sandwich, c'est que, dans ce dernier, comme dans le dialecte de Tahiti, l'emploi des consonnes est inoins fréquent. Arii $(a)$ des îles Sandwich devient Ariki à la Souvelle-Zélande ; Ranakira, (a) devient Rangatira ; Tanata devient Tangata et, de la mène manic̀re, Hawaii est devenu Hawaïki. L'u et le $w$ ont la même valeur dans tous les dialectess polynésiens, la prononciation étant un son internédiaire entre les deux, c'est pourquoi il n'y a ausune différence do son entre Taulai et Tawai. 》

(3) Ce n'est pas la Nouvelle-Zélan'e que ces traditions font pêcher par Mraui, mais seulement Ika-na-Maui ou l'lle-Nord.

(4) T. II, ch. VI, p. 85.

(5) Il n'est ici question que de l'Ile-Nord.

(6) Te, les; tupuna, aieux; kau, nus ; matua, parents.

(7) On doit écrire Nga-Puhi : Puhi personne estimée, sorte d'anguille.

(a) Ce mot ne peut être d'Hawaii, puisque le $r$ n'existe ras dans cette lavgue. 
étaient derrière eux, et les Ngat-te-Roïnangi, à la poupe. An milieu du canot se trouvaient les femmes, et un homme appelé Tama-te-Tupua. Ce dernier fut coupable d'adultère avec la femme d'un Nga-Pui.

"Le canot s'arrêta et ne reprit sa course qu'après qu'on eût apaisé la colère divine par un charme et par la punition du coupable. Cette invocation ou charme est encore conservée. Les paroles, no te uru o te Arawa kae sịgnifient : "Tu es de l'Arawa » c'est-à-dire, tu es un fourbe et un menteur, et elles sont devenues prover. biales.

- Ils arrivèrent à la Nouvelle-Zélande. i.es Nga-Pui, débarqquèrent dans la Baie des Iles, les Karewa, à Oruru, dans la baie Lauriston ; les Ngata-te-Wakaua, et les Ngate-Roïnangi, à Maketu, dans la baie d'Abondance, d'où les premiers allèrent s'établir à Roto-Rua, et les derniers au lac de Taupo, dans l'intérieur : ceux-là furent les ancêtres de leurs tribus respectives.

" Le second canot Kotahi nui aborda sur la côte Ouest, à Kauwhia, et les gens de son équipagee furent les ancètres des nombreuses tribus des Waïkato. On assure qu'une portion de ce canot est encore conservée, c'est-à-dire qu'elle devint un rocher qui se voit près du cap Nord du hâvre Kauwhia. C'est un gros bloc de pierre de chaux, qui sort des dunes de sable qui l'entourent.

* Il est parfaitement établi que le Kotahi nui, qui étais allé à la côte Ouest, arait doublé le cap Nord.

"Le troisième canot Matatua, apporta les Nga-te-Awa, qui débarquèrent ì Whakatane sur la côte Est, et dont une branche alla sétablir plus tard à Taranaki. »

Dieffenbach répète un peu plus loin (1) que, d'après la tradition, les canots venaient de l'Est, de l'Hawahiki. Et quelques pages plus bas, il ajoute encore : $(2)$ \& La tradition quej'ai trouvée universelle à !a Nouvelle-Zélande est que les canots venaient de l'Est et non de l'Ouest, comme on l'a

(1) Thid. p. 8\%

(2) Ioid. p. 98. 
dit pour appuyer la théorie des migrations opérées directement de l'Asie. "

Il termine enfin en disant : " Le taro et les chiens furent les seules choses appontées par les émigrants et elles n'existaient pas dans l'île. (l)" Mais, remarquons-le, en même temps qu'il fait connaître la tradition qui, suivant lui, donne aux canots une provenance orientale, il relate justement une autre tradition, d'après laquelle les patates donces, ou kumara, auraient été apportées dans l'IleNord de la Nouvelle-Zélande par une femme nommée Pani, venant de l'ile Tawai. Et, ce qui est plus à remarquer encore, il dit que son mari, Tiki, parlait la mème langue que les Nouveaux-Zélandais et leur ressemblait par la couleur de la peau. Il est vrai qu'il ajoute aussitôt: cette île Tawai n'était pas celle d'où, suivant la tradition, étaient venus les ancêtres des Nouveaux-Zélandais.

Voici du reste les paroles de Dieffenbach i ce sujet (2) :

"Si l'on demande aux indigrènes à quelle époque ils ont reçu lo cadeau de cette saine nourritire (les kumara ou patates douces), et quel a été leur bienfaiteur, ils répondent ne rien savoir quant au premier point: leur souvenir se rapporte seulement au fait, mais non au temps. Cependant leur mémoire a conservé le nom du donateur. C'est E-Pani ou Ko-Pani, la femme de E-Tiki (3), qui apporta les premières semences de l'ille de T'awai, qui n'est pas celle d'où, suivantlatradition, sont venus les ancètres des NouveauxZélandais. Tiki arriva à la Nouvelle-Zélande avec sa filmille (4): Etait-ce à l'aide de canots moins frêles que ceux d'aujourd'hui, et à dessein, ou entraîné par accident ? C'est ce que la tradition ne dit pas. Bien accueilli, il ne tarda nas à s'apercevoir que la nourriture y était plus rare que dans l'île heureuse d'où il venait, et il eut la pensée de

(1) Ibid. p. $3 \%$.

(:) Ouvr. cité, t. II, p. 4i.

(3) E, un, une ; e-tiki, e-pani, un tiki, une pani: Ce n'est en un mot que l'article indéfini.

(4) Nouvelle-Zélands est un nom enployé à tort, la tradition ne parlant que d'ụne île, l'Ile-Nord, 
l'augmenter, mais sans savoir comment il y parviendrait. Par bonheur sa femme s'offrit de retourner prendre des kumara, pour que ceux qui les avaient accueillis n'en fussent pas plus longtemps privés. Elle fit le voyage et revint bientôt saine et sauve à la Nouvelle-Zélande. Li-Tiki, son mari, était étranger aux Nouveaux-Zélandais, quoiquiil eût la même couleur et parlât le mème langag'e qu'eux. »

Dieffenbach se demande, à ce sujet, si ce fait doit être attribué à la race polynésienne, ou s'il ne faut pas plutôt y voir la venue, à la Nouvelle-Zélande, d'anciens navires espagnols qui auraient apporté cette importante production de l'île de Tauaï, l'une des Sandwich, où le kumara est encore cultivé. Car, ajoute-t-il, (1) « il n'est presque pas douteux que la Nouvelle-Zélande a été visitée par quelque peuple avant Tasman. Kaïpuke est le nom donné à un navire à la Nouvelle-Zélande : Buque est un mot espagnol; kaï signifie manger, vivre, homme. Aucune autre nation polynésienne n'a ce mot pour désigner un navire. Pero chien et poaca, cochon, sont aussi des mots espagnols. Tawaï, d'où Pani apporta les kumara, est située à l'Est de la Nouvelle-Zélande, d'après les traditions; et les premiers découvreurs dans le Grand Océan, Alvaro de Mendana (1595), Queiros (1606), Lemaire et autres venaient de l'Est, ainsi qu'ils firent à Tahiti, suivant la tradition. "

Puis il continue en disant (2): "Si nous cherchons maintenant à savoir quelle confiance peut être accordée à la tradition, quand elle dit que les Noureaux-Zélandais sont venus en dernier lieu des îles Sandwich, et s'il y a rérita. blement possibilité ou probabilité qu'un pareil voyage ait pu s'effectuer, nous rencontrons des difficultés, qui seront probablement toujours insurmontables. Tout ce que nous pouvons faire, dans l'histoire obscure des premières migrations de ces races, c'est de grouper les différentes îles d'après les analogies qui existent entre leurs habitants, sous le rapport du langage et des coutumes, et de voir dans les

(1) Ouvr. cité, t. I, p. 48.

(2) Ibid. p. 91. 
traditions si l'on trouve quelque chose qui vienne confirmer ces indices de rapprochement. Il y a une grande affinité entre les dialectes des habitants des Sandwich et ceux de la Nouvelle-Zélande, et cette affinité est beaucoup plus grande que celle qui unit les Polynésiens entre eux. Les arbrisseaux et les arbres d'un même genre, quoique d'espèces différentes, portent les mêmes noms à la Nouvelle-Zélande et aux îles Sandwich. Le Kawa fait avec le piper methysticum, n'est pas pris en boisson à la Nouvelle -Zélande ; mais, dans cette mème contrée, le piper excelsum porte le mème nom. Le Rata et l'Aki, sont des espèces de metrosideros dans la Nouvelle-Zélande, comme dans les îles Sandwich; le Ti est un Dracena ou plutôt une cordyline dans les deux. Les traits des indigènes sont semblables, de mème que leurs sculptures, leurs industries, etc.

a Suivant les traditions qui ont cours à la Nouvelle-Zélande, leurs ancêtres avaient fait un long voyage, en partant de l'Est, avant d'arriver à cette île? Ne pouvons-nous pas reconnaître dans les indigènes de l'île de Pâques, qui, d'après les navigateurs qui les ont visités, ressemblent plus aux Nouveaux-Zélandais qu'à tous les autres Polynésiens, le chaînon qui unit le groupe d'Hawaii et de Ahi-na-Maui, ou Nouvelle-Zélande? (1) L'lle de Pâques est aux limites des vents alisés du Sud-Est, et les émigrants d'Hawaii pouvaient $y$ arriver sans peine; les habitants actuels de cette île, point perdu dans l'immensité de l'Océan. paraissent avoir rétrogradé en civilisation. Du moins, les hautes statues, tirées de pierres volcaniques tendres, qu'y virent Cook et La Pérouse, ne furent point attribuées à la geénération du moment, mais à leurs ancêtres ; et l'étrange forme de ces statues nous rappelle, plus que tout autre chose, les grotesques sculptures en bois des indigènes de lik Nouvelle-Zélande. Il n'est pas probable que les ancètres des deux peuples, maintenant si éloignés l'un de l'autre, aient été les mêmes.

(1) C'est pour la premièrs fois que lo mot ahi, feu, est employé a u lieu de $i k a$, poisson. Nuus le verrons bientôt répété par Taylor. 
Malheareusement nous n'arons aucun moyen de comparer le dialecte de lile de Pâques avec celui de la Nouvelle-Zé. lande, et les outrágres commis dans ces derniers temps par ceux qui s'intitulent eux-mêmes chrétiens, sur les naturels de ce point intéressant, ne nous laissent pas beaucoup l'espoir que les relations deviennent bientòt plus intimes. Le nom indigène de l'ìle de Pàques est Waihu, et l'on retrouve le mème nom à la Nouvelle-Zélande, où il est donné au hâvre Coromandel sur la côte Est de l'lle-Nord.

«Il est vrai que les îles Sandwich sont, de toutes les îles Polynésiennes, les plus éloignées de la Nouvelle-Zélande, puisqu'elles sont situées au $24^{\circ}$ de Lat. Nord et $161^{\circ} 45^{\prime}$ de Long. Ouest, tandis que le point le plus Nord de la Nouvelle-Zélande ne se trouve que par $34^{\circ} 27^{\prime}$ Lat. Sud et $173^{\circ} 4^{\prime}$ Long. Est; ce qui embrasse presque les limites extrêmes de l'Océan polynésien, ou de cette partie qui est occupée par la vraie race océanienne. Le lecteur, qui sait combien lespace intermédiaire à ces îles est plein de terres, sourent inhabitées, mais produisant des fruits en assez grande quantité pour nourrir l'homme, dira perat-être : n'est-il pas plus vraisemblable que les insulaires des îles Hawaii, en quittant leur première résidence, soit à dessein, soit par hasard, auraient rencontré quelqu'une de ces îles et se seraient établis là où le climat était doux et agréable, plutôt que d'aller là oì il est toujour's variable et sourent rigoureux? Je n'ai pas de réponse à cette objection et c'est en vain qu'on essaicrait d'expliquer cette séparation et le mélange infini, non seulement des différentes races, mais encore des différentes divisions d'une seule et mème race, qu'on trouve dans les îles du Grand Océan. La proximité réelle des îles et même les vents régnants n'expliquent rien. Dans les îles Chatham, par exemple, qui sont à environ 300 milles au Sud-Est de la Nouvelle-Zélande, vivent les restes d'une race aborigène, qui aura bientôt disparu, avant d'être mêlée aux Zélandais et qui, bien que polyrésienne, (1) n'a rien de commun avec ces derniers. Les Nou-

(1) Cette assertion est à remarquer, venant d'un observateyp 
veaux-Zélandais ne savaient rien de cette île avant que les navires Européens les eussent conduits.

- La migration de l'homme dans un grand océan n'est pas plus mystérieuse que celle des plantes ou des animaux; le sujet est abstrait, mais c'est une raison pour n'en pas fuir l'étude. Si un oiseau de terre, qui n'a pas le pouvoir de voler, se trouve dans ces deux groupes d'îles, les Chatham et la Nouvelle Zélande, on si l'Apteryx australis, qui est dépourvu complètement d'ailes se rencontre dans la petite île Barrière, près de la côte de la Nouvelle-Zélande, et dans la Nouvelle-Zélande elle-mème, n'arons-nous pas raison de trouver dans la structure géologique les indices d'une ancienne réunion de ces îles avec la Nouvelle-Zélande, qui est certainement le centre de certaines plantes et de certains animaux particuliers? Car ce serait trop accorder à la théorie que de considérer chacune des îles environnantes comme un centre pareil, ou d'attribuer à un accident miraculeux la distribution d'animaux qui, par leur conformation, sont dans l'impossibilité d'émigrer par mer.

" N'est-il pas possible, même très probable, qu'une révolution physique ait séparé ce qui était d'abord uni, et que cet accident ait détruit le chemin par lequel une pareille émigration était possible ? Je n'ai trouvé aucune objection, soit dans la structure géologique, soit dans les plintes et les animaux, à la théorie qu'une chaîne d'îles était jointe anciennement à la Nouvelle-Zélande, et il est même très probable que la terre de la Nouvelle-Zélande, l'ìle Chatham et l'Ile Norfolk sont les restes et les fragments de la masse qui occupait autrefois uı très grand espace.

a Suivant les rapports des baleiniers, il y a maintenant peu de profondeur d'eau entre l'île Chatham et la Nouvelle-Zélande ou entre la dernière localité et l'île Norfolk ; c'est pour cela qu'ils font de ces endroits leurs lieux de pèche, bien que je ne sois pas certain que des sondages aient eu lieu par-

sur piace ; elle est contraire à calle de presque tous les antres écrivaius: 
tout. Ne peut-on pas croire, d'après cela, qu'un vaste continent a été englouti dans les abîmes de l'Océan ? Et puisque nous nous aventurons à raisonner sur les migrations des races humaines, ne pouvons-nous pas dire que la grande route a été interrompue après que celui qui est un insulaire aujourd'hui eût atteint sa résidence actuelle ? Il est toutefois infiniment plus croyable pour moi que l'habitant de l'lle Chatham a atteint par hasard cet endroit a l'aide d'un frèle canot, quoique à travers une mer toujours tempétueuse. Ici encore nous serions appuyé par la tradition. Les inciigènes de la Nouvelle-Zélande ont des souvenirs obscurs d'évènements géologiques importants. Ils disent que l'Ile-du-Milieu était unie anciennement à celle du Nord. Le géologue et le philosophe ne méprisent jamais de pareilles traditions, parce qu'elles servent à les conduire à de nouvelles vérités.

«De tous les langages existants, celui des Polynésiens me paraît le plus primitif et le plus ancien par sa structure. Nous trouvons, dans beaucoup d'îles, que l'indigène est un heureux enfant, aussi simple qu'innocent, virant des dons de la nature. Il croit à l'existence d'un Grand-Esprit, mais il le craint et il n'a cependant pas spéculé sur lui : c'est pour ainsi dire une pure croyance abstraite, résultat de l'instinct, et que nous regardons comme implantée dans l'homme au commencement de son existence. Ces diverses circonstances nous portent à penser que les îles dı Grand Océan ont été peuplées à une époque très reculée. D'un autre côté, nous sommes conduit à supposer que la souche primitive, d'où sont sortis tous les insulaires, possédait un certain degré de civilisation, dont on ne roit maintenant que les.restes.

" Mais quel était le véritable herceau, quelle était la résidence originelle de cet ancien peuple ? Etait-ce Java ou le continent d'Asie lui-mème, cette fertile source des nations? Devons-nous la voir à l'Est, direction dans laquelle la placent véritablement les traditions ? Est-ce en Amé. rique, lieu qui possédait autrefois une grande civilisation, qui a été brisée par une cause ou par une autre, pendant 
que son peuple se répandait au loin ? Il ne reste rien pour résoudre ce problème.

- Sur tous ces points, le champ est ouvert aux investiga tions et aux travaux de toutes sortes, surtout linguistiques. Les nations se transforment rapidement, et là où n'existe pas l'art d'écrire, l'histoire des ancêtres et l'origine tornbent promptement dans l'oubli; bientôt on n'a plus d'autre guide que le langage qui seul persiste chez les nations qui se sunt séparées les unes des autres. Il est à remarquer que, même dans la courte période de soixante ans, pendant laquelle les Européens ont été en contact avec les Noureaux-Zélandais, la connaissance de ces derniers en navigation a diminué, et avec elle cet esprit aventureux qui leur faisait braver les dangers des longs voyages côtiers. C'est ainsi que le capitaine Cook a trouvé qu'ils possédaient des doubles canots qu'ils n'emploient jamais aujourd'hui.»

Nous avons tenu à transcrire cette longue citation de Dieffenbach : elle était indispensable pour faire bien conprendre la réfutation de son opinion. Elle établira en nutre combien nombreux sont les emprunts faits à cet écrivain par ses successeurs, sans que ceux-ci aient pris la peine de le citer. Enfin elle montrera pourquoi ces derniers ont émis tant d'assertions inexactes.

D'après quelques auteurs, Dieffenbach aurait avancé que les trois canots venant de ''Est sa sont dirigés sur les Taches Magellaniques pour atteindre la Nouvelle-Zélande : rien dans son ouvrage n'y fait allusion. Mais il est certain qu'en venant des îles Sandwich, comme des Tunga et des Samoa, il aurait fallu, en effet, que les émigrants se dirigeassent sur ces Taches pour arriver à la Nouvelle-Zélande, puisque cette terre se trouve dans le S.-S.-O. des premières.

L'hypothèse émise par Dieffenbach, venant d'un homme si autorisé, explique parfaitement l'adoption qui en a été faite par quelques ethnologues. Nous allons néanmoins, malgré les preuves dont il cherche à l'appuyer, essayer d'établir qu'elle ne repose que sur des faits nayant pas la 
signification qu'il leur donne, et qui même tendent plutot is la détruire : tel est surtout celui de l'introduction des patates douces à la Nouvelle-Zélande.

Nous ferons remarquer d'abord que Dieffenbach, comme tous les écrivains qui l'ont suivi, désigne à tort, d'après son propre texte et celui des légendes qu'il cite, l'île IkaNa-Maui sous le nom générique de Nouvelle-Zélande. T'outes les légendes ne parlent, en effet, que d'une île, celle qui est connue sous le nom d'lle-Nord de la Nouvelle-Zélande. Ce fait est de la plus haute importance, comme on le verra bientôt.

Le naturaliste anglais est en outre le seul jusque-là qui, d'après les traditions, ait trouvé pour " opinion universelle " à la Nouvelle-Zélande, que les ancètres provenaient de l'Est. Cook, on l'a vu, a bien parlé de la venue de quelques canots du Nord ; mais ces faits ne prouvaient absolument rien, et la tradition d'un lieu appelé Heawise était trop vague pour qu'on put songer à en déduire la situation. Banks, Forster, Anderson, les compagnois de Cook, n'en ont eux-mêmes rien dit non plus. Et, arant Dieffenbach, il n'y avait guère que a'Urrille, Moërenhoüt, Eilis et J. Wil liams qui eussent attribué, à peu près sans preures, les premiers habitants de la Nouvelle-Zélande à une provenance orientale. Mais pas un des missionnaires fixés à la Nonvelle-Zélande depuis si longtemps, et si versés dans la langue du pays, n'avait jusque-la exprimé cette opinion ; l'un d'eux même, Kendall, avait rapporté, comme on a vu, un chant qui laissait supposer que les Néo-Zélandais sé dirigeaient vers l'Est plutôt que d'en renir.

Depuis, il est vrai, cette opinion a été adoptée pour ainsi dire par tous les successeurs de Dieffenbach, comme si elle n'en était que l'écho, mais sans plus de fondement, ainsi que nous le démontrerons. C'est donc bien à lui qu'elle appartient, de même que l'idée de considérer l'Ile de Pâques comme première et facile étape aux émigrants des Sandwich, sans doute parce que Beechey avait trouvé que les habitants de cette île ressemblaient plus aux Maori, par le tatouage surtout, qu'à tous les autres Polynésiens. 
Il est évilent, d'abord, que les trois canots désignés par Dieffenbach portent le mème nom que trois des sept, dont parlent les légendes que Sir Grey a fait connaître quelques années plus tard. Ces canots sont :

L'Arawa,le Taïnui etle Matatua. C'était dans l'Arawa, en effet, que se trouvait 'Tama-te-Kapua, qui même en était le chef, d'après la légende publiée par Sir Greý; la femme souillée était celle de Nga-Toro-i-Rangi, grand prêtre renommé de la tribu des Nga-Puhi, d'après la légende de Dieffenbach.

Le second canot, quoique désigné par les mots Kotahinui, était le Taz̈nui, la syllabe $k o$ étant la préfixe que les Maori placent devant les noms de personnes et de choses. Comme un le verra plus loin, c'était sur ce canot que se trouvait Nga-Toro, avant que Tama-te-Kapua, ne l'attirât par ruse avec sa femme, dans l'Arawa. Après son enlèvement ce fut Hotunui qui en pritle commandement.

Quant au troisième canot, les lég'endes ne disent pas quel en était le chef (1); mais celle citée par Dieffenbach apprend que les gens qui le montaient étaient de la tribu des Nga-te-Awa (2), fait important, quand on saura qu'une tribu de ce nom occupait un point de la côte Sud-Ouest de l'Ile-du-Milieu, la Tavaï-Pounamu de d'Urville.

Mais si c'étaient les mêmes canots et les mèmes légendes, qu'en conclure? Que la trarlition qui fournitle plus de détails, qui indique le plus nettement la route faite par les canots, et précise la route qu il fallait faire en partant d'Hawahiki, pour atteindre Ahi ou Ika-na-Maui, doit approcher de la vérité plus que l'autre. Or ce sont les légendes rapportées par Sir Grey qui donnent, en général, et dans ce cas particulier, les détails les plus nombreux, les plus circonstanciés, qui désignent nettement et la route faite et la route à suivre, tandis que la tradition citée par Dieffenbach n'en dit absolument rien ; c'est pourtant sur elle qu'il s'appuie

(1) Dautres légendes, publiéespar Taylor, montrent que ce chef était Rauru ou Ruaauru.

(2) Il y avait aussi des Ngati-Kahungunu, et c'étaient des Ngati-Ruanui qui, d'après Taylor, remplaçaient les premiers. 
pour établir l'origine polynésienne orientale des Maori, ou autrement dit, la venue de l'Est des canots que les légendes de Sir Grey font venir de l'Ouest ou du Sud-Ouest.

Ainsi, dès le début. nous voyons que Dieffenbach appuie son opinion sur un fait qu'on peut, au moins, croire mal interprété, mal entendu, d’après les légendes si précises publiées par Sir Grey. Il est bien probable, en effet, comme tout ce que nous dirons le démontrera, que celui qui lui a fait connaître la légende qu'il rapporte, a donné, comme point de départ, ce qui n'était que le but à atteindre, c'est-à-dire l'Est. Mais, que ce soit ou non une erreur d'interprétation, il est certain qu'elle serait suffisante à elle seule pour détruire son hypothèse, quand celle-ci ne serait pas combattue par toutes sortes d'autres raisons.

Par exemple, quand Dieffenbach dit que les Néo-Zélandais ressemblent plus, par le langage, aux habitants des îles Sandwich qu'à ceux des autres îles polynésiennes, il avance certainement un fait inexact (1) : Beechey, Moërenhoüt, et surtout J. Williams, ont montré que certaines îles, comme Rarotonga, Mangareva, possèdent un langáge plus analogue. Il est vrai qu'ailleurs, tout en les faisant venir des Sandwich, il trouve les Néo-Zélandais plus ressemblants aux Malais par leur extérieur et par leurs coutumes. Mais cela ne prouve qu'une chose, c'est que Dieffenobh n'a probablement jamais vu les peuples malais et les autres polynésiens. Quant à la légende qu'il rapporte, elle ne dit pas un seul mot qui autorise à soutenir que les Néo-Zélandais sont en dernier lieu venus des Sandwich : cette assertion n'est qu'une interprétation purement personnelle.

Dieffenbach est plus exact quand il dit que l'analogie exis tant entre les Maori et les habitants de l'Ile de Pâques est plus grande qu'entre les Maori et les autres Polynésiens mais il faut qu'on n'en sépare pas quelques autres îles telles que les Hervey, les Mangareva, etc. Ce fait prouve que des rapports ont nécessairement existé entre des populations

(1) Il ne dit cela évidemment que parce que d'Urville trouvait, avec raison, plus d'analogie entre le Maori et l'Hawaiien qu'entre le Maori et le Tahitien. 
séparées par une si grande distance. Mais son assertion n'est plus aussi évidente, quand il prétend que les émigrants d'Hawaii pouvaient arriver sans peine à l'île de Pâques: le plus souvent, avant d'atteindre cette île, ils auraient infailiiblement rencontré les Marquises, sinon les Paumotu. Or, on l'a vu, les traditions des Marquises, de même que celles des îles de la Société et même des Sandwich, laissent supposer que ce sont, au contraire, des émigrants des deux premiers archipels qui sont allés peupler les îles Hawaii. Est-il supposable, d'ailleurs, que les émigrants de ces îles; s'ils avaient suivi la route que leur fait faire Dieffenbach, soient allés au hasard chercher un point perdu dans l'espace, plutôt que de rester dans les Marquises ou les Paumotu qu'ils auraient rencontrées presque infailliblement? L'Ile de Pâques, en effet, est tellement éloignée de toute terre, qu'elle n'a dû être atteinte que par des canots égarés, quel que fût leur point de départ.

Dieffenbach, du reste, fait lui-même à son hypothèse cette objection insurmontable : "N'est-il pas plus vraisemblable, dit-il (1), que si les enfants des îles Sandwich avaient quitté, à dessein ou au hasard, leur première résidence, ils seraient tombés sur quelqu'une des terres qui occupent l'intervalle qui sépare la leur de l'île de laàques, et se seraient établis là où le climat était plus doux et plus agréable, au lieu d'aller où il est toujours variable et souvent rigoureux? \$ Nous n'avons point, ajoute-t-il, de réponse à faire à cette objection, et il est certain qu'il serait difficile d'en faire une bonne. Suivant nous, c'est bien la plus forte objection opposable à cette supposition, même en admettant que la route aurait pu être faite directement. Nous croyons, avec tous les ethnologues, sans en excepter ceux qui, comme MM. Gaussin et Shortland, admettenı que les Nouveaux-Zélandais sont venus de l'Est, que la distance des îles Sandwich à Pâques, et à plus forte raison dẹ Pâques à la Nouvelle-Zélande, est par trop grande, pour qu'il soit

(1) Ouvrage cité, p. 93. 
possible de supposer que les pirogues des émigrants aient pu effectuer de pareils voyages.

En supposant la route directe, il est à peu près certain que les émigrants auraient rencontré quelques terres ou même des archipels entiers, tels que les Samoa, les Tunga, les Fiji, placés sur leur route, et qu'ils s'y seraient arrêtés sans songer à continuer leur voyage; de même que, par la route indirecte, c'est-a-dire en passant par Pâques, ils en auraient également trouvé quelques-uns, et au moins les îles Marquises. Or, pas une des traditions polynésiennes ne fait allusion à ce fait, alors qu'elles en rapportent nettement tant d'autres beaucoup moins importants. Les îles Sandwich, qui semblent avoir si bien conservé le souvenir de leur premier peuplement par les îles de la Société et même celui de quelques voyages lointains, n'en disent absolument rien non plus, à moins que l'on ne reconnaisse la Nouvelle-Zélande dans la mystérieuse Haupokane des légendes Hawaiiennes, terre qui, sous ce nom du moins, n'a jamais été retrouvée dans les îles polynésiennes. Les légendes maori elles-mêmes ne parlent que d'une petitê̂le rencontrée par les émigrants pendant leur trajet de l'Hawahiki à l'ŝle Ika-na-Maui ; et cependant elles sont riches de souvenirs, confus il est vrai, mais variés. Elles ne disent rien de plus que les traditions des archipels polynésiens Samoa et Tunga qui se taisent à ce sujet; mais elles apprennent un fait, resté ignoré jusqu'aux légendes publiées par Sir Grey, et que lui-même n'a pas remarqué, c'est que l'Hawahiki ou terre d'origine était placée dans une direction tout-à-fait opposée à celle qu'occupent les îles Havaii.

S'ils étaient venus de l'île de Pâques, comme le suppose Dieffenbach, les canots, il est vrai, auraient pu arriver à la Nouvelle-Zélande sans rencontrer aucune terre, mais après une traversée tellement longue, qu'il n'est véritablement pas permis d'en admettre la possibilité. D'ailleurs, l'expérience a appris qu'il est difficile, même aux navires européens, de faire cette route directement. D'un autre côté, les égendes de Sir Grey montrent que les canots ne s'éloi- 
gnaient guère d'Hawahiki qu'en suivant pour ainsi dire les côtes de vue.

Mais c'est surtout l'introduction des patates douces dans l'île Ahi-na-Maui qui achève de détruire l'hypothèse de Dieffenbach. En effet, c'est à tort qu'il place à l'Est l'île Tâwaï, d'oủ Pani apporta les Kumara et où elle était née, mais quii « n'était pas celle d'où, suivant la tradition, étaient venus les ancêtres des Nouveaux-Zélandais. (1) »

Il n'y a pas d'île de ce nom dans cette direction, par rapport à la Nouvelle-Zélande, à l'exception toutefois de l'île Tauai ou mieux Kauaï des Sandwich, qui gît dans le NordEst. Dieffenbach n'a pas remarqué que, du côté opposé, au contraire, et à toucher pour ainsi dire Ahi-na-Maui, existe l'île de la Nouvelle-Zélande appelée Tawai et qui, presque certainement, est celle dont la légende a voulu parler. Ce qui le prouve surtout, c'est ce qu'elle dit de la facilité du voyage de Pani allant chercher les patates douces. Pani n'aurait évidemment pu aller aux îles Sandwich et en revenir aussi promptement et aussi facilement, si le voyage eût été fait de ce côté. En outre, pas plus que son mari, elle n'eût parlé la langue maori, comme le rapporte la tradition, si l'un et l'autre fussent partis des Sandwich. Qu'on se rappelle, en effet, cette phrase qui termine la légende citée par Dieffenbach : a E-Tiki, son mari, était étranger aux Nouveaux-Zélandais, quoiqu'il eût la même couleur et parlât le même langage qu'eux. »On verra plus tard quelle est l'importance de cette tradition; mais, en attendant, on en conviendra, c'était aller chercher bien loin ce qu'on avait pour ainsi dire sous la main.

L'erreur propagée par Dieffenbach provient de ce que, pour appuyer son hypothèse, il regarde ce mot Tawai comme le nom d'une île se trouvant dans l'Est, et surtout de ce qu'il confond toutes les îles du groupe, sous le nom de Nouvelle-Zélande. C'est ce que nous achèverons de démon trer, quand nous aurons fait connaître les légendes de Sir Grey. En confondant l'Ile-Nord de la Nouvelle-Zélande avec

(1) Ouvr, cité, t. II, p. 4i7, lig. 18. 
l'Jle-du-Milieu du même groupe, Dieffenbach ne pouvait évidemment se douter que cette dernière était la véritable Tawai dont il est parlé par la légende.

Dieffenbach, enfin, dit que Hawahiki et Tawai dérivent de Hawaii et Tauai ; mais il est tout aussi croyable que le contraire a eu lieu et que les deux premiers ont fourni les deux derniers. Aux Sandwich, en effet, le mot tauai se prononce aussi et même plus fréquemment kauai; or la transformation du $k$ en $t$ semble plus naturelle que celle du $t$ en $k$.

Dieffenbach, on l'a ru, suppose que des navires espagnols ont, plus probablement que les Polynésiens, apporté les premiers les patates douces à la Nouvelle-Zélande ; mais les mots sur lesquels il s'appuie pour étayer cette opinion sont tous erronés. Ainsi le mot kaïpuke ne vient pas, comme il le prétend, de l'Espagnol buque: kä, homme et puke, colline, sont des mots purement maori, de même que waïpuke, flot, courant, puke puke, lieu élevé, montueux, etc. Le mot pero, que Dieffenbach donne comme le nom du chien à la Nouvelle-Zélande n'est pas plus exact : le chien y est appelé peropero, et ce mot se prononce tout autrement que le perro espagnol. L'analogie est encore moins grande pour le mot poaka. En Espagnol, porc se dit puerco, tandis que, dans les îles polynésiennes, c'est puaka, buaka, puaa, etc. Ce mot est donc encore tout polynésien.

Avant Dieffenbach, du reste, une foule d'écrivains avaient cru pouvoir dire. d'après les premiers Européens établis aux Sandwich, qu'on trouvait dans ces îles un grand nombre de mots d'origine espagnole : On citait entre autres les mots pono et poco, que l'on faisait venir de l'Espagnol bueno ou du Portugais bono, et de l'Espagnol poco. Nous avons déjà montré plus haut que ce sont des mots polynésiens signifiant: le premier, «vrai, vérité », le second, « court, petit. \$

En résumé, de tout ce que nous venons de dire, il est impossible, croyons-nous, de partag'er l'opinion de Dieffenbach, qui est sans aucun fondement. Même quand il 
n'y aurait pas contre elle l'objection si considérable que l'auteur lui-même lui adresse, la direction ordinaire et la force des vents, ainsi que la position de quelques archipels sur la route, auraient suffi pour mettre obstacle à des migrations se dirigeant du Nord-Est vers le Sud-Ouest.

Dieffenbach se trouvait à la Nouvelle-Zélande de 1839 à 1841, alors que nous étions nous-même dans les îles polynésiennes. Embarqué comme naturaliste sur un bâtiment de la Compagnie, il ne put suivre que la direction tracée à son navire par les besoins de la nouvelle colonisation. C'est ce qui explique pourquoi il n'a pu bien voir que le détroit de Cook et l'Ile-Nord de la Nouvelle-Zélande. Son livre fut publié en 1843, alors que le commodore Wilkes venait à peine de terminer son voyage commencé en 1838 . Ses observations d'histoire naturelle sont pleines d'intérêt; mais, à part quelques objets, elles ont peu ajouté aux connaissances déjà acquises par les naturalistes de Conk, de Vancouver, de d'Urville, de Duperrey, etc. Il suffira, pour s'en convaincre, de jeter un coup d'œil sur l'énumération qu'il fait des plantes de la Nouvelle-Zélande.

En somme, Dieffenbach, de même qu'Ellis et d'Urville, n'a guère fourni, malgré le nombre considérable de ses renseignements, qu'un ramassis d'opinions contradictoires ; après l'avoir lu, on se demande même quelle est celle à laquelle il s'est arrèté, et l'on serait fort embarrassé de le dire sans quelques-unes de ses propres objections. Il résulte de tout son livre que, de toutes les peuplades polynésiennes, il n'avait vu que celles de la Nouvelle-Zélande et peut-être celles des îles Sandwich, mais que les autres lui ėtaient inconnues. Pourtant, au point de vue des matériaux, ce n'en était pas moins l'ouvrage le plus impor. tant qui eût paru jusque-là.

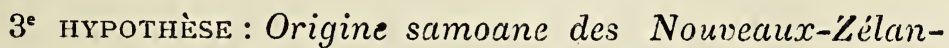
dais. - Cette hypothèse, d'après laquelle Savaii est la première étape des émigrants malais et le point de départ des colonies pour toutes les îles polynésiennes, est due au 
savant ethnologue Horatio Hale, l'un des compagnons de Wilkes, dans son expédition au pôle Sud (1). On peut dire que c'est celle qui, aujourd'hui, est généralement adoptée, avec quelques variantes.

En s'appuyant alternativement sur les traditions, sur la philologie, sur la carte de Tupaia, et plus particulièrement sur l'assertion de ce dernier que Savaii était « la mère des autres îles, M. Hale a conclu que c'était de cette île Savaii qu'étaient partis, non-seulement les Polynésiens les plus orientaux, mais encore ceux qui étaient allés peupler la Nourelle-Zélande.

Pour lui, c'était ce nom que les colonies issues de Savaii, l'une des Samoa, avaient porté successivement, d'abord dans l'Est, le Sud-Est, et même dans le Nord, c'est-à-dire aux îles de la Société, Paumotu, Marquises et Sandwich ; puis, dans le Sud et le Sud-Ouest, c'est-à-dire aux îles Manaia, Rapa, etc. ; enfin à la Nouvelle-Zélande. Pour arriver à cette conclusion, il s'appuyait surtout sur la signification identique de ce mot Savaii et de tous ceux par lesquels la plupart des autres archipels polynésiens désignent le pays d'origine première. Ces mots, nous l'avons déjả dit, sont : Havaï aux Iles de la Société ; Hapaï aux Tunga; Avaiki dans l'archipel de Cook, à Rarotonga, Rapa, Mangareva, dans les Paumotu; Havaïki aux Marquises; Hawaii aux Sandwich, et Hawahiki à la Nouvelle-Zélande.

En effet, tous ces mots sont bien les mêmes; ils ont à peine été modifiés suivant les lieux, et ils possèdentla même signification, comme l'avaient déjà reconnu Dieffenbach et plusieurs autres voyagreurs. Mais il est loin d'être aussi démontré que semble le croire M. Hale, que ces diver's mots soient les dérivés du mot Savaii, car lui-mème reconnaît que l'île ainsi nommée n'est point la terre d'origine première, mais seulement la première étape des émigrants, qu'il fait venir des îles asiatiques. Comme il a

(1) United States exploring expédition narrative, during the Years 1838-1842. Philadelphia, 1844, 
admis, d'un autre côté, que cette terre d'origine première portait un autre nom que celui de Savaii, il faut nécessairement reconnaître que son explication manque d'exactitude, ou que, tout au moins, elle a besoin d'être complétée.

Si Savaii représente bien, comme il l'a dit, le nom qui était donné au lìeu d'origine première, il importe de savoir, et il aurait dû dire aussi, comment il se fait que le nom donné par les émigrants à leur première étape, dans les Samoa, ne soit pas celui que portait le lieu de départ, qu'il appelle Borotou. Comment alors se fait-il que les colonies parties de Savaii n'aient seulement répandu que ce dernier mot? Il eût été au moins utile de chercher à savoir si Savaii, au lieu d'avoir fourni les autres mots, ne dérivait pas plutôt, d'après la linguistique elle-même, de l'un d'entre eux.

C'est ce que nous allons essayer de déterminer dans les pages qui vont suivre. Car tous ces mots ont bien une même signification, ainsi que l'a dit M. Hale, et c'est avec raison qu'il les a regardés comme « la clef des migrations polynésiennes. "Avec la distinction qu'il faut nécessairement établir entre les îles composant le groupe de la NouvelleZélande, il n'est aucun autre fait, dans l'histoire de la Polynésie, qui aide autant que cette détermination à suivre la marche des émigrants et à remonter, par conséquent, à leur véritable point de départ.

C'est justement parce que les mots en question ont l'importance que leur reconnait M. Hale, qu'il est indispensable d'entrer, à leur sujet, dans quelques développements et de demander à la linguistique l'explication de leur signification réelle et de leur origine.

Comme l'a fait M. Hale lui-mème, c'est donc à la philo logie que nous nous adresserons nous aussi, puisqu'elle seule peut éclairer une pareille question.

Certainement nous aurions pu, comme tant d'autres, ad mettre, sans critique, l'opinion du savant américain, opi-* nion si généralement acceptée, et en apparence si bien motivée. Mais, du moment que nous ne croyons pas ses 
assertions complètement exactes, c'est un devoir de chercher à le démontrer, et c'est ce que nous allons tenter.

Aussi bien ce sera, croyons-nous, le meilleur moyen, en même temps que le plus simple, de montrer que son hypothèse ne repose que sur une erreur étymologique.

Nous allons donc chercher d'abord la valeur exacte de chacun des mots employés par les divers archipels, puisque c'est la signification qu'ils possédent quiseule peut débrouiller cette question.

Aux îles Hervey, ce mot, sous la forme Avaïki, signifie le pays des ancêtres, et ce pays est placé, par les traditions, " sous le vent, » c'est-à-dire, du côté du couchant : «le vent » ou le dessus étant, pour toutes les îles polynésiennes, le Sud-Est.

Sous la même forme, aux îles Mangareva, aussi bien qu'à Rapa, aux îles Paumotu, etc., il est aussi le nom de la terre d'origine, laquelle est toujours placée plus à l'Ouest.

A Tahiti, comme dans les autres îles de la Société, sous la forme Havai, c'est encore le nom de la patrie commune, située de même vers l'Ouest.

Aux îles Marquises, le pays des ancêtres est placé dans la direction du soleil couchant, et là il porte le nom d'Havaïki.

Il en est de même aux îles Sandwich, sous la forme Hawaii. Seulement, dans ces îles, on y paraît moins fixé sur sa position, quoiqu'on la place toujours plus Ouest ou SudOuest. Il semble, et l'on verra pourquoi plus tard, que les souvenirs de la patrie première sont plus confus dans ces îles que partout ailleurs.

Il est bien évident, comme l'ont dit les ethnologues, que ce nom n'a été imposé à l'île principale des Sandwich, qu'en souvenir de la patrie commune; mais là, comme ailleurs, rien de plus que l'analogie existante entre Savaii et Hawaii, ne dit que le dernier mot dérive du premier. D'après la phılologie, tant invoguée par M. Hale, il est à supposer qu'ils viennent plutôt l'un et l'autre d'un troisième.

Nous ferons remarquer, en outre, à cette occasion, que la 
manière d'écrire et de prononcer ce mot Hawaii aux Sandwich pourrait être considérée comme un indice que ces îles n'ont dû recevoir les premiers émigrants de Tahiti que longtemps après le départ des premiers émigrants de la même île pour les Marquises, mais qu'elles ont reçu ces émigrants de Tahiti, avant ceux qui paraissent avoir été fournis aussi par les îles Marquises. Il doit sembler pro. bable, en effet, que puisque les Sandwich ont adopté 'ou conservé la forme tahitienne de leur nom, c'est que cette forme leur est arrivée la première ; dans le cas contraire, c'est-à-dire les colonies des Marquises arrivant les premières, il est à croire qu'elles auraient pris et gardé la forme Havaïki, employée par ces îles.

Dans les Samoa, c'est le mot Savaii qui est l'équivalent des mots précédents. Si ce mot s'écrit Savaii, pendant qu'un autre est écrit ou prononcé Hawaii ou seulement Havaï, c'est que les habitants des îles Samoa remplacent, dans leur dialecte, le $h$ expiré des autres archipels, par Je $s$, de même qu'ils remplacent, avec ceux de Tahiti et de beaucoup d'autres îles, le $w$ par un $v$ simple, etc. Nous avons remarqué nous-même aux îles Tunga, comme à Tahiti, que quand les indigènes veulent parler de l'île Savaii, ils ne l'appellent que Havaii ou simplement Havaï, comme l'a écrit le tahitien Mare, dans l'essai de mythologie qu'il a donné au goouverneur Lavaud. Il en est de même pour tous les autres noms des îles prononcé par les Tahitiens ou les Tongans; le nom de tout le groupe n'est plus que Hamoa ou mieux Haamoa, au lieu de Samoa que lui donnent les habitants.

Enfin, à la Nouvelle-Zélande, c'est encore sous la forme Hawahiki qu'est connu le nom de la terre d'origine commune, comme le prouvent tous les faits venus, dans ces dernières années, à la connaissance des ethnologues. Mais là seulement, au lieu d'être prononcé avec douceur, comme dans les îles Samoa, ce mot est prononcé au contraire avec une forte expiration et, fait bien plus remarquable, c'est toujours dans l'Ouest ou Couchant, par rapport à l'Ile-Nord 
de la Nouvelle-Zélande, que ce lieu d'origine première se trouvait placé d'après les traditions.

En résumé, tous ces mots semblent bien appuyer cette assertion de M. Hale: "Ils sont les noms du pays d'origine, » et même a ils dérivent les uns des autres. » En effet, il y a non seulement, analogie de son et d'orthographe, mais analogie de signification et rapport géographique : On ne peut le nier, Savaii est placée plus à l'Ouest que toutes les îles polynésiennes où ses colonies paraissent être allées s'établir ; et si l'on tient compte de l'assertion de Tupaia, on peut très bien admettre, qu'après avoir perdu le souvenir de la patrie première, ces colonies n'ont voulu propager que le nom de leur dernier point de départ, Savaii.

Mais, si telle est bien la signification de tous ces mots, rien n'indique qu'ils dérivent, comme le dit M. Hale, du mot Savaii ; la linguistique elle-mème vient plutôt prouver le contraire, c'est-à-dire que c'est Savaii qui dérive đ6 l'un des autres mots. La logique veut que le mot le plus émas. culé et le plus adouci dérive du plus màle et du plus complet. Nous allons donc maintenant essayer de démontrer, contrairement à l'opinion de M. Hale, que non-seulement les autres mots ne sont pas des dérivés du mot Savaii, mais que celui-ci, le même, que tous les autres, dérive du mot Hawahiki.

Si ce que nous allons dire suffit à cette démonstration, nous aurons réfuté en même temps l'hypothèse du peuplement de la Nouvelle-Zélande par les îles Samoa.

M. Hale, il faut le remarquer, a reconnu que Savaii n'était point la terre d'origine, mais seulement la première étape des émigrants qui, suivant lui, venaient des îles asiatiques. Or, il donne à cette terre d'origine le nom de Borctou ; mais, il faut en convenir, cela ne suffit pas pour faire comprendre comment Savaii n'est, comme il le dit, que le nom de cette terre d'origine première. Sa déduction eût été plus légitimée, s'il eût expliqué comment les émigrants, pour conserver le nom de la patrie, avaient donné à l'île, la première rencontrée par eux, un nom qui n'était pas 
celui de cette patrie. Il est à regretter que M. Hale ne se soit pas aperçu de cette lacune; il est probable qu'elle l'eût mis sur la voie de la véritable situation du lieu qui a servi de point de départ.

Suivant nous, la cause du silence de M. Hale provient de l'erreur propagée par Mariner, qui, le premier, a dit que le point de départ des Polynésiens était appelé Borotu. M. Hale a adopté cette opinion toute faite, comme tant d'autres, depuis lui ; mais, comme nous l'avons déjà dit, ce mot Borotu n'est qu'un mot purement mélanésien, adopté plus tard par les Polynésiens pour remplacer le nom qu'ils donnaient d'abord au pays de leurs ancêtres, et qui, en effet, était celui qu'ils ont voulu rendre par le mot Savaii. Puisque ce dernier nom a été porté dans toutes les îles plus orientales que les Samoa, par les colonies sortant de ces îles, il faut nécessairement admettre que ces essaims se sont opérés avant l'adoption du mot Borotu : autrement on eût retrouvé ce dernier dans quelques îles. Or, on l'a $\mathrm{vu}$, celui qui existe estpartout un équiralent du mot Savaii, jamais du mot Borotu.

On le sait, il n'y a absolument que les îles Samoa et Tunga qui, aujourd'hui, se servent de ce mot pour désigner le pays des ancêtres ; ce sont justement les îles qui avoisinent le plus les îles mélanésiennes, où ce mot est employé pour désigner le séjour des dieux et des àmes. Si les colonies issues des Samoa ont propagé le premier nom plutôt que le second, c'est donc, nous le répéterons, qu'il était le seul existant au moment de leur départ, et qu'il était véritablement le nom du pays d'origine.

Ce n'était certainement pas, comme le prétend M. Hale, pour conserver le nom de l'île Savaii que les colonies répandaient ce nom à mesure qu'elles s'éloignaient : c'était tout simplement pour rappeler le nom de la patrie primitive, qui ne s'appelait pas plus Borotu que Savaii, mais bien Hawahiki.

Il y aurait d'ailleurs une autre difficulté à cette explication de M. Hale, ce serait de comprendre comment le mot 
qui, suivant lui, est celui de Savaii, aurait pris, dans quelques archipels, une prononciation aussi dure. Il semble que s'il eût été apporté par des colonies de Savaii, il aurait dû au moins conserver la douceur de prononciation qu'il a aux Samoa. Evidemment, cela doit faire conclure que ce mot Savaii ne s'est ainsi transformé qu'après le départ des colonies qui ont portéles mots Havaï, Havaïki et Havaii aux îles de la Société, Marquises et Sandwich,

Il faut inférer de tout cela, ainsi que nous l'avons déjà dit, que si l'un de ces mots dérive de l'un des autres, c'est plutôt le mot le plus modifié et se prononçant avec le plus de douceur qui dérive du mot le plus complet et se prononçant le plus durement. C'est donc plutôt Savaii qui dérive d'Hawahiki, que Hawahiki de Savaii. Cette conclusion, on le voit, est complètement opposée à celle de M. Hale.

Non seulement si Hawahiki était dérivé de Savaii, comme le pense M. Hale, on ne s'expliquerait pas sa rude prononciation, mais, fait plus important, on ne s'expliquerait pas surtout la position que les Nouveaux-Zélandais de l'IleNord donnent au pays de leurs ancêtres, ainsi appelé par eux, et qu'ils placent plus à l'Onest encore que leur île. Il est évident que si les Maori de l'lle-Nord étaient venus des îles où M. Hale place leur point de départ, c'est-à-dire de Savaii, dans les Samoa, ils n'auraient pas pu dire, comme ils le font dans leurs traditions, que leur pays d'origine se trouvait dans l'Ouest par rapport à eux. (1) Dans ce cas, en effet, il se serait placé dans le N. N.-E. c'est-à-dire dans une direction tout-à-fait opposée. Cette circonstance suftit à elle seule pour faire douter de l'exactitude de l'interprétation de M. Hale.

Qu'en conclure, en somme? C'est que la dérivation de ces mots n'est pas, aussi sûrement qu'on le croit généralement, celle qu'a donnée M. Hale, et que Savaii est le dérivé de l'un des autres, plutôt que Hawahiki.

Bientôt nous ferons voir que ce dernier mot n'est, comme le sont également tous les autres, qu'un composé de mots distincts, signifiant bien patrie, pays d'origine, mais sans

(1) Voir Sir Grey, Légende de l'émigration de Turi. 
préciser autrement le lieu, sans dire si c'est une île ou seulement quelque partie de cette île. On verra, en même temps, que ce nom, fût-il celui d'une contrée, ne le deviendrait qu'à la condition de le décomposer en plusieurs mots, et que, par conséquent, il a, dans tous les cas, été mal orthographié jusqu'ici par tous les voyageurs.

M. Hale s'est également appuyé sur l'assertion de Tupaia que Savaii était la mère des autres îles. Cette assertion, il faut bien le reconnaître, a probablement servi, plus encore que la linguistique, à donner plus de créance à l'opinion du savant américain. Mais nous croyons qu'elle, non plus, n'a pas l'importance qu'on lui a généralement accordée; c'est ce que nous allons essayer de démontrer.

Malgré ses connaissances géographiques, malgré ses pérégrinations, Tupaia, en effet, ignorait probablement l'existence exacte des ìles Sandwich, ainsi que celle de la Nouvelle-Zélande, qu'il ne devait voir qu'avec Cook, à la fin du premier voyage de ce navigateur. (1) Quand il plaçait sur la carte, dictée et donnée par lui à Banks, une île Oheavaï, dans l'Ouest de Tahiti, il ne faisait et ne pouvait faire allusion qu'à la terre d'origine première ou Hawahiki, mot qui se rend par Havaï, dans les ìles de la Société. Les traditions de ces îles faisant venir de l'Ouest les premiers habitants du groupe, il était tout naturel qu'il plaçât cette île Oheavai dans cette direction. C'est même probablement cette position qui a porté Banks et les premiers navigateurs a attribuer à l'île Savaii, ce que Tupaia n'avait pu vouloir dire que de la patrie première, placée, de même que Savaii, dans l'Ouest de Tahiti. Ceque Tupaia dit de l'étendue de l'île portée sursa cartesous le nom de O-Hea-Vai, ainsi du moins que l'ont écrit les Anglais, prouve bien que ce n'était qu'une erreur d'interprétation, faite par les Européens, et qu'il ne pouvait s'agir de

(1) Cependant nous montrerons, quand nous étudierons dans tous ses détails la carte de Tupaia, que non seulement l'Archipel des Sandwich ne devait pas être complétement inconnu du grandprêtre tahitien, mais peut-être même celui de la Nouvelle-Zélande, qu'il semble avoir désigné traditionnellement. 
Savaii. Il l'indique quatre fois plus grande que Tahiti. Or, comme Tupaia connaissait parfaitement Savaii, qui n'a que le double d'étendue, il faut bien conclure qu'il n'a pu vouloir parler de cette île, car il l'eût fait alors avec plus d'exactitude. (1) Presque certainement, au contraire, il n'a voulu parler que de l'île d'où étaient venus ses ancêtres, île qui lui était inconnue, mais que les traditions plaçaient dans l'Ouest de Tahiti. Quand on saura quelle est cette contrée d'origine, on verra, en effet, qu'elle a au moins l'étendue signalée par lui.

Pour nous, les paroles de Tupaia ne s'appliquaient donc bien probablement qu'au pays d'origine première, que M. Hale croyait avoir retrouvé dans l'île Boro des Moluques. 11 estvrai pourtant, et c'est sans doute ce qui a induit en erreur les ethnologues, que Tupaia, qui ne connaissait pas de visu de terre plus à l'Ouest que Savaii et les Fiji. et qui attribuait, avec raison, à Savaii et aux autres Samoa la provenance de ses ancêtres (2), aurait pu vouloir parler de cette île en l'appelant «la mère des autres. » Mais alors il n'aurait certai. nement voulu parler que des îles qu'il connaissait et qu'il a fait connaître à Banks, c'est-à-dire toutes les îles plus orientales que les Samoa. Il aurait d'autant moins pu songer à faire peupler par Savaii certaines îles de l'Ouest, qu'il en ignorait sans doute l'existence.

En un mot, nous croyons qu'en disant que les îles de la Société, comme les autres îles plus à l'Est, avaient été peu plées par Savaii, Tupaia ne considérait pas pour cela cette île comme la " mère» des îles plus occidentales qu'elle. Cette opinion, il est vrai, est bien celle que les voyageurs et les ethnologues européens lui ont attribuée, mais nous espé-

(1) Ce n'est pas une objection pour M. de Quatrefages, qui glisse rapidement sur cette difficulté. (V. l'Espèce humaine, Ch. XVII.)

(2) Nous avons montré précédemment que cela résulte de certains mots tels que Havai, Upolu, Orohena, Manunu, etc. retrouvés dans lesîles de la Société, plus encore que des traditions ellesmêmes. (Voy. vol. Il, p. 327, 329, 336, etc.). 
rons que ce que nous venons de dire fera douter de son exactitude.

Ainsi s'écroule le témoignnag’e sur lequel M. Hale et ses partisans s'appuient le plus pour soutenir l'origine polynésienne des Maori; et si notre étymologie des mots qui, d'après Hale lui-même, sont la clef des migrations, est exacte, il ne resterait plus à réfuter que des témoignages de trop peu de valeur pour qu'il soit nécessaire de nous $\mathrm{y}$ arrêter ici ; nous l'avons déjà fait d'ailleurs pour quelquesuns, et nous aurons plus tard l'occasion de réfuter également les autres.

Si un même nom est donné par tous les Polynesiens au pays d'origine, ce n'est point parce qu'il dérive de Savaii, comme le dit M. Hale, mais seulement parce que partout, comrne nous l'avons fait pressentir, il signifie, quelle que soit sa forme, " patrie, pays nourricier."

C'est cette étymologie seule qui permet de comprendre comment il se fait que les Polynésiens, quoique venus dans leurs îles de directions différentes, les uns de l'Ouest, d'autres du Sud, comme les habitants des Sandwich, par exemple, d'après leurs propres traditions, ne placent pas moins tous la patrie première au couchant. Car il faut le remarquer, les habitants des Samoa et des Tunga, qui se servent d'un nom différent, ne font même pas exception. Tous, en ne faisant pas allusion au mot Savaii seulement, comme l'a cru M. Hale, mais bien au nom du pays d'origine première, qui était placé dans l'Ouest, tous pouvaient, en effet, employer ce mot, quelle que fût la position relative, même les habitants de l'Ile-Nord de la Nouvelle-Zélande, qui n'auraient pu le faire, s'ils fussent venus des îles Samoa, comme le croit M. Hale.

Nous l'avons déjà dit, et nous croyons devoir le dire encore, c'est dans la direction du Couchant que tous les Polynésiens, Samoans et Tongrans comme les autres, plaçent leurpays d'origine. Cette circonstance, à elle seule, suffirait, s'il n'y en avait pas tant d'autres, pour faire inférer, comme on l'a tant dit depuis quelque temps, que c'est de l'Ouest vers l'Est que les migrations se sont opérées; mais elle fait 
en même temps supposer que la ·Nouvelle-Zélande n'a pu recevoir ses habitants de Savaii, puisque cette dernière île se trouve dans le Nord-Est par rapport à elle.

Il eût fallu, pour cela, d'abord que les émigrants fissent exception à la marche généralement suivie, ce qui est peu probable; ensuite qu'ils se rendissent à la NouvelleZélande (Ile-Nord), avec des vents qui sont le plus souvent violents et contraires, ce qui n'est guère possible; puis qu'ils traversâssent, sans s'y arrêter, les archipels Tunga et Fiji qui barrent la route, ce qui n'est guère croyable. Ils n'eussent pu le faire d'ailleurs qu'avec des vents de la partie de l'Est, et dans ce cas, il est certain que des canots, au moins quelques-uns, seraient allés aborder à la Nouvelle-Hollande, entraînés involontairement. Or, nous l'avons dit déjà, aucune des traditions des divers archipels polynésiens ou mélanésiens, ne parle de semblables entraînements, pas mème les traditions maori, qui contredisent ainsi un fait, que l'absence complète d'animaux polynésiens dans cette contrée rend encore moins admissible.

Enfin, parmi les autres faits s'opposant à la venue des Néo-Zélandais directement des Samoa, il faut ajouter, avec M. Gaussin (1), que le rapport existant entre le dialecte Néo-Zélandais et celui des Samoa exige un autre intermédiaire.

Pourtous ces motifs, nous ne croyons donc pas qu'on puisse admettre l'hypothèse de M. Hale.

Dans le but d'appuyer son hypothèse, le savant américain a rapporté que, vers l'année 1740, une colonie de Polynésiens est arrivée à la Baie des Iles, venant, dit-il, d'Hawahiki, et il en a conclu que l'émigration de la Polynésie à la Nouvelle-Zélande, n'a eu lieu qu'à une époque très peu reculée. Mais M. Thompson s'est chargé de réfuter cette nouvelle assertion. " Des recberches personnelles faites avec le plus grand soin en 1850, sur le point même où M. Hale avait obtenu ce renseignement, m'ont mis à même,

(1) Ouvr. cité, p. 279. 
dit-il, d'avancer qu'il a été mal. informé ; car aucune migration moderne n'a eu lieu de la Polynésie à la NouvelleZélande. Seulement, vers l'année 1830 , un canot chargé d'émigrants partit de l'île Mayor, dans la Baie d'Abondance pour Hawahiki, et depuis on n'en a jamais entendu parler (l). " Comme on voit, ce serait tout le contraire.

Peut-ètre pourrions-nous, dès à présent, clore l'examen des diverses hypothèses concernant l'origine polynésienne des Nouveaux-Zélandais, car les trois que nous venons d'exposer, résument assez complètement les opinions fondámentales sur cette question.

Mais, comme depuis la dernière hypothèse, plusieurs autorités, plus ou moins compétentes, sont venues lui faire subir quelques modifications, nous ne croyons pas devoir nous dispenser, avant d'arriver à notre propre hypothèse, d'examiner avec soin les témoignages nouveaux sur lesquels on s'est appuyé pour soutenir la provenance polynésienne des Maori.

En suivant, comme toujours, l'ordre chronologique, nous commencerons par l'examen de l'opinion de M. Gaussin ; puis, nous arriverons successivement à celles de MM. Shortland, Grey, Taylor, Thompson et de Quatrefages.

$4^{\mathrm{e}}$ HYPOTHÈSE : Origine Samoane indirecte, - La première modification apportée à l'hypothèse de $\mathrm{M}$. Hale est due à un écrivain de mérite, M. Gaussin, ingénieur hydrographe de la marine, qui a commencé sa carrière en 1843 en Océanie, et qui a publié, dix ans après, le livre qui lui a valu le prix de linguistique fondé par Volney (2). Ce n'est, par le fait, qu'une des variantes de l'hypothèse de $M$. Hale, mais elle réunit si bien les trois hypothèses précédentes, qu'on peut la considérer comme originale.

Avec Dieffenbach, en effet, M. Gaussin admet que les premiers habitants de la Nouvelle-Zélande ont été amenés par

(1) The Story of the New-Zealand, vol. I, p. 66.

(2) Du dialecte de Tahiti, des îles Marquises et en général, de la langue polynésienne. Paris 1853.

18. 
trois canots venant de l'Est; avec Hale, que ces canots étaient partis des îles Samoa plutôt que des Sandwich, et qu'ils commencèrent par passer par des îles plus orientales ; enfin, comme le croyait d'Urville, que de là les canots se rendirent directement à la Nouvelle-Zélande.

a Les traditions à la Nouvelle-Zélande établissent avec certitude, dit-il,(1) quela Nouvelle-Zélande a été peuplée par. des hommes venus de l'Est dans trois canots. » Et il ajoute : « Cook appelle le lieu de départ Heavise et M. Hale voit avec raison Hawahiki dans ce nom. En effet la même tradition est rapportée par Dieffenbach et, d'après ce voyageur, Hawahiki est l'île d'où sont venus les trois canots qui apportèrent dans l'île les premiers habitants. ”

Nous avons montré précédemment ce que cètte dernière assertion de Dieffenbach avait d'inexact: il est inutile de nous y arrêter de nouveau ici. Mais ce que nous devons faire remarquer, c'est que, tout en reconnaissant le rapport frappant signalé par Dieffenbach, M. Gaussin ne croit pas que la distance qui sépare les îles Sandwich de la NouvelleZélande ait pu permettre aux pirogues polynésiennes d'effectuer un pareil voyage (2). Il fait la même objection à Horatio Hale qui admet que les émigrants pour la NouvelleZélande sont partis directement de l'île Savaii. Il préfère adopter l'opinion qu'ils proviennent d'une île Hawahiki, qui ne serait autre que l'ìle Savaii dans les Samoa, mais sans remarquer, lui non plus, que si les migrations s'étaient bien faites de l'Est, comme il le dit, ce ne pourrait pas plus être de l'île Savaii que des Sandwich, puisqu'il n'y a rien dans l'Est de la Nouvelle-Zélande, et qu'il n'y a, dans le NordEst, que les îles de Cook, Rapa, Tupuai, Tahiti, etc. Aussi, comme Dieffenbach l'a fait pour les Sandwich, en supposant que les colonies commencèrent par se rendre à l'île de Pâques, M. Gaussin, pour prévenir sans doute cette difficulté, fait d'abord passer les émigrants des Samoa à la

(1) Ouv. cité, p. $2 \% \%$

(2) Ibid. p. $2 \% 8$. 
Nouvelle-Zélande par des iles plus orientales que leur point de départ. Voici ce qu'il dit à ce sujet :

« Nous ferons la même objection à $\mathbf{M}$. Hale qui suppose les Nouveaux-Zélandais venus directement de l'île Savaii. Nous préférons admettre que ces migrations ayant eu lieu à une époque où les colons gardaient encore le souvenir récent de Savaii, leur première patrie, ils ont, dans leurs colonisations successives à la Nouvelle-Zélande comme aux Marquises et aux îles Sandwich, attaché une importance secondaire aux îles d'où ils venaient en dernier lieu. D'ailleurs il est une raison qui ne permet pas de rattacher sans intermédiaire les Nouveaux-Zélandais aux habitants des îles Savaii, c'est le rapport qui existe entre leur dialecte et ceux de la Polynésie orientale. Il faut en outre remarquer que la tradition porte que les premiers habitants de la Nouvelle-Zélande sont venus d'une île située à l'Est. »

Il termine en disant: (1) « Les traditions que nous venons de rapporter établissent donc qu'il y a eu une île primitivement nommée Hawahiki, qui a été, dans la Polynésie, le premier point de départ des Polynésiens. On pourrait, eu égard à la conformité des noms, voir cette île dans Hawaii des îles Sandwich, aussi bien que dans Savaii des Iles Samoa. Mais l'éloignement de Hawaii, le souvenir que les Polynésiens paraissent avoir gardé de l'archipel Samoa, et l'ignorance des Tahitiens relativement à l'existence des îles Sandwich, car on peut remarquer que cet archipel n'est pas porté sur la carte de Tupaia, décident la question en faveur de Savaii。 $\bowtie$ Et il avait dit un peu plus haut (2) : «La discussion que M. Hale a faite des traditions de chaque île, ne permet point de douter que ce ne soit Savaii qui ait été le point de départ des Polynésiens orien. taux. »

De sorte, que pour M. Gaussin, les émigrants de Saraii, avant d'arriver à la Nouvelle-Zélande, se seraient arrêtés dans des îles plus orientales que les Samoa, c'est-à-dire

(1) Ibid. p. 279.

(2) Ibid. p. 273. 
les îles de la Société, Tubuai, ou tout au moins les îles Hervey; ce serait de là que, sans en retenir le nom et pendant qu'ils conservaient encore celu de la patrie première, Savaii, ils auraient gagné la Nouvelle-Zélande. M. Gaussin ne désigne aucune île ou groupe d'îles en particulier ; mais il est bien probable que c'est des îles Hervey qu'il a voulu parler, en en jugeant par l'appui que nous lui verrons donner plus tard à cette mème hypothèse, empruntée à Thompson, par M. de Quatrefages.

M. Gaussin qui, ainsi qu'on a pu voir par nos premières citations, ne croit pas à la possibilité d'un voyage direct de Savaii àl a Nouvelle-Zélande, en raison de la grande distance qui sépare ces îles, admet donc que ces voyages ont pu être faits en partant d'îles plus à l'Est, et par consé. quent plus éloignées.

Il est certain que, de ce côté, les émigrants de Savaii n’auraient pas eu l'obstacle que présentent les deux archipels Fiji et Tunga à une route directe vers la Nouvelle-Zélande, et que, malgré cette distance, le voyage est plus facile à comprendre. Mais, comme nous l'avons déjà dit, une pareille route aurait été faite contre les vents alisés ordinairement régnants, et en sens inverse des autres émigrations : cela suffirait, quand il n'y aurait pas tant d'autres témoignages contraires, à faire douter de sa possibilité. On verra du reste bientôt, quand nous en serons à l'hypothèse de M. Thompson, quels faits doivent empêcher d'accepter une opinion qui, d'ailleurs, est à peine formulée ici, et qui ne s'appuie guère que sur celle de Dieffenbąch, que nous croyons avoir suffisamment réfutée.

Pour M. Gaussin, comme pour nous, c'est avec les vents de la partie de l'Ouest que les migrations se sont opérées vers l'Est; seulement il les fait venir directement de l'Ouest, c'est-à-dire de la Malaisie ; il accepte par conséquent l'ancienne opinion émise à ce sujet, mais sans apporter aucun fait nouveau à l'appui ; (1) tandis que nous

(1) On a vu précédemment, d'après $M$. Garnier l'impossibilité de la provenance des Polynésiens soit de la Malaisie, soit de l'Asie, et sa réfutation de l'opinion de M. Gaussin. 
les croyons venus du Sud-Ouest, comme nous espérons le démontrer bientôt.

Ce qui prouve que M. Gaussin a bien voulu indiquer la Malaisie en parlant de l'Ouest, c'est ce qu'il dit de l'impossibilité de remonter contre les vents: * Nous pensons, comme la plupart de nos devanciers, dit-il, que les migrations ont dû se faire de l'Ouest à l'Est. Cette direction étant contraire à celle des vents alisés, quelques auteurs regardent comme impossible que les Polynésiens aient réussi à remonter contre le vent et à gagner les îles de l'Est; nous reconnaissons que, avec les moyens qu'ils ont aujourd'hui, de semblables voyages ont dû ètre en effet, très difficiles; mais il suffit que, sur cent expéditions, une seule ait réussi. ('est ce qui a pu arriver lorsqu'une des pirogues doubles, montée par des marins habiles et entreprenants, aura profité des vents d'Ouest qui, dans l'Océan Pacifique, soufflent quelquefois avec persistance. »

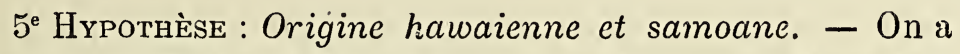
vu que Dieffenbach faisait venir les Nouveaux-Zélandais des îles Sandwich, en passant par l'Ile de Pâques, c'est-àdire qu'il leur donnait une provenance orientale; Hale, des îles Samoa, par une route directe ; M. Gaussin, des mêmes îles en les faisant passer d'abord par des îles plus Est, c'està-dire par une route indirecte. Maintenant nous allons voir un écrivain anglais emprunter quelque chose à chacune de ces hypothèses, et faire venir à la fois les Nouveaux-Zélandais des îles Sandwich, des îles Samoa, du Nord-Est, de l'Est, et même de Tahiti avec d'Urville.

Cet écrivain est le docteur E. Shortland, longtemps résident à la Nouvelle-Zélande et particulièrement à Maketu, dans la Baie d'Abondance, en qualité de protecteur des indigènes.

Il publia d'abord, en 1851, un livre intitulé a Les districts Sud de la Nouvelle-Zélande », (1) et ce fut en $18 \check{4} 4$ que parurent pour la première fois ses « Traditions et Superstitions

(1) The Southern districts of Newv-Zealand, London,1851. 
des Nouveaux-Zélandais, (1) 》ouvrage quia été réédité en 1856 avec beaucoup d'emprunts faits à l'ouvrage précieux de Sir Grey, qui avait paru dans l'intervalle, et dont nous aurons plus tard à parler longuement.

Résultat d'une longue résidence et d'une étude suivie, l'ouvrage de M. Shortland est du plus haut intérêt. Le premier, il donne, quoique d'une manière incomplète, le texte des traditions maori les plus importantes touchant le lieu d'origine des habitants. Ces traditions étant les mêmes que celles que Sir Grey a fait connaître avec plus de détails, nous ne nous y arrêterons pas ici. Mais nous dirons dès à présent que leur concordance, dans les principales circonstances, avec celles de Sir Grey, Taylor et autres, leur donne une valeur qu'on ne peut méconnaître et qui doit aider singulièrement à remonter à l'origine des Nouveanx-Zélandais.

M. Shortland, comme ses prédécesseurs, commence par dire que les Maori sont arrivés d'une terre appelée Hawahiki.

«Les traditions nous apprennent, dit-il (2), que les ancêtres de la race actuelle sont venus d'une île éloignée, appelée Hawahiki, située dans le Nord ou le Nord-Est de la Nouvelle-Zélande, ou d'un groupe d'îles dont l'une porte ce - nom. On n'a trouvé, parmi les indigènes, aucun souvenir d'une autre provenance, et les traditions s'accordent, au contraire, à dire que la migration venait d'Hawahiki. »

Ainsi, il n'admet qu'un Hawahiki ; mais il 'semble embarrassé entre Savaii et Hawaii, comme représentant cette terre: c'est sans doute ce qui lui fait adopter aussi bien l'une que l'autre.

"Il y a quelque intérêt, ajoute-t-il plus loin (3), à rechercher où se trouve Hawahiki, l'île de laquelle les NouveauxZélandais disent que leurs ancêtres sont venus. Ia réponse

(1) Traditions and superstitions of the New-Zealanders, Wich illustrations of their manners and customs. London, Longman 1854 . $2^{\circ}$ é dit. 1856.

(2)Traditions, etc., p. 2.

(3) Ibid. p. 33 . 
que nous pouvons faire n'est que conjecturale. Mais il y a des raisons de croire que l'île à laquelle il est fait allusion était, soit la principale du groupe des îles Sandwich, dite Hawaii par les habitants actuels, l'Owaihee de Cook; soit l'une des îles des Navigateurs dite Savaii par ses habitants : ces formes de prononciation sont des différences dialectiques de la prononciation Hawahiki des Nouveaux-Zélandais. »

Comme on voit, il admet sinon deux origines, du moins deux points différents comme ayant pu fournir les émigrants à la Nouvelle-Zélande, mais il laisse au lecteur à choisir, tout en montrant qu'il penche pour les îles Sandwich.

En effet, supposant que les migrations premières sont parties des îles Philippines, il les fait d'abord arriver dans les îles Carolines et Mariannes, puis, de là, aux Sandwich, et des Sandwich aux autres îles polynésiennes. La preuve la plus convaincante, dit-il, de cette provenance asiatique, c'est l'analogie qui existe dans les langages, qui sont construits d'après les mêmes principes grammaticaux, et offrent plusieurs points de contact sous d'autres rapports,

Des Sandwich,il les conduit sans difficulté aux Marquises et aux Iles de la Société, car dit-il encore (1): « Dans ce voyage un canot ne rencontre pas les difficultés qui existent pour aller des Philippines aux Sandwich, et le vent de Nord-Est oblige les partants de ces îles à aller vers les plus orien. tales de la Polynésie. $\gg$

«Supposons, ajoute-t-il encore, qu'une flottille de ca* nots, comme ceux dont parlent les traditions maori, ait été équipée pour un vóyage de découvertes, à l'aide de tous les moyens au pouvoir des indigènes ei qu'elle se soit dirigée vers le Sud. Quelques-uns d'eux tomberont probablement sur quelqu'une des îles de la Polynésie tropicale, tandis que quelques autres passeront au travers de toutes, en allant du Nord sur le Sud, sans en rencontrer une seule. Ces derniers canots, en rencontrant les vents alisés du SudEst, seront dans la nécessité de faire un peu plus d'Ouest,

(1) Ibid. p. 104. 
ce qui les conduira vers la Nouvelle-Zélande; et si le voyage était fait pendant l'été de cet hémisphère, en perdant les vents alisés, on rencontrerait le vent alors régnant, qui est le Nord et l'Est, et l'on ne pourrait pour ainsi dire pas manquer de tomber sur quelque point de la côte de la Nouvelle-Zélande, qui a plus de 600 milles du Nord au Sud. $D$

Il est bien certain, dirons-nous à cette occasior, qu'un navire voulant ailer des Sandwich à Tahiti, n'a qu'à courir le plus possible au Sud jusqu'au $16^{\mathrm{e}}$ ou $18^{\mathrm{e}}$ degré de latitude Nord; puis, une fois là, à prendre et à garder constamment le plus près jusqu'à Tahiti. C'est la route que nous recommandait le consul Dudoit, qui était venu nous faire ses adieux avec le roi T'amehameha, le jour de notre départ, et c'est en la suivant exactement que notre navire, après dix-huit jours de traversée, atterrit directement sur les Teturoa, petites îles qui se trouvent dans le Nord et à peu de distance de Tahiti (1).

Voilà ce que l'expérience a appris aux navigateurs européens qui savent en tout temps où ils se trouvent. Mais il est certainement permis de douter que les émigrants des Sandwich aient pu recourir à cette même expérience: l'eussent-ils possédée, elle se serait trouvée à chaque instant en défaut, dans l'impossibilité où ils étaient, après chaque coup de vent, de se fixer sur leur position réelle. Quoi qu'il en soit, l'explication de M. Shortland, tout insuffisante qu'elle paraisse, n'en est pas moins originale, et elle prouve surtout ses connaissances nautiques.

On remarquera que cette supposition fait faire aux émigrants d'Hawahiki à Tahiti une route inverse à celle généralement admise depuis Hale. Son auteur prend, pour étape des émigrants des Sandwich, l'île qu'on s'accorde à regarder comme ayant envoyé une partie des premiers colons à cet archipel, et qui, d'après ses traditions, dit avoir reçu ses premiers habitants de Raiatea.

C'est d'ailleurs de Tahiti que Shortland fait arriver à la

(1) Voyage du Pylade, 1840. (Inédit). 
Nouvelle-Zélande la colonne venant des îles Sandwich : il fournissait de la sorte un appui à l'opinion soutenue par d'Urville. Ce voyage s'était-il opéré directement ou indirectement? Il ne le dit pas formellement, mais on peut croire qu'il admet la voie directe, puisqu'il parle des vents de Sud-Est comme favorisant le voyage à la Nouvelle-Zélande.

Il ne dit pas non plus comment les émigrants qui, d'après lui, (l) seraient partis de Savaii, la plus grande et la plus Ouest des îles des Navigateurs, pour aller à la Nouvelle-Zélande, ont fait le trajet : mais de son silence inême on peut conjecturer qu'il admettait une route directe.

Shortland appuie d'ailleurs sa double hypothèse sur les témoignages fournis par Ellis, Kotzebüe et autres. Mais il laisse voir qu'il croit davantage au peuplement de la Nouvelle-Zélande par les Sandwich que par les Samoa, dont le langage, dit-il avec raison, ne se rapproche pas autant de celui de la Nouvelle-Zélande que le dialecte des îles Sandwich. Il cite, entre autres, à l'appui de cette préférence : la coutume du tangi (2) commune aux Sandwich et à la Nouvelle-Zélande; les noms des dieux Tane, Rono, Tanaroa et T'u; celui de l'île Maui ; etc.

Il semble attacher une grande importance à ce fait traditionnel des Nouveaux-Zélandais, que la patate douce ou Kumara, apportée par leurs ancètres à Aotearoa ou IieNord de la Nouvelle-Zélande, acquérait un plus grand volume en Hawahiki qu'en aucun autre endroit de l'Ile-Nord de la Nouvelle-Zélande. Ce fait, à notre avis, ne prouve pas grand'chose, car il pouvait $\mathrm{y}$ avoir, et nous montrerons qu'il y avait encore, plus au couchant que cette dernière île, une terre qui produisait justement une forte patate douce,dont le nom, anu rangi, ciel troid, semble mème indiquer le climat qu'elle préférait.

(1) Ouv. cité, p. 50.

(2) Cette coutume consiste à crier, à se lamənter l'un sur l'autre lors du retour ou de la rencontre de quelque parent ou ami qu'on n'a pas vu depuis longtemps. 
Shortland fait observer, d'après Ellis (1), que dans les îles Sandwich, les Kumara sont un des principaux moyens de subsistance, tandis que, dans les îles de la Société, elles sont moins cultivées et de beaucoup inférieures à celles des îles du Nord. Mais il faut remarquer égralement la note dont il accompagne son observation, car elle suffit pour expliquer ce fait: « En outre de la variété de Kumara introduite par les Nouveaux-Zélandais et dont la racine estpetite, les Européens, dit-il, ont introduit une autre variété d'Amérique, je pense, qui est bien plus grosse et d'une couleur plus claire; mais, quoique sa culture ne réclame pas autant de soir, on ll'en fait pas le même cas que de l'autre, par suite de l'infériorité de son g’oût. »

Sans doute une variété de Kumara, donnant aux Sandwich de gros rhyzomes, a pu être importée par les Européens et ne pas trouver là le sol qui lui convenait; mais il n'est pourtant pas moins certain qu'à la Nouvelle-Zélande même, les variétés de cette plante étaient nombreuses, et qu'il y en avait entre autres qui, ainsi qu'une foule d'autres végétaux, se plaisaient mieux dans l'île la plus Sud que dans l'Ile-Nord. Ce serait donc à tort, croyons-nous, que M. Shortland aurait dit : « S'il est vrai, comme nous sommes porté à le conclure du fait précédent, que la Kumara ne prospère pas dans les îles les plus tropicales de la Polynésie, qui ont un sol et un climat pareils à celui des îles de la Société, la tradition des Nouveaux-Zélandais touchant la grosseur de la racine apportée d'Hawahiki, quelle que soit son importance, nous porte à considérer les îles Sandwich, qui sont les plus éloignées, comme la source probable d'où est sortie la migration. „Il n'a sans doute voulu parler que de la Kumara apportée d'Hawahiki à l'île Nord par les émig'rants. On verra bientôt d'où venait cette patate douce.

Enfin, pour montrer que les Sandwich et les îles Samoa ont bien probablement peuplé la Nouvelle-Zélande, Shortland s'appuie en dernier lieu sur une observation du $\mathrm{b}^{\mathbf{r}}$

(1) Polynesian researches: p. 46. 
Pickering (1), d'après lequel ces deux groupes d'îles sontles seuls dans ces mers qu'on ait trouvés couverts de torrents de laves. Cette observation est inexacte : c'est ce qui a existé aux îles Fiji, dans des temps très éloignés ; la nature volcanique de ces îles n'est pas douteuse et l'action des volcans s'y fait encore sentir par des secousses de tremblements de terre, ainsi qu'on l'a observé à Waïnunu, Na-SavuSavu ou Vanua-Levu, ainsi qu'à Ngau, où existent des sources d'eau bouillante, comme à la Nouvelle-Zélande.

En somme donc, comme ses devanciers Dieffenbach, Hale et Gaussin, M. Shortiand concluait que les ancêtres de la race actuelle des Nouveaux-Zélandais étaient venus d'une île éloignée, appelée Hawahiki, île située dans la direction du Nord ou du Nord-Est de la Nouvelle-Zélande; ou bien encore du groupe des Samoa, qui se trouve lui-même, en effet, dans le Nord-Est de la Nouvelle-Zélande.

Mais c'était à tort qu'il s'appuyait sur les traditions quant à la direction dans laquelle se trouvait l'Hawahiki ; car si toutes les légendes donnent bien ce nom au lieu d'où provenaient les émigrants, pas une ne désigne foimellement cette direction, pas même les traditions que Shortland, le premier, a fait connaître. Bien mieux, comme il nous sera facile de le démontrer, la plupart de ces traditions prouvent que les émigrants venaient d'une direction tout-à-fait contraire au Nord-Est. Déjà nous avons fait remarquer que Dieffenbach, qui a le plus cherché à étayer cette opinion, n'a pas cité un mot des traditions qui précise cette direction, et que Hale n'en a rien dit non plus. Shortland n'apportant aucun témoignage nouveau à l'appui, il est permis de supposer qu'il s'est contenté de répéter l'assertion de Dieffenbach, qui n'était que l'induction tirée de certains faits, mais non l'expression des traditions connues. Nous avons déjà longuement refuté cette opinion; nous ne nous y arrêterons pas plus longtemps.

Toutefois, avant de terminer, qu'il nous soit permis de relever quelques erreurs de faits :

(1) Races of man, in-4, p. 74. 
Shortland cite (l) une légende qui parle de six canots ; cependant ce n'est qu'à trois seulement, mais surtout à l'Arawa et au Taïnui qu'il attribue le peuplement de la Nouvelle-Zélande.

Ce que nous voulons surtout faire remarquer, c'est qu'il ne fait point arriver tous les canots dans le même point, auprès du Cap Est, quoique la légende qu'il rapporte le dise formellement. Cette légende, après avoir cité les six canots par leurs noms, dit, en effet, que le premier lieu abordé par eux, sur la côte Est d'Aotearoa, a été Whaiapu (2), c'est-àdire le Cap Est de Cook. On dirait que M. Shortland a deviné l'importance de ce fait, car il s'empresse d'ajouter en note que ce n'est pas ce que la légende a voulu faire entendre. Mais il ne reconnaît pas moins que 4 canots sur 6 ont abordé à cet endroit. Ce fait est surtout important pour la question qui nous occupe, car si les canots fussent venus d'un Hawahiki bien éloigné et en traversant de vastes mers, on ne comprendrait pas qu'ils eussent pu arriver presque tous justement dans le même point, tandis qu'il serait facile de le comprendre, s'ils n'avaient eu qu'à suivre pour ainsi dire les côtes. En effet, en longeant la côte, il aurait fallu, quelle que fût la route suivie, que tous doublassent le Cap, et, pourvu qu'un port s'y trouvât, il était tout naturel de s'y arrêter.

Quant aux deux autres canots, Shortland les fait aller aborder dans un point beaucoup plus Nord, sur la mème côte Est d'Aotearoa ; mais nous sommes convaincu qu'il ne le fait que parce qu'il confond un point avec un autre, Whangaparaoa avec Whangaparaua. Avec sa croyance d'une provenance polynésienne surtout, il est impossible que l'arrivée de ces canots ait pu s'effectuer dans le lieu qu'il indique, et qui se trouve à peu de distance de la rivière Waïmata, sur les bords de laquelle est bâtie la ville d'Au-

(1) Ouvr. cité, p. 23.

(2) Et c'est également ce que le vieux chef Hahakai cité par Taylor, (p. 194), disait pour tous les canots. (Voir plus bas, p. 288, ce que nous disons du récit fait par ce chef à Taylor.) 
ckland, dans le fond du golfe Hauraki. En effet, 'comment en venant de l'Est ou du Nord-Est, c'est-à-dire de la Polynésie, comme le croit M. Shortland, les deux canots le Taïnui et l'Arawa, auraient-ils pu atteindre ce port, qui est placé assez avant dans le fond du golfe (l), sans être arrêtés, soit par l'une des îles Grande ou Petite-Barrière, soit par les îles Mercure, d'Haussez, ou du moins sans voir forcément l'une d'elles, tant elles barrent le passag'e et tant elles sont voisines de l'Ile Nord ? Comment, en les rencontrant après une traversée aussi longue que celle qu'eût nécessité le départ de la Polynésie, ne s'y seraient-ils pas arrêtés de préférence ? D'ailleurs, avant d'arriver à Whangaparaoa, en venant de l'Est ou du Nord-Est, il eût fallu commencer par côtoyer le rivage et on n'eût pas manqué de rencontrer d'autres ports, où l'on serait probablement descendu. En effet, de. puis le cap Rodney, il y en a plusieurs autres, tels que Oma et plus particulièrement la baie Kawau et la fameuse île de ce nom.

On comprendrait difficilement que, venant de la mer et rencontrant nécessairement l'une des îles désignées, on nc s'y fût pas arrêté ; mais ce que l'on ne comprendrait pas surtout, ce sont les allées et venues qui ont lieu après la sortie de Whangaparaoa. On voit (2) qu'en quittantcepoint, l'Arawa se rend à Aotea ou île de la Grande Barrière, qu'il revient ensuite à Hauraki, puis qu'il retourne à Moehau ou cap Colleville.

A quoi bon retourner à la Grande-Barrière puisqu'il n'aurait pu passer, en venant de la Polynésie, sans la rencontrer? Puis, une fois à la Grande-Barrière, pourquoi revenir à Hauraki, où il était d'abord, pour aller à

(1) Le hâvre de Waïtemata ou Waimata a son entrée dans le fond du golfe Hauraki, à 40 milles du hâvre Coromandel ; à 45 milles de l'entrée de la rivière Tamise ; à 40 milles de la pointe Rodney et à 45 milles du Cap Colleville. Il y a 40 milles du Cap Rodney au cap Colleville, c'est-à-dire toute la largeur du golfe. Waïhao ou le hâvre Coromandel est à 25 milles du cap Colleville; Moehau ou baie Cabbage est à moitié chemin.

(2) Shortland, ouvr cité, p. 14. 
Moehau, qui touche le cap Colleville ? Car la Grande-Barrière est assez éloignée de Hauraki, tandis qu'elle est voisine du cap Colleville, ainsi qu'on peutle voir en jetantles yeux sur la carte.

Une légende citée par M. Shortland, à propos de l'origine des Ngati-Kahuunuunu, des Nga-Puhi et des Rarawa,semble élle-même prouverque son Whangaparaoa n'est pas le Whangaparaoa des légendes de Sir Grey. Cette légende dit: L'endroit où les canots Tainui, Arawa, Kurahoupo, Maikukura, Mahuhu et Mamari abordèrent, fut Whaiapu. Or, Whaiapu n'est autre que le cap Est, et c'est après l'avoir doublé en venant du Sud-Ouest que se trouve le Whangaparaoa des légendes de Sir Grey. Ce n'est, à peu près certainement, que celui dont parle M. Shortland, quoiqu'il le place plus au Nord. Il est vrai que Shortland, semblant pressentir l'importance de cette citation pour l'opinion contraire à la sienne, s'est empressé de l'affaiblir en disant en note, ainsi que nous l'avons déjà fait remarquer : "Le narrateur ne voulait pas dire que tous les canots avaient touché à Whaiapu, mais seulement le Kurahoupo et les trois autres dans lesquels étaient venus leurs ancêtres. Nous avons déjà vu, ajoute-t-il, que le Taïnui et l'A rawa abordèrent à Whangaparaoa. »

Cela n'est pas douteux; sa lég'ende parle elle-même d'un Whangaparaoa, mais non de celui qu'il suppose, commele prouvent les itinéraires si clairement rapportés par les légendes de Sir Grey, et sur lesquelles nous aurons plus tard à revenir, et comme le prouve aussi la légende ellemême rapportée par Shortland pour la première fois.

Mais puisque rien, dans les textes, ne vient à l'appui de l'opinion de Shortland, il faut bien reconnaître que ce n'est qu'une interprétation sans fondement.

Shortland dit que le port de Whangaparaoa a été ainsi dénommé parce qu'un cachalot ou baleine a été trouvé échoué sur le rivage, et que le cachalot est appelé paraoa; mais il doit s'être trompé au moins d'orthographe; en Maori le cachalot est désigné par le mot paraua et la baleine par le mot tohora, ou tohoraha. Le mot paraua qui sert à dési- 
gner le cachalot sert également à désigner les os de la baleine, ainsi qu'une sorte de bâton de commandement des chefs fait avec l'os de ce cétacé. Paraoa, au contraire, ne signifie, en Maori, que farine, et n'est qu'une transformation du mot anglais floor.

Evidemment, puisque ce port a été ainsi appelé par les premiers émigrants, parce qu'ils y ont trouvé un cachalot, il faut écrire son nom Whangaparaua au lieu de Whangaparaoa (1) M. Shortland a donc confondu le point darrivée.

Shortland, après avoir dit que l'émigration d'Hawahiki à Aotearoa s'est probablement faite il y a cinq à six cents ans, ajoute (2) : «On dit que plusieurs canots partirent à la même époque pour aller à la recherche de nouvelles terres. Une partie seulement d'entre eux atteignit cette côte, et le lieu où chaque canot fut tiré à terre fut pris par les hommes de l'équipage, qui se répandirent ensuite de ce centre sur les districts les plus fertiles, jusqu'a ce qu'ils devinssent une tribu nombreuse. „ Ces lignes nous paraissent avoir la plus grande importance: elles semblent témoigner en faveur de migrations faites vers d'autres îles, qui pour nous sont des îles polynésiennes, en même temps que les migrations d'Hawahiki s'établissaient à Aotearoa, et non à la NouvelleZélande, comme il le dit lui aussi.

Si nous suivions l'ordre chronologique, il nous faudrait parler ici des deux ouvrages les plus importants qui aient été publiés sur la Nouvelle-Zélande, la a Mythologie polynésienne »de Sir Grey, et "Te Ika a Maui » du Révér. Richard Taylor. Ils ont paru l'un et l'autre à Londres dans le courant de 1855. Mais nous aurons à nous arrêter longuement sur ces deux livres, si riches de faits pour la question

(1) Peut-être aussi pourrait-on lire Whangaparoa: whanga, attendre, veiller, observer ; $p a$, village fortifié, tomber, refluer, dessous;'roa, grand. Mais la circonstance d'un cachalot, trouvé sur la côte, doit faire préfèrer l'étymologie précédente:

(1) Ouvrage cité, p. 304. 
qui nous occupe, lorsque nous leur demanderons des témoignages à l'appui de notre propre système. Nous nous bornerons donc ici, avant d'aborder l'examen critique des deux variantes de l'hypothèse d'Horatio Hale soutenues par MM. Thompson et de Quatrefages, et qui complètent tout ce qui a été écrit jusqu'à ce jour sur cette question, à rapporter le récit sur la provenance des Maori, que fit au Rév. Taylor un vieux prêtre de Parapara, sur l'lle-Nord, nommé Hahakai.

Nous ferons néanmoins remarquer dès à présent que si MM. Thompson et de Quatrefages se sont, pour appuyer leur opinion, adressés surtout à Sir Grey et au Rév. Taylor, ils nous paraissent avoir presque toujours dépassé le but en leur faisant dire ce qu'ils n'avaient pas dit. Nous essaierons de le prouver plus loin. Au surplus, Sir Grey n'a, au sujet de la provenance des Maori, que l'opinion de Hale; il n'y avait par conséquent rien à en dire de nouveau. Quant à Taylor, il semble avoir celle de Dieffenbach, puisqu'il croit que les Néo-Zélandais sont arrivés de l'Ile de Pâques, en venant en dernier lieu des Sandwich et primitivẹment de l'Asie. Il n'est même pas éloigné de croire, comme nous l'avons déjà dit, qu'ils étaient l'une de ces tribus juives dont on n'a jamais eu de nouvelles depuis leur sortie de l'Assyrie.

Le récit d'Hahakai ne dit, pas plus que les autres, où se trouvait exactement l'Hawahiki : mais il montre du moins que le vieux prêtre de Parapara croyait lui-même à l'origine polynésienne des Maori. Il nous semble n'être que l'interprétation d'un Néo-Zélandais ayant eu, depuis plus ou moins longtemps, des rapports avec les Européens. En somme, malgré sa distinction et ses fonctions, le vieil Hahakai ne parlait du lieu d'origine de ses ancêtres que d'après des lambeaux de traditions conservés dans sa mémoire.

a Les émigrants, disait le vieux prêtre à Taylor, étaient partis des îles appelées Hawahiki, Matatera et Wairota. » Taylor plaçait toutes ces îles dans l'Est ; mais bientôt nous ferons voir, d'après les noms mêmes que portaient ces 
lieux, quelle était leur véritable situation et quelle confusion faisait le vénérable Hahakai.

Suivant lui, a les montagnes dès îles d'où leurs ancêtres étaient partis, étaient couvertes de Kumara, qui y croissaient spontanément. » Ce fait s'est présenté, non seulement à Tahiti, aux îles Sandwich, etc., mais même dans les montagnes de l'Ile-du-Milieu de la Nouvelle-Zélande ; là, seulement, l'espèce était différente et portait un nom particulier.

"Une querelle les avait fait partir, mais sans qu'ils se fussent battus, parce qu'ils n'avaient pas' d'armes et qu'ils n'étaient pas encore une race guerrière. " On comprend difficilement que la tribu du vieux prêtre n'eût pas d'armes, à moins qu'il n'ait voulu dire, d'armes capables d'égaler celles des hommes qui venaient les attaquer.

a Ils étaient arrivés sur une flotte de canots et avaient d'abord atterri à Whaiapu, près du Cap Est de l'Ile-Nord de la Nouvelle-Zélande. » Nous dirons ailleurs pour quelle raison presque tous les canots ont touché dans ce point. Longeant pour ainsi dire constamment les côtes à vue, ils ne pouvaient pas aller plus loin sans rencontrer ce cap fort avancé en mer ; il était donc tout naturel qu'ils s'y arrêtassent.

«Ce ne fut qu'à la troisième génération que Po arriva dans l'île et se fixa à Taimaro. » Il en ressort nettement, qu'après la grande émigration, d'autres émigrations partielles, isolées, continuèrent, et eurent lieu même assez longtemps après la première. Celle-ci, d'après les traditions, avait elle-même été précédée de plusieurs autres, telle que celle de Turi, ainsi que de plusieurs royages de découvertes, tels que ceux de Kupe, de Ngahue, etc.

Le même vieux prêtre disait à M. Taylor : « Dans une île voisine des leurs, il y avait des bêtes qui portaient les hommes sur leur dos, et dans plusieurs de ces îles, il y avait des haches ayant des trous par lesquels passaicnt les manches, de manière à n'avoir pas besoin de les amarrer comme les leurs. „Ici, il faudrait se transporter évidemment vers l'Asie ou l'Amérique, ou tout au moins vers les îles Malaisiennes, pour trouver le pays dont Hahakai aurait voulu 
parler, si ce n'était pas tout simplement un récit, n'ayant d'autre base que ce que les Européens ont montré et qu'ils ont rapporté eux-mêmes.

Ce qui doit le faire croire davantage encore, c'est ce que dit ensuite Hahakai : “ Dans une autre île du voisinage, il y avait des hommes dont la peau était tout-à-fait noire ; ils allaient tout nus et n'avaient mêmepas, le plus souvent, de tablier devant eux.» Il n'y a peut-être pas un seul peuple qui ne recouvre plus ou moins quelque partie de leur corps, et particulièrement une, comme le prouverait au besoin le fait rapporté en latin par Claret de Fleurieu (1) et emprunté par lui à M. Labé, compagnon de Surville. A moins donc que Hahakai n'ait voulu parler des habitants de la Nouvelle-Hollande qui, en effet, abritent plutôt leur dos que les autres parties de leur corps, nous croyons que cette asser" tion n'estqu'une réminiscence de narration européenne.

Il en est de mème de l'assertion suivante : «Dans une autre île encore, il existait des hommes ayant des cheveux roux, qu'ils enduisaient d'huile de noix de cocos; ils portaient des vêtements faits en écorce d'arbre. » On sait aujourd'hui que les cheveux roux ne se trouvent naturellement que chez les Albinos de toutes les contrées. Quand on en trouve de pareils en Polynésie, c'est que cette couleur, comme les couleurs rouge ou blanche, est procurée par l'art. Toutefois ce que le vieux prêtre dit de l'usagede l'huile de cocos et des vêtements en écorce d'arbre, est plus à remarquer, car ce fait n'appartient qu'aux îles Polynésiennes ou Malaisiennes. Evidemment, il n'a pu vouloir parler des premières, puisqu'il ditque, dans le voisinage du pays d'origine, existaient des îles qui avaient l'usagge des bêtes de somme et des hommes à peau tout-à-fait noire. Il faudrait donc admettre qu'il s'agissait des îles de la Maíaisie ou même de Madagascar: Mais il est bien difficile de le croire. En outre, rien ne démontre que ces îles comnaissaient les bêtes de somme à l'époque des migrations hawahikiennes à

(1) Découveries des Français au Sud-Est de la Nouvelle Guinée, etc. par Claret de Fleurieu. Paris, 1\%90, p. 145. 
l'Ile-Nord de la Nouvelle-Zélande. Quand on tient compte de toutes les différences linguistiques, anthropologiques et autres que nous avons signalées, il est viraiment impossible d'admettre que les Maori ont pu provenir d'îles voisines de celles désignées par le vieux prêtre. A moins douc que quelques canots soient revenus à l'Ile-Nord de la NouvelleZélande, après l'émigration vers la Polynésie, ou qu'il s'agisse d'un récit fait au retour d'un canot qui avait été entraîné jusqu'à Ulimarao, dans les Carolines, il faut rester convaincu que l'assertion d'Hahakai n'était encore qu'une réminiscence européenne.

Le même vieux prêtre disait aussi « que leurs ancêtres avaient apporté le Tapu avec eux, c'est-à-dire leur religion. » Cela devait être ; mais, comme nous l'avons déjà fait remarquer, puisque le Tapu, sous des noms peu différents n'appartient qu'à la race polynésienne ou mavri, c'est une raison de plus de la reconnaître comme une race spéciale ; en effet, elle ne pouvait pas prendre cette interdiction là où elle n'existait pas.

Il ajoutait: «Ils n'étaient pas cannibales dans l'origine; cette coutume était peu ancienne; elle n'avait commencé que lorsqu'il était enfant; elle n'était due, en somme, qu'à la colère et non à la faim; elle commença dans sa tribu qui s'appelait alors Patu. „ Cette assertion est démentie par les traditions, quant à l'ancienneté, puisque les plus anciennes disent nettement que cette coutume existait en Hawahiki avant l'émigration; mais elle vient appuyer l'opinion, générale aujourd'hui, quel'anthropophagie n'est pratiquée que par vengeance ou superstition. Il faut remarquer ici le nom que portait dans l'origine la tribu du vieux prêtre : ce mot patu signifie tuer, frapper. Il est la première partie du nom patu-parehe que les traditions donnentaux habitants, probablement autochthones, qui ont été trouvés sur l'Ile-Nord de la Nouvelle-Zélande, par la tribu conquérante des Whanganui (1).

Enfin, le vieux prệtre disait " qu'ils ne tatouaient point

(1) Voir Taylor, ouvr. cité, p. 46, 49. 
leur visage à leur arrivée; ils avaient seulement l'habitude de le noircir avec du charbon, comme le font encore les jeunes gens en temps de guerre; le tatouage ne fut mis en pratique que plusieurs générations après leur venue, en un mot il n'était qu'une invention récente. » Comme il importe assez peu de savoir si cet usage est moderne ou ancien, nous ne nous y arrêterons pas.

En résumé, excepté l'assertion du vieil Ariki, relative aux noms deś lieux qu'il regarde comme pays d'origine, et à la situation qu'il leur supposait, toutes les autres assertions ne semblent être que des réminiscences confuses, et elles n'ont qu'une médiocre importance pour la question qui nous occupe. Mais il n'en serait plus de même si le vieux prêtre avait voulu parler d'une tribu occupant l'Ile-Nord de la Nouvelle-Zélande, (les environs de la Baie Lauriston de Surville), avant l'arrivée des émigrants de l'Hawahiki, et c'est ce qu'on pourrait croire, quand on voit le nombre de 26 générations qu'il donne à sa tribu, puisque c'est celui qui était donné aux premiers occupants de l'Ile-Nord à l'arrivée des émigrants d'Hawahiki. T'elle n'a pu être l'intention du vieux prêtre, car il commence par dire qu'ils étaient partis de l'Hawahiki et de deux autres lieux qu'ilappelle Matatera et Waïrota ou Waïroti : ceux-ci ne sont bien probablement, comme on a déja yu, et comme on verra mieux encore, que les mots Mataura, nom d'une rivière, et Waïota, nom d'un lac dans le Sud-Ouest de l'Ile-du-Milieu.

Son récit, bien que regardé comme des plus importants par M. Taylor, n'est donc, par cela même, à notre avis, qu'un souvenir persomel, plus confus encore que beaucoup d'autres, et qui ne dispose guère à accorder grande confiance à ses assertions. Bientôt nous aurons à revenir sur ces lieux, et à mieux préciser encore leur situation; mais nuus nous bornerons ici à faire remarquer que ces assertions n'ont pas plus de valeur que ceiles de tous les auteurs qui placent l'Hawahiki en Polynésie, puisqu'aucune tradition ne vient les appuyer formellement par son texte : elles sont seulement une manière de voir de celui qui les exprime, mais sans la moindre preuve précise. 
6e Hypothèse : - Origine samoane indirecte par Rarotonga. - Cette hypothèse est due à $M$. Thompson qui, en qualité de.chirurgien-major cu $58^{\mathrm{e}}$ régiment, a résidé pendant onze années à l'Ile-Nord de la Nouvelle-Zélande : c'est après ce séjour qu'il publia l'histoire de cette contrée(1), ouvrage plein de faits observés et contrôlés par lui-même ou empruntés à ses devanciers. En rapport avec les hommes du gouvernement comme avec les indigènes, M. Thompson s'est trouvé dans la meilleure position pour réunir les documents les plus variés sur le pays et les évènements ; il eut, de plus, le rare privilége de pouvvir entendre un ancien chef de Rotorua, Maihi-te-Rangi-Haheke, resté pendant quelques années son commensal, lui fairele récit des évènements passés, ce qui lui permit de donner à son opinion un cachet d'autorité que n'ont pas la plupart des écrits de ses prédécesseurs.

Nous avons déjà signalé le résultat des études et des observations de M. Thompson sur l'origine première des Polynésiens ; on a pu voir que le savant docteur est partisan, comme M. Hale, du peuplement de la Polynésie par la race Malaie et qu'il fait arriver aux îles Samoa, par le dé. troit de Torrès, les émigrants venant de Sumatra.

Or, c'est également, comme M. Hale, des îles Samoa qu'il fait partir les colonies d'émigrants pour la Nouvelle-Zélande, l'examen attentif de cette question l'ayant convaincu, dit-il, que l'Hawahiki des Nouveaux-Zélandais est, comme l'avance le savant américain, l'île Savaii de l'archipel Samoa. Seulement, au lieu de les y faire arriver directement, il les fait passer et s'arrèter d'abord à l'île Rarotonga, dans le groupe Hervey. C'est de cette étape que les colonies partent ensuite pour la Nouvelle-Zélande.

Comme on voit, c'est à peu près l'opinion de Hale, légèrement modifiée et débarrassée de l'obstacle qu'opposait l'existence, sur la route directe, des archipels Tunga et Fiji. Thompson étaie cette opinion d'un nombre considérable de preuves.

(1) The Story of the New-Zealand, 2 vol. London, 1859. 
Voici les raisons qui, suivant lui, prouvent le plus que les ancêtres des Nouveaux-Zélandais étaient Malais et qu'ils venaient en dernier lieu de l'île Rarotonga :

$1^{\circ} \mathrm{La}$ généralité de la génération actuelle de la Nouvelle-Zélande aurait, encore aujourd'hui, le langage, les coutumes et les caractères physiques et moraux des Malais ;

$2^{\circ}$ Tous les Nouveaux-Zélandais rapportent leur origine à un lieu appelé Hawahiki, et cet Hawahiki n'est pas connu dans les îles Samoa;

$3^{\circ}$ Il est fait allusion, à la Nouvelle-Zélande, à deux Hawahiki, l'un plus éloigné et plus grand, l'autre plus proche et plus petit:

$4^{\circ}$ Une tradition désigne les îles Waerota, Rarotonga, Waeroti, Parima et Manono, comme des îles voisines de l'Hawahiki ;

$5^{\circ}$ Les Nouveaux-Zélandais, quand on leur demande la position de l'Hawahiki, montrent la direction de Rarotonga;

$6^{\circ}$ Le nom de a route d'Hawahiki », est encore le surnom de l'Ile Rarotonga, et les traditions apprennent que c'est dans l'île Rarotonga que les émigrants ont construit plusieurs de leurs canots ;

$7^{\circ}$ Les chiens, les rats, et bien des plantes apportées à la Nouvelle-Zélande par les émigrants, seraient les mêmes que ceux qui existent dans les îles des Navigateurs ;

$8^{\circ}$ Enfin les habitants de Rarotonga existaient dans leur île depuis 29 générations, tandis que les NouveauxZélandais de l'lle-Nord n'étaient dans la leur que depuis 15 à 20 génération:

Ces preuves sont aussi imposantes que nombreuses, et elles donnent, à priorí, au système de l'auteur, une apparence de vérité qui porte avec elle la conviction. Aussi ont-elles suffi pour porter M. de Quatrefages à changer d'opinion et ont-elles valu à M. Thompson d'être traité comme le sont à peu près tous les observateurs de mérite, et comme l'ont été plus particulièrement les voyageurs Ellis et R. P. Lesson. On l'a beaucoup cité, mais en même temps d'autres lui ont 
fait des emprunts à la manière de Rienzi, c'est-à-dire sans se donner la peine d'en indiquer la source (1).

Mais ces preuves ont-elles bien toute la valeur que $M$. Thompson leur a donnée? Les faits qui les lui ont fournies ont-ils cette exactitude indispensable pour que les conséquences qu'on en tire soient inattaquables? En un mot, peut-on leur accorder toute confiance sans qu'il soit utile de les contrôler?

Nous ne le croyons pas. En effet, si quelques-uns de ces faits, pris isolément, sont embarrassants, la plupart cessent de l'être dès qu'on les examine de près, qu'on les rapproche de faits contradictoires. Or, comme plusieurs même nous ont semblé être rendus inexactement, il importe de signaler ces inexactitudes, car si elles ont pu être commises sans intention, elles n'en sont pas moins capables d'induire en erreur. Nous allons donc reprendre une à une chacune des preuves de M. Thompson.

$1^{\circ}$ Nous ne nous arrêterons pas longtemps à réfuter l'assertion de M. Thompson, d'après lequel a les habitants actuels de la Nouvelle-Zélande présentent encore dans leur langue, leurs coutumes, leur apparence extérieure et leur caractère, des preuves de leur origine malaie » (2).

Il reconnnaît lui-mème qu'il y a une grande différence de langage, et cela doit suffire. Il est vrai qu'il explique cette différence par le long temps écoulé depuis la séparation, 10 à 12 siècles; il dit en outre que le Malai ancien différait du Malai moderne, et que les racines et la structure des deux dialectes permettent encore de découvrir des ressemblances dans les mots qui expriment les choses les plus usuelles et les actes les plus simples de la vie. Mais son explication ne repose que sur des faits d'observation, entachés eux aussi d'inexactitude, et qui sont contestés par bon nombre d'ethnologues.

(1) Voir, pour n'en citer qu'un exemple, dans le Tour du Monde, no 281, p. 311, l'emprunt fait par M. de Hochstetter aux pages 16

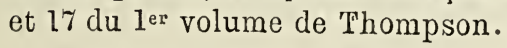

(2) Ouvrage cité, p. $5 \%$. 
Qui a vu les deux peuples ne peut leur trouver les ressemblances physiques et morales que signale M. Thompson. Leurs mœurs sont également différentes; leurs coutumes sont tout autres; et si l'on trouve quelques mots analogues, ces mots sont beaucoup plus rares qu'on ne croit, ainsi que nưus l'avons montré précédemment.

Mais c'est surtout par les caractères physiques que les Néo-Zélandais et les Malais diffèrent entre eux. Or nous avons déja assez indiqué ces caractères pour qu'il soit inutile d'y revenir ici (l).

$2^{\circ}$ Nous ne nous arrêterons pas davantage au nom que les Nouveaux-Zélandais de l'lle-Nord donnent à la contrée d'où leurs ancêtres avaient émigré. Nous avons déjà cherché à démontrer que le nom de cette contrée est Hawahiki, aussi bien pour les Polynésiens que pour les habitants de l'Ile-Nord de la Nouvelle-Zélande. Ce fait prouve une cho. se, c'est que le nom de la contrée d'origine était généralement le même, mais qu'on n'en précisait pas la véritable situation, quoiqu'on s'accordât à dire qu'elle se trouvait vers l'Ouest ou le Couchant.

Quant à la preuve que M. Thompson tire de l'absence, dans l'archipel Samoa, de toute tradition relatant que leurs ancêtres sont venus originairement d'Hawahiki, comme ceux de la Nouvelle-Zélande et des îles Hervey, bien que les habitants des Samoa admettent, dit-il, qu'ils sont sortis de l'île voisine Savaii (2), cette preuve est peu importante et n'a aucune valeur. Elle ne saurait prouver que les Samoa sont l'Hawahiki mème, ou que l'Hawahiki se trouve dans l'ure d'entre elles. Nous avons déjà suffisammentmontré que, si elles n'ont pas ce nom, elles en ont pourtant l'équivalent dans le mot Bolotou (3). Ce mot, emprunté à une nation voisine, n'a été adopté aux Samoa qu'après le départ des émigrants vers les îles plus orientales, et il a remplacé le

(l) Voy. vol. I, p. 139.

(i) Ouvr. cité, p. 58.

(3) Voy. vol. II, p. 483, 486 et 500. 
mot Hawahiki, qui y avait nécessairement existé dès le principe, ainsi que le montre son existence dans toutes les îles que l'on reconnaît avoir été peuplées par les Samoa et les Tunga. Ce fait même viendrait plutôt appuyer l'opinion quenous soutenons, puisqu'une légende samoane établit que les îles Samoa ont reçu leurs premiers habitants des îles Tunga.

$3^{\circ}$ a Dans toute la Nouvelle-Zélande, dit M. Thompson (1), les indigènes disent que leurs ancêtres ont émig'rés d'une contrée appelée Hawahiki. » Et il ajoute : Les naturels, dans leurs traditions, font, à ce sujet, allusion aussi à une Hawahiki plus éloignée et à une Havahiki plus voisine et plus petite.

Il a dû emprunter ce fait à quelques lignes du révérend Taylor, le seul qui, jusque-là, eût fait allusion à plusieurs Hawahiki ; mais cette assertion, bien que fournie par une pareille autorité n'en a pas pour cela plus de valeur. Quand nous en serons à l'examen de l'hypothèse de M. de Quatrefages, nous ferons connaître les raisons péremptoires de l'impossibilité de ce fait.

Nous nous bornerons ici à montrer que les paroles citées par'le révérend Taylor n'ont point la signification qu'il leur a donnée, et que, par conséquent, elles ne peuvent servir de preuve à M. Thompson.

Aucun des renseignements obtenus jusqu'à Taylor sur la Nouvelle-Zélande n'avait parlé de plusieurs Hawahiki; tous, au contraire, semblaient s'accorder à dire qu'il n'y en avait qu'un seul : Dieffenbach n'en cite qu'un; Shortland ne dit rien de plus ; toutes les légendes de Sir Grey se taisent sur la multiplicité des Hawahiki; elles établissent partout, au contraire, qu'il n'y en avait qu'un. John Williams lui-même, le savant missionnaire auquel Thompson a emprunté tous ses renseignements sur les îles Hervey, l'homme si compétent, qui a résidé longtemps dans ces îles avant d'aller trouver la mort à Erromango, l'une

(1) Ouvrage cité, p. 5\%. 
des Hébrides, John Williams, qui a publié toutes les traditions de Rarotonga, ne dit pas un seul mot, lui non plus, qui fasse allusion à deux Hawahiki. Cependant il parle

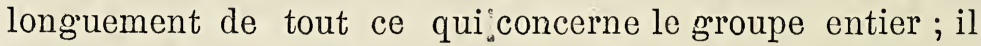
indique même jusqu'aux noms des plus petites localités de Rarotonga, et d'après lui, enfin, il n'y a qu'un Hawahiki, d'où sont venus les ancêtres des habitants actuels, et qui était placé dans l'Ouest de ces îles.

Ce silence général suffirảit déjà à faire douter de l'ìmportance attribuée à cette remarque. Mais comme on va voir, cette citation a encore beaucoup moins de valeur qu'on a cru, si elle n'est, comme nous le pensons, qu'un emprunt fait au révérend Taylor, le premier et le seul écrivain, avant M. Thompson qui eût parlé de plusieurs Hawahiki. Sans doute, Thompson, aurait pu obtenir ce renseignement de quelque autre source, et plus particulièrement de son commensal le chef de Rotorua; mais comme il n'en dit absolument rien, alors que cela eût été si naturel, comme il ne cite aucune tradition qui aurait pu le fournir, nous croyons qu'il a fait cet emprunt à Taylor, et en rue seulement de l'hypothèse qu'il voulait soutenir ; cet emprunt, en effet, a pour elle une importance considérable.

Voici ce que dit à ce sujet le révérend Taylor : (1) «Dans leurs traditions, les indigènes conservent le nom de l'île d'où ils sont venus, lequel est Hawaiki, et, dans ce nom qui est identique avec celui de Hawaii, nous avons la preuve du changement des langues avec le temps. Les Maori ont encore l'usage du $k$ et du $n g$; leurs ancêtres l'ont perdu.

« Hawaii, continue-t-il, est encore le nom de la plus grande des îles Sandwich. Celle-ci, à laquelle manque seulement le $k$, était appelée par les Nouveaux-Zélandais Hawaïki-tawiti-nui, ou l'Hawaii très éloignnée; de là il allèrent à Hawaiki-patata ou l'Hawaîki plus proche, littéralement la plus petite île, l'île plus petite qu'Hawaïki, c'est-à-dire Tahiti. Etant restés là, jusqu'au moment où

(1) T’̉ Ika a Maui, p. 192. 
l'île s'est trciuvée trop petite pour leur nombre, ils partirent de nouveau et émigrèrent à Hawaïki-ki-te-montere. En admettant que celle-ci était l'île de Pâques, qui est située à l'extrémité Sud-Est des vents alisés, on a un trajet très facile et très naturel jusqu'au hâvre Coromandel de la Nouvelle Zélande, qui, ainsi que nous l'avons déjà fait remar quer, porte le même nom que l'île de Pâques.

"Toutes leurs traditions établissent qu'ils venaient de l'Est. Ainsi donc, la mémoire des indigènes a conservé le souvenir de trois étapes principales : combien d'autres, en plus grand nombre, ont été oubliées ! »

Nous l'avons déjà dit ailleurs et nous ne pouvons que le répéter, toutes les traditions établissent bien que la terre de provenance était appelée Hawahiki, mais pas une ne dit que c'était plutôt Hawaii qu'une autre île, pas une ne dit textuellement que cet Hawahiki se trouvait dans l'Est, comme on ne cesse de le répéter. Ce n'est̂ absolument qu'une déduction des Européens, plus nécessitée par leurs hypothèses que fondée sur les textes: si les uns disent que c'était Tahiti, les autres que c'étaient les Samoa, ceux-ci, les îles Sandwich, il n'y a rjen dans les traditions qui l'exprime nettement.

Bien mieux, la traduction faitc par le révérend Taylor, des mots cités, n'est même pas tout-à-fait exacte. En effet, Hawaïki tawiti (1) nui signifie bien, comme il le traduit, « Hawaïki très éloigné » et Hawaïki patata (2), « Hawaïki proche, voisin, contigu ; " mais c'est à tort qu'il dit « plus proche $\gg$ au lieu de «proche s seulement, et qu'il ajoute surtout ; " littéralement l'île plus petite, qui est plus petite que l'Hawahiki, c'est-à-dire Tahiti. » Toutcela n'est qu'une interprétation de M. Taylor qui avait besoin, peut-être à son insu, d'appuyer son opinion préconçue. Il en est de même quand il dit qu'en partant de l'Hawaiki-tawiti-nui,

(1) Il faut écrire Tavhiti, mot qui signifie « distance, éloignement, éloignú.»

(2) Patata, près, être proche, contre. 
ils allèrent à Hawaïki patata; une simple citation du texte eût certainement mieux fait l'affaire des ethnologues.

Mais c'est la traduction qu'il donne du troisième Hawaïki qui doit surtout faire douter de la signification qu'il attribue à cette citation des vieilles légendes: Quand il dit qu'après avoir demeuré à Hawaiki-patata, jusqu'à ce que l'île devînt trop petite pour les contenir, ils émigrèrent encore à Havaiki-ki-te-moutere, il paraît n'avoir pas compris ces derniers mots qui semblent, à eux seuls, détruire tout son échafaudage, et qui, pas plus que les premiers ne parlaient de Tahiti, ne font allusion à l'Ile de Fâques, comme il aime le supposer.

Si l'on cherche ce que signifie moutere, on voit que ce mot, ainsi écrit du moins, n'est pas maori et qu'il doit être écrit mau tere, c'est-à-dire qu'il faut lire: Hawa-iki-temau-tere, dont voici la traduction littérale:

Hawaiki pour hawahiki; $k i$, à; te, le ; mau, porté, entraîné, emporté ; tere, en dérive, dériver, aller vite, légrer. Mou, pour toi, ne serait qu'un nom sens. Cette expression signifie donc:

“ En quittant l'Hawahiki, on fut entraîné en dérive; " mais elle ne dit pas du tout, comme on voit, que la tradition ait voulu parler d'un troisième Hawahiki. C'est ce qui explique probablement pourquoi Thompson s'est borné à n'en reconnaître que deux.

En supposant, comme le fait Taylor, que ces derniers mots voulaient désigner Waihu, l'Ile de Pâques, et le hâvre Coromandel (1) de la rivière Tamise de la Nouvelle-Zélande, il est facile certainement de faire croire aux ethnologues que les Nouveaux.Zélandais avaient pu, malgré l'énorme distance, venir de cette petite île ; mais, après avoir reconnu quel est le sens littéral des derniers mots cités, à moins de vouloir soutenir à tout prix qu'ils signifient l'île de Pâques et la troisième étape des émigrants d'Hawahiki. pas un

(1) Waïhu, d'après presque tous les écrivains, est le nom réel de l'île de Pâques; mais, comme nous l'avons vu plus haut, le nom du hâvre Coromandel est Waïho. 
seul linguiste ne verra dans ces textes ce que Taylor a cru y trouver.

C'est pourtant là-dessus que $\mathbf{M}$. Thompson s'est probablement fondé pour reconnaître deux Hawahiki, tandis que M. Taylor en voyait trois au moins. Mais, jusqu'à preuve du contraire, et en nous étayant de l'absence de citations indigènes précises dans toutes les traditions connues, ainsi que de l'ensemble de tous les faits polynésiens, nous croyons pouvoir regarder cette assertion comme n'ayant aucune valeur et répéter avec la plupart des écrivains, comme avec toutes les traditions connues, qu'il n'y avait qu'un Hawahiki.

C'est ce que M. Taylor établit lui-même en maints passages de son excellent livre. Ainsi, en parlant de la quatrième période mythologique, qui fait connaître les îles nées de l'alliance du ciel et de l'Hawahiki, (1) il ajoute : (2) * Ce sont les noms des terres ou des îles qu'on suppose avoir été les premières créées; Hawaiki est l'île d'où ils sont venus dans l'origine et qui est regardée comme le berceau de leur race. „Plus loin, (3) M. Taylor cite les paroles indigènes suivantes, qui semblent prouver elles-mèmes qu'il n'y avait qu'un Havahiki :

\section{Kune mai i Kawaiki,}

Te kune kai, te kune Tangata.

Qu'il traduit;

a La semence (graîne) de notre venue est Hawaiki,

« La semence de la nourriture, la semence de l'homme. "

La vraie signification de ce vieux dicton, si elle est bien

(l) Ces îles sont O-Taporapora-Tauwarenikau, Kuku-Paru, Wawau-ata, Whiwhi-te-rangiora.

M. Taylor n'a point cherché à découvrir quelles pouvaient être ces îles, et c'est en vain que nous avons nous-même essayé de le faire; mais il est à croire que les noms donnés comme étant ceux des îles premières nées signifient toute autre chose que ce qu'on a dit.
(2) Ouvrage cité, p. 15.
(3) Ourrage cité, p. 192. 
celle donnée, ne permet guère, en effet, d'admettre plusieurs Hawahiki. (1)

$4^{0}$ - La preuve que M. Thompson tire de la tradition rapportée par SirGrey sous le nom de Ko te Hekenga mai (2), semble, à première vue, beaucoup plus explicite ; mais, nous allons montrer qu'elle n'a pas l'importance qu'on pourrait être disposé à lui accorder, et que, si elle en a, c'est plutôt pour l'opinion opposée.

Voici ce que dit Thompson à ce sujet : (3) “ Une tradition des Nouveaux-Zélandais rapporte que Waerota, Rarotonga, Waeroti, Parima et Manono, sont des îles voisines d'Ha. wahiki. Les Nouveaux-Zélandais de la génération actuelle prononcent machinalement ces noms, en récitant la tradition; ils ignorent la position géographique de ces endroits et tout ce qui les concerne.

Puis il ajoute : « Rarotonga est une des plus grandes îles du groupe Hervey, mais ce n'est pas l'Hawahiki des Nouveaux-Zélandais, puisque les habitants de Rarotonga rapportent que leurs ancêtres étaient venus aussi d'Hawahiki. La situation de Waerota et de Waeroti est inconnue ; mais Parima et Manono sont les noms indigènes de deux îles dans le groupe des Navigateur's, dont les habitants n'ont aucune tradition, comme celle des Nouveaux-Zélandais et des insulaires du groupe Hervey, qui fasse venir leurs ancêtres d'un

(1) Le mot kune paraît ne pas être maori ; ce serait plutôt $h u$ $n e$, signifiant duvet des semences du Raupo, et probablement autre chose. En Maori semence, graine, se disent kopura, purapura, huri, kakano.

Nous ferons remarquer aussi l'orthographe du mot que M. Taylor traduit par Hawaïki, et qui était probablement celle des anciens temps ; ce mot, avons-nous déjà dit, doit s'écrire Kawahiki.

On sait que le Raupo, trpha angustifolia,est une espèce de glaïeul ou jonc qu'on emploie dans la construction des maisons.

(2) Sir Grey's Poems : ko te hekengamai, l'émigration; heke, descendre, refluer, émigrer; hekenga, descente, reflux, émigration; mai, vers, ici.

(3) Ouvr. cité, p. 58. 
Hawahiki, quoiqu'ils admettent qu'ils sont sortis de l'île voisine, de Savaii. »

Ainsi, M. Thompson reconnaît dans les deux îles Parima et Manono, citées par la tradition, celles qui occupent l'entrée du canal séparant Upolu de Savaii ; et, si la situation de deux autres est inconnue, il voit la Rarotonga de la tradition dans l'île du groupe des îles Hervey, où, dit-il, «d'autres traditions montrent que les canots ont été construits.' $n$

S'il n'y avait qu'une île Rarotonga, il serait difficile de nier l'importance de la preuve qu'il tire d'un pareil fait, aidée qu'elle est par la coïncidence des deux autres noms d'îles, Parima et Manono. Mais il est loin d'en être ainsi : non-seulement il y a ailleurs une île du nom de Rarotonga, mais, ce qui est bien autrement important, c'est autour de cette autre île Rarotonga même que se trouvent groupés tous les autres noms de la tradition, comme nous allons le montrer.

Si M. Thompson n'en a rien dit, c'est sans doute que l'existence de cette île lui était inconnue; mais il n'est pas moins vrai qu'elle figure sur la carte de la Nouvelle-Zélande et qu'elle se rencontre près de la côte Sud-Ouest de l'Ile-duMilieu, dans le détroit de Foveaux. C'est l'île dite du Centre sur les cartes anglaises, entre la Grande Terre et Rakiura et c'est près d'elle qu'on voit les lieux appelés Aparima, Waïraki et Waiota. Pourquoi, dès lors, ne serait-ce pas plutôt de cette île que la légende aurait voulu parler et dont elle a parlé certainement, si l'on en juge par la légende que Sir Crey a fait connaître sous le nom « Fmigration à la Nouvelle-Zélande? „

On voit, en faisant certains rapprochements, que cette tradition n'a pu faire allusion qu'à l'île Rarotonga du détroit de Foveaux : ce n'est que sur l'Ile-du-Milieu, que pouvait se trouver un lac nommé Waïharakeke (1), lac où, d'après la légende, aurait été abattu le Totara, arbre qui devait servir à faire l'Aotea, le canot de Turi, plusieurs années

(1) Wai, eau ; harakeke, phormium tenaz. 
avant qu'on ne construisit l'Arawa et les autres canots sur l'île Rarotonga. Fait bien curieux, c'est près de là qu'est la rivière Waiharakeke, qui se déverse dans la grande rivière Mataura. Ce nom de Waiharakeke suffirait à lui seul, comme nous le montrerons plus tard, à prouver que l'Hawahiki ne pouvait exister en Polynésie, puisque les Polynésiens n'auraient pu songer à donner à un de leurs lacs le nom de "Lac du Phormium " : Cette plante leur étant inconnue et n'existant absolument qu'à la Nouvelle-Zélande et à l'île Norfolk. Il en est de même, du reste, de l'arbre abattu : le Totara ne se trouve pas non plus en Polynésie.

Ainsi, voilà d'abord une des cinq îles de la légende re. trouvée ailleurs qu'en Polynésie; nous allons démontrer qu'elle n'est pas la seule.

Non loin de cette île, en effet, existe une rivière nommée Aparima.justement comme celle des îles Samoa, car le $l$, on le sait, remplace, dans ces îles, le $r$ de la plupart des autres archipels. Le même nom est d'ailleurs donné, à la Nouvelle-Zélande, à une baie dans laquelle débouche la rivière Aparima.

Il est vrai que M. Thompson appelle Parima l'île du groupe Samoa ; mais c'est évidemment à tort, puisque son autorité, J. Williams, lui donne le nom de Apolima, nom qu'il traduit par « creux de la main. (1) n

L'Apolima (2) de John Williams se rapproche d'ailleurs trop du mot maori aparima pour que ce ne soit pas le mêmème ; il faut pourtant reconnaître que les oreilles Euro-

(1) Qu'on nous permette de dire ici que J. Williams semble s'être trompé. En Maori, apo ne signifie que cupidité, assembler, et rima, cinq. En Tahitien apo veut dire, attraper quelque chose jetée à une autre, et creux d'un rocher; rima, la main, Je bras, cinq.

(2) L'île à laquelle les Samoans donnent ce nom est un ancien cratère de volcan éteint, au centre duquel on n'arrive que par une étroite ouverture, ce qui a permis aux indigènes d'en faire une forteresse imprenable. Elle est située entre Manono et Savaii, à sept milles seulement de cette dernière; elle a deux milles de circonférence et une population estimée à 2000 àmes: 
péennes saisissent si mal les sons que rien n'est plus facile qu'une semblable erreur. Le révérend Taylor nous semble n'y avoir pas échappé lui-même en appelant Akarima la rivière Aparima de la Nouvelie-Zélande (1). Mais si Thompson a donné le nom de Parima, c'est, nous le répétons, contrairement aux lég’endes et aux cartes géographiques.

Voilà donc encore la deuxième des cinq localités citées par la légende retrouvée, du moins comme désignation ; et, fait des plus curieux, c'est dans cette rivière Aparima que se déverse une autre rivière qui porte le nom de Waïraki.

Comme le mot Wairoti de la tradition n'a pu être que mal rapporté puisqu'il n'est pas maori, il est presque certain pour nous que ce nom est celui de Waïraki (2) comme nous allons voir que Waïrota n'est que le nom de Waiota. (3).

Ce nom Waiota est en effet celui d'un lac vis-à-vis et à toucher la rivière Taiari, près de Dunedin ou Otakou, entre la baie Molyneux et le cap Saunders, non loin par conséquent de la grande rivière Mataura, où se déverse la rivière Waiharakeke, et du port Awarua qui semble jouer un si grand rôle dans les traditions.

Sans doute, il n'y a là rien de certain, puisque ces mots, tels qu'on les a écrits, ne sont pas maori ; mais ils ont pour eux la première syllabe qui est plus maori que polynésienne, et quand on les voit accolés dans la tradition à deux autres noms qui se trouvent nettement désignés sur la côte Sud-Ouest de l'lle-du-Milieu, on est autorisé, croyons-nous, à les reconnaître dans ceux que nous venons de citer : car

(1) Apa, en Maori, signifie compagnie de travailleurs; rima, cinq.

(2) Wai, eau; raki, sec, être à sec, desséclié.

(3) On écrit également Waeroti et Waerota; mais si wae, signifie jambe, pied, roti n'est ni maori, ni tahitien ; dans ce dernier dialecte, sous la forme rotia, il signifie un poisson. Rota, en Maori est également le noin d'un poisson. Ro, insecte, fourmi en Maori et en Tahitien ; $t i$, cordylina australis, (Nouvelle-Zélande), et Dracœna terminalis, (Iles de la Société). Wai, eau ; ota, cru, mauvais. 
ceux-ci ne s'en rapprochent pas seulement par l'analogie, mais encore par le voisinage immédiat. Il est d'ailleurs bien facile de comprendre que les émigrants, en venant d'un Hawahiki tout autre que Savaii, auraient aussi bien pu dire, comme le fait Thompson, que les îles inconnues Waerota et Waeroti étaient, comme Rarotonga, Parima et Manono, voisines de l'Hawahiki. Quand nous aurons démontré où se trouvait cet Hawahiki, il ne sera plus possible d'en douter.

Reste toutefois à letrouver le lieu auquel la tradition donne le nom de Manono, et que M. Thompson a cru appli. qué spécialement à la petite île qui, avec A parima, se trouve entre Savaii et Opulu.

On sait que Manono a cinq milles de circonférence, et cinq à six mille habitants; elle tient à Upolu par un récif et n'en est éloignée que de trois milles. (1)

Il nôus semble évident que siỉon retrouvait quelque localité de ce nom, près de celles que nous venons d'indiquer sur l'lle-du-Milieu, il n'y aurait pour ainsi dire plus de doute à avoir. Or Manono est un nom de lieu qui existe sur la côte Sud-Ouest de l'Ile-du-Milieu de la Nouvelle-Zélande.

En outre, il y a justement, dans les traditions, des passa. ges qui font allusionà ce mot Manono, en Hawahiki. Les traditions, il est vrai, ne précisent pas la position du lieu auquel il est appliqué, aussi bien que celle des localités précédentes; mais elles disent toutes qu'il était en Hawahiki. Qu'on prenne les légendes de Tinirau, de Kae, et l'on verra que la demeure de ce dernier, aussi bien que le lieu sur lequel

(1) En Tahitien, manono ne peut être composé que des mots suivants : $M a$, blanc, propre, net, compagnie ; no de, à, concernant; nono, nom du fruit du Morinda citrifolia.

En Maori : ma, blane, propre, net, être blanc, propre; no, de, appartenant à, quand; mano mille. Et si l'on tient compte des milliers (mano) de personnes abattues par chaque coup de cordes. appliqué par Whakatau, d’après une légende qui 'cite le Tihio-Manono comme brûlé par lui, il se pourrait que l'étymologie fût maori. De même qu'en Tahitien le mot manono pourrait bien être manomano par élision. 
elle était établie, portait le nom de Tihi, ou Tini-o-Manono (1). Ce lieu ne pouvait être éloigné d'Hawahiki, puisque Whakatau put s'y rendre promptement avec son canot, de l'endroit qu'il habitait lui-même en Hawahiki (2). Si l'Hawahiki est, comme nous espérons le démontrer, l'Iledu-Milieu de la Nouvelle-Zélande, n'en faut-il pas conclure que c'est dans cette île encore que se trouvait le Tihi-o-Manono, comme c'est là que se rencontraient les autres localités désignées par les traditions, et si difficilement rapportées par tous les écrivains à la Polynésie ?

On a retrouvé dans l'Ile-du-Milieu et l'Ile-Nord de la Nouvelle-Zélande des localités appelées Tungra, Matavai, Rotuma, Otaheiti, Oheavai, Papaiti, Rapa, Amo, etc. ; et puisqu'on y retrouve égralement les noms Aparima, Rarotonga, Waïraki et Waiota, qui ont tant intrigué les ethnologues, ainsi que celui de Manono, réunis pour ainsi dire tous dans un espace fort restreint sur la côte Sud-Ouest de l'Ile-du-Milieu, il est plus que probable que c'est de ces localités que parlent les indig̀ènes, quand « ils récitent ces traditions machinalement en ignorant leur position ; " c'est d'elles qu'on pent dire avec plus de vérité ce qu'a dit M. Thompson (3) : «de Parima ou Manono dans les îles des Navigateurs, le voyage à Rarotonga pouvait être fait facilement, car il y avait entre ces îles de nombreux rapports. » En effet, si tous ces points étaient si rapprochés sur la côte Sud-Ouest de l'Ile-du-Mílieu, il est évident que les rapports devaient être fréquents et faciles.

Après cela, quand M. Thompson dit que « les émigrants

(1) M. Shortland traduit Tihi-o-Manono parle pic de Manono. Or, tihi, d'après Williams, signifie sommet et la même légende de Shortland apprend que c'était également le nom de la maison habitée par Kae et la tribu des Ati-Hapai, maison brûlée par Whakatau. Quant à Manono le dictionnaire de Williams, n'en dit rien.

(2) Voir la légende de Whakatau rapportée par Shortland, p. 68; Taylor p. 10\%, et Sir Grey : légendes de Tinirau, Whakatau, etc. Nous insérerons toutes ces légendes dans l'Appendice du IVंe volume.

(3) Ouvr. cité, p. 64́ 
s'arrètèrent évidemment à Rarotonga, "il ne fait que développer son hypothèse d'une provenance des îles Samoa; mais quand il ajoute que «les émigrants s'y arrêtèrent évidemment et que plusieurs tribus s'y établirent probablement, parce que les dialectes ont une étonnante ressemblance, » il nous donne le droit de lui demander comment il se fait qu'en remarquant l'étonnante analogie des dialectes, il n'ait pas remarqué que celui des îles Hervey n'est pas le dialecte des Samoa. Il est vrai que s'il eût fait cette remarque, il n'aurait pas pu signaler l'étonnante analogie qu'il indique et que cela eût été contraire à la provenance qu'il admet. Certes, chacun sait qu'il y a de l'analogie entre les dialectes samoan et maori ; mais cette analogie est plus grande entre les dialectes rarotongan et maori, qu'entre les autres, comme J. Williams, le premier, l'a démontré (1). Si cette analogie eût été reconnue, il eût fallu conclure que les émigrants venaient plus probablement d une toute autre contrée que les Samoa; or, comme ce ne pouvait pas être des îles de la Société, pour les raisons que nous avons données ailleurs, il devait naturellement répugner d'admettre la conclusion logique qui renversait l'hypothèse soutenue.

En résumé, cette preuve elle-même ne résiste pas à un examen attentif ; contrairement à ce qu'on a cru, elle est plutôt opposée que favorable à une provenance polynésienne. Nous le démontrerons quand nous en serons arrivé à préciser la véritable situation de l'Hawahiki.

$5^{\circ}$ - La cinquième preuve de M. Thompson est déduite de la réponse que font, d'après lui, les Nouveaux-Zélandais, quand on leur demande où gît l'Hawahiki. « Ils montrent, dit-il, la direction de Rarotonga.» Et il ajoute (2): « ce qui démontre que telle est la véritable direction de l'île d'où ils étaient partis en dernier lieu, c'est que chaque canot émigrant avait commencé par voir la côte Est de la Nou-

(1) Voy. ci-dessus, p. 192 et suiv.

(2) Uuvr. cité, p. 64. 
velle-Zélande. " Cette dernière assertion est de trop, à notre avis ; elle est suffisante, à elle seule, pour détruire l'importance de cette preuve.

Par suite sans doute de l'expérience de leurs ancêtres transmise par les traditions, les Nouveaux-Zélandais semblent savoir qu'il n'y a pas de terres dans l'Est de leurs îles, et à plus forte raison dans le Sud-Est, excepté les Chatham. Quand on leur parle de terres plus orientales, c'est vers l'E.-N.-E. ou le N.-E., qu'ils les supposent exister. Or, lorsqu'ils montrent cette direction, ils indiquent nécessairement celle de Rarotonga ; mais il est certainement douteux qu'en la montrant, quand on leur demande ou gît l'Hawahiki, ils veuillent parler de Rarotonga, dont le position geéographique leur est inconnue, d'après Thompson luimême, qui dit d'autre part: «Rarotonga est une des plus grandes îles du groupe Hervey, mais non l'Hawahiki des Nouveaux-Zélandais, puisque les habitants de Rarotonga disent aussi que leurs ancètres étaient venus d'Hawahiki. » Il aurait pu ajouter : d'un Hawahiki placé dans l'Ouest et par conséquent dans une direction, par rapport à leur île, toute différente de celle dans laquelle se trouve Savaii, que M. Thompson regarde comme la grande Hawahiki. Cela seul dénote que les habitants de Rarotonga eux-mèmes ne croyaient pas provenir de Savaii, car, vu le peu de distance des deux groupes, ils devaient certainement en connaître la position relative.

La distinction de deux Hawahiki établie par Thompson doit faire supposer qu'il n'a voulu parler de Rarotonga que comme de la petite Hawahiki, quoiqu'il ne l'exprime pas nettement; mais cela n'aide guère à comprendre comment il se fait que la génération actuelle de la Nouvelle-Zélande sache qu'il faut suivre cette direction pour aller en Hawahiki. Qui le lui aurait appris, d'ailleurs ? Elle n'a pas émigré depuis des siècles (1) ; les émigrants qui ont pu partir

(I) Excepté pourtant en 1830, d'après Thompson et Shortland : Un canot chargé d'émigrants essaya de se rendre en Hawahiki, en partant de l'Ile Mayor, d'après le premier, ou de Tauranga d'après le second. 
ne sont jamais revenus, et les traditions maori, loin d'ètre explicites, comme on pourrait le croire d'après tous les écrivains, disent plutôt, contrairement à ce qu'on leur a fait dire, qu'au lieu de recevoir des émigrants de l'Est, c'était ver's l'Est que les émigrants se dirigeaient.

Si la légende sur laquelle s'appuie $\mathbb{M}$. Thompson a bien dit, avec apparence de raison, en supposant l'Hawahiki en Polynésie, que Manono et Parima étaient des îles voisines, on eŝt en droit d'être surpris qu'elle ait dit la même chose de Rarotonga, puisque cette île en est éloignée de six à sept cents milles. Lîle Rarotonga, dont la tradition parle comme du point où des canots ont été construits pour l'émigration, ne pouvait donc pas être, ainsi que l'a cru M. Thompson, celle de la Polynésie, mais bien celle du groupe de la Nouvelle-Zélande. C'est l'île de la Polynésie qui a reçu son nom d'émigrants venant de la Nouvelle-Zélande : nous le démontrerons bientôt.

Nous croyons, en somme, que si on a montré à M. Thompson la direction de Rarotonga pour la route d'Hawahiki, c'est sans faire allusion à cette île; l'auteur anglais a cru la reconnaître, parce qu'il avait en mémoire les quelques lignes indéterminées des lég’endes que nous avons dû rappeler. Si les indigènes ontindiqué cette direction, ce n'est bien probablement de leur part que par confusion de souvenirs traditionnels, car presque toutes les légendes prouvent, dans les migrations qu'elles rapportent, que la route était faite du Sud-Ouest vers le Nord-Est, de l'Ouest à l'Est. Quelle qu'ait pu être l'époque des migrations de l'Ile-Nord. de la Nouvelle-Zélande, ou mème de celles. venant directement d'Hawahiki vers la Polynésie, ces émigrations n'ont pu manquer de se porter dans la même direction, c'est-àdire d'aller de l'Ouest vers l'Est. C'est sans doute ce souvenir lointain, si confus qu'il est inversé (1), qui a guidé

(1) Les habitants de l'Ile-du-Milieu, par exemple, appliquent le mot raro, qui signifie dessous, sous, à tout ce qui est au Sud d'eux, tandis qu'à Auckland, raro est appliqué à ce qui se trouve au Nord. 
dans leur réponse les naturels interrogés par M. Thompson. Cette réponse, cependant, a été accueillie avec d'autant plus d'empressement, qu'elle cadrait davantage avec le système préconçu de l'auteur. C'est la mème confusion de souvenir qui a fait dire, sans plus de preuves, que la Nouvelle-Zélande a été peuplée par trois canots venant de l'Est: Or ces canots portaient, comme on a vu, absolument les mêmes noms que ceux que les légendes de Sir Grey montrent être venus du Sud-Ouest ou de l'Ouest. On a tout simplement pris la direction du point de départ pour celle de l'arrivée.

Il est facile de s'expliquer cette erreur, quand on se reporte à cette partie de la légende qui désigne Rarotonga, où des canots ont été construits, comme une île «située de l'autre côté de l'Hawahiki " (1) et dans son voisinagre. Il était tout naturel qu'en plaçant l'Hawahiki aux Samoa, on vit la Rarotonga des légendes dans l'île du groupe Hervey. Mais, nous l'arons dit, n'y aurait-il que l'existence signalée du Totara à Rarotonga, qu'il est impossible que ce soit la Rarotonga polynésienne.

N. Thompson s'est d'ailleurs chargé lui-même, par les dernières lignes de la citation que nous avons faite, de détruire l'importance de ses inductions; et son assertion n'est pas exacte, quand il avance que chaque canot émigrant commença par voir la côte Est de la Nouvelle-Zélande,(Ile - Nord). Il suffira, pour s'en assurer, de jeter les yeux sur les traditions si importantes publiés par Sir Grey, et dont Thompson ne donne qu'un résumé fort incomplet. Nous allons en citer quelques exemples:

La tradition de Kupe montre que ce navigateur a commencé et fini par le détroit de Cook : on dit bien qu'il a fait le tour de lîle; mais la tradition ne parle que des lieux qu'il a découverts et entre autres de Patea dans le détroit.

Le canot de Turi, quoiqu'en dise M. Thompson, n'est pas allé sur la côte Est d'Aotearoa ou Ile-Nord de la NouvelleZélande, mais il a seulement visité une partie de la côte

(1) Sir Grey, Polynesian mythology, p. 134. 
Ouest de cette île et une partie du détroit de Cook lui-même : c'est là qu'il avait presque certainement commencé, et qu'il termina son voyage.

Tama-te-Kapua, Manaia et autres chefs Nouveaux-Zélandais, ont longé avec leur's canots la côte Est de l'Ile-Nord, mais en allant vers le Nord-Est, c'est-à-dire en venant d'un point plus Sud-Ouest, comme avait fait Turi en particulier. C'est ce que dit nettement la légrende de son émigration, quand elle indique la nécessité de faire route du côté où le soleil se lève pour atteindre Aotearoa, en partant d'Hawahiki. (1).

La légende de Ngahue prouve qu'il a passé, lui aussi, dans le détroit de Cook et qu'il a pris au moins son point de départ d'un lieu voisin, puisqu'il possédait, en partant d'Hawahiki, du jade vert qui ne se trouve que dans l'Ile-du-Milieu.

D’après ces mèmes lég’endes, c'était également du détroit de Cook que tous les canots prenaient leur point de départ pour retourner en Hawahiki. D'où il faut conclure que les preuves tirées de pareils faits n'avaient pas l'importance que M. Thompson leur donnait.

Il n'y a rien d'étonnant à ce que quelques indigènes de la génération actuelle, chaque jour plus ignorante des vieilles traditions, aient répondu à la demande qui leur était faite que l'Est était la position de l'Hawahiki : les Polynésiens, de tous les temps et de toutes les îles, ne sont jamais embarrassés pour répondre, alors même qu'ils ignorent, comme nous en avons si souvent fait l'expérience nous-même.

Aujourd'hui qu'ils sont démoralisés, presque constam. ment en lutte entre eux, peu disposés à écouter les enseignements de leurs prêtres, comment sauraient-ils indiquer, aussi bien que les générations qui les ont précédés, la route suivie par leurs ancêtres en émigrant d'Hawahiki ? Or toutes les traditions connues, les plus anciennes comme les

(1) Le nom donné à une pointe près du cap Palliser, te Rawhiti, «le soleil se lève, (littéralement, le soleil passe outre, traverse), n a pu être donné que par quelques émigrants venant de P'Ouest. 
plus modernes, ne disent absolument rien ni de l'existence de deux Hawahiki, ni de la situation de l'Hawahiki dansl'Est. Et cependant c'est sur ces légendes que quelques auteurs se sont basés pour soutenir queles ancêtres des Maoriétaient venus de l'Est. Il est vrai que ces auteurs diffèrent eux-mêmes entre eux quant à la direction qui leur aurait été indiquée par les indigènes: Hale avait entendu qu'ils venaient de l'Est ; c'est ce que Dieffenbach et Gaussin ont répété après lui. Shortland a dit qu'ils venaient du Nord ou du NordEst ; mais ni les uns ni les autres n'ont fourni d'autre témoignage que leur assertion. Car, nous le répéterons en. core, aucune des légendes citées ou rapportées par eux. mèmes pour la première fois, ne parle de l'Est comme direction de provenance.

Shortland lui-même dit et montre (1) que la situation de l'Hawahiki était inconnue aux indigènes, qu'elle était toute conjecturale. Quelle confiance, dès lors, avoir dans la réponse qui a pu être faite à $\mathrm{M}$. Thompson ? On ne pourrait lui en accorder que si les traditions parlaient nettement de la position précise ; mais elles n'en disent absolument rien. Bien mieux, elles disent que les émigrants d'Hawahiki vers l'ile-Nord de la Nouvelle-Zélande venaient d'un point placé plus à l'Ouest.

Taylor, il est vrai, a écrit : (2) « Toutes lez traditions rapportent qu'ils sont venus de l'Est. » Mais le savant missionnaire a beau affirmer que toutes les traditions le rapportent, son assertion, comme celles de ses prédécesseurs, ne repose que sur une interprétation toute européenne. Pas une seule des traditions connues ou citées par lui ne le dit; pas une ne se sert de ce mot Est, ou de mots qui puissent être interprétés ainsi. Evidemment une pareille opinion, comme celle de tous les écrivains précédents, n’est que le résultat d'une idée préconçue : après avoir placé l'Hawahiki dans la Polynésie, il fallait bien qu'on supposât les émigrants venus de l'Est. Mais nous le répéterons encore, pas un des

(1) Ouvr. cité, p. 28 et 33.

(2) Te Ika a Maui, p. 193. 
textes de ces légendes, et nous croyons les connaître presque toutes, ne parle de l'Est; toutes se bornent à nommer l'Hawahiki, mais sans désigner aucunement sa position.

Une seule pourtant a paru le faire : c'est sur elle que Hale et plus tard Pritchard se sont appuyés pour soutenir cette opinion. Mais, comme nous l'avons déjà montré, ni l'un ni l'autre n'a remarqué que les mots employés par la tradition disent précisément tout le contraire de ce qu'ils les ont cru signifier, c'est-à-dire Ouest ou Nord-Ouest au lieu d'Est.

$6^{\circ}$ La preuve que M. Thompson trouve dans le nom de « route d'Hawahiki, " que porterait l'île Rarotonga, est encore moins importante que la précédente : clle est même presque certainement contraire à son opinion.

Pour que l'on puisse mieux en juger, nous transcrivons ici le texte original de l'auteur anglais : (1) «For these reasons, it is infered that the ancestors of the New-Zealanders migrated from the Navigator's Islands through Rarotonga, because the latter island is still denominated the Road to Hawahiki, and is described as lying on this side of it. 》

Plus on examine ce texte, moins il signifie ce que $\mathbf{M}$. Thompson a cru y voir : Il ne dit pas " route d'Hawahiki, » comme on le traduit d'ordinaire, mais " route à, vers $(t o)$ l'Hawahiki, " par conséquent vers un autre point que celui d'où venaient les émigrants. Ces émigrants, que M. Thompson faisait sortir des Samoa, ne pouvaient donc pas regarder Savaii comme leur Hawahiki, puisqu'ils allaient vers celui-ci en s'éloignant de Savaii. Cela prouve aussi que l'Hawahiki devait être encore plus loin que Rarotonga, puisque Rarotonga n'était qu'une étape et qu'elle « se trouvait sur ce côté de l'Hawahiki.»

(1) Ouvr. cité, p. 59. « Pour ces raisons, il faut conclure que les ancêtres des Néo-Zélandais ont émigré des îles des Navigateurs en passant par Rarotọnga, car la dernière île est encore appelée la route vers l'Hawahiki, et elle est décrite comme se trouvant sur ce côté de lui (de l'Hawahiki). 》 
Si l'Hawahiki eût été Savaii, à quoi bon, en effet, passer par Rarotonga pour s'y rendre, en partant de Manono et de Parima, comme Thompson le fait supposer ? Il eût certainement été plus simple de débarquer de suite à Savaii, qui n'est éloignée de ces deux petites îles que de quelques milles seulement. Cela seul suffirait pour que l'on mette en doute la provenance de Savaii.

Le dernier membre de phrase qui termine la citation que nous venons de faire est assez obscur : pcut-être is described ne doit-il pas s'appliquer à Rarotonga, mais à la route suivie, ce qui semble plus rationnel. Néanmoins il resterait toujoursà se demander sur quel côté, car le texte, peutêtre intentiunnellement, se borne à dire: «on this side of it. "Une des légendes publiées par Sir Grey, et qui parle d'une île Rarotonga où les émigrants allèrent abattre le Totara destiné à construire l'Arava, se borne ellemême à dire que «cette île était de l'autre côté de l'Hawahiki. $\gg$ Sans doute M. Thompson, dans son texte, n'a fait allusion qu'à ce membre de phrase de la légende maori. Mais, ainsi que nous l'arons déjả fait remarquer, le nom seul donné à l'arbre abattu prouve qu'il ne pouvait s'agir de l'île Rarotonga du groupe Hervey, puisque le Totara ne vient pas dans cette île.

Quoiqu'il en soit, il résulte cu texte même de M. Thompson que les émigrants ont passé par Rarotonga, et qu'ils s'y sont arrètés pendant plusieurs générations avant d'émigrer à la Nouvelle-Zélande (1). Mais cette citation n'aide en rien à préciser la véritable situation de l'Hawahiki, c'està-dire le point de départ des émigrants.

Des émigrants venant de la Nouvelle-Zélande auraient, du reste, pu passer par cette île bien mieux que caux qu'on fait sortir des Samoa, puisque Rarotonga est sur la route directe de la Nouvelle-Zélande à la Polynésie. Ils auraient même tout aussi bien pu donner à cette île le nom de Rarotonga, et lui appliquer l'épithète de * route d'Hawahi.

(1) Ouvr. cité, p. 59 。 
ki, (1) »comme on le dit. Bientôt nous démontrerons que ce mot Rarotonga est Maori et que, comme celui de Tunga, dont nous avons déjà parlé, il ne pouvait être donné que par des Maori.

En résumé, cette preuve invoquée par M. Thompson est un témoignage plus favorable aux migrations venant de la Nouvelle-Zélande qu'à celles qu'on fait venir des îles Samoa à la Nouvelle-Zélande.

$7^{\circ}-\mathrm{M}$. Thompson trouve encore une preuve de l'origine samoane des Nouveaux-Zélandais, dans l'existence aux îles Samoa de chiens sauvages, ressemblant au chien domestique trouvé par Cook à la Nouvelle-Zélande. Il l'emprunte au missionnaire J. Williams, qui décrit, de la manière suivante, l'animal dont on lui avait parlé : (2) \& Une particularité de l'histoire naturelle du groupe Samoa, est qu'on trouve un chien sauvage dans les montagnes. J'ai vainement cherché à m'en procurer un. D'après la description qui m'en a été faite, il paraît être un petit animal, de couleur noire, gris sale ou de plomb, avec peu ou pas de poil, et de grandes oreilles droites. »

M. Thompson, tout en trouvant que les chiens de la Nouvelle-Zélande sont identiques à ceux des Samoa, et qu'ils prouvent la situation de l'Hawahiki à Savaii, n'admet pas naturellement que ces chiens fussent indigènes : a On compte, dit-il (3), parmi les mammifères indigènes de la Nouvelle-Zélande, les chiens et les rats, mais il n'en est rien. Il est vrai que le capitaine Cook a trouvé des chiens et des rats en 1769 ; mais ces deux animaux avaient été apportés dans le pays par les Nouveaux-Zélandais, et il est à remarquer que tous les deux sont presque éteints aujour-

(1) Nous citerons, à ce sujet, un proverbe maori qui, d'après M. Taylor, peint les actions désespérées: ka hotia te tai tapu $k i$ Hawahiki, « la route à l'Hawahihi est coupée. "C'est l'alea jacta est, le passage du Rubicon des Maori.

(2) A Narrative, etc., p. 498.

(3) Ouvr. cité, t. I, p. 21. 
d'hui. Le grand rat de Norway, importé dans la NouvelleZélande par les colons Anglo-Saxons, a détruit le rat indigène ; et les chiens indigènes qu'on élevait et propageait anciennement pour servir de nourriture, ont tous été mangés ou détruits, parce qu'après l'introduction des cochons, les Nouveaux-Zélandais n'ont pris aucune précaution pour en conserver la race.

« Des royageurs attentifs peuvent encore voir, de temps en temps, sur les bords du lac Taupo, quelques mauvais chiens, croisés de chiens maori et anglais, qui ont la queue touffue, le poil couleur du renard, les oreilles dressées et un hurlement au lieu d'un aboiement : ce sunt les derniers vestiges de la race des chiens apportés par les naturels à la Nouvelle-Zélande. Ceux que les bergers de l'Ile-du-Milieu appellent chiens indigènes, ne sont que des animaux anglais libies, non sauvages.

" Il est prouvé que le véritable chien indigène a été introduit à la Nouvelle-Zélande et par'les traditions, et par le mot maori qui sert à désigner le chien, mot qui est tout-à-fait polynésien, et, par les os calcinés d'hommes, de moa et de chiens qui ont été trouvés par M. Mantell sur un banc de sable, près de Taranaki, l'un des points les plus ancienne. ment occupés par les Nouveaux-Zélandais.

«Il est également prouvé, par les traditions et par l'existence de rats semblables dans toute la Polynésie, que les rats indigènes de la Nouvelle-Zélande, qui étaient petits et frugivores, $y$ ont été détruits. (1) D

(1) Shortland (p. 26) semble ne pas partager l'opinion de Thompsou: après avoir dit que les Néo-Zèlandais avaient des nattes de chiens au temps de Cook et que les livres qui lui attribuent l'introduction des chiens à la Nouvelle-Zélande ne prouvent nullement que les légendes parlant des chiens ne datent que d'une centaine d'années, il ajoute : « de plus la race indigène des chiens existe encore à la Nouvelle-Zélande, quoique peut-être rarement dans sa pureté originelle. Elle est élevée dans certains lieux pour sa peau. En apparence, elle est très différente des races européennes : son corps est long; ses jambes courtes ; sa tête pointue; sa queue longue, droite et touffue. Le poil est épais, droit et assez long, de couleur variant du blanc au brun, mais sans tarhes.: 
Sans rechercher si l'animal décrit par J. Williams est bien le même que celui. de la Nouvelle-Zélande, ce qui est probable, et sans entrer dans des recherches d'histoire naturelle qui nous entraîneraient trop loin, nous devons du moins faire remarquer qu'un pareil fait serait aussi facilement expliqué en supposant le transport en Polynésie opéré par les Nouveaux-Zélandais, qu'en admettant le contraire. Si les chiens ont disparu à la Nourelle-Zélande, il est certain qu'il en a été de même dans les îles Polynésiennes et particulièrement dans les grands archipels, aux Sandwich, par exemple, où on les élevait, comme à la Nouvelle-Zélande, pour les festins des chefs. On n'en retroure guère plus que dans les îles isolées et où les disettes n'ont pas été trop fréquentes.

Nous pouvons aussi assurer que, malgré la chasse qu'on leur fait dans certaines îles, malgré l'introduction du rat de Norvay à Tahiti, par exemple, les rats indigènes y pullulent, et qu'ils ne le cèdent peut-être en nombre qu'à ceux des îles Marquises. S'ils ont disparu à la Nouvelle-Zélande autant qu'on le dit, c'est que, sur cette grande terre improductive, se sont trouvées réunies à la fois les circonstances les plus défavorables : grand nombre d'hommes, disette de certains végétaux nourriciers, absence complète de quadrupèdes et particulièrement du cochon, guerres incessantes, chasses répétées aux oiseaux par les naturels eux-mêmes. Avant l'arrivée des Européens, des chats et d'autres chiens, ces causes avaient déjà diminué considérablement le nombre des pigeons, des Tui, des Kiwi, si grand autrefois d'après les traditions, et détruit complètement les oiseaux à ailes rudimentaires, tels que les Moa.

Certainementles mêmes légendes disent bien que les émigrants d'Hawahiki avaient emporté avec eux des chiens, des rats, des oiseaux, et en outre, des patates douces, des gourdes, et le Taro, qui, dit M. Thompson, sont indigènes aux îles des Navigateurs. Mais qui donc a pu apprendre que ces animaux et ces plantes ne l'étaient pas aussi dans l'IleNord comme dans l'Ile-Sud, quand les émigrants ont abordé la première? 
Les légrendess apprennent que les graines di Karaka, entre autres, faisaient partie du bagage des émigrants d'Hawahiki, et que Turi en fit semer sur la route depuis Aotea jusqu'à la rivière Patea sur l'Ile-Nord : mais comment cet arbre, qui est le Corynocarpus loevigata, (Forster), aurait-il pu être apporté de la Polynésie puisqu'il ne s'y trouve pas? M. Thompson, il est vrai, ne parle pas de cet arbre ; mais la légende en parle, et cela suffit. Si donc il a été apporté d'Hawahiki, il faut bien en conclure encore que l'Hawahiki ne pouvait être en Polynésie. Il en est de même des Moa, des Kiwi et de tous les oiseaux sans ailes qui ont existé ou existent encore à la Nouvelle-Zélande. Il est évident qüils ne pouvaient provenir de la Polynésie, et, par conséquent, il faut reconnaître que ceux-là du moins étaient autochthones, puisqu'on ne les trouve qu'a la Nouvelle-Zélande.

Ces dernières raisons, sans parler de toutes celles que nous avons déjà indiquées, nous semblent donc bien suffisantes pour détruire toute l'importante de cette preuve de M. Thompson.

En résumé, de l'examen de toüs les preuves précédentes, il faut conclure qu'elles sont plutôt contraires que favorables à l'opinion soutenue par le savant anglais. Tout ce que l'on pourrait dire à leur égard de moins défavorable, c'est que si plusieurs laissent planer quelque lég’er doute, toutes, du moins, laissent voir que les traditions citées par l'auteur n'ont jamais précisé la situation réelle de l'Hawa. hiki.

$8^{0}$ - Il nous reste encore à examiner une preuve plus difficile que toutes les précédentes : c est celle qui est relative à l'époque des migrations. Au premier abord, cette preuve est embarrassante, puisqu'elle est tirée de ce que les Nouveaux-Zélandais émigrés d'Hawahiki n'ont séjourné dans leur île que pendant la durée de 19 ģénérations, tandis que les habitants de Rarotonga ont demeuré dans la leur pendant 29 générations. Mais on n'a pas remarqué qu'elle 
n'est embarrassante que pour celui qui admet à priori la provenance polynésienne et plus particulièrement celle de Rarotonga. Car pour ceux qui donnent un autre lieu d'origine aux Nouveaux-Zélandais, il est évident que cette différence importe peu. Pour ceux-ci, elle ne serait embarrassante que si elle aidait à déterminer la position de l'Hawahiki autrement que par induction. Or elle ne dit rien de plus que ceque nous avons rapporté, et elle repose d'ailleurs sur des données si incomplètes, qu'il est sage, croyonsnous, de ne lui accorder qu'une confiance relative, mème en ce qui touche le nombre des générations.

C'est avec raison certainement que M. Thompson a le premier fait remarquer que les 29 générations de chefs, signalées par Williams à Rarotonga, témoignent que les habitants de cette île y ont passé un temps plus long que les Néo-Zélandais à l'Ile-Nord de la Nouvelle-Zélande, depuis leur émigration, s'il est vrai que ces derniers ne comptent que 15, 18 à 20 g’énérations.

En effet, si ces calculs étaient exacts, et s'il était démontré surtout que les Néo-Zélandais sont venus de Rarotonga, les plus jeunes auraient été évidemment les émigrants etles habitants de Rarotonga seraient leurs ancêtres, Mais on l'a vu, rien jusqu'à présent ne l'a prouvé ; rien n'a aéterminé la position de l'Hawahiki, et une pareille comparaison ne peut ètre un témoig'nag’e que pour celui qui, plaçant d'avance l'Hawahiki dans les îles des Navigateurs, en fait provenir les Néo-Zélandais.

Comme le dit Thompson, (1) « le temps a fait sortir de la mémoire des Néo-Zélandais le nombre des années écoulées depuis l'arrivée de leurs ancêtres, et ce n'est qu'indirectement qu'on a pu obtenir quelque renseigrnement sur cet intéressant sujet. » De l'examen attentif qu'il a fait de deux arbres geénéalogiques, il a conclu qu'il y a eu 20 générations de chefs depuis l'arrivée des premiers émigrants d'Hawahiki, c'est-ä-dire que cette arrivée avait eu lieu vers 1419. Il croyait qu'on devait d'autant plus se fier à ces deux

(1) Ouvr. cité, p. 67. 
généalogies qu'elles avaieut été débattues par les deux parties devant le juge anglais. Avant lui, du reste, Shortland en avait publié deux obtenues de la même manière et par lui-même: elles ne portaient ces générations qu'à 18 .

En admettant ces 20 générations, chiffre le plus élevé auquel on rapporte généralement leur nombre (1) et, pour Rarotonga, les 29 générations qui sont généralement admi ses, il en résulterait que les migrations d'Hawahiki, dont parlent les légendes de Shortland et Sir Grey, seraient postérieures à celles qui se sont faites à Rarotonga. Mais c'est là tout ce que prouvent ces calculs, sans rendre plus certaine la provenance polynésienne des Maori. D'un autre côté, toutes les légendes maori connues montrent que l'é. migration d'Hawahiki a eu lieu vers une même époque; mais ce que l'on n'a pas remarqué, c'est qu'elles font connaître en même temps plusieurs départs, antérieurs, tels que ceux de Kupe, Turi, Ngahue et même de Uenuku, qu'elles disent s'être rendu à Aotearoa en pagayant.

Or si des voyages antérieurs à l'émigration d'Hawahiki ont pu être faits du même point habité par tous les personnages que nous venons de désigner, ne pourrait-on pas supposer, qu'avant la grande émigration d'Hawahiki, d'autres émigrations vers l'lle-Nord de la Nouvelle-Zélande se seraient opérées du même point ou de points environnants, et de la même manière qu'ont fait les émigrants dont parlent les légendes? Il faudrait seulement admettre alors que le souvenir de ces premiers voyages aurait été perdu et pour ainsi dire absorbé par celui de l'émigration rapportée par la légende. Il est évident qu'une émigration pareille aurait pu avoir lieu à une époque très reculée, peut être double de celle connue. Si donc on admet, d'après la généalogie d'un descendant d'Hotunui, le chef du Taïnui, que la grande émigration d'Hawahiki s'est faite 450 ans avant 1850 , l'ancienne aurait pu se faire 900 ans auparavant, autrement

(1) Il n'y en aurait que 15 d'après la légende de Sir Grey, mais bien davantage, 29, d'après la tradition rapportée par un grand prêtre à Taylor. 
dit à la même époque que le peuplement de.Rarotonga d'après ses 29 générations.

La supposition que nous faisons n'est probablement pas aussi paradoxale qu'elle le paraît. En effet, il est démontré aujourd'hui que les émigrants d'Hawahiki, dont parlent les traditions, ont rencontré quelques colonies d'habitants primitifs, ou du moins plus anciens qu'eux sur l'Ile-Nord de la Nouvelle-Zélande. Les légendes de Sir Grey en citent au moins deux exemples observés sur des points différents de l'île : l'un sur les bords du lac Roto-Rua, près de la côte Est, et l'autre à Rohutu (Waïtara), sur la côte Ouest (1). Or ces colonies parlaient la même langue que les émigrants d'Hawahiki, avaient les mêmes usages et les mêmes croyances religieuses qu'eux. Pour qu'il en fût ainsi, il fallait nécessairement qu'elles vinssent d'une même contrée et que leur venue datât de bien loin, puisqu'elles étaient inconnues aux houveaux arrivants. Si elles venaient du même point, l'Hawahiki, pourquoi n'auraient-elles pas pu en provenir à une époque double peut-être de celle des émigrants dont parlent les légendes ? Cela ramènerait justement à l'époque de la migration faite aux îles Hervey.

Tout cela est fort conjectural, nous le reconnaissons; mais s'il est si difficile, comme le dit Thompson lui-même, de séparer la vérité de l'erreur, il n'est pas moins vrai qu'en s'en rapportant aux estimations de MM. Hale et Grey, l'époque des migrations doit être reculée beaucoup plus encore : ce dernier la reporte à 2000 ans, ce que nous serions plus porté à admettre que les 450 ans seulement qui résultent des généaologies de Shortland citées également par Thompson (2). Car, quel que soit le lieu d'où l'on fasse

(1) Le révérend Taylor en cite également plusieurs exemples : Kupe, Turi, etc.

(2) Ces généalogies sont forcément inexactes: un vieux grandprêtre actuel a donné au révérend Taylor une liste de 29 générations depuis le moment de l'arrivée dans l'île, (Taylor, p. 193.) Le même missionnaire (p. 155), dit qu'on fait peu de cas d'un chef qui ne peut pas remonter à 20 ou 30 générations, et que les grandes familles vont même jusqu'au commencement de toutes choses. 
venir les habitants de l'Ile-Nord de la Nouvelle-Zélande, la même difficulté existe. Si l'on admet qu'ils venaient de Rarotonga, il faut admettre également que les colonies trouvées par eux en étaient aussi venues à une époque fort éloignée. De toute façon donc il y aurait eu oubli des migrations antérieures; car il faut le répéter : migrations de l'Hawahiki et colonies trouvées par elles, étaient de la même race, quoiqu'on ait voulu y voir des races différentes.

En somme, il résulte du long examen que nous venons de faire de l'opinion de M. Thompson :

Que les Nouveaux-Zélandais n'ont ni le langage, ni les caractères physiques des Malais comme il le dit, et qu'ils ne reconnaissent qu'un seul Hawahiki ;

Que si tous rapportent leur origine à un lieu appelé Hawahiki, rien ne prouve que ce lieu soit Savaii ou Rarotonga, ni Aparima et Manono, îles voisines de la première;

Que l'histoire naturelle ne prouve pas davantage, ou plutôt prouve, de même qu'une foule d'autres témoignages, que le lieu d'origine des Maori ne pouvait pas être en Polynésie.

Le travail de M. Thompson, malgré l'intérêt qu'il présente, renferme un assez grand nombre d'inexactitudes, principalement dans le résumé qu'il donne des itinéraires des émigrants. Comme il a emprunté ce résumé aux légendes publiées par Sir Grey, il suffira de comparer les deux textes pour s'en convaincre. Nous nous bornerons à signaler ici les inexactitudes relatives : aux motifs qui ont forcé Ngahue à émigrer ; à l'époque du départ de l'Aotea ; à l'absence d'habitants sur l'île. Aotearoa, lors de l'arrivée des émigrants ; à l'itinéraire de l'Arawa; à la situation du Whangaparaoa, où abordèrent le Tokomaru et le Tainui, et après eux, l'Arawa; à l'itinéraire de l'A.otea, le canot de Turi, et à celui du Tokomaru; etc.

M. Thompson, qui a fait à ses prédécesseurs Dieffenbach, 
Shortland, Grey et Taylor, tant d'emprunts, beaucoup plus même qu'on aurait pu s'y attendre d'après sa préface, s'esî abstenu de citer une seule fois, dans son ouvrage, les trivaux géographiques si consciencieux et si importants, par. ticulièrement dans le détroit de Cook, des compagnons de d'Urville. Il se borne à dire (l) que le capitaine d'Urville, de l'armée navale, a passé, en 1827, deux mois sur l'Astrolabe à examiner les côtes de l'Ile-du-Milieu, et que de nombreux baleiniers français ont voltigé autour de ces îles avant que l'Angleterre n'en prît possession. Mais il ne dit pas un seul mot de la découverte de l'île d'Urville, de l'île Adèle, de la passe des Français, de l'exploration du lieu où a été fondée la ville Nelson, de la belle et dangereuse exploration de la baie d'Abondance si peu connue jusque-là.

De même qu'il passe sous silence les travaux géographiques des Français, il oublie de mentionner les recherches d'histoire naturelle, si nombreuses et si neuves, des natutalistes Quoy, Gaimard et Lesson ; ce n'est guère que par hasard qu'il dit, à l'art. Bibliographie, en parlant des planches botaniques du voyage de l'Astrolabe, qu'elles sont excellentes : ce qui nous touche infiniment.

Dans tout son livre, par ses raisonnements aussi bien que par ses prétentions, Thompson se montre Anglais dans la force du terme : il y trahit à chaque instant l'ambition et l'orgueil de son pays. "Les Anglais, a dit Malte-Brun, partagent le genre humain en deux classes : l'une composée de ceux qu'ils haïssent, l'autre de ceux qu'ils méprisent. Les nations n'ont que le choix. 》

Le livre de M. Thompson, œuvre de compilation de tous les travaux modernes, et de recherches propres, n'en est pas moins l'un des plus intéressants qui aient été publiés dans ces dernières années sur la Nouvelle-Zélande.

7e Hyротнѐse : Origine samoane indirecte. - M. de Quatrefages a successivement soutenu deux opinions diffé-

(1) Ouvr. cité, p. 270 
rentes : Dans la première, qui date de 1864, (1) Savaii était l'Hawahiki des Néo-Zélandais qui, de lá, avaient fait route directe vers la Nouvelle-Zélande. Ce n'était en somme que l'opinion d'Horatio Hale, appuyée d'un témoignage qui avait manqué au naturaliste Américain. Dans la seconde, qui date de la fin de 1866, (2) il fit, avec Thompson, passer les émigrants par Rarotonga avant de se rendre de Savaii à la Nouvelle-Zélande.

Ce fut après la lecture du premier travail du savant professeur, que nous adressâmes à la Société d'Anthropologie de Paris, deux mémoires, dont $M$. Gaussin fut nommé rapporteur le 7 décembre 1865; l'un était l'appréciation de quelques parties du travail de M. de Quatrefages; l'autre avait pour but de prouver qu'on avait mal interprété les traditions maori publiées par Sir Grey, et dont nous donnions la traduction.

Alors M. de Quatrefages était tout-à-fait partisan de l'hypothèse de Hale. Comme lui, après avoir fait partir les émigrants de l'íle Bourou, après les avoir conduits en deux colonnes aux Samoa et aux Fiji, et, de là, aux îles Tunga, il les faisait aller directement à la Nouvelle-Zélande, en partant des îles Samoa.

Pour prouver cette opinion, il invoquait la plupart des témoignages de $M$. Hale, témoignages que nous avons déjà fait connaître, et plus particulièrement celui que semblait fournir une des légendes publiées par Sir Grey et que le savant américain n'avait pu connaître. Il pensait, comme ce dernier, que de l'île désignée sur la carte de Tupaia (3) sous le nom de Oheavai, dérivait le mot Hawahiki

(1) Revue des Deux-Mondes, t. XLIX, 3e et $4^{e}$ livraison, février 1864 .

(2) Comptes-Rendus de l'Académie des Sciences, vol. LXIII, p. 813 et 816 , séance du 12 novembre 1866 .

(3) Cette carte fut donnée à Banks et non à Forster, comme le dit M. de Quatrefages : Tupaia, en effet, est mort à la fin du premier voyage de Cook, et Forster ne faisait partie que du deuxieme voyage; mais c'est par ce dernier qu'elle fut publiée pour la première fois dans le volume $\mathrm{V}$ du deuxième voyage. 
de la Nouvelle-Zélunde; «car, disait-il, il n'y a pas à douter: les chants nationaux publiés par Sir Grey le démontrent de la manière la plus précise et la plus détaillée : ces chants citent comme point de départ l'Hawahiki. »

Cette citation ne prouve nullement que le mot Hawahiki dérive de Savaii, et surtout elle ne prouve pas quel'Hawahiki se

- trouvât placé en Polynésie, quoiqu'elle soit regardée comme si décisive par M. de Quatrefages. Elle n'établit, à notre avis, qu'une chose: l'origine étrangère des habitants de l'lle-Nord de la Nouvelle-Zélande et leur venue d'un lieu appelé Hawahiki; mais elle ne dit en aucune façon où était situé cet Hawahiki, ou pays des ancêtres. Pour qu'on n'en puisse douter, nous allons citer les lignes sur lesquelles s'appuyait M. de Quatrefages. Ce sont les premières du réc $t$ légendaire relatant les causes des guerres survenues en Hawahiki; elles furent publiées par Sir Grey sous le nom de légende de Toï-te-Huatahi et de Tamate-Kapua (1).

"Autrefois nos ancêtres se séparèrent : les uns restèrent en Hawahiki, (2) les autres vinrent ici, (3) dans des canots. "

M. de Quatrefages ne manque pas de conclure à cette occasion, comme il fit aussi dans son travail ultérieur: "Il est superflu d'insister sur ce que ces lignes ont de décisif, et, n'eût-on aucune autre preuve, cela suffirait pour mettre hors de doute, pour tout esprit non prévenu, l'origine étrangère des Nouveaux-Zélandais. Des hommes qui avouent être étrangers à la terre qu'ils habitent peuvent être crus sur parole, la plus haute prétention des peuples sauvages étant d'être enfants du sol. »

Sans contredit, telle est bien la signification de ces lignes, et personne n'a témoigné à ce sujet le moindre doute, si ce n'est peut-ètre d'Urville ; car toutes les traditions s'accordent à le dire. Mais encore une fois, ce n'est pas là la.

(1) Polynesian mythology, p. 123.

(2) Le texte, en effet, ne dit pas à̀, de, $\gg$ comme le traduit M. de Quatrefages, mais bien « en, dans. 》

(3) Le mot a ici » est pour l'Ile-Nord de la Nozivelle-Zélande ou Aotearoa. 
question : elle consiste à savoir où se trouvait l'Hawahiki ayant fourni les émigrants qui sont allés peupler l'Ile-Nord de la Nouvelle-Zélande. Evidemment de pareilles paroles ne disent pas qu'il se trouvait placé dans les îles Samoa, et si M. de Quatrefages eût fait attention aux lignes qui les suivent, il aurait pu remarquer qu'elles semblent indiquer la faible distance qui séparait Aotearoa d'Hawahiki, puis que Uenuku l'avait franchie en pagayant.

M. de Quatrefages, sans doute, a conclu de la sorte parce que M. Hale l'avait dit; mais cette supposition n'est pas fondée. Pour le prouver, il nous suffira de recourir aux mêmes légendes que cite le célèbre professeur. On reconnaîtra facilement que ces légendes, mal interprétées par celui-là même qui les a fait connaître, puisqu'il partageait l'opinion de Hale, quant au lieu d'origine des Maori, prou* vent le contraire de ce qu'on leur a fait dire touchant la véritable situation de l'Hawahiki. Elles établissent nettement, en effet, que les émigrants sont venus de l'Ouest, et par conséquent, d'une direction opposée à celle qu'on admet généralement, de mème qu'elles distinguent constamment l'île qui a reçu ces émigrants des autres îles de la Nouvelle-Zélande, et qu'elles ne parlent jamais de l'IleNord que sous le nom d'Aotearoa. Cette distinction, avonsnous dit ailleurs, est de la plus grande importance.

Si les légాendes n'ont voulu parler que de l'Ile-Nord, comme nous le démontrerons bientôt, il faut donc commencer par isoler de cette île la grande île voisine, appelée Tavai-Pounamu, qui se trouve placée dans le Sud-Ouest et par conséquent plus dans l'Ouest qu'elle, et il ne faut jamais perdre de vue que, quand un écrivain européen rend par Nouvelle-Zélande le nom de l'ìle qui a reçu les émigrants, il ne s'agit absolument que de l'lle-Nord de la Nouvelle-Zéllande, que ces mêmes légendes appellent Aotearoa.

Il est évident, d'après cela, que c'est à tort qu'on a confondu jusqu'à ce jour toutes les îles de ce groupe sous le nom de Nouvelle-Zélande : Sir Grey lui-même a commis cette méprise, qui, naturellement, a été répétée par tous 
ceux qui ont écrit après lui. Si nous insistons autant sur ce fait, c'est qu'il a été le plus grand obstacle à la découverte du véritable point de départ des premiers colons de l'lle-Nord.

Telle était donc l'opiniori de $\mathbf{M}$. de Quatrefages en 1864, alors qu'il ne connaissait pas encore l'ouvrage de Thompson, publié en 1859. Mais, imitant en cela d'Urville et Ellis, et témoignant en même temps avec quel soin il s'est occupé de cette question, le savant professeur abandonna l'opinion de Hale pour adopter complètement celle de Thompson.

Dans ce nouveau travail, qui n'est que la reproduction du premier, revu, corrigé et augmenté, l'auteur continue à faire venir les Polynésiens de l'île Bourou, par le Nord de la Nouvelle-Guinée, et avec Hale, il les fait arriver aux Fiji et aux Samoa. Mais là, il se sépare du naturaliste américain, et il admet que les îles Tunga ont reçu des habitants directement de la Malaisie, par une troisième colonne d'émigrants. Puis, revenant à l'opinion de Hale, adoptée par Thompson, il tait partir des îles Samoa les émigrants pour la Nouvelle-Zélande. Seulement, avec ce dernier, il les fait passer et séjourner d'abord à l'île Rarotonga du groupe Hervey; puis, de cette île, sinon de toutes les Manaia, il les fait enfin sortir et arriver directementà la Nouvelle-Zélande. Ce fait, suivant lui, se serait passé plusieurs siècles après l'émigration tahitienne au lieu d'en être contemporaine, comme Hale le croyait.

S'appuyant tout particulièrement sur l'assertion de Thompson, que les Nouveaux-Zélandais reconnaissent deux Hawahiki, et, suivant son habitude, beaucoup plus hardi dans ses inductions que J'écrivain anglais, M. de Quatrefages ne se borne pas à faire passer les émigrants se rendant de Savaii à la Nouvelle-Zélande par Rarotonga, mais il trouve que c'est à une partie de cette île Rarotonga qu'ils ont donné le nom d'Hawahiki. Il se fonde: Sur ce fait, rapporté par les légendes, que c'est à Rarotonta qu'a été abattu le Totara qui a servi à construire l'Arawa; sur le surnom de " route d'Hawahiki » donné à cette île; sur cet autre 
fait que les habitants de Rarotonga ont des caractères physiques et un langage presque pareils à ceux des Maori, et enfin sur tous les témoignages apportés en faveur de cette opinion par M. Thompson; il en conclut qu'il est difficile de ne pas reconnaître, d'après tous ces faits, que les Nouveaux-Zélandais viennent des îles Hervey.

« Enfin, dit-il, (1) c'est aussi de Rarotonga que viennent les Maori, conformément à l'opinion de Thompson, et contrairement à celle de Hale que j'avais d'abord embrassée. »

Puis, après avoir exposé les raisons qui l'ont porté à changer d'opinion et à ne plus voir un seul point de départ dans Savaii, " cette île qui était pour Tupaia le père de toutes les autres, 》 il ajoute: « Thompson nous apprend qu'au dire des Néo-Zélandais il existe deux Hawaïki, l'une plus grande et plus éloignée, l'autre plus rapprochée et moins étendue. Il est clair que cette petite Hawaïki est ou une île, ou une partie d'île, à qui des émigrants avaient donné ce nom en souvenir de la mère-patrie, comme les Tahitiens avaient appelé Hawaii la plaine sacrée de Raiatea.

* Dès lors toutes les difficultés s'aplanissent : les Maori deviennent les descendants de cette colonie de Samoans que nous avons vu se rencontrer et se fondre avec les Tahitiens à Rarotonga. Tout en adoptant le dialecte de leurs vassaux, probablement plus civilisés, ils ont conservé le souvenir de leur première patrie et donné au district qu'ils habitaient le nom d'Hawaïki, laissant le nom tout Tahitien de Rarotonga à la partie de l'île occupée par leurs voisins. De là les deux Hawaïki dont ils ont emporté le souvenir à la Nouvelle-Zélande, quand leurs guerres intestines ont amené la grande émigration dont nous avons raconté les principaux évènements; de là aussi les rapports linguistiques signalés par les deux auteurs qui ont combattu l'opinion de Hale. »

M. de Quatrefages, pour soutenir son opinion, ne s'appuie en somme que sur les témoignages du $\mathrm{D}^{\mathrm{r}}$ Thompson. Après

(1) Les Polynésiens et leurs migrations, p. 156. 
la longue réfutation que nous avons faite de ces témoignages, il serait certainement suffisant d'y renvoyer le lecteur ; mais nous avons réservé à l'examen de l'opinion de M. de Quatrefages, la preuve décisive que Rarotonga n'a pu peupler la Nouvelle-Zélande, et qu'elle a plutôt été elle. même peuplée par la Nouvelle-Zélande. Nous allons donc ici exposer cette preuve, afin de compléter notre première réfutation, et de refuter en même temps la dernière opinion de M. de Quatrefages. C'est aux faits eux-mèmes, mais surtout à la linguistique que nous nous adresserons.

Si les choses s'étaient passées comme le dit M. de Quatrefagres, s'il y avait eu deux Hawahiki, si ce nom avait été donné à un district de Rarotonga par les Samoans, alor's qu'une autre partie de l'île était appelée Rarotonga par les Tahitiens, il n'existerait aucune difficulté, rien ne serait plus simple. On comprend parfaitement que la grande Hawahiki, ou Savaii, envoyant, comme il le dit, une colonie à Rarotonga, aurait pu commencer par soumettre celle venue de Tahiti, puis par adopter le dialecte des Tahitiens ses vassaux; c'est même ce qu'on ne cesse de répéter depuis que Williams a fait connaître la légende de Karika et de Tangiia dont nous avons déjà parlé et qui pour nous dit le contraire. On comprend aussi. fort bien qu'à la suite de guerres intestines, des émigrations auraient pu s'opérer vers un point quelconque, en emportant le souvenir de la grande et de la petite Hawahiki, si Rarotonga eìt été véritablement la dèrnière (1).

Mais, pas plus que ses autorités, M. de Quatrefages n'a remarqué qu'une pareille théorie ne repose que sur des faits qui la détruisent. Il n'a pas remarqué que le mot, Raroțongâ, par exemple, loin d'être tout tahitien, comme il

(1) Nous avons accepté, avec tous les écrivains, le mot Rarotonga comme le nom de l'île ; mais nous devons dire que quelques voyageurs ont écrit Rorotonga : roro, le devant d'une ruaison, (le devant étant « dessus, au vent. ") L'île se trouve, en effet, au vent de Tunga par rapport aux vents alisés d'Est et de Sud-Est. Peutêtre, à cause de cela, serait-il préférable d'adopter Rorotonga. 
le dit (1), n'est ni tahitien ni samoan, et qu'il ne pouvait être donné par conséquent par l'une ou l'autre colonie; que le mot Hawahiki pouvait d'autant moins être appliqué par les Samoans, que ce mot est inconnu aux Samoa, où il est remplacé par le motBulotu; que le mot Rarotonga se retrouve ailleurs qu'aux Samoa, de même que les mots Aparima, Manono, etc.; qu'enfin la similitude entre les dialectes rarotongan et maori, est encore plus grande que MM. Gaussin et Thompson ne l'ont remarqué, avec tous les linguistes, depuis les recherches de J. Williams, que Rienzi, le premier, a fait connaitre en France.

M. de Quatrefag'es n'a pas remarqué non plus, pas plus du reste que ne l'ont fait Thompson et tous les autres écrivains, qu'on retrouve dans l'une des îles de la Nouvelle-Zélande, en outre des mots Manono, Oheavai, Tunga, Aparima, Hapai, etc., ce mot Rarotonga, qui est donné à une île placée sur la côte Sud-Ouest de l'Ile-du-Milieu, dans le détroit de Foreaux. Il n'était donc pas aussi légitime qu'on l'a dit, de conclure que c'étaient les émigrants de l'île Rarotonga du groupe Hervey qui avaient « nécessairement » peuplé la Nouvelle-Zélande, puisqu'il serait tout aussi logique, en s'appuyant sur les mèmes raisons, d'attribuer aux habitants de l'Ile-du-Milieu le peuplement et même la dénomination de l'île Rarotonga. Un pareil fait ne prouve pas plus en faveur du peuplement de la Nouvelle-Zélande par l'île Rarotonga, que du peuplement de Rarotonga par la Nouvelle-Zélande. D'oú il faut conclure que ce fait était insuffisant pour justifier la solution proposée par M. Thompson, et adoptée par M. de Quatrefages : cétait ailleurs qu'il fallait en chercher l'explication.

Or, aucun des renseignements sur lesquels s'appuie $\mathbf{M}$. de Quatrefages ne dit qu'une partie de Rarotonga ait porté autrefois le nom d'Hawahiki. M. Thompson, l'autorité invoquée, dit même: (2) « Rarotonga est une des plus grandes îles du groupe Hervey ; mais ce n'est pas l'Hawahiki des

(1) Les Polynésiens, p. $15 \%$.

(2) Ouvr. cité, p. 58. 
Nouveaux-Zélandais, puisque les habitants de Rarotonga rapportent que leurs ancêtres étaient venus aussi d'Hawahiki. » Et il ajoute plus loin (1) : “J'ai été, par mes propres recherches, conduit à conclure que la Nouvelle-Zélande a été peuplée par un seul lieu, et en une seule fois. $\gg$ Cétait une réponse anticipée qu'on nous semble n'avoir pas assez remarquée.

Nous avons déjà montré qu'aucune tradition ne parle de plusieurs Hawahiki, quoiqu'en ait dit Taylor, et après lui Thompson. Ellis, affirme-t-on généralement, aurait avancé que les Tahitiens ont autrefois donné, en souvenir de la mère patrie, le nom de Havaï à la plaine sacrée d'Opoa, dans l'île de Raiatea. Mais, ainsi que nous l'avons dit précédemment, Ellis garde à ce sujet le silence le plus complet, et c'est seulement dans l'ouvrage de Barff que l'on trouve écrit ce mot Havaï (2).

D'un autre côté, J. Williams, l'historien de Rarotonga, n'a jamais rien avancé qui pût faire supposer que des émigrants aient donné à un district de cette île le nom d'Hawahiki en souvenir du pays d'origine; et pourtant, il désigne avec soin chaque localité nominativement. Bien mieux, il fait connaître une légende très explicite et très nette, d'après laquelle les habitants de Rarotonga et des autres îles Hervey étaient venus d'un Hawahiki placé sous le vent, c'est-à-dire dans l'Ouest. Ils ne pouvaient donc venir ni de Tahiti, ni des Samoa, puisque Tahiti est dans le Nord-Est et les Samoa dans le Nord-Ouest de Rarotonga, et qu'il n'y a dans l'Ouest que les îles Tunga. L'assertion de M. de Quatrefages relativement à la « petite Hawahiki » n'est donc pas aussi claire qu'il semble le croire.

Quelques recherches linguistiques démontreront encore mieux qu'il doity avoir erreur dans les conclusions du savant français, erreur qui provient, il faut le reconnaître, des autorités sur lesquelles il s'est appuyé.

Comment, en effet, les Tahitiens auraient-ils pu désigner

(1) Ibid. p. 66.

(2) Vol. II, p. $33 \%$. 
lîle Rarotonga par ce nom qui n'est pas tahitien ? Ils ont, il est vrai, le mot raro, qui signifie « vers l'Ouest, sous le vent, dessous, sous; „ mais ils ne se servent pas du mot tonga, ni sous cette forme, ni sous la forme tunga. Tonga, à la Nouvelle-Zélande, signifie « vent du Sud». A Tahiti, ce vent est appelé aujourd'hui maramu, mot qui a remplacé celui de maraai des anciens temps. Les Tahitiens n'auraient donc pu l'appeler ainsi que si le nom donné à leur île eût été Tonga, ou si ce nom eût existé autrefois dans leur langage avec la signification qu'il a à la Nouvelle-Zélande. Dans ce dernier cas, en effet, on comprend qu'on aurait pu dire que Rarotonga se trouvait, par rapport à Tahiti, sous le vent alisé ; car, on le sait, une île est au vent d'une autre, quand elle est plus occidentale, par rapport aux vents d'Est et de Sud-Est. Mais alors il faudrait être sûr que ce mot tonga a bien existé et signifié autrefois, à Tahiti, a vent $\mathrm{du}$ Sud, s pour persister à soutenir que ce sont les Tahitiens de Tangiia qui ont donné à cette île le nom de Rarotonga. Or, rien ne l'indique, et l'absence complète du mot tonga à Tahiti doit plutôt faire supposer le contraire.

Pas plus que Tahiti, du reste, les îles Samoa et les îles Tunga elles-mêmes ne peuvent, par leur position, prétendre à cette désignation ; les Tunga surtout sont placées directement dans l'Ouest de Rarotonga, et les émigrants qui seraient partis de ces îles, quand même ils auraient été les découvreurs de Rarotonga, n'auraient pu dire qu'elle se trouve sous le vent des T'unga, puisque ce sont les îles Tunga qui, comme les iles Samoa, scnt sous le vent de Rarotonga.

Mais il y a une contrée, parfaitement placée au contraire pour pouvoir donner cette appellation : c'est la NouvelleZélande. Il est certain que, par rapport ì cette dernière, l'île Rarotonga du groupe Hervey est presque directement sous le vent du Sud. Qu'on jette les yeux sur la carte et l'on reconnaîtra que, pour expliquer une pareille désignation, il faut supposer que le mot tonga provient des îles où il a la signification de vent du Sud, îles qui sont elles-mêmes plus au Sud que Rarotonga, et les seules, relativement 
à cette île de la Polynésie, qui soient plus au vent dans cette direction.

Une remarque de $M$. Thompson, remarque des plus importantes et sur laquelle nous aurons à revenir, ne permet pas d'ailleurs de mettre cette étymologie en doute : c'est que, pour les Maori, le Sud signifie $\alpha$ en haut, dessus, s et le Nord, " en bas, dessous ". Voici ce qu'il dit à ce sujet (1):

"The North island was first peopled, and as a proof of this, the South means up, and the North down. »

C'était ce que Shortland et Taylor avaient déjà appris, et l'on verra plus tard de quelle importance est une pareille observation pour le système que nous soutenons.

11 faut done conclure de cette remarque que le nom de Rarotonga a été donné par les Maori. Par leur position dans le Sud du monde, ils étaient les seuls qui pussent regarder le Nord comme placé a en bas, dessous, "par rapport à eux, et Rarotonga comme se trouvant « située sous le vent. »Cette même remarque prouve plutôt qu'au lieu d'être peuplée par Rarotonga, c'est la Nouvelle-Zélande qui a découvert et peuplé cette île.

Toujours est-il qu'à la Nouvelle-Zélande on trouve les mots à significations distinctes de: raro, sous, dessous; tonga, vent du Sud, et Rarotonga, nom d'une île. On y trouve même une île dont le nom est écrit Tonga, mais doit être orthographié, comme nous l'avons dit ailleurs, Tunga.

Evidemment, d'après tout ce que nous venons de dire, c'est à tort que l'on a toujours regardé jusqu'à présent le mot rarotonga comme ne pouvant provenir que du Tahitien.

Certainement on a eu raison de trouver de l'analogie entre le dialecte de Tahiti et celui de Rarotonga : il y en a entre tous les dialectes polynésiens; mais on a eu tort de dire avec M. Gaussin que "le dialecte rarotonga est essentiellement tahitien. (2) $) 11$ suffit de comparer quelques mots

(1) Ouvr. cité, p. 63.

(2) De Quatrefages, ouvr. cité, p. 156. 
pour voir, comme l'avait déjà dit de Rienzi, d'après les renseignements des missionnaires anglais, que c'est avec le dialecte maori que le dialecte rarotongan a le plus d'analogie : comme lui, il n'emploie pas le $f$ et il emploie au contraire le $k$ et le $n g$, qui ne sont pas plus usités à Tahiti qu'aux Samoa, mais qui le sont aux îles Tunga. En un mot, le dialecte de Rarotonga ne diffère du Maori qu'en ce qu'il n'emploie ni le $f$, ni le $h$, car, comme lui, il emploie le $r$ que les Samoa et les Tunga ont remplacé par le $l$.

Si cependant M. Gaussin a affirmé à M. de Quatrefages que le dialecte maori était essentiellement tahitien, c'est qu'il n'a donné qu'un des membres de la phrase de J. Williams. Celui-ci dit bien, en effet, alors qu'il a à faire admettre une provenance tahitienne, que « le langage est pur tahitien »; mais il ajoute aussitôt, ce que n'a sans doute pas remarqué M. Gaussin : " avec une infusion de consonnes dures et des sons nasaux qui caractérisent les dialectes de l'Ouest ; » (l) c'est-à-dire qu'il ressemble plus au Maori qu'au Tahitien.

Il n'cst, du reste, pas permis de douter que Williams ne s'est servi de cette qualification que par inattention, car il dit ailleurs : “ Le dialecte des ŝles Hervey est plus original et a une affinité plus grande avec les autres dialectes de la Polynésie que le Tahitien. " (2) « Le dialecte des îles Hervey et de Rarotonga se distingue du Tahitien par deux particularités : d'abord par le rejet du $f$ et du $h$, ensuite par l'usage du $k$ et du $n g$. * (3) a Le dialecte des NouveauxZélandais est, dans ses principales particularités, semblable à celui de Rarotonga; la seule différence étant que les Nouveaux-Zélandais se servent du $h$ que les habitants de Rarotonga n'emploient pas $\gg$ (4).

Dans ses remarques sur la langue des îles Hervey, il avait commencé par dire qu'il ne prenait le Tahitien pour

(1) John Williams, ouvr, cité, p. 196.

(2) Ibid. p. 522.

(3) Ibid. p. 524.

(4) Ibid. p. 525. 
terme de comparaison que parce qu'il avait été réduit en système : $\propto$ Pour être plus clair, dit-il, après avoir admis huit dialectes (1), je choisirai comme étalon le dialecte tahitien, et je lui comparerai les autres dialectes. Je le ferai, non cependant parce que je pense qu'il est primitif (original) car, à ce titre, le dialecte des îles Hervey semble avoir de plus grandes prétentions, de même qu'il est parlé beaucoup plus généralement et qu'il a une aftinité plus grande avec les autres dialectes que le Tahitien; mais parce que le Tahitien a été le premier réduit en système. »

C'est clair. N'en faut-il pas conclure que si on ne l'a pas remarqué, c'est par défaut d'attention, et que ces diverses citations de $\mathrm{J}$. Williams prouvent à peu près le contraire de ce qu'on lui a fait dire? En effet, les dernières observations sont les seules exactes, parce qu'elles résultent réellement de la comparaison des dialectes : elles constatent la ressemblance presque complète des langages des îles Hervey et de la Nouvelle-Zélande, et, par contre, les différences plus grandes qui existent entre le Maori et le Tahitien.

M. de Quatrefages, pour appuyer son opinion, n'a pas manqué de recourir à l'histoire du. peuplement de Rarotonga rapportée par Hale, et que J. Williams a, le premier, fait connaître. Cette histoire, suivant lui « confirme de tout point quant an langage, que le dialecte tahitien, très dominant, y est mêlé de mots et de quelques tournures empruntées aux Samoa. "Nous en avons déjà longuement parlé ‘illeurs, mais il ne nous paraît pas moins indispensable d'y revenir ici, pour montrer qu'elle confirme plutôt le contraire.

Les ethnologues et J. Williams lui-même n'ont pas remarqué que tous les mots cités dans cette légende (2), au lieu d'être des mots tahitiens ou samoans sont des mots maori : tels sont: Karika, Tangiiu, Makea, Aru, Takai, etc.

Nous pouvons citer aussi, en les empruntant encore à J. Williams, les mots A rorangi, Avarua et Ngatangiia, noms

(1) Ibid. p. 522.

(2) J. Williams, A Narrative, etc., p. 92. 
de lieux à Rarotong’a. Ces trois mots, tels qu'ils sont écrits, sont plus maori que tahitiens. Si on les faisait tahitiens, il faudrait écrire les deux premiers aro-raï et ava-rua (l); quant au troisième, il ne saurait être tahitien, puisque la particule $n g$ n'existe pas à tahiti. Nous ajouterons enfin que l'un des chefs suprêmes de Rarotonga, quand Williams alla s'y établir, se nommait Makea : ce nom était, à la Nouvelle-Zélande, celui du père de Maui.

Or, aucun de ces mots ne pouvait évidemment exister aux Samoa et à Tahiti. Aux Samoa, rangi, par exemple, se rend par lagi; tangaloa par tagaloa; tangi par tagi; papalangi par papalagi; etc. Le $n g$ n'y était donc pas plus usité qu'à Tahiti, où les mots rangi, tangi, etc., de la Nouvelle-Zélande et de Rarotonga, se rendent par rai et tai.

D'un autre côté, on a dit que la colonie qui était allée peupler Rarotonga, conduite par le chef samoan Karika (2), était partie de Manua, l'une des îles Samoa. Mais le texte, qui appelle cette île Manuka au lieu de Manua, se contente de dire que l'île d'où ce départ avait eu lieu gisait dans l'Ouest de Rarotonga. Or l'île Manua des Samoa ne se trouve pas dans l'Ouest, mais dans le N.-N.-O de Rarotonga. Il est donc bien probable qu'il y a li encore une erreur.

Cette erreur provient de J. Williams qui, dans son désir de retrouver le pays des ancètres du roi Makea, et oubliant que la légende le disait placé dans l'Ouest, avait cru le découvrir dans Manua, que, dans son texte, il appolait néanmoins Manuka. Voici, en effet, ce qu'il dit à ce sujet: (3) « Makea fut heureux d'apprendre que j'avais re-

(1) En Maori, aro, détour, incliner; rangi, ciel.

En Tahitien, aro, vu, être oublié, perdu, inconnu; rai, ciel.

En Maori, awarua, fosse, rivière. En Tahitien, ava, entrée, ouverture de rivière; rua, trace, ouvert, deux.

En Mari, nga, particule, respirer; tangi, crier, saluer; $i a$, passif.

(2) Noter, que Karika était le no:n de l'un des chefs premiers émigrants d'Hawabiki à Aotearoa.

(3) Ouvi. cité; p. 359. 
trouvé Manuka, d'où était venu, suivant la tradition, le grand et célèbre Karika, l'ancêtre de la famille de Makea. " Le studieux observateur ne remarque pas, dans sa préoccupation, que le mot manuka est aussi maori que les autres mots que nous avons cités, et que, pas plus que le mot karika, il ne pouvait être samoan, puisque les Samoans n'emploient pas le $k$. La position qu'il donnait à Manuka, dans l'Ouest, prouve d'ailleurs que ce ne pouvait être Manua, qui est dans le N.-N.-O.

Puisque Manuka se trouvait dans l'Ouest, la légende avait bien probablement voulu parler d'une île qui porte un nom presque pareil, c'est-à-dire de l'île Na-Muka, une des îles Hapaï, placée tout-à-fait à l'Ouest de Rarotong'a.

D'un autre côté, Na-Muka (1) n'avait bien certainement pu être dénommée ainsi que par des Maori : eux seuls pouvaient croire à l'existence du Phormium tenax ailleurs qu'à la Nouvelle-Zélande et songer à donner un nom pareil. Dans la direction indiquée par le texte, c'est-à-dire à l'Ouest de Rarotonga, il y a bien une île Manu portée sur la carte de Tupaia; mais il ne peut s'agir de cette île, qui figure sur les cartes modernes dans le groupe Hervey au Nord de Rarotonga, et qui est bien probablement l'ìle Manuai ou Hervey de Cook.

A moins donc que $M$. Williams ait commis une méprise en indiquant l'Ouest comme étant la direction dans laquelle se trouvait placée la contrée d'où venait Karika, on doit, à notre avis, reconnaître dans Na-Muka, malgré l'inversion de lettres que présente ce mot, l'île Manuka du texte et non l'île Manua des Samoa. Il en résulterait alors que Karika serait venu de l'une des îles Tunga. C'est là, en effet, que le $k$ et le $n g$ sont employés comme à la NouvelleZélande, quoiqu'on trouve aussi dans le langage l'usage du $l$ à la place du $r$. Il suffit d'indiquer ce fait pour qu'on en saisisse toute l'importance.

J. Williams ne s'est pas contenté de signaler les différences de langage que nous venons de démontrer entre le Ta-

(1) Na, du ; muka, phormium. 
hitien et le Rarotongan ; il a montré en outre qu'a Rarotonga les rangs ne sont pas dénommés comme à Tabiti, mais bien comme à la Nouvelle-Zélande. Là, dit-il, quatre rangs se partagent la population : les Ariki ou chefs ; les Mataiapo ou gouverneurs de districts; les Rangatira ou propriétaires fonciers, et les Unga outenanciers, fermiers, vassaux. Un homme est grand en raison du nombre plus grand de Kainga ou fermes qu'il possède. Or tous ces mots encore ont le cachet Maori.

On sait qu'à la Nouvelle-Zélande les prêtres et même les premiers chefs dans l'origine étaient appelés Ariki (1); nous avons déjà dit pourquoi ce nom a été adopté en Polynésie pour le titre le plus, élevé. En Maori, mataiapo signifie précieux, estimé, alors qu'il ne désigne que le premier né à Tahiti ; rangatira signifie chef; unga, envoyer, arrivée, et, pour ainsi dire, colon, colonisateur : ce dernier mot est tout-à-fait inconnu à Tahiti. Il en est de même du mot kainga, qui n'existe pas non plus à Tahiti ; on le retrouve, an contraire à la Nouvelle-Zélande, où il signifie lieu de résidence, demeure, village, etc.; aux Tunga il signifie parenté.

En résumé, malgré ce que Williams a dit une seule tois de l'analogie du Rarotongan et du Tahitien, toutes ses autres assertions montrent la différence de ces langages; de plus, comme on le voit, tous les mots que nous venons de citer prouvent qu'ils sont maori au lieu d'être tanitiens ou samoans.

La dernière opinion de M. de Quatrefages sur le peuplement de la Nouvelle-Zélande par Rarotonga ne repose donc pas sur des bases plus solides que ne le faisait la première.

Certainementla supposition de deux Hawahiki, faite par M. Thompson etadoptée par M. de Quatrefages, rend plus facile l'explication de l'origine polynésienne admise par ces écrivains; mais c'est à la condition de ne pas tenir compte du lan-

(1) D’après Thompson, ce nom est encore celui du premier pouvoir. 
gage. Autrement, cette supposition devient tout-à-fait insuffisante, sans parler de toutes celles qu'il faudrait faire, en outre, pour chaque archipel plus oriental.

D'autre part d'ailleurs, et cela seul suffirait pour faire rejeter cette opinion, il est impossible d'appliquer à Rarotonga le récit des légendes rapportées par Sir Grey, ainsi que le font MM. Thompson et de Quatrefages. Car, nonseulement la plupart des témoignages de Thompson prouvent le contraire de ce qu'il a avancé ; mais, de plus, on ne saurait comprendre comment des guerres intestines survenues, même à la longue, dans cette petite île, auraient pu produire la grande émigration dont parlent les légendes. Ces mêmes légendes montrent, en outre, que les tribus qui fournissaient les émigrants étaient non-seulement nom. breuses, mais qu'elles se trouvaient souvent placées à de grandes distances l'une de l'autre : ce qui, certes, n'aurait pas eu lieu s'il se fût agi d'une île aussi restreinte que Rarotonga. Elles établissent enfin, d'une manière positive, qu'avant d'atteindre la mer, les canots avaient presque toujours une rivière à descendre, et qu'une fois en mer ils se dirigeaient vers le Levant, vers l'Est, pour atteindre Aotearoa ou l'Ile-Nord de la Nouvelle-Zélande. Tout ceci démontre de la manière la plus péremptoire que la petite Hawahiki n'avait pu exister à Rarotonga, île petite, et par conséquent dans l'impossibilité d'avoir jamais contenu une grande population (1); île sans rivières navigables, et d'où les émigrants, au lieu de se diriger vers l'Est, comme le disent les légendes, auraient dû faire routè vers le SudOuest pour atteindre la Nouvelle-Zélande ; île enfin où l'on ne trouve pas un seul de ces lacs si nombreux dans la pa. trie première, où ne croissent ni le Totara, ni le Karaka, etc.

La distance entre la Nouvelle-Zélande et Rarotonga, u'est pas très grande, puisqu'elle n'est guère que de 1000 milles,

(1) Williams a estimé la population de Rarotonga à.6 ou 7000 âmes, et celle de tout le groupe à 14 ou 16000 ; mais Dibbes, le capitaine de son navire, ne poitait qu'à 2000 le notabre des habitants de Rarotonga. 
et non de 3000 milles comme la dit Thompson : ceci, d'ailleurs, ne proure pas plus en faveur d'une provenance que de l'autre. Mais ce qu'il ne faut pas perdre de vue, c'est qu'en partant de Rarotonga, les émigrants se seraient trouvés dans la nécessité d'avancer contre les vents d'Ouest (S.-O. et N.-O) : ce sont les plus fréquents et surtout les plus forts dans ces parages, et ce sont ceux qu'on reconnaît généralement avoir servi aux migrations polynésiennes. Cette dernière raison suffirait seule, à notre avis, pour faire douter de la possibilité du peuplement de la Nouvelle-Zélande par Rarotonga, tandis que, au contraire, elle expli . querait très bien l'arrivée facile de colonies maori aux île Hervey, Tunga et autres îles Polynésiennes.

En résumé, parmi les écrivains qui ont cherché à expliquer le peuplement de l'Ile-Nord de la Nouvelle-Zélande, ou mieux de toutes les îles de ce groupe, les uns ont admis que les émigrants sont venus de Tahiti; d'autres, qu'ils sont arrivés des Sandwich; quelques-uns de l'île de Pâques; d'autres enfin, et ce sont les plus nombreux, des fles Samoa, soit directement, soit indirectement; mais tous s'accordent à les faire venir de la Polynésie. D'Urville, Dieffenbach, Horatio Hale, Gaussin, Shortland et Thompson, résument les diverses variantes de la croyance en une origine polynésienne ủes Maori.

Mais comme aucun des témoignnagres présentés à l'appui de ces diverses opinions ne vient les justifier, nous allons maintenant exposer à notre tour le système rationnel auquel les faits nous paraissent nécessairement conduire.

Cette dernière opinion n'a jamais été soutenue avant nous; elle est absolument opposée à toutes celles qui ont été émises jusqu'à ce jour; elle est la résultante de toutes les données que nous avons déjà signalées, et surtout de toutes celles qu'il nous reste à faire connaître. 


\title{
IIVIRE QUATRIEMM
}

\author{
HAWAHIKI
}

\section{CHAPITRE PREMIER}

\section{RECHERCHE DE L'HAWAHIKI}

Heawise de Cook. - Traditions relatives à l'Hawahiki, publiéès par sir Grey et Taylor.- Conséquences qui en découlent. - Céqu'était l'Hawahiki.- Erreurs résultant de la confusion faite entre les îles qui composent le groupe de la Nouvelle-Zélande. - L'Hawahiki était placé à l'Ouest et fort près d'Aotearoa ou Ile-Nord de la Nouvelle-Zélande. Les émigrants de l'Hawahiki ont tous vécu vers la même époque et se sont expatriés pour les mêmes motifs. - Voyage de Kupe. - Itinéraire de Turi: Version de sir Grey; version de Taylor. - Voyage de Ngahue: Version de sir Grey ; version de Taylor. - Voyage à la Nouvelle-Zélande, d'après sir Grey: Itinéraire de l'A rawa; itinéraire du Taïnui ; itinéraire du Tokomaru. - Conséquences tirées de ces itinéraires: l'Hawahiki se trouvait situé dans l'lle-du-Milieu de la NouvelleZélande,

Comme pour tant d'autres faits océaniens, c'est d'abord à Cook, malgré ses erreurs, si excusables d'ailleurs, que nous demanderons le premier mot de cette question. S'il ne l'a pas résolue, tant s'en faut, il n'est pas moins vrai qu'il a été le premier à la soulever (1).

Parmi les premières traditions relatives à l'origine des Nouveaux-Zélandais qui lui ont été données sur leslieux, il en est une, en effet, qui attribuait cette origine à un pays appelé Heawise ou Heaveejee ; ce nom, comme l'a dit, le premier, M. Hale, n'était que le mot Hawahiki, mal entendu et mal orthographié par le navigateur anglais.

: Aujourd'hui, il est à peu près démontré que c'est biẹn le

(1) Cook, Premier voyage, t. III, p. 298. 
mot Hawahiki qui a été dit à Cook, et qu'il a rendu par Heaveejee ou Heawise. Mais il est pourtant vrai que quelques écrivains ont cru y reconnaître, à première vue, le mot Fiji. Les îles de ce nom ne sont, comme on sait, qu'à 900 milles environ de.l'lle-Nord de la Nouvelle-Zélande, et, certainèment, des canots auraient pu en être entraînés jusque-là. De plus, si les observations des premiers navigateurs étaient exactes, il faudrait en conclure que la venue d'un ouplusieurs canots de ces îles expliquerait, mieux que tout ce qu'on a dit, les différentes nuances et même les variétés de type qu'on a cru voir dans la population de la Nouvelle-Zélande. Mais nous avons déjà assez démontré l'erreur d'observation commise par ces navigateurs et particulièrement par Crozet, qui a le plus contribué à la répandre; il est inutile de nous y arrêter de nouveau, etnous nous bornerons à répéter que c'est certainement de l'Hawahiki que l'on a parlé à Cook, quand il a entendu Heaveejee ou Heawise. On verra tout à l'heure, quarıd nous dirons où se trouvait placé cet Hawahiki, combien Hale avait raison de le regarder comme le lieu d'origine de ces populations, mais combien en même temps il avait tort de le placer dans les îles Samoa.

Nous ferons remarquer en passant que ce mot Heavejee, qu'il signifiât ou nom Hawahiki, indiquait toujours que les Nouveaux-Zélandais de l'Ile-Nord, contrairement à ce que d'Urville a avancé, d'après le chef Tuaï, se regardaient comme provenant d'une autre terre que celle qu'ils occupaient.

Du reste, on l'a vu, tous les auteurs précédemment cités ont également rapiportél'origine des Nouveaux-Zélandais à un même lieu nommé Hawahiki ; ils ne diffèrent entre eux que sur la véritable situation de ce lieu, qu'ils supposent tous plus Est ou plus Nord que la Nouvelle-Zélande, tandis que nous le regardons, au contraire, comme placé encore plus à l'Ouest que l'Ile-Nord, c'est-à-dire dans l'Iledu-Mịlieu de la Nouvelle-Zélande: c'est ce que nous allons démontrer.

Pour faire cette démonstration, nous n'aurons qu'à exa- 
miner quelques-unes des traditions publiées par sir Grey et le révérend Taylor; et nous croyons, qu'à moins de ne pas vouloir voir, il faudra bien conclure que l'Hawahiki faisait partie de l'Ile-du-Milieu, et n'était même probablement que cette île elle-même.

On sait que sir George Grey, qui fut à deux reprises gouverneur de la Nouvelle-Zélande, a traduit et publié à Londres, en 1855, la plupart des traditions indigènes de cette contrée, qui lui avaient été dictées par des prêtres et des chefs de la race Maori. Ce travail considérable est des plus précieux pour la solution de la question qui nous occupe (1).

Ce sont ces traditions que nous avons traduites nousmême sur le texte anglais, et que nous avons adressées en décembre 1865, à la Société d'anthropologie de Paris, où elles ont été le sujet d'un rapport faitle 18 juillet 1867, par M. Gaussin (2). Il nous est impossible de présenter ici ce travail fort longuement annoté ; nous ne pouvons que renvoyer à la traduction complète que nous avons faite du livre de sir Grey. Nous exposerons néanmoins les conclusions auxquelles conduit l'étude de ces traditions, et nous en citerons même quelques-unes afin de faire accepter plus facilement l'opinion que nous voulons établir.

C'est en 1855 aussi que parut le livre, peut-être plus important encore, du Révérend Taylor, qui,.pendant longtemps, fut missionnaire à la Nouvelle-Zélande. Ce livre est intitulé Te Ika-a-Maui ou la Nouvelle-Zélande et ses habitants (3).

(1) Polynesian Mythology and ancient traditional History of the New-Zealand race, as furnished by their Priests and Chiefs, by sir George Grey, late governor in chief of New-Zealand, in-8 ${ }^{\circ}$, London 1855 .

(2) Bull. soc. d'anthrop., 1867, p. 436.

(3) Te Ika a Maui, or New-Zealand and its inhabitants. London; 1856. Cette appellation est inexacte, puisque, comme le reconnaît l'auteur lui-même, Ika-a-Maui, a le poisson de Maui, » n'est que le nom de l'Ile-Nord de la Nouvelle-Zélande. Cook, le premier, 
Les traditions qu'il contient sont du plus haut intérêt, car elles complètent très souvent celles de sir Grey, les corroborant toujours et sont surtout précieuses par les données nouvelles qu'elles fournissent.

Il en est une, entre autres, qui semble dire exactement où se trouvait l'Hawahiki, et, des lambeaux d'une autre, on arrive à comprendre, pour la première fois, ce que c'était que cette fameuse Wharekura ou a Maison Rouge, » dont Uenuku étaitl'un des directeurs. Nous nous bornerons à dire ici que les faits les plus variés abondent dans ce travail immense, faits entassés lentement par un homme qui comprenait parfaitement la langue, et qui avait de grandesconnaissances en histoire naturelle.

Comme sir Grey, le Révérend Taylord, montre, du reste, qu'il croyait la Nouvelle-Zélande peuplée par des émigrants venant en dernier lieu de la Polynésie, et, comme on a vu, il n'était même pas éloigné de croire que les Maori étaient les descendants de l'une des tribus perdues d'Israël.

Nous allons maintenant examiner les traditions publiées par ces deux écrivains et, avant d'entrer dans les détails, nous essaierons d'en résumer brièvement les données.

Trois sortes de traditions se trouvent dans ces deux ouvrages, comme d'ailleurs dans ceux de Shortland et de White (1).

$1^{\circ}$ Celles qui ne sont que des mythes touchant l'origine du monde et des hommes;

$2^{\circ}$ Celles qui sont relatives à certains héros ou demi-dieux des temps anciens;

$3^{\circ}$ Celles qui datent, soit de l'époque de la grande émigration, soit de quelque temp̦s peu antẹrieur ou très peu postérieur.

l'avait déjà fait remarquer, en écrivant, il est vrai, le son entendu par lui d'une manière si étrange, que ce mot était difficile à reconnaître.

(1) John White, Maori Superstitions, Auckland, 1856. 
Les premières sont pour ainsi dire sacrées pour tout le monde; les secondes, au contraire, sont considérées par beaucoup d'indigènes comme des fables, qu'ils appellent Korero-Tara (1) ; mais tous regardent les dernières, malgré le merveilleux qui les enveloppe, comme fondées sur des faits qui ont réellement existé.

Il n'est guère permis, en effet, de douter de leur importance, quand on remarque que, quelque soit le lieu de l'IleNord de la Nouvelle.Zélande où l'on se procure ces traditions, les naturels s'accordent presque complètement à donner les mêmes noms aux canots qui ont amené leurs ancêtres, aux chefs qui les commandaient, aux équipages qui les composaient, et à désigner jusqu'aux choses diver. ses apportées par eux. C'est, du moins, une preuve presque certaine de l'exactitude de la tradition générale, et c'est pourquoi, croyons-nous, on peut avoir recours à ce dernier genre de traditions sans crainte d'être induit en erreur.

Toutes les traditions des livres de Taylor et de sir Grey, qu'on peut appeler historiques, prouvent, en somme, que les premières émigrations ont eu lieu d'Hawahiki à l'IleNord de la Nouvelle-Zélande ou Aotearoa, par des canots forcés de s'expatrier et se dirigeant tous vers l'Est pour atteindre cette île. Elles montrent qu'en arrivant à Aotearoa, les émigrants s'emparaient simplement des lieux, quand ils étaient inhabités, ce qui avait le plus souvent lieu, mais qu'ils commençaient par exterminer les populations primives, quand ils en rencontraient. Quatre légendes au moins en rapportent des exemples.

Ces traditions sont l'histoire des colonisations sur Aotearoa d'émigrants arrivant presque tous à la fois, ou du moins dans un intervalle assez restreint, de la contrée d'origine appelée Hawahiki.

Rien ne peutdonner une idée plus exacte des mœurs et des usages des Nouveaux-Zélandais que ces traditions qui, pour la plupart, n'ont évidemment été dictées que par de vieux prêtres Maori, nés dans l'lle-Nord, et encore tout

(1) Korero, discours, récits ; tara, courage, hauts faits. 
imbus des vieilles croyances. Mais il est regrettable qu'elles aient été fournies presque toutes par des personnages de l'Ile-Nord, et qu'elles présentent de temps en temps des la. cunes et des divergences, qui s'expliquent d'ailleurs parfaitement par les procédés que le gouverneur Grey et le missionnaire Taylor ont été dans la nécessité d'employer pour se les procurer. Ainsi que le fait remarquer le premier, ce n'était souvent qu'après beaucoup de temps et à des sources différentes qu'il finissait par obtenir quelque fragment manquant pour compléter la tradition. Mais il n'est pas moins digne de remarque que ces traditions, si elles diffèrent souvent par les détails, s'accordent au conțraire toutes parle fond ; c'est la preuve qu'on peut leur donner quelque confiance.

Il doit sembler étonnant que ces traditions n'aient pas été interprétées, depuis le temps de leur publication (1855), comme elles auraient dû l'être; nous croyons même qu'on pourrait se demander comment il se fait que ceux qui s'en sont servi pour appuyer leur opinion, en en citant de nombreux passages, n'aient pas signalé ou combattu les passages voisins qui étaient contraires à cette opinion. On comprend très bien qu'en rencontrant les explications toutes faites d'Horatio Hale, quelque savant les accepte et s'en contente; mais quand ce savant se donne la peine de parcourir les traditions publiées depuis lui, et de leur faire des emprunts, à toucher des faits tout-à-fait opposés, on ne comprend plus aussi bien le silence qu'il garde sur ces derniers, car il ne peut venir à l'idée qu'il ne les a pas vus, et dès lors, ce silence peut sembler intéressé.

$1^{\circ}$ Le premier fait qui résulte de ces légendes, c'est que les émigrants venaient tous d'une même contrée appelée Hawahiki (1).

(1) C'était, avons-nous déjà dit, l'opinion de Thompson, opinion que ne partageait pas le Rév. Maunsell. Celui-ci pensait, au contraire, que les Néo-Zélandais étaient venus de différentes îles, en raison de trois particularités linguistiques, (Grammar of the New-Zealand Language, 1842) qui ne sont pas exactement obser- 
Cet Hawahiki était le pays des ancêtres, la résidence des dieux, et c'est là, s'il fallait en croire le mythe de Maui, qui n'a de valeur qu'à Aotearoa, que les enfants des hommes auraient cessé, par sa faute, d'être immortels. Maui était devenu le plus remarquable de ses 4 ou 5 frères; sa vie ne paraît avoir été qu'une succession de prodiges. C'est lui, dit la légende, qui pêcha à la lignne Aotearoa, qui fut surnommé depuis Ika-na-Maui (poisson de Maui), et ce fut là qu'il alla s'établir et mourir.

C'est encore en Hawahiki que la religion fut fondée, et certainement il n'existe, dans aucune île polynésienne, une cosmogonie plus complète que celle des Nouveaux-Zélandais. Auprès de cette cosmogonie, celle dès Polynésiens n'est véritablement composée que de lambeaux qui en proviennent, mais qui, avec le temps, se sont complètement transformés et obscurcis.

Ainsi écrit, et en un seul mot, Hawahiki n'est pas maori; mais on trouve dans cette langue les radicaux qui servent $\grave{a}$ le former, de même qu'on les retrouve dans toutes les îles polynésiennes où l'usage et la signification de ce mot ont été conservés. Partout ce mot est le synonyme de pays d'origine, de patrie : on a donc dit à tort que les Zélandais n'avaient conservé aucun souvenir de leur pays d'origine. Non-seulement, depuis les légendes publiées par sir Grey et Taylor, il n'est pas permis de douter que ce soit le mot employé dans l'Tle-Nord au moins, mais de plus il n'est̂ peut-être pas une contrée qui ait conservé plus soignneusement le souvenir du pays des ancêtres; rien n'en précise plus nettement lá position que les traditions Néo-Zuélandaises.

vées. Ces particularités sont, suivant lui, que les Nga-Puhi, qui vivent dans les environs de la baje des Iles, prononcent le $h$ comme s'il y avait sh: ainsi, shongi pour hongi; $2^{\circ}$ que les naturels de Taranaki ne prononcent pas du tout le $h$ et le remplacent par une secousse dans la voix: Hei devient ei et hohoro, orro, dans leur bouche; 30 que quelques tribus dans la baie d'Abondance, nesdonnent pas le $n g$, son nasal particulier aux bons linguistes, et emploient à sa place na. 
Dans la Polynésie, au contraire, comme nous l'avons fait vuir, ce n'est absolument qu'un souvenir lointain et confus qui a été cause que, pendant bien des années, presque tous les voyageurs et les missionnaires surtout, faute de comprendre, n'ont fait de l'Hawahiki qu'un enfer, un lieu de rendẹz-vous des âmes. Mais jamais les Polynésiens n'ont pu donner sur ce lieu et sur sa position que les indications les plus vagues ; ils laissaient ainsi le champ libre aux interprétations les plus extrêmes ${ }^{\circ}$ des voyageurs. Les NéoZélandais de l'lle-Nord, du moins, ont toujours dit nettement que leurs ancêtres venaient d'un lieu appelé Hawahiki: c'est même ce qu'ils avaient dit à Cook qui, il est vrai, avait, comme toujours, si mal écrit le mot entendu par lui, qu'il avait été impossible, jusqu'à ces derniers temps, de le reconnaître.

C'est donc à tort, nous le répéterons, qu'on a dit que les Néo-Zélandais n'avaient pas conservé le moindre souvenir du pays d'origine, puisque, d'après les traditions aujourd'hui connues, ceux del'Ile-Nord, du moins, avaient encore des souvenirs aussi frais que s'ils eussent été de la veille. Toutefois il se pourrait que la remarque fût plus applicable à la contrée où se trouvait l'Hawahiki. En effet, si ce mot, composé des racines que nous ferons connaître, y était probablement connu et parfois usité dans le même sens, il est clair qu'on devait s'en servir moins fréquemment que ne devaient, avec le temps surtout, le faire les émigrés, une fois éloignés du pays d'origine. Bientôt, en effet, tous les émigrants de points différents, en perdant le souvenir de leurs localités diverses, ne devaient plus avoir recours qu'au mot générique qui, compris de tous, les rappelait à chacun d'eux, c'est-à-dire au mot Hawahiki, « pays nourricier, qui avait vu naître. »

Il se pourrait donc, pour ces raisons, que ce mot eût été beaucoup moins usité, comme l'ont dit quelques écrivains, mais seulement dans le pays d'origine, c'est-à-dire dans l'ne-du-Milieu qui, ainsi que nous allons le démontrer, est ce pays. Pourtant, comme cette île est à peine connue, quoique plusieurs points soient occupés déjà depuis assez long- 
temps, comme les Shortland et autres n'en disent rien, nous croyons qu'il est permis de douter de cette assertion dans ce qu'elle a d'extrème.

On comprend, du reste, que si c'est en s'éloignant davantage et avec le temps que cette expression Hawahiki est devenue, pour ainsi dire, le seul souvenir dela patrie, elle a dû en même temps, être de plus en plus obscure. C'est ce qui explique si bien comment on l'a trouvée remplacée par un autre mot dans cêrtaines îles : Samoa et Tunga; conservée parfaitement dans d'autres : îles Hervey et Marquises, et presque oubliée dans quelques-unes, telles que Tahiti et les Sandwich.

Il résulte d'une citation di Rév. Taylor (1) qu'Hawahiki était la terre primitive, celle qui fut employée pour former les autres terres. Ce qui semble le prouver, c'est qu'il dit: « Le ciel s'unit à l'Hawahiki et la terre fut produite.» Te porapora, tauware-nikau, kuku paru, wawauatea, wiwhi te rangiora.

Taylor n'a pas cherché à donner la signification de ce texte maori, et nous l'avons nous-même cherchée vainement. Mais, quelle qu'elle soit, il n'en est pas moins à remarquer que, d'après lui, le nom Hawahiki est donné à la première terre formée. Dans toutes les autres traditions, au contraire, on se borne à dire que «le ciel s'unità la terre."

N'est-ce pas encore un témoignage que la signification véritable de ce mot est bien a le pays nourricier, la terre nourricière, $n$ et que ce mot est un nom abstrait au lieu d'être le nom propre d'une île ou d'une terre.

$2^{\circ}$ Le deuxième fait résultant des légendes, c'est qu'il faut bien distinguer les unes des autres les îles qui composent le groupe de la Nouvelle-Zélande. Quand les légendes parlent de l'île qui a reçu les émigrants d'Hawahiki, elles ne font absolument allusion qu'à l'Ile-Nord de la Nouvelle-Zélande, qu'elles appellent Aotearoa.

Cette île Aotearoa, en effet, n'est, d'après toutes les tradi(1) Ouv. cit: p. 15 , 
tions, comme d'après les cartes et d'après Taylor et sir Grey eux-mêmes, que l'Ile-Nord de la Nouvelle-Zélande, c'est-àdire celle, qui, en outre d'une foule de noms antérieurs que nous avons signalés ailleurs, porte encore le nom de lka-naMaui ou « Poisson de Maui. »

Il est bien certain que toutes les îles ont des noms particuliers, sans en excepter celle qui avoisine le plus Aotearoa, et que Cook et d'Urville ont appelée Tovai ou Tavai-Poenamu. Mais quand les légendes désignent l'île où se sont rendus les émigrants, elles n'entendent parler formellement que de l'Ile-Nord de la Nouvelle-Zélaride. Ce fait est de la plus haute importance, cc.mme il est facile de le pressentir, et il ne fautjamais le perdre de vue, quand on recherche le lieu d'origine des émigrants arrivés sur cette île.

De cette remarque, jusque-là passée inaperçue, il résulte d'abord, en effet, que tous les ethnologues, aussi bien que le Rév. Taylor, sir Grey, Thompson, Shorland et autres, ont à tort confondu toutes ces îles sous le nom collectif européen de Nouvelle-Zélande. Or, une pareille désignation ne peut qu'induire en erreur par son inexactitude. Il en résulte ensuite que, lorsqu'on lit les traditions interprétées par les Européens, il ne faut jamais oublier que ce mot NourelleZélande doit être remplacé par le mot Aotearoa, qui répétons-le, est celui de l'ìle qui a reçu les émigrants, c'est-àdire seulement l'Ile-Nord de la Nouvelle-Zélande.

Nous croyons devoir insister d'autant plus sur cette distinction, que c'est faute de l'avoir faite, nous en sommes convaincu aujourd'hui, qu'on n'est jamais parvenu, jusqu'à présent, à préciser la situation véritable du point de départ ou Hawahiki : bientôt nous le démontrerons. Comment, d'ailleurs, aurait-on pu le faire avec les données contradictoires qui résultaient de cette confusion?'Il fallait forcément qu'on allât bien loin chercher un lieu d'origine qui, comme tant d'autres choses, se trouvait plus près qu'on ne croyait. Aujourd'hui, depuis la publication des traditions maori, il n'est plus guère possible de faire cette confusion; mais comme c'est nous qui la faisons re. marquer pour la première fois, il était indispensable d'in- 
sister sur la distinction à faire, distinction qui résulte nettement, quoique à leur insu, des beaux travaux de sir Grey et du Révérend Taylor.

Une telle distinction est, suivant nous, si importante, que nous n'hésitons pas à dire d'elle, comme Hale l'a dit du mot Hawahiki, qu'elle est la clef de l'origine des Maori.

Il est inutile de répéter longuement ici que le nom de Nouvelle-Zélande, appliqué, on ne sait par qui, à la terre vue par Tasman, appelée Staten-Land et regardée à tort par lui comme ne faisant qu'une seule terre, est donné à un ensemble d'îles et d'îlots, renfermés entre le $64^{\mathrm{e}}$ et $176^{\circ}$ degrés de longitude à l'Est de Paris, et s'étendant depuis le $34^{\circ} 12$, jusqu'au $48^{\circ}$ lat. S., et que le groupe est composé de deux îles principales, d'une troisième, encore assez grande, nommée Rakiura, et de plusieurs autres petites. Les deux grandes sont Tka-na-Maui ou Aotearoa, au Nord du détroit de Cook, et Tavai-Poenamu ou mieux Kawai, autrement dit l'Ile-du-Milieu des Anglais, l'Ile-Sud de d'Urville, au Sud du même détroit. La dernière est séparée de l'île Stewart par le détroit de Foveaux.

Mais ce sur quoi nous insisterons encore une fois, c'est que ces îles avaient chacune un nom particulier, 'qui était le seul employé par les indigènes quand ils voulaient les désigner, et qu'ils neles confondaient jamais sous un mème nom, pas plus qu'on ne le faisait aux Sandwich, avant Tamehameha I ${ }^{\mathrm{r}}$.

Cette distinction entre chacune des îles, semble trouver un appui dans la différence des noms donnés à certaines mêmes choses dans les deux îles principales, au dire du Révérend Taylor.

Ainsi, le dieu de la guerre est appelé Tu dans l'lle:Nord et Maru dans l'Ile-du-Milieu (1).

(1) Taylor, p. 35, dit que ce dieu avait une foule de noms: Maru-i-te-Aeva, Maru-Koeta, Maru-Anaunau, Maru-Wakatamara, Maru-tu-Huri-mai, Maru-Takotua, Maru-Tuwakarere, Maru-Riri, Maru-Nguha, Maru-Mataitai. Tous ces noms indiquaient les diverses mauvaises qualités de Maru ; ses allées de côté et d'autres comme ennemi ; cause de défiance, fauteur de maladies, le cour- 
Ainsi, les termes d'appel sont: e hoa, e tama, dans l'Iledu-Milieu ; e koro, e mara dans l'Lle-Nord (1).

Il y avait surtout une différence remarquable dans la prononciation: Ainsi, les mots rarotoka, rakituma, moeraki, takitata, hikuraki, hakaroa, whakanui ou hakanui de l'Iledu-Milieu, sont les mêmes qu'on prononce et qu'on écrit, dans l'Ile-Nord : rarotonga, rangituma, moerangi, rangitata, hikurangi, whangaroa. On en trouve la preuve dans le récit des guerres faites aux habitants de l'Ile-du-Milieu par Rauparaha, et cité par Shortland, p. 253. Tous les observateurs, d'ailleurs, s'accordent sur ce sujet.

$3^{\circ}$. - Ce que les légendes établissent surtout formellement, c'est que, pour aller de l'Hawahiki à Aotearoa, il fallait faire route vers a le côté où le soleil se lève, * c'est-àdire vers l'Est.

Après la distinction précédemment signalée, il n'en est certainement pas de plus importante que celle-là.

On verra plus loin que ce conseil est donné à l'émigrant Turi par Kupe, qui revenait à l'instant même de son voyage. Kupe avait découvert la rivière Patea, sur Aotearoa, dans le détroit de Cook, et il avait fait d'autres découvertes "encore au dire des traditions; il insiste auprès de Turi pour qu'il s'y rende, et il lui renouvelle deux fois sa recommandation de faire route « vers le côté où le soleil se lève, \$ ce qui prouve que lui aussi avait fait la même route.

roucé, le plein de colère et de tromperie, etc. Etant descendu sur la terre, Maru y avait été tué et mangé, mais sa divinité était remontée au ciel et la planète Mars avait pris son nom.

(1) Quand les habitants de l'Ile-du-Milieu entendent ces mots ainsi employés par ceux de l'Ile-Nord, ils se moquent d'eux, dit Taylor. Sans doute, ajouterons-nous, parce qu'ils n'ont plus tout à tait le même sens que les leurs. Ainsi, e hoa, e fama, signifient ami, enfant; koro, une personne, et mara, un cultivateur, un fermier Les premiers mots sont évidemment plus affectueux.

III

23. 
Voici, du reste, ses paroles, que nous nous bornons à citer ici sans commentaires: nous y reviendrons plus tard.

a Maintenant, rappelle-toi bien de toujours te diriger vers l'Orient où le soleil se lève, et que l'avant de ta pirogue soit toujours dirigé droit vers cette partie du ciel. »

Ces paroles sontrépétées et appuyées plus tard par Turi lui-même, dans sa dispute avec Poturu, le chef de l'un des canots qui étaient partis en même temps que lui. Poturu, après la relâche dans une île appelée Rangitawha, voulait retourner vers l'Ouest, d'où on venait, tandis que Turi voulait, au contraire, continuer la route vers l'Est. « Ne te rappelles-tu pas, disait Turi, ce que Kupe qui a visité ces îles, nous a tout particulièrement recommandé ? « Mainte«nant, rappelez-vous bien de ne pas dévier la proue de vo«tre canot du point des cieux où se lève le soleil.".

Il fallait donc bien faire route vers l'Est.

Du reste, comme on le verra encore, les légendes établissent également que tout le chemin fait, surtout depuis le cap Est de l'île Aotearoa, l'a été en allant du Sud vers le Nord ou mieux du Sud-Ouest vers le Nord-Est, c'est-à-dire dans le sens de la direction des deux îles principales de la Nouvelłe-Zélande. Ce fait ne serait guère compréhensible, si l'on supposait que les émigrants venaient des îles Samoa dans la Polynésie, car alors, il leur eût certainement été plus naturel de continuer la route commencée du Nord-Est vers le Sud-Ouest, que de revenir sur leurs pas à la moitié à peu près d'Aotearoa.

Ce qu'on comprendrait encore moins, en admettant la provenance des Samoa, c'estl'arrivée des premiers canots (1) d'emblée et sans voir aucune terre, dans le détroit de Cook, qui est le point de l'Ile-Nord le plus éloigné des îles Samoa. On ne comprendrait pas davantage, enfin, le choix que les émigrants auraient fait de ce détroit pour retourner en mawahiki, si cet Hawahiki se trouve en Polynésie. D'ordinaire, on ne part que du point le plus proche ou lo mieux

(1) Par ex. Kupe, Turi, Hou, Uenuku, peut-être Ngalıe, Mawa: keroa à Kaupokonui. 
placé du moins pour profiter des vents; et l'on ne voit pas quel aurait été, pour se rendre aux Samoa, l'avantage de partir du point de l'île, non seulement le plus éloigné, mais en même temps le moins bien placé peut-être (1). C'est ailleurs que nous aurons à insister sur ce fait; nous dirons seulement encore ici que les mêmes légendes, par tous leurs témoignages, montrent quel'Hawahiki n'était et ne pouvait être situé que dans une direction toute contraire à celle jusque-là admise.

$4^{\circ}$. - Puisqu'il fallait faire route vers l'Est, pour aller de l'Hawahiki à Aotearoa, les légendes disent donc implicitement que l'Hawahiki était placé plus à l'Ouest que cette île, et non pas, comme on le croit généralement, dans le NordEst, c'est-à-dire dans les îles Samoa.

Il est bien certain, en effet, que si on fût parti des Samoa, il eût fallu faire une route toute autre, toute opposée même à celle qui était conseillée, puisque İes Samoa se trouvent dans le Nord-Est de la Nouvelle-Zélande. C'est vers' le Sud-Ouest que, dans ce cas, il eût fallu se diriger pour arriver à cette dernière île, autrement, en partant des Samoa et en faisant route vers l'Est, les émigrants auraient tourné le dos à la Nouvelle-Zélande, et, s'ils avaient prolongé leur voyage dans cette direction, ils seraient, comme nous l'avons dit ailleurs, arrivés en Amérique. Or personne, avec raison, n'a jamais cru que telle avait pu être la direction qu'ils avaient suivie; tous les écrivains s'accordent, au contraire, à leur faire faire depuis les Samoa la route qui conduit directement ou indirectement à la Nouvelle-Zélande, c'est-à-dire une route qui esćt démentie par les traditions et que toutes les autres considérations ne permettent pas d'ac.

(1) Quand nous aurons dit où l'Hawahiki étaii placé, on comprendra parfaitement, au contraire, que des émigrants aient pu se rendre en pagayant à Aotearoa; on verra également pourquoi les premiers canots étaient tous arrivés dans le détroit de Cook, et surtout pourquoi c'était de ce détroit que les canots partaient pour retourner directement en Hawahiki. 
cepter quand on ne se contente pas de la première hypothèse venue.

$5^{\circ}$. - Il résulte encore des mêmes légendes que l'Hawahiki, situédans l'Ouest d'Aotearoa, n'était même pas éloigné de cette île. Ce qui le prouve, c'est la fréquence et la facilité des voyages, aller et retour, d'un point à l'autre; c'est la possibilité d'accomplir ces voyages à la pagaie seulement. Ainsi, les légendes citent une foule de faits démontrant qu'il suffisait de suivre les côtes de l'île, et elles indiquent particulièrement le voyage de Uenuku et de Tamatua, fait d'Hawahiki à Aotearoa, en pagayant.

Quelques-unes des légendes montrent même que des personnages qui n'avaient jamais fait ce voyage jusque-là, ne craignaient pas de se rendre aux points les plus éloignés de l'île Aotearoa, pour y devancer et y attendre leurs ennemis. Ainsi elles citent Ruaeo, qui se rendit à Maketu, dans la Baie d'Abondance, pour se venger de Tama-te-Kapua, qui avait enlevé sa femme. Ainsi le prêtre Rakataua, dont le fils avait été tué par Rata ou Hotu-Roa, quelques jours avant le lancement du Taïnui, etc.

Certes, il ne viendra à l'idée de personne que, s'ils étaient venus des îles Samoa, ils auraient pu faire un pareil voyage à la pagaie, si promptement et si sûrement. Pour comprendre ce voyage, il faut nécessairement admettre qu'il suffisait de suivre les côtes, et qu'on était assuré, après plus ou moins de temps, de rencontrer le point cherché, que des voyages antérieurs avaient sans doute fait connaître. Car, fait bien curieux, il résuite de l'examen approfondi de toutes les traditions connues, que la terre d'Aotearoa, ainsi dénommée par Turi, portait, avant cet émigrant, une foule de noms qui dénotent l'ancienneté de sa découverte. Or, ces noms que nous avons déjà cités, tels que Nuku-roa, UkuRangi, Tuawhenua, Tauwhenua (1), ont nécessairement pré-

(1) Nuku, distance, étendue ; roa, grande. Uku, argile blanche ; rangi, ciel. Tua, intérieur, de l'intérieur; whenua, terre. Tau, étrangère. 
cédé le surnom de Ika-na-Maui, puisque Maui, qui vivait du temps de Tinirau et de Whakatau, n'a émigré à l'IleNord de la Nouvelle-Zélande que peu d'années avant Kupe, Turi, et probablement nombre d'autres inconnus.

Ce qui prouve que cette terre avait dû être bien souvent contournée de près, c'est la connaissance exacte qu'on avait de sa forme, qui était comparée à celle d’un poisson plat, à une raie. Telle est, en effet, la ressemblance qu'on peut lui donner avec les traditions ; et cela témoigne surtout d'une observation attentive et vraiment surprenante. Qu'on jette les yeux sur la carte de cette île, et l'on verra que si l'on n'y retrouve passans un peu de bonne volonté la forme d'un turbot, d'une plie, etc., ce n'est pas moins un poisson de ce genre que les indigènes $y$ ont reconnu. Ils disent même que l'un de ses yeux est Whanganui-a-te-Ra ou port Nicholson : l'autre, Wairarapa ou baie Palliser; la mâchoire supérieure, la pointe Nord du port Nicholson ; la mâchoire inférieure, la pointe Sud du même port; la tête, à Turakirae ; le ventre, à Taupo et à Tongariro; la queue, au cap Nord ou Reinga.

Il faut reconnaître que, pour en être arrivés là, il fallait qu'ils eussent bien souvent exploré cette terre.

Mais, fait encore plus curieux, ces mêmes légendes ne se bornent pas à montrer que l'Hawahiki se trouvait plus à l'Ouest que l'île Aotearoa, et à une très petite distance d'elle, elles rapportent même, dans plusieurs passages, que l'Hawahiki n'en était séparé que par le détroit de Cook, et qu'avant cette séparation, les deux terres n'en faisaient qu'une. On ne pouvait certainement rien dire de plus précis (1). Il est probable que c'est ce fait qui a donné lieu au proverbe Maori : a Le chemin de l'Hawahiki est coupé, „ Ka kotia te tai tapu ki Hawahiki.

$6^{\circ}$. - Quoi qu'il en soit, il résulte encore de la lecture de ces traditions que les hommes dont elles parlent ont tous

(1) Voir particulièrement l'ourrage du Rév. S. Ironside, NewZealand and its aborigines, Sydney, 1863. 
vécu à la même époque et qu'ils ont presque tous quitté leur patrie pourle même motif et à peu près dansle mème temps.

Ainsi Kupe, après avoir fait noyer Hotu-Rapa, beau-frère de Turi, enlève sa femme et s'enfuit sur l'Océan dans le canot Mata-horua, pour éviter la vengeance des parents.

Turi, quatre ans après avoir tué le fils du grand-prêtre Uenuku, s'éloigne dans son canot l'A otea, pour échapper à la vengeance de Uenuku.

Ngahue s'enfuit d'Hawahiki pour conserver le jade vert qu'il possédait, et dont une puissante cheffesse était jalouse. C'est avec la hache faite du morceau de jade qu'il rapporta en Hawahiki, que le chef de l'Arawa, Tama-te-Kapua, coupe la tête de Uenuku.

Tama-te-Kapua et ses frères s'expatrient pour ne pas laisser exterminer leur tribu, et ils emmènent avec eux par ruse le célèbre grand-prêtre Ngatoro-i-Rangi et sa femme.

Manaia, beau-frère de Ngatoro s'éloigne, pour le même motif, sur le Tokomaru, en même temps que les canots l'Arawa et le Taïnui.

Porua, sur le Ririno, accompagne Turi dans son émigration, et se perd avant d'arriver à Aotearoa.

Hotu-Roa commande le Taïnui, sur lequel se trouvaient les enfants de Uenuku.

Ruaeo part, toujours pour le même motif, sur son canot le Pukea-te-awanui, après avoir été laissé à terre par Tama-teKapua, qui enlevait sa femme.

De même Rongomai, sur le Mahuhu, qui fait naufrage dans la Baie d'Abondance, ainsi que tous ceux dont on pourra voir les noms sur la liste que nous avons dressée, et que nous insérons à la fin de ce livre.

D'où il résulte bien, en somme, que tous les chefs dont il est parlé, vivaient à la même époque et qu'ils se sont éloignés pour fuir le parti le plus fort.

Nous ferons remarquer en passant combien les femmes sont causes déterminantes du départ de beaucoup de canots.

Ainsi Hau entrepritson voyage pourchercher Wai-Raka 
sa femme, qui s'était enfuie avec Weku (1). Il la retrouva avec son amoureux à Te Paripari, extrémité de la chaîne Tararua; il l'envoya lui chercher de l'eau et, par ses charmes, il la transforma en un rocher qu'on voit encore aujourd'hui dans la mer, avant d'arriver à Wairarapa.

Kupe, d'après la version de Taylor (2), partit également pour aller à la recherche de sa femme, Kura-Marotina, qui avait été enlevée par son plus jeune frère, Hoturapa. La version relatée par Sir Grey, dit que Kupe fit noyer Hoturapa son cousin, afin de prendre sa femme, et qu'il se sauva avee elle dans son canot, le Matahorua. Ce canot, comme l'Aotea, avait été fait par Toto, qui les avait donnés à chacune de ses filles, l'une femme de Turi, et l'autre d'Hoturapa. Cette dernière est appelée avec plus de raison Kura. Marotini par Sir Grey.

Toujours est.il que Kupe revint en Hawahiki assez tôt pour dire à Turi quelle route il fallait suivre afin d'atteindre Patea dans le détroit de Cook. Seulement les légendes n'en parlent plus, et comme il était l'ami de Uenuku, il est à supposer qu'il partagea son sort.

On ne voit pas que Turi ait eu à se plaindre de sa femme Rongo-Rongo; du moins, il n'en est rien dit et son nom “l'obéissante » est en sa faveur. Mais il n'en est plus cie même des chefs suivants.

Les gens deTupenu ayant violé la femme de Manaia, celui-ci s'en vengea en les tuant, et il en résulta une grande guerre. Plus tard, Manaia, au retour de son émigration, se vit attaqué par son beau-frère, Ngatoro, venu exprès d'Aotearoa pour venger la malédiction qu'il avait adressée à sa sœur; puis, en voulant se venger is son tour de Ngatoro, Manaia périt devant Motiki où il était allétrouver son beaufrère.

Ruaeo était l'un des chefs qui partaient sur l'Arawa avec leur famille; Tama-te-Kapua l'ayant laissé à terre, par ruse, pendant qu'il emmenait sa femme, Ruaeo se rendit aussi-

(1) Taylor, ouvr. cité. p. 140 .

(2) Ibid, p. 116. 
tôt dans son propre canot à Maketu, où il arriva avant Tama, et, après l'avoir battu et couvert de honte, il s'éloigna de cet endroit en lui laissant sa femme (lj.

Ngatoro-i-Rangi, que Tama-te-Kapua avait aussi enlevé par ruse du Taïnui, avec sa femme, ne se conduisit pas comme Ruaeo; car, quoique sa femme eût été souillée par Tama dans la traversée, Tama etlui restèrent toujours unis; mais on voit que, cette fois encore, la femme eût pu être la cause d'une querelle.

D'après l'une des plus vieilles traditions, c'est aux deux grandes prêtresses Rito-Wara et Rito-Maopo, que serait dû le commencement des querelles parmi les chefs de la fameuse Maison rouge, Whare-Kura, dont le grand-prêtre Uenuku était l'un des directeurs. Cette tradition apprend que jusque-là les tribus étaient restées unies, et que, à cause de ces deux prêtresses, survint la grande querelle qui les sépara toutes (2).

En résumé, les résultats les plus importants fournis par ces légendes, sont :

Que l'Hawahiki était situé plus à l'Ouest que l'île Aotearoa, et que, par conséquent, contrairement à ce qu'on a cru jusqu'ici, il fallait faire route vers l'Est pour aller du premier lieu au second.

Que l'île Aotearoa, la seule du groupe doṇt les légendes parlent, était uniquement l'Ile-Nord de la Nouvelle-Zélande et non toutes celles auxquelles les Européens donnent ce dernier nom, cause presque certaine de l'erreur dans laquelle on est resté jusqu'à ce jour.

Nous allons maintenant essayer de prouver ces assertions.

Pour arriver à cette preuve, il nous suffira, croyons-nous,

(1) Le canot de Ruaeo s'appelait Pukea te Awanui: Pukea, l'inondé, inondation; te awanui, de la grande rivière.

(2) Voy. Taylor, ouvr sité, p. $6 \%$ 
d'exposer aussi brièvement que nous le pourrons, quelquesunes des légendes qui offrent le plus de témoignages en faveur de notre assertion : telles sont celles de Turi, qui précise si bien la route qu'il faut faire, et celle des canots l'Arawa, le Taïnui, etc., qui indique si nettement la routequ'ils ont suivie.

Il est indispensable de présenter cet exposé, atin que chacun puisse bien juger par soi-même de la valeur de l'opinion que nous soutenons, opinion contraire à toutes celles admises jusqu'à ce jour. Nous nous bornerons, du reste, aux faits les plus démonstratifs de la marche des émigrants, sans relever aucun de ceux qui peignent sibien leurs mœurs et leurs usages. Cet exposé aura, en outre, l'immense avantage de nous permettre, au fur et à mesure que nous le donnerons, de mieux faire ressortir l'impossibilité d'une provenance polynésienne.

VoYAGE DE KUPE. - Il existe de ce voyage deux versions qui se complètent l'une l'autre. Mais, dans les deux, Kupe est la première personne qui 'aborde à Aotearoa ou Ile. Nord de la Nouvelle-Zélande. Son voyage est presque un voyage d'exploration, quoiqu'il n'eût pour cause que la nécessité de fuir la vengeance des parents de la femme qu'il enlevait.

On voit, dans la version de Sir Grey, qu'il commence par se rendre directement dans le détroit de Cook où ildécouvre, sur l'île Aotearoa, la rivière Patea ; puis, sans qu'aucune relâche ou découverte soit désignée, la légende dit qu'il fait le tour de l'île, et elle le fait reparaître sur la côte Est, près de Castle-point de Cook, d'où s'enfuit devant lui, en se dirigeant vers le détroit de Cook, un poulpe gigantesque qu'il poursuit et qu'il finit par tuer. C'est dans le canal Awa-iti, le Tory.Channel des Anglais, que Kupe pourfend ce fameux Kraken zélandais. Après cela, il pénètre dans les canaux qui sont formés par les îles de la Reine Charlotte, de Cook, et dans les divers bras de mer qui s'enfoncent dans l'intérieur des terres; il donne des noms à 
quelques lieux; enfin, après avoir terminé l'exploration de ces localités, il part de là pour retourner directement en Hawahiki, où il arrive justement quand Turi allait s'en éloigner.

Nous ferons remarquer en passant que la lég’ende signale tout particulièrement les courants qui sont si violents dans les canaux du détroit de Cook et qui nous rappellent si bien ceux que l'Astrolabe eut à traverser avant de découvrir et de franchir la Passe des Français sous le commandement de Dumont d'Urviıle, son premier découvreur en 1827.

Dans la version du Révér. Taylor (1), Kupe est également le premier qui aborde à Aotearoa, d'après tous les indigènes. Il y arriva dans le canot Mata-o-rua, évidemment le même que le Mata-horua de Sir Grey; il alla débarquer à Wanganui-a-te-Ra, le port Nicholson actuel, à la recherche de sa femme, Kura-Marotini, qui avait été enlevée par son jeune frère Hoturapa (2).

De là, Kupe alla jusqu’à Patea, où il entendit le cri du Kokako dans l'intérieur des terres; il prit ce cri pour celui d'un homme ; aussi s'écria-t-il : Hua noa he reo te tangata, «on dirait que c'est une voix d'homme.» Mais il eut beau envoyer voir ce que ce pouvait être, on ne put rien découvrir. Après avoir planté un poteau dans l'endroit, il retourna à Wanganui-a-te-Ra ; puis, de là, à Hawahiki, où il demeura sans rouloir entreprendre d'autres voyages; d'où le proverbe : HokiKupe, e kore ia e hoki mai, « rerenu (de ce pays), Kupe ne voulut plus y retourner.

Il résulteévidemment de cette version, que la première a singulièrement grossi le voyage du navigateur zélandais, et qu'au lieu de faire un voyage autour de « la terre ét:angère, » Tauwhenua, comme l'appellent quelques légendes, Kupe semble s'être borné à explorer le détroit de Cook, et les environs du cap Kawakawa ou Palliser.

Si l'on admettait qu'il a fait le tour d'Aotearoa, il faudrait

(1) Ouvr. cité, p. 116.

(2) Dans la première version, Hoturapa n'était que son cousin, et le beau-frère de Turi. 
nécessairement admettre, en effet, qu'il a dû commencer son voyage par un des points du détroit de Cook, puisque c'est dans ce détroit qu'il découvre Patea dès le début, et qu'on le voit finir son voyage dans le même détroit. De la sorte seu. lement, il aurait pu faire le tour de ce monde nouveau, comme la première version semble le faire croire. Mais dès lors, comment concevoir qu'en partant des îles Samoa, comme on le suppose, il aurait pu arriver justement dans le détroit de Cook sans voir aucune terre ? Il y a là une impossibilité qui doit faire préférer la version du Rév. Taylor ; et ce qui vient à l'appui, c'est le choix que fait Kupe du détroit de Cook pour retourner en Hawahiki. Il est évident qu'il n'eût pas choisi un pareil point pour se rendre directement aux îlès Samoa.

D'un autre côté, comment s'expliquer qu'après être arrivé dans ce détroit, en venant du Nord-Est, comme il aurait fallu qu'il fìt s'il était parti des Samoa, Kupe aurait pris la routè du Nord par l'Ouest pour remonter jusqu'au cap Nord̄, puis celle du Sud par l'Est pour aboutir à son premier point d'arrivée, et tout cela, sans voir terre et sans relâcher nulle part? Car il est certain que la version de Sir Grey ne désigne aucun lieu : il est bien dit, en note, que Kupe en a vu plusieurs; mais la légende se tait complètement sur eux, et, comme elle entre, pour tout le reste, dans des détails fort étendus, il est permis de supposer qu'elle ne s'est tue que parce qu'elle n'avait rien à dire à ce sujet.

Pour nous, nous pensons qu'il est plus probable qu'en venant d'Hawahiki, Kupe s'est d'abord rendu dans le détroit de Cook où il a découvert Patea ; puis, continuant la route qu'il devait conseiller plus tard à Turi, c'est-à-dire celle de l'Ouest à l'Est, qu'il a longé la côte d'Aotearoa depuis Patea jusqu'au cap Palliser d'abord, et depuis ce cap jusqu'à Castle-point, pointe où il s'arrêta pour revenir au détroit de Cook en poursuivant la poulpe ou monstre marin de la légende.

De la sorte, au lieu de faire le tour de l'île, Kupe se serait borné, suivant nous, à l'exploration du détroit de Cook et 
à celle d'une portion fort restreinte de la côte Est d'Aotearơ.

Si l'Hawahiki était bien placé où nous le supposons, il lui était, en effet, d'autant plus facile d'y retourner directement qu'il n'en était qu'à une faible distance. C'est à Kupe que les traditions attribuent tout le mérite d'une première découverte de l'Ile-Nord de la Nouvelle-Zélande. Elles prétendent même que cette a grande terre » était unie à l'Hawahiki, et que c'est Kupe qui la divisa et fit passer la mer entre les deux parties. Ce fait est des plus importants pour l'hypothèse que nous soutenons.

A son arrivée sur la terre qu'il avait découverte et que la tradition appelle Tuawhenua, c'est-à-dire grande terre, continent, Kupe avait trouvé, ce qu'il importe de faire remarquer, une population désignée par lui sous le nom de Kahui-toka (1) et dont les chefs se nommaient Keu, Rehu et Monoa (2). Ce fut cette même population que, quelque temps après, Turi extermina en partie, à son arrivée.

Comme on le voit, la nouvelle terre n'était pas aussi déserte qu'on l'a dit, et nous en citerons bientôt d'autres exemples.

Voici, du reste, le chant Maori qui a été conservé sur Kupe (3): il a été composé, longtemps après lui, par un prêtre qui se regardait comme son descendant.

Ka tito au, ka tito au, ka tito au,

Je chante, je chante, je chante,

Ki a Kupe te tangata,

Kupe, l'homme,

Nana $i$ topetope te whenua,

Celui qui a divisé (coupé) la terre,

(1) Kahui, troupeau; toka, être plein de pierres ou roches de mer.

(2) Keu, tirer; keukeu, remuer.

Rehu, haché, fente.

Monoa, surpris, étonné. Il faut remarquer qu'en Hawahiki existait un Monoa, qui était le troisième fils de Whiro ; ce fut le seul qui échappa au meurtre prémédité contre toute sa famille par les chefs de Warekura, du temps de Uenuku.

(3) Taylor, ourr. cité, p. 117. 
Tu ke a Kapiti,
A fait étrangère (isolé) Kapiti (1), Tu ke Mana,
A fait étrangère (isolé) Mana, (2),
Tu ke Arapawa.
A fait étrangère (isolé) Arapawa (3).
Konga tohu tena,
Ce sont les marques celles-là,
O taku tupuna,
De mon ancêtre,
A Kupe nana $i$ waka
De Kupe qui en pirogue
To mene Titapua,
Vint (traversa) jusqu'à Titapua (4).
$K a$ to mene au te whenua, $E$ !
Vint (traversa) jusqu'à la terre. Eh !

ITINÉRAIRE dE TURI. - Ici encore il y a deux versions qui diffèrent assez, pour qu'il soit nécessaire de les examiner séparément: la première est de Sir Grey, la seconde du Rév. Taylor.

Dans l'une comme dans l'autre, c'est à son retour en Hawahiki que Kupe trouve Turi sur le point de prendre la mer, afin de fuir la vengeance de Uenuku, dont ii avait tué le fils quatre ans auparavant; ce fut sur les renseignements donnés par Kupe que, d'après la légende, Turi se décida à se rendre dans l'île où se trouvait la rivière Patea.

Première version. - Turi commandait l'Aotearoa (5) et

(1) Nom de l'île appelée de l'Entrée par Cook.

(2) Ile de la Table, de Cook, dans le détroit de Cook.

(3) Arapawa ou-Arapaoa, île duns le détroit de Cook.

(4) Nom d'une île que les traditions disent avoir disparu sous les flots, dans le détroit de Cook.

(5) Le révérend Taylor cite l'Arawa, le Tainui, l'Aotearoa, le Takitumu, le Kurahaupo et le Tongamaru; mais il y a presque certainement erreur, puisque Turi est purti avant la mort de Uenuku, tué par Tama-te-Kapua, le capitaine de l'Arawa. 
cinq autres canots l'accompagnaient. On voit dans la version de sir Grey que le Ririno était un de ces canots. Tous partirent à la fois. Kapo était le nom du prêtre de Turi: celui-ci le jeta à la mer peu après le départ, sous prétexte qu'il était sale ; mais il le reprit bientôt. C'est par la bouche de Kapo que Maru, le dieu de l'Ile-du-Milieu, apprend que l'Ile-Nord de la Nouvelle-Zélande, avant d'être appelée Aotearoa par Turi, portait les noms de Uku-Rangi, Nuku. Roa, etc.

Avant de partir, Turi pria vainement Kupe de l'accompagner; celui-ci ne voulut pas y consentir : d'où le proverbe que nous avons cité. Toutefois il lui donna et lui renouvela le conseil de tonjours faire route à l'Est et de ne pas dévier de cette direction, s'il voulait arriver à Patea et aux îles qu'il venait de découvrir. Nous avons cité plus haut les recommandations de Kupe à Turi.

D'après la version de Sir Grey, Toto, beau-père de Turi, avait construit l'Aotearoa sur les bords d'un lac appelé Waiharakeke, et il dut commencer par descendre la rivière Waima-tu-i-Rangi, avant d'atteindre la mer.

Aussitôt qu'ils furent en pleine mer, les canots furent dirigés « du côté où le soleil se lève, » et après un temps assez court, ils arrivèrent à une île appelée Rangitawha. Le canot de Turi faisait eau par ses fargues, et il avait le plus urgent besoin d'être réparé.

Nous ferons remarquer dès à présentque, puisqu'il fallait faire route à l'Est pour atteindre Aotearoa, les canots avaient évidemment dû partir d'un point plus Ouest que cette île: c'est-à-dire que ce point, ou autrement dit l'Hawahiki, d'où venaient les émigrants, était encore plus à l'Ouest. On verra par les renseignements qui vont suivre, que si l'on prend à la lettre les mots Est et Ouest, il aurait fallu que les canots fissent route du cap Farewell de Cook, qui se trouve sur la côte Nord-Ouest de l'Ile-du-Milieu; car ce n'est qu'en partant de là qu'il est possible de faire route directement à l'Est et d'arriver à l'une des petites îles qui occupent le détroit de Cook, particulièrement à celle qui porte le nom de $d$ Urville. Mais on ne voit, dans « le côté où le soleil se lève, » 
que le quartier du globe qui s'étend du Sud-Est au NordEst, et nous pensons que c'est la véritable interprétation(1). Les canots auraientpu partir aussibien de la côte Est del'Iledu-Milieu que de la côte Ouest, contrairement à ce que nous avions d'abord cru pouvoir dire dans notre mémoire à la Société d'anthropologie. Nous aurons, d'ailleurs, une fois les faits exposés, à revenir sur ce sujet qui ne peut être développé ici.

Toujours est-il qu'on ne sait à quelle île était donné le nom de Rangitawha. Seulement, comme on voit, sur les cartes européennes, les îles Rangitoto, Stephens et autres, figurer dans le détroit de Cook, nous croyons pouvoir dire qu'il est très probable que l'île Rangitawha, dont parle la légende, était l'île d'Urville elle-même, à laquelle Dieffenbach donne le nom de Rangitoto. Il est certain du moins que ce n'est qu'en partant de l'une de ces îles pour aller à l'Ouest qu'il est possible de se perdre sur quelque récif plus encore à l'Ouest qu'elles.

Les réparations de l'Aotearoa terminées, une dispute s'éleva entre Poturu, le capitaine du Ririno, et Turi, au sujet de la route à faire en quittant Rangitawha. Pénétré des con-. seils donnés par Kupe, Turi voulait qu'on continuât la route faite jusque-là, c'est-à-dire vers le côté a où le soleil se lève. »Mais Poturu (ou Porua, son autre nom) était d'avis contraire: il voulait qu'on mit le cap à l'Ouest, c'est-à-dire que les canots retournassentsur leurs pas. Turi eut beau lui dire: « Mais ne sais-tu pas ce que Kupe, qui a visité ces îles, nous a recommandé tout particulièrement, en nous disant:

"Maintenant, rappelez-vous bien de ne pas laisser dévier la proue de votre canot du point de l'horizon a où le soleil se lève. $\gg$ Poturu persista néanmoins à vouloir aller du côté opposé, et Turi finit par céder. De sorte qu'en laissant Rangitawha, les canots firent voile vers l'Ouest, et, peu après,

(1) Nous avons expliqué ailleurs qu'on doit entendre par Ouest l'intervalle compris entre le Sud-Ouest et le Nord-Ouest. 
entraîné par les courants, le Ririno alla se briser sur un récif que la légende appelle Taputapu-atua (1).

C'est même depuis lor's qu'existe le proverbe: «Tu es aussi entêté que Poturu, qui persista à se jeter sur le récif pour sa propre destruction. $\gg$

Les cartes modernes ne signalent pas ce récif, sous ce nom du moins, mais elles en indiquent un certain nombre sur le prolongement de la pointe du cap Farewell. Evidemment, pour que le Ririno pût se perdre sur l'un d'eux en faisant routeà l'Ouest, il fallait qu'il vînt de l'une des îles du détroit de Cook que nous venons de citer. Cela résulte également de la situation du port où alla aborder l'Aotea, après avoir repris la route vers l'Est, dès que le Ririno eût été perdu. Partant de tout autre point que celui que nous supposons, après avoir fait un peu de route à l'Ouest, puis remis le cap à l'Est, le canot de Turi n'aurait pas pu arriver au hâvre auquel il a donné son nom, sur la côte Ouest d'Aotearoa: d'où il faut absolument conclure, puisqu'il a commencé par faire route à l'Ouest, que son point de départ de l'île Rangitawha ne pouvait se trouver placé que dans le détroit de Cook, comme le récif Taputapu-atua luimême.

Devenu libre de ses mouvements après la perte du Ririno, Turi reprit sa course vers le côté « où le soleil se lève ». Là, la légende dit qu'un fils lui naquit alors « au milieu de l'Océan, " ce qui a fait supposer à quelques ethnologues qu'il était bien loin de terre; mais cette même légende montre presque aussitôt que le canot de Turi était fort près d'Aotearoa, puisque Turi ayant jeté par dessus bord un de ses compagnons récalcitrants, celui-ci put s'y sauver à la nage, et que, peu après, le canot arriva, en cotoyant la terre, au hâvre qui fut appelé, de son nom, Aotea.

Ce hâvre est placé sur la côte Ouest d'Aotearoa par 37\% 59' $36^{\prime \prime}$, lat.Sud et $174^{\circ} 5^{\prime} 10^{\prime \prime}$, long. Est, méridien de Grenwich. En supposant le récif sur lequel s'est perdu le Ririno, près de la pointe Farewell, Turi aurait donc fait beaucoup plus

(1) Ce nom, en Polynésie et particulièrement aux îles de la Société, était donné à ce qui était doublement sacré ou défendu. 
de Nord que d'Est, non à son insu, cormme on l'a cru, mais, sans nul doute, par suite des vents et surtout des courants qui portent dans l'Ouest.

Dans une note de satraduction de cette tradition, Sir Grey dit: a Il paraîtrait que Turi ne suivit pas les directions indiquées par Kupe, parce qu'il supposait que ce dernier, ami de Uenuku, avait voulu le tromper. •Il est évident qu'il y a là erreur, et rien n'indique cette défiance. Certainement elle aurait pu exister ; mais elle est détruite par l'empressement que Turi, à peine débarqué, met à rechercher la rivière Patea que lui avait indiquée Kupe. Il est plutôt à croire que s'il n'a pu aborder qu'à Aotea, sur la côte Ouest de l'île Aotearoa, c'est qu'ilavait été entraîné beaucoup plus qu'il ne pensait vers l'Ouest, et que c'est justèment en faisant de l'Est qu'il a atterri si peu Nord de son dernier point de départ. La route suivie par lui plus tard prouve bien qu'il s'était parfaitement aperçu de cette différence de direction.

Mais c'est ici qu'il faut surtout se demander comment, en partant des îles Samoa, comme on le croit généralement, et en faisant, depuis ces îles, route vers l'Est, Turi aurait pu venir aborder au point pour ainsi dire extrême d'Aotearoa, vers l'Ouest, sans voir d'autres terres que l'île Rangitawha et un récif. Il est évident que cela aurait été de toute impossibilité, quel que soit le point où l'on place l'île Rangitawha.

Quand Turi eut atteint le havre Aotea, il y amarra son canot, dit la légende, et il se mit à suivre, par terre, les contours du rivage pour aller à la recherche de la rivière Patea. A partir de là, il y avait pour lui deux routes à prendre, celle du Nord ou celle du Sud. Sıns hésiter, il prit celle du Sud, ce qui prouve qu'il s'était bien aperçu du chemin qu'il avait fait vers le Nord. En effet, il prenait cette route pour aller à l'Est, où on lui avait dit que 'se trouvait Patea, relativement a Hawahiki. Il suivait donc alors les conseils de Kupe, et cela montrait en mème temps que, s'il ne les avait pas complètement suivis jusque-là, c'est qu'il y avait eu force majeure.

Il commença par se diriger, en suivant la côte, sur III 
Kawhia, qui est plus Sud qu'Aotea, et qui gît par $38^{\circ} 05^{\circ}$ environ de lat. En continuant d'aller au Sud jusqu'au mont E'gmont (Taranaki), puis après à l'Est, il finit par arriver à Patea, où il se fixa. En cheminant le long du rivage, il donna des noms à toutes les localités rencontrées, noms qui figurent sur lescartes anglaises, pour la plupart, des deux côtés du mont Egmont, et particulièrement sur cette partie d'Aotearoa qui concourt à former l'un des bords du détroit de Cook. Nous avons déjà dit, Patea se trouve justement dans le détroit sur Aotearoa, par 39044' lat. Sud environ, et par $174^{\circ} 30^{\prime}$ de longitude Est. La légende dit que ce fut là que Turi s'arrêta ; mais comme elle dit en même temps qu'il était l'ancêtre des Whanganui, tribu qui habitait un peu plus à l'Est, il faut supposer qu'il alla jusqu'à la rivière de ce nom, c'est-à-dire jusqu'au $175^{\circ}$ de longit. à peu près, et par conséquent presque à toucher Patea. A partir de la, toutes les localités, jusqu'au cap Palliser, reçurent leurs noms du chef Hou qui, d'après un chant curieux, serait venu dansle canot de Turi après avoir navigué sur le $K u$ rahaupo.

Comme on le voit, le voyage de Turi, d'après la version de Sir Grey, s’était borné à l'extrémité Sud-Cuest de l'IleNord de la Nouvelle-Zélande ou Aotearoa, et pour ainsi dire au détroit de Cook. Il serait impossible d'expliquer ce fait, dans la supposition d'un départ des îles Samoa, mais il se comprend, au contraire, parfaitement, en admettant que les canots sont venus d'un point plus Ouest ou plus SudOuest que l'île Aotearoa ; car, dans cette dernière supposition, c'était bien la route \& vers le côté où le soleil se lève » qu'il fallait faire, et le titre d'ancêtre des Whanganui que la légende donne à Turi, peut aider même à soupçonner, $a$ priori, quelle était la véritable situation de son point de départ.

En somme, le récit de ce royage est celui qui indique le plus nettement la route qu'il fallait faire pour atteindre Aotearoa, en partant d'Hawahiki et, par conséquent, la situation de ce dernier lieu par rapport au premier. Il est en 
même temps le fait qui combat le plus victorieusement l'hypothèse d'Horatio Hale.

Deuxième version. - Ce fut, dit Taylor (1), sur les renseignements donnés par Kupe à son retour en Hawahiki, que d'autres canots partirent pour Nuku-roa. Six, dit-on, partirent à la fois (2). Turi était le chef de cette seconde expédition, et il passe généralement pour être la première personne qui s'établit sur la côte Ouest. Il était même regardé comme un demi-dieu par tous les habitants de cette partie de l'île. On dit qu'il abandonna Hawahiki à la suite d'une querelle. Popouakoako, son jeune frère, lors de la récolte des Kumara, en ayant offert une à l'Ariki Uenuku, celuici fut si indigné du peu d'importance de l'offrande, qu'il avala à la fois et l'offrande et celui qui la faisait. Dans sa colère, Turi tua Oe-Potiki, fils de Uenuku, et le mangea. Les manawa (poumons) furent envoyés à Uenuku, qui ne s'aperçut, qu'après les avoir mangés, que c'étaient ceux de son propre enfant. Alors il eut recours à un charme puissant, que Taylor dit être le suivant :

Tiki na atu te tini o Ngati-Rongotea ;

Fais qu'ils arrivent en grand nombre, les Ngati-Ron gotea :

Whaka takamai, kia tini ;

Qu'ils arrivent, qu'ils soient une multitude :

Kia mano,

Qu'ils soient par milliers,

Kianga kia te mate Oe-Potiki.

(Pour) qu'ils vengent la mort de Oe-Potiki.

Koreka te kai mua.

La première vengeance (nourriture) est il suce.

Runamai Rongo E!

Qu'ils s'assemblent les Rongo !

(1) Ouvr. cité, p. 117.

(2) Il est probable qu'il y a crreur ct qu'on nc cite six canots que parce que c'était le nombre de ceux de la grande émigration partant à la fois : ce qui semble le prouver, c'est qu'on numme l'Aotearoa parmi les canots de cette émigration. 
Ka runa liai!

Qu'ils s'assemblent!

Nous ferons remarquer ici que Sir Grey (1) montre qu'il a eu un autre texte sous les yeux, car, en outre des Rongotea, les seuls désignés dans la traduction de Taylor, il cite les Ngati-Kua-Nui, et en laisse soupconner d'autres.

C'est ainsi' qu'il fait dire :

" Oh ! laissez se rassembler les tribus du Sud.

"Oh! laissez se rassembler les tribus du Nord;

* Laissez venir les Ngati-Rua-Nui en foule ;

« Laisez aussi les guerriers Ngati-Rongoa arriver ici,

- Pour que nous puissions détruire tous nos ennemis

* Et les balayer complètement d'ici.

- Oh ! Ils ont mangé qui était autrement noble qu'eux ! n

Quand Turi eut entendu cette menace, il alla demander un canot à son beau-père, Toto, qui lui donna l'Aotea. Turi s'embarqua ; mais, dans son empressement, il oublia le tata ou escope de son canot, qui s'appelait Tupua-Oronuku. Sa pagaie étaitappelée Kautu-ki-te-rangi. Le Pukeko, le rat, le perroquet vert, le Moeone (petit insecte couleur bronze), l'Awato (ver du papillon sphynx qui dévore les Kumara), les Kumara, le Karaka, la calebasse indigène, furent embarqués avec lui ainsi que son dieu, qu'avait apporté Tapo; mais, avant qu'il ne fût loin, il jeta Tapo à la mer sous le prétexte qu'il était sale. Maru fut mécontent, en voyant le peu de cas que Turi faisaitde son prêtre ; il dit par la bouche de Tapo: a Si tu restes sur ton canot sans mon serviteur, tu n'atteindras pas Nulkuroa (2); mets-moi sur le balancier, (tu ama) et nous atteindrons Uku-Rangi. \Turi y consentit et le reprit à son bord.

Il fit terre à Motiwhatiwha (3), où il tua son chien,

(1) Ouvr. cité, p. 205.

(2) Probablement l'lle-Nord de la Nouvelle-Zélande, car Taylor dit (p. 125): "Quand cette flotte arriva, elle appela l'île Aotea-roa et la grande barrière, Aotea-iti.

(3) Motiwhatiwha remplace ici Rangitawha. Ce mot n'est probablement qu'une expression figurée signifiant; mo, pour tiwhatiwha, être sombre, noir. Scrait-ce la baie obscure de Cook ? 
Iki-iki-rawea. Poturu en mangea : après en avoir mangé, il devint fou et il se perdit avec son canot dans le golfe de Parata (1).

Turi débarqua à Whangaparaoa, où il planta le Karaka(2). De là il fit voile vers Aupo-Uri (Cap-Nord); puis il alla à Aotea, où il laissa son canot qui fut transformé en une roche qu'on y voit encore.

Il continua son voyage par terre et dénomma toutes les rivières depuis Aotea jusqu'à Patea. Hou nomma toutes celles existant depuis cet endroit jusqu'à Wairarapa (3). A Patea, Turi planta la Kumara dans un endroit appelé Hekeheke-i-Papa (4) où il vit le poteau que Kupeavait planté sur le Rangitawhi (5). Il prit dans sa main un peu de terre, il la sentit er reconnut que c'était un sol riche; d'où le

(1) Te waha o te Parata signifie la bouche (la gorge) de Parata, et sans doute, l'entrée du gouffre de ce nom. On supposait que le flot et le jusant étaient formés par l'Océan en se précipitant dans la gorge de Parata qui, après aroir reçu l'eau, la vomissait de nouveau. Il en était de même pendant une grosse mer. Kupe arait échappé avec peine au Korokoro-e-Parata, d'où le proverbe : " Aucun canot n'ira où Kupe est allé. D

Ce lieu n'était évidemment pas éloigné de Rangitawha; ct si cette île était celle de d'Urville, le Korokoro-o-Parata était bien probablement l'un des canaux à courant de foudre qui se trouvent dans le détroit de Cook, peut-être même celui que nous avons franchi sur l'Astrolabe et qui a recu le nom de Passe des Fr.ançais.

(2) Le Karaka est le Corynocarpus loevigata, de la famille des Myrsinacece. C'est un bel arbre, ressemblant au laurier, mais de grandes dimensions.

(3) Voici les noms de la plupart des rivières : Kawia, Narakopa Mokau, Moakatino, Tonga-Porutu, Mimi, Rini, Waitara, Wai-oNgana, Wai-Wakaio, Kaupokonui, Puni, Wai-Nga-Ngoro, Tangaoe, Hinga-Ape.

(4) Hekeheke-i-paya, marque en planchs ou terre marqués.

(5) On a vu que, dans la légende de Sir Grey, lỉle où se fit la relâche est appeléc Rangitawhi : ici, Rangitawhi n'est plus qu'un point de la grande île Nord, à Patea. Il est probable qu'il y a confusion dans les traditions. Rangitawhi signifie : tawhi, nourriture ; rangi du ciel ou divine. 
dicton : « Quand il s'agit d'un bon sol, c'est la terre qu'a sentie Turi. »

Là, il tua son chien Mata-Ware; il dit à Taneroa, sa fille, que les hommes ou ses enfants l'avaient volé. A ces mots, Taneroa s'enfuit, et alla vivre à Papa-Wero, où elle eut deux enfants. Elle leur dit : «Quand vous serez grands, il y aura assez de nourriture pour vous à Rawaira-ra. » Cette localité était située de l'autre côté de la rivière, dans l'endroit habité par son frère Turanga-i-Mua.

Turi et son fils tuèrent les hommes de cette île : cette race était appelée les Kohi-Kohi (1).

Ainsi voilà encore un exemple d'une population primitive, et avec laquelle il fallait compter, comme le prouvent les précautions prises par Turi lorsqu'il s’éloignait de son $\mathrm{Pa}$.

Le révérend Taylor dit en note : «Il est probable qu'il y avait eu des habitants sur cette terre avant l'arrivée de la race Maori ; car ils ne le disent pas seulement dans leurs traditions, mais ils se rappellent aussi avoir chassé successivement une race bien inférieure à eux et l'avoir finalement forcée à chercher un refuge dans les îles Chatham. Ce peuple était appelé par dédain Kiri-Waka-Papa, qu'on peut traduire par a côtes pelées, nues, „ par suite de leur ignorance de se vêtir.

Quand Turi sortait de son Pa pour aller pêcher ou travailler à sa ferme, il y laissait, afin d'empêcher que ses ennemis pussent se douter de son absence et afin de provoir emmener tous ses hommes, il y laissait, pour garder le $P a$, un Matuku ou butor, dont le cri $h u$, $h u$, ferait croire à ceux qui en approcheraient, qu'il était dans sa maison ; pour appuyer le Matuku dans la défense de son $\mathrm{Pa}$, il récitait le charme suivant :

Ko te matuku $i$ hea?

Le butor de quel endroit?

Te matukui Wai-aua.

Le butor de Wai-aua.

(1) Kohi, signifie dépérissement ; Koilikohi, ramasser, recueillir. 
He matuku, aha te matuku?

Un butor, qu'est-ce que ce butor?

Mataku tau taki,

Un butor gardien, surveillant,

Tau aro aki,

Qui fait un bruit étrange en volant,

Te whaka rangona mañwa;

L'imitateur du bourdonnement des hommes ;

Te korero te whaka rongona a te

Qui est attentif à la parole en

\section{Wananga whoka tikaia}

Se tenant droit sur les pieux du $\mathrm{Pa}$.

Kia ika.

Sois exact (correct, attentil').

Whaka tonu hi a kia tonu hau, e!

Sois attentif continueliement dans ton coin, Eh!

Kia tonu.

Sois attentif tout à fait (incessamment).

Ko te matuku i hea?

Le butor d'où?

Ko te matuku $i$ Waingongoro.

Le butor de Waingongoro.

Ce chant était répété à chacune des rivières Tangahoe, Hingahape, Patea, Whenua-Kura, Waitotara. Quand le Matuku entendait cette incantation de Turi, il était porté à crier, $h u, h u, h u$, dans le $\mathrm{Pa}$; alors ceuxqui venaient, en entendant sa voix, croyaient que c'était celle de Turi, et ils s'enfuyaient effrayés,

Un profond regret pour Hawahiki, son pays, s'empara bientôt de Turi; il se suicida en se précipitant dans la rivière Patea, et il s'y noya. « C'est tout, $\gg$ dit en terminant la tradition indigène (1).

On montre encore les lieux occupés par la maison de *

(1) Puisque, d'après la première version, Turi était parti, alors que l'un de ses enfants, Taneroa, était allaité par sa femme Rongorongo, il est à croire qu'il ne s'est suicidé qu'après avoir séjourné longtemps, car on voit que Tancroa avait alors plusieurs enfants. 
Turi : Matangirei et sa ferme de Kumara, à Patea. Un vieillard, demeurant dans ce lieu, disait qu'il avait vu, dans sa jeunesse, les pierres sculptées, au nombre de soixante, qui marquaient les limites de ses terres, mais qu'elles avaient été toutes détruites par eux à la venue de l'Evangile. On montre également le puits de Turi.

Comme on le voit, il y a entre les deux versions une difference considérable touchant l'itinéraire suivi par Turi, seul point que nous ayons à examiner ici. Aussi croyons-nous devoir entrer dans quelques développements qui aideront peut-être à lever les doutes.

Dans la version de Sir Grey, le canot l'Aotea part de la rivière Waima-Turi-Rangi, celle-là même où il avait fait baigner les enfants de la tribu pour attirer le fils de Uenuku. Une fois à la mer, et sans qu'il soit dit si c'est immédiatement ou après avoir suivi pendant quelque temps la côte, Turi fait route à l'Est, et sa première relâche, pour réparer le canot, a lieu dans une île appelée Rangitawha. De là, il fait d'abord route à l'Ouest, puis, revenant à l'Est, il va enfin aborder la côte Ouest. Son canot avait été construit sur les bords du lac Waiharakeke.

Dans la version de Taylor, au contraire, le canot fut construit sur les bords d'une rivière Tautoru. Turi part d'un point appelé Whiti-Mąrama; puis il relâche, pour réparer son canot, à une côte nommée Motiwhatiwha. De là, il va directement à Whangaparaoa, sur la côte Est de l'Ile-Nord, et, de Whangaparaoa, en doublant Aupo-uri (Cap Nord), à Aotea. Enfin, il se rend par terre aussi à Patea. En un mot cette version lui fait faire le tour de l'lle-Nord, depuis Motiwhatiwha au moins, et le fait aller se fixer à Patea où, pris de nostalgie, il finit par se suicider.

Evidemment, si ces différents noms, ou seulement un certain nombre d'entre eux étaient retrouvés sur quelque terre connue, cette terre, selon toute probabilité, serait celle qui aurait fourni les émigrants. Or, disons-le de suite, pas un de ces mots ne se retrouve en Malaisie d'où tous les 
écrivains font venir les Néo-Zélandais, aussi bien que les autres Polynésiens; et dans la Polynésie elle-même qui, pour la plupart, est le dernier point de départ des Maori, ces mots, à l'exception d'un petit nombre, manquent presque complètement. Au contraire, on les rencontre réunis en grand nombre surl'une des îles de la Nouvelle-Zélande, sur celle qui est appelée Ile-du-Milieu. Ce fait est bien significatif, comme nous le montrerons quand nous prouverons que cette île n'était autre que l'Hawahiki lui-mème ; tout ce que nous pouvons dire, dès à présent, c'est que si l'Iledu-Milieu n'avait pas été l'Hawahiki, on ne comprendrait pas comment cette agglomération de mots se rencontre dans une localité qu'on croit si généralement avoir été peuplée par l'Ile-Nord de la Nouvelle-Zélande, tandis que cette dernière ne possède pas ces mots. Il est évident, en effet, que si l'Ile-du-Milieu eût été, comme on le dit,peuplée par l'Ile-Nord, c'est sur cette Ile-Nord, où sont d'abord arrivés les émigrants d'Hawahiki, qu'on eût dû trouver tous les noms que citent les légendes. Or, nous venuns de le dire, ils n'existent pas plus sur l'Ile-Nord qu'en Malaisie; si l'on en retrouve un petit nombre, à peine compris des indigènes, c'est en Polynésie, où l'on voit, entre autres, les mots Manono et Apalima qui ont tant intrigué les ethnologues, et qui ne sont eux-mêmes, cornme on l'a vu, qu'un témoignage en faveur de la thèse que nous soutenons.

Quoi qu'il en soit, et c'est le seul fait qu'il importe de signaler ici, il résulte des deux versions que le canot de Turi s'est avancé du Sud-Ouest vers le Nord-Est, en un mot, de l'Ouest vers l'Est, en partant d'Hawahiki pour atteindre Nuku-roa ou Aotearoa.

C'est tout ce que nous voulions prouver en citant cette tradition, sur laquelle nous allons d'ailleurs avoir bientôt à revenir.

Avant de terminer ce qui a trait à Turi, nous croyons devoir transcrire ici un chant inconnu jusqu'au Révér. Taylor (1): C'est le récit du voyage à Aotearoa, fait par

(1) Ouvr. cité, p. 140. 
Hou, père de 'lama-te-Kapua, probablement à la même époque et sur le même canot que Turi. Ce récit est intitulé : « Chant de Rangitakoru, pour sa fille Wharauliangi. $\gg$

Hau ou Hou se rendit à Nukuroa dans l'un des deux canots Kurahaupo ou Aotea, mais plutôt dans ce dernier. Le chant ne parle pas de son retour en Hawahiki, peu de temps après ; mais ce retour, sans qu'il soit dit sur quel canot, est indiqué par quelques traditions, entre autres par la première de Sir Grey.

La cause de son départ n'aurait èté, d'après le chant de Rangitakoru, que son désir de retrouver sa femme WaiRaka, qui s'était enfuie avec un homme nommé Weku.

En arrivant à la première rivière il l'appela, par suite de sa grande largeur, Wanga-nui, k la grande embouchure $\gg$.

La rivière la plus voisine fut appelée Wanga-e-hu (1) parce qu'elle était si proche qu'elle éclaboussait l'eau de la Wanganui.

La suivante était si peu éloignée que si un arbre, croissant sur le bord de la Wanga-e-hu, fût tombé, sa cime aurait atteint cette rivière qu'il appela Tura-ki-na (2).

Ayant eu à parcourir une grande distance jusqu'à la rivière suivante, il l'appela Tikei, « un pas » de tikei, l'action des jambes en marchant. Aujourd'hui elle est appelée Rangi-tike.

Continuant de s'éloigner, il arriva à une grande rivière qu'il craignit de ne pouvoir traverser, c'est pourquoi il l'appela Manawa-tu, « l'esprit abattu ».

Pendant qu'il cheminait, le vent siffla à ses oreilles, et il appela l'endroit où il se trouvait alors Hokio (3).

Il nomma la petite crique voisine $\mathrm{O}-\mathrm{Hau}$, peut-être d'a près son nom(4).

(1) $H u$, bouillir ; tiheu, éclabousser.

(2) Turaki, renverser, abattu .

(3) Hokio, descendre.

(4) Il est à noter qu'il y a, dans l'intéricur de l'Ile-du-Milieu, un lac O-Hou, par le travers à peu près de la baie Jakson. Ce lac, en 
Après $\mathrm{O}-\mathrm{Hau}$, il pointa horizontalement son bâton ; c'est yourquoi la rivière voisine fut appelée O-taki, de taki, « diriger une lance dans une charge».

Quand il se fut fortifié par la prière, il appela l'endroit Wai-Meha, de mehameha, "rendre sacré ».

Arrivé à la rivière voisine, il s'efforça de découvrir adroitement sa femme, et il appela l'endroit Waïkanae (1).

Il était tout en nage quand il atteignit l'endroitoù Wairaka se trouvait avec son amant, à Te Paripari, extrémité de la chaîne de Tararua. Il lui dit:Wairaka,j'ài une soif extrême ; apporte-moi de l'eau. Elle se leva et descendit à la mer avec une calebasse dans chaque main. Quand elle eut de l'eau jusqu'aux genoux, elle commença à remplir ses calebasses. Il lui cria d'aller plus loin : elle entra dans l'eau jusqu'à la ceinture. Il lui ordonna d'aller encore plus loin : elle avança jusqu'à ce que l'eau lui couvrît les épaules. Alors il récita une Karakia : elle se trouva pétrifiée, et, depuis, elle est toujours restée ainsi. Il la laissa là, et une roche de la mer porte encore aujourd'hui son nom.

Il s'en alla ensuite gaiement, et nomma le lieu voisin Waïrarapa $\propto$ la rivière de la joie $\gg$, de rarapa, \& le brillant des yeux ou le plaisir $»$. Le poète apprend alors à sa fille que c'était la joie de son ancêtre, sa réjouissance : Ta rarapatanga o to tupuna, e hine!

Voyage de NGahue. - Deux versions sont encore à examiner à l'occasion de ce poème; nous nous bornerons à l'analyse de celle de sir Grey, mais nous croyons indispensable de citer en entier la version du Rév. Taylor qui précise la situation de quelques lieux laissés dans le doute par la première.

Le poème de Ngahue, le propriétaire du jade vert, qui s'expatrie avec son jade pour le préserver de la convoitise passant par une riviere près du mont Tahawaiki, va se décharger, sous le nom de Waïtangi, sur la côte Est près de Mloeraki ou Moerangi, et non loin de la rivière Waimataitai.

(1) Wai, rivière, eau ; Kanae, nom d'un poisson, sorte de saumon. 
d'une cheffesse d'Hawahiki (1), est beaucoup plus légendaire que celui de Turi, et, par conséquent, beaucoup moins clair. Mais il fournit pourtant, à notre avis, quelques témoignages en faveur de l'opinion que nous soutenons.

Ainsi, d'après la version de Sir Grey, la première relâche de Ngahue, après qu'il eût quitté l'Hawahiki, eut lieu dans une île appelée Tuwha (2). Or, d'après sir Grey, comme d'après les cartes, Tuhua est l'île Mayor de Cook dans la baie d'Abondance, au large de Tauranga et au Sud des îles Mercure du navigateur anglais.

Que Ngahue fut parti des îles Samoa ou de l'lle-du-Milieu, sa première étape n'aurait, comme on voit, eu lieu qu'à une distance considérable de son point de départ ; mais en voyant celle qu'il aurait eu surtout à franchir en venant de Samoa, il est presque impossible d'y croire, car, avant la petite île de Mayor, il aurait eu certainement en vue plusieurs grandes îles, telles que le Grande-Barrière de Cook ou seulement les îles Mercure, dont le chant ne parle pas.

Toujours est-il que la légende le fait aller de l'île Mayor à Aotearoa, que, dit-elle, $\propto$ il trouva dans la mer $\bowtie$. Puis elle le fait longer cette lle, $<$ loin, bien loin, $>$ jusqu'à Arahura, où il cache son jade. De là, Ngahue revient sur ses pas, en côtoyant la terre, et il touche d'abord à Wairere, puis à Wangapararoa, et en dernier lieu à Tauranga. C'est de ce dernier point qu'il retourne " directement » en Hawahiki.

Pour Sir Grey, la plupart de ces lieux sont bien ceux qu'on rencontre sur la côte Est d'Aotearoa, dans la baie d'Abondance; mais il place Arahura sur la côte Ouest de l'Ile-du-Milieu. En effet, il y a sur cette côte un lieu appelé Arahura ou mieux Arehura, comme on y trouve un Wairere

(1) Cette cheffesse et grande prêtresse s'appclait Hine-tu-aHoanga ; elle était la sœur de Rata d'après les versions de Sir Grey et de Taylor.

(2) Ce mot signifie obsidienne, et il est à remarquer, quand on sait que le poème n'est que le récit de la dispute surrenue entre l'obsidienne et le jade rert. 
et un Tauranga. Seulement on ne comprend pas que la légende, telle du moins qu'elle a été traduite, fasse sauter sans transition de la côte Est d'Aotearoa à la cote Ouest de l'Ile-du-Milieu, pour ramener, sans transition eucore, à la côte Est de la première. Ily a là évidemment erreurdu légendaire ou du traducteur, ou du moins oubli certain des lieux intermédiaires, par le premier. On pourrait croire tout aussi bien que l'on a voulu parler de lieux tous placés sur la côte Ouest de l'Ile-du-Milieu que sur la côte Est d'Aotearoa. Pourtant, comme Tuhua et Whangaparoa (1) ne se trouvent absolument que dans la baie d'Abondance, il faut bien reconnaître qu'il s'agit de ces deux localités dans la légende.

Ce qui prouve encore que c'est du Whangaparaoa de la côte Est d'Aotearoa qu'on a voulu parler, c'est ce que rapporte Ngahue de sa découverte des Moa (Dinornis) qu'on sait n'avoir été trouvés pendant longtemps qu'au cap Est. Cette circonstance doit faire supposer que Ngahue avait commencé par doubler le cap en allant à Tuhua, puisque la légende dit que c'est « en revenant sur ses pas », c'est-à-dire vers. le Sud-Ouest, qu'il les rencontra, pendant qu'il longeait la côte d'Aotearoa. Ce qui prouve qu'il se dirigeait alors vers le Sud-Ouest, c'est qu'on le voit commencer par passer à Wairere avant d'atteindre Whangaparaoa. Si donc il allait vers le Sud-Ouest, en revenant sur ses pas, il faisait, en sens inverse, le long de la terre, le chemin qu'il avait fait à la mer pour arriver à Tuhua; et, il faut bien le reconnaître, il se rapprochait du détroit de Cook d'où il était bien probablement venu d'abord, car il possédait déjà le jade vert qui ne se troure que dans ses environs ou sur d'autres point de l'Ile-du-Milieu : il rapporte, dans son récit, « l'avoir trouvé en abondance dans les pays qu'il avait visités $>$.

On sait que c'est dans le Sud-Ouest de la montagne neigeuse appelée Tako, près du cap Campbell, sur l'Ile-du-

(1) Pour Whanga-paraua, " port du Cachalot ". Voir ii-dessus, p. 284 . 
Milieu qu'on s'accorde généralement à dire qu'existe le jade vert. Nous avons nous-même entendu le chef Tehinui et son esclave Kakiore, recueillis par l'Astrolabe dans le détroit de Cook, dire à M. d'Urville que le jade ne se trouvait que dans l'intérieur. Ils répétèrent même, à plusieurs reprises, qu'il n'y avait de Pounamu ou jade rert que sur Tawai (comme on crutentendre), mais qu'il n'y avait point de cochons dans cette île ; tandis qu'on trouvait, au contraire, des cochons sur l'Ile-Nord, mais point de Pounamu. D'autres indigènes disaient, et ils avaient probablement raison, que la contrée du jade était fort éloignée du détroit de Cook, et qu'on le trouvait dans un ou plusieurs lacs, mais toujours sur l'Ile-du-Milieu. On verra plus tard quels sont les lieux précis qui le produisent.

Ce que nous devons surtout remarquer ici, c'est que Ngahue, d'après le texte de la tradition, possédait ce jade vert en Hawahiki même, et avant de s'éloigner pour empêcherla sœur de Rata de le lui enlever. Si donc il en possédait un gros morceau, n'en faut-il pas conclure qu'il avait eu probablement déjà des rapports avec les lieux qui le produisent, ou même qu'il était parti d'un point plus ou moins éloigné de ces lieux de production, mais toujours sur la même île. C'est à cette conclusion que conduisent toutes les données des traditions; mais en attendant que nous en fournissions la preuve, il est certain qu'il était impossible à Ngahue d'apporter son jade d'ìles qui, comme les Samoa, n'en produisent point. On ne supposera pas qu'il ait pu faire un voyage antérieur pour se le procu. rer, et surtout qu'il ait pu se rendre, dans ce but, al point le plus extrême de l'Ile-du-Milieu, car la distance est véritablement trop grande entre ce point et les îles Samoa. Si Ngahue avait du jade en Hawahiki, c'est donc tout simplement, comme nous allons le montrer, parce qu'il habitait quelque point de l'île qui le fournit.

D'après la version de Sir Grey, Tuhua, Wairere et Whangaparaoa semblent bien être les lieux visités par Ngahue; mais il n'en est plus de même pour Tauranga. Il existe bien 
un lieu de ce nom sur la côte Est d'Aotearoa ; mais alor's, la légende ne l'eût pas indiqué comme le dernier lieu que visita Ngahue et d'oùil prit son point de départ directement pour Hawahiki ; elle l'aurait nommé avant Whangaparaoa, puisqu'il se trouve entre ce lieu et Wairere. D'un autre côté, on ne comprendrait pas comment Ngahue, qui se trouvait près du cap Est, à Whangaparaoa, aurait préféré le point le plus profond de la baie pour mettre à la voile et retourner en Hawahiki, tandis qu'il était parfaitement placé pour cela dans le premier port, quelle que fût la véritable situation de l'Hawahiki. Il est donc à peu près certain que la légende n'a pas voulu désigner ce Tauranga, mais bien probablement le Tauranga de la côte Ouest de l'Ile-du-Milieu, c'est-à-dire cette pointe de terre appelée cap Foolwind par Cook.

Il n'y a plus à en douter, en effet, quand on voit Sir Grey placer Arahura sur cette côte etquand on sait que cet Arahura est l'un des points sur l'Ile-du-Milieu qui fournit le jade vert en plus grande abondance er qu'il est voisin de Tauranga, d'où la légende fait partir Ngahue pour retourner directement en Hawahiki. Si l'Hawahiki n'est autre que l'Ile-du-Milieu, comme nous le croyons, il ne pouvait être difficile à $\mathrm{Ngahue}$ de revenir à son point de départ en parant de ce lieu, puisqu'il n'avait à suivre que les contours de la côte. Mais il est évident, par cela même, que son point de départ n'avait pas eu lieu de la côte Ouest de l'Ile-duMilieu, et qu'il s'était opéré plutôt de la côte Orientale. Il en résulte aussi qu'il doit y avoir une lacune considérable dans la légende, depuis Whangaparaoa, lacune qui sera comblée en partie, comme on verra, par la version du révérend Taylor.

T'oujours est-il que le Tauranga qui a induit Sir Grey en erreur, et qui se trouve placé un peu plus au Nord que Maketu, dans la baie d'Abondance, n'était pas le Tauranga de la légende, mais seulement celui de la côte Ouest de l'Iledu-Milieu. De même que l'Arahura de la tradition n'était et ne pouvait être que celui qui existe sur ia côte Ouesî de 
l'Ile-dn-Milieu, puisque c'est le seul lieu de ce nom qui fournisse du jade vert.

Aujourd'hui cette histoire de jade emporté d'Hawahiki, et dont la découverte semble être attribuée à Ngahue, puisque la légende le fait provenir du poisson dit de Ngahue, n'est plus qu'un mythe auquel on a rattaché quelques faits historiques et que l'on ne comprend pour ainsi dire plus. Telle qu'elle est néanmoins, elle fait parfaitement comprendre l'importance que les indigènes accordent à cette découverte siutile pour eux. Elle atteste également la rareté de cette pierre et ses qualités précieuses, quand elle dit que Ngahue n'en rapporta en Hawahiki qu'un morceau avec lequel fut fait la hache dont se servit Tama-te-Kapua pour couper la tête du grand-prêtre Uenuku.

En somme, le récit de la légende de Ngahue semble établir, à notre avis, qu'il est parti d'une terre placée plus au Sud-Ouest, pour aller d'abord à Tuhua dans la baie d'Abondance, sur la côte orientale d'Aotearoa. D'après ce récit, Ngahue, ayant atteint la côte de cette île vis-à-vis Tuhua, se serait dirigé d'abord au Nord, jusqu'à un lieu nommé Arahura ; mais comme tout démontre qu'il ne s'agit que de l'Arahura de l'Ile-du-Milieu, comme la légende signale ellemême le retour de Ngahue sur ses pas en suivant la côte et en allant vers le Sud-Ouest, il faut admettre, quoiqu'elle n'en dise rien, qu'il est arrivé au détroit de Cook, qu'il l'a traversé et, qu'après avoir doublé le cap Farewell et le cap Foolwind sur la côte Ouest de l'Lle-du-Milieu, il a borné sa course à Arahura, où il cacha une partie de son jade (1).

Sans doute un pareil royage est bien long ; mais il pouvait être fait sans perdre la terre de vue. En arrivant $\dot{a}$ l'entrée du détroit, il suffisait de prendre immédiatement le bord formé par l'lle-du-Milieu, et là, comme on sait, les bords du détroit sont fort rapprochés. A cette époque, d'ailleurs, les côtes d'Aotearoa, comme celles de l'lle-du-Milieu devaient être bien connues. Ourte Kupe et Turi, Triki et

(1) N'est-il pas curieux de voir que ce mythe lui fait cacher son jade justement dans le poirtsur la côte qui en produit le plus ? 
probablement bien d'autres, sans parler de Maui, avalent déjà fait leur voyage avant Ngahue, qui ne fit que précéder immédiatement la grande émigration.

Voici maintenant la version donnée par le Rév. Taylor (1): * Ngahue vint d'Hawahiki, à la suite d'une guerelle sarvenue entre le Mata (poisson) et le Pounamu, qui était originaire de cette île. Il aborda sur la cô!e Est, à Wangaparau ; il se rendit à Tauranga, et, de là, à Wairere et à Taupo. Alors, il traversa jusqu’à Kapiti, Arapawa et Arahura, près de Wakatipa. Quant il eûtatteint cet endroit, il se procura le Pounamu (pierre verte), dans un état brut, et là, ils'empara du Kaukaumatu et du Tukurangi; puis il retourna aux montagnes Arawa où se rencontraient les Moa, près de la Cascade. Il en tua un, et l'emporta dans un Taha (panier en écorce). De là il retourna à Hawahiki, où il dit aux chefs T'ama-te-Kapua, Ngatoro-i-Rangi et Hotu-Roa, qu'il venait. de la belle et grande contrée appelée Aotearoa. Ces chefs lui dirent: "Comment pourrions-nous nous y rendre? »- « En construisant des canots, »leur répliqua-t il. Les canots furent aussitôt commencés: le premier, l'A rawa; le deuxième, le Taïnui; le troisième, l'Aotearoa; le quatrième, le Takitumu; le cinquième le Kurahaupo; le sixième, le Tongamaru. Ils quittèrent l'Hawahiki tous à la fois. Alors qu'ils étaient occupés à placer l'Haumi ou l'arrière du canot, pièce séparée qu'on joint à l'extrémité, ils tuèrent par accident le fils de Manaia qui s'appelait Tute-Nana-Hau. C'est pourquoi les constructeurs se hâtèrent de terminer afin de pouvoir partiravant qu'on ne s'en apercût. Comme c'était un fils de chef, qui avait l'habitude d'aller visiter ses amis et de rester parfois plus de dix jours absent, ils saraient qu'on ne le chercherait pas de quelque temps. Ils se hâtèrent donc et s'éloignèrent d'Hawahiki, après avoir caché le jeune inomme sous les copeaux, près de l'endroit où ils avaient construit les canots.

"Une autre version dit que cet enfant ne fut pas tué par mégarde, mais bien intentionnellament par Hoturoa, parce

(1) Ouvr. cité, p. 120. 
qu'il s'étart moqué de son travail pendant qu'il construisait son canot, et que, pour le cache, il l'enterra lui même en recouvrant son corps arec les copeaux des canots (1). "

Nous allons maintenant examiner l'itinéraire que cette version fait suivre à Ngahue.

On voit d'abord qu'elle le fait arriver à Wangaparau, au lieu de Tuhua; mais comme Wangaparau n'est évidemment que le mot Whangaparaoa de la première version, ce point se trouverait également dans la baie d'Abonủance, c'est-àdire, commele dit la seconde version, sur la côte Wst de l'île Aotearoa. La différence est done à peu près nulle. De là, elle le fait aller à Tauranga qui semble être, cette fois, le Tauranga situé plus au Nord que Wangaparau dans la même baie d'Abondance; c'est une preuve que, dans ce moment du moins, Ngahue allait du Sud vers le Nord. De Tauranga, elle le fait passer à Wairere avant d’arriver à 'Taupo. Il est difficile de dire quel était le point réellement

\section{-}

(1) Cette tradition emploie, pour la première fois, le mot Mata au lieu du mot Putini de la version de sir Grey. Mata est le nom d'un poisson, de même que Pounamu, qui était le nom du poisson de Ngahue.

Pour la première fois aussi, Ngahue est rendu par $\mathbb{N}$ gahai. Or, hui, signifie tressaillir, ôter'; ngahue, en un seul mot, n'est pas maori; mais on trouve les mots ngauene, remuer, branler; ngawhi, souffrir; ngawe, aller, crier; ngawhewhe, déchiré, être usé, etc. Hue est le nom d'un poisson; nga est la particule pour former le pluriel des substantifs.

Le mot Aotearoa, donné à l'Ile-Nord de la Nouvelle-Zél nde par' Ngahue, suffirait à lui seul, quand il n'y aurait pas d'autres témoignages, pour prouver que son voyage n'a eu lieu qu'après celui de 'Turi. C'est, en effete ce dernier qui a ainsi désigné l'île, connue avant lui sous les noms de Nuku-roa, Uku-rangi, Tua-whenua, Tau-whenua et même, depuis Kupe, sous celui d'Aotea-toa.

Quant au mot Kaukau-matu, il est évidemment ici pour Kaukaumatua. Or Kaukau signifie oindre et lance; matu, graisse; matua, premier et père. D'après la version de sir Grey, le Kaukau-matu était un pendant d'oreille, un ornement.

Tuku-rangi, de tuku, tomber, descendre, et rangi, ciel, est le mot hahail-te-rangi de la version Grey, c'est-à-dire le nom de la hache faite par Ngahue ou par un autre avec le morceau de jade rapporté par lui en Hawahiki. 
appelé Wairere; mais ce qui est encore plus difficile à comprendre, c'est comment il a pu se rendre à Taupo, qui est un lac de l'intérieur. Le voisinage de ce lieu du point où il était arrivé expliquerait sans doute cette excursion dans l'intérieur; mais ce qui ne s'expliquerait pas sans admettre forcément que son canot a dû se rendre lui-même dans le détroit de Cook, c'est son arrivée à Kapiti, île de l'Entrée de Cook, après avoir passé à Taupo. On ne voit pas comment il aurait pu, sans son canot, franchir le bras de mer qui sépare Kapiti de la grande Terre; et ce qui ne permet pas de douter de la présence de ce canot, c'est l'itinéraire que trace la légende après son arrivée à Kapiti. De là, elle le fait traverser le détroit et aller à l'île Arapawa, qui avoisine l'Ile-du-Milieu, dans le canal de la reine Charlotte de Cook; puis, de cette île, à Arahura qui, dit la tradition, est près de Wakatupa.

De sorte qu'il aurait fait à pied, dans l'île Aotearoa, tout le chemin qui conduit de Taupo au détroit de Cook, où il aurait retrouvé son canot, pour continuer, en suivant la côte, jusqu'à Arahura sur la còte Ouest. Cet Arahura est bien certainement, dans cette version, celui de l'Ile-duMilieu, puisqu'elle fait remarquer qu'il se trouve près de Wakatupa.

Wakatupa, où Ng'ahue se procure du jade brut, n'est au . tre, en effet, que le fameux lac de l'Ile-du-Milieu si renommé par la production du jade vert. Ce lac gît dans le SudSud-Ouest d'Arahura, le Sud-Ouest de Waiora et l'Ouest de Moerangi, en un mot dans ce que les Anglais appellent aujourd'hui la province d'Otago (Otakou). Seulement il est, le plus souvent, écrit, avec plus de raison, Wakatupua. Mais c'est bien le même mot, et, à lui seul, il suffit, à notre avis, pour indiquer que la lég'ende a bien réellement voulu parler de l'Arahura qui l'avoisine. Il faut aussi remarquer que ces mots ara et hura signifient «chemin » et « découvrir, découverte: " ce qui semblerait indiquer qu'ils n'ont été donnés qu'après la découverte importante faite du jade vert en cet endroit. 
Ngahue, on l'a vu précédemment, possédait déjà du jade, car c'était pour empêcher Hine-tu-Hoanga de le lui enlever, qu'il s'était enfui d'Hawahiki. Arahura, où il alla cacher son jade ou en prendre d'autre, était également situé sur l'Hawahiki d'après la légende elle-même, qui dit que « le jade était originaire de cette île (l'Hawahiki) (1). s Il faut donc en conclure : D'abord, que Ngahue était d'un autre point de l'Hawahiki, point certainement éloigné et probablement opposé ; ensuite, comme nous avons déjà eu tant de fois l'occasion de le dire, que cet Hawahiki n'était qu'une partie de l'Ile-du-Milieu, sinon toute l'île de ce nom. Car, nous ne saurions trop le répéter, ce n'est que. dans cette île du groupe de la Nouvelle-Zélande que se trouvent la plupart des lieux que les traditions placent en Hawahiki, et, plus particulièrement, Arahura, Wakatipua (2) et autres localités produisant du jade vert.

Il faut convenir, d'ailleurs, que si cette version ne permet pas de douter qu'il s'agit de l'Arehura de la côte Ouest de l'Ile-du-Milieu, elle présente une particularité bien difficile à résoudre, quand elle dit qu'en partant de là, Ngahue retourna aux montagnes Arawa, où se rencontraient les Moa, près de la Cascade, et qu'il partit de ce point pour retourner en Hawahiki. La légende semble dire qu'il retourna à l'Ile-Nord, non loin sans doute de son point d'arrivée, c'està-dire Wangaparau ou mieux Whangaparaua, avant de se mettre en route pour Hawahiki. Nous n'avons pas vu sur les cartes qu'il existât des montagnes de ce nom dans cette partie de l'Ile-Nord; et si elles y existent, elles semblent n'avoir pu porter ce nom lors du voyage de Ngahue, puisque l'Arawa ne s'y est rendu que postérieurement à ce voyage. Il a donc dû là, comme dans tant d'autres occasions, y avoir confusion de la part du narrateur, qui, de même que presque tous, sinon tous ceux qui ont fourni les

(1) Taylor, loc. cit. p. 120.

(2) Notons en passant que Wakatipua doit probablement être écrit Whaka-Tipua : waka signifie pirogue, canot; whaka, faire ; tipua est le nom d'une divinité. 
traditions, était de l'Ile.Nord elle-même. C'est même ce qui aide si bien à entretenir l'erreur dans laquelle on est depuis si longtemps sur le véritable point d'origine des habitants de la Nouvelle-Zélande.

A cette version, nous préférerions naturellement la première, qui fait partir Ngahue de Tauranga pour retourner en Hawahiki, si ce Tauranga était bien celui qui a été nommé cap Foolwind par Cook ; mais, il faut en convenir, de là même jusqu'au point qu'habitait Ngahue dans l'Hawahiki, il y aurait une lacune impossible à combler, car it n'aurait pu s'y rendre sans faire quelques relàches que la légende ne désigne pas.

Quoiqu'il en soit, les deux versions réunies ëtablissent que Ngahue a commencé par arriver dans la baie d'Abondance, sur la côte Est d'Aoteaoa qui ne produit pas de jade, et qu'il venait d'une contrée qui en produit, puisqu'il allait cacher le morceau qu'il possédait avant de s'éloigrner d'Hawahiki; ce n'est qu'en retournant sur ses pas, d'après la première version, qu'il se rend, comme le dit également la seconde, à Arehura sur la cạte Ouest de l'Ile-du-Milieu.

Quelle que soit donc la version adoptée, il en résulte évidemment que $\mathrm{Ngahue}$ avait dû passer deux fois dans le détroit de Cook, en allant et en revenant.

- Au surplus, si ce poème pouvait, par son obscurité, laisser quelque doute, nous pensons que les traditions suivantes ne permettront pas d'en conserver.

Voyage a la Nouvelle-Zélande. - Le récit légrendaire intitulé « Voyage à la Nouvelle-Zélande » etrapporté par Sir Grey, indique d'abord qu'on alla abattre l'arbre destiné à construire l'Arawa sur une île appelée Rarotonga, située " de l'autre côté d'Hawahiki. "

T'ous les écrivains modernes ont cru reconnaître cette île dans celle qui fait partie du groupe des îles Manaia ou Hervey ; mais nous avons démontré ailleurs (1) qu'il ne pou*

(1) Voir particulièrement notre traduction des légendes de Sir Grey, et ci-dessus, p. 302 et suiv. 
vait s'agir de cette dernière île, quel que puisse être le lieu d'origine première des Polynésiens. D'abord, la distance est beaucoup trop grande; puis tonga, on Maori, signifie Sud, et raro, sous, dessous, comme si l'on disait « sous le vent du Sud, »'est-à-dire en se rapprochant de l'Ouest. D'ailleurs, l'île Rarotonga du groupe des îles Hervey ne produit pas de Totara (1), arbre qui a servi à construire l'A rawa. Ici, il ne s'agit, tout simplement, que d'une île du même nom, placée justement sous le vent du Sud, par rapport à certain point de l'Hawahiki, c'est-à-dire dans le Sud-Ouest ou l'Ouest-Sud-Ouest de l'Ile-du-Milieu, et, pour mieux préciser, dans le détroit de Foveaux, vis-à-vis l'île Stewart ou Rakiura.

Nous croyons devoir indiquer dès à présent un fait bien curieux: C'est près de cette île ou à une faible distance sur la même côte, qu'on trouve, en allant de ce point vers lo Nord-Est, tous les principaux lieux que les traditions signalent comme faisant partie de l'Hawahiki. Tels sont Aparima, O-Maui, Awa-Rua, Tautuku, Waiota, Moeraki, O-Amaru, Horo-Whenua, Waiora, Wairewa, etc.

Nous ne pouvons entrer ici dans des développements que nous avons déjà donnés ailleurs. Nous nous bornerons seulement à dire que, d'après cette tradition, six ou sept canots au moins partirent à la fois d'Hawahiki pour se rendre à Aotearoa. Il y en avait même probablement un plus grand nombre, à en juger par la liste de tous les canots cités par les légrenđes, liste que nous essaierons d'établir à la fin de ce chapitre.

Mais comme la tradition n'entre dans quelques détails que sur le voyage de trois d'entre eux, l'Arawa, le Tainui et le Tokomaru, c'est nécessairement aux itinéraires de ces trois

(1) Le Totara est le Podocarpus asplenifolius de Labillardière. C'est du moins ce que croyait Richard, d'après un mauvais échantillon rapporté par d'Urville, de la baie des Iles. Hooker l'a appelé Podocarpus Totara et Polack Taxus australis.

The remarque à faire à propos de cet arbre, c'est que les canots sont construits avec le Kauri, dans le Nord et avec le Totara dans le sud de l'fle-Nord de la Nouvelle-Zélande. 
seuls canots que nous demanderons des témoignages, renroyant à notre traduction du livre de Sir Grey, pour les détails sur lesquels nous ne pouvons revenir.

Le premier de ces canots était commandé par Tama-teKapua, l'un des fils d'Hou, et le même qui tua Uenuku avant d'émigrer; le second par Hotu-Roa, le père de Hatu-Patu, qui vengea l'incendie de l'A rawa en tuant Raumati; et le troisième par Manaia, suivant une tradition, ou par Rakiora, suivant une autre (1).

ItinḱRAIRE DEL'ARAWA, - Tous les canots, après avoir quitté l'Hawahiki à la fois ou séparément (car des légendes font partir l'A rawa (2) le premier, tandis que d'autres disent qu'il n'est parti qu'avec les autres), arrivèrent au mème point sur l'île Aotearoa, ¿̀ Whangaparoa ou Whangaparau, d'après les traducteurs: ce lieu est le Whangaparaua qui se trouve au Nord du Cap Est dans la baie d'Abondance, de Cook.

Le Tokomaru y aborda le premier; puis vint le Taïnui qui s’empara des établissements déjà faits par les gens de ce canot, enfin, l'Arawa, qui essaya vainement de déposséder ces derniers, plus capables par le droit et le nombre de résister (3).

Le premier point de relâche signalé par cette version, de.

(1) D’après une tradition, le Tokomaru àppartenait au beau-frère de Manaia. Serait-ce Rakiora par sa sœur, puisque Manaia était aussi beau-frère de Uenuku par sa femrne? La première tradition de l'émigration de Manaia dit que Rakeiora était le nom du dieu de Manaia.

(2) Taylor, p. 121, le fait partir le premier. Cependant, à la page 120, il le fait construire et purtir d'Hawahiki avec les autres canots. Shortland, (p. 3) fait partir l'Arawa avec lo Kuraaupo et le Mataaiua. Le même écrivain, (p. 120) nomme les canots Arawa. Tainui, Aotearoa, Takimumu, Kuraaupo, Tongamaru. Il fait, du reste, remarquer avec raison (p. 125) que, tous les indigènes s'ac* cordant sur les faits princip ıux, ces divergences mêmes sont la preuve que les traditions sont exactes.

(3) Voir sir Grey, p. 143. 
puis le départ d'Hawahiki, était donc le Whangaparaua qui se trouve àl'entrée de la baie d'Abondance, en venant du Sud-Ouest, après avoir doublé le cap Est ou Waiapu (1) : car la fin de l'itinéraire ne permet pas d'admettre que c'était le Whangaparaoa du golfe Hauraki, comme l'ont cru Shortland et Thompson (2).

De là, en effet, la légende dit que l'Arawa se rendit à Tauranga ou Te Ranga, port situé dans la baie d'Abondance, plus au Nord que Whangaparaua : il dépassa ainsi Makutu sans s'y arrêter. Dans le trajet, l'Arawa, longea la côte, pendant qu'un détachement d'hommes suivait les contours, par terre. Le canot aperçut en route la petite île Motiti, qui est presque vis-à-vis Makutu; il revint sur ses pas bientôt après, pour aller d'abord à cette île, qui devait devenir la demeure favorite de Ngatoro-i-Rangi, puis à Makutu mème, sur la grande terre. Ce fut dans ce dernier lieu que se fixa pourquelque temps Tama-te-Kapua, après son combat singulier avec Ruaeo, qui y était arrivé pour se venger de ce que Tama-te-Kapua arait enlevé sa femme. Ruaeo n'ayant jamais fait de voyage antérieur, ce fait semble faire croire qu'il suffisait de suivre les contours des terres.

Il résulte, en somme, de ces détails, que le canot, avant de revenir un peu sur ses pas, était allé du Sud vers le Nord, et on va le voir se diriger encore plus vers le Nord. Ainsi, la légende dit qu'après être resté quelque temps à Maketu, Tama-te-Kapua et Ngatoro-i-Rangi se transportèrent à Tauranga, où nous avons vu qu'ils étaient allés déjà et qui se trouvait plus au Nord que Maketu. De là ilss se rendirent à Katikati, point encore plus au Nord; et, en allant de place en. place, torijours vers le Nord, ils finirent par arriver à Moehau où ils se fixèrent. Ce point n'est autre que la baie Cabbage actuelle des Angluis. Elle se trouve

(1) Fait intéressant à noter, d'après Shortland ( $\mu$. 23) et TayJor (p. 194), e'est à Waiapu même que seraient arrivés tous les canots venant d'Hawahiki, ainsi que cela résulte du récit de Hahakai.

(2) Voy. ci-dessus p. 284, où nous avons cherché à le démontrer. . 
dans le golfe Hauraki presque à toucher le cap Colleville ou Moehau des indigènes. En route, ils s'étaient arrêtés un instant à la grande île Mercure ou Whakahau, qui précède Aotea ou l'île de la Grande-Barrière, quand on avance du Sud vers le Nord. Ce ne fut qu'après la mort de Tama-teKapua dans Moehau, que les enfants de ce chef retournèrent avec Ngatoro s'établir à Makutu et à Motiti.

Ainsi, comme on le voit, on était allé, depuis Whangaparaua, toujours du Sud vers le Nord ; or, puisqu'on s'était arrêté a Moehau, il est évident que ce lieu n'était pas le Whangaparoa que Thompson et Shortland regardent comme celui où les émigrants sont arrivés. Ce dernier, en effet, est encore plus Nord, quoique également dans le golfe Hauraki.

La version du Rév. Taylor, bien que plus incomplète, ne rapporte pas les faits différemment. C'est aussi à Whangaparaua qu'elle fait arriver le canot. Seulement, en allant de là vers le Nord, elle le fait s'arrêter à Maketu, mais sans parler de son excursion jusqu'à Moehau. (1)

(1) Nous croyons intéressant de transcrire intégralement en note la version relatée par Taylor, p. :21:

"L'Arawa partit le premier. Le chef de ce canot, Tama-teKapua, appela Ngatoro-i-Rangi, pour qu'il vînt faire tupeke, c est-à-dire lever le tapu sur leur nourriturc, en la rendant noa (libre) pour eux; iis n'auraient pu manger pendant le voyage si le principal chef n'eût levé le tapu. Ils parvinrent à attirer à leur bord Ngatoro et sa femme Keharoa, et par suite, ils allèrent avec eux à Aotearoa. Ngatoro-i-Rangi était trop sacré pour pouvoir se tehir dans l'intérieur du canot; aussi se tint-il en haut, les canots ayant des maisons de bois construites sur le pont et recouvertes en raupo.

a lls atterrirent à Whangaparau, et ils allèrent ensuite à Wakatane (comme on le voit, du Sud vers le Nord) et à Maketu. Là, ils laissèrent l'A rawa qui y est toujour's resté depuis, changé en pierre.

"Le Tainui alla à Kawhia: son chef était Hotu-roa.

a L'Aotearoa resta quelque temps à Hauraki, et de là, en compagnie du Tainui et du Tongamaru, il se rendit à Otakuhu où les canots furent hâléş par dessus l'isthme. L'Aotearoa resta à Aotea; e Tainui à Kawhia; et le Tongamaru à Ngate-awa.»

D’après Dieffenbach, Ngatoro-i-Rangi était un Nga-Puhi, et il ajoute qu'en arrivant à Aotearoa, les Nga-Puhi s'arrêtèrent à la 
M. F. de Hochstetter (1) a recueilli de la bouche même du vieux chef Te Heuheu une tradition rapportée dans le Tour du Monde (n²80, p. 298.) Voici ce qui lui a été dit, à l'aide d'un interprète sans doute:

«Parmi les premiers hommes venus d'Hawaïki (2), à la Nouvelle-Zélande, l'un des plus renommés est le chef Ngatiroirangi (3), littéralement « le messager du Ciel ». Il débarque, dit la légende, sur la côte Orientale de l'île du Nord. De là, il se met en route avec son esclave Ngauruhoe, pour visiter le nouveau pays. Il traverse la contrée, fait jaillir de terre des sources d'eau dans les vallées stériles, gravit collines et montagnes et apercoit au Sud un grand mont, le Tongariro. Il veut s'y rendre pour contempler de ces hauteurs, le pays tout entier. Il arrive dans les plaines voisines du lac Taupo: los buișsons lui déchirent un excellent vêtement fait de feuilles de Kielcie; les lambeaux frappent les

baie des Iles : les Rarewa à Oruru, baie Lauriston; les NgatiøWakaua et les Ngatiro-i-Rangi, à Maketu, dans la baie d'Abondance, d'où les premiers partirent pour aller se fixer à Roto-Rua et les derniers dans l'intérieur, près du lac Taupo.

Ngatoro, comme on a vu, faisait partie de l'équipage du Tainui. Ce ne fut qu'au moment du départ que Tama-te-Kapua, de l'A rawa, l'attira à son bord par ruse et l'emmena avec lui. Or, le Tainui avait son équipage composé de Ngati-Rakawa, de Ngati-Puhi, de Ngati-Awa et de Waikato. Il n'y avait sur l'Arava que des NgatiWakaue ou Wakawa et des Ngati-Porou. Ce dernier canot ne dépassa mème pas Mokau, tandis que le Tainui, avant de revenir au golfe Hauraki, était allé jusqu'au cap Nord ou Reinga. On ne dit rien de plus des Rarewa ou Rarawa; seulement Shortland apprend qu'à l'époque de l'émigration, ils étaient appelés Aewa, probablement du chef Ruaewa.

(1) M.Hochstetter était l'un des savants embarqués sur la frégate autrichienne la Novara, qui relâcha à la Nouvelle-Zélande vers la fin de l'année 1858. Ayant recu une mission du gouvernement Colonial, il visita piusieurs points de l'Ile-Nord et un seul de l'tleSud, le port Nelson, dans le détroit de Cook, pendant les neuf mois qu'il passa dans cette contrée.

(2) 11 dit en note: "L'île de Sawai dans les Samoa.»

(3) Nom qui est évidemment celui de Ngatoro-i-Rangi des légendes traduites par Sir Grey. 
racines qui se transforment en jolis acacias à fleurs jaunes assez abondants dans les environs du lac Taupo.

"Le chef monte ensuite surle Tongariro couvert de neige; mais il y fait si froid que le maître et l'esclave sont en danger de mourir. Ngatiroirangi appelle alors ses sœurs, qui sont restées sur l'île Whakaari, afin qu'elles lui envoient du feu, du feu sacré inextinguible, qu'elles avaient apporté d'Hawaiki; elles lui en envoientpar l'entremise de deux Taniwhas (esprits souterrains de la montagne et des eaux). Le feu arrive juste à temps pour sauver le chef, mais quand il veutengager son esclave à se réchauffer aussi le pauvre Ngauruhoe est déjà mort. Jusqu'aujourd'hui, l'issue souterraine que le feu s'est frayé dans la montagne, c'est-à-dire le plus puissant cratère du Tongariro, a porté le nom de l'esclave, Ngauruhoe; mais comme c'était le feu sacré d'Hawaiki, il continue toujours à brûler, eł il brûle sur tout l'espace compris entre le Whakari etle Tongariro, aux endroits où il a jailli quand les Taniwhas sont sortis de terre. De lá aussi l'origine des sources chaudes innombrables de cette contrée. (1)»

ITINÉRAIRE DU TAÏNUI. - Quand on examine la marche du Taïnui, la démonstration de la direction suivie du Sud

(1) Nous ferons remarquer que le mot Tongariro doit être écrit Tunga-riro: Tunga, halte, station, lieu frappé; riro aller, venir. Ce ne peut-être tonga signifiant vent de Sud.

Ngatiroirangi ne peut être que Ngatoro-i-Rangi: Ngati n'est pas Maori, ni ngatero non plus; c'est nga, les; toro, regardeurs; $i$-rangi, du ciel, au ciel, et pour ainsi dire les astronomes. La légende traduite par Sir Grey ne permet pas d'ailleurs d'en douter.

Quant au nom de l'esclave Ngauruhoe, ce ne peut gruère être que ngau, mordre, rong'er, piller, voler ; ru, tremblement de terre ; hoe, pagaie, pagayer. Car si l'on admettait nga, art. pluriel, il faudrait lire uru, cheveu, s'associer à un parti, extrémité supérieure d'une plantation, et hoe, pagaie.

Kiekie est le nom d'une plante rampante (Freycinetia Banksii.)

Taniwha, est le nom d'un dieu on d'une déesse de la mer.

Whakari, enfin, doit être écrit whakaari, élever pour être vu, et te heuheu, doit être traduit par broussailles, être dispersé, débarrasser. 
vers le Nord devient complète ; car, en partant de Whangaparaua, où nous l'avons vu arriver, le canot se rend, en suivant la côte, et, comme dit la légende, «presque la même direction que l'Arawa, » jusqu'auprès du cap Nord. Il est vrai que la légende n'indique, dans ce trajet, que les points principaux des relâches, tels que Hauraki, CapBrett ou Rakau-Mangamanga, et la terre voisine du cap Nord, Muri-Whenua; mais cela est certainement suffisant; et quand le Taïnui revient sur ses pas après avoir trouvé que la terre finit au Cap-Nord, on le voit passer dans divers lieux qui sont parfaitement indiqués par les cartes, avant d'arriver au fond du golfe Hauraki et d'atteindre la mer de l'Ouest, en passant avec quelques autres canots à Otahuhu, par-dessus l'isthme qui sépare les deux mers.

Il est donc démontré, par ces deux itinéraires, que les canots.avaient suivi la côte orientale d'Áotearoa en allant du Sud vers le Nord, à partir de Whangaparaua. Si cela ne dit pas quelle avait pu être la route faite depuis Hawahiki jusqu'à Whangaparaua, il faut bien convenir que cela aide du moins beaucoup à faire soupçonner qu'elle avait dû être la même, c'est-à-dire que, comme dans la légrende de Turi, on était parti d'un point plus Onest que l'île Aotearoa. Le nom seul de Muri-Whenua donné à la terre qui avoisine le cap Nord, ne permettrait pas d'en douter, car il signifie « la dernière terre, la terre de derrière : $\gg$ Ce nom ne pouvait être donné que par des gens venant d'une direction opposée au Nord. On comprend, en effet, que si les canots fussent venus des Samoa, comme on le croit généralement, cette terre, au lieu d'être la dernière, eût été pour eux la première.

Disons en passant que c'est dans cette tradition qu'on voit le troisième fait d'une population primitive trouvée par les émigrants sur Aotearoa. En chassant les Kiwi, le chien de l'un des chefs de l'Arawa, nommé Ihenga, découvre les lacs Roto-Rua et Roto-Iti; et, sur les bords du premier de ces lacs, ce chef rencontre un peuple qui, non seulement avait tous les caractères physiques des émigrants, mais qui, 
de plus, parlait absolument la même langue et avait le même visage, la même croyance qu'eux.

Mais c'est surtout la dernière des légendes qui, par son itinéraire, aide à déterminer la véritable position de l'Hawahiki : Elle est intitulée « Emigration de Manaia. »

ITINERAIRE DU ToKomaru. - Manaia, avons-nous dit, commandait le Tokomaru, d'après la version de Sir Grey, tandis que c'était Rakiora d'après celle de Taylor.

Sans nous arrèter ici à examiner si les légendes ne parlent pas d'un même voyage, ce que nous croyons, bien qu'elles donnent deux versions un peu différentes, nous dirons seulement que celle intitulée « Emigration de Manaia » le fait partir d'Hawahiki et arriver le premier sur Aotearoa dans le port de Whangaparaua(1); mais il est forcé presque aussitôt de l'abandonner aux gens du Taïnui. (2)

Ainsi depuis Hawahiki, Manaia ( ou Rakiora) avait exactement fait la mème route que l'Arawa et le Taïnui, quoiqu'il soit arrivé avant eux.

D'après une version, en quittant Whangaparaua, il suit les côtes de l'ìle à petite distance et double le cap Nord en allant, lui aussi, du Sud vers le Nord. Le cap Nord doublé, il se rend "directement " à Taranaki, en suivant la côte Ouest, en sens inverse de celui suivi sur ]a côte Est ; le premier point qu'il atteint est Tongaporotu, sur cette côte Ouest d'Aotearoa; puis, après quelques allées et venues, il se fixe à Routu, à l'embouchure de la rivière Waïtara.

Il résulte de cette version que Manaia commence, sur la côte Est, par aller du Sud vers le Nord, depuis Whangaparaua jusqu'au Cap-Nord; et qu'il se dirige, au contraire, du Nord vers le Sud, le long de la côte Ouest d'Aotearoa jusqu'à Waïtara; c'est-à-dire qu'il contourne cetteîle dans la moitié à peu près de son étendue.

(1) Whanga, sur un côté, être en attente, attendre ; Paraua, cachalot. Ce nom n'est même donné que parce que le chien que Manaia prit à son beau-frère après l'avoir tué, lui fait découvrir sur le rivage un cachalot mort.

(2) Voir Sir Grey, p. 232 ; Shortland p. 26. 
D'après l'autre version (1), après être arrivé au cap Nord, le Tokomaru revient sur ses pas jusqu'au fond du golfe Hauraki: C'est le premier canot transporté par dessus l'isthme dans la rivière Manukau, qui communique avec la mer de l'Ouest; puis, de ce point, il se rend à Waïtara, comme dans la première version.

En somme, d'abord, même route que les canots précédents sur la côte Est, du Sud vers le Nord; et sur la côte opposée, seulement, route inverse, au moins depuis Manukau, si l'on préfère la version de la légende du Taïnui à celle de la légende de l'émigration de Manaia. Mais comme on voit, les deux versions s'accordent sur le seul faic important pour la question qui nous occupe, la marche du Sud vers le Nord, après être arrivé à Aotearoa.

S'ils étaient venus des îles Samoa ou d'un autre point de la Polynésie, on ne comprendrait pas que les émigrants, une fois arrivés à Whangaparaua, près du Cap-Est, eussent - préféré revenir pour ainsi dire sur leurs pas en prenant la route qui les rapprochait du Nord, et il leur eût été certainement plus naturel de continuer dans le sens du chemin déja fait par eux. Si donc tous les canots avaient fait route du Sud vers le Nord, c'est tout simplement, comme nous l'avons déjà dit, et comme le prouvent la recommandation de Turi, l'arrivée de tous les canots au cap Est, et vingt autres témoignagges que nous avons signalés ou que nous signalerons, sans parler dunom de Muri-Whenua donné aux terres voisines du cap Nord, c'est que tous les canots venaient, en suivant pour aussi dire les contours des côtes, d'une terre placée encore plus au Sud (2) que l'île Aotearoa.

Avant d'aborder cette démonstration, nous ferons remarquer que c'est dans la légrende de l'Emigration de Manaia

(1) Voir Sir Grey, p. 145.

(2) Si nous nous servons le plus souvent des mots Nord et Sud, c'est qu'ils suffisent au lecteur non marin pour lui indiquer la direction généralement suivie; mais pour être exact, ce sont les mots Sud-cuest et Nord--Est qu'il faut lire. 
qu'on voit lequatrième fait d'une population primitive trouvée par les émigrants sur Aotearoa dans un lieu appelé Routu. Cette population parlait égralement le même langage que les émigrants d'Hawahiki, comme le démontre le changement que Manaia fait subir au nom de la rivière Onaheru qu'il remplace par celui de Tu-ure-nui. (1). La légencie dit textuellement que Manaia ne trouva rien de mieux pour rester maître du pays que d'exterminer cette population.

Nous ajouterons que l'on retrouve plus tard Manaia en Hawahiki. Il faut donc supposer, quoique les légendes ne le disent pas, qu'il y était revenu. Il avait sans doute pu le faire d'autant plus facilement, lui aussi, qu'il s'en trouvait assez peu éloig'né à Waïtara. De là, en effet, si l'Hawahiki était bien où nous le plaçons, il n'avait eu pour ainsi dire qu'à traverser le détroit de Cook, au point, il est vrai, où son embouchure est la plus large, mais où néanmoins elle n'a pas plus d'une trentaine de lieues marines.

On doit nécessairement admettre ce retour malgré le silence des légendes et l'opinion contraire de M. de Quatrefages (2) parce qu'on voit Manaia partir plus tard d'Hawahiki et périr devant Motiti en voulant se venger de son beaufrère Ngatora-i-Rangi.

Tels sont, en résumé, les témoignagres que, malgré leur longueur, nous avons, cru indispensible d'invoquer pour appuyer notre opinion.

Ce qu'ils établissent formellement c'est done, comme nous l'avons d'abord annoncé, que:

$1^{\circ} L^{\prime}$ Hawahiki est bien le pays des ancêtres;

$2^{\circ}$ L'île Aotearoa est la seule île de la Nouvelle-Zélande qui a reçu les émigrants venant d'Hawahiki, et les traditions l'isolent complétement des autres îles du groupe;

(1) Ona, son, sa, ses; heru, peigne, peigner; $i u$, facon de, être frappé, touché, servi; ure, membre viril; nui, grand.

(2) Les Polynésiens, etc., p. 131. 
$3^{\circ}$ Pour arriver d'Hawahiki à Aotearoa il fallait faire route du côté où le soleil se lève, c'est-à-dire vers l'Est

$4^{\circ}$ En conséquence l'Hawahiki était placé plus à l'Ouest que l'île Aotearoa qui est, comme on a vu, l'Ile-Nord de la Nouvelle-Zélande ;

$5^{\circ} \mathrm{La}$ distance entre les deux contrées n'était pas grande puisqu'on y allait et qu'on en revenait si facilement, même à la pagaie seulement;

$6^{\circ}$ De même que le détroit de Cook semble avoir été le point d'arrivée d'une foule de canots (1), c'est aussi le point qui était généralement choisi pour retourner en Hawahiki;

$7^{\circ}$ C'est pour ainsi dire à la même époque ou dans un intervalle fort restreint, pour le même motif et par des émigrants de la même génération, que les émigrations dont parlent les légendes ont été faites ;

$8^{\circ}$ Enfin, comme nous le montrerons, l'île sur laquelle ont abordé les émigrants n'était pas aussi déserte que l'ont dit quelques écrivains.

Il est bien vrai qu'en indiquant l'Hawahiki comme le point de départ des émigrants, les tradition s’abstiennent de désigner nettement sa situation; mais, comme elles indiquent formellement que pour arriver à Aotearoa, en partant d'Hawahiki, il fallait faire route «vers le côté où le soleil se lève, » il est dès lors évident que l'Hawahiki était situé encore plus à l'Occident que l'île Aotearoa.

Non seulement cette conclusion résulte de la recommandation faite à Turi par Kupe, des itinéraires de ces deux chefs et de tous ceux que nous avons analysés, mais elle découle encore de toutes les données des lég'endes, ainsi que nous allons le montrer.

Il est certain, en effet, qu'excepté peut-être le voyage de Ngahue, tous les autres établissent nettement qu'on est allé du Sud-Ouest, vers le Nord-Est, sur la côte orientale d'Aotearoa, au lieu davancer du Nord-Est vers le Sud-Ouest, ainsi qu'il eût fallu le faire si l'on fût

(1) Tels furent ceux de Kupe, Turi, Hou, Uenuku, peut-être de Ngahue, le Ringaringa et autres. 
venu des îles Samoa ou seulement des îles Manaia, comme quelques écrivains le soutiennent aujourd'hui. Si donc, comme le disent les partisans d'Horatio Hale, il est établi avec certitude par les traditions que les ancêtres des Maori de l'Ile-Nord sont venus d'une autre contrée pour s'y fixer, il n'est pas moins certain, ainsi que le montrent toutes les traditions précédentes, qu'ils sont arrivés d'Hawahiki à Aotearoa en suivant une route contraire à celle qu'ils auraient eu à faire s'ils fussent partis des îles Samoa. C'est-à-dire, les traditions le prouvent implicitement, que l'Hawahiki était situé plus à l'Ouest que l'île Aotearoa, laquelle, il ne faut jamais l'oublier, est uniquement l'Ile-Nord de la Nouvelle-Zélande.

Or on le sait, il n'y a qu'une seule terre plus à l'Ouest. qu'Aotearoa: c'est l'île appelée Tovaï ou Tavaï-Poenamu par Cook et d'Urville et Ile-du-Milieu, par les cartes anglaises. D'où il faut nécessairement conclure que c'était sur cette terre que se trouvait l'Hawahiki.

Pour nous, après tout ce que nous avons déjà dit, il n'y a nul doute; c'est là qu'existait l'Hawahiki. Mais pour entrainer plus sûrementla conviction dans l'esprit du lecteur, nous allons maintenant fournir des témoignages qui lui démontreront la vérité de cette assertion, ou qui, tout au moins, le mettront à mème d'établir exactement une autre opinion.

C'est encore aux traditions, mais surtout aux cartes géographiques, que nous demanderons ces témoignages. Nous allons donc étudier ces cartes et examiner les dénominations indigènes qu'elles signalentelles-mêmes commeétant çlles des diverses localités des deux îles principales de la Nouvelle.Zélande.

Cet examen est des plus importants et le plus favorable à l'opinion que nous voulons faire accepter. Evidemment, ces cartes ont été dressées par leur's auteurs sans la moindre préoccupation ethnologique; et si les résultats qu'elles donnent s'accordent avec notre opinion, c'est que cette opinion est celle qu'il faut préférer.Or, le fait qu'elles fournissent, et qui jusque-là n'avait pas été remarqué, c'est qu'une seule III.

26. 
des deux grandes îles, l'Ile-du-Milieu, présente, réunis et attribués à ses localités, presque tous les noms que les traditions attribuent aux localités de l'Hawahiki; tandis que l'autre, l'Ile-Nord, en offre à peine quelques-uns : c'est, à notre avis, un fait capital et bien dig'ne d'être remarqué : On ne peut guère l'expliquer qu'en admettant que l'Hawahiki se trouvaitsur l'Ile-du-Milieu, si celle-ci n'était pas l'Hawahiki lui-même.

Sì en effet l'Ile-du-Milieu eût été peuplée par l'Ile-Nord, comme on le dit généralement, c'est sur cette dernière plutôt que sur la première qu'on en̂t dû trouver en plus grand nombre les noms de l'Hawahiki. Les émigrants, en arrivant la avec les souvenirs tous frais du pays d'origine, auraient naturellement dû donner les noms de la patrie plutôt aux localités de cette île qu'à celles d'une île peuplée plus tard par eux. Or, nous venons de le dire, c'est toutle contraire qui a eu lieu, puisque ces mots, si nombreux surl'Ile-du-Milieu, manquent à peu près complétement sur l'Ile-Nord. L'erreur dans laquelle on est resté jusqu'à présent à ce sujet, vient tout simplement de ce qu'on a toujours cru que les émigrants avaient fait une route inverse à celle qu'ils ont véritablement parcourue : en un mot, qu'ils venaient de la Polynésie. Du moment qu'on les faisait partir des îles polyné. siennes et aborder d'abord, comme le disent toutes les tradidions, à l'lle-Nord de la Nouvelle-Zélande ou Aotearoa, il était presque indispensable de supposer que l'île la plus éloigrnée avait été peuplée la dernière; d'autant mieux que des chefs, comme Tuai, de la baie des Iles, soutenaient cette opinion, par amour-propre il est vrai, et que la plupart des tra ditions maori étaient encore inconnues. Néanmoins c'était une erreur. Nous croyons l'avoir déjà démontré, mais nous le prouverons bientôt encore quand nous aurons fait connaître les importants témoignages si propres à déterminer la véritable situation de l'Hawahiki.

Si les hommes les plus compétents, tels que Dieffenbach, Shortland, Taylor et Thompson,partagent, depuis d'Urville, une opinion contraire, c'est parce qu'eux-mêmes ne se sont pas rendu compte de la marche suivie par les émigrants. 
lls n'ont pas remarqué que beaucoup de faits, qu'ils avaient été les premiers à citer, établissaient à peu près le contraire de l'opinion tout faite qu'ils avaient adoptée. L'examen critique de leurs données nous permettra même, nous l'espérons, d'en déduire quelques remarques farorables à l'opinion contraire à la leur.

En somme, dès à présent, grâce au fait que nous allons démontrer, et malgré la croyance contraire g’énéralement admise, nous croyons pouvoir avancer que c'est l'Ile-duMilieu qui a nécessairement dû peupler l'Ile-Nord, au lieu d’avoir été peuplée par elle. Après avoir reconnu que les émigrants ont fait une route inverse à celle qui a été tracée jusque-là, on reconnaîtra également, nous n'en doutons pas, qu'au lieu de se trouver dans les Samoa, l'Hawahiki était situé sur l'Ile-du-Milieu. 


\title{
- CHAPITRE DEUXIÈME
}

\author{
ILE-DU-MILIEU
}

Témoignages fournis par l'étude des cartes géographiques. - Examen des localités situées sur les deux îles principales : Ces localités se retrouvent toutes dans les chants historiques des émigrants. - Autres preuves : Phormium tenax ; Phoques ; Neige ; Piopio ; Kumara; Hekengamai; Jade vert. - L'Hawahiki ne pouvait être situé en Polynésie : Preuves à l'appui. - Situation de l'Hawahiki sur l'lle-du.Milieu. Point de départ de Turi. - Tribus existant dans l'Hawabiki. - Signification du mot Hawahiki.- Kawaii.

Examen des cartes géographiques. - Si l'on jette d'abord ses yeux sur la carte de l'Ile-Norḍ de la Nouvelle-Zélande, on voit que les noms cités par les traditions de l'Arawa, du Taïnui et des autres canots dontnous avons rapporté les itinéraires, se présentent dans un ordre tel, qu'il est impossible de méconnaître la route faite par ces canots.

Ainsi, en allant du Sud vers le Nord, sur la côte Est d'Aotearoa, mais surtout à partir du cap Est ouWaïapu, se présentent successivement les lieux appelés Whangaparaua, Whakatane, Maketu, Motiti, Tauranga, Katikati, Whakahau, etc., et l'on peut suivre pas à pas, pour ainsi dire, jusqu'au cap Nord, l'itinéraire des émigrants, ainsi que nous croyons l'avoir démontré.

En allant au contraire du Nord vers le Sud, sur la côte Ouest de la même île, particulièrement depuis Manukau jus. qu'à Patea, dans le détroit de Cook, ce sont absolument, et dans l'ordre indiqué par les légendes, les localités qu'elles désignent et dont elles attribuent les noms au Taïnui, surtout à Turi et à Hou.

Enfin dans l'intérieur de l'ìle, on voit quelques losalités portant des noms qu'on retrouve en Hawahiki, où il sont 
donnés égalementà certaines localités; mais ces noms y sont en si petit nombre, qu'on ne peut qu'être frappé du contraste, quaud on compare ia carte de cette île arec celle de l'Ile-du-Milieu.

Il fautbien le reconnaître, tous ces mots n'ayant été donnés que par les émigrants d'Hawahiki, ne servent qu'à indiquer leur marche d'un point vers un autre; sous ce rapport, ils le font de la manière la plus complète, comme nous croyons l'aroir démontré. Par cela même qu'on ne trouve parmi eux que quelques mots de l'Hawahiki, ils ne sont d'aucune utilité pour aider à découvrir la situation véritable de cet Hawahiki, ou du moins, ils n'y aident que fort indirectement, c'est-à-dire par leur absence.

Pour ces motifs et bien d'autres encore, nous ne nous y arrêterons pas plus longtemps, et nous passerons de suite à l'examen de la carte de l'Ile-du-Milieu,

Qu'on prenne les cartes de cette île dressées par les géographes Stockes, Richards, etc., ou seulement celles qui accompagnent les ouvrages de Taylor et de Thompson, et l'on sera prebablement tout aussi surpris que nous l'avons été, en y voyant la plupart des noms qui servent à désigner les localités ou les personnages en Hawahiki. Cette surprise devra être d'autant plus grande et d'autant plus significative en même temps, que ces mots, ainsi que nous venons de le dire, sont en très petit nombre sur l'Ile-Nord de la Nouvelle-Zé lande. Ce qui est bien digne d'attention, en effet, c'est qu'excepté quelques noms que nous signalerons et que nous n'avons pu découvrir, malgré nos recherches, tous les autres noms cités par les traditions se retrouvent dans l'Ile-du-Milieu donnés à des localités de ses bords et de l'intérieur. Sur ses bords, ces noms sont même tellement disposés que, s'il est impossible de déterminer avec certitude la position relative des localités, on peut an moins dire quel était le centre de l'Hawahiki, et peut-être mème ses limites, s'il ne comprenait pas, ce que quelques détails autorisent à croire, l'Ile-duMilieu tout entière.

Ces noms sont même si nombreux que peut-ètre, en s'aidant de toutes les données des traditions, on pourrait arri- 
ver à préciser ou à décuuvrir quelques-uns des points d'où sont partis les canots, de mème que la position relative des principales tribus. C'est ce que nous essaierons de faire pour Turi particulièrement.

De pareilles recherches ne peuvent être que conjecturales ; aussi nous n'y attachons qu'un intérèt bien secondaire. Mais nous recommanderons au lecteur, pour qu'il puisse asseoir son opinion, l'inventaire des principales localités que relatent les cartes de l'Ile-du-Milieu.

Ainsi sur la côte Nord-Ouest de l'Ile, en allant du cap Farewell ou Poukou-Wau, jusqu'au cap Ouest, entre les baies Dusky et Chalky de Cook, on voit figurer les noms auxquels les légendes nous ont habitué, comme existant en Hawahiki. Tels sont: Wanganui, Kaurangi, Tauranga, Kararoa, Waïma, Arahura, Totara, Waihau, etc. C'est un peu plus au Sud de la rivière Whanganui que coule la rivière Awarua-nui. L'Arehura de cette côte est évidemment celle que visita Ngahue, puisque en remontant cette rivière, qui charrie parfois du jade, on parvient au fameux lac Wakatipua, qui passe pour le fournir en plus grandeabondance. Sur cette même côte encore se voit la pointe Waïrere, etc.

En continuant depuis le cap Ouest jusqu'à Tautuku, près du lac Waiota, sur cette partie de l'île qui est la plus Sud et qui est séparée de l'île Stewart par le détroit de Foveaux, on voit d'abord, à peu de distance du cap-Ouest, une île Tamatea; puis une île Rarotonga qui, avons-nous déjà dit, est celle où l'Arawa a été construit. Tout près de là, est la rivière Aparima, dont le nom a tant intrigué les partisans de l'origine polynésienne des Maori, ce qui les a conduits à supposer que les Néo-Zélandais proviennent de la petite île de ce nom dans les Samoa. C'est dans l'A parima que se déverse la-rivière Waïraki. Après cette rivière viennent : celle de O-Maui; l'îlot Motu-Piu;.le port Awarua, et plusieurs autres rivières, parmi lesquelles il faut surtout citer la grande rivière Mataura ou Totoi, la Punawai des cartes anglaises, dans laquelle se décharge la rivière appelée Waïharakeke.

Sur la côte Sud-Est ou Est, en allant d'abord jusqu'ì la 
presqu'île de Banks, abondent les autres noms importants de l'Hawahiki; c'est là que l'on voit groupés, pour ainsi dire, depuis Tautuku, d'abord: Matau ou la baie Molyneux; le lac Waiota; le lac Taieri; Papanui ou le cap Saunders ; Otakou où est fondée la ville de Dunedin; Rangiriri; la rivière Waima-Taitaï; Moeraki ; Te-Awa-Mokihi ou Waïma-Kihikihi ; enfin parmi vingt autres, les mots qui paraissent le plus souvent dans les légendes, tels que O-Amaru, Te-Maru, Horo-Whenua, Rakitata, Wanganui, Waiora, Wairewa, etc. L'avant-dernier nom est même celui du fameux lac, fontaine ou source de vie, à laquelle les Maori croyaient comme les habitants des Sandwich.

Sur l'autre portion de cette côte, jusqu'au cap Campbell on Karaka, se voient, en partant de la prosqu'île : Kaiapohia et la rivière Waïma-Kariri, J'île Motı-Nau, la presqu'île Kai-Koura, et près du mont Tako, le lac et la rivière Waiharakeke (1). Ce dernier nom suffirait à lui seul, s'il n'y avait pas tant d'autres témoig'nages, pour prouver que l'Hawahiki ne pouvait être que sur l'Ile-du-Milieu : il n'y avait que des Maori qui pussent nommer un lac a le Lac du Phormium : v cette plante, avons-nous dit ailleurs, n'ayant jamais été rencontrée, avant son introduction dans diverses autres contrées, qu'à la Nouvelle-Zélande et dans la petite île Norfolk.

Du cap Campbell jusqu'au cap Farewell, si l'on entre dans le détroit de Cook par son extrémité orientale, on voit d'abord la baie que Cook a appelée Cloudy-bay ou baie Obscure, à laquelle semble si bien convenir le nom de Motiwhitiwha des traditions, nom qui a la même signification. Puis, en allant vers l'Ouest et aussi bien dans le canal que sur les bords de l'Ile•du-Milieu : les îles Motu•Ara, Arapaoa, MotuRoa, Moioio, Mana, Kapiti, Tokomapura, Tauramoria, Matapara; les baies Te-Awa-Iti, Wanganui, Hokokuri ; et plus à l'Ouest que toutes les précédentus, l'île Rangitoto qui, si elle n'est pas l'île Rangitawha de la lég’ende de Turi, ne pouvait -en être éloignée. C'est en effet en faisant route de cette

(1) Wai, eau; harakeke,phormium tenax. 
le vers l'Ouest que le Ririno s'est perdu. La légende, il est vrai, aurait pu ne vouloir parler que de l'une des îles 'Stephens qui sont près de là; mais c'est à l'île d'Urville elle-même que, d'après Dieffenbach, est donné le nom de Rangitoto. En outreles dernières ìles se touchent presque et on ne peutlonger le détroit, en venant de l'Est, sans les rencontrer, de même qu'on ne peut venir de l'Ouest et faire route à l'Est, depuis le cap Farewell, sans arriver directement sur l'une d'elles. Il est certain aussi que ce n'est qu'en partant de l'une de ces îles, pour aller à l'Ouest, qu'il était possible à un canot de se perdre sur quelque brisant, la prolongation de la pointe Farewell, dans le détroit, en offrant plusieurs.

C'est dans ce détroit, avons-nous dit, qu'on vcit le canal Awa-Iti, où Kupe pourfendit le poulpe gigantesque qu'il avait poursuivi.C'est dans ce même détroit, appelé par lui RauKawa, que se trouvent les ouvertures descanaux qu'il explora et qu'il laissa, d'après la légende, comme marque de son passage. Parmi ces ouvertures figure certainement, si l'on s'en rapporte à la description qu'il en donna, celle que nous avons franchie nous-même avec d'Urville, en y laissant la fausse quille de l'Astrolabe: C'est celle que les compagnons de ce navigateur ont baptisée du nom de Passe-des-Français. C'est encore dans ce même détroit, mais sur la côte opposée, qu'existe la rivière Patea découverte par Kupe. Il y avait trouvé non-seulement deux oiseaux, le Kokoka et le Piwapiwaka, qu'il signale tout particulièrement, mais même une population primitive massacrée, quelque temps après, par Turi, quand il alla se fixer dans ce même lieu.

Les localités les plus à citer de ce côté du détroit, depuis le cap Whaka-Taranaki près du mont Taranaki ou Egmont, jusqu'au cap Palliser on Kawakawa, sont: Kaupokonui, où fit terre le canot Ringaringa lors de la grande émigration; puis les rivières Waitotara et Whenua-Kura; Te-Rawhiti ou pointe Ouest de la baie Wellington; Wairarapa ou la baie Palliser, dans laquelle se trouve le port aujourd'hui appelé Nicholson. Tous ces noms reviennent à chaque instant dans les chants historiques des émigrants ; ils ont été 
donnés, disent ces chants, depuis Aoteajusqu'à Patea par Turi, et depuis Patea jusqu'à Wairarapa par sun compagnon Hou, le père du commandant de l'A rawa.

Il n'y a guère à citer, sur la côte opposée, que Waka-tu, lieu qui a été découvert et exploré par l'Astrolabe en 1827, et où depuis, a été élevée la ville de Nelson, non loin des rivièresWaïrau et Waïma; non loin des îles Adèle et Pepin, noms de la femme et du beau-père de Dumont-d'Urville; non loin de la baie Croiziller, nom de l'oncle de d'Urville, et non loin enfin des pointes Guilbert et Adolphe Lesson, noms de deux des compagnons de ce navigateur.

On le voit, la carte de l'Ile-du-Milieu contient presque toutes les désignations que les légendes attribuent à des localités de l'Hawahiki. Si l'on y ajoute les noms, encore plus importants peut-être, qui sont donnés à des lieux, lacs, rivières ou montagnes de l'intérieur, tels que ceux de Horowhenua, Tuhuruhuru, Wai-Ariki, Roto-Rua, Wakatipua, Tuhawaiki, etc., il n'y a guère qu'une seule conclusion admissible: c'est que l'Hawahiki existait sur l'Ile-du-Milieu, ou même était cette île entière. C'est cette conclusion que nous n'hésitons pas à en tirer.

Pour nous, l'Ile-du-Milieu n'est donc que l'Hawahiki oú du moins c'est l'île sur laquelle se trouvait cet Hawahiki.

Nous le répéterons, une pareille réunion des noms de l'Hawahiki sur cette île, alors que ces noms manquent à peu près complètement sur l'île voisine, ne peut s'expliquer qu'en admettant que l'Ile-du-Milieu était le pays des ancêtres ou que du moins c'était sur elle que ce pays existait. Si, en effet, les émigrants fussent venus d'une autre île que l'Ile-du-Milieu, il est évident qu'au lieu d'y trouver cette agglomération de noms on l'eût rencontrée sur l'île abordée et peupléela première par eux. Or on a vu que c'est justement sur Aotearoa, où sont arrivés les émigrants, que ces noms font défaut: preuve indirecte, il est vrai, mais preuve, à notre avis, que ces émigrants ne pouvaient venir que de l'Ile-du-Milieu. S'ils fussent venus d'un Hawahiki polynésien ou tout autre, on ne comprendrait pas que ceux-ci eussent attendu leur nouvelle émigration d'Aoteara à l'Ile-du-Milieu, pour 
songer à conserver lessouvenirs de leur patrie. Il eût été plus naturel de le faire dans la première île envahie par eux, alors que ces souvenirs étaienttout frais. S'ils nel'ont pas fait, c'est tout simplement, comme le démontre tout ce que nous avons déjà dit, qu'ils venaient de l'île qu'on a cru, à tortjusqu'à ce jour, avoir été peuplée par eux, de même qu'on a cru également à tort à une route toute contraire à la route véritable. Cetteorigine, du reste, explique non-seulement l'absence de la plupart des noms de l'Hawahiki sur l'Ile-Nord, mais encore le souvenir qui, en Polynésie, en a été conservé de plus en plus confus avec l'éloignement.

Autrespreuves. - Néanmoins, pour lever tous les doutes, nous allons encore exposer ici quelques faits irréfutables à l'appui de la thèse que nous soutenons :

$1^{\circ}$ Parmi les noms donnés à des localités de l'Hawahiki, on remarque des mots qui n'ont évidemment pu être trouvés et employés que par des Maori; il n'y avait qu'eux, sur le globe entier, qui pussent appeler un lac et une rivière Waiharakeke, c'est-à-dire lac et rivière du Phormium: cette plante, en effet, ne se trouve absolument, comme on le sait, que dans les îles du groupe de la Nouvelle-Zélande et dans la petite île Norlfolk, qui en est à 140 lieues dans le Nord-Ouest. Evidemmentce sont les îles qui possédaient la chose qui ont dû donner ce nom, au lieu de le recevoir d'émigrants d'une contrée oì cette chose n'existait pas. Donc, puisque ces noms se trouvaient en Hawahiki, c'est que l'Hawahiki était l'lledu-Milieu.

20 L'Hawahiki étaitla patrie des phoques ou veaux marins. C'est ce qui résulte des traditions générales, et plus particulièrementd'un chant cité par Shortland(1). C'est ce qui résulte

(1) Ouvr. cité, p. 172. Nous transcrivons ici ce chant, qui passe pour être un des plus anciens Ngeri Zélandais.

Kia Kutia! Qu'il soit tenu (embrassé) ferme !

Au, au! Moi, moi !

Kia wherahia! Qu'il soit relâché !

$A u$, au ! Moi, moi! 
également de la légende de Tawhaki, entre autres: Ce héros commença ses hauts faits paraller tuer les Ponaturi pour venger la mort de son père et délivrer sa mère. Ur ces Ponaturi étaient des veaux marins et l'on sait que l'Ile-du-Milieu de la Nouvelle-Zélande était, avant l'extermination qu'en ont fait les pêcheurs européens, l'une des contrées les plus riches en animaux de cette sorte. On ne pourra donc pas y voir une simple coïncidence.

$3^{\circ}$ Non-seulement il y avait des phoques en Hawahiki, mais les habitants de cet Hawahiki connaissaient parfaitement les gelées, la neige et.même la glace. C'est ce que prouvent les mots Tapatapa-Hukarere et Hakerere (1), noms. de deux des mille canots qui, d'après les plus anciennes légendes, allèrent, sous le commandement de Whakatau, ce chef sii renommé en Hawahiki, détruire Whare-Kura a la Maison rouge, ou suivant une autre version, Tihi-o-Manono.

C est ce que prouvent encore les mots maori suivants : Haupapa, gelée, glace; Huka et Hukarere, neige; Hauhunga, Hukapapa, glace; etc.

$4^{\circ}$ Le Piopio (Tanagra macularia), oiseau décrit pour la première fois par Quoy et Gaimard (2), passe parmi les in digènes pour avoir été apporté à l'Ile-Nord par les premiers émigrants de l'Hawahiki, ainsi que le prouve le pro-

Kia rere, Qu'il coure,

Atu te, s'éloigne, le

Kekcno, Veau marin,

Ki tahiti, à distance

Titiro, pour 'qu'on le regarde.

Mai ai, Par ici.

Ae, ae, ae! Oui, oui, oui !

(1) Tapatapa, donner le nom d'une personne à quelque chose pour rendre cette chose sacrée. Huka, écume, neige ; Rere, cascade, courir, voler. Hake, tasse, vase, coupe.

(2) Voyage de l'Astrolabe, Zoologie, p. 186, pl. 7, fig. 1. Ils l'ont rapproché des Tanagra de Linnúe. 
verbe suivant de l'Ile-Nord (1): Piopio wirunga nga tau ko Matatua te waka. «Le Piopio vint sur l'avant du Matatua." Pour les Maori, le Piopio est un oiseau de passage.

Cet oiseau est le même que le Rév. Taylor appelle Tur. nagra crassirostris, d'après G. R. Gray (2). Forster, qui l'avait vu à la baie Dusky, avait entendu Golobigo comme nom indigène. C'est un oiseau de la grosseur d'une grive, avec un bec court, étroit, la queue rouge, la poitrine jaune et le dos brun (3).

Cette croyance des indigènes que le Piopio était venu pour la première fois sur le Matatua et qu'il avait émigré du Sud, comme il continue encore à le faire, cette croyance est bien curieuse. Elle signifie implicitement que les canots, ou du moins le Matatua, venaient également du Sud. On a vu que le Matatua était l'un des premiers canots qui ont émigré d'Hawahiki. Rauru, son capitaine, passe pour avoir apporté le Taro; il aurait en même temps apporté le Piopio. Par conséquent, l'Hawahiki était plus Sud ou plus SudOuest que l'Ile-Nord, puisque c'était de l'Hawahiki que, d'après toutes les légrendes, ce canot, comme les autres, était parti.

Une pareille situation de l'Hawahiki fait même parfaitement comprendre la surprise des émigrants à la vue des Pohutu-Kaua (4) en fleurs sur les rochers escarpés de leur premier lieu de relâche dans l'lle--Nord. Ce lieu se trouvait, comme on a vu, à l'entrée de la baie d'Ab indance, près du cap Est. Or, on sait aujourd'hui que le l'ohutu-Kaua ne vient que dans la partie Nord de l'Ile-Noril, et qu'il ne dépasse guère, vers le Sud, la limite du cap Est. On ne le trouve pas plus loin qu'à quelques milles de Mokau.

$5^{\circ}$ Parmi les choses que les légendes font apporter à Ao-

(1) Taylor, ouvr. cité, p. 403.

(2) G. R. Gray l'avait d'abord appelé Keropia crassirostris dans la première édition de sa List of genera of birds. (Voir Dieffenbach, t. I, p. 190.)

(3) Taylor, ouvr. cité, p. 403.

(4) Le Pohutu-Kaua est le Metrosideros Tomentosa. 
tearoa par les émigrants, se trouvait une espèce de Kumara, appelé Anurangi. Son importation est attribuée à HotuRoa, le chef du Taïnui, comme la patate douce l'est à la femme de Tiki, l'igname ou Paratawhiti à Turi, etc.

Or, anu, signifie froid, le froid, et rangi, ciel: on pourrait donc traduire ce mot par « Kumara d'un ciel, d'un climat froid. "Ce qui s'expliquerait tout naturellement si, comme nous avons des raisons de le croire, le Taïnui était parti des environs d'Otokou, sinon d'Utokou même.

Il est d'ailleurs un fait bien connu aujourd'hui, c'est que c'est justement dans l'île la plus froide de la Nouvelle-Zélande que se trouvaient en plus grande abondance et que se trouvent encore des Moa, s'il en existe toujours, ainsi que l'espèce la plus petite de ces oiseaux, encore vivante aujourd'hui.

$6^{\circ}$ Un fait, prouvant peut-être plus encore que tout autre que les habitants de l'Ile-Nord croyaient eux-mêmes, du moins dans les anciens temps, être venus d'une contrée située plus au Sud ou plus au Sud-Onest que leur île, c'est l'emploi qu'ils font, pour désigner la grande émigration de leurs ancêtres, d'un mot signifiant a descente, descendre. » Hekengamai n'a littéralement pas d'autre signification : Mai, ici, vers l'endroit où l'arrivée s'est faite; hekenga, descente, de heke, quitter sa résidence première, son pays, descendre, tomber, refluer, en un mot, émigrer, émigration. S'ils étaient venus du Nord-Est, comme on le dit, ils se seraient plutôt servi des mots ekenga, kakenga, pikitanga, qui signifient « montée, ascension; » car ils s'accordent à dire que le Sud est « en haut, » runga, et le Nord " en bas, dessous, " raro. Il est donc évident, d'après cela, que les premiers émigrants se regardaient comme venant "d'en haut », c'est-à-dire du Sud ou mieux du Sud-Ouest, puisqu'ils se croyaient $\alpha$ être descendus $»$ en venant se fixer dans l'Ile-Nord de la Nouvelle-Zélande. Si aujourd'hui les habitants de cette île n'ont plus que des souvenirs tellement confus, qu'il leur est impossible de dire de quel côté étaient 
venus leurs pères (1), il n'en est pas moins vrai que le mot hekenga semble lui-même aider à déterminer la position de l'Hawahiki. Les linguistes apprécieront.

Toutefois, nous croyons devoir insister encore sur cette preuve importante. Thompson, par exemple, fournit luimême, sans s'en douter, il est vrai, un témoignage en faveur du peuplement de l'Ile-Nord par l'Ile-du-Milieu, quand il dit (2): Ce qui prouve que l'Ile-Nord aété la première peuplée par les habitants d'Hawahiki, c'est qu'en Maori, Sud signifie « en haut » et Nord * en bas ». (3) Car, en outre qu'il donne par ces mots, sans s'en douter non plus, l'explication de l'origine du mot Rarotonga, il avance implicitement, comme tant d'autres, le contraire de ce qu'il suppose, c'est-à-dire que c'est l'Ile-Nord qui a peuplé l'fle-du-Milieu. Il paraîtra évident, en effet, que si, pour les Néo-Zélandais de l'Ile-Nord, le Sud était «le haut» et le Nord « le bas, » e'est qu'ils regardaient leurs ancêtres comme venus d'un point plus voisin du Sud que du Nord; en d'autres termes, comme nous cherchons à le démontrer, d'un point plus Sud ou plus Sud-Ouest que l'Ile-Nord.

Le nom qui a été donné à l'extrémité la plus Nord de l'Ile-Nord de la Nouvelle-Zélande prouve lui-même que les

(1) C'est la confusion de ces souvenirs et rien qu'elle, qui fait que les Maori actuels, après avoir observé les habitudes des deux Coucous qui sont de passage à l'Ile-Nord de la Nouvelle-Zélande, où ils arrivent en septembre pour en partir en mars, ảisent qu'ils se partagent l'année entre leurîle et l'Hawahiki, que les Européens leur répètent être placé en Polynésie. Comme ces oiseaux voyageurs sont plus ordinairement dans les pays intertropicaux, les Européens semblent, avec quelque raison, pouvoir conclure que l'Hawahiki est de ce côté; mais ils ne réfléchissent pas que les indigènes, en les voyant arriver d'un pays étranger, ne supposent naturellement qu'une chose, c'est qu'ils viennent du seul pays dont ils avaient connaissance par tradition. Donc ce fait ne préjuge rien quant à la situation de l'Hawahiki. (Voir pour le Kohoperoa, Eudynamys taitensis, et pour le Piwarauroa, Cuculus nitans, Taylor, p. 405.)

(2) Ouvr. cité, p. 63.

(3) « The North island war first peopled, and as a proof of this the South means up u and the North «down. 》 
émigrants devaient venir du Sud. Cook est le premier qui l'ait fait connaitre: ce nom, rectifié, est Muri-Whenua. Or, on sait aujourd'hui qu'il ne signifie que « la terre de derrière, la dernière terre. $\gg$ Evidemment, pour que cette extrémité d'Aotearoa fût ainsi désignée, il fallait que les émigrants vinssent du Sud ou du Sud-Ouest. S'ils fussent venus du Nord-Est ou des Samoa, comme on le croit, cette extrémité de l'Ile-Nord eût été presque certainement la première rencontrée, et appelée en conséquence: « la terre de devant, » au lieu « de la terre de derrière, » en un not « la première terre $»$ au lieu de «la dernière. »

Peut-être en existe-t-il une autre preuve dans le nom donné à la pointe Ouest de la baie appelée aujourd'hui Wellington, dans le détroit de Cook: (1) C'est le nom Te-Ra-Whiti, qui signifie : a Le soleil traverse, passe outre, luit, brille, » et, pour ainsi dire, «le soleil levant. $\gg$ Un pareil nom, semble-til, n'aurait pu être donné par des émigrants venant du NordEst, puisque, pour eux, c'eût été plutôt le soleil couchant. C'était, au contraire, le seul à appliquer par des émigrants venant de l'Ouest, qui avaient nécessairement à se diriger sur cette pointe et à la doubler pour atteindre la côte orientale d'Aotearoa. Mais que ce dernier nom ait été donné par des émigrants venant de l'Ouest ou de l'Est, il est un fait certain, c'est que les habitants de l'Ile-du-Milieu qui occupent toutes les terres au Sud du détroit de Cook emploient les mots Te-Ra-Whiti pour signifier le Nord par rapport à eux, et pour indiquer les terres qui s'y trouvent. Ainsi, ils disent que l'île Kapiti, ou île de l'Entrée, de Cook, est «dans le Nord, du Nord, appartient au Nord: » No te Ra whiti (2). C'est une nouvelle preuve, à notre avis, que, puisqu'ils se placent «en haut » dans le Sud, ils se croyaient eux-mêmes venus d'un point plus Sud que le détroit de Cook ou que, tout au moins, s'ils ignoraient leur véritable lieu de provenance, ils ne le plaçaient pas plus Nord que le détroit de Cook.

(1) C'est entre cette pointe et Arapaoa que le détroit de Cook a le moins de largeur.

(2) Voy. Shortland, Southern districts, p. 312. 
Mais ce qui semble prouver mieux encore que les émigrants de l'Hawahiki venaient du Sud, c'est, nous le répéterons, le nom que porte la légende de Sir Grey, intitulée: Hekenga-Mai, « émigration à la Nouvelle-Zélande. »Or, en Maori, nous venons de le dire, hekenga signifie «descente.»

Puisque les Maori placent «le haut » vers le Sud, en disant « descendre, $\gg$ ils entendaient donc dire évidemment qu'ils venaient du Sud, du moins ceux de l'Ile-Nord qui, il faut le faire remarquer, sont ceux qui ont fourni aux Européens presque tous les documents que l'on possède sur la Nouvelle-Zélande. De là résulte, d'ailleurs, beaucoup plus que l'on ne suppose, les difficultés que les ethnologues rencontrent à chaque pas dans cette question. Il n'y en aurait pour ainsi-dire pas, si au lieu de confondre, comme on le fait, toutes les îles sous un même nom, on voulait se rappeler que, quand on parle de la Nouvelle-Zélande, quand on cite la manière de voir des Zélandais, il ne s'agit, le plus souvent, que de l'Ile-Nord et de ses habitants. Ici, qu'on nous permette une digression linguistique à l'occasion des mots « en haut» et «en bas, » employés par les Maori quand ils veulent parler du Sud et dia Nord.

Pour Taylor (1), comme pour Dieffenbach et Thompson, le Sud est «en haut», et se rend par Runga; le Nord est « en bas » et se rend par Raro. C'est ainsi qu'il traduit : I haere mai $i$ runga; I haere mai $i$ raro, par : «Il vient du Sud, il vient du Nord. » Il traduit de mème quelques lignes d'un chant de Ngahuru (2). Enfin, il rend la phrase suivante : haere ki Raro ra, ki Hauraki ra ia, par « quand nous arrivâmes au Nord de Hauraki. »

En effet, Raro est le nom que les Maori de l'Ile-Nord donnent à tout ce qui est sous le vent d'eux, c'est-à-dire plus au Nord qu'eux, et l'on vient de voir que ceux de l'Iledu-Milieu se servent du mot Raro dans le même sens, puisque, pour eux, tout ce qui est au Nord du détroit de Cook est Raro, ou autrement dit «sous, dessous. »

(1) Ouvr. cité, p. 80.

(2) Ibid. p. 144. 
Comparé au Raro des Polynésiens, il semblerait y avoir une différence assez sensible dans le sens de ces deux mots : le premier signifie « vers le Nord, dessous, » et celui de la Polynésie, « vers le Nord-Ouest » et également « dessous, sous. $\gg$ On dirait que le mot Raro maori signifie seulement «dans la direction du Nord, » comme celui des Polynésiens signifie «dans la direction du Nord-Ouest. » Mais, par le fait, c'est à peu près le même sens, puisque dał̆s les deux contrées c'est le Sud qui est « en haut. »

Shortland reconnaît du reste que le sens général du mot Raro est le même à la Nouvelle-Zélande que partout ailleurs. Mais, comme cet observateur a cru, à tort, voir une difficulté dans un fait observé par lui à Otokou dans l'Iledu-Milieu, nous devons nous y arrèter un instant et chercher à le rectifier.

\& Là, dit-il, (1) le mot Raro est employé pour désigner une partie de l'île qui est située dans le Sud ou Midi, tandis que le même mot, à Auckland, indique les parties de la Nouvelle-Zélande qui sont au Nord. »

a De même, dit-il encore, « le motRunga «sur, dessus, * est employé par les tribus Kaïtahu, comme le mot Raro, dans un sens complètement différent de celui qu'on lui donne à l'Ile-Nord, où il signifie Sud à Auckland.»

Si l'observation était exacte, ce serait en effet une difficulté bien inexplicable; mais nous croyons tout simplement que Shortland n'a pas assez tenu compte de la position reiative de ceux qui lui ont donné ces renseignements. S'il y eût réfléchi, il eût vu probablement qu'on n'employait le mot Raro que quand il s'agissait de terres plus au SudOuest ou au Nord-Ouest que le point où on s'en servait. Comme il le reconnaît lui-même, le sens ordinaire du mot Raro est sous, dessous. \Or, si à Otokou, on appelait Raro les terres fuyant vers le Sud-Ouest jusqu'au détroit de Foveaux, c'est que pour ce point, elles étaient, en effet, plus «sous le vent du Sud.» Elles n'étaient pas, comme il l'a cru, désignées ainsi parce que Raro voulait dire Sud, mais seulement «sous, dessous. »

(1) Southern districts, p. 312. 
D'un autre côté, si les Kaitahu, qui habitaient la cồte orientale de l'Ile-du-Milieu, après l'avoir conquise sur les Ngati-Mamoe, se servaientdu mot Runga pour dire « Nord» et " sous, » contrairement à son sens ordinaire «sur, audessus, "c'est que, presque certainement, ils faisaient allusion à un point plus Sud qu'eux, et place entre eux et le Nordi. L'interprète seul donnait à ce mot une signification qu'il n'avait pas, en l'appliquant à une direction quand il n'était appliqué qu'à un point plus Sud que celui où la remarque était faite.

$7^{\circ}$. - Le jade vert qui existait en Hawahiki, comme le prouve la légende de Ngahue, n'est produit, au dire de tous les écrivains et de toutes les traditions, que par certaines rivières et certains lacs de la Nouvelle-Zélande (1).

Cette circonstance, plus que les autres encore, suffirait à prouver à elle seule que l'Ile-du-Milieu et l'Hawahiki ne faisaient qu'un; autrement, on ne s'expliquerait pas le nom identiquement le même donné au lac qui produisait le jade vert en Hawahiki et à celui qui le produit en plus grande abondance aujourd'hui dans l'Ile-du-Milieu. Or cette île, ainsi que nous l'avons dit, passe aux yeux des indigènes euxmêmes pour être la seule des deux grandes îles à le produire.

Nous disons avec Taylor et Shortland que l'Ile-du-Milieu est la seule qui produise le jade vert, parce qu'il n'a été rencontré jusqu'à présent que dans cette île. Mais il paraît avoir été trouvé dans quelques autres contrées, telles que la Nouvelle-Calédonie, le Hartz, la Corse, la Chine, l'Egypte, etc. Est-ce absolument le même? Nous ne saurions le dire. Nous avons, d'ailleurs, traité précédemment cette question (2).

Toujours est-il que, quand on remarque que l'Ile-du-Mi-

(1) Taylor, en parlant de Ngahue (p. 120) dit que le Pounamu avait son origine dans l'Hawahiki. Shortland, (Southern districts, p. 98) dit également que le Pounamu ne se trouvait que sur l'Iledu-Milieu.

(2) Voy. ci-dessus, p. 171 et suiv. 
lieu est la seule du groupe qui passe pour produire le jade vert ; quand on se rappelle que Ngahue en possédait avant de quitter l'Hawahiki et avant d'aller cacher son bloc à Arehura, près du lac Whakatipua, et que ces lieux sont, avec Ohonu et Piopiotahi, ceux qui en produisent le plus sur les côtes Nord-Ouest et Sud-Ouest de l'Ile-du-Milieu; quand on sait que les Ngatimamoe, les anciens habitants de l'Ile-duMilieu, il y a plus de 300 ans, paraissent n'avoir été attaqués si souvent, et exterminés à la longue, que parce qu'ils possédaient le jade vert; quand on remarque plus particulièrement que les Ngati-Rua-Nui, qui composaient les équipages de la plupart des canots, étaient justement les habitants des lieux les pius voisins de la contrée du jade; quand on sait enfin que, de notre temps, des chefs tels que Rauparaha et Rangihaeta, n'avaient d'autre but, en allant faire la guerre aux tribus de l'Ile-du-Milieu, que de leur enlever le jade vert qu'elles possédaient; qu'ils allaient, pour cela, jusqu'à Otokou, d'un côté, et jusqu'à la baie Jackson et à la rivière Awa-Rua-Nui, au moins, de l'autre : Il faut en conclure que non seulement le jade vert était la seule cause des attaques incessantes des habitants de l'IleNord contre ceux de l'Ile-du-Milieu, ainsi que de l'extermination qu'ils en ont faite, grâce aux armes à feu qu'ils avaient les premiers pu se procurer, mais encore que, ainsi que le disent Shortland et particulièrement Taylor, le jade n'était produit que par certaines localités de l'Ile-duMilieu et, par conséquent, de l'Hawahiki.

Shortland rapporte (1) qu'on trouve des échantillons de jade vert, en blocs détachés, dans plusieurs des torrents de la côte Ouest de l'lle-du-Milieu, et que les points cù il y en en a le plus sont, sur cette côte, Arehura et Ohonu; Whakatipua dans l'intérieur, et enfin le torrent Piopiotahi sur la côte Sud-Ouest. Il raconte même la tentative faite par une compagnie pour exploiter l'énorme bloc que l'on avait reconnu au milieu de ce dernier torrent ; il paraît qu'on était parvenu après beaucoup de peine à en obtenir quelques tonneaux en morceaux; mais sa qualité granuleuse l'avait fait

(1) Southern districts, p, 34 . 
rejeter sur les marchés de Chine et les travailleurs avaient dû se disperser. Ce jade inférieur était néanmoins acheté, dit-il, un schelling la livre. .

Tous ces faits viennent donc encore témoigner de l'identité de l'Hawahiki et de l'Ile-du-Milieu. Si maintenant l'on y ajoute ceux qui semblent prouver que l'Hawahiki ne pouvait pas être en Polynésie, il ne devra guère être possible de conserver quelque doute.

Ce qui aide à prouver, en effet, que l'Hawahiki ne pouvait pas être situé en Polynésie, c'est qu'on ne trouve pas dans les îles polynésiennes, et encore moins dans les îles malaisiennes, plusieurs des plantes et des animaux que les traditions disent avoir été apportés par les émigrants à Aotearoa (1).

Ainsi, le Karaka, dont il a été tant parlé, et dont l'introduction à l'lle-Nord de la Nouvelle-Zélande, est attribuée à Turi, ne vient point dans les îles de la Polynésie ; il en est de même du Totara, et de beaucoup d'autres végétaux, tels que le Kauri, le Kahika (Podocarpus dacrydioides R. et L.), mais surtout le Phormium tenax ou Harakeke. Puisque ces plantes y sont inconnues, il est évident qu'elles n'ont pu en provenir. Croire le contraire serait raisonner comme ceux qui, attribuant le peuplement de l'Amérique aux Européens, supposent que ceux-ci y ont porté avec eux des animaux ou des plantes qui n'ont jamais existé en Europe, tels que l'Alpaca, le Lama, etc.

Ce qui prouve aussi que l'Hawahiki ne pouvait pas être

(1) Les traditions citent entre autres : La patate douce, apportée - par la femme de Tiki ; le Karaka ou Corynocarpus lovigata; la Paratawhiti ou igname coureuse; le Pukeko ou Porphyrio Melanotus; le Kiore ou rat indigene; le Kakariki ou perroquet vert; le Moeone ou scarabée bronzé ; l'Awato ou chenille du sphynx qui ronge les Kumara; la Calebasse ; tous les oiseaux (Taylor p. 123) apportés par Turi ; une espèce de Kumara, dite Anu-Rangi, apportée par Hotu-Roa et le Taro, Arum esculentum, apporté par Rua-Auru.

Or, parmi ces choses, le Karaka et l'Anu-Rangi surtout manquent complètement en Polynésie. 
en Polynésie, c'est qu'on ne rencontre pas dans cette dernière contrée les rivières navigables si nombreuses qui sont signalées en Hawahiki par toutes les traditions; c'estque les lacs d'eau douce, si nombreux encore en Hawahiki, et qui y portent les mêmes noms que les lacs des îles de la NouvelleZélande, sont infiniment plus rares en Polynésie et qu'en outre ils sont dénommés différemment.

Enfin, une dernière citation, empruntée au Rév. Taylor, prouvera plus péremptoirement encore l'évidence de notre assertion : elle montre que l'Hawahiki était uni à l'ìle Aotearoa et que c'était par conséquent une même terre avant que, d'après les traditions maori, Kupe ne l'eût divisée en $\operatorname{deux}(1)$.

«Ce fut Kupe, disent les traditions, qui sépara les deux îles en faisant passer la mer entre elles et en formant le détroit de Cook, et qui sépara ainsi Aotearoa d'Hawahiki, à laquelle, dit-on, elle était d'abord unie. »

Plus loin, Taylor ajoute : (2)

" La Tuawhenua ou Grande Terre était unie à l'Hawahi$\mathrm{ki}$, avant la venue de Kupe. Ce fut lui qui la coupa en deux et fit passer la mer dans l'intervalle. »

Il est vrai que Taylor, pour rendre le mot Tuawhenua, se sert des mots Nouvelle-Zélande, au lieu d'Aotearoa, mais nous avons assez démontré l'erreur de tous les écrivains à ce sujet, pour n'avoir pas besoin d'y revenir.

Après ces citations, il nous semble qu'il n'est plus permis de conserver le moindre doute, car il en résulte qu'avant la séparation attribuée à Kupe, les deux terres n'en faisaient qu'une (3).

Pour les Maori, comme pour nous, c'était donc de l'Iledu-Milieu, puisqu'il n'y a qu'elle qui soit séparée d'Aotea-

(1) Taylor, ouvr. cité, p. 117.

(2) Ibid. p. 124 .

(3) C'était ce qu'avait déjà rapporté Dieffenbach (t. II, ch. 6, p. 95), où il dit: « Les indigènes racontent que l'Ile-du-Milieu était unie anciennement avec l'lle-Nord. » Le Rév. S. Ironside est tout aussi précis dans son ouvrage sur la Nouvelle-Zélande. 
roa par le détroit de Cook, qu'avaient dû partir les émigrants. C'est sur cette île qu'existait l'Hawahiki.

Cela, il faut en convenir, explique parfaitement que Maui, auquel les traditions attribuent la pêche d'Aotearoa, n'ait eu qu'à s'éloigner avec son canot à perte de vue de la terre d'Hawahiki, pour découvrir ou pêcher l'île qui, à cause de cela, a été surnommée " le Poisson de Maui » ou Ika-NaMaui.

Cela explique de même l'arrivée de tant de canots dans le détroit de Cook et le choix fait de ce détroit pour retourner « directement » en Hawahiki. Or, ce choix, pour des canots cherchant à retourner en Polynésie, eût été aussi incompréhensible que leur arrivée dans le détroit.

Cela explique encore la perte du canot le Ririno, en faisant route à l'Ouest; la facilité des voyages pour ceux-là même qui ne les avaient jamais faits jusque-là, car il n'y avait qu'à suivre les côtes, une fois le détroit traversé, et il semble qu'on le traversait de préférence à son entrée la plus étroite, c'està-dire là où l'on ne perd jamais à la fois les terres de vue, entre Te-Ra-Whiti sur l'île Aotearoa et l'îleArapaoa près de l'Ile-du-Milieu (1).

Il est facile de comprendre que les Maori actuels aient, en général, presque complétement perdu le souvenir de pareilles croyances, et que ceux de l'Ile-Nord, en particulier, prétendent, par amour-propre national, avoir conquis et même peuplé l'Ile-du-Milieu. Il leur était difficile de conserver le souvenir des événements au=delà d'un petit nombre de générations, surtout dans des contrées où les guerres étaient incessantes et les pouvoirs changeants. Quoi qu'il en soit, d'après les citations que nous venons de faire, les plus vieilles traditions établissent que les Maori considéraient l'Hawahiki et l'Ile-Nord de la Nouvelle-Zélande

(1) Taylor, ouvr. cité, p. 117: «Several extraordinary works are attributed to Kupe: such as severing the two islands asunder, thus forming Cook's straits, and also cutting off New-Zealand from Hawahiki to which it is said to have been previously united. 
comme faisant partie d'une même terre, avant que Kupe n'eût découvert le détroit (1).

D'après une autre citation de Taylor, l'Hawahiki n'était autre chose que \& la terre primitive celle qui avait servi à former les autres terres. »Voici la traduction incomplète qu'il en a donnée. « Le Ciel se tenait au-dessus del'Hawahiki et la terre fut produite. Taporapora, Tauware nikau, kuku paru, wawau.atea, whiwhi te rangi ora. (2) 》

C'est pour la première fois qu'une tradition donne le nom d'Ḧawahiki à la première terre formée; dans toutes les autres il est seulement dit: “ Le ciel s'unit à la terre. • Comme on le voit, c'est à peu près le même sens; seulement cette dénomination prouve, comme nous l'avons avancé, que la signification véritable de ce mot est bien a le pays nourricier, la terre nourrice, la terre d'origine; n en un mot, c'est un nom abstrait, au lieu d'être, ainși qu'on l'a dit, un nom propre d'île ou de terre.

En somme, tout indique donc, à notre avis, que l'Hawahiki était au moins situé sur l'Ile-du-Milieu, s'il n'était pas toute cette île elle-même; nous croyons donc inutile de chercher à le prouver davantage

Cette identité de l'Hawahiki et de l'Ile-du-Milieu admise, nous allons essayer d'indiquer quelles étaient les parties de l'Ile-du-Milieu plus particulièrement occupées par l'Hawahiki; nous chercherons même à découvrir, d'une manière bien approximative sans doute, quel a pu être le point de départ de Turi, par exemple, dont nous avons tracé l'itinéraire, et enfin, quelle était la position relative de quelques-unes des tribus principales de l'île.

Nous avions d'abord pensé, en ne tenant compte que de la recommandation faite à Turi par Kupe de « toujours faire

(1) Ibid. p. 124: « The Tuwhenua or Mainland was united to Hawahiki before Kupe came; he cut it in two, and made the sea between. $D$

(2) Nous avons vainement cherché à traduire les mots qui ne l'ont pas été par Taylor. "The sky above dwelt with Hawahiki, and produced land: Taporapora, Tauvarenikau, kukuparu, wawau. atea, wiwhi te rangiora. 
route du côté où le soleil se lève, » que les émigrants n'avaient pu partir de la côte Ouest de l'Ile-du-Milieu, et que c'était seulement sur cette côte que se trou vait l'Hawahiki. Telle était l'opinion que nous avions émise dans le Mémoire adressé en décembre 1865, à la Société d'anthropologie de Paris.

Mais, en remarquant que, sur la côte opposée, les noms appartenant à l'Hawahiki étaient encore plus nombreux, et quelà, surtout, se trouvaient réunis les plus importants, ceux qui aident le mieux à faire comprendre les traditions; en voyant qu'il résulte de ces traditions qu'il ne faut pas prendre le mot Est à la lettre, mais que ce mot signifie seulement l'Orient, puisqu'elles se bornent à parler de «la route vers le côté où le soleil se lève ; »en remarquant encore que, non seulement un départ de ce côté de l'île permettait d'arriver à Aotearoa, en faisant route vers le côté où le soleil se lève, mais expliquait même, mieux que tout autre, l'arrivée de la plupart des canots au cap Est d'Aotearoa ; en réfléchissant enfin que ce côté de l'île était celui qu'avaient dû habiter Kae, Tinirau, Whakatau, etc., c'est-à-dire les personnages les plus célèbres avant le départ de la grande émigration, ainsi que cela résulte des recherches biographiques que nous avons faites sur ces différents personnages (1), nous avons compris que notre premièreopinion, toute fondée qu'elle était sur des faits, était incomplète, et que l'Hawahiki, au lieu d'ètre borné au côté Ouest de l'lledu-Milieu, s'étendait au côté opposé, à une grande distance dans le Sud-Ouest, jusqu'au détroit de Foveaux, et que peut-être même il occupait toute l'île, car c'est à son extrémité Nord que se trouve le lac Waïharakeke. Dans tous les cas, lHawahiki occupait au moins, à notre avis, cette partie de l'Ile-du-Milieu qui s'étend, en ligne droite, de la rivière Mawhera (Rivière de Grey) sur la côte Ouest, à l'île Motu-Nau sur la côte Est, d'une part; et de l'autre, vers les limites des terres situées dans le Sud-Est, le Sud et le SudOuest, c'est-à-dire jusqu'aux bords du átroit de Foveaux ;

(1) Consulter à ce sujet Taylor et Shortland, passim, ainsi que l'appendice inséré à la fin de cet ouvrage. 
en un mot, il se trouvait dans cet espace que les Anglais appellent aujourd'hui les provinces de Canterbury et d'Otago (Otakou) ; car c'est sur les côtes de cette partie de l'île aussi bien que dans l'intérieur que se trouvent agglomérés la plupart des noms attribués par les traditions à des localités de l'Hawahiki.

De cette façon, l'Hawahiki, au lieu d'être séparé par la chaîne de montagnes qui se déreloppe dans le sens de la longueur de l'île, aurait compris ces montagnes elles-mêmes ainsi que tous les lieux intermédiaires aux côtes : C'est ce que semblent prouver les noms de quelques-uns de ces lieux, et particulièrement ceux de plusieurs lacs. Mais si l'on en juge d'après la plus grande agglomération des noms, c'est là où les montagnes laissent le plus d'espace entre elles et la mer, c'est-à-dire sur la côte méridionale de l'ŝle, que se trouvait le centre de l'Hawahiki. C'est là, en effet, depuis Rarotonga et Aparima, d'un côté, jusqu'à Waiora, de l'autre, que se voient tous les noms des lieux qui, suivant les traditions, ont joué le plus grand rôle. Là se trouve Moeraki (1) qui paraît avoir été le berceau des idées religieuses; quant à Waiora (2), c'est le lac ou a fontaine de vie » des Maori, près de la presqu'île de Banks : ce nom doit être remarqué quand on rapproche cette croyance des NéoZélandais de celle des habitants des îles Sandwich. C'est également sur cette même côte que se trouvait presque sû rement le fameux Tihi-o-Manono, habité par Kae et incendié par Whakatau : d'après des données qui ne peuvent trouver place ici, c'était probablement la grande et célèbre

- maison dite Whare-Kura, dont Uenuku était l'un des directeurs (3).

Nous allons essayer maintenant de retrouver le point d'où Turi s'était éloigné de l'Hawahiki. Nous ne pourrons guère

(1) Moe, dormir, songer, sommeil, rêve; raki, sec, séché, brûlé. Raki étant le mot rangi de l'Ile-Nord, peut-être faut-il le traduire par \& ciel.»

(2) Wai, eau ; ora, santé, salut.

(3) Voy. Shortland, p. 67 ; Taylor, p. 65. 
présenter que des conjectures ; mais comme ces conjectures s'appuient sur un certain nombre de faits de détail, nous n'hésitons pas à les faire connaître.

On a vu, dans la version de Sir Grey, que le beau-père de Turi alla construire le canot l'Aotea près de la rivière et du lac Wai-Harakeke. Or, il y a une rivière et un lac du même nom sur l'Ile-du-Milieu, entre la presqu'île Kaï-Koura et le cap Karaka ou Campbell, de Cook, sur la côte Est. Il y a en outre une rivière Waiharakeke, qui se déverse dans la grande rivière Mataura ou Totoï, vis-à-vis Ruapuke, à l'en. • trée du détroit de Foveaux.

La même version parle de la rivière Waima-tu-i-Rangi, comme de celle d'où serait parti Turi. Or on rencontre, sur la côte Ouest de l'Ile-du-Milieu, une première rivière Waima, sans autre épithète, entre les rivières Mawhera ou rivière de Grey, et Arahura ou rivière de Brunner.

On trouve une seconde rivière Waima, qui débouche a Kaiapohia, sur la côte Est, dans la baie Pégase: elle a pour vis-à-vis, sur la côte Ouest, justement la rivière Arahura et elle porte le nom de Waïma-Kariri.

Une troisième rivière appelée Waïma-Taitai, existe entre la baie Waikoua-iti et Moeraki,non loin des récifs Takite-Uru et Taki-Amaru.

Enfin, d'après Shortland, il y en a une quatrième, appelée Waima-Kihikihi, entre Moeraki et la rivière Oamaru, c'estla même que les cartes désignent sous le nom de Awa-Mokihi.

En outre, une rivière Waimea débouche près d'une île du . même nom, dans le fond de la baie découverte en 1827 par l'Astrolabe, et où l'on a fondé, en 1842, sur le Waka-tu, la ville de Nelson.

Il est vrai qu'aucune de ces rivières Waima n'a l'épithète donnée à celle de la légende ; mais quand on sait que les habitudes des Maori, comme de tous les Polynésiens, leur permettent, en certaines occasions, et les forcent même, dans d'autres, de remplacer un mot par un autre, il ne doit pas paraître étonnant que cette épithète ait disparu. Il suffit 
bien certainement de trouver tant de Waima (1) sur l'Iledu-Milieu, et surtout un mot comme celui de Wai-Harakeke, pour être frappé d'une pareille coïncidence et.pour être porté à penser que parmi eux se trouvent ceux dont la légende a voulu parler.

Nous avions cru pouvoir dire, dans notre Mémoire à la Socièté d'anthropologie, qu'il ne s'agissait que du Waima de la côte Ouest, parce que, avec lui, s'expliquait plus facilement la route à l'Est ou au Nord-Est que Turi avait eu à faire pour arriver à Aotearoa. Pour la même raison, nous avions pensé que le Waiharakeke de la légende était celui qui se trouve du côté du détroit de Foveaux. Mais depuis, en remarquant que presque tous les noms de l'Hawahiki se retrouivaient plus nombreux sur la côte opposée, et qu'il était même plus facile d'expliquer l'ensemble des faits en supposant le départ opéré de ce côté de l'île, nous avons cherché ailleurs quel était le véritable Waima qui avait été le point de départ de Turi.

Si le lac Waiharakeke, où Toto, le beau•père de Turi avait abattu son arbre, est le lac situé auprès du cap Campbell, il ne faut plus chercher ce Waima sur la côte Ouest, à cause de la grande distance qui sépare ces deux localités et des difficultés du trajet. Mais il existe un Waima sur le côté Est de l'île: ce Waima, qui dọ̣t être préféré à l'autre, est celui qui est surnommé Kariri. Il est placé, en effet, à une petite distance sur le même côté, et c'est le plus voisin de tous les lieux portant le même nom. Pour aller d'un point à l'autre, il n'y a aucune difficulté: il suffit des vents du large ou de terre, puisque cette rivière déverse dans la rivière Kaiopohia ou Poe, qui débouche sur la presqu'île de Banks, dans la baie Pégase.

Un fait qui mérite d'être signalé, si l'on se rappelle ce que nous avons dit du départ en division des six canots sous le commandement de Turi, c'est que le mot Kariri, qui est ajouté au mot Waïma, signifie « mettre à la voile, prendre

(1) Ce mot Waima se trouve aussi dans trois ou quatre îles des Sandwich, et il est donné, à Hawaii, à plusieurs lieux différents. 
la mer ensemble. $\gg$ Cette expression ne pourrait-elle pas être celle qui a remplacé le Tu-i-Rangi des légendes?

Il est certain que si Turi eût fait voile de ce dernier Waima, plutôt que du premier, ce serait non seulement de la côte Sud-Est de l'île qu'il se serait éloigné ; mais, au lieu d'entrer dans le détroit de Cook par l'extrémité occidentale, comme nous l'avions d'abord pensé, il y aurait pénétré par l'extrémité orientale, avant d'aller aborder à Aotea, sur la côte Ouest, et de revenir de là sur ses pas, par terre, jusqu'à Patea. Dans cette supposition, il aurait eu à faire nécessairement plus de Nord-Est que d'Est, puisque l'Est direct l'eût éloigné du détroit, tandis que le Nord-Est eût suffi pour le conduire d'emblée à son entrée, d'autant plus sûrement que là, la déclinaison est de 18 degrés vers le Nord-Est. Dans cette supposition encore, l'île Rangitawha de la version Grey n'aurait toujours été que l'une des îles du détroit de Cook: peut-être l'île Mana ou l'île Arapaoa, ou même l'île Rangitoto (île d'Urville), comme nous l'avons dit déjà, etcomme quelques nouvelles raisons pourraient porter à le croire.

Mais il y a d'autres Waima d'où Turi aurait pu partir. L'un d'eux, le Waima-Taitai, est placé beaucoup plus vers le Sud-Ouest que le précédent, et de l'autre côté de la presqu'île de Banks. Il y a, il est vrai, entre lui et le lac Waiharakeke une assez grande distance; mais ce ne serait pas une raison suffisante pour faire rejeter l'opinion que ce Waima estle Waima-tu-i-Rangi de la légende. Il faut même reconnaître que si le départ de Turi se fût opéré de Waima-Taïtaï ou de Waima-Kihikihi, il expliquerait tout aussi bien, sinon mieux que les premiers, et son itinéraire et la position relative des principales tribus de l'Hawahiki. C'est, en effet, autour de ces Waima que sont surtout groupés les noms des principales localités del'Hawahiki : telles sont Moeraki, Rangiriri, Tautuku, etc. Ce dernier nom est donné à une rivịère et à une baie, qui se trouvent à peu de distance de la rivière Totoi et de la baie Molyneux dans le Sud de l'île, non loin, par conséquent, de l'île Rarotonga ou du Centre, 
et non loin également de la rivière Aparima ou Jacobs, du lac Waiota et du hâvre Awa-Rua.

Pourtant, la distance existant entre le lieu où aurait été abattu l'arbre destiné à faire le canot de Turi, et son point de départ, aurait été si grande, quoique sur le même côté de lîle, qu'il est permis de douter qu'il se soit agi de ces deux localités. On ne comprendrait pas, en effet, que Turi fût allé si loin au Nord pour trouver un arbre, quand il y en avait tant vers le Sud et à une distance bien moins grande,comme le montre la connaissance actuelle des localités,

S'il fallait s'en rapporter à la version du Rév. Taylor, il est vrai que ce serait de ce côté que l'arbre aurait été abattu, dans une rivière appelée Tautoru, nom qui ne se retrouve plus dans l'Ile-du-Milieu, mais qui est presque certainement la rivière Tautuku, dont nous venons de parler. Ce qui donne quelque créance à cette opinion, c'est d'abord que la distance entre les deux localités est assez faible et qu'ensuite c'est dans leur intervalle que se voient particulièrement les lieux d'où auraient pu provenir les compagnons de Turi, tels que les Oa-Maru, les Wanganui, les A wa-Rua. Nous aurons bientôt à revenir sur ce fait.

Il est bien certain d'ailleurs que si Turi fût parti de Tautuku, il aurait eu à faire route d'abord à l'Est, comme le dit la version de Sir Grey, puisque cette rivière gît dans l'OuestSud-Ouest de l'île; ensuite au Nord-Est, comme dans la supposition précédente, afin d'atteindre l'extrémité orientale du détroit de Cook. Ici encore, Turi aurait suivi la côte Est de l'Ile-du-Milieu, et il aurait eu à en parcourir toute la longueur avant d'arriver au détroit.

Il est vrai que, d'après le Rév. Taylor, ce n'est pas de Tautoru que T'uri s'est éloigæné d'Hawahiki : Tautoru était seulement la rivière où le canot avait été fait; mais Turi était parti d'un lieu appelé Whiti-Marama.

Ce qu'était ce lieu, rien absolument ne le dit, et ces mots manquent sur toutes les cartes. Cornme aucune légrende au. tre que celle citée par le savant missionnaire anglais n'en parle, il faut se borner à des conjectures sur sa véritable situation. Pour nous, nous croyons que c'est par erreur que 
les Européens ont regardé ces mots comme un nom de lieu. Whiti signifie «briller, luire ; marama, « lune. " Or, si l'on se rappelle que, d'après la version de Sir Grey, Turi descendit la rivière Waima-tu-i-Rangi pendant la nuit, on est autorisé à penser que le narrateur s'est servi des mots Whiti-Marama pour dire qu'on était parti à la clarté, an clair de la lune.

Quoi qu'il en soit de cette supposition, il est probable que le lieu ainsi nommé ne pouvait pas être bien éloigné de la rivière où l'arbre avait été abattu. Or, en admettant que cette rivière était Tautuku, il n'aurait pu être placé que dans le Sud-Ouest ou dans le Nord-Est, c'est-à-dire soit du côté d'Aparima et de Rarotonga, soit du côté de la baie Molyneux et d'Otago ; et comme c'est à Rarotonga qu'on était allé construire l'Arawa, le Taïnui et divers autres canots, il faut reconnaître que ces circonstances donnent une certaine valeur à cette dernière supposition.

Si enfin le mot Waimea, qu'on trouve donné à une rivière du détroit de Cook, avait été le mot Waima, mal entendu ou mal orthographié, Turi aurait pu partir de cette localité en même temps que son canot aurait été construit à Waiharakeke, comme le dit la première version.

Dans cette supposition, Toto et Turi se seraient trouvés voisins du lac Waiharakeke, aussi bien par terre que par mer, puisque la rivière Waïmea se trouve à mi-distance à peu près de côte la Ouest et de la côte Est. En admettant un pareil point de départ, il en̂t naturellement fallu faire route au Nord-Est pour doubler l'île d'Urville ; de là, en courant à l'Ouest, on aurait nécessairement aussi trouvé les récifs sur lesquels le Ririno s'est perdu. Mais on ne comprendrait pas alors comment Turi aurait eu si promptement besoin de relâcher en quittant Waimea qui se trouve presque à toucher; puis il faudrait encore admettre que Toto aváit ramené son canot de Waiharakeke. Tout ceci est peu admissible; aussi, nous ne nous arrêterons pas plus longtemps à cette supposition.

Après tout ce que nous venons de dire, il nous semble qu'll n'y. a à opter qu'entre les deux conjectures: Waiha- 
rakeke et Waïma-Kariri ou Taituku et Waima-Taitai. Ce sont du moins les plus satisfaisantes bien qu'elles soient loin d'aplanir toutes les difficultés.

Quel que soit, en somme, le lieu qui a servi de point de départ à Turi, il est un fait certain, dont nous ne pouvons trop faire ressortir l'importance, c'est qu'en s'éloignant d'Hawahiki, il s'est dirigé du Sud-Ouest vers le Nord-Est pour atteindre l'Ile-Nord de la Nouvelle-Zélande. Nous avions d'abord pensé, comme on a vu, qu'il avait dû partir de la côte Ouest; mais l'examen que nous venons de faire laisse supposer qu'il aurait aussi bien et même mieux pu suivre la côte opposée et en partir. L'île que les légendes appellent Rangitawha ou Motiwhatiwha n'était presque certainement, quoique l'on ne retrouve plus ces noms, que l'une des îles du détroit de Cook.

Que Turi fût parti de l'Est ou de l'Ouest de l'Ile-du-Milieu, il est certain, encore une fois, qu'il s'était dirigé vers le point où le soleil se lève, et que, par conséquent, il n'avait pu venir d'un Hawahiki placé dans les îles Samoa: car alors, en faisant route à l'Est, il eût tourné le dos à la Nouvelle-Zélande.

Presque tous les écrivains ont remarqué que les canots de la grande émigration sont, pour la plupart, arrivés au cap Est de l'Ile-Nord ou Waiapu. Cette remarque vient ellemême prouver, avons-nous déjà dit, qu'ils avançaient en suivant la côte et en allant du Sud-Ouest vers le Nórd-Est. s'ils fussent venus des îles Samoa, une pareille route aurait été impossible à comprendre; elle s'explique, au contraire, tout naturellement dans notre hypothèse, puisqu'en avançant il fallait qu'ils rencontrassent le cap Est et le port Whangaparaua, où on les voit tous relâcher.

Nous allons encore chercher à retrouver quelques-unes des localités occupées par certaines tribus de l'Hawahiki.

Des renseignemènts donnés par le Rév. Taylor, il résulte que certaines tribus ont été dans la nécessité d'émigrer. Parmi ces tribus, il faut surtout citer celle des Ngati-RuaNui. 
Ainsi, on voit cette tribu former à elle seule les équipages:

De Kupe, sur le Mata-Horua;

De Uengapuanaki sur l'Orouta (1) ;

De Tama-te-Ahu-Tahi-Nuku-Roa, sur le Taki-Tumu ;

De Mawha-Keroa, sur le Waka-Ringaringa;

De Tama-te-a-Rokai, sur le Te-Rangi-ua-Mutu.

On la retrouve sur l'Aotea, commandé par Turi, en même temps que s'y trouvaient des Nga-Rauru, des Wanganui, et des Ngati-Maru;

Sur le Kurahaupo, commandé par Ruatea, avec des Ngati-Apa, des Taranaki, et des Ngati-Kahungunu;

Sur lo Matatua, avec Rua-Auru, il y avait des NgatiRua-Nui et des Ngati-Kahungunu.

Rakewananga, sur le Papa-Ka-Toru ou Pangatoru, avait des Ngati-Rua-Nui, et des Nga-Rauru : quelques traditions disent que les habitants primitifs de l'Ile-Nord les empêchèrent d'aborder.

Rakeora, le chef du Tokomaru, d'après certaine version, était accompagné de Ngati-Rua-Nui, de Ngati-Tama, de Ngati-Motunga, et de Ngati-A wa.

Sur le Motumotu-Ahi, commandé par Puatautahi, se trouvaient des Nga-Rauru et des Ngati-Rua-Nui.

Seuls le Taïnui et l'Arawa n'avaient pas de Ngati-RuaNui. L'équipage du Tainui, commandé par Hoturoa, se composait de Waïkato, de Ngati-Rau-Kawa (2), de NgatiAwa et de Nga-Puhi ; celui de l'Arawa, ayant pour chef Tama-te-Kapua et pour grand-prêtre Ngatoro-i-Rangi, était composé de Ngati-Wakaue et de Ngati-Porou.

Comme on le voit, il y avait des Ngati-Rua-Nui dans presque tous les canots, et, dans cinq d'entre eux, l'équipage n'était formé que par cette tribu, c'est-à-dire qu'ils faisaient partie de l'équipage de onze canots sur treize.

Les tribus citées le plus fréquemment après eux, sont les

(1) Probablement pour Horouta : horo, tomber, ébouler; uta, terre.

(2) On lit dans la légende de Kupe rapportée far Sir Grey, que le détroit de Cook était appelé Raukawa. 
Nga-Rauru, qu'on voit dans quatre canots; les Ngati-Awa etles Ngati-Kähungunu qu'on voit dans deux. Toutes les autres, c'est-à-dire les Wanganui, les Ngati-Maru, les Ngati-Apa, lés Taranaki, les Ngati-Tama, les Ngati-Motunga, les Waïkato, les Ngati-Rakawa, les Nga-Puhi, les NgatiWakaue et les Ngati-Porou, ne sont citées qu'une fois.

Enfin, un chant attribué à Uenuku apprend que les Ngati-Rua-Nui, de même que les Rongotea, étaient les alliés de ce grand-prêtre, qui fut tuépar Tama-te-Kapua, au moment de son émigration pour Aotearoa.

Maintenant, nous allons rechercher quel pouvait être le point de l'Hawahiki habité par les Ngati-Rua-Nui. On voit d'abord quili y a une rivière appelée Awa-Rua-Nui sur la côte Ouest de l'lle-du-Milieu, entre le hâvre Milfort et la baie Jakson, un peu plus au Sud que la rivière. Wanganui, et presque vis -à-vis Moerangi ou mieux Moeraki qui se trouve sur la côte Est. Cette rivière sort des lacs Wanaka et Wairaki, qui sont voisins du fameux lac à jade vert, appelé Wakatipua.

Il n'y a pas d'autre rivière de ce nom ; mais on trouve une baie Awa-Rua, près la pointe de séparation, dans le détroit de Cook, et un port ou hâvre Awa-Rua, tout-à-fait à l'extrémité Sud de l'Ile-du-Milieu, vis-à-vis l'île Stewart, c'està-dire aux deux points extrêmes de l'île.

Serait-ce ce dernier Awa-Rua qui aurait été habité par les Ngati-Rua.Nui, plutôt que le premier" Tous les deux l'auraient-ils été par la mème tribu? C"est ce qu'il est difficile de dire d'une manière certaine; mais, pour ure foule de raisons, il est à croire qu'ils habitaient le premier lieu et ses environs.

Quand on remarque que c'est dans cette partie de l'île que se trouvent leș lieux produisant le jade vert en abondance, on a pour ainsi dire toute l'explication de leur expulsion etde celle des Ngati-Kahungunu qui, daprès d'anciennes traditions, occupaient, il y a plusieurs siècles, toutes les côtes Est de l'Ile-du-Milieu. Il est même très probable que les Ngati-Rua-Nui, s'étendaient jusqu'à la rivière Waitangi, de l'autre côté de l'île, c'est-à-dire vers le mont III

28. 
Tuhawaiki, près de Moerangi, lieu d'origine à peu près certain des idées religieuses des Nouveaux-Zélandais.

Quoi qu'il en soit, quels que fussent l'étendue et le point principal des lieux occupés par les Ngati-Rua-Nui; les canots de Kupe et de quatre autres chefs n'étaient montés que par des gens de cette tribu, et l'on doit supposer', d'après cela, que ces chefs en faisaient eux-mêmes partie.

Quant à Turi, il semble avoir été un Wanganui, bien qu'il eût à la fois dans son équipage des hommes des tribus Ngati-Maru, Nga-Rauru, Wanganui et Ngati-Rua-Nui. C'est la'conclusion à laquelle conduit le nom de Wanganui-a-teRa, qu'il donna, d'après la légende, à la rivière qu'il découvrit sur Aotearoa, dans le détroit de Cook. C'est également ce que montrent les noms des lieux qu'il habitait. Qu'on choisisse le Waima de la côte Ouest, ou le W'aima-Kariri qui débouche sur la côte Est; qu'on préfère la rivière Wanganui de la côte Ouest, ou. celle qui a son embouchure sur la côte Est près de Rakitata ou rivière Alford, tout cela place sa résidence dans l'espace existant entre Moerangi et la pres. qu'île de Banks d'une part, la baie Jakson et la rivière Arehura de l'autre, c'est-à-dire plus au Nord que les Ngati-Rua Nui, et presque vers le milieu de l'île, dans ce qu'on appelle aujourd'hui la province ou district de Canterbury.

Rien, dans les traditions, ne permet de soupconner quelle pouvait être la localité occupée par les Ngati-Rauru; mais de quelques noms retrouvés justement dans le même espace, on pourrait peut-être supposer que c'était là qu'habitaient les Ngati-Maru, ces autres compagnons de Turi. En effet, il existe une rivière $\mathrm{O}$-Amaru, près de la rivière TeAwa-Mokihi, puis un Te-Maru (Road Stead), non loin de la rivière Whanganui, de Waiteruati et de la rivière Alfort ou Rakitata. On sait que Maru était le Dieu de la guerre dans l'Ile-du-Milieu, et on a vu que Kapo, jeté à la mer et repris par Turi, était un prêtre de ce Dieu.

Quelle qu'ait pu être la position relative de toutes ces tribus, il est certain qu'elles ne pơvaient pas être bien éloignées les unes des autres. Cela explique suffisamment 1» variété des hommes composant l'équipage de Turi, et 
surtout la présence des Wanganui, puisque ce chef, comme Uenuku et tant d'autres, semblait appartenir à cette tribu.

Ce grand-prêtre Uenuku, Hou, le père de Tama-te-Kapua et une foule d'autres chefs, habitaient justement aussi l'espace dont nous venons d'indiquer les limites, probablement du côté oriental ou mieux Sud-Est de l'île. Ce qui prouve qu'ils étaient proches voisins, c'est ce que disent les légendes du moyen employé par Turi pour attirer le fils de Uenuku e tuer; c'est ce qu'elles rapportent des excursions nocturnes de Tama-te-Kapua et de Whakaturia, pour aller manger les fruits de Uenuku ; etc. Mais ce n'est pas ici le lieu de traiter cette question incidente, et nous nous bornons à renvoyer à la traduction que nous avons faite de ces légendes.

En résumé, tout semble donc bien prouver que les émigrants, au lieu de venir d'un Hawahiki placé dans les Samoa, c'est-à-dire dans le Nord-Est, venaient d'un Hawahiki situé dans l'Ile-du-Milieu, c'est-à dire plus à l'Ouest encore que l'île envahie par eux. Seul ce point de départ peut expliquer la croyance générale des Polynésiens que, quelle que fût la positịon de leurs îles, c'était vers le Couchant que se trouvait leur patrie première.

Telle est, on le sait, la croyance de tous les Polynésiens; mais ce que l'on ne savait pas peut-être, c'est que le mot Hawahiki et ses équivalents ne sont, ainsiécrits, ni maori, nj polynésiens, et que ces mots ne sont pas davantage le nom particulier d'une contrée, comme on l'a cru. En effet, quoi qu'en aient dit les voyageur's, il n'y a point d'île de ce nom, et le mot Hawahiki n'est qu'une expression collective, composée de plusieurs mots distincts ayant chacun une signification particulière. C'est, pour ainsi dire, un terme abstrait qui, à la Nouvelle-Zélande, fait entendre aux oreilles européennes à peu près le son Hawaïki, pendant qu'ailleurs c'est celui de Havai, Avaiki, Hawaii, etc. Ainsi écrit, le mot Hawahiki n'existe même pas dans l'Ile-Nord de la NouvelleZélande; mais là; comme dans tous les archipels polynésiens, ef dans l'Ile-du-Milieu, on trouve les mots qui ser- 
vent à le former et qui, réunis, rendent le son que les voyageurs ont voulu représenter.

Ces mots, à la Nouvelle-Zélande, sont:

$H a$ (1) et $k a$, de, sur, c'est ;

$W a$, pays, contrée;

Hiki, qui nourrit, nourrice, qui porte, terre:

C'est-à-dire « pays nourricier, Patrie. »

Il en résulte que tous les mots donnés jusqu'à ce jour par les navigateurs ont été mal écrits, mais qu'ils sônt cependant les véritables représentants du nom « Patrie, s et qu'ils rendent assez exactement le son produit par chacun d'eux, quand, prononcés par les indigènes, ils sont entendus par des oreilles européennes. Ce son est: Hawaïlci à la Nouvelle-Zélande; Savaii aux Samoa; Havai, dans les îles de la Société; Havaïki aux Marquises: Avaïki aux Mangareva et dans les îles du groupe Hervey; probablement Hapai aux îles Tunga ; enfin Hawaii aux Sandiwch.

Nous sommes convaincu que ce mot, à la Nouvelle-Zélande, aurait dû être écrit et prononcé Hawahiki ou Kawahiki, et cela, pour deux raisons : D'abord parce qu'ainsi on rend mieux la prononciation; puis parce qu'on approche davantage de l'orthographe exigée par la' langue Maori. Tous ceux qui se sont occupés des langues polynésiennes savent que, dans les îles où le $h$ a été adopté, cette lettre représente la forte expiration, (aspiration des écrivains,) ouvrant la prononciation des mots qui, en Maori, commencent par un $k$. Dans les îles Samoa, cette dernière lettre, déjà adoucie en $h$ dans les autres archipels, s'est transformée en $s$ par suite du voisinage des Fijiens qui se servent de cette lettre.

Mais il ne suffit pas, nous nous en sommes assuré nousmême sur les lieux, d'une seule aspiration pour rendre exactement la prononciation des indigènes. Si cela a paru suffisant aux Européens, c'est qu'ils se sont contentés de rendre assez exactement, mais non d'une manière aussi exacte que l'exige la'linguistique, les sons entendus par

(1) $H a$, dans l'Ile-du-Milieu, presqu'île de Banks. 
eux. Nous avons trop souvent entendu, aux îles Marquises même, le mot Havaïki des voyageurs, pour ne pas être certain que ce mot devrait être écrit Hawahiki, afin de rendre exactement sa prononciation, quoiqu'en ait dit le missionnaire Mathias. Il en est de même du mot Hawaii, qui devrait, croyons-nous être écrit Ha-wa-hii ; de même Savaii, qui devrait l'être Sa-va-hii, comme celui des îles dela Société, Ha-va-ii. Car les mots hii et ii ne sont que le mot hiki, modifié d'après l'euphonie polynésienne locale. Comme lui, ils signifient : « porter, élever, nourrir.»

Quelle que soit, 'en somme, la manière d'écrire tous ces mots, ils ne signifient que x pays nourricier, patrie; $\gg$ mais nous croyons qu'ils devraient être orthographiés de la manière suivante :

A l'Ile-du Milieu de la Nouvelle-Zélande : Ha-wa-hiki;

A l'Ile-Nord de la Nouvelle-Zélande : Ka-wa-hiki;

Aux îles Hervey: Ha-va-hiki;

Aux Mangareva: Ha-va-hiki;

Aux Samoa: Sa-va-hii;

Aux Tunga: Ha-pa-hii;

Aux Iles de la Société : Ha-va-ii;

Aux Marquises: Ha-va-hiki;

Aux Sandwich: Ha-wa-hii;

C'est l'origine que nous avons reconnue comme étant celle des Maori, qui nous a conduit à l'adoption de cette étymologie ; mais il est à remarquer que l'île oì no'ı's pla. cons l'Hawahiki, porte un nom assez peu connu jusqu'à ce jour, celui de Kawaï. Les navigateurs qui ont le plus approché du nom véritable sont Cook et d'Urville.

Serait-ce donc ce mot Kawaï qui aurait servi à former le mot Hawahiki, plutôt que les mots que nous avons indiqués? C'est possible; mais, dans ce cas mème, le mot Kawahiki, ainsi écrit, c'est-à-dire avec le qualificatif hiki, ne serait pas davantage le nom d'une contrée. Kawaï étant le nom de l'île, il faudrait alors écrire : Kawaï-hiki, « Ka waï, la terre nourricière. (1) De la sorte seulement, ce

(1) Kawaï signifie rejetons, lignée, race. 
mot collectif pourrait, comme on l'a dit sans s'en rendre compte, être le nom d'une contrée. Mais cette contrée ns serait elle-même, ainsi que nous avons cherché à le prouver, que l'Ile-du-Milieu de la Nouvelle-Zélande. (1) Nous croyons donc, en somme, qu'il faut préférer la première étymologie.

(1! Nous ferons remarquer ici qu'il existe, dans l'Hle-du-Milieu, une montagnne appelé Tu-Hawahiki ou Tu-Hawaïki, et dont nous avons précédemment cité le nom plusieurs fois. 


\section{CHAPITRE TROISIÈME}

\section{PEUPLEMENT DE L'ILE-NORD}

Opinions à ce suijet, de d'Urville et de Kendall; de Dieffenbach; de Taylor ; de Thompson; de Quatrefages. - Indigènes trouvés à Aotearoa par les Hawahikiens: Preuves à l'appui. - Maero et Ngati-Mamoe; Patu Paearehe; Mere Punanamu ; étymologie du mot Tunga; Ngati Kahungunu. - Résumé général.

En exposant les témoig’nag’es qui, d'après nous, prouvent que l'Hawahiki était situé dans l'Ile-du-Milieu, nous avons avancé que cette île avait peuplé l'lle-Nord de la NouvelleZélande, ou Aotearoa, eî nous nous sommes borné à dire que l'opinion contraire était sans fondement, bien qu'elle ait été et qu'elle soit soutenue par les ethnologues les plus compétents.

Nous allons maintenant rappeler les raisons sur lesquelles ceux-ci se sont appuyés pour étayer cette opinion et nous montrerons le peu d'importance de leurs arguments. Puis nous examinerons si l'île Aotearoa était on n'était pas habitée lor's de la venue des émigrants d'Hawahiki; nous chercherons si ces émigrants y sont arrivés, en une ou plusieurs fois, d'un seul ou de plusieurs points ; éc nous essaierons de conjecturer l'époque de la grande émigration. Enfin, nous terminerons par quelques recherches linguistiques.

Tous ceux qui ont écrit sur la Nouvelle-Zélande s'accordent à dire que ce n'est pas l'He-du-Milieu qui a peuplé l'Ile-Nord, mais bien l'Ile-Nord qui, après avoir reçu ses habitanıs d'Hawahiki, en a envoyé une portion peupler l'Ile-du-Milieu. Toutefois, nous l'avons dit ailleurs, cet ac. cord ne doit nullement surprendre; il ne pouvait pas ne 
pas exister : du moment qu'on faisait venir les habitants de l'lle-Nord d'un Hawahiki placé dans la Polynésie, il fallait bien qu'on regardât l'île la plus éloignée comme la dernière peuplée,

D'Urville et le missionnaire Kendall semblent avoir les premiers émis cette opinion, qu'ils tenaient d'un chef zélandais de la Baie-des-Iles, nommé Tuaï. Ce chef, mort six mois après le passage de la Coquille en 1824, désignait les habi.. - tants de l'Ile-Nord comme les véritables indigènes. Il les appelait, ainsi que nous l'avons déjà dit précédemment (l), Kainga-Maori, «autochthones, "tandis qu'il désignait les habitants de l'Ile-du-Milieu sous le sobriquet de Kaikoura ou * mangeurs d'écrevisses. » Au surplus, d'Urville et Kendall ignoraient que des populations eussent existé sur l'Ile-Nord avant l'arrivée des émigrants, et l'on ne possédait guère, à cette époque, que les renseignements les plus erronés sur l'Ile-du-Milieu, même quand ces renseignements étaient fournis par des Maori de l'lle-Nord. On peut dire que le témoignage de ces deux écrivains et celui de leur autorité Tuai n'avait aucune valeur.

Après eux, Dieffenbach dit nettement qu'il n'y avait pas d'habitants sur l'Ile-Nord avant l'arrivée de ceux qui l'occupent aujourd'hui, et que cette terre était couverte de forêts (2). "Déjà il avait dit (3) qu'excepté les Rangitawe et les Ngaitahu, il n'y avait pas d'indigènes dans l'lle-du. Milieu, et qu'il n'y avait, à l'île Stewart, que ceux qui y accompagnaient les baleiniers. Mais il ne s'appuyait guère, pour la première île, que sur la tradition qu'il rapportait et que nous avons longuement examinée ; quant à la seconde, son voyage s'étant borné au détroit de cook, il ne pouvait avoir que des renseignements sans importance, que détruisent ceux que nous allons voir donner par Shortland.

Nous ne savons quelle était l'opinion de M. Hale à ce sujet mais, de l'ensemble de son hypothèse, on pourrait

(1) Voy. ci-dessus, chap. I, p. 1\%, 18.

(2) Travels in New-Zealand, t. II, p. 85.

(3). Ibid. p. 81. 
conclure qu'il regardait la Nouvelle-Zélande comme inhabitée avant l'arrivée des émigrants qu'il fait partir de Savaii.

Celle de Shortland semble plus formelle, car il dit (1) : < Toutefois, l'opinion que ces îles étaient inhabitées à une période éloignée, trouve un appui dans la rareté générale de la population, au temps de la découverte de Cook, et plus particulièrement dans l'lle-du-Milieu et celles du Sud qui, d'après les rapports des Nouveaux-Zélandais, ont été colonisées par l'Ile-Nord.» Et comme il dit ailleurs que l'Ile-Nord était déserte à l'arrivée des émigrants d'Hawahiki, il faut nécessairement en conclure que, pour lui, l'Ile-duMilieu était encore moins habitée que l'Ile-Nord à l'époque dont il parle.

Mais, quelle confiance peut-on accorder à une pareille assertion, quand on voit le même écrivain (2) signaler les Ngati-Mamoe, comme très nombreux et comme occupant presque toute l'Ile-du-Milieu, trois siècles auparavant? Quand ailleurs (3) il dit, en renvoyant à la page que nous venons de citer des Southern districts, que les Ngati-Mamoe étaient les premiers colons de l'Ile-du-Milieu, et qu'ils furent conquis, plus țard, par une portion de la tribu Ngati-Ka-Hungunu venant de l'Ile-Nord, et, précédemment, d'Hawahiki, plusieurs siècles auparavant ? Si, en effet, les Ngati-Ka-Hungunu, dont il parle, sont allés sur l'Ile-du-Milieu il y a 270 ans, il est certain, d'après les traditions, qu'ils venaient eux-mêmes d'Hawahiki et que, par conséquent, ils étaient arrirés à l'lle-Nord plusieurs siècles auparavant; si donc l'Hawahiki était sur l'Ile-duMilieu, c'est de cette dernière île qu'ils étaient partis,

Le Rév. Taylor, sans oser se prononcer, rapporte les récits demi-fabuleux des indigènes de l'Ile-Nord concernantl'exis. tence d'êtres humains que les émigrants d'Hawahiki auraient trouvés à leur arrivée dans cette île. 11 semble disposé à admettre que ces récits font allusion à une race arborigène, et il ajoute même: "Beaucoup de choses font croire

(1) Traditions and Superstitions, p. 30.

(2) Southern districls, p. 98.

(3) Traditions and Superstitions, p. 28. 
que les Maori de l'Ile-Nord n'ont point été les premiers habitants de cette terre. »Ainsi, on lui a assuré qu'il y a encore, dans la chaîne des monts Tararua, une tribu nombreuse appelée Mariri, et identique à celle des Ngati-Mamoe. A certains détails donnés par Taylor, l'on ne peut, croyons-nous, douter que les récits n'aient voulu parler de populations antérieures, populations dont l'existence est démontrée par les traditions elles-mẹmes.

Du reste, pour le Rév. Taylord (1), il était évident qué, d'après leurs propres récits, les Néo-Zélandais n'étaient pas, tous en même temps, venus d'un même lieu, ni arrivés d'un même point (2).

Il était arrivé à cette conclusion en remarquant la différence existant entre les dialectes des diverses tribus, différence qui lui semblait suffisante pour que le philologue de la Polynésie pût préciser le lieu d'où chacune d'elles était partie. Ce qui le lui démontrait le plus, c'était la variation

(I) Te Ika a Maui, p. 190.

(2) S'il fallait. s'en rapporter au récit de Hakakai, ce grand-prêtre qui a pu citer au Révérend Taylor 26 générations depuis l'ạrivée des premiers émigrants jusqu'en 1840, ces émigrants, au lieu de venir d'un seul point, seraient venus, comme nous l'avons déjà dit, de trois îles différentes qu'il appelle Hawahiki, Matatera et Waïrota. « Toutes ces îles, ajoute Taylor, gisent dans l'Est. »

Aucune île portant ces noms ne se trouve en Polynésie, et aucune ne pouvait s'y trouver avec l'orthographe qu'on leur donne, orthographe tout e Maori. Mais, fait plus important, les deux derniers noms semblent, eux-mêmes, appartenir plus spécialement à cette partie de l'Ile-du-Milieu, que nous avons dit être l'Hawahiki ou du moins en être voisine : ce seraient alors les mots Mataura ou Totoi et Waïota, noms qui, on l'a vu, sont ceux de la grande rivière dans laquelle se déverse la rivière Waïharakeke, et d'un lac situé entre la rivière Molyneux ou Matau et la rivière Taieri.

Vraiment, quand on voit que c'est là encore que se trouvent les noms Aparima ét Wairaki, qui sous la forme Apalima et Wairoti ont tant intrigué les ethnologues, de même que c'est là, presque nécessairement, qu'existait le Tini-o-Manono, demeure de Kae, on ne peut, sans idée préconçue, refuser de reconnaître que l'Hawahiki devait exister surtout de ce côté de l'lle-du-Mi* lieu. 
de certains noms dans différentes parties de l'île; cette variation prouvait, disait-il, que chaque émigration avait donné ces noms d'après lïmpression éprouvée au moment du débarquement; et il citait les suivants qui se rendent différemment dans l'Ile-Nord et dans l'Ile-du-Milieu:

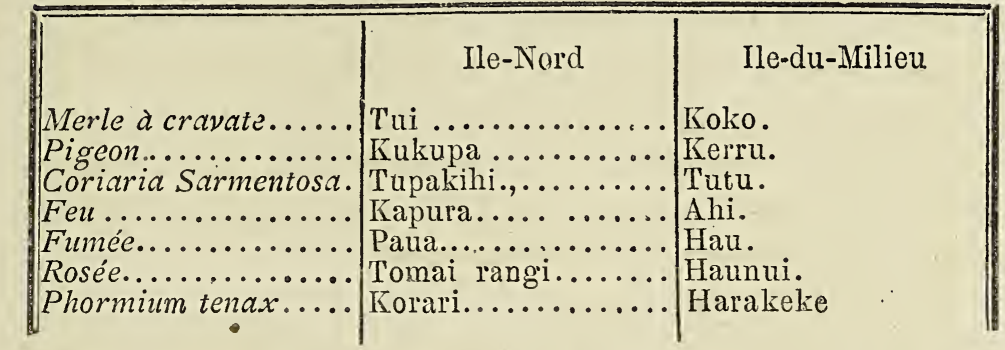

Il en était de même, suivant lui, de presque tous les noms de plantes.

Mais les citations de Taylor ne sont pas tout à fait exactes : si, par exemple, le nom donné au Phormium dans l'Ile-Nord est Korari et Harakeke dans l'Ile-du-Milieu, le mot Korari est également employé dans cette dernière île et appliqué à la fleur seule du Phormium. Il en est de même pour tous les autres mots: Le nom générique du pigeon est bien Kutipa dans l'Ile-Nord; Kuku et Kerįru dans l'Ile-du-Milieu; mais Kereru est aussi le nom donné à cet oiseau par les habitants diu cap Est de l'Ile-Nord. Koko et Tuisont des synonymes, et si le premier est le nom du merle à cravate dans l'Ile-du-Milieu, il désig’ne aussi le même oiseau au cap Est sur l'Ile-Nord. Le mot Tupakihi est le synonyme de Tutu, de Puhou et de Taweku : or, dans l'Ile-Nord, les Waïkato emploient ce dernier mot. Ahi est également usité dans la mème île. Fumée ne se dit pas Paua, mais Paoa et Hau est Auahi; enfin, Tomai rangi et Haunui sont synonymes.

Ainsi, la preuve qu'il tirait de la variation de certains noms n'était pas aussi démonstrative qu'il l'avait eru ; la dif* férence qu'il signalait, et qui existe réellement, n’ètait guère significative, car elle s'explique aussi bien par la différence des localités, par la séparation des tribus, dans des îles très étendues, où les rapports amicaux étaient rares, que par la 
supposition de provenances diverses opérées de la Polynésie. Ces provenances, d'ailleurs, il les réduit lui-même à deux: l'Hawahiki éloigné ou les.îles Sandwich, et l'Hawahiki proche ou l'île de Tahiti. C'est ce que nous avons fait voir précédemment.

Thompson, s'est chargé de détruire cette assertion. Voici ce qu'il dit à ce sujet (1) : \& Mes propres recherches m'ont porté à conclure que la Nouvelle-Zélande a été peuplée par une seule source et à la même époque; mais le révérend M. Maunsell pense, au contraire, que les Nouveaux-Zélandais, en raison de trois particularités linguistiques, sont venus d'îles différentes (2).

Ces particularités sont que:

$1^{\circ}$ Les Nga-Puhi, qui vivent dans les environs de la baie des Iles, prononcent le $h$ comme s'il y avait sh; le mot hongi, par ex., est prononcé shongi;

$2^{\circ}$ Les naturels de Taranaki ne prononcent pas du tout le $h$, mais le remplacent par une curieuse saccade de la voix, de sorte que, dans leur bouche, hei devient eï, et ho. horo, orro;

$3^{\circ}$ Quelques tribus, dans labaie d'Abondance, ne font pas entendre le singulier son nasal ng des bons linguistes Maori ; elles emploient à sa place la syllabe $n a$.

Thompson terminait en ajoutant, comme conclusion : ces particularités de langage sont bien légères quand on les compare à celles que présente l'Anglais, parlé par des Anglais mêmes, dans des comtés différents, et elles sont insuffisantes, à notre avis, pour prouver que les Nouveaux-Zélandais sont venus de sources diverses. $\gg$

C'estaussi notre opinion; mais comme cette question n'est ici que très secondaire et que nous l'avons déjà précédemment traitée (3), nous ne nous y arrêterons pas plus longtemps. Nous allons donc examiner l'opinion de M. Thompson concernant le peuplement de l'lle-Nord, et la

(1) The Story of the New-Zealand, vol. I, p. 66.

(2) Grammar of the New-Zealand Langage, 1842.

(3) Vol. 1II, L. II, ch. III, p. 208. 
présence ou l'absence de populations sur cette île à l'arrivée des émigrants d'Hawahiki.

Nous le dirons de suite, le témoignage de M. Thompson à cesujet, témoignagesur lequel M. de Quatrefages s'est tant appuyé dans son travail sur les Polynésiens, a bien certainement moins de valeur encore que celui de M. Shortland; il prouve même plutôt en faveur de l'opinion que nous soutenons que contre elle.

Thompson manque évidemment d'exactitude quand il avance (1) qu'il n'y avait aucun être humain sur les îles à l'arrivée des émigrants; que' ce sont des conflits, survenus plusieurs siècles auparavant, que les traditions ont transformés en combats entre les émigrants et les habitants primitifs, mais qu'il n'y avait rien de vrai dans ces rapports. En effet, les traditions, en outre de certains conflits entre émigrants, qu'elles distinguent parfaitement, comme nous l'avons surabondamment montré, établissent nettement que des populations ont été trouvées par les Hawahikiens à leur arrivée sur Aotearoa. Elles le font même si clairement que nous ne concevons pas comment l'auteur anglais a pu nepas le voir dans les livres qui lui ont servi pour écrire son ouvrage.

Quoi qu'il en soit, ce sont bien certainement les assertions précédemment réfutées de Shortland, Thompson et Taylor, qui ont porté M. de Quatrefages à soutenir, lui aussi, que l'Ile-Nord était à peu près déserte à l'arrivée des émigrants d'Hawahiki. Voici ce qu'il dit à ce sujet (2):

* D'autre part, tous les émigrants semblent avoir abordé, comme Kupe, sur des terres désertes. L'histoire de leur colonisation ne mentionne aucune population antérieure, et, s'ils rencontrent des hommes, ce sont toujours des compatriotes qui les ont précédés. Manaia lui-même fait une rencontre de ce genre. »

Et i.l ajoute: « Ces faits très précis, ont conduit la plupart des historiens modernes de la Nouvelle-Zélande à regarder cette terre comme ayant été absolument inhabitée à l'époque de l'arrivée des Maori. .

(1) Ouv. cité, p. 61 .

(2) Les Polynésiens, p. 132. 
Pour soutenir son opinion, le savant français s'est surtout appuyé sur ce que les traditions ne citent, dit-il, qu'un exemple de population peu nombreuse trouvée sur Aoatearoa par les émigrants. C'est une erreur : Sir Grey luimême en cite aụ moins deux exemples dans son livre, et Taylor en fournit plusieurs autres dans le sien. L'exemple cité n'est du reste que celui rapporté dans « l'Emigration de Manaia » et observé à Routu sur la côte Ouest de l'Ile-Nord.

Or M. de Quatrefages n'avu, dans cette population, qu'une race inférieure en force physique et en courage (1), et il a admis qu'elle avait pu être formée par des Mélanésiens entraînés jusque-là par les courants : "Très probablement, dit-il, quelques tribus de nègres océaniens ont les premières habité ces cantons jusque-là désẹrts et, en partie exterminées par les Hawaïkiens, en partie réduites en escla. vage, elles se sont fondues peu à peu avec les basses classes de la société nouvelle (\%). 》

Il est plus que probable, en effet, que, quel qu'eût été le lieu de provenance, les choses se seraient ainsi passées: Extermination ou esclavage. Mais ce n'est pas moins à tort qu'on a conclu de la population exterminée par Manaia, et surtout du silence gardé, croyait-on, par les traditions sur l'existence d'autres populations à Aotearoa, que ces populations étaient rares. Nous avons déjà montré (3) qu'il n'en était pas ainsi, et il va nous suffire de citer quelques ręlevés des traditions elles-mêmes, pour prouver le contraire.

Nous ne nous arrêterons donc pas ici à faire remarquer que Manaia avait commencé, en effet, par avoir une dispute avec d'autres émigrants partis en mème temps que lui d'Hawahiki. Nous nous bornerons à renvoyer à notre traduction des légrendes de Sir Grey, qui décrivent avec tant de détails cette dispute arrivée entre les gens du Tokomaru et ceux du Taïnui, dans le port du Cachalot ou Whangaparaua (4). Mais il n'en était pas de même de la rencontre faite

(1) Ouvr. cité, p. 134.

(2) Ces nègres Océaniens étaient pour lui des Australiens.

(3) Voy. ci-dessus, p. 322, 364, 3\%4, 396, 399.

(4) Sur la côte Est de l'Ile-Nord, près du cap Est. 
par Manaia à Routu, vers l'embouchure de la rivière Waïtara, sur la côte Ouest de la même île. La légende dit nettement que les habitants rencontrés étaient « indigènes, originaires de ces îles. »

Voici du reste les quelques exemples que nous avons relevés dans les traditions, et que nous croyons devoir citer en détail pour qu'on ne puisse les nettre en doute.

Sir Grey rapporte (1) la renestre faite par Ihenga, en chassant le Kiwi, d'une popula ion assez considérable sur les bords du lac Roto-Rua. Cette population parlait la même langueque les envahisseurs, commele propve la dispute qui s'éleva entre son chef et Iheng*a, et qui est longuement rapportée par Sir Grey; elle avait toutes leurs coutumes, toutes leurs croyances.

Plus loin (2) il relate le fait cité par $\mathrm{M}$. de Quatrefag'es et qui est attribué à Manaia, le capitaine du Tokomaru.

Les autres exemples sont fournis par le révérend Taylor. Ainsiil dif(3), contrairementà ce qu'avance M.de Quatrefag'es, que Kupe, capitaine un Matahorua, trouva sur la Tauwhenua ou Tuawhenua, " terre étrangère s ou a grande terre, » en un mot, sur Aotearoa, une population nommée KahuiToka, et dontles chefs étaient appelés Ket Rehu et Monoa : Ces noms, comme nous l'avons déjà fait remarquer (4), sont tous Maori.

Le même écrivain cite (5) une tradition rapportant que Turi, sur l'Aotea, et son fils, trouvèrent des hommes là ou ils s'arrêtèrent sur Aotearoa, et qu'ils les tuèrent. La tradio tion ajoute que ces hommes étaient appelés Kohikohi et qu'ils avaient reçu des émigrants le sobriquet de Kiri-WakaPapa, c'est-à-dire de côtes nues, pelées ou mieux, de «peau faite en planches. "lls étaient si nombreux que Turi jusqu’à

(1) Pólynésian mythology, p. 153.

(2) Ibid. p. 233.

(3) Te Ika a Maui, p. 124.

(4) Voy. ci-dessus, p. 364.

(5) Ouvr. cité, p. 119. 
sa mort, ne cessa de prendre des précautions pour empêcher leurs attaques $(l)$.

Il est vrai que la tradition de Ngahue ne parle pas d'une pareille rencontre pendant tout son voyage; mais dans celle qui est relative au canot le Pangatoru ou Papakatoru, commandé par Rakewa-Nanga-Ora, il est dit que l'équipage de ce canot, venant d'Hawahiki, ne put débarquer à Aotearoa par suite de l'opposition que lui firent les populations de la localité.

Voilà donc cinq canots sur six qui ont rencontré des populations primitives dans les points de l'île où ils ont abordé ; et il est à supposer que plusieurs autres, dont il n'est pas parlé, en ont également rencontré. Mais n'y aurait-il que cinq canots, ils suffiraient évidemment à prouver que l'île Aotearoa n'était pas aussi déserte qu'on l'a dit.

Il est certain, qu'après de pareils faits, il faut au moins hésiter à se prononcer un peu plus que ne l'a fait $M$. de Quatrefages quand il écrit (2): «Le petit nombre d'habitants primitifs est incompatible avec l'idée d'une population filie du sol, et même avec celle d'une population parvenue depuis longtemps dans ces îles. Il est évident que ces prétendus indigènes degaient être eux-mêmes des étrangers, arrivés depuis peu, et qui n'avaient pas eu le temps de'se multiplier. D

Nous n'admettons pas, commele célèbre professeur, et nous avons cherché ailleurs à le démontrer, que les caractères physiques des classes inférieures chez les Maori * diffèrent. essentiellement $>$ de ceux des autres classes, et permettent de répondre * presque avec certitude $\gg$, parce qu'ils accusent la prédominance du sang nègre; nous sommes bien convaincu, au contraire, que cette croyance ne provient que d'une erreur d'observation, et qu'il n'y a pas, nous l'avons déjà dit et répété, une seule physionomie nègre, même dans les classes inférieures. Il nous est donc impossible de croire, avec le savant français, que ce sont des Mélanésiens entraînés jusque-là, qui ont donné aux classes

(1) Voy. ci-dessus, p. 374 .

(2) Ouv, cité, p. 134. 
inférieures la physionomie que leur reconnaît celui-là seul qui ne les a pas vus. Car, il faut bien le dire, $\mathbf{M}$. de Quatrefages est plus explicite à ce sujet que tous ceux qui ont vu et étudié les Néo-Zélandais sur les lieux mêmes.

Quand on lit les écrits des voyageurs, on voit, en effet, que ceux qui ont émis cette opinion, ne l'ont émise qu'avec quelque hésitation, quelque restriction, parfois même en citant des exemples qui la détruisaient : c'est ce qu'ont fait Dieffenbach et Crozet, Crozet surtout, ce compagnon de Marion, dont l'opinion n'a cessé pourtant d'ètre invoquée depuis lors. Maispour M. de Quatrefages, pas d'hésitation. Il a vu des portraits donnant le type nègre : donc c'étaient des nègres, à nez aquilin sans doute, puisque Crozet lui-même l'a dit. M. de Quatrefages n'a pas même songé à se demander si ces portraits ne pouvaient pas être ou n'étaient pas des portraits de véritables nègres, fixés depuis plus ou moins longtemps à la Nouvelle-Zélande, comme nous en avons vu nous-même un certain nombre. Il est vrai que c'était inutile avec la thèse qu'il soutenait.

Du reste, ainsi que nous avons cherché à le démontrer dans nos considérations sur la Nouvelle-Zélande, il est certain, pour nous, qu ill n'a jamais existé de nègres véritables dans ce groupes d'îles, du moins avant la venue d'un certain nombre d'hommes de cette race avec les Européens.

Il faut bien l'arouer pourtant, malgré le nombre assez grand de foyers de populations trouvés sur Aotearoa par les émigrants d'Hawahiki, il n'est pas facile, si ces populations n'étaient pas filles du sol, de dire à quelle époque elles y étaient arrivées.

De même qu'on a vu les écrivains admettre que c'est l'Ile. Nord qui a peuplé l'Ile-du-Milieu, de même tous ont supposé que les populations rencontrées n'étaient là que depuis assez peu de temps, parce qu'elles n'occupaient que des points éloignés les uns des autres et qu'elles étaient incapables de résister aux envahisseurs. On en concluait que cela prouvait leur petit nombre et, partant, leur peu d'ancienneté. Nous ne croyons pas que cela soit tout-à-fait exact pour les raisons que nous allons donner. S'il est vrai que 
toutes ces populations ont fini par être vaincues, exterminées ou repoussées, il ne l'est pas moins que, d'après quelques renseignements, elles ont duré, malgré les conquérants, jusqu'à une époque peu reculée et qu'elles existent même encore dans quelques lieux.

Il est certain, d'un autre côté, que ces populatíons primitives avaient, comme nous l'avons déjà indiqué, les mêmes coutumes, les mêmes croyances et qu'elles parlaient la même langue que les émigrants d'Hawahiki. Il faut donc en inférer du moins, si cela ne prouve rien de bien précis pour leur ancienneté, qu'elles étaient de la même race que ces émigrants, et que, si elles n'étaient pas les enfants du sol qu'elles cccupaient, elles étaient presque sûrement d'une même contrée. Dans tous les cas elles n'étaient point de l'Australie, comme on l'a dit, les Australiens ne navigant jamais, et n'ayant même pas de canots.

Parce que les populations trouvées dans quelques endroits ont été facilement détruites, et nous pourrions citer celles rencontrées par Turi qui prouvent le contraire, nous ne croyons pas que cela donne le droit de conclure qu'il n'y avait là que « des étrangers arrivés depuis peu.» On comprend parfaitement que ces populations, plus faibles et surtout moins courageuses que les envahisseurs, durent céder, devenir esclaves ou se faire exterminer; mais il n'est pas moins vrai qu'elles étaient de même race, c'est-à-dire que c'étaient des Maori, venus presque certainement de l'Hawahiki. Ils étaient partis probablement de points autres que ceux laissés par les émigrants de la grande émigration, quelques-uns, peut-être, depuis assez peu de temps, comme on le dit, mais les autres depuis une époque sans doute très éloignée. C'est ce qui semble résulter des légendes de Kupe, de Manaia, de Turi, et même de la tradition de Tiki rapportée par Dieffenbach et que nous avons fait connaître précédemment (1).

Là on peut voir ce que nous avons dit de l'erreur commise par Dieffenbach relativement à la situation de l'île Tawaï, d'où venaient Tiki et sa femme Pani. Nous ne répé-

(1) Voy. ci-d essus, p. 24\% 
terons pas ce que nous avons écrit à ce sujet; mais ce que nous voulons faire remarquer ici, c'est qu'en parlant de cette tradition, il citait les lignes suivantes, à notre avis, si importantes: «Le mari de Pani, Tiki, était de la même couleur que les habitants de l'île Aotearoa et parlait la même langue qu'eux (1). »

Or, si l'on rapproche ce fait de la facilité avec laquelle Pani put retourner à l'île d'où elle venait, afin d'y prendre une espèce de pomme de terre qui manquait dans celle où elle se trouvait alors; si, surtout, on. compare le nom Tawaï, donné par la légende de Dieffenbach à l'île d'où venait Pani et son mari, au nom Tovai ou Tavai, sous lequel Cook et Dumont-d'Urville ont les premiers fait connaître l'Ile-duMilieu, il n'y a guère qu'une conclusion à tirer, c'est que Tiki et Pani étaient presque certainement des Maori de l'île ainsi désignée par les deux navigateurs, c'est-à-dire de celle qui est pour nous, comme elle nous semble l'être pour les indigènes, l'île Kawai. Evidemment, il fallait que l'île Tawaï, d'où était venue Pani, fut bien voisine, pour qu'elle put y retourner et en revenir si facilement. Or, nous l'avons assez répété, une seule île, portant un nom identique, permettait, par son voisinage, un voyage aussi rapide: c'est toujours l'Ile-du-Milieu, sur laquelle se trouvait l'Hawahiki, si elle n'était pas tout l'Hawahiki lui-même.

Cela sans doute ne dit pas plus à quelle époque a été fait le voyage de Tiki que cela n'aide à fixer l'arrivée des populations primitives et celles des émigrants d'Hawahiki; mais, de l'ensemble de tous ces faits, il nous semble résulter que le voyage du Maori Tiki a dû s'effectuer longtemps avant la grande émigration, et même avant les voyages de Kupe et de Turi, qui ont trouvé, eux aussi, des habitants sur l'île Aotearoa. Quand on remarque, en effet, que le nom de Tiki ne figure dans aucune des traditions contemporaines de la grande émigration, pas même dans les traditions antérieures relatives aux chefs de l'Hawahiki, Wa-

(I) Dieffenbach, comme tous les autres écrivains, se sert toujours du mot Nouvelle-Zélande pour désigner l'Ile-Nord ou Aotearoa. 
katau, Maui, etc., tandis que les plus anciennes disent qu'il est l'un des ancêtres des habitants actuels de l'Ile-Nord; quand on remarque, d'un autre côté, que la pomme de terre apportée par sa femme aurait été inutile, après la grande ẻmigration décrite par les légendes, puisque les émigrants en avaient apporté plusieurs espèces, il faut presque nécessairement admettre que Tiki a dû précéder, de fort longtemps même, les voyageurs connus (1). Quand on remarque encore que Tiki, d'après les plus anciennes traditions mythologiques, était le deuxième fils du Ciel et de la Terre; que c'est de lui qu'est descendu l'homme, fait par lui-même à son image (2); qu'on ne s'accorde même pas sur son sexe, puisque certaines traditions en font une fernme (3); n'en peut-on pas conjecturer que cette tradition n'est plus qu'un mythe, renvoyant le peuplement d'Aotearoa à une époque fort reculée et pour ainsi dire au commencement des choses.

L'ancienneté seule de ce fait expliquerait le silence des traditions à ce sujet. Il est bien certain, comme on l'a dit, que les populations rencontrées par les émigrants à Aotearoa, n'étaient geénéralement pas en grandes agglomérations; mais on sait qu'il est impossible à des peuples sans annales écrites de ne pas confondre les époques au delà d'un certain nombre de générations: Ce nombre semblerait être compris entre 15 à 20 grénérations, d'après les observations de tous les voyageurs, et comme le prouvent celles faites à Tahiti même. Ici, lorsqu'il s'agit de la grande émigration, il est évident qu'elle s'est faite à une époque assez peu reculée, quoique probablement beaucoup plus éloignée

(1) Il y a eu plusieurs Tiki et celui de la légende de Dieffenbach est probablement le Tiki surnommé Tahito ou l'Ancien. Ce vieur Tiki était un grand voyageur ; c'est peut-être le même qui a porté le premier l'Hibiscus (Haul) aux îles Marquises, comme le disent les traditions de ces îles. On sait que là, le pays d'origine est appelé Havaîki, c'est-à-dire presque absolument comme à la NouvelleZélande, ce qui s'expliquerait parfaitement si le Tiki auquel les Marquésans attribuent l'introduction du Hau eût été Maori.

(2) Voy. Taylor, ouvr. ciité, p. 18 et 23.

(3) TayIor, ibid. p. 23. 
qu'on ne le dit généralement: en effet une tradition porte le nombre de générations à 26 (1). Mais si les traditions ne parlent pas plus qu'elles ne le font des populations rencontrées par les émigrants, c'est bien probablement parce que ceux-ci ne sont arrivés à l'Ile-Nord qu'après les guerres qui là, comme dans l'Ile-du-Milieu, s'étaient élevées entre les habitants. Ces guerres avaient contraint à émigrer la plus grande partie de la population et l'avaient réduite à un nombre incapable de résister aux envahiseurs. Vaincues, ces populations ne méritaient plus qu'on s'occupât d'elles : c'est ce que les faits modernes semblent démontrer, puisqu'on voit aujourd'hui, à l'Ile-du-Milieu même, les descendants des conquérants et des Ngati-Mamoe, produits par l'alliance des vainqueurs et des vaincus, ne plus vouloir se rappeler, de leur double origine, que celle qui les fait descendre des premiers (2).

Il en résulte qu'on ne pouvait attacher une grande importance aux vaincus de l'Ile-Nord, eussent-ils été plus nombreux que ne semblent le faire croire les quelques mots des traditions qui en parlent.

En somme, pour nous, l'Ile-Nord était habitée à l'arrivée des émigrants d'Hawahiki et les habitants trouvés n'étaient bien probablement que de plus anciens émigrants de l'Hawahiki ou de l'Ile-du-Milieu, comme semblent le prouver et leurs usages et leur langage.

Ce seraient ces anciens émigrants qui, à leur tour, auraient émigré vers la Polynésie à une époque bien antérieure à l'arrivée des derniers ; cette époque semble pouvoir être reportée à un nombre d'années égal au moins à celui qui paraît exister entre la nôtre et la grande émigration dont parlent les légendes. Ainsi s'expliquerait parfaitement le peuplement assez ancien de quelques-uns des archipels de la Polynésie, indépendamment des envois qui ont pu être faits par les derniers émigrants d'Hawahiki, dont plusieurs canots, ainsi que le rapportent les traditions, n'ayant pu, à cause des po-

(1) Voy. Taylor p. 193, et note. Nous y reviendrons quand nous rechercherons la date des migrations.

(2) Voy. à ce sujet Shortland, Southern Districts, p. 98. 
pulations, aborder à Aotearoa, durentaller chercher d'autres terres (1). Ainsi s'expliquerait aussi pourquoi les populations rencontrées sur Aotearoa ne paraissaient pas connues des nouveaux arrivants, quoiqu'elles eussent le même langage et qu'elles provinssent évidemment de la même contrée. Cela expliquerait même leur petit nombre; car si des migrations considérables s'étaient opérées de l'lle-Nord vers la Polynésie, c'est que des guerres avaient dû, comme à l'Ile-du-Milieu, contraindre tous les théocrates et leurs partisans à abandonner une terre où ils n'avaient d'autre perspective que l'extermination: d'où réduction considérable du nombre des habitants; d'où leur affaiblissement et leur impossibilité de se défendre contre les envahisseurs venus d'une autre contrée.

Quelques écrivains des plus compétents croyaient à l'existence de populations primitives surl'Ile-Nord avantl'arrivée des émigrants d'Hawahiki, et, fait bien curieux, le nom Maero que portaient ces populations, semble indiquer qu'elles étaient les premières. En effet, ce mot signifie «race, famille, courant d'eau, source » et, dans quelques îles de la Polynésie, telles que les Sandwich et les Marquises, ce mot a pour ainsi dire la même signification, puisque il y signifie « postérité, descendance.» On diraitvraiment quelemot Maori, nom sous lequel les Nouveaux-Zélandais se désignent euxmêmes et qui signifie « indigène, naturel, pur, » est le mème mot, ayant la même signification, mais modifié avec le temps et transformé par une orthographe différente.

On sait que ce mot Maori était, dans le principe, c'est-àdire fort anciennement, le mot Mauri, dont, suivant Taylor (2), la racine uri signifie “ obscur, noir »: mais ce mot uri signifie aussi « postérité », c'est-à-dire absolument la même chose que le mot Maero aux Sandwich et aux Marquises, et presque la même chose qu'à l'Ile-Nord de la Nouvelle-Zélande, où il signifie « race.»

(1) Voy. Taylor, p. 123.

(2) Te Ika a Maui, p. 179. Uri est la racine de plusieurs autres mots: Pouri, ténèbres; Wheuri, eau profonde, noire; Tua uri uri, nuages noirs; etc. 
Nous allons compléter ici ces recherches étymologiques, afin de répondre en même temps à l'opinion de M. de Quatrefages sur les Maero de l'Ile-Nord et les Ngati-Mamoe de l'Ile-du-Milieu; et surtout à la note qui suit l'exposé de cette opinion. Après avoir fait remarquer (1) que les faits ont, d'après lui, conduit la plupart des historiens modernes de la Nouvelle-Zélande à regarder cette terre comme ayant été « absolument inhabitée à l'époque de l'arrivée des Maori, »M. de Quatrefages ajoute: “Cependant les indigènes ont diverses traditions d'où il résulterait que, dans les régions les plus inaccessibles, et au fond des forêts vierges de leurs îles, vivent encore aujourd'hui des hommes sauvages, qu'ils déclarent ne pas être de leur race et appartenir à une population antérieure à la leur. lls nomment ces indigènes Maero dans l'Ile-Nord, et Ngati-Mamoe dans l'île du Sud ou du Milieu des Anglais (2).

« Malgré ces affirmations, Hochstetter a adopté l'opinion la plus générale; il ne voit, dans ces prétendus indigènes, que des Maori dispersés et ayant perdu le peu de civilisation qu'ils avaient apportée d'Hawaïki. Il se fonde surtout sur les renseignements fournis par un chef de la côte occidentale de l'Ile-du-Milieu (des Anglais, ou Sud de d'Urville) mort en 1861. D'après les dires de ce chef, les Ngatimamoe étaient, il y a un siècle environ, une tribu habitant du côté de la baie Jackson et soumise aux Ngati-Tahus. Shortland (3), deson côté, nous apprend qu'ils formaient, il y a trois siècles environ, une population nombreuse et puissante qui occupait presque en totalité l'île méridionale, du cap Campbell à l'île Stewart.

« Sur leur territoire se trouvaient des carrières de jade. Ce fut la cause de leur perte. Diverses tribus de l'Ile-Nord s'unirent pour les dépouiller, et après plusieurs défaites, elles durent accepter la domination de ces étrangers. Comme signe de leur ancienne grandeur, les Ngatimamoe n'avaient conservé qu'un Mere Punanamu, c'est-à-dire un de ces

(1) Les Polynésiens, p. 132.

(2) Hochstetter, New-Zealand, 1863.

(3) The Southern districts of New-Zealand, 1851. 
casse-têtes en jade, auxquels ces peuples attachaient une si grande valeur. Cette arme portait le nom de Taonga ou Tonga. Les Ngatitahus cherchèrent à s'emparer à la fois de ce palladium et du chef Te Uira, « l'Eclair, » dont ils semblent avoir redouté la bravoure. Ils réussirent par ruse; mais Te Uira trouva le moyen de s'échapper, puis de s'introduire de nuit au milieu de ses ennemis et de leur reprendre l'arme sacrée dont il frappa deux envahisseurs. Attaqués et prévoyant une défaite inévitable, ce chef et ses compatriotes mirent le feu à leur forteresse et s'enfoncèrent dans les solitudes centrales de l'île, où les restes de leurs descendants vivent, dit-on, encore. ”

Et M. de Quatrefages ajoute : « Hochstetter applique aux Maero de l'Ile-Nord, les conséquences qui ressortent de cette histoire, et peut-être a-t-il raison. »

D'abord, nous ferons remarquer que M. de Hochstetter aurait eu d'autant moins raison d'appliquer ces conséquences aux Maero de l'lle-Nord, que cette île ne produit pas de jade vert. Il est donc certainement dans l'erreur, comme les renseignements sur lesquels il se fonde suffiraient à le prouver. Le chef qui lui a fourni ces renseignements disait que les Ngati-Mamoe étaient, il y a un siècle, une tribu habitant du côté de la baie Jackson, c'est-à-dire sur la côte Ouest de l'Ile-du-Milieu. Or, ce chef pouvait d'autant moins lui affirmer que cette tribu était soumise alors aux Ngati-Tahu, que ceux-ci, comme nous allons le montrer, n'ont émigré du détroit de Cook qu’à une époque très voisine de la nôtre, vers 1828 ou 1830, chassés comme les Rangitaue par le grand exterminateur Rauparaha. C'est à Thompson, auquel il a tant fait d'emprunts pour son livre, que Mi. de Hochstetter doit cette erreur.

Certes, l'opinion de M. Shortland qui a vu l'Ile-du-Milieu, a vécu parmi ses habitants et les a beaucoup étudiés, doit être préférée à la. sienne.

Or, l'auteur anglais rapporte, dans un de ses ouvrages sur la Nouvelle-Zélande, (1) le récit suivant qui lui a été

(1) Southern Districts of Nev-Zealand, 1851, p. 98. 
donné et garantipar Tuhawaïki et quelques autres indigènes:

- Il y a trois cents ans environ, ou dix générations passées, toute cette partie de l'Ile-du-Milieu, qui s'étend depuis Waipapa, point situé à environ 20 milles au Sud du cap Campbell, jusqu'à Rakiura ou l'île Stewart, y compris le détroit de Foveaux et probablement une grande partie de la côte Ouest, était possédée par une tribu appelée NgatiMamoe.

«Elle était bornée au Nord par la tribu nommée Te Huataki, dont les ancêtres étaient venus de l'Ile-Nord, et s'étaient fixés à Wairau, le Cloudy Bay de Cook. A l'Ouest, la contrée appelée Totaranui, était possédée par la tribu des Ngaitara, dont les ancêtres étaient venus aussi de l'IleNord, sous le commandement du chef Te Puhirere, qui, disait Tuhawaiki, était du même lignage que la tribu des Nga-Puhi.

a Il paraît qu'à la même époque une forte et puissante tribu s'étendait de Turanga-Nui-a-Rua, ou baie de Pauvreté, tout le long de la côte Est et des côtes Nord du détroit de Cook, y compris Wairarapa, Porirua, et même plus à l'Ouest. Seulement, cette tribu avait été contrainte de revenir à Waïrarapa, sa limite actuelle, refoulée par Te Rauparaha, et on l'appelle encore par son nom primitif de Ngati-KahuUnu-Unu. Le désir de posséder le Pounarnu, qui ne se trouvait que dans l'Ile-du-Milieu, paraît être le principal motif qui poussa plusieurs fortes tribus, à différentes époques, à envahir le pays des Ngati-Mamoe, qui étaient devenus célèbres par la possession de ce trésor.

« La plus ancienne de ces invasions eut lieu il y a envi-. ron 270 ans, car Tuteahunga, chef de cette tribu, qui vivait neuf générations auparavant, passe pour avoir été tué à Kaikoura. Sa famille était appelée Ngaitahu, de son grand père Tahu. Une autre famille appelée Te-Aitanga-Kuri, descendait de Kuri. Kuri, cousin de Tuteahunga, arriva peu après, et unit ses forces à celles des Ngaïtahu ; mais ils ne purent s'emparer de Kaikoura, où leur chef Manawa fut tué dans une escarmouche par Tuikau, chef des Ngati-Mamoe. 
« Vers le mème temps, un renfort puissant de Ngati-Kahu-Unu-Unu, fut expédié par un chef nommé Turakautahi, dont le père et le grand-père, en faisant une pareille tentative devant Kaikoura, s'étaient noyés avec leur équipage en face de Raukawa (1), où leur canot avait chaviré. Turakautahi, avec son plus jeune frère Moki, débarqua ses forces à Totaranui ; il eut à se frayer un chemin à travers les Ngaïtara et les Tehuataki, pour pouvoir joindre ceux de sa propre tribu qui l'avaient précédé, et qui étaient alors établis à Kaikoura.

« Réunis, ils attaquèrent un $\mathrm{Pa}$, appelé Parawakatu. Peu après, les Ngati-Mamoe furent encore défaits, dans un endroit nommé Parakakariki ; puis, à Waïkakahi, où l'un de leurs chefs, nommé Tute-Kawa, fut tué, et où un autre, appelé Rangitamau, fut fait prisonnier. La vie du dernier fut épargnée; on le condamna à résider à Kaiảpoï, pour pêcher des anguilles et préparer la nourriture de son vainqueur quand il irait de ce côté.

« Après cela, les terres conquises furent partagées entre les envahisseurs. Te Ruakihikihi, fils de Manawa, qui était retourné dans sa tribu sur l'Ile-Nord, pour lever de nouvelles forces parmi ses parents, afin de venger la mort de son père, revint vers cette époque et s'établit à Taumutu (2). Ce point, le plus Sud du nouveau territoire conquis, était le lieu le mieux placé pour qu'il pût rencontrer son ennemi et obtenir l'utu (3) ou la satisfaction désirée.

« Les Ngati-Mamoe se retirèrent vers le Stid, et, à la fin, se trouvant trop affaiblis pour espérer pouvoir reprendre leurs positions perdues, ils firent la paix avec leurs envahisseurs et cimentèrent une alliance entre eux. Alors, les deux races ne firent qu'une tribu, qui, ayant plus de sang de Tahu dans les veines, fut appelée généralement Ngaitahu ou Kaïtahu.

(1) Raukawa, est le détroit de Cook.

(2) Taumutu est sur la presqu'île de Banks, au Sud; Kaiapoï est sur la même presqu'île, au Nord.

(3) Utu, tribut, compensation, dette. 
« J'ai trouvé, ajoute Shortland, que toutes les familles de quelque importance, rapportent aujourd'hui leur origine à une source de Turanga ou baie de Pauvreté de Cook. Comme c'est le parti vainqueur, et par cela même le plus honorable, elles négligent de parler des sources Ngati. Mamoe d'avant la conquête, et c'est ce qui fait qu'il est très difficile d'obtenir quelques renseignements sur l'ancienne histoire de cette tribu. Pour en obtenir, il faudrait s'adresser aux familles qui restent de ce vieux tronc. Il y en a deux qui vivent aujourd'hui à Waiateruati, et qui s'appellent Kati-Rakai et Kati-Hine-Kato ; il y en a un plus grand nombre dans le détroit de Foveaux, mais je n'ai pas eu l'occasion d'apprendre d'elles ce qu'elles pouvaient savoir de leur propre histoire. »

Enfin, le même écrivain dit : (l) « L'Ile-du-Milieu était habitée autrefois, dans sa plus grande partie, de même que les îles du Sud, par des colonies de Ngati-Kahu-UnuUnu, les mêmes qui occupent aujourd'hui toute la côte Est de l'Ile-Nord, depuis le cap Waïapu jusqu'a la baie Palliser ou port Nicholson, et qui, plus puissants jadis, s'étendaient le long des côtes Nord du détroit de Cook, jusqu'à Rangitikei, avant d'en avoir été chassés par les Ngati-Awa, qui avaient eux-mêmes été chassés de Taranaki par les Waïkato.»

Il ajoute qu'il devait ces renseignements au chef de la justice, à la Nouvelle-Zélande, qui les avait reçus du révérend Puckey. Ce dernier avait résidé vingt ans au milieu de la tribu Ngati-Kahu-Unu-Unu sur l'Ile-du-Milieu.

Nous allons montrer qu'il a probablement confondu des événements assez récents avec des faits fort anciens, et que ces Ngati-Kahu-Unu-Unu, quand ils se seraient fixés, il y a 270 ans, pour la première fois, sur les bords Nord du détroit de Cook et sur une partie de la côte Est voisine de l'Ile-du-Milieu, n'étaient pas moins arrivés d'abord sur l'lle-Nord en venant de l'Hawahiki.

Ainsi, comme on le voit tout d'abord d'après Shortland lui-même, les Ngati-Mamoe habitaient déjà l'Ile-du-Milieu, il y a trois cents, ans environ, et en occupaient la plus

(1) Traditions and Superstitions, p. 23. 
grande partie. Ce ne serait que plus tard, c'est-à-dire 270 ans avant l'époque où il prenait ses renseignements, que se seraient opérées les plus anciennes invasions des NgatiKahu-Unu-Unu, habitant la côte Est de l'Ile-Nord; ils étaient conduits par le chef Tute-Ahunga, qui aurait été tué à Kaïkoura, comme plusieurs autres chefs de sa tribu.

Qu'on remarque en passant combien était dangereuse, à cette époque, la moindre traversée en canot, puisque les envahisseurs préféraient débarquer dans le détroit de Cook presque vis-à-vis leur dernier point de départ de l'Ile-Nord, et se frayer un passage à travers l'ennemi, afin de pouvoir joindre les gens de leur tribu déjà arrivés à Kaïkoura : ce point est, comme on sait, la presqu'île Lookers'on de Cook. Qu'on remarque aussi que ces ermemis n'étaient pas des Ngati-Mamoe, mais des tribus issues de l'Ile-Nord,qui étaient venues s'implanter sur les bords Sud du détroit de Cook dans l'Ile-du-Milieu. Ces tribus, qui s'appelaient Te-Huataki et Ngaïtara, étaient parties évidemment avant les Ngaïtahu; la dernière descendait, d'après l'autorité de Shortland, des Nga-Puhi.

Ce ne fut qu'après plusieurs défaites que les Ngati-Mamoe finirent par abandonner toutes leurs forteresses de la côte, depuis Kaïkoura jusqu'à Taumutu, localité au Sud de la presqu'île de Banks, où l'un des chefs envahisseurs alla se fixer pour être plus à même de se venger. Alors, ils se retirèrent tout-à-fait au Sud, vers Waiteruati, Jtakou, etc. Mais ils résistaient si bien, que, de notre temps même, il était nécessaire de renouveler les attaques, bien que tous ceux qui sont restés dans le rayon conquis, se fussent, à la longue, mêlés aux vainqueurs et confondus avec eux, après avoir fait la paix, comme le dit Shortland, faute de pouvoir résister aux armes à feu de leurs ennemis.

Il résulte donc des paroles même de Shortland que les Ngati-Mamoe n'étaient pas aussi peu nombreux que quelques écrivains l'ont cru.

A propos de ce mot Ngati-Mamoe, nous ferons remarquer icique Shortland ne semblait pas très fixé sur l'orthographe qu'il faut lui donner, car il admet comme synonymes les 
mots Ngati-Mamoe et Ngati-Mamui. Ainsi, après avoir répété ce que dit une des légendes de Sir Grey, que de Turi et de sa femme Rongo-Rongo sont sortis les Wanganui, il ajoute (1): « et les Ngati-Mamui. » Puis il dit en note, «Ngati-Mamoe? nom de tribu des premiers colons de l'Iledu-Milieu, plus tard conquis par une division de la tribu Ngati-Kahu-Unu-Unu. (Vide South. districts, p. 98.»)

Comme on voit, il semble se demander si Ngati-Mamoe et Ngati-Mamui sont synonymes, et à en juger par le point d'interrogation qu'il place après le premier, on pourrait croire qu'il en doutait, quoi qu'il n'en parle pas moins, ensuite, comme si c'était bien le même peuple. Mais les Ngati-Mamoe étaient pour lui-mème, contrairement à l'opinion de ceux qui admettent que les îles de la Nouvelle-Zélande étaient désertes à l'arrivée des émigrants d'Hawahiki, les premiers colons de l'Ile-du-Milieu, conquis plus tard par des Kahu-Unu-Unu del'Ile-Nord. Cette assertion, venant de lui, mérite surtout d'être remarquée.

Si donc Shortland ne dit, pas plus que les traditions indigènes, quelle était la patrie de ces peuples, il faut du moins reconnaître que cet observateur semblait admettre qu'ils avaient plutôt une origine locale qu'une origine étrangère. Si en effet il ne précise pas leur origine, en disant qu'ils étaient les premiers colons de l'Ile-du-Milieu, il indique, par contre, la patrie de leurs voisins.

Quoi qu'il en soit de son opinion à cet égard, il est certain que Mamui, en un seul mot, n'est pas Maori et que ce ne pourrait être que $M a$, blanc, pur, net, propre, et $M u i$, en tourer, environner.

Nous avons déjà ditailleurs ce que signifie $\mathrm{Ngati}$, et nous n'y reviendrons pas ; mais nous allons chercher à découvrir l'étymologie du mot Mamoe.

En un seul mot Mamoe n'existe pas en Maori ; on ne trouve d'approchant dans cette langue que le not Mamore, qui signifie nu, pelé.

$M a$, au contraire est Maori, ainsi que nous venons de le voir, et Moe signifie dormir, songer, sommeil, rêve, songe.

(1) Traditions and Superstitions, p. 28. 
Serait-cel'un de ces mots? Il est permis d'en douter, à moins qu'on ne leur donne la signification qu'ils ont probablement eue d'abord et qu'ils conservent encore aujourd'hui à Tahiti. Là, en effet, $M a$ signifie compagnie, net, non souillé, et Moe, (1) sommeil, dormir, être par terre, perdu, oublié. De plus, on trouve, là aussi, un ancien mot aujourd'hui tombé en désuétude, Mamo, « race, lignée, descendance, " qui, suivi du signe vocatif $e$, rend parfaitement le sens $d u$ Maero des Maori, et signifie "différent, autre, étranger.» Il est remplacé maintenant par le mot Huaai a semence, graine, progéniture. » Mais c'est bien un des mots des ancêtres des Tahitiens, comme le signale Je Dictionnaire. Nous avons déjà fait remarquer que ce mot Maero estemployé aux îles Marquises et aux Sandwich pour signifier descendant, postérité, descendre, venir de, et nous allons montrer qu'il a absolument la même signification à la Nouvelle-Zélande.

Nous ferons remarquer enfin qu'en Maori, momo signifie lignée, descendance; momoe, dormeur ; momo-hanga postérité, lignée, les survivants d'une tribu massacrée. N'en pourrait.on pasconclure qu'au lieu de mamoe il faut écrire momoe ? (2)

Certainement', toutes ces homologies n'établissent pas nettement quelle pouvait être la signification du mot mamoe dans l'Ile-du-Milieu; pour nous, nous serions assez disposé à croire qu'il veut dire « la race, les anciens. „A moins que ce ne soit tout simplement un sobriquet donné plus tard, suivant leurs habitudes, par les conquérants venant de l'Ile-Nord. Dans tous les cas, il semble bien avoir le sens que nous lui donnons.

(1) Remarquons que Moeraki est le nom d'un lieu célèbre dans l'Ile-du-Milieu, où la mythologie semble avoir pris naissance et où, de nos jours encore, les habitants sont les plus versés dans les traditions.

(2) A Tahiti, Meho est le nom que l'on donne aux fugitifs dans les montagnes en temps de guerre. Les Tahitiens appellent le mouton Puaa-Mamoe, ce qu'on peut traduire par le cochon d'une race différente ou le cochon qui rêve, qui sommeille. On sait, en effet, que Puaa cochon, est le terme de comparaison employé pour désigner tous les quadrupèdes. 
Dans l'Ile-Nord, comme le dit M. de Hochstetter, on donnait un nom différent aǔx indigènes vivant dans les lieux inaccessibles de l'île et que les habitants actuels regardent comme appartenant à une autre race que la leur : ce nom était justement le mot Maero que nous venons de voir employé par les Marquésans et les Hawaïens pour signifier descendance, postérité.

Taylor nous apprend (1) que ce nom Maero est donné à un homme sauvage, vivant dans les montagnes inaccessibles et en descendant parfois pour emporter ce qu'il peut saisir. "Il est couvert de poils, dit-il, il a de longs doigts et de longs ongles, et mange sa nourriture crue. Les indigènes disent que la chaîne de montagnes nommée Tararua est aujourd'hui le seul point habité par lui dans l'Ile-Nord. C'est là qu'il existe encore une tribu nombreuse appelée Te-Hapu-Mariri, identique avec celle des Ngati-Mamoe qui vivent sur les montagnes élevées de l'Ile-du-Milieu. »

Comme Taylor parle de cet homme à propos d'êtres fa. buleux, M. de Hochstetter a cru devoir adopter l'opinion que ces hommes ne sont que des Maori traqués par leurs compatriotes et devenus sauvages, mais non d'une race différente des autres Maori. Taylor, en effet, parle des Maero à l'occasion des Patu-Paearehe (2) ou Tua-Riki, (petites divinités) êtres humains vivant en communauté et construisant des forteresses ou $\mathrm{Pa}$ au sommet des montagnes. Ils passent, dit-il, pour avoir été les premiers habitants du pays, avant l'arrivée des Maori, et pour s'être retirés successivement à mesure que ceux-ci avançaient. Mais il nous semble qu'il y a là du merveilleux comme dans toutes les croyances Maori; certains détails ne permettent pas de douter qu'on a bien voulu parler de populations antérieures à la venue des Maori de la grande Emigration ; on a vu, d'ailleurs, que les légendes en citent an bon nombre d'exemples qu'il est impossible de nier plus longtemps.

(1) Te Ika a Maui, p. 49.

(2) Ou mieux, Patu-Parehe : Parehe, courbé, plié ; Patu, mur de maison, objet pour frapper, battre, tuer. 
L’importance de quelques-uns de ces détails, nous engage à les faire connaître au lecteur.

« Les Wanganui, dit Taylor (1), rapportent que quand ils allèrent se fixer sur les bords de cette rivière, presque tous les sommets étaient occupés par des Patu-Paearehe, qui s'éloignèrent successivement de la rivière après y être restés jusqu'à une époque peu reculée, après en avoir fait leur demeure de prédilection. "Et Taylor ajoute avec raison : “ Ces récits demi fabuleux doivent faire allusion à une race abo. rigène; il y a beaucoup de choses qui font croire que les Maori ne furent point les premiers habitants de la terre (l'lle-Nord). »

On a vu, répéterons-nous, que cinq ou six canots de ces émigrants ont rencontré des populations qu'ils indiquent nếtement, et qui ne permettent pas de douter, comme quelques écrivains le font, que cette île ne possédat des habitants avant la grande émigration d'Hawahiki.

Taylor dit encore: " Les Patu-Paearehe ne se montraient que le matin, et l'on dit que c'étaient des êtres blancs, vêtus de vètements blancs, ayant la forme de ceux des Maori, et faits avec la même substance. On les disait fort grands, comme des géants, quoique, à quelques égards, ils ressemblassent à nos fées. On ne les voyait généralement qu'en grand nombre et rarement seuls ; ils parlaient très haut et aimaient jouer de la flûte (Putorino). On dit qu'ils portaient leurs enfants dans leurs bras comme le font les Européens, mais non à la manière des Maori, sur le dos ou la hanche. Leurs visages étaient Papatea (2), non tatoués, et, sous ce rapport aussi, ils ressemblaient aux Européens. Ils avaient des réunions prolongées et chantaient très haut; ils se rendaient souvent vers les cultures des Maori, et on les trouvait fréquemment bouleversées, mais jamais le sol n'était injurié. »

Certes, bien que ce récit soit mêlé de fables, il ne permet guère de douter que les émigrants d'Hawahiki eussent con-

(1) Ouvr. cité, p. 46.

(2) Papatea, non tatoués : Papa, planche, peau blanche, lisse. Serait-ce Papatahi, plaine, surface plate? 
servé le souvenir vague de populations antérieures à leur arrivée; seulement il est impossible d'en rien conclure quant à l'espèce d'hommes qui formaient ces populations. Peut-être pourrait-on le faire à l'aide des légendes Maori qui ci ient quelques-unes des peuplades rencontrées par les émigrants, et, tout particulièrement, à l'aide de celle qui rapporte la dispute de Ihenga avec le chef des bords de Roto-Rua.

Toujours èst-il que de pareilles croyances contredisent l'opinion de M. de Hochstetter et de ceux qui l'ont adoptée.

Ce sont sans doute ces Patu-Parehe ou Maero que M. J. Garnier regardait comme les autochthones de la NouvelleZélande ou de son Australasie. « Le peuple autochthone de la Nouvelle-Zélande, dit-il (1), s'est fondu peu à peu dans le courant persistant des Polynésiens lorsqu'ils ne furent plus qu'en très petit nombre et cette race inférieure, refoulée dans la montagne, y périt de misère. Cependant on en trouve encore des traceś parmi les Taranaki, au Sud-Ouest de l'île. »

C'est à ce peuple, disparu devant les Polynésiens, qu'il attribue la coutume des Néo-Zélandais de pousser, pendant de longues heures, des hurlements retentissants auprès des cadavres de ceux qui viennent de mourir : \& Ce fait, dit-il, ne se retrouve pas chez les autres Polynésiens. » Il en conclut qu'il doit nécessairement être une vieille coutume des autochthones. C'est une erreur; rien, au contraire, n'est plus ordinaire dans les habitudes des vrais Polynésiens que les cris poussés autourdes corps morts.

Il est, du reste, impossible, d'après les renseignements que l'on possède, de dire exactement quelles pouvaient être les populations trouvées par les envahisseurs. Si l'indice nasalpouvait suffire, il faudrait en conclure à l'existence de Papua, de Négritos ou d'Australiens. Mais la description que 'laylor en donne, d'après les indigènes, ne vient guère appuyer cette manière de voir, et nous pensons qu'il faut en faire une population pareille à celle des envahisseurs venant de l'Hawahiki.

(1) Les migrations humaines en Océanie. Mémoire p. 61, 62. III. 
Quantà ce qui concerne le nom Mere-Punanamu, donné à l'arme que les Ngati-Mamoe conservaient comme signe de leur grandeur passée, nous ferons remarquer qu'il n'est pas aussi exactement traduit qu'on l'a cru jusqu'à présent. Mere est bien le nom donné à une arme de guerre, à un petit casse-tête souvent en jade vert, plus souvent encore en basalte, obsidienne ou toute autre substance; mais le mot Punanamu, ainsi écrit, n'est pas Maori. Ce ne pourrait être que puna, source d'eau, et namu, mouche de sable. Or, ces mots n'ont jamais été le nom du jade vert qui, d'après Williams, Dieffenbach, Taylor et Shortland, serait Pounamu. Pourtant cela n'est pas biẹn sûr, car Williams, dans son dictionnaire, ne lui donne que le sens de «bouteille.» C'est pourtant ce mot qui, depuis Cook et d'Urville, n'a cessé d'être donné au jade vert. Nous avons montré ailleurs que c'était probablement par erreur. Peut-être a-t-on voulu dire tout simplement Mere-pu-nanau (1).

Quelle que soit l'étymologie de ces derniers mots, il est à peu près certain que le Mere dont il est parlé dans la citation de M. de Quatrefages, s'appelait plutôt Taonga que T'onga. On a déjà vu que ce dernier mot, ainsi orthographié, signifie vent du Sud, ce qui, appliqué à un Mere, n'aurait paś de sens. Taonga, au contraire, signifie trésor, propriété, et ces dernières significations semblent convenir davantage à une arme précieuse ; mais pourtant, nous ne voudrions pas l'assurer (2).

A l'occasion de ces divers mots, M. de Quatrefages dit en note (3): «Ce nom Tonga. est remarquable. Faut-il y voir un souvenir des îles Tonga? Les Ngati-Mamoe étaientils venus directement de cet archipel? Les traditions indigènes ne disent pas quelle était la patrie de ce peuple qui occupait une si grande étendue de terre, tandis qu'elles nous disent bien formellement, d'après Shortland, que tous

(1) Mere, arme ; pu, froche, précis ; nanau, colère.

(2) Voy. Maunsell, Grammar of the New-Zealand language, eitée par Thompson.

(3) Les Polynésiens, etc:, p. 138, note- 
leurs voisins avaient émigré de l'Ile-Nord. Je ne puis que poser ces questions; mais les auteurs qui croient trouver à la Nouvelle-Zélande les traces d'unc origine multiple, pourraient peut-être invoquer ces faits à l'appui de leur opinion. »

Jusqu'à nous, personne n'avait encore soutenu aussi complétement, personne n'avait émis aussi nettement l'opinion que c'est par la Nouvelle-Zélande que la Polynésie a été peuplée: par conséquent, cette note, publiée près d'un an après l'envoi de nos mémoires à la Société d'anthropologie de Paris, est tout spécialement à notre adresse. Nous ne pouvons donc nous dispenser d'y répondre.

Commele dit M. de Quatrefages, le mot Tonga mérite, en effet, d'être remarqué, parce qu'il aide lui-même à prouver que l'un des deux peuples descend de l'autre; mais, bien que nous soyons encore seul, depuis 1865, a soutenir que les Polynésiens proviennent plutôt des Maori que les Maori des Polynésiens, nous n'avons pas le moindre besoin d'invoquer un pareil fait à l'appui de notre opinion. Nous sommes habitué, d'ailleurs, à ne pas nous contenter d'à peu près ou de ressemblances de mots.

Pour nous, ce mot Tonga n'est pas plus un souvenir des îles Tonga de la Polynésie, qu’il n’est le souvenir du mot maori Tonga " vent du Sud, » ou celui de la petite île de même nom qu'on trouve dans le détroit de Cook, à la Nourelle-Zélande.

, Ce mot Tonga, ainsi écrit, a d'abord une signification qui ne peut être la même dans les îles Tunga et à la NouvelleZélande. Nous venons de le dire, il ne signifie, à la Nouvelle-Zélande, que vent du Sud, tandis que le vent du Sud à Tunga-Tapu, dans le groupe des îles des Amis, porte un nom tout différent. Evidemment, les Néo-Zélandais n'auraient pas pu vouloir dire que les îles Tunga se trouvaient dans le Sud de leurs îles ou que le vent renant de cette direction soufflait du Sud, car c'est la Nouvelle-Zélande elle-même qui est plus Sud que les T'unga. La NouvelleZélande ne pouvait donc tenir ce mot de l'une des îles des 
Amis ; elle n'employait tout simplement qu'an mot presque pareil, mais signifiant toute autre chose.

Déjà ailleurs (1), nous avons cherché à démontrer que le mot par lequel tous les écrivains désignent une ou plusieurs des îles des Amis, ne doit pas être orthographié Tonga. Cette erreur, avons-nous dit, provient du $\mathrm{D}^{\mathbf{r}}$ Martin, l'auteur de l'ouvrage de Mariner; Mariner n'avait pas commis cette erreur, et dans son dictionnaire ilécritToonga. Or, le oo anglais, ramené à la prononciation française, doit être remplacé par ou et écrit $u$, suivant l'orthographe adoptée pour les langues polynésiennes. On a donc absolument le mot que nous avons entendu prononcer nous-mème sur les lieux, c'est-à-chire Tunga ou Tounga. Ce mot, que nous avons vu être le nom de l'île Tunga-Tapu, signifie, aussi bien aux îles Tunga elles-mèmes qu'à la Nouvelle-Zélande, " station, lieu où l'on s'arrête, halte. „C'est ce dernier sens que possède évidemment la petite île du détroit de Cook, près la Pointe de Séparation (2) et dont le nom est aussi écrit Tonga par tous les navigateurs.

Il n'y a absolument qu'une conclusion à tirer de ce qui précède, c'est que c'est la Nouvelle-Zélande qui a fourni le mot Tunga à la Polynésie. Il est bien évident, en effet, que le nom d'une île ne serait pas devenu un terme concret à la Nouvelle-Zélande, tandis que ce terme concret aurait fort bien pu être appliqué, et qu'il l'a été, suivant nous, au premier point atteint par des émigrants, après une traversée plus ou moins fatigante. Dès lors ce serait donc plutôt un souvenir de la Nouvelle-Zélande, si ce n'était pas tout simplement l'application toute naturelle faite par les émigrants du mot de leur langue exprimant l'action de « s'arrêter, faire halte. »

Après cela, il devientinutile, pour répondre plus expli. citement a la question que pose M. de Quatrefages, de chercher à réfuter la venue directe des Ngati-Mamoe des îles Tunga, car nous semble-t-il, il résulte de ce que nous ve-

(1) Vol. II, p. 382 , note 1.

(2) * Pointe de séparation, * nom donné par d’Urville et Guilbert à une pointe séparsnt deux baies. 
nons de dire que, pas plus que les autres Maori, les NgatiMamoe n'auraient pu venir de ces îles.

Si donc les traditions indigènes ne disent pas, d'après $M$. de Quatrefages, «quelle était la patrie de ce peuple qui occupait une si grande étendue de terre sur l'Ile-du-Milieu, tandis qu'elles disent formellement, d'après Shortland, que tous leurs voisins avaient émigré de l'Ile-Nord, 》 c'est tout simplement parce qu'on n'a pas voulu voir ce qu'elles disent. Shortland, lui-même, qui confond des faits pour ainsi dire récents avec les plus anciens, témoigne, par les détails qu'il rapporte, que les Ngati-Mamoe étaient les populations primitives de l'Ile-du-Milieu. Ces populations, vaincues plus tard par des envahisseurs venus de l'Ile-Nord, finirent par s'allier et se confondre avec eux, quoique beaucoup, encore aujourd'hui, préfèrent vivre isolées. C'est enfin parce qu'on n'a pas remarqué que Thompson regarde les NgatiMamoe comme les restes de ce qu'il appelle avec raison «les Maori de l'Ileadu-Milieu.» Comme Shortland, d'ailleurs, Thompson semble prendre des faits nouveaux pour des faits anciens. Voici ce qu'il dit au sujet des Ngati-Mamoe (1) :

«Dans plusieurs des ports de refuge qui existent sur la côte de Fer, qui est dans l'Ouest de l'lle-du-Milieu, et autour des lacs inexplorés de l'intérieur, vivent des NouveauxZélandais peu nombreutx, qui sont rarement vus, si ce n'est par les baleiniers et les pêcheurs de phoques, et qui, tels que des Bohémiens, errent d'un point à un autre. Ce sont les restes des Maori, que la nation Rangitane a presque dé. truits à son arrivée dans l'Ile-du-Milieu, et on les appelle Ngati-Mamoe. Cette nation quasi-éteinte, était une colonie de Wanganui. »

C'est positif : pour lui, ces Néo-Zélandais, errants et peu nombreux, sont des Ngati-Mamoe; mais ils seraient aussi des descendants des Wanganui de l'Ile-Nord, ce qui est beaucoup moins certain. En effet, l'ancêtre de ces Wanganui, Turi, était lui-mème, comme nous l'avons dit, un Wanganui ; c'est sans doute pour cela qu'il a donné ce nom à la colonie qu'il avait fondée près de Patea dans le détroit

(1) The Story of the New-Zealand, t. I, p. 92. 
de Cook. Il est certain qu'il n'existe aucune rivière de ce nom dans toute la Polynésie ; mais on a vu qu'il y en a, au contraire, plusieurs dans l'Ile-du-Milieu, de même qu'il y en avaits'appelantainsi en Hawahiki. Il est donc plutôt à croire que les Wanganui du détroit de Cook n'étaient que les descendants de ceux venus d'Hawahiki avec Turi, et que, bien probablement, ils appartenaient à la grande nation des Ngati-Mamoe.

Ce que dit Thompson de leur extermination par les Rangitane, est un témoignage plus favorable que contraire à l'ancienneté des Ngati-Mamoe sur l'Ile-du-Milieu ; cette assertion prouve une chose, c'est qu'il s'est trompé, lui aussi, et qu'il a pris une époque assez récente pour une époque reculée.

Nous avons déjà fait remarquer que les Rangitane et les Ngaïtahu qui, d'après lui, occupent la côte Est de l'Ile-duMilieu, depuis le cap Campbell jusqu'à Otokou, et descen. dent des Ngati-Kahungunu, ne peuvent pas avoir émigré de l'Ile-Nord deux siècles auparavant, comme il le prétend ; ils ne l'ont fait qu'à une époque très rapprochée de la nôtre, chassés du détroit de Cook par le fameux Rauparaha, vers $1828(1)$.

Il est bien évident que si l'expulsion a été faite, comme c'est certain, par Rauparaha, ellen'a pu s'opérer deux siècles auparavant, comme le dit Thompson, puisque cette expulsion n'a eu lieu que vers 1825 ou 1826 (2). Tout ce qu'il est permis de dire, c'est que probablement des colonies de la mème nation avaient occupé les mêmes lieux assez long * temps avant l'expulsion de ceux dont il est parlé.

(i) C'est d'ailleur's ce que Thompson dit lui-même quand il écrit, (ouvr. cité, p. 92) : «On the East coast of the Middle-Island, from cap Campbell to the neighbourood of Otago are scattered 1500 persons known br the name Ngaitahu and Rangitane. These nations driven away from Cook's strait by Rauparaha, sprang from the Ngati-Kahungunu, and migrated from the North to the MiddleIsland, two centuries ago in the hope of obtaining possession of the District in which the invaluable green stone in found. 》

(2) Voy, à la fin du volume IV les notes biographiques sur Rauparaha. 
On n'a jamais fait attention, et il importe de faire remarquer, que cette tribu Ngati-Kahungunu, de laquelle on s'accorde à faire descendre ces colonies, était elle-même venue de l'Hawahiki à l'Ile-Nord avec les premiers émigrants. Les traditions disent, en effet, que les Ngati-Kahungunu composaient les équipages des deux canots, le Matatua et le Kurahaupo. Ce fait est de la plus haute importance si l'Ile-du-Milieu était bien l'Hawahiki, comme nous espérons l'avoir démontré ; car l'on sait que l'on s'accorde à faire remonter la venue de ces canots à cinq ou six cents ans et, par conséquent, à plusieurs siècles avant le départ de l'Ile-Nord de colonies Ngati-Kahungunu pour les points les plus voisins de l'Ile-du-Milieu.

N'y aurait-il que ce fait, il faudrait conclure que Shortland et Thompson ont soutenu, et que M. de Quatrefages a adopté à tort l'opinion que nous combattons, c'est-à-dire le peuplement de l'Ile-du-Milieu par l'Ile-Nord.

Que, plusieurs siècles après l'établissement sur la côte d'Aotearoa la plus voisine de l'Ile-du-Milieu, des NgatiKahungunu soient retournés vers les points les plus rapprochés de cette dernière île, à mesure que leur tribu devenait plus puissante, et dans le but de s'y procurer le jade précieux qui se trouvait là seulement; qu'ils l'aient fait surtout, comme l'histoire l'apprend, de 1825 à 1840, enhardis par les armes à feu qu'ils avaient pu se procurer avant les habitants de l'Ile-du Milieu, et attirés toujours soit par l'appât du jade, soit seulement par le goût des conquêtes (1), ce sont des faits certains ; mais cela n'empêche point qu'ils ont pu venir sur l'Ile-Nord plusieurs siècles auparavant, avant d'envoyer leurs colonies s'établir sur quelques points de l'Ile-du-Milieu. Par conséquent, ces faits ne prouvent pas plus le peuplement de l'Ile-du-Milieu par l'Ile-Nord que l'absence, sur cette dernière île, d'une ancienne population primitive. Il faut même reconnaître qu'ils prouveraient

(1) C'est ce que nous avons vu faire nous-même en 182\%, par des chefs tels que Hongi, Pomare, Rauparaha, etc. Voir à ce sujet le texte du voyage de l'Astrolabe, où d'Urville cite les rencontres que nous avons faites de ces chefs. 
que c'est l'Ile-du-Milieu qui a peuplé l'Ile-Nord, plutôt que l'Ile-Nord l'Ile-du-Milieu, si, comme nous le soutenons, l'Hawahiki était l'Ile-du-Milieu ou une portion seulement de cette île.

Pour nous, en définitive, les colonies Ngaïtahu et Rangitane n'étaient que des colonies de tribus venues ellesmèmes, plusieurs siècles auparavant, de l'Ile-du-Milieu ; ces colonies, parties du bord opposé du détroit de Cook sur l'Ile-Nord, allèrent se fixer sur son autre bord dans l'Iledu-Milieu, à côté de populations dont les écrivains n'indiquent pas l'origine, mais qui étaient presque certainement, indigènes de l'Ile-du-Milieu elle-même. Telles sont celles qui touchaient les Tehuataki et les Ngaïtara. Ces populations, quoique réduites à des agglomérations assez peu considérables, cherchèrent à s'opposer au passage des envahisseurs. Longtemps ces colonies durent vivre dans ces lieux, en paix ou en guerre avec leurs voisins, avant de songer ấ conquérir des points plus éloignés ; ce ne fut qu'après la venue de guerriers appartenant à la souche qui les avaient fournies, et quand les armes à feu eurent été connues des habitants de l'Ile-Nord, qu'elles osèrent avancer jusqu'à Kaikoura d'abord, puis, successivement, jusqu'à la presqu'île de Banks, enfin, plus tard encore, jusqu'ì Otokou. Car, il faut bien le remarquer, c'est à l'introduction des armes à feu que les habitants de l'lle-Nord, réduits, pendant des siècles peut-être, à n'occuper que les bords du détroit de Cook formés par l'Ile-du-Milieu, ont fini par devoir les succès qu'ils ontremportés sur lesanciens habitants ou Ngati-Mamoe, occupant toute la côte Est depuis Kaikoura jusqu'à Otokou.

Aujourd'hui, il reste encore assez de Ngati-Mamoe pour qu'on puisse espérer savoir quelle était la croyance de ce peuple sur son origine, comme sur les causes de sa décadence. Il est vivement à regretter qu'on n'en ait pas déjà profité et qu'au lieu de se borner, comme l'a fait Shortland, par exemple, à interroger les vainqueurs, on n'ait pas demandé ou fait demander des renseignements à quelquesunes des familles qu'il cite lui-même. Ces renseignements 
auraient jeté un jour nouveau sur l'histoire des populations de l'Ile-du-Milieu, à peine connues jusqu'à présent, mais qui, pour nous, nous le répéterons, n'est que celle des habitants de l'Hawahiki.

Résumé. - Ainsi, en ne cessant de remonter, et guidés à la fois par les traditions et par tous les témoignages, nous sommes parvenus, croyons-nous, au véritable lieu d'origine des Polynésiens.

Commençant par les îles Sandwich, point le plus extrême en Polynésie, nous avons pu rétrograder jusqu'aux îles qui paraissent les avoir peuplées, telles que les ìles de la Société, Hapaï et probablement les Marquises.

Des Marquises, nous sommes arrivés aux îles de la Société encore, aux Hapaï et peut-être aux Samoa;

Des Mangareva, à Rarotonga et probablement à Tahiti par la voie indirecte des Paumotu;

De Rapa, aux Tunga, aux Manaïa et probablement aussi à Tahiti ;

Enfin, des Manaia et des îles de la Société, aux Samoa, et de celles-ci aux Tunga.

D'où il semble résulter, comme on le voit, que les îles de la Société et les Tunga scnt celles qui ont le plus contribué à peupler les îles les plus orientales, les plus Sud et même les plus Nord.

Arrivés aux Tunga, il fallait trouver le véritable lieu d'origine de leurs habitants, et l'on a vu que nous avons cru le reconnaître dans l'Ile-Nord de la Nouvelle-Zélande.

Enfin, rétrogradant toujours, nous sommes parvenus à l'Iledu-Milieu, et c'est là que nous avons rencontré l'Hawahiki, cette patrie première de tous les Polynésiens Maori.

Après tous les développements dans lesquels nous sommes entrés, nous croyon s qu'il n'est pas permis d'en douter. Mais il reste maintenant une grande difticulté à résoudre, celle de savoir d'où étaient venus eux-mêmes les premiers habitants de l'Hawahiki. C'est ce qui va faire le sujet du chapitre suivant. 


\title{
CHAPITRE QUATRIÈME
}

\author{
PROVENANCE DES HAWAHIKIENS
}

Les Hawahikiens étaient autochthones sur Kawaï. - Spécialité de la faune des îles de la Nouvelle-Zélande. - Spécialité de la flore de ces mêmes îles. - Spécialité de la race humaine de ce groupe. - Isolement dans l'espace des terres de la Nouvelle-Zélande. - L'île Kawaï a été le centre de création de la race Maori.

Il est peu de questions aussi difficiles à résondre que celle de la provenance des habitants de l'Hawahíki. Aussi nous bornerons-nous à exprimer là conclusion à laquelle nous avons été conduit par toutes nos études et par toutes les observations que nous avons pu faire nous-même pendant nos voyages répétés et notre long séjour en Océanie.

Il est certain qu'il n'existe aucune terre dans l'Ouest et le Sud-Ouest de l'Ile-du-Milieu, et, par conséquent, aucune population polynésienne ou autre, d'où auraient pu venir les premiers habitants de l'Hawahiki. Il n'y a, dans le Sud, que la petite île Stewart que tout annonce avoir été peuplée par l'Ile-du-Milieu ; il n'y a, dans le Sud-Est de l'Ile-Nord et l'Est de l'Ile-du-Milieu, que les îles Chatham qui, d'après les traditions, avaient une population toute Maori, avant qu'elle ne fût exterminée par d'autres tribus Maori chassées elles-mêmes, de notre temps, des bords du détroit de Cook; mais l'idée ne viendra à personne d'attribuer à ces îles de médiocre étendue le peuplement de l'He-du-Milieu.

Il y a bien, à une petite distance, 750 milles, dans l'OuestNord-Ouest et l'Ouest, la Nouvelle-Hollande et Van Diemen ; mais il est évident que ces terres n'ont pu fournir la race 
dite Polynésienne par les auteurs, et que nous appelons race Maori.

Ainsi, pas une seule terre, dans l'Ouest, le Sud-Ouest, le Sud-Est et même l'Est, à laquelle on puisse rapporter l'origine des Maori de l'Ile-du-Milieu. Or, s'il est vrai qu'ils n'ont pu provenir de la Polynésie, comme nous l'avons soutenu, qu'en conclure? Une seule chose, c'est qu'ils étaient autochthones.

Nous allons essayer d'appuyer cette conclusion par des raisons tirées :

$1^{\circ}$ De la spécialité de la faune et de la flore de l'Ile-du Milieu et des îles du même groupe ;

$2^{\circ}$ De la spécialité de la race humaine qui les habite, ainsi que de celle de son langage;

$3^{\circ}$ De la séparation probablement constante entre la Nouvelle-Hollande et la nouvelle-Zélande;

$4^{\circ}$ Enfin, de l'opinion des savants qu'on regarde comme les maîtres de la science.

Quand on remarque, en effet, que des pays voisins l'un de l'autre, tels que la Nouvelle-Guinée et la Nouvelle-Hollande, possèdent non seulement une flore et une faune distinctes, mais même des populations qui diffèrent geénéralement et ne se rapprochent que par quelques traits secondaires, on ne peut qu'ètre conduit à se demander pourquoi la Nouvelle-Zélande, qui est plus éloignée de l'Australie que l'Australie ne l'est de la Nouvelle-Guinée, et qui a, elle aussi, une faune et une flore différentes, n'aurait pu avoir une race humaine particulière?

C'est une erreur de croire queles productions tant animales que végétales de la Polynésie sont, comme on l'a tant répété, les mêmes que celles de la Malaisie (1). Il est cer-

(1) Le traducteur d'une partie des ouvrages de Sir Raffles et Crawfurd, Marchal, fait remarquer dans sa préface qu'il y a une difference même dans l'archipel indien: "C'est ıne erreur, dit-il, de croire que la végétation et les animaux notamment sont les mêmes dans toutes les îles ; c'est le contraire qui existe ; il y a une grande différence entre les productions de chacune de ces îles et entre les races de leurs habitants. " 
tain, au contraire, que la Polynésie a une végétation geénéralement distincte qui, parfois seulement, se rapproche de celle de la Nouvelle-Zélande, mais non de celle de la Malaisie et de l'Australie. Aussi d'Urville a-t-il pu dire, avec quelque raison, que la flore de la Nouvelle-Zélande semblait intermédiaire de celle de la Polynésie et de l'Australie.

La Polynésie, en outre, a des oiseaux, des poissons particuliers, tandis qu'elle n'a presque rien, en zoologie comme en botanique, de a Malaisie. Tout le monde sait enfin que la zoologie des îles malaisiennes est aussi riche et aussi variée que celle de la Polynésie l'est peu, et qu'elle semble attester, par les nombreuses espèces qui lui sont propres, que les îles malaisiennes ont fait partie du continent asiatique: En effet, plusieurs des grands quadrupèdes qui vivent dans un certain nombre d'entre elles sont ceux de ce continent. Par contre, on sait aujourd'hui qu'il n'y a jamais eu d'autres mammifères en Polynésie que le chien, le cochon, le rat et quelques roussettes et chauves-souris.

C'est donc bien à tort, nous ne saurions trop le dire, que les premiers navigateurs, et même des naturalistes, comme Chamisso entre autres (1), le compagnon de Kotzebüe en 1816 , ont soutenu que les productions naturelles des îles polysiennes sont semblables à celles des pays malais ou asiatiques : il n'en est absolument rien pour presque toutes, comme l'avait déjà remarqué l'infatigable Péron, pendant son voyage aux Terres Australes avec. Baudin (2).

Mais, s'il en est ainsi pour ia Polynésie, ce serait se tromper bien plus encore que d'accorder à la Nouvelle-Zélande les mêmes productions que celles des îles asiatiques, ou de croire seulement que la Nouvelle-Zélande possède les principales productions de la terre qui l'avoisine le plus, l'Australie.

Sans doute, il y a eu d'abord quelques dissidences à ce sujet, faute de documents assez nombreux et assez exacts ;

(1) Mémoires du Grand-Océan, de ses îles et de ses côtes, Annales maritimes, 1825, $2^{\mathrm{me}}$ partie.

(2) Voyage de découvertes aux Terres Australes (1800-1804). Paris, 1824. Tome IV, Mémoires sur divers sujets. 
mais il est démontré aujourd'hui que les différences l'emportent de beaucoup sur les analogies, et que si la NouvelleZélande se rapproche de la Nouvelle-Hollande, de la Polynésie, et même de l'Amérique et de l'Europe par quelques plantes, elle s'en éloigne davantage par le plus grand nombre, tout en restant, naturellement plus proche par sa flore, de celles des deux contrées qui l'avoisinent le plus, la Polyré sie et l'Australie (1).

Mais c'est surtout par la zoologie que les îles de la Nouvelle-Zélande diffèrent de la Nouvelle-Hollande, bien que ces deux contrées ne soient séparées que par 750 milles. On ne trouve à la Nouvelle-Zélande aucun des quadrupèdes et des oiseaux si remarquables de la Nouvelle-Hollande, tels que le Kangoourou, le Dasyure, l'Echidné, le Casoar, le Faisan-lyre, le Prince-régent et le paradoxal Ornithorhynque. La Nouvelle-Zélande n'a même aucun des animaux malfaisants de l'Australie, tels que certaines fourmis, les serpents, etc. Elle a, au contraire, des animaux qui n'ont jamais existé ni en Australie, ni en Polynésie, ni en Malaisie, tels que le Moa ou Dinornis, le Kiwi ou Apteryx, le Kaka ou Psittacus hypopalius de Forster, le singulier animal plante appelé Aweto-hotete, par les indigènes et Sphœria Robertsia par les naturalistes, etc.

Que conclure de l'absence à la Nouvelle-Zélande des animaux malfaisants de la Nouvelle-Hollande? Qu'évidemment ces deux grandes terres n'ont jamais été jointes ensemble. En effet, ainsi que l'a ditlepremier le président Debrosses (2): « Quand on trouve des animaux malfaisants ou venimeux dans une contrée, c'est une preuve certaine que cette contrée, qui est aujourd'hui une île, a été autrefois jointe au continent. Il est évident, d'une part, que les hommes qui

(1) Nous avons vu plus haut, (vol. III, p. 30 à 33), que le savant missionnaire Taylor corrobore cette opinion : pour lui, la flore de la Nouvelle-Zélande diffère autant de celle de la Nouvelle-Hollande que celle-ci diffère, par ses diverses productions, de toutes celles des autres parties du globe. Sur 2,000 espèces environ à la Nouvelle-Zélande, il n'y en a que 123 semblables.

(2) Histoire des navigations aux Terres Australes, t. II, p. 382 
auraient été peupler ces îles en colonies, n'y auraient pas, exprès, transporté avec eux des races mâles et femelles de telles bêtes nuisibles, tels que tigres, serpents, etc.; d'autre part, il n'est pas moins certain que les animaux n'ont pu ni voulu quitter le continent et traverser de vastes bras de mer, pour aller se gîter dans ces îles. Ainsi, puisqu'ils y sont, c'est une marque qu'ils y étaient déjà quand l'eau a commencé d'isoler ces régions du continent. On n'y en verrait point dès à présent, si dès lors les races n'y avaient été pour se reproduire. »

Nous croyons avec lui que, dès que les animaux malfaisants de la Nouvelle-Hollande ne se retrouvent pas à la Nouvelle-Zélande, il faut reconnaître que ces terres n'ont jamais été jointes ensemble. C'était aussi, comme on l'a vu, l'opinion du comte Carli qui, tout en admettant que la Nou-. velle-Zélande avait pu awoir des rapports avec Tahiti, par une suite de terres intermédiaires à sec, disait que le canal qui sépare la Nouvelle-Zélande de la Nouvelle-Hollande existait antérieurement à l'inondation. Comme on l'a vu encore, et pour les mêmes motifs, Dieffenbach a pu conclure avec raison, suivant nous, qu'autrefois l'île de la Barrière tenait à la grande île Ika-na-Maui, puisqu'on y retrouve le Kiwi qui, par sa conformation, est incapable de voler d'une île à l'autre.

Mais que les grandes îles de la Nouvelle-Zélande aient été ou non séparées de tout temps de l'Australie, il n'est pas moins vrai qu'elles ont dẹs oiseaux particuliers qui n'ont jamais été rencontrés ni en Malaisie, ni en Polynésie, ni même en Australie.

Cette opinion n'est pas seulement la nôtre; c'était également celle des naturalistes zoologistes de l'expédition de Dumont d'Urville, en 1827, MM. Quoy et Gaimard. Voici ce qu'ils écrivaient à ce sujet (1):

« La Nouvelle Zélande, par son isolement et sa position reculée vers le Sud, possède dans ses productions des caractères qui lui sont propres.

«Sa végétation a une physionomie toute particulière, et

(1) Voyage de l'Astrolabe, t. II, 2e partie, p. 391. 
diffère totalement de celle de la Nouvelle-Hollande, terre la plus voisine et avec laquelle on aurait pu lui supposer de grands rapports.

a Le règne animal n'offre pas moins de différence dans ses divisions. Les mammifères sont presque nuls : chien et rat (1). Il paraît que le cochon, qu'on trouve maintenant en assez grande abondance, est une acquisition moderne due aux Européens. Ainsi, cette nombreuse famille de marsupiaux qu'on rencontre d'une manière non interrompue dans les îles de l'Asie, les Moluques, la Nouvelle-Guinée, qui pullule dans la Nouvelle-Hollande, s'est arrêtée à l'île de Van-Diemen.

"Les oiseaux, moins bornés dans leurs migrations, sont cependant peu nombreux et ne présentent pas cette diversité qu'on trouve à la Nouvelle-Hollande. Bien qu'il y ait des genres communs aux deux terres, l'ensemble est cependant spécial à la Nouvelle-Zélande. Ainsi, par exemple, il paraît y avoir peu d'oiseaux de proie. Le Glaucope à caroncules, le Philédon à cravate (Tui), un nouveau Tangara, le grimpereau que nous avons nommé hétéroclite, l'oiseau connu sous le nom d'Apteryx, sorte de casoar ? a long bec grêle, (Kiwi), etc., sont des êtres qui n'appartiennent qu'à cette ìle. Elle a de commun avec d'autres contrées, d'avoir des philedons, des cailles, des alouettes, des moucherolles, des mésanges, des synallaxes, des tourterelles, perruches, perroquets, etc. Mais la Nouvelle-Zélande a ses perroquets

(i) Crozet avait déjà ảit : « Je n'ai vu dans ce pays d'autres quadrupèdes que des chiens et des rats. Les Nouveaux-Zélandais n'ont absolument d'autre animal domestique que le chien.

"Les chiens sont une es pèce de renards domestiques tout noirs ou blancs, très bas sur jambes, les oreilles droites, la queue épaisse, le corps allongé, la gueule très fendue, mais moins aigüe que celle du renard; ie même cri : ils n'aboient pas comme nos chiens. On en avait embarqué plusieurs sur nos vaisseaux, on n'a jamais pu les apprivoiser. $\triangleright$

En parlant des rats, Crozet disait: "Ils sont de la même espèce que ceux qui se trouvent dans nos champs et dans nos forêts. Les sauvages les mangent comme ils mangent les chiens. : 
propres, dont le Nestor (Nestor meridionalis GM.) est le plus remarquable. $n$

On sait, du reste, aujourd'hui, que les oiseaux de l'Océanie ou de cette partie du globe qu'on appelle Polynésie depuis que d'Urville et les navigateurs anglais l'ont ainsi désignée, comparés aux oiseaux de l'ancienne Polynésie des géographes, c'est-à-dire à ceux de cette partie du monde appelée pour la première fois Malaisie par R.P. Lesson (1), n'offrent que de rares analogues dans les espèces. Chaque système de terres possède des individus de genres rencontrés dans un grand nombre de localités, mais qui sonttoujours distincts. Ainsi, de même qu'à la NourelleZélande, on trouve des espèces particulières à l'île Norfolk, ainsi qu'à la Nouvelle-Calédonie ; aux Sandwich, on trouve des perruches et ces héorotaires (2) qui paraissent pourtant avoir existé aussi aux îles Tunga et à T'ahiti, mais qu'on n'y rencontre plus aujourd'hui ; aux îles Marquises, comme à Tahiti, on retrouve les perruches Vini, les tourterelles Kurukuru, mais avec des nuances si différentes, qu'elles semblent être autant de variétés.

Pour la Nouvelle-Calédonie particulièrement, il résulte d'un travail de M. Decaisne (2) professeur au Muséum d'histoire naturelle de Paris, que cette île appartient par sa flore à la même formation que la Nouvel!e-Hollande, malgré la distance assez grande, 600 milles, qui les sépare: que son climat océanique ainsi que sa situation, lui donnent d'assez nombreux rapports avec les archipels polynésiens et en particulier avec l'île de Timor ; que la population végétale de

(1) Voir ce que dit à ce sujet Balbi (Introduction, p. 14). « Nous proposons de remplacer le nom inconvenant et ridicule de Nouvelle-Guinée par celui de Paponasie, dont la racine Papoua indique le peuple qui habite cette grande île, de mème que celui de Malaisie, si heureusement imaginé par M. Lesson, pour remplacer l'archipel d'Orient d'Asie, rappelle l'habitation des nations malaisiennes dans la partie occidentale du monde maritime.

(2) Oiseaux à plumes rouges très recherchées par les Polynésiens comme ornement.

(3) Extr. de la Revue et Magasin de Zoologie. Sept. 1860 p. 2. 
la Nouvelle-Calédonie prouve, en un mot, qu'elle participe à deux grandes flores, en se rapprochant beaucoup plus de celle de l'Australie orientale et tropicale que de celle des archipels de l'Océanie; mais, d'un autre côté, la faune prouve le contraire.

Il résulte, en effet, du relevé fait par MM. J. Verreaux et 0. des Murs (1) que, sur 76 espèces d'oiseaux rapportés de la Nouvelle-Calédonie, 45 ou les $4 / 10^{\text {es }}$ et demi, sont exclusivement propres à cette île. Parmi ces espèces se trouvent les trois beaux types génériques Gazzola pour les corvidées, Phœnorrhina pour les colombins et Rhynochetos (2) pour les ardéidées. Dix-huit espèces ou près des $2 / 10^{\text {es }}$ lui sont communes avec la Nouvelle-Hollande, dont une avec la terre de Van-Diemen et treize seulement ou un peu plus d'un dizième, se retrouvent dans la Polynésie proprement dite, $\mathrm{y}$ compris la Nouvelle-Guinée.

La conclusion qu'en ont tiré, avec raison, ces naturalistes, c'est que la faune ornithologique de la Nouvelle-Calédonie est, ainsi qu'on aurait pu le supposer, loin de se compoirter comme sa flore et que, par conséquent, l'opinion de $\mathbf{M}$. Decaisne pour celle-ci est infirmée par celle-là. En un mot, contrairement à ce qu'exprime le savant botaniste, au liea de se rapprocher beaucoup plus de l'Australie orientale et tropicale que des archipels océaniens, elle se tient à une distance presque égale de l'une et de l'autre, fla différence n'étant que 18 à 13); elle oftre un caractère et une homogénéité qui lui sont propres et que ne pourront que confirmer les découvertes ornithologiques à venir dans ce nouveau centre de création si restreint et si singulier.

Ajoutons ici que la Nouvelle-Calédonie semble appartenir à la Nouvelle-Zélande par sa formation géologique.

Quoi qu'il en soit, il est certain que la faune de la Nou-

(1) Description d'oiseaux nouveaux de la Nouvelle-Calédonie, etc., Extrait de la Revue et Magasin de zoologie, septembre 1860.

(2) Deux de ces oiseaux rares et curieux ont été possédés à Rochefort par notre ami le comte Pouget, qui a publié en 1878 un curieux travail sur leur remarquable intelligence. 
velle-Zélande est parfaitement distincte de celle de l'Australie et de la Polynésie (1); si l'on s'accorde un peu moins sur la flore, ce que nous allons en dire suffira, croyonsnous, pour établir qu'elle aussi doit être considérée comme différente.

Quand le professeur Richard décrivit, en 1832, les plantes collectées par nous pendant le voyage de découvertes de l'Astrolabe, et plus particulièrement celles de la NouvelleZélande, auxquelles d'Urville en avait ajouté quelques-unes provenant de la même contrée, il n'y avait alors de connu qu'un très petit nombre de plantes océaniennes. Le prodrome des deux Forster, compagnons de Cook avec Sparmann, en 1772, et dans lequel figuraient toutes les découvertes de Banks et de Solander, faites en 1769 et restées jusque-là inédites, ne portait le nombre des espèces qu'à 274 , dont 121 dicotylédones, 151 monocotylédones et 22 fougères. En y ajoutant les plantes phanérogames rapportées de la baie Dusky par Menziès, compagnon de Vancouver en 1791, et qui avaient été publiées par le professeur sir W. Hooker (2), il y en avait en tout ì peu près 300 à 320 espèces appartenant à la Nouvelle-Zélande.

. Nos collections permirent à A. Richard de porter ce nombre à 379 espèces environ, savoir: 211 phanérogames, dont 152 dicotylédones, 52 monocotylédones et 169 cryptogames. Ce nombre sans doute est peu considérable si on le compare aux augmentations faites depuis; mais alors il avait son importance ; surtout quand on tient compte de la brièveté des relâches dans une campagne d'exploration, et de l'impossibilité dans laquelle se trouvait alors le botaniste de franchir les limites du littoral.

(1) C'est ce que dit particulièrement Thompson quand il écrit : (p. 20) a Nous allons maintenant décrire la faune de la NouvelleZélande, sujet qui est bien digne de fixer l'attention des naturalistes, car le pays offre l'une des meilleures preuves de ce monde que chaque partie de la terre a ses animaux et ses végétaux de forme particulière. 》

(2) Voy. entre autres ouvrages dans lesquels ces plantes ont été étudiées par Hooker, les Arusei exotici et ses planches de fougères. 
Richard, comparant la végétation de la Nouvelle-Zélande avec celle des autres contrées, trouva que non seulement des rapports multipliés existaient avec la végétation des pays situés`à petite distance, mais encore avec celle des pays situés à une grande distance, et même dans un autre hémisphère (1). Ainsi, il établit qu'elle avait des points de contact avec celle du cap de Bonne-Espérance, et même avec celle du cap Horn : Tous les botanistes savent, en effet, que quelques genres de ce dernier point existent à la Nouvelle-Zélande, de même que plusieurs genres de la Nouvelle-Hollande. Il trouva également beaucoup d'identité entre les fougères de la Nouvelle-Hollande et celles que l'on rencontre si abondamment sur les côtes baignées par l'Océan Pacifique; enfin, il signala jusqu'à des végétaux européens.

En résumé, pour lui, c'était avec la flore des côtes méridionales de la Nouvelle-Hollande, que celle de la NouvelleZélande offrait le plus de ressemblance (2), tout en trouvant, comme on vient de le voir, qu'elle en avait avec le cap dt Bonne-Espérance et le cap Horn, et, par ses lichens, avec les régions hyperboréennes, de même que, par ses forgères, elle se rapprochait de la Nouvelle-Hollande, des côtes de l'Amérique méridionale, des îles de l'Océanie et notamment de l'île Juan-Fernandez.

Mais s'il signalait toutes ces analogies incontestables, il laissait passer inaperçues les différences, qui sont encore plus nombreuses; c'est à peine s'il s'arrêtait à quelques-unes des plantes les plus remarquables par leur spécialité d'habitat. Tel est le Phormium tenax, qui n'a jamais été trouvé ailleurs qu'à la Nouvelle-Zélande et à l'île Norfolk. Il faisait seulement remarquer dès lors que les légumineuses, les malvacées, les rubiacées manquaient presque compléte-

(1) Introduction : partic botanique du Voyage de l'Astrolabe, 1832.

(2) C'est surtout près du cap Nord de la Nouvelle-Zélande et dans la partie Nord de cette île, qu'on trouve le plus de plantes communes à la Nouvelle-Zélande et à la Nouvelle-Hollande. (Voir l'art. botanique de Taylor). 
ment a la Nouvelle.Zélande et à l'Ile-Nord, tandis que les épacridées, les myrticées, y formaient un nombre assez considérable d'espèces, et que les ombellifères, les crucifères et les œnothérées, prédominaient après les fougères, les graminées et les cypéracées.

D'Urville avait à peu près la même manière de voir, autant qu'on en peut juger par les lignes suivantes (1) : «Certainement c'est avec la flore de l'Australie que celle de la Nouvelle-Zélande a le plus de rapport,relativement au nombre des espèces ; mais le ton général de la végétation se rapproche plus de celui des îles de l'Océanie intertropicale par la forme des fougères, par le faciès général des plantes, surtout par la teinte verte et prononcée des arbres qui forment les forêts. »

On le voit, ni l'un ni l'autre ne précisaient les différences existantes ; il ne faisaient guère que répéter ce qu'avaient dit les naturalistes de l'Astrolabe, quand ils écrivaient que a la végétation de la Nouvelle-Zélande a une physionomie toute particulière, différant totalement de celle de la Nouvelle-Hollande par le ton général. »

Il faut arriver jusqu'à ces derniers temps, pour trouver un naturaliste formulant nettement la différence qui existe entre la flore de la Nouvelle-Zélande et celle des autres contrées.

Ce naturaliste est le $\mathrm{D}^{\mathrm{r}}$ Dieffenbach qui a publié en 1843 deux volumes sur la Nouvelle-Zélande (2).

On sait que Dieffenbach se trouvait à la Nouvelle-Zélande dans l'intervalle de 1839 à 1847 ; son opinion pouvait alor's s'appuyer sur les nombreuses découvertes faites depuis la publication des collections de l'Astrolabe. Entre les deux époques, W. Hooker (3) avait publié les plantes découvertes par les deux frères Allan et Richard Cunningtiam, en 1826

(1) Voyage de l'Astrolabe, t. II, 2e partie.

(2) Travels in New-Zealand, 2e vol. London 1843. La botanique

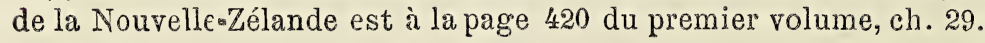

(3) Flora Novo Zelandice, by W. D. Hooker, with plates, Murray, London, 1853, Published by the Admiralty. 
et 1833-34, et mises en ordre par le premier que nous avons eu l'avantage de connaître en 1827, à la Nouvelle-Hollande, en même temps que Frazer. Le catalogue dressé par le $\mathrm{D}^{\mathrm{r}}$ Hooker sur leurs matériaux et ceux de leurs devanciers, avait élevé le chiffre total des plantes de la Nouvelle-Zélande à 632. C'est après cela que Ie $D^{r}$ Diffenbach (I) n'hésita pas à dire : «Quoique la Nouvelle-Zélande ait quelques rapports par sa flore avec les deux grands continents entre lesquels elle est située, l'Amérique et l'Australie, et qu'elle possède même des espèces identiques avec celles. d'Europe, sans qu'on puisse attribuer l'introduction de ces dernières aux Européens, cependant le plus grand nombre des espèces et même des genres, sont particuliers à cette contréc : ce qui, fait surprenant, avait déjà frappé l'esprit des premiers explorateurs.»

Et il ajouta : « La Nouvellc-Zélande avec quelques-unes des îles voisines, les Chatham, Auckland et Macquarie, forme un centre botanique. »

Il écrivait, avons-nous dit, en 1843, par conséquent bien des années avant Taylor et Thompson qui ne firent paraître leurs ouvrages qu'en 1855 et 1859 , et qui partagèrent, eux aussi, cette manière de voir de Dieffenbach.

Déjà, dans nos Considérations générales (2), nous avons montré que, sur les 632 plantes connues alors comme appartenant à la Nouvelle-Zélande, 89 étaient de l'Amérique du Sud ; 77 de l'Australie et de l'Amérique méridionale, dont 50 communes à l'Eurọpe ; 60 complétement européennes.

406 espèces ou près des deux ticrs, et même 507 d'après Taylor, lui étaient donc particulières dès ce moment ; elles établissaient, comme ce dernier le disait lui-même, après Dieffenbach, le droit de la Nouvelle-Zélande à être considérée comme un centre botanique, d'avoir, en un mot, la plus grande partie de sa flore complètement distincte.

('était ce que reconnaissait également le $D^{r}$ Thompson

(1) Ouvr. cité, p. 420.

(2) Voy. ci-dessus, p, 31. 
quand, indiquant la connaissance incomplète que l'on avait de cette flore, il la signalait comme particulière.

On pouvait craindre que de nouvelles découvertes ne vinssent modifier une pareille conclusion ; mais loin de là : malgré que les découvertes aient été considérables depuis ce moment, elles n'ont fait que l'appuyer et la sanctionner.

Ces découvertes, en effet, ont plus que doublé le nombre précédent. Elles sont dues, pour un grand nombre, au docteur Hookंør lui-même qui, après s'être occupé une partie de sa vie des plantes de la mer du Sud, se décida à aller étudier celles de la Nouvelle-Zélande, lors de l'expédition antarctique du capitaine Ross (1839-43). Après avoir coordonné et mis en ordre tous les matériaux connus jusque-là, le savant botaniste publia la flore, dans laquelle se trouvent décrites environ dix-neuf cents plantes.

Aujourd'hui, on compte 123 plantes australiennes; 117 fougères dont 42 sont particulières à la Nouvelle-Zélande, etc. (1) ; mais, quel que soit le nombre exact de toutes les plantes connues, il résulte du dernier travail du $\mathrm{D}^{\mathrm{r}}$ Hooker que la majorité des plantes du groupe de la Nouvelle-Zélande ne se trouve que dans cette contrée.

Le même savant pensait qu'il s'en fallait qu'on connût toutes les productions végétales de la Nouvelle-Zélande. En effet, ce n'était guère alors que dans l'Ile-Nord qu'on avait pu pousser les recherches jusque dans l'intérieur ; le littoral seul de l'Ile-du-Milieu avait été visité, mais jamais son intérieur et surtout ses montagnes alpestres. Au contraire, depuis une trentaine d'années, on a pu faire de tous côtés des explorations botaniques; on a vraisemblablement découvert bon nombre de plantes nouvelles; mais il est peu probable qu'elles viennent modifier Je résultat fourni par les plantes les plus en vue; il est même plutôt à croire qu'elles viendront le confirmer.

Quel que soit donc, en résumé, le degré de différence de la faune et de la flore do la Nouvelle-Zélande, comparées à celles des autres contrées, il est un fait reconnu par tous les

(1) Voy. ci-dessus, p. 33 , 
écrivains, c'est qu'elles sont dissemblables par l'ensemble, c'est-à-dire que l'ensemble a été créé sur place.

On ne met pas en doute aujourd'hui que les flores et les faunes aient pu être créées sur place; ce que nient, de nos. jours comme autrefois, les partisans d'un démiurge,c'est que la puissance créatrice, qui a fait ces faunes et ces flores, ait pu produire en même temps, sur le même sol, une espèce humaine particulière.

Nous ne chercherons pas à démontrer que l'homme suit constamment une phase évolutive identique à celle qui est suivie par les autres animaux : le transformisme s'est chargé de prouver la vérité de cette assertion. Nous nous bornerons ici à redresser une erreur qui a généralement cours dans la science, et qui, certainement, a le plus contribué à entretenir la croyance biblique, c'est-à-dire l'analogie de la race polynésienne avec les races de la Malaisie et de l'Asie.

Nous l'avons déjà dit, et nous ne saurions trop le répéter, tant cela importe à la question qui nous occupe : Les Maori, qui appartiennent à la même race que les Polynésiens, ont non-seulement les mèmes caractères physiques, mais, chez les uns comme chez les autres, ces caractères diffèrent de ceux de toutes les autres races. Ils forment une race à part, distincte, typique, qui n'a jamais été rencontrée en grandes agglomérations ailleurs qu'en Polynésie et à la NouvelleZélande, qui, en un mot, ne ressemble pas plus à la race malaise, d'où on la fait descendre, que la faune et la flore de la Nouvelle.Zélande et de la Polynésie, ne ressemblent à celles de la Malaisie. Telle était l'opinion de M. Périer, quand il disait (1): «qu'on ne pouvait rattacher les races de la Polynésie ni à celles de l'Amérique, ni à celles de l'Asie et de la Malaisie. « Nous croyons, avec M. Sanson (2), « que chaque race a son aire-géographique naturelle, d'où le type spécifique qu'elle représente est originaire. »

Nous avons assez longuement indiqué les caractères phy-

(1) Bulletins de la Soc, d'anthrop., t. I, p. $19 \%$.

(2) Société d'anthropologie, séance du 21 sept. 1871. 
siques, moraux et intellectuels des Maori et des Polynésiens pour n'avoir pas besoin d'y revenir. Ces caractères sont absolument les mêmes, avec cette seule différence qu'ils sont plus accentués chez les Maori. Si l'on ajoute enfin que la langue est elle-mème semblable, et que l'opinion de Cook, de Crozet, de d'Urville, sur l'existence de plusieurs races à la Nouvelle-Zélande n'est pas fondée, on reconnaitra avec nous que Maori et Polynésiens appartiennent à une race spéciale, distincte.

Pourquoi donc, si ces caractères sont aussi tranchés que nous le disons, s'ils n'appartiennent qu'à une race dónt on n'a pu retrouver l'origine nulle part ailleurs, pourquoi cette race n'aurait-elle pas pu être également créée sur place, là où la faune et la flore paraissent l'avoir été ? Lorsque l'on raisonne froidement et scientifiquement sur l'origine des races, il faut nécessairement reconnaitre que les foyers de création sont multiples, et que, dans chaque foyer, il existe une corrélation naturelle entre la flore, la faune et l'homme. Tous les arguments qui ont été mis en avant pour soutenir l'unité des races ne sont, quand on les passe au creuset de la critique, qu'un vain effort pour concilier les faits avec une théorie préconçue.

Pour M. de Quatrefages, qui est monogéniste, les Polynésiens ne sauraient être autochthones et, dans une discussion fameuse sur le croisement des races, il répondait à ses adversaires ( 1 ): « Cette opinion, qui a joui pendant quelque temps d'une certaine faveur, perd aujourd'hui du terrain; les ethnologues américains l'ont, pour la plupart, abandonnée, quoi qu'ils soient partisans de la multiplicité des origines de l'humanité. »

M. de Quatrefages avait certainement raison s'il entendait seulement par là que les Polynésiens sont nés sur les îles polynésiennes actuellement occupées par eux; mais il avait tort si les émigrants d'Hawahiki étaient, comme nous avons cherché à le prouver, des émigrants de l'Ile-du-Milieu et les ancêtres des Polynésiens. Ceux-là, évidemment, ne pouvaient être qu'autochthones, puisqu'ils

(1) Bulletins de la Soc. d'antrop., t. I, p. 193. 
n'avaient pu provenir d'aucune contrée ayant une race de même type. On comprend très bien, après cela, que les ethnologues américains aient abandonné l'opinion de l'autochthonie des Polynésiens, telle du moins que $M$. de Quatrefages parait l'entendre. Mais il n'est pas moins vrai qu'ils sont restés partisans en général de la multiplicité des origines de l'humanité.

Il faut bien le dire d'ailleurs, les arguments sur lesquels s'appuie M. de Quatrefag'es sont loin d'avoir la valeur qu'il leur accorde. Voici en effet ce qu'il dit (1):

«Quand on lit les relations des voyages du XVI siècle, et qu'on les compare aux relations plus modernes, on est porté à croire que diverses modifications se sont produites depuis trois siècles par suite de migrations et de mélanges dans la population de certaines îles. Wallis et Cook ont trouvé, dans l'archipel de Tahiti, des hommes blonds aux cheveux bleus, et c'est seulement parmi les chefs ou dans leurs familles qu'ils ont observé ce type, comme si les hommes blonds descendaient d'une race de conquérants. D'un autre côté, les traditions établissent qu'il y a eu autrefois des nègres dans plusieurs îles de la Polynésie. Cette race noire aurait donc été exterminée ou chassée par la race actuelle. Il y a encore des nègres dans la Nouvelle-Zélande où la plus grande partie de la population appartient pourtant à la race polynésienne. Nous possédons le portrait d'un Néo-Zélandais qui fut conduit à Londres, il y a quelque temps: les principaux caractères du type éthiopien sont réunis dans ce portrait. »

Il est certain d'abord qu'il ne s'estopéré que très peu de modifications depuis les premières migrations, comme le prouveraient au besoin les caractères physiques des habitants des Marquises, par exemple, lesquels sont absolument aujourd'hui ceux que Mendana leur a reconnus en 1595, et ceux de tous les autres Polynésiens, même de ceux qui avoisinent le plus les Fiji : c'est ce que nous avons cherché à prouver.

(1) Bulletins cités, ler volume, et Revue des Deux-Mondes, ler février 1864, p. 525. 
D'un autre côté, si on a vu des hommes plus blancs, moins foncés relativement, et aux cheveux bleus ou rouges, seulement dans les familles des chefs, ce n'est pas parce que ces fils de chefs, trouvés blonds, (1) descendaient d'une race de conquérants, - ce qui aurait pu être d'ailleurs, que la race fût blanche ou noire, - mais tout simplement parce qu'ils se soignaient davantage, qu'ils vivaient plus abondamment et qu'ils évitaient, avec plus de soin que le peuple ne pouvait le faire, les causes qui auraient pu nuire à la beauté de ieur corps. C'est ce qui explique, en outre, leur développement plus grand, l'épanouissement plus prononcé de leurs traits et surtout leur tendance à l'embonpoint. Mais, ainsi que nous l'avons déjà dit, cette plus grande blancheur attribuée seulement aux chefs n'est pas un caractère constant, puisque dans la même famille, on rencontre des nuances diverses et qu'il y a même des familles de chefs où tous les membres sont plus foncés que le reste de la population : telle est la famille des Pomaré.

Nous pourrions, à cette occasion, rapporter ici les curieuses observations que nous avons faites dans les îles Marquises; mais nous nous sommes déjà assez étendu sur ce sujet pour n'avoir pas besoin de nous y arrêter plus longtemps.

Quant à la couleur des cheveux, on sait assez aujourd'hui par quels moyens artificiels et dans quel but elle est obtenue: elle n'est qu'un objet de pure coquetterie, et c'est même ce qui explique si bien pourquoi ce sont les fils de chefs qui s'y abandonnent le plus. C'est ce qu'avait déjà remarqué, avec tant de raison, M. de Quatrefages qui, toutefois, disons-le, supprime cette remarque, dans son dernier ouvrage sur les Polynésiens (2).

Nous avons assez montré déjà combien était douteuse l'existence préalable de nègres à Tahiti, pour qu'il

(1) M. de Quatrefages le répète dans la séance du 5 juillet 1860 , p. 403 des Bulletins, alors que M. Broca reconnaît avec raison que les blonds vus par les anciens voyageurs, ne sont que des Albinos (Forster).

(2) Voir p. 10 et pro 525 de la Revue des Deux-Mondes du ler février 1864 . 
soit utile d'y revenir. Cependant, nous croyons devoir le répéter, les traditions disaient seulement que des hommes de couleur plus foncée que celle des Tahitiens existaient dans les montagnes avant l'arrivée de Cook; ce navigateur, qui a le plus répandu cette croyance en une autre race, n'avait pas eu l'occasion de voir ces hommes. Ils auraient certainement pu être des Fijiens, mais ils n'étaient bien plus probablement, comme nous avons essayé de le démontrer, que des hommes plus sauvages de la même famille, vivant ainsi par goût, mais surtout par nécessité. Il est certain d'ailleurs que le langage tahitien n'a gardé aucune trace du langage tout différent qu'aurait nécessairement parlé une autre race préalable.

Nous croyons ensuite que si il y a encore des nègres dans la Nouvelle-Zélande, comme le dit M. de Quatrefages, c'est qu'un assez grand nombre de véritables nègres ont été déposés sur cette terre par les baleiniers et autres navires, et que le cas cité par le savant français pourrait bien n'être qu'un métis négro-maori, ainsi que nous l'avons déja dit précédemment. Quoi qu'il en soit, malgré ce qu'ont avancé Queiros pour la Polynésie et Crozet pour la NouvelleZélande, il n'y a jamais eu de nègres à type africain dans cette dernièrecontrée, avant les rapports de ses habitants avec les navigateurs.

De pareils arguments ne prouvent donc rien, à notre avis, contre l'autochthonie des Nouveaux-Zélandais, pas plus qu'ils ne le font contre la multiplicité des origines du genre humain. Mais il faut le reconnaître, si l'Hawahiki était bien placé là où nous avons dit qu'il se trouvait, M. Périer n'aurait eu que le tort d'attribuer aux Polynésiens ce qui revenait seulement à leurs pères. Avec lui et $\mathrm{M}$. Broca, nous aimons mieux croire, en résumé, qu'il y a eu divers foyers de création aussi bien pour les hommes que pour les autres règnes. Allant seulement plus loin que ces savants, nous croyons pouvoir regarder l'Ile-du-Milieu ou peut-être le continent auquel elle tenait avant d'être aussi réduite, comme le berceau des habitants de la Nouvelle-Zélande.

Nous répéterons donc ce que disait $M$. Broca, dans une 
discussion sur l'ancienne race égyptienne : (1) « Je suis polygéniste ; je crois à la multiplicité des origines du genre humain. Chaque grande région du globe a sa faune et sa flore, et les naturalistes modernes admettent avec raison qu'il y a eu, pour les animaux comme pour les végétaux, plusieurs foyers de création. Or, je suis de ceux qui pensent que le principe général est applicable aux groupes qui composent le genre humain. »

En résumé, après de pareilles autorités, après tout ce que nous avons rapporté des traditions maori, après leur examen critique le plus attentif, nous croyons qu'il nous est permis non seulement d'admettre la multiplicité des foyers d'origine ou de création, mais encore l'autochthonie particulière des habitants de l'Hawahiki.

L'Hawahiki se trouvant dåns l'Ile-du-Milieu ou Kawai, ce serait donc cette île qui aurait été le foyer de création ou d'organisation de la race maori. Et, si nous avons bien interprété tous les faits, c'est du centre de ce foyer, de l'Hawahiki, en un mot, que seraient partis nécessairement, et pour ainsi dire d'après des lois fixes et nécessaires (2), tous les individus qui sont allés s'établir d'abord sur l'lle-Nord, en absorbant ou exterminant les populations qui s'y étaient déjà établies et qui provenaientbien probablement du même lieu, puisqu'elles parlaient la même langue. Puis,émigrant encore de leur nouvelle patrie, et pour les mêmes motifs, ces mêmes individus ou leurs descendants formèrent successivement les groupes divers qui devaient être appelés Polynésiens de race jaune ou Maori.

Avant de clore cette discussion, et dans le but de mieux étayer encore notre opinion, nous citerons textuellement, en changeant toutefois le nom de lieu, le passage suivant par

(1) Bulletins Soc. d'anthrop. t. II, p. 593.

(2) Ces lois n'étaient ici que le besoin d'échapper à l'extermination, ainsi que la force et la direction ordinaires des vents qui poussaient toujours du côté opposé au point de départ, c'est-àdire vers le Nord-Est ou la Polynésie. 
lequel Moërenhoüt défendait sa théorie d'un continent placé dans l'Est des îles polynésiennes (1):

" S'il est vrai, comme l'a dit un auteur moderne, que les foyers des populations puissent se reconnaître à la beauté et à la perfection corporelle de chàcune des familles qui les constituent, et si chacun de ces foyers est le centre d'une langue mère, d'où sont descendusles différents idiomes ou dialectes, il est certain que la Nouvelle-Zélande est le foyer de la grande famille polynésienne. Car dans cette île seule et les îles polynésiennes, cette race joint à une haute stature et à de belles proportions une régularité et une beauté de corps qui ne se trouvent nulle part dans les îles malaises, où non seulement le langage, les habitudes, les mœurs, mais même les traits diffèrent et semblent partout corrompus par le mélange d'espèces moirs belles et d'idiomes moins parfaits $\gg(2)$.

(1) Vorages aux îles du Graní-Océan, p. 259. Moërenhoüt parlait des îles polynésiennes en général, à propos de l'origine malaisienne.

(2) On a vu que, pour Bory de Saint-Vincent, (L'homme, liv. II, p. 299), « les hommes et les femmes de la Nouvelle-Zélande l'emportent sur les autres Polynésiens, 》 et que M. de Quatrefages lui-même dit (Revue des Deux-Mondes 1864 et Bulletins Soc. d'anthrop. 1860), que les Nouveaux-Zélandais sont supérieurs aux autres Polynésiens. 



\title{
Table des Matières
}

$\mathrm{DU}$

\author{
TROISIFIME VOLUME
}

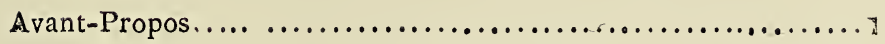

\section{TROISIEME PARTIE}

\section{LIVRE PPREMIER}

'N OUVELLE-ZÉLANDE

CONSIDÉRATIONS GÉNÉRALES SUR LA NOUVELLE-ZÉLANDE.

Réflexions préliminaires...............................

\section{CHAPITRE Ier}

GÉOGRAPHIE ET HISTOIRE NATURELLE.

Aperçu géographique et topographique sur le groupe de la Nouvelle-Zélande. - Trois îles principales. - Description de l'Ile-Nord. - Description de l'Ile-du-Milieu. - Examen des noms donnés par les premiers navigateurs. - Recherches linguistiques: Pounamu; Kawai ; Kaikoura ; Pakeha. - Météorologie. - Vents régnants. - Noms des vents. - Tempêtes. Température. - Tableaux météorologiques. - G£ologie. Constitution volcanique. - Iles disparues. - Botanique. - Nature et espèces des différentes plantes. - Le groupe de la Nouvelle-Zélande constitue un centre botanique. - Faune. Mammifères terrestres : Kuri ; Kiore ; Kaurehe. - Oiseaux : Kiwi ; Moa : Remarques sur l'extinction des Moa. - Ruru : Kakapo. - Reptiles ; Lézards. - Amphibies. - Poissons. Coquilles. - La géologie, la faune et la flore prouvent que les îles de la Nouvelle-Zélande ont été un centre de création......

\section{CHAPITRE II}

MAORI.

Population de la Nouvelle-Zélande. - Evaluations contradictoi res faites par les voyageurs: - Recensements: - Extinction 
graduelle des indigenes. - Etymologie du mot Maori. - Division des Maori en nations, tribus et sous-tribus. - Opinions de Shortland et de Thompson. - Iwi ; Hapu. - Devises caractéristiques des tribus. - Signification du mot Ngati. ... Unité de race à la Nouvelle-Zélande. - Examen critique des opinions contraires. - Caractères physiques des Néo-Zélandais d'après les différents observateurs : Crozet ; d'Urville; Moërenhoüt ; Dieffenbach ; Shortland; Taylor; Thompson. - Les Maori ne forment qu'une seule race et ne parlent qu'une même langue. - Les variétés signalées parmi eux ne sont que de simples nuances. - Caractères physiques des Néo-Zélandais, d'après nous-même. - Leurs caractères crâniens - Portraits des NéoZélandais. - Les Maori étaient le plus beau type de la race polynésienne. -- Comparaison de leurs caractères physiques et moraux au commencement du siècle et à notre époque : Quoy ; Marsden; Thompson................................

\section{VRE DEUXIĖME}

\section{NOUVELLE-ZÉLANDE \\ LIEU D'ORIGINE DES POLYNÉSIENS. \\ REMARQUES PRÉLIMINAIRES.}

Analogie du Tahitien et du Maori.- Usage de l'arc et des flèches. - Premiers partisans de l'origine Néo-Zélandaise des Poiynésiens : Banks; Crozet; Bory de Saint-Vincent................

\section{CHAPITRE Ier .}

\section{EXPOSÉ ET RÉFUTATION DES OBJECTIONS.}

Objections faites contre le peuplement de la Polynésie par la Nouvelle-Zélande. - Pirogues Néo-Zélandaises. - Existence à la Nouvelle-Zélande de canots doubles et de pirogues à balancier. - Absence des Maori à la Nouvelle-Hollande. - Uwhi. Kawa. - Cochons et poules. - Direction des vents............

CHAPITRE II

\section{TÉMOIGNAGES FAVORABLES.}

Légende de Kendall. - Chant cité par Taylor. - Mots communs aux deux contrées : - Maori ; - Maui ; - O-tu ; - Tina ; Rama et Tiare ; - Motu et Fatu ; - Ariki ; - Tui-Tunga ; Vea-iti. - Jade vert. - Coutume d'avaler l'œil de la victime. Absence des colonies polynésiennes ou zélandaises à la Nouvello-Hollande...................................... 


\section{CHAPITRE III}

\section{EXAMEN LINGUISTIQUE.}

Comparaison du Maori et des dialectes polynésiens. - La langue Maori est la langue polynésienne la moins altérée. - Opinion de M. Gaussin. - Opinion de M. John Williams. - Tradition relative au peuplement de Rarotonga. - Chant "d'Oromea. Le Maori était la langue primitive des Pólynésiens. - Alphabets des principaux archipels polynésiens : Nouvelle-Zélande ; Tunga ; Samoa ; Rarotonga ; Tahiti ; Mangareva ; Paumotu ; Marquises ; Sandwich. - Ces alphabets dérivent tous de celui de la Nouvelle-Zélande. - Le Maori est la langue-mère des dialectes polynésiens. - Les noms de lieux en Yolynésie ont une origine Néo-Zélandaise. - Conclusions. - Fables Néo-Zélandaises.........................................

\section{LIVRE TROISIÈME}

\section{ORIGINE DES NÉO-ZÉLANDAIS}

Distinction à établir entre les îles composant le groupe de la Nouvelle-Zélande. - Traditions relatives à l'origine des NéoZélandais, rapportées par Cook : Ulimaroa. - Arrivée d'étrangers à l'lle-Nord. - Heawise. - Opinion de Bory de SaintVincent; de R. P. Lesson. - Principales hypothèses émises sur l'origine des Néo-Zélandais........................ I $^{\circ}$ Origine tahitienne : Dumont d'Urville; son opinion sur les langues polynésiennes; son explication du peuplement de la Nouvelle-Zélande. - Réfutation de cette hypothèse........... $2^{\circ}$ Origine hawaïenne: Dieffenbach; les Hawaiiens sont venus à la Nouvelle-Zélande en passant par l'lle de Pâques; arrivée de trois canots ; introduction des Kumara à l'Ile--Nord. - Réfutation de cette hypothèse... . ..........................

$3^{\circ}$ Origine samoane : H. Hale ; Savaii, première étape des émigrants malais et point de départ des colonies polynésiennes; recherches linguistiques: Savaii dérive d'Hawahiki. - Réfutation

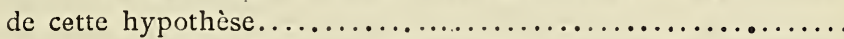

$4^{\circ}$ Origine samoane indirecte: Gaussin. - Exposé et réfutation de cette hypothèse.................................. 50 Origine hawaiienne et samoane : Shortland. - Exposé et réfutation de cette hypothèse. - Erreurs d'interprétation : Van-

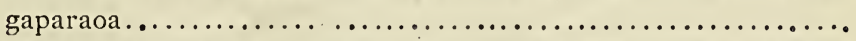
$6^{\circ}$ Origine samoane indirecte par Rarotonga : Thompson; raisons sur lesquelles repose cette hypothèse; réfutation des preuves 
invoquées en sa faveur ; différences existant entre les Malais et les Néo-Zélandais: croyance en un Hawahiki dans les îles Samoa; un seul Hawahiki; localités voisines de l'Hawahiki ; direction de l'Hawahiki ; route de l'Hawahiki ; chiens sauva. ges aux Samoa ; époque des migrations. - Erreurs et inexactitudes de l'ouvrage de Thompson.......................

$7^{\circ}$ Origine samoane indirecte: de Quatrefages ; sa première opinion ; sa deuxième opinion ; raisons sur lesquelles elle est appuyée ; Rarotonga n'a pu peupler la Nouvelle-Zélande ; consi. dérations linguistiques. - Réfutation de cette hypothèse......

Nécessité d'une hypothèse rationnelle......................

\section{LIVRE QUATRIÈME}

\section{HAWAHIKI}

\section{CH AP I T RE I er}

\section{IECHERCHE DE L'HAWAHIKI.}

Heawise de Cook. - Traditions relatives à l'Hawahiki publiées par sir Grey et Taylor. - Conséquences qui en découlent. Ce qu'était l'Hawahiki. - Erreurs résultant de la confusion faite entre les îles qui composent le groupe de la Nouvelle-Zélande. - L'Hawahiki était placé à I'Ouest et fort près d'Aotearqa ou Ile-Nord de la Nouvelle-Zélande. - Les émigrants de l'Hawahiki ont tous vécu vers la même époque et se sont expatriés pour les mêmes motits. - Voyage de Kupe. - Itinéraire de Turi : Version de sir Grey; version de Taylor. Voyage de Ngahue: Version de sir Grey; version de Taylor. - Voyage à la Nouvelle-Zélande d'après sir Grey : Itinéraire de l'Arawa; itinéraire du Tainui ; itinéraire du Tokomaru. Conséquences tirées de ces itinéraires: l'Hawahiki se trouvait situé dans l'Ile-du-Milieu de la Nouvelle-Zélande.............

\section{CHAPITRE II}

$$
\text { ILE - D U - M I L IE U. }
$$

Témoignages fournis par l'étude des cartes géographiques. Examen des localités situées sur les deux îles principales. Ces localités se retrouvent toutes dans les chants historiques des émigrants. - Autres preuves : Phormium tenax; Phoques; Neige ; Piopio ; Kumara ; Hekenga-Mai ; Jade vert. - L'Hawahiki ne pouvait être situê en Polynésie : Preuves à l'appui. Situation de l'Hawahiki sur l'Ile-du-Milieu. - Point de départ 
de Turi. - Tribus existant dans l'Hawahiki. - Signification tiu mot Hawahiki. - Kawai..........................

\section{CHAPITRE III}

\section{PEUPLEMENT DE L'ILE-NORD.}

Opinions à ce sujet de d'Urville et de Kendall ; de Dieffenbach, de Taylor; de Thompson; de Quatrefages. - Indigènes trouvés à Aotearoa par les Hawahikiens : Preuves à l'appui. - Maero et Ngati-Mamoe ; Patu-Paearehe ; Mere Punanamu ; étymologie du mot Tunga ; Ngati-Kahungunu. - Résumé général........ 439

\section{CHAPITRE IV}

\section{PROVENANCE DES HAWAHIKIENS.}

Les Hawahikiens étaient autochthones sur Kawaï. - Spécialité de la faune des îles de la Nouvelle-Zélande. - Spécialité de la flore de ces mêmes î es.- Spécialité de la race humaine de ce groupe. - Isoler.ent dans l'espace des terres de la Nouvelle-Zélande. - L'île Kawaï a été le centre de création de la race Maori..................... 474

FIN DE LA TABLE DES MATIL̈RES DU TROISILMME VOLUME.

CLERMONT-DE-L'OISE. - IMP. A. DAIX, PLACE SAINT-ANDRÉ, 3. 
(34) 8847 ( 



I

$-$

1.

1. 
SMITHSONIAN INSTITUTION LIBRARIES

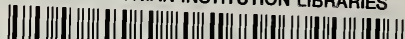

